\title{
Allgemeine Chirurgie
}

1.1 Prinzipien chirurgischer Diagnostik - 4

A. H. Hölscher, J. R. Siewert

1.1.1 Grundlagen - 4

1.1.2 Akutes Abdomen (akuter Abdominalschmerz) - 5

1.1.3 Erbrechen - 5

1.1.4 Dysphagie -7

1.1.5 Gastrointestinale Blutung - 8

1.1.6 Ikterus -12

1.1.7 Raumforderungen im Abdomen - 16

Weiterführende Literatur -16

1.2 Indikationen und Kontraindikationen zum operativen

Eingriff -17

J. R. Siewert, R. Bumm

1.2.1 Rechtliche Aspekte - 17

1.2.2 Fachliche Grundlagen - 18

Weiterführende Literatur -21

1.3 Grundprinzipien der Operationstechnik - 21

H. Feußner, B. Detter, J. R. Siewert

1.3.1 Grundbegriffe - 21

1.3.2 Instrumentarium -23

1.3.3 Operationstechnik -31

1.4 Pathophysiologische Folgen, Vorbehandlung und

Nachbehandlung bei operativen Eingriffen und Traumen $\quad-40$

H. Bartels

1.4.1 Pathophysiologische Folgen von Traumen und operativen

Eingriffen -40

1.4.2 Voruntersuchung und Vorbehandlung bei operativen Eingriffen - 42

1.4.3 Postoperative Therapie -48

1.4.4 Postoperativer Verlauf und seine Störungen - 53

Weiterführende Literatur -57

1.5 Wunde, Wundheilung und Wundbehandlung - 57

O. Jannasch, H. Lippert

1.5.1 Geschichtlicher Hintergrund -57

1.5.2 Wunde -58

1.5.3 Wundheilung -59

1.5.4 Störungen der Wundheilung -61 
1.5.5 Behandlung akuter Wunden -66

1.5.6 Chronische Wunden - 68

1.5.7 Behandlung des Wundbettes nach dem TIME-Prinzip - 70

1.5.8 Wundauflagen - 73

1.5.9 Wunddokumentation -74

Weiterführende Literatur $\quad-75$

1.6 Chirurgische Infektionslehre - 75

T. Miethke, H. Wagner

1.6.1 Allgemeine Infektionslehre - 75

1.6.2 Endogene Infektionen durch Enterobakteriazeen und Anaerobier - 78

1.6.3 Gasbrand -81

1.6.4 Tetanus -83

1.6.5 Aktinomykose -86

1.6.6 Tuberkulose -87

1.6.7 Syphilis -89

1.6.8 Sonstige bakterielle Infektionen -89

1.6.9 Virusinfektionen - 95

1.6.10 Parasitäre Erkrankungen - 97

Weiterführende Literatur -99

1.7 Ursachen und Prävention postoperativer

Wundinfektionen -99

I. Kappstein

1.7.1 Entstehung von Wundinfektionen - 99

1.7.2 Prävention von Wundinfektionen - 104

1.7.3 Wundverbandswechsel - 111

1.7.4 Surveillance postoperativer Wundinfektionen - 112

1.7.5 Baulich-technische Maßnahmen zur Prävention postoperativer

Infektionen - 112

Weiterführende Literatur - 113

1.8 Chirurgisch relevante Schockformen - 113

P. Krebs, J. Bail, A. Junger

1.8.1 Systemisches inflammatorisches Response Syndrom (SIRS) - 113

1.8.2 Multiorganversagen -115

1.8.3 Hypovolämischer Schock - 117

1.8.4 Septischer Schock - 122

1.8.5 Neurogener Schock - 124

1.8.6 Anaphylaktischer Schock - 125

1.8.7 Kardiogener Schock (Lungenembolie, Fettembolie,

Contusio cordis) -125

Weiterführende Literatur -127 
$1.9 \quad$ Anästhesie -127

M. Kaufmann, A. Urwyler, W. Ruppen, D. Scheidegger

1.9.1 Präoperative Maßnahmen - 127

1.9.2 Präoperative Verordnungen - 131

1.9.3 Anästhesieverfahren - 133

1.9.4 Postoperative Schmerztherapie - 141

1.9.5 Häufige postoperative Komplikationen - 145

Weiterführende Literatur $\quad-148$

1.10 Klinische Studien und Forschung in der Chirurgie - 148

1.10.1 Klinische Studien - 148

M. K. Diener, Ph. Knebel, Chr. Fink, I. Rossion, B. Maichle,

M. W. Büchler/B. Vollmar

Weiterführende Literatur - 153

1.10.2 Chirurgische Forschung -153

B. Vollmar

Weiterführende Literatur -160

1.11 Klassifikationen von Tumoren -160

C. Wittekind

1.11.1 Klinisches und biologisches Verhalten von Tumoren - 161

1.11.2 Ausbreitung maligner Tumoren - 162

1.11.3 Präkanzerosen und Krebsfrüherkennung - 164

1.11.4 Diagnostik - 166

1.11.5 Klassifikationen von Tumoren -167

1.11.6 Ziele der operativen Tumorbehandlung - 172

1.11.7 Multimodale Primärtherapie maligner Tumoren - 174

1.11.8 Prognose -176

1.11.9 Tumornachsorge -177

Weiterführende Literatur - 178

1.12 Molekulare Biologie und Genetik in der Chirurgie - 178

H. K. Schackert

1.12.1 Techniken der molekularen Biologie und Genetik - 178

1.12.2 Molekulare Grundlagen der Entstehung maligner Tumoren - 181

1.12.3 Gezielte Vorsorge und präventive chirurgische Therapie - 182

1.12.4 Molekulargenetische Diagnostik und Prävention maligner Tumoren am Beispiel des vererbbaren kolorektalen Karzinoms - 182

1.12.5 Gentherapie maligner Tumoren - 184

Weiterführende Literatur - 185 


\subsection{Prinzipien chirurgischer Diagnostik}

\section{A. H. Hölscher, J. R. Siewert}

Die chirurgische Diagnostik, bestehend aus Anamnese, klinischer Untersuchung und der meist nachfolgenden technischen Diagnostik, unterscheidet sich in ihren Grundprinzipien grundsätzlich nicht von denen anderer klinischer Fachgebiete. Bei akuten Erkrankungen muss sie schnell und zielführend erfolgen, um die Indikationsstellung zu einer Operation oder dem interventionellen oder konservativem Behandlungsverfahren nicht zu verzögern.

\subsubsection{Grundlagen}

Die Erhebung einer Anamnese bei Patienten, die bewusstseinseingeschränkt oder intubiert und beatmet eingewiesen werden, kann unmöglich sein oder muss sich auf eine Fremdanamnese (Zeugen, Notarzt) beschränken. Die klinische Diagnostik muss sich bei Vorliegen von Verletzungen, Blutungen, Ileuszuständen oder Sepsis auf das schnelle Erfassen weniger entscheidender Merkmale beschränken. In solchen Situationen muss schnell die Entscheidung zur gezielten Diagnostik erfolgen oder die Indikation zur sofortigen Operation. Dies gilt auch beim Auftreten von postoperativen Komplikationen.

Unter elektiven Bedingungen, z. B. Tumorerkrankungen und Funktionsstörungen, verlieren auch in der Chirurgie und trotz der Verfügbarkeit von vielen hochwertigen diagnostischen Maßnahmen von hoher Qualität, die Befragung und körperliche Untersuchung des Patienten keineswegs an Bedeutung. Nicht weiterführende, unnütze Diagnostik ist kostspielig und kann insbesondere auch mit Risiken und einer Belastung des Patienten verbunden sein.

\section{$>$ Anamnese und klinische Untersuchung bleiben unverzichtbare Basis des ärztlichen Handelns des Chirurgen.}

Häufig erfasst man mit der Befragung und der sorgfältigen körperlichen Untersuchung die richtige Diagnose. Alle nachfolgenden Zusatzuntersuchungen dienen der Sicherung der Arbeitsdiagnose bzw. dem Ausschluss von Differenzialdiagnosen und der Planung der optimalen Behandlungsstrategie.

Eine eingehende Anamnese und körperliche Untersuchung steht am Anfang einer sich entwickelnden Arzt-Patient-Beziehung und entscheidet oft über das weitere Vertrauensverhältnis.

\section{Anamneseerhebung}

Kernpunkt der Anamneseerhebung sind die Erhebung und genaue Differenzierung der aktuellen Beschwerden des Patienten. Hier handelt es sich meist um Schmerzen, aber auch um ungewöhnliche Körpererscheinungen: Schwellungen, Blutungen, Stuhlgangsveränderungen u.v.m.

Steht genügend Zeit zur Verfügung können Anamnese und Untersuchung sich am allgemeinen klinischen Vorgehen orientieren (siehe ausführliche Lehrbücher der Anamnese und Krankenuntersuchung) mit einer ausführlichen, strukturierten Eigen- und Systemanamnese.

Chirurgisch essentiell wichtige Fragen sind:

- Aktuelle Beschwerden

- Voroperationen

- Medikamenteneinnahme

- Organfunktionsstörungen (Nierenfunktion, Herzfunktion, Lungenfunktion)

- Allgemeine Belastbarkeit, Körpergewicht

\section{Klinische Untersuchung}

Die klinische Untersuchung in der Chirurgie gliedert sich grundsätzlich in Inspektion, Palpation, Auskultation, Perkussion und Funktionsprüfung.

\section{- Definition}

Beschwerden und Befunde (= Symptome) mit diagnostisch hoher Vorhersagekraft werden als Leitsymptome bezeichnet.

Die chirurgische Diagnostik orientiert sich an diesem jeweiligen Leitsymptom des Patienten. Dieses gilt es durch gezielte Anamnese und nähere Analyse der Symptomatologie zu präzisieren mit dem Ziel, zu einer Verdachtsdiagnose im Sinne einer Arbeitshypothese zu kommen. Von dieser Hypothese ausgehend wird die Reihenfolge der weiteren, meist apparativen Diagnostik festgelegt. Dabei ist es von Vorteil, eine sequenzielle Diagnostik statt einer "Schrotschussdiagnostik« zu betreiben. Sequenziell bedeutet, dass das Ergebnis eines diagnostischen Verfahrens den jeweils nächsten diagnostischen Schritt bestimmt, während beim anderen Vorgehen viele diagnostische Verfahren parallel und unabhängig voneinander angeordnet und ausgeführt werden. Chirurgische Diagnostik ist insbesondere beim akuten Abdominalschmerz und gastrointestinalen Blutungen dringlich, weil das Ergebnis ausschlaggebend für die Operationsindikation ist. Daher hat die rasche und konsequente Abklärung des Patienten mit solchen chirurgischen Leitsymptomen große klinische Bedeutung.

\section{Technische Diagnostik}

Bei der technischen Untersuchung gibt es einen Minimalstandard, der den meisten chirurgischen Maßnahmen vorangestellt werden sollte (-Tab. 1.1).

Die weitergehende und entitätspezifische Diagnostik (erweiterte Laboruntersuchungen, Tumormarker, Hormonbestimmungen, Urinuntersuchung, spezielle Sonographie, Endoskopie, Schnittbilddiagnostik, Szintigraphie, PET u.v.a.) wird in den entsprechenden Kapiteln differenziert abgehandelt.

Bei einigen Krankheitsbildern stehen unterschiedliche Therapieverfahren zur Verfügung (Operation, radiologischinterventionelle Maßnahmen, Endoskopie). Hier muss abgewogen werden, welches Verfahren zielführend und mit geringem Trauma für den Patienten optimal geeignet ist. Die Verfahren sollten nicht konkurrierend, sondern komplementär eingesetzt werden. 
- Tab. 1.1 Chirurgisch technische Basisdiagnostik

\begin{tabular}{|c|c|c|}
\hline Laborchemisch & Ultraschall- und Röntgendiagnostik & Weitere apparative Diagnostik \\
\hline $\begin{array}{l}\text { Kleines Blutbild: Leukozyten, Erythrozyten, } \\
\text { Hämoglobin, Hämatokrit, Thrombozyten }\end{array}$ & Sonographie $^{d}$ & EKG $^{d}$ \\
\hline Blutgerinnung: INR ${ }^{\mathrm{a}}, \mathrm{PTT}^{\mathrm{b}}, \mathrm{TZ}^{\mathrm{c}}$ & Röntgenthoraxaufnahme ${ }^{d}$ & Lungenfunktionsuntersuchung ${ }^{d}$ \\
\hline \multicolumn{3}{|l|}{ Serumelektrolyte: Natrium, Kalium, Kalzium } \\
\hline \multicolumn{3}{|l|}{ Kreatinin, Serumglukose, } \\
\hline Blutgruppe mit Rhesusfaktor und Kreuzprobe & & \\
\hline
\end{tabular}

Das einführende Kapitel ist nach 6 wichtigen Leitsymptomen geordnet, die bei chirurgischen Erkrankungen am häufigsten im Vordergrund stehen. Nach Anamnese und Symptomatologie wird jeweils das Grundprinzip der sequenziellen Diagnostik dargestellt.

\subsubsection{Akutes Abdomen (akuter Abdominalschmerz)}

Zu Definition und Diagnostik, $>$ Abschn. 7.10.

\subsubsection{Erbrechen}

Definition -
Unter Erbrechen versteht man den retrograden Transport
von Magen- bzw. Dünndarminhalt durch Speiseröhre und
Mund nach außen. Der Vorgang des Erbrechens wird im
Allgemeinen durch Übelkeit (Nausea) und immer durch
Würgen eingeleitet.

Nicht selten werden mit dem Erbrechen verwechselt:

- Reflux: Dabei kommt es infolge einer Inkompetenz der Kardia zum Einstrom von Mageninhalt in die Speiseröhre.

- Regurgitation: Dabei öffnet sich auch der obere Ösophagussphinkter und der Mageninhalt kann - ohne Nausea und Würgen - in den Mund eintreten.

- Rumination: Es handelt sich um ein meist unwillkürliches, bissenweises Zurückfließen von Nahrung in den Mund. Nach Wiederkauen wird die Nahrung wieder geschluckt.

Erbrechen ist nicht nur ein gastrointestinales Leitsymptom, sondern kann auch auf eine endokrinologische, kardiologisch-pulmonologische, gynäkologische, ophthalmologische, otologische und neurologisch-psychiatrische Ursache hinweisen und eine entsprechende Spezialdiagnostik erforderlich machen.

\section{Anamnese und Symptomatologie}

$\mathrm{Zu}$ wichtigen anamnestischen Gesichtspunkten, die bei der ursächlichen Abklärung des Erbrechens weiterhelfen, • Abb. 1.1 .

\section{Unterschieden werden muss zwischen akutem und chronischem Erbrechen als Leitsymptom. In beiden Fällen ist es therapeutisch wichtig abzuklären, ob ein Stenoseerbrechen vorliegt.}

\section{Klinische Untersuchung}

Der Zeitpunkt des Erbrechens in Relation zur Nahrungsaufnahme und das Aussehen bzw. der Geruch des Erbrochenen können Hinweise auf die Lokalisation des Passagehindernisses geben (•Tab. 1.2).

Auf ein Erbrechen infolge einer oberen gastroduodenalen Passagestörung weisen folgende klinische Zeichen hin:

Bei einer Magenatonie ist das Plätscherzeichen charakteristisch: Bei Perkussion der Bauchwand wird aufgrund der Flüssigkeitsretention im Magen ein plätscherndes Geräusch hörbar. Die Flüssigkeitsansammlung lässt sich auch sonographisch leicht erkennen. Falls keine Magenatonie, sondern verstärkte Peristaltik des Magens bei Magenausgangstenose vorliegt, ist es bei schlanken Patienten möglich, die Magenperistaltik durch die Bauchdecken hindurch zu beobachten. Diagnostisch am zielstrebigsten ist die Ösophagogastroduodenoskopie.

\section{Stenoseperistaltik als sicht- und palpierbare Peri- staltik oder als klingende Darmgeräusche bei der Auskultation erkennbar, ist ein wesentliches kli- nisches Merkmal beim mechanischen Dünndarm- ileus.}

Bei Verdacht auf ein intestinal verursachtes Stenoseerbrechen sollte in jedem Fall eine Abdomenübersichtsaufnahme angefertigt werden. Lässt sich dabei eine klare Dünndarmileuskonstellation (Dünndarmspiegel) nachweisen, so ist keine weitere Diagnostik notwendig, da sich daraus direkt eine Operationsindikation ergibt. Bei unklarem Röntgenbild oder postoperativem Ileus ist eine Gastrografinpassage angezeigt, 


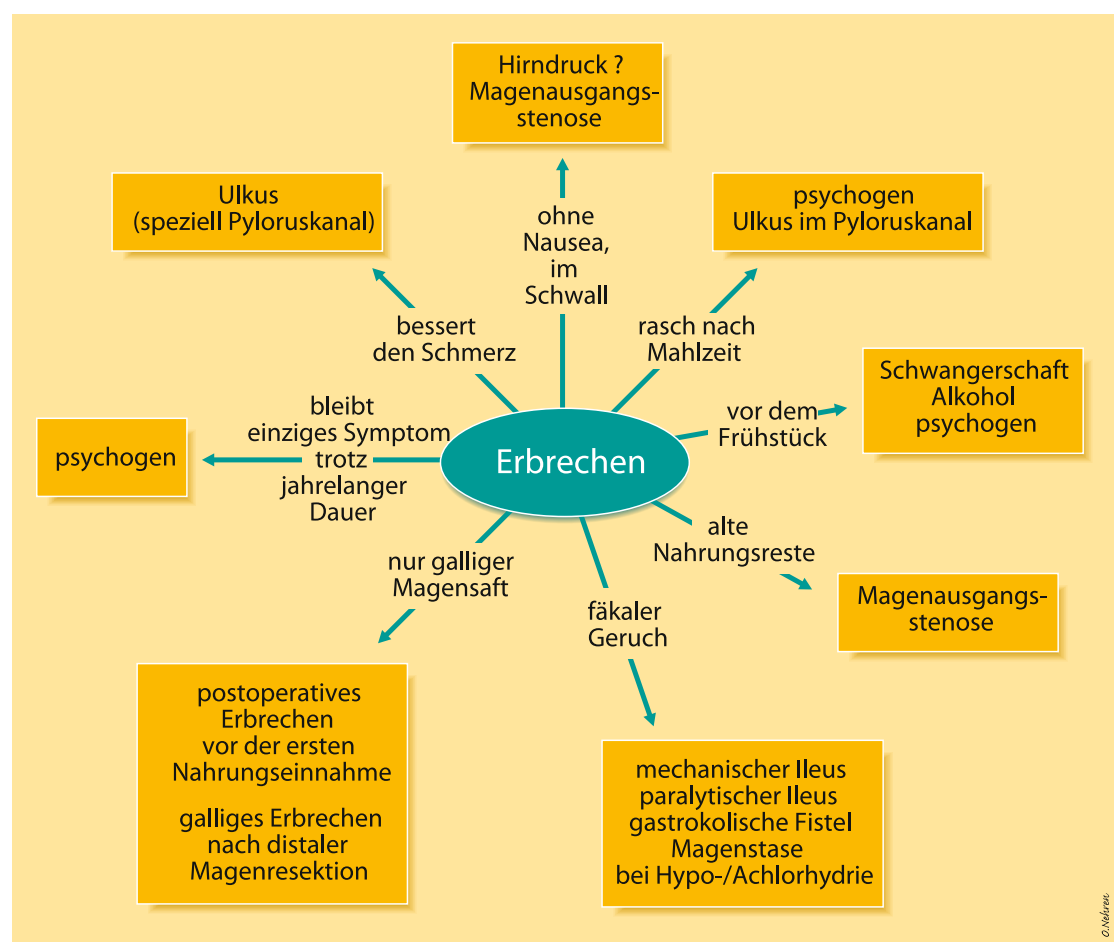

- Abb. 1.1 Anamnestische Fragen beim Erbrechen

um ein mögliches Passagehindernis zu lokalisieren oder eine verzögerte Passage (Paralyse) nachzuweisen.

Besteht klinisch kein Verdacht auf ein mechanisches Hindernis, liegt aber gleichzeitig ein akutes Abdomen vor, so sollte die weitere Diagnostik entsprechend dem Leitsymptom akutes Abdomen ( $\triangleright$ Abschn. 7.10) erfolgen.

Besteht neben dem Erbrechen eine Durchfallsymptomatik, so sind eine Nahrungsmittelintoxikation oder eine bakteriologische, virologische oder protozoische Exposition auszuschließen.
Handelt es sich um ein chronisches Erbrechen, so kann die Passagebehinderung ebenfalls durch eine Röntgenuntersuchung mit Gastrografin, unter bestimmten Voraussetzungen auch mit Bariumbreipassage, lokalisiert werden. Besteht kein mechanisches Hindernis, so sollten funktionelle Ursachen durch Spezialuntersuchungen ausgeschlossen werden.

\section{Apparative Diagnostik}

Zum diagnostischen Procedere im Einzelnen, • Abb. 1.2.

- Tab. 1.2 Erbrechen bei gastrointestinaler Passagebehinderung in Abhängigkeit von der Lokalisation des Hindernisses

\begin{tabular}{|l|l|l|}
\hline Zeitpunkt des Erbrechens & Passagehindernis & Aussehen und Geruch des Erbrochenen \\
\hline Bei Nahrungsaufnahme & Ösophaguskarzinom, peptische Stenose, Achalasie & Unverdaute Nahrung, neutral \\
\hline $\begin{array}{l}\text { Während bzw. rasch nach den } \\
\text { Mahlzeiten }\end{array}$ & $\begin{array}{l}\text { Ulcus ad pylorum, Differenzialdiagnose Psycho- } \\
\text { neurose }\end{array}$ & Angedaute Nahrung, sauer \\
\hline Bis ca. 1 h postprandial & $\begin{array}{l}\text { Syndrome der zuführenden und abführenden } \\
\text { Schlinge }\end{array}$ & Angedaute Nahrung, gallig \\
\hline Intervalle bis ca. $12 \mathrm{~h}$ & $\begin{array}{l}\text { Postvagotomiestase, Magenszirrhus, stenosier- } \\
\text { endes Magenkarzinom, A.-mesenterica-superior- } \\
\text { Syndrom }\end{array}$ & Angedaute Nahrung, gallig-faul \\
\hline Intervalle $>12 \mathrm{~h}$ & $\begin{array}{l}\text { Magenausgangsstenose, diabetische Gastroparese, } \\
\text { Dünndarmileus }\end{array}$ & Alte Nahrungsreste, faulig-fäkulent \\
\hline
\end{tabular}




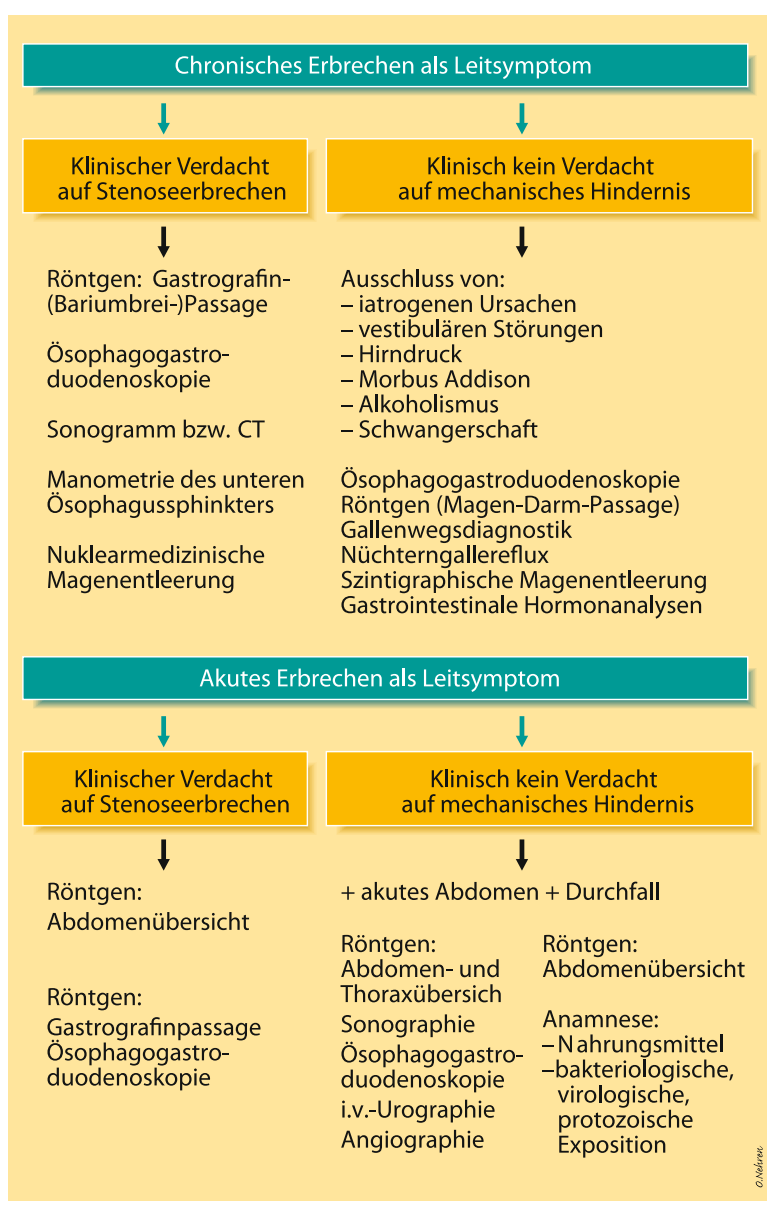

- Abb. 1.2 Diagnostische Schritte beim Erbrechen

\section{In Kürze}

\section{Erbrechen}

Gastrointestinales Leitsymptom, viele Ursachen. Abgrenzung zu Reflux, Regurgitation, Rumination.

Diagnostik: Anamnese (akut oder chronisch, Art, Beziehung zur Nahrungsaufnahme, andere Erkrankungen), klinische Untersuchung (Palpation, Auskultation: Magenatonie, Stenoseperistaltik), Röntgen (Abdomenübersicht: Dünndarmspiegel, Magen-Darm-Passage), CT, Ösophagogastroduodenoskopie u. a.

\subsubsection{Dysphagie}

- Definition

Die Dysphagie ist eine schmerzlose Behinderung des Schluckaktes. Schmerzen beim Schlucken werden als Odynophagie bezeichnet. Im klinischen Alltag wird Dysphagie aber als Oberbegriff für alle schmerzhaften und schmerzlosen Schluckstörungen verwendet.

\section{Anamnese}

Bei der Dysphagie erbringt die exakte Befragung des Patienten fast immer eine recht zuverlässige Verdachtsdiagnose.

\section{Fragen bei ösophagealer Dysphagie}

- Seit wann bestehen die Beschwerden? Bei einer Dauer von > 1 Jahr ist ein Karzinom unwahrscheinlich. Jahrelange Beschwerden sind bei der Achalasie typisch. Die rasche Zunahme der Beschwerden innerhalb weniger Wochen spricht für ein Karzinom.

- Nehmen die Beschwerden beim Essen zu? Die Zunahme ist typisch für Divertikel, die sich progressiv füllen. Bei der Achalasie mit starker Ösophagusdilatation tritt die Dysphagie ebenfalls erst nach Auffüllen des Ösophagusreservoirs in Erscheinung. Bei organischen Stenosen führen besseres Kauen und Nachtrinken zu weniger Beschwerden im Verlauf der Mahlzeit.

- Besteht die Schwierigkeit für feste und flüssige Speisen? Bei einer Achalasie besteht von Anfang an eine Dysphagie für flüssige und feste Speisen. Beim Karzinom ist das Hindernis »unelastisch « und besteht zuerst nur für feste, später auch für flüssige Speisen. Bei Ösophagusringen kommt es bei sonst völligem Wohlbefinden plötzlich zur Impaktation schlecht gekauter Fleischstücke (sog. SteakhouseSyndrom).

- Ist das Steckenbleiben schmerzhaft? Patienten mit Ösophaguskarzinom verspüren Schmerzen, bis der impaktierte Bissen regurgitiert oder geschluckt werden kann. Viele Ösophaguskarzinompatienten lokalisieren den Schmerz retroaurikulär. Spastische retrosternale Schmerzen sprechen für einen Ösophagusspasmus.

- Wo spürt der Patient das Hindernis? Praktisch alle Patienten mit einer Dysphagie verspüren das Hindernis an einem umschriebenen Ort.

- Gingen der Schluckstörung andere Beschwerden voraus? Epigastrische Schmerzen, Sodbrennen und Regurgitation sind typische Vorläufer bei peptischen Stenosen. Eine ähnliche Anamnese kann jedoch auch bei einem Adenokarzinom im Endobrachyösophagus erhoben werden. Angina-pectoris-artige Retrosternalschmerzen als Vorboten der Dysphagie sprechen für diffusen Ösophagusspasmus. Gurgeln und Spannungsgefühl im Hals sind Symptome eines Divertikels).

- Besteht ein Gewichtsverlust? Bei Achalasie und bei psychosomatischen Dysphagieformen tritt im Vergleich zur Schwere der geschilderten Beschwerden häufig kein Gewichtsverlust auf, während andererseits bei malignen Erkrankungen ein rascher Gewichtsverlust typisch ist. 


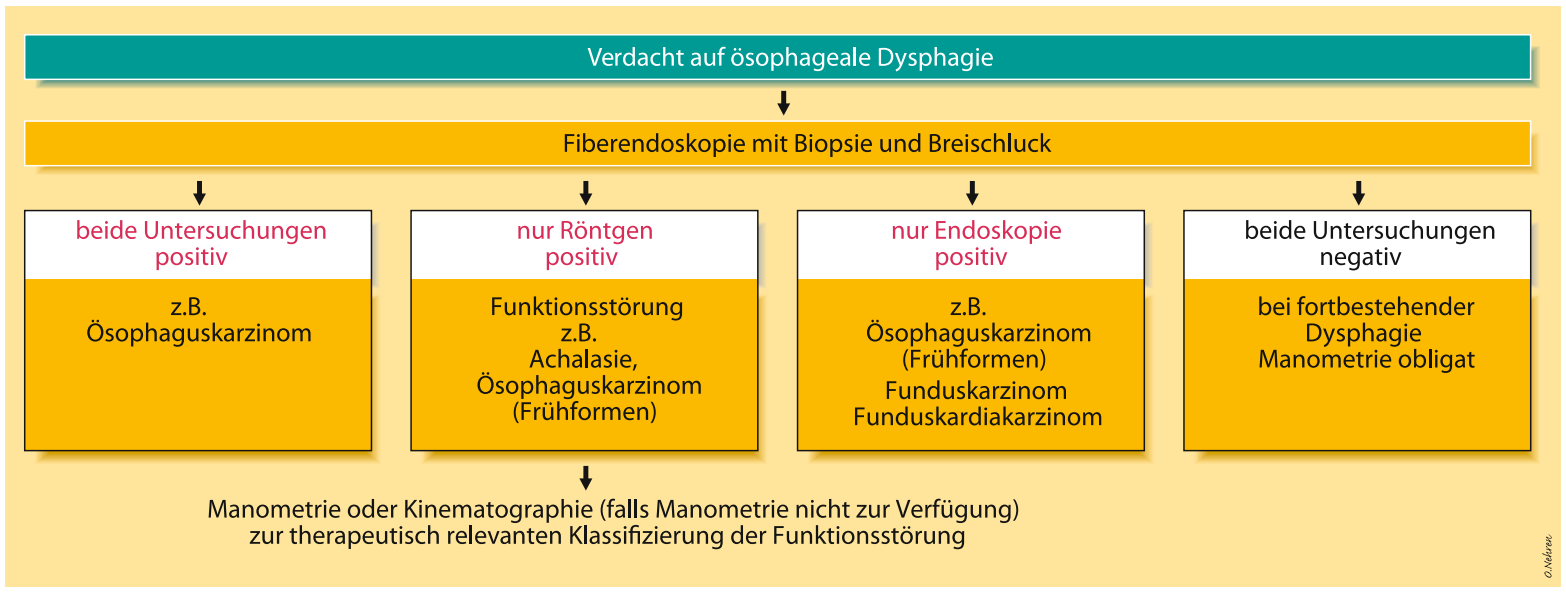

- Abb. 1.3 Abklärungsgang bei Verdacht auf ösophageale Dysphagie

\section{Apparative Diagnostik}

Zum diagnostischen Procedere bei Dysphagie, • Abb. 1.3. Bei der ösophagealen Dysphagie stehen maligne Tumoren, bei der oropharyngealen Dysphagie Funktionsstörungen an erster Stelle:

- Bei oropharyngealer Dysphagie nimmt der Breischluck den zentralen Platz ein. Divertikel erfordern keine weiteren Untersuchungen.

- Eine ösophageale Dysphagie von mehr als 2 Wochen Dauer ist ein ernstzunehmendes Zeichen und erfordert die Durchführung einer Fiberendoskopie bzw. einer radiologischen Untersuchung. Die Manometrie ist bei Funktionsstörungen der Speiseröhre von Wert.

$\checkmark$ Dysphagie ist immer als ein ernstzunehmendes Symptom anzusehen, das rasch einer Abklärung bedarf. Diagnostik der ersten Wahl bei ösophagealer Dysphagie ist die Endoskopie und Biopsie, bei oropharyngealer Dysphagie der Breischluck.

\section{In Kürze}

\section{Dysphagie}

Immer ein ernstzunehmendes, dringend abklärungsbedürftiges Symptom. Oft durch maligne Erkrankungen hervorgerufen, schmerzhafte Schluckstörung (= Odynophagie).

Diagnostik: Anamnese: Dauer, Schmerzcharakter, Ort, Zunahme beim Essen, auch beim Trinken, Gewichtsverlust. Röntgen (Breischluck), Endoskopie mit Biopsie, evtl. Manometrie.

\subsubsection{Gastrointestinale Blutung}

- Definition

Hämatemesis entspricht dem Erbrechen von rotem Blut.
Sie kann auftreten, wenn die Quelle proximal des duodenojejunalen Überganges liegt. Beim Kontakt mit Magensaft wird das Blut innerhalb von Minuten bis wenigen Stunden präzipitiert und braun verfärbt (sog. Kaffeesatz).

Alleiniges Kaffeesatzerbrechen deutet entweder auf eine relativ geringgradige Blutung proximal des Pylorus hin (eine rasche Blutfüllung des Magens provoziert Erbrechen von rotem Blut) oder ist mit einer massiven Blutung distal vom Pylorus vereinbar. Dabei fließt das Blut vorwiegend in Dünndarm und Kolon ab.

\section{Definition \\ Meläna: Eine Schwarzfärbung des peranal abgesetzten Blutes. Kommt durch bakterielle Umwandlung des Blutes im Kolon zustande.}

\section{Leitsymptome}

Prinzipiell ist zwischen einer Hämatemesis und Meläna als Leitsymptom zu unterscheiden. Ferner ist zu berücksichtigen, ob ein Patient wegen einer Blutung aus seiner häuslichen Umgebung notfallmäßig in die Klinik kommt, oder ob ein bereits wegen einer anderen Erkrankung stationär behandelter $\mathrm{Pa}$ tient eine Blutung erleidet.

\section{Hämatemesis}

\section{$>$ Bei zugewiesenen Patienten ist unverändert das} Ulcus duodeni die häufigste Blutungsursache.

Blutungen aus Ösophagus- bzw. Fundusvarizen und Ulcera ventriculi sind am zweithäufigsten. Seltene Ursachen sind die Refluxösophagitis, das Anastomosenulkus nach Magenresektion oder verschlucktes Blut nach Nasenbluten. Magenkarzinome, Polypen und Phlebektasien sind sehr seltene Ursachen.

Bei stationären Patienten ist in erster Linie an akute gastroduodenale Läsionen (sog. Stressulkus) oder Medikamentenulzera zu denken. 
Fallbeispiel

Ein 65-jähriger Patient wird in die chirurgische Notaufnahme eingeliefert. Der Patient ist blass, kaltschweißig und tachykard. Er berichtet über das Auftreten von Bluterbrechen und seit 2 Tagen bestehenden epigastrischen Schmerzen. Der Patient hat aufgrund einer Polyarthritis seit 2 Monaten ein nichtsteroidales Antiphlogistikum eingenommen. Auf Befragen verneint der Patient frühere Episoden von dunklem Stuhlgang, eine Ulkusanamnese besteht nicht.

Die klinische Untersuchung zeigt ein geblähtes Abdomen mit lokalem Druckschmerz im Epigastrium, der in die rechte Flanke einstrahlt. Es besteht keine Abwehrspannung oder Peritonismus. Resistenzen sind nicht zu tasten. Der Blutdruck beträgt $90 / 70 \mathrm{mmHg}$, der Puls ist 120/min. Die Kontrolle der Blutwerte und Serumparameter ergibt einen Hämoglobinwert von $7 \mathrm{~g} / \mathrm{dl}$.

Weiteres Vorgehen:

A. Infusion geben und Spontanverlauf abwarten.

B. Notfallendoskopie.

C. Diagnostische Laparotomie.

D. Abdomen-CT.

Antwort:

Das Leitsymptom Hämatemesis führt zur Durchführung einer Notfallendoskopie. Dabei findet sich ein exkaviertes Ulkus an der Duodenalhinterwand mit einer arteriell spritzenden Blutung aus einem sichtbaren Gefäßstumpf. Der Endoskopiker stellt die Indikation zur Clipversorgung des Gefäßstumpfes. Es kommt zu einem Blutungsstillstand.

Der Patient wird postoperativ auf die Intensivstation übernommen und es werden insgesamt 4 Erythrozytenkonzentrate substituiert, wobei es zu einem Anstieg des Hämoglobinwertes auf einen Wert von $12 \mathrm{~g} / \mathrm{dl}$ kommt. Die weitere Überwachung des Patienten während der 2 Folgetage ergibt keine Besonderheiten. Der Patient ist mit Omeprazol suffizient antisekretorisch abgedeckt. Am 3. Tag nach Aufnahme kommt es zu einem massiven Blutdruckabfall des Patienten, die Magensonde fördert frisches Blut. Eine sofortige Notfallendoskopie zeigt ein Blutungsrezidiv aus dem vorbekannten Duodenalulkus an der Bulbushinterwand. Nachdem eine endoskopische Blutstillung jetzt nicht möglich ist, wird der Patient notfallmäßig in den Operationssaal verbracht, wo es nach Duodenostomie gelingt, die Blutungsstelle zu umstechen. Trotz fortlaufender Volumensubstitution verstirbt der Patient $6 \mathrm{~h}$ später an Herzversagen und letztlich an den Folgen eines hämorrhagischen Schocks.

Kritik:

Die getroffenen Primärmaßnahmen sind sinnvoll. Das Leitsymptom Hämatemesis lässt eine obere gastrointestinale Blutung vermuten, und die unverzügliche Notfallendoskopie sichert die Diagnose. Der Nachweis des Gefäßstumpfes am Ulkusgrund und die Ulkuslokalisation im nachblutungsgefährdeten Areal an der Duodenalhinter$\nabla$ wand hätte die Indikation zur elektiven extra- und intraluminalen Gefäßumstechung mit einer Duodenostomie nahe gelegt. Eine Rezidivblutung ist bei älteren Patienten mit einer hohen Letalität belastet. Das Fallbeispiel zeigt, dass eine suffiziente initiale Diagnostik und Klassifikation der vorliegenden Erkrankung die Weichen für den weiteren Verlauf des Patienten stellt.

\section{Meläna}

\section{Massive peranale Blutung}

Bei zugewiesenen Patienten mit massiver peranaler Blutung sind Blutungsquellen im oberen Gastrointestinaltrakt 5-10mal häufiger als im Kolon. Unter den Blutungsquellen im Kolon sind Angiodysplasien, solitäre Kolonulzera, ischämische Kolitis und Kolondivertikel (Divertikel im rechten Kolon, keine Divertikulitis!) relativ häufig. Relativ selten treten massive Blutungen beim Kolonkarzinom oder bei entzündlichen Kolonkrankheiten, z. B. Colitis ulcerosa auf.

\section{Subakute peranale Blutung}

Häufige Ursachen der subakuten peranalen Blutung sind neben den Analerkrankungen Kolonpolypen, Kolonkarzinome, entzündliche Kolonerkrankungen, speziell die Colitis ulcerosa und solitäre Kolonulzera. In der Mehrzahl der Fälle mit angeblich subakut blutenden Divertikeln finden sich koloskopisch Malignome, Polypen, solitäre Kolonulzera, Gefäßdysplasien und andere Blutungsquellen, die radi ologisch nicht gesehen werden. Sehr selten sind Blutungsquellen im Dünndarm lokalisiert (z.B. Meckel-Divertikel oder Tumoren). Erhebliche Blutungen können aus Hämorrhoiden auftreten. Blutende anale Varizen bei portaler Hypertension sind eine extreme Seltenheit.

Bei stationären Patienten gilt es in erster Linie, an die Folgen therapeutischer Maßnahmen zu denken:

- blutende Analfissuren oder Druckulzera infolge von Einläufen oder Darmrohr,

- blutende Hämorrhoiden bei multiplen Abführversuchen etc.

Nach Ausschluss sog. posttherapeutischer Blutungsquellen sind hier die gleichen Überlegungen gültig wie bei Patienten, die wegen einer gastrointestinalen Blutung neu aufgenommen werden.

\section{Abschätzen des Ausmaßes und der Prognose einer Blutung Blutungsintensität}

Der Hb-Wert zum Zeitpunkt des Behandlungsbeginns gibt nur bedingt Hinweise auf das aktuelle Ausmaß der Blutung (da sich dieser Wert mit zeitlicher Verzögerung einstellt).

( Der relevanteste Wert zur Abschätzung der Intensität einer Blutung ist der Konservenverbrauch, der benötigt wird, um über einen bestimmten Zeitraum den Kreislauf stabil zu halten. Er zeigt auch am zuverlässigsten an, ob die Blutung sistiert oder fortbesteht. 


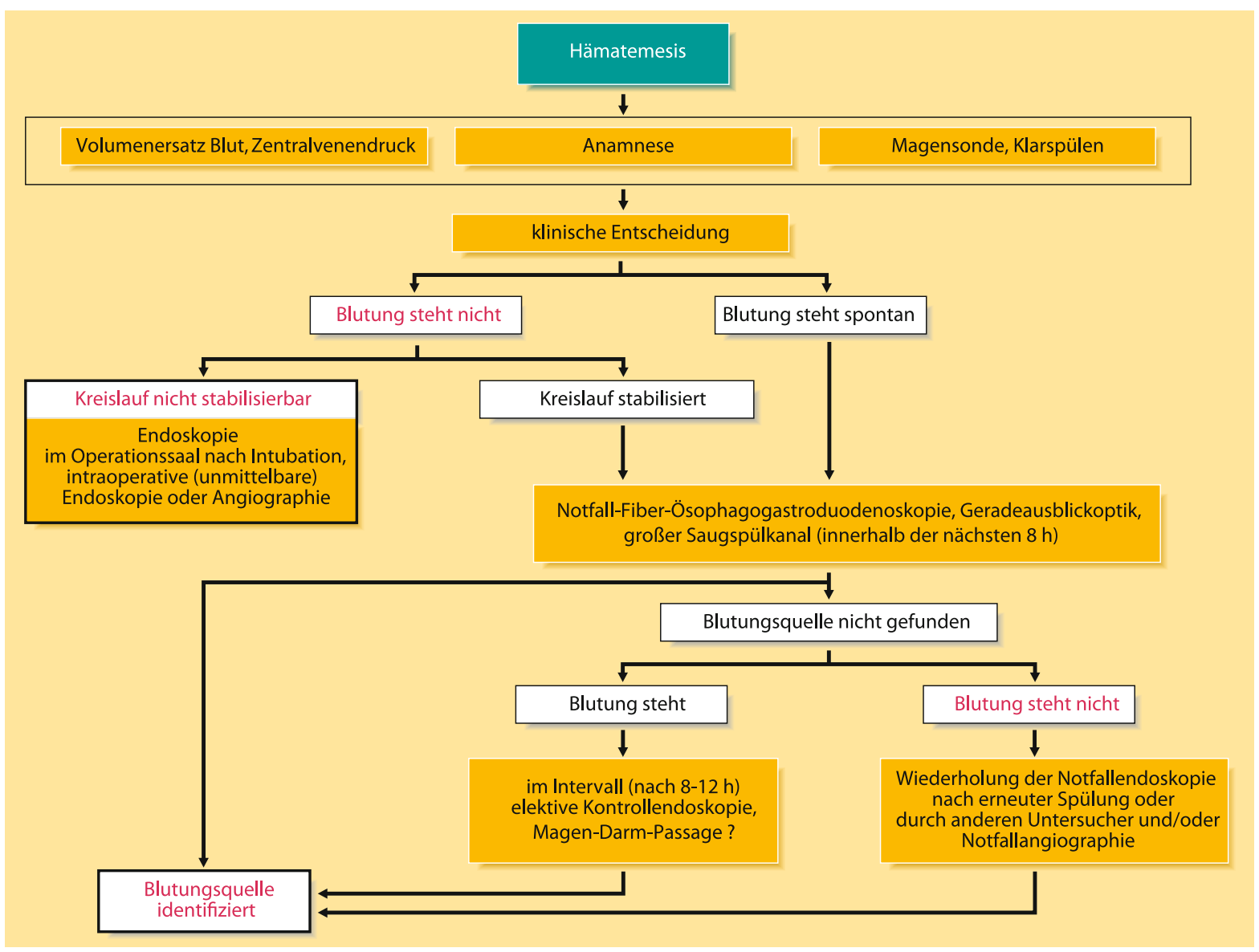

- Abb. 1.4 Diagnostik der Hämatemesis

Ein weiterer wichtiger Parameter ist der Zentralvenendruck (ZVD). Da ohnehin ein zentraler Venenzugang therapeutisch notwendig ist, sollte die Registrierung des Venendrucks nicht unterlassen werden. Das Ausmaß der massiven Blutung kann aufgrund der Messung von Blutdruck und Puls geschätzt werden.

$(>$ Bei einem üblicherweise normotonen Patienten zeigen ein Absinken des systolischen Blutdrucks unter $100 \mathrm{mmHg}$ und eine Herzfrequenz von über 100/min einen Volumenverlust von $30 \%$ an (sog. Schockindex nach Allgöwer, $>$ Abschn. 1.8).

\section{Prognose}

Das Risiko einer gastrointestinalen Blutung ist von verschiedenen Faktoren abhängig, wie Charakteristika des Patienten, Blutungsquelle, Blutungsintensität und Operationszeitpunkt.

\footnotetext{
Negative Prognosefaktoren der gastrointestinalen Blutung bei Patienten

- Jenseits des 60. Lebensjahres

- Schwere Begleiterkrankungen

- Ausgangs-Hb unter 6-7 g/dl

- Initialer Konservenverbrauch von über 6 Einheiten
}

\section{Apparative Diagnostik}

Das diagnostische Verfahren der 1. Wahl zur Abklärung einer gastrointestinalen Blutung ist die Endoskopie. In welcher Form und wann sie eingesetzt wird, richtet sich in erster Linie nach der Intensität der Blutung.

\section{Hämatemesis}

Zum diagnostischen Vorgehen bei der Hämatemesis, $\bullet$ Abb. 1.4. Die Vermutungsdiagnose aufgrund anamnestischer Hinweise (z. B. Ulkusanamnese) ist so unsicher, dass sie bei der Diagnostik nur in geringem Maße berücksichtigt werden kann.

\section{Notfallendoskopie}

Für die Entscheidung über konservative oder operative Therapie und deren Zeitplanung ist die Kenntnis der Lokalisation und der Natur der blutenden Läsion von ausschlaggebender Bedeutung. Daher sollte die Notfallendoskopie möglichst rasch durchgeführt werden, d.h. bei persistierender Blutung je nach Intensität der stattgehabten Blutung innerhalb der nächsten 6-12 h. Dies führt zu einer Lokalisation der Blutungsquelle. Die Klassifikation der Blutungsaktivität wird bei der gastroduodenalen Ulkusblutung nach Forrest vorgenommen (•Tab. 1.3). 
- Tab. 1.3 Klassifikation der Aktivität der gastroduodenalen Ulkusblutung nach Forrest

\begin{tabular}{|c|c|}
\hline la & Aktive Blutung, arteriell \\
\hline $\mathrm{Ib}$ & Aktive Blutung, venös \\
\hline Ila & Keine aktive Blutung, sichtbarer Gefäßstumpf \\
\hline IIb & $\begin{array}{l}\text { Keine aktive Blutung, Blutkoagel oder Hämatin- } \\
\text { belag }\end{array}$ \\
\hline III & $\begin{array}{l}\text { Keine aktive Blutung, kein Zeichen stattgehabter } \\
\text { Blutung, aber potenzielle Blutungsquelle, z. B. Ulkus }\end{array}$ \\
\hline
\end{tabular}

Neben der reinen Diagnostik sind bei der Endoskopie auch Blutstillungsmaßnahmen durch Sklerosierung, Elektrokoagulation oder Laserstrahlen möglich.

\section{Radiologische Diagnostik}

Eine radiologische Diagnostik mit Bariumsuspensionen oder resorbierbaren Kontrastmitteln ist unzuverlässig und zeit- raubend. Die Angiographie ist keine primäre diagnostische Methode. Sie hat ihre Indikation bei Suche nach Blutungsquellen im Dünndarm, bei bestimmten postoperativen Blutungssituationen und bei Einzelfällen okkulter Dickdarmblutungen ( $\triangleright$ Abschn. 1.1.5).

\section{Peranale Blutung Massive peranale Blutung}

Zum diagnostischen Vorgehen bei massiver peranaler Blutung, - Abb. 1.5. Bei entsprechenden anamnestischen Angaben (z. B. bekannte Ulkuskrankheit, frühere obere Gastrointestinalblutung), Aspiration von Blut aus der Magensonde (Cave: Saugartefakte!) und normaler rektaler digitaler Untersuchung wird zunächst eine Notfallösophagogastroskopie durchgeführt. Der Entschluss zur technisch weitaus aufwändigeren Notfallkoloskopie sollte dann gefasst werden, wenn die Wahrscheinlichkeit einer unteren Blutung um ein Vielfaches größer ist als die Wahrscheinlichkeit einer oberen Blutung oder nach negativer oberer Endoskopie.

Das weitere Vorgehen in Fällen negativer oberer und unterer Endoskopie ist die Notfallangiographie. Sie zeigt einen

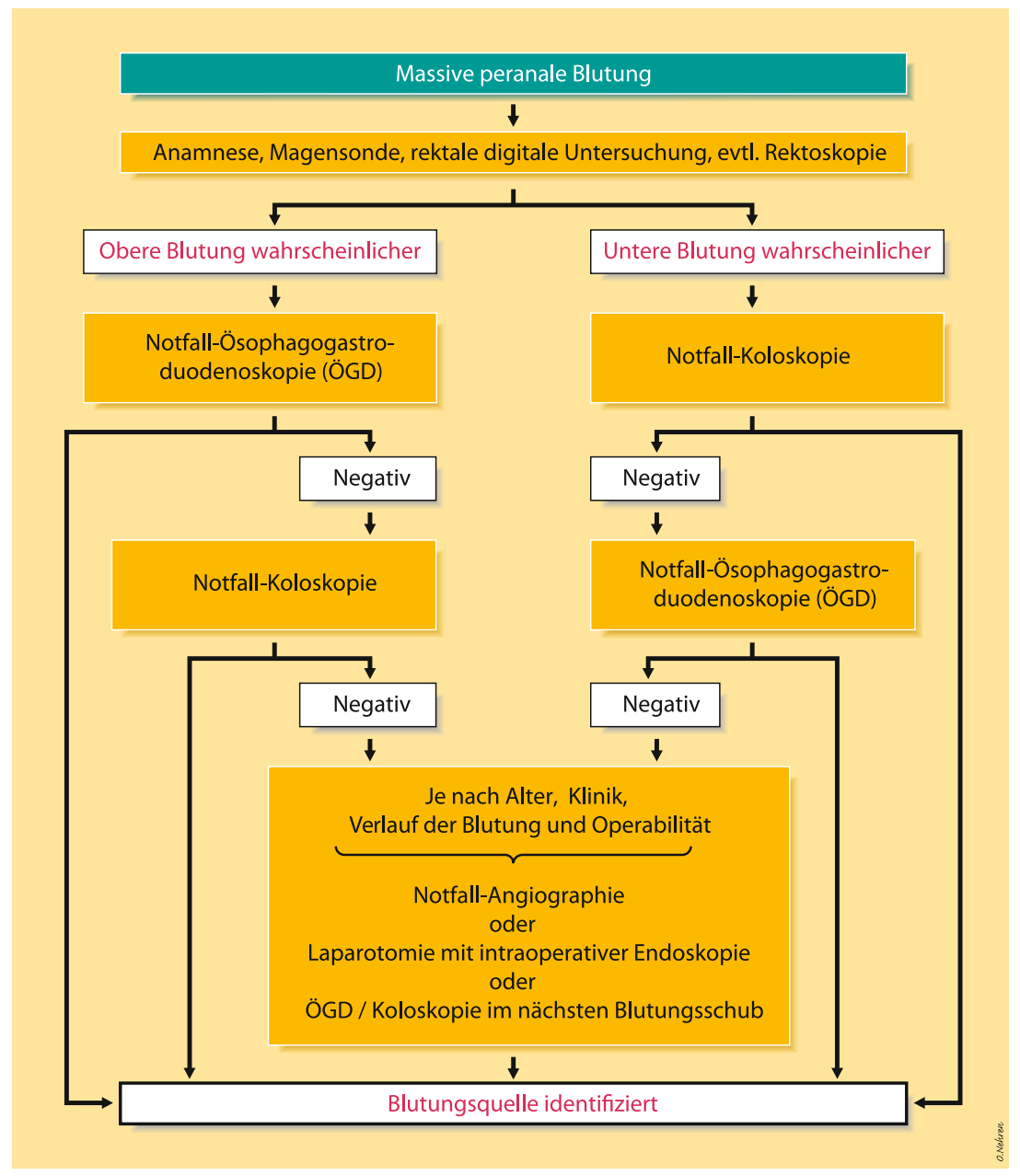

- Abb. 1.5 Diagnostik der massiven perianalen Blutung 
positiven Befund aber nur bei sehr starker Blutung (über $1,5 \mathrm{ml} / \mathrm{min}$ ), bei Gefäßdysplasien und/oder Blutungen in ein Divertikel, das das ausgeflossene Kontrastmittel während einiger Minuten zusammenhält. Lohnend ist auch der Versuch einer Lokalisation der Blutungsquelle mit Technetiummarkierten Erythrozyten, die jedoch auch eine Mindestblutungsintenstität erfordert. Die Laparotomie mit intraoperativer Endoskopie ist nur beim Verdacht auf eine Dünndarmblutung indiziert.

\section{Subakute peranale Blutung.}

Das diagnostische Vorgehen unterscheidet sich nicht grundsätzlich von dem bei der massiven peranalen Blutung, die Blutungslokalisation mit Angiographie oder markierten Erythrozyten ist jedoch wenig erfolgversprechend.

\section{Okkulte Blutung}

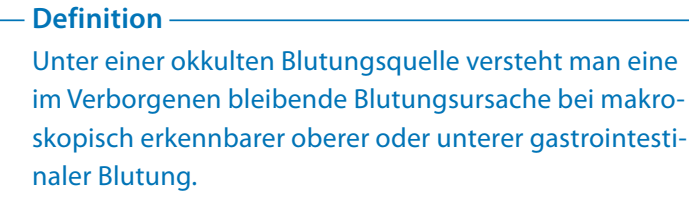

Dabei lässt sich die Ursache der Blutung im Gastrointestinaltrakt durch die üblichen endoskopischen Untersuchungen wie Gastroskopie bzw. Koloskopie oder erweiterter Diagnostik wie Angiographie nicht klären, so dass zwar eine makroskopische Blutung vorliegt, die Blutungsquelle aber im Verborgenen bleibt. Die Blutungsquellen lassen sich oft erst durch Wiederholung der Diagnostik klären.

Die okkulte Blutung ist eine charakteristische Situation der Vorsorgeuntersuchung. Der beste z. Zt. zur Verfügung stehende Test zur Verifizierung einer okkulten Blutung ist der Hämokkulttest, weil er bei relativ wenig falsch-positiven Resultaten relativ viele Patienten mit Blutungsquellen im Kolon identifiziert. Er beruht auf einer positiven Peroxidasereaktion des Hämoglobins im Stuhl. Peroxidasen finden sich jedoch nicht nur im Blut, sondern - in kleineren Mengen - auch in den Verdauungsrückständen von Gemüse und Fleisch und in den Kolonbakterien, so dass ein falsch-positives Ergebnis möglich ist.

\section{Praxisbox}

\section{Faustregeln für den Hämokkulttest}

- Der Test ist bei einer Blutung von über 1,5-2 ml/ $100 \mathrm{~g}$ Stuhl im Allgemeinen bei etwa 4/5 der Untersuchten positiv. Es muss angenommen werden, dass mit dem Hämokkulttest etwa 1/5 der potenziell blutenden Läsionen übersehen wird.

- Die Ausbeute bei Läsionen im Zökum ist wahrscheinlich besser als bei tiefer sitzenden Läsionen, da sich das Blut umso besser mit dem Stuhl mischt, je länger der Transit zwischen Quelle und Anus ist. Bei tiefsit-

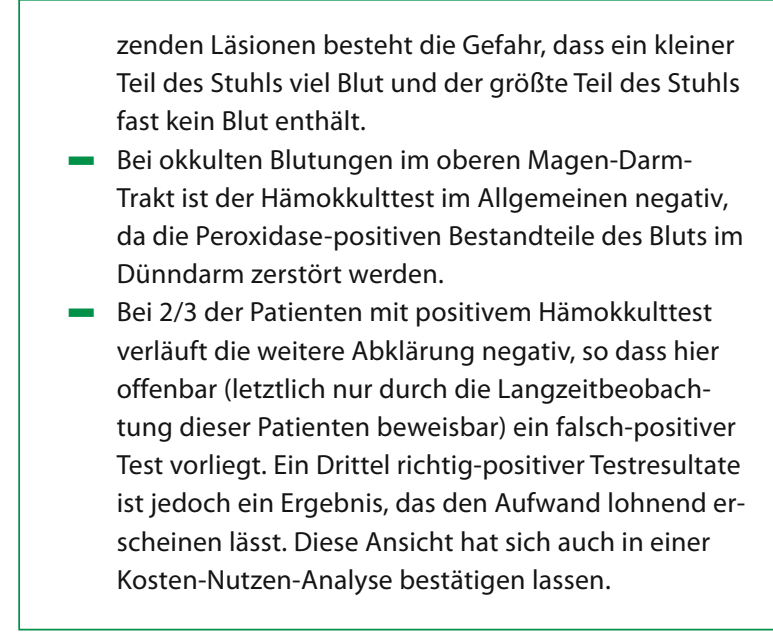

\section{In Kürze}

\section{Gastrointestinale Blutung}

Blutungsintensität: Hb-Wert, ZVD, Blutdruck und Puls, Anamnese.

- 1. Hämatemesis (Kaffeesatz): Quelle proximal des duodenojejunalen Überganges durch Ulcus duodeni, Ösophagus- bzw. Fundusvarizen und Ulcera ventriculi, bei stationären Patienten: Stressulkus.

Diagnostik: (Notfall-)Endoskopie: Blutungsaktivität nach Forrest, auch Blutstillungsmaßnahmen durch Sklerosierung, Elektrokoagulation oder Laserstrahlen.

- 2. Meläna: massive peranale Blutung: oberer Gastrointestinaltrakt, Kolon; subakute peranale Blutung: häufiger Kolon und Rektum, Folgen therapeutischer Maßnahmen.

Diagnostik: rektale Untersuchung, Rektoskopie, ÖGD, Koloskopie, evtl. Angiographie. Okkulte Blutung: Hämokkulttest.

\subsubsection{Ikterus}

Definition
Ikterus ist die Gelbfärbung von Haut, Skleren, Schleim-
häuten und Körperflüssigkeiten durch Retention von
Bilirubin.

Wenn die Serumkonzentration etwa $3 \mathrm{mg} / \mathrm{dl}$ ( $51 \mathrm{~mol} / \mathrm{l}$ ) übersteigt, wird der Ikterus klinisch sichtbar.

\section{Ursachen und Klassifikation}

Die Ursachen des Symptoms Ikterus sind vielfältig. Ihre Einteilung nach pathophysiologischen Gesichtspunkten richtet sich nach der Lokalisation der Ausscheidungsstörung innerhalb des Bilirubinstoffwechsels, der sich klinische Krankheitsbilder und laborchemische Merkmale zuordnen lassen. 


\section{Klassifikation des Ikterus}

- Produktionsikterus (prähepatischer oder hämolytischer Ikterus): Vermehrte Bildung von Bilirubin, z. B. durch Hämolyse.

- Transportikterus (intrahepatischer Ikterus): Die Bindung des Bilirubins an Albumin und/oder die Aufnahme in die Leberzelle sind gestört, z. B. durch Drogen oder beim Gilbert ${ }^{1}$-Syndrom.

- Speicherungs- und Konjugationsikterus (intrahepatischer lkterus): Die Bindung des Bilirubins an Trägerproteine in der Leberzelle ist defekt, z. B. beim Rotor²Syndrom. Die Konjugation des Bilirubins mit Glukuronsäure funktioniert nicht, z. B. beim Crigler ${ }^{3}-\mathrm{Najjar}^{4}$ Syndrom, dadurch bleibt das Bilirubin wasserunlöslich und kann nicht ausgeschieden werden.

- Exkretionsikterus (intrahepatischer Ikterus): Verminderte Ausscheidung des Bilirubins in die Gallenkanalikuli, z. B. bei Hepatitis, Leberzirrhose, Dubin ${ }^{5}$ Johnson ${ }^{6}$-Syndrom, Rotor-Syndrom.

- Kanalisationsikterus (posthepatischer oder Verschlussikterus): Obstruktion der Gallenwege.

Einige Ikterusformen beeinträchtigen mehrere Schritte des Bilirubinstoffwechsels.

Die Klassifikation des Ikterus nach der Lokalisation des Stoffwechseldefektes unterscheidet prähepatische, intrahepatische (hepatozelluläre), posthepatische und kombinierte Formen.

( Für den Chirurgen ist die Frage entscheidend, ob der Ikterus durch eine mechanische Obstruktion der Gallenwege (Verschlussikterus) verursacht wird. In diesem Fall wird chirurgisch oder endoskopisch behandelt.

\section{Anamnese und Symptomatologie}

Die Anamnese kann wichtige Hinweise zur Differenzierung des Ikterus liefern. So können Gallensteine oder eine chronische Leberkrankheit in der Vorgeschichte im Zusammenhang mit Geschlecht, Alter, Schmerzanamnese und Trinkgewohnheiten gelegentlich schon einen "Steinikterus« vom "Zirrhoseikterus« unterscheiden lassen. Besondere Sorgfalt verdient die Fahndung nach Medikamenten, da viele Arzneimittel, aber auch Haushalts- und industrielle Gifte einen Ikterus induzieren können.

Die maligne Obstruktion führt nicht immer zum sog. schmerzlosen Ikterus, über $60 \%$ der Patienten mit malignem Verschluss geben Oberbauchschmerzen an, bei der benignen Obstruktion sind es $80 \%$.

1 Nicolas A. Gilbert, Internist, Paris, 1858-1927

2 Arturo B. Rotor, Internist, Manila, 1907-1988

3 John F. Crigler jun., Pädiater, Boston, geb. 1919

4 Victor A. Najjar, Pädiater, Boston, geb. 1914

5 Isidore Dubin, Pathologe, Washington, 1913-1981

6 Frank B. Johnson, Pathologe, Washington, geb. 1919
( Wenn die Oberbauchschmerzen von Schüttelfrost begleitet werden, ist am ehesten an Cholangitis, Leberabszess oder Virushepatitis zu denken.

Juckreiz kann dem Ikterus wochen- oder monatelang vorausgehen. Als Ursache des Juckreizes wird die Ablagerung von Gallensäuren in der Haut verantwortlich gemacht. Zahlreichen Patienten fällt die Dunkelfärbung des Urins früher auf als die Gelbfärbung von Haut und Skleren. Ursache ist der Übertritt von konjugiertem Bilirubin in den Blutstrom infolge des biliären Exkretionsstaus. Das renal ausgeschiedene Bilirubin färbt den Urin braun. Abhängig vom Ausmaß der Cholestase entfärbt sich der Stuhl. Er nimmt eine graue bis hellgelbe Farbe an. Bei partieller Obstruktion kann der Stuhl bei gleichzeitiger Ausscheidung von braunem Urin seine normale Farbe behalten.

Sehr oft ist der Ikterus - unabhängig von der Dignität des Grundleidens - begleitet von Appetitlosigkeit, Übelkeit und Schwäche.

\section{Körperliche Untersuchung}

Bei der körperlichen Untersuchung erlaubt das Maß der Gelbfärbung von Haut und Skleren eine grob quantitative Abschätzung der Hyperbilirubinämie. Vergrößerte, druckdolente Leber und Splenomegalie lassen oft auf eine akute oder chronische Hepatitis, eine Alkoholzirrhose mit akutem Schub oder eine primär biliäre Zirrhose schließen. Wenn weder Milz noch Leber vergrößert sind, kommen sowohl hepatozelluläre als auch extrahepatische Ursachen des Ikterus in Betracht. Die harte, vergrößerte Leber ist oft Ausdruck einer tumorösen Infiltration.

Wenn sich die gestaute Gallenblase prallelastisch tasten lässt, liegt meist ein länger bestehender mechanischer Verschluss der Gallenwege vor. Dieses sog. Courvoisier ${ }^{7}$-Zeichen ist jedoch nicht immer eindeutig von einer tumorösen Gallenblase zu unterscheiden.

Wichtig ist die Fahndung nach sog. Leberhautzeichen, wie Spider naevi, die auf eine chronische Leberkrankheit schließen lassen.

Kachexie und derbe Lymphome weisen auf eine maligne Ursache des Ikterus hin. Meist gelingt es mit Anamnese und klinischer Untersuchung, eine Verdachtsdiagnose zu stellen, die die weitere Diagnostik leitet (• Abb. 1.6).

\section{Apparative Diagnostik Labordiagnostik}

Für die Differenzierung des Ikterus stehen unzählige Labormethoden zur Verfügung. Für den Chirurgen sind bei der Erstuntersuchung des ikterischen Patienten nur wenige Werte von Belang. Sie grenzen die Frage ein, ob ein Verschluss der Gallenwege vorliegt, ob eine bakterielle Infektion im Spiel ist und - für den Fall einer chirurgischen oder endoskopischen Intervention - ob die Blutgerinnung gestört ist.

7 Ludwig G. Courvoisier, Chirurg, Basel, 1843-1918 


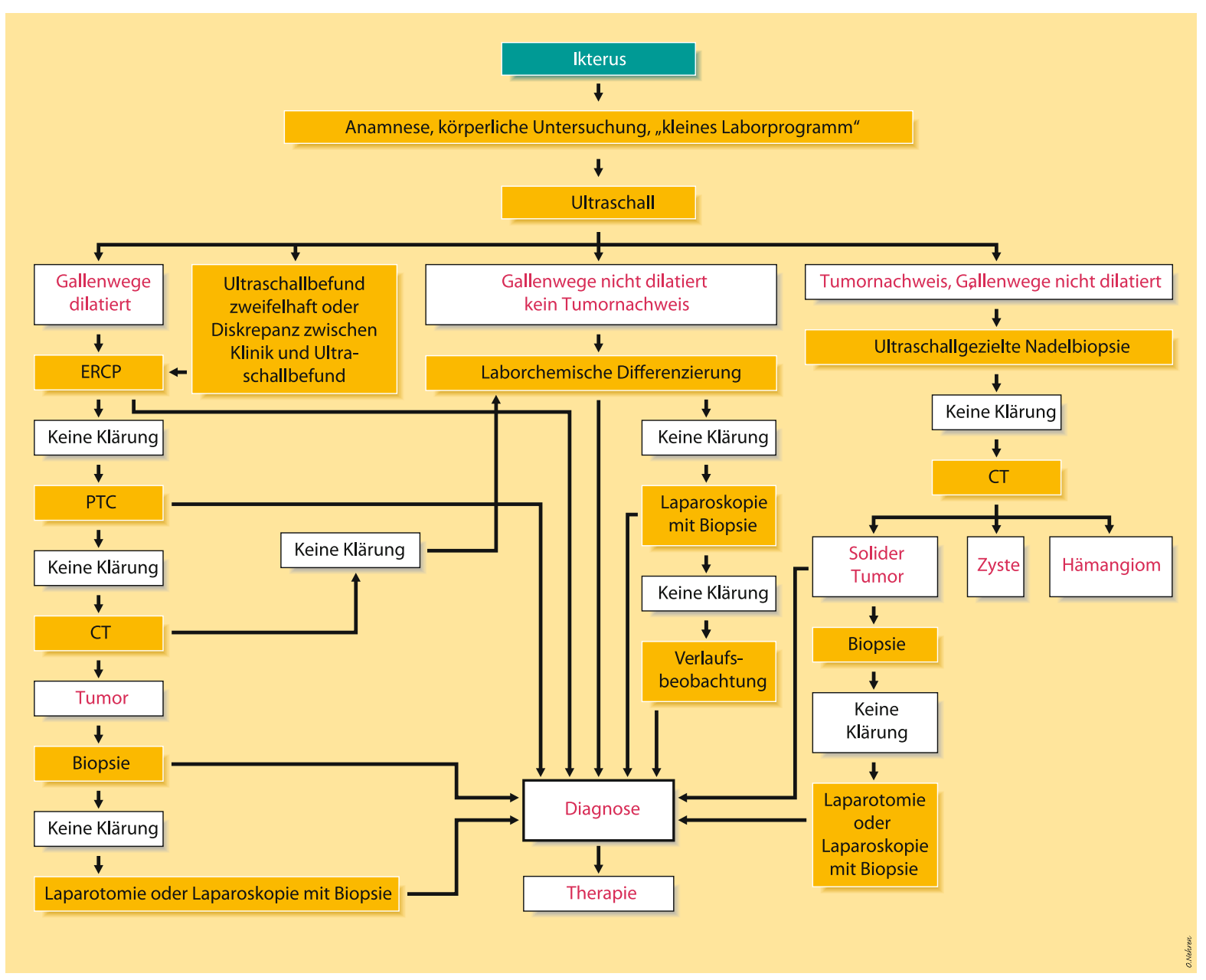

- Abb. 1.6 Diagnostisches Vorgehen beim Ikterus

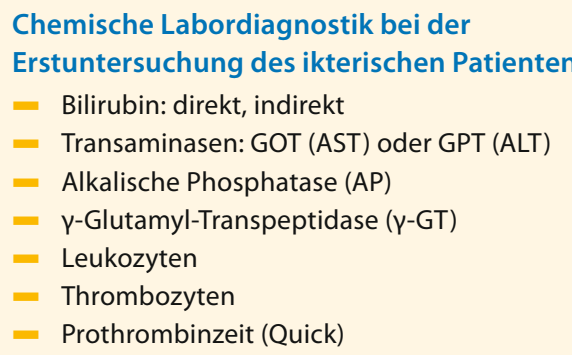

\section{Ultraschalluntersuchung}

Die Ultraschalluntersuchung des Abdomens ist beim Ikterus obligat. Ihr Ziel ist der Nachweis bzw. Ausschluss einer Dilatation der extra- bzw. intrahepatischen Gallenwege und die Fahndung nach Leberparenchymveränderungen, Tumoren und Steinen im hepatobiliären System.

Wenn die Ultraschalluntersuchung tumoröse Raumforderungen aufdeckt, kann in demselben Arbeitsgang die Feinna- delbiopsie der Läsion vorgenommen werden. Steine im distalen Ductus choledochus sind im Ultraschallbild schwer zu erkennen, da sie oft von Duodenalluft überlagert sind.

( Aufgrund ihrer hohen Empfindlichkeit im Auffinden extrahepatischer Verschlüsse fungiert die Ultraschalluntersuchung als Weichensteller für das weitere diagnostische Vorgehen. Sie führt die Patienten mit Verschlussikterus der direkten Cholegraphie zu und schützt andererseits Patienten ohne dilatierte Gallenwege vor dieser Maßnahme.

\section{Computertomographie}

Das Computertomogramm (CT) ergibt bei der Differenzierung des Ikterus ähnliche Resultate wie die Ultraschalluntersuchung. Bei zweifelhaftem Ergebnis der Ultraschalluntersuchung ist das CT eine wertvolle Ergänzung, sofern nicht bereits die Indikation zur direkten Cholegraphie gegeben ist. Gelegentlich ist eine Sonographie wegen Meteorismus (z.B. beim akuten Abdomen) oder frischer Bauchwunden mit Ver- 
bänden und Drains (z. B. beim postoperativen Ikterus) nicht durchführbar. Diese Probleme werden mit dem alternativen Einsatz des CT gelöst.

\section{Direkte Cholegraphie}

Für die röntgenmorphologische Darstellung der Gallenwege stehen die endoskopisch-retrograde Cholangiopankreatographie (ERCP) und die perkutan-transhepatische Cholangiographie (PTC) zur Verfügung. Die ERCP hat eine höhere technische und diagnostische Trefferquote und weniger Komplikationen als die PTC. Außerdem liefert sie diagnostische Informationen nicht nur für die Gallenwege, sondern auch über das Duodenum, die Papilla Vateri und das Pankreasgangsystem. Deshalb wird die ERCP als primäres Verfahren der direkten Cholegraphie eingesetzt. Die PTC dient als ergänzendes Verfahren bei Misslingen der ERCP.

\section{Magnetresonanzcholangiopankreatikographie (MRCP)}

( In den letzten Jahren hat sich die Magnetresonanzcholangiopankreatikographie (MRCP) zur führenden nichtinvasiven Darstellungsmethode für das pankreatobiliäre Gangsystem entwickeln können.

Heute stellt die MRCP in bestimmten Indikationsbereichen eine zuverlässige Alternative zur invasiven und mit einer Pankreatitisrate von etwa $1,5 \%$ immer noch risikoreichen ERCP dar. Damit kommt ihr auch zur Klärung eines Ikterus eine immer größere Bedeutung zu.

\section{Praxisbox \\ MRCP}

Technische Grundlage der MRCP-Technik ist die selektive Darstellung statischer oder quasistationärer Flüssigkeiten durch stark T2-gewichtete schnelle Spinechosequenzen. Durch diese spezifische Sequenzwahl kommen statische Flüssigkeiten wie die intra- und extrahepatische Gallenwege und der Bauchspeicheldrüsengang ohne Anwendung positiver Kontrastmittel gegenüber den umgebenden Organgeweben signalintens zur Darstellung.

Neben allgemeinen Kontraindikationen zur Kernspintomographie wie Herzschrittmacher und Metallteile in vitalen Bereichen ist speziell für die MRCP das Vorliegen von Aszites zu nennen. Patienten mit orthopädischen Metallprothesen im Schulter-, Knie- und Hüftbereich können in aller Regel problemlos untersucht werden. Die Dauer der Atemanhaltephase für Sequenzen in Atemanhaltemodus liegt bei modernen Geräten bei $3 \mathrm{~s}$. Ist ein Patient nicht in der Lage, Atemkommandos einzuhalten, kann die Untersuchung mit atemgetriggerten Sequenzen durchgeführt werden.

Bei vielen diagnostischen Indikationen - so auch beim Ikterus - hat die MRCP die ERCP als Methode der 1. Wahl abgelöst.

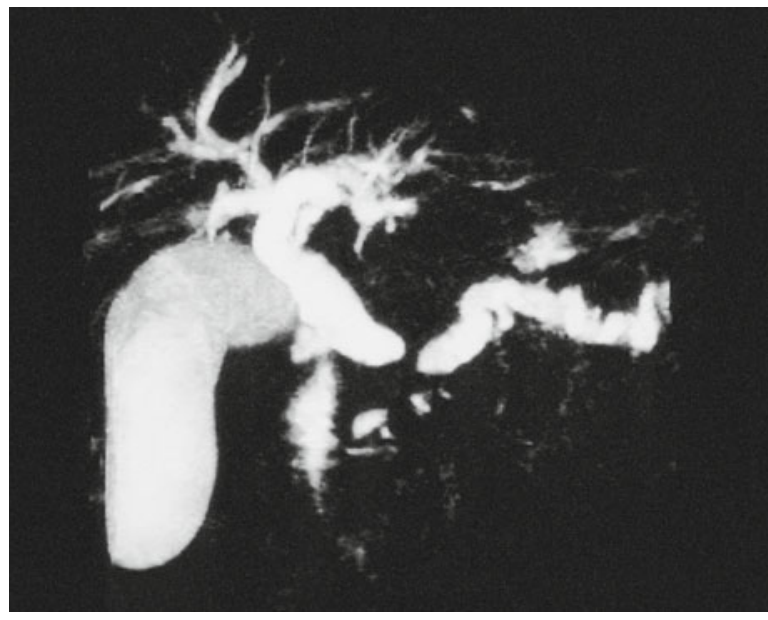

- Abb. 1.7 MRCP beim Pankreaskopfkarzinom zur Abklärung eines Verschlussikterus

So können Gallengangsteine, biliäre Stenosen und chronisch pankreatische Komplikationen wie die Pankreasgangstrikturen und intraduktale Konkremente zuverlässig dargestellt werden (• Abb. 1.7).

Da die MRCP im Gegensatz zur ERCP dilatierte Gallengangäste sicher zur Darstellung bringt, eignet sich diese Methode zur Planung endoskopisch therapeutischen Maßnahmen, insbesondere der endoskopischen Gallenwegsdrainage, z. B. beim Ikterus.

\section{Laparoskopie und Leberbiopsie}

Die Indikation zur Laparoskopie und Leberbiopsie bei der Ikterusdiagnostik beschränkt sich auf Patienten mit länger bestehender Cholestase, wenn ein mechanischer Verschluss im Bereich der Gallenwege ausgeschlossen ist. In dieser Situation geht es meistens um den Nachweis einer chronischen Hepatitis, einer Leberzirrhose oder fokaler hepatischer Veränderungen.

( Entscheidend bei der chirurgischen Diagnostik der Gelbsucht ist die Erkennung eines Verschlussikterus und die Klärung, an welcher Stelle und wodurch die Gallenwege obstruiert sind.

\section{In Kürze}

Ikterus

Prähepatisch (Produktion: Hämolyse), intrahepatisch (Transport: Drogen, Konjugation, Exkretion), posthepatisch (Kanalisation oder Verschlussikterus: Obstruktion der Gallenwege). Für den Chirurgen entscheidend, ob die Gelbsucht durch eine mechanische Obstruktion der Gallenwege verursacht wird. 


\section{Diagnostik:}

- Anamnese: Geschlecht, Alter, Schmerzanamnese und Trinkgewohnheiten (»Steinikterus« vs. »Zirrhoseikterus«), körperliche Untersuchung, Courvoisier-Zeichen.

- Labor: Bilirubin, Transaminasen, AP, Y-GT, Leukozyten, Thrombozyten, Quick.

- Ultraschalluntersuchung des Abdomens (Weichensteller für das weitere diagnostische Vorgehen), CT, Cholegraphie (ERCP, PTC), MRCP, evtl. Laparoskopie und Leberbiopsie.

\subsubsection{Raumforderungen im Abdomen}

Definition
Unter intraabdominaler Raumforderung versteht man
nach klinischen Kriterien jede tastbare oder sichtbare
Resistenz bzw. Vorwölbung im Abdominalbereich, die der
Peritonealhöhle zugeordnet werden kann.

Nach Kriterien bildgebender Verfahren werden intraabdominale Raumforderungen als Kontrastmittelaussparung definiert, die zu einer Veränderung normaler Organkonturen oder einer Verdrängung von Organen und Organsystemen geführt hat.

\section{Ursachen und Klassifikation}

Ursache intraabdominaler Tumoren sind bösartige oder gutartige Neubildungen, entzündliche Prozesse oder reparative Vorgänge nach Entzündungen (z. B. Pankreaspseudozysten). Intraabdominale Raumforderungen können nach klinischen Kriterien klassifiziert werden, z.B. solide oder zystisch, schmerzhaft oder nicht schmerzhaft, derb oder weich, verschieblich oder nicht verschieblich. Zur Klassifikation intraabdominaler Tumoren können auch die Echogenität in der Sonographie oder die Dichte im CT herangezogen werden.

\section{Anamnese und Symptomatologie}

Anamnestisch sind Begleitsymptome und Entwicklungszeit der Raumforderung (schnelles oder langsames Wachstum) wichtig. Bei Inspektion und Palpation ist auf Schmerzhaftigkeit, Atemverschieblichkeit, pulssynchrones Verhalten, Darmsteifung, Konsistenz des Tumors und begleitende Hautverfärbungen zu achten.

\section{Apparative Diagnostik Laborparameter}

Neben unspezifischen Laborparametern, die lediglich Hinweisfunktion haben, z. B. Erhöhung der BSG, Erhöhung der $\alpha_{2}$ - und $\beta$-Fraktion in der Elektrophorese, Erniedrigung des Serumeisenspiegels und Erhöhung des Ferritinspiegels, können in der klinischen Praxis eine Reihe von Tumormarkern wie CEA, CA 19-9 und $\alpha$-Fetoprotein wichtige Hinweise geben.

\section{Sonographie und CT}

Bei der Fahndung nach intraabdominalen Tumoren nehmen die nichtinvasiven bildgebenden Verfahren Sonographie und CT die führende Stellung ein. Eine Ausnahme sind Tumoren des Magens und des Darmes, die nach wie vor durch Endoskopie und Biopsie sowie Röntgenkontrastmitteluntersuchung diagnostiziert werden. Unter den bildgebenden Verfahren sollte die Sonographie zuerst eingesetzt werden. Bei Verdacht auf Tumorbildung in einem parenchymatösen Organ kann ein CT folgen.

\section{Invasive Verfahren}

Invasive Verfahren sollten möglichst erst dann zum Einsatz kommen, wenn eine definitive Diagnostik mit den oben angeführten Methoden nicht möglich war oder wenn bei einem geplanten operativen Eingriff zur Resezierbarkeit des Tumors Stellung genommen werden soll.

$\mathrm{Zu}$ nennen ist die angiographische Darstellung der abdominalen Gefäße in der arteriellen und venösen Phase, die z. B. bei Lebertumoren zur Artdiagnose herangezogen werden kann und hier auch wie bei einigen anderen Tumoren (Pankreaskarzinom) zur Feststellung der Resezierbarkeit des Tumors dient. Einen wichtigen Platz nehmen auch endoskopische Untersuchungen ein, hier v. a. die ERCP und PTC. Durch die Ultraschall- oder CT-gezielte Feinnadelpunktion kann die zytologische oder histologische Sicherung der Tumordiagnose erreicht werden. Dieses kann zur Operationsindikation bzw. zur Vermeidung von Eingriffen bei nicht resezierbaren Tumoren entscheidend beitragen.

\section{In Kürze}

\section{Raumforderungen im Abdomen}

Gut- oder bösartige Neubildungen, Pankreaspseudozysten.

Diagnostik: Ultraschalluntersuchung und CT (entscheidende Untersuchungsmethoden). Anamnese, körperliche Untersuchung, Labor (BSG, Elektrophorese, Serumeisen, Ferritin, Tumormarker), Angiographie u. a., evtl. Feinnadelpunktion.

\section{Weiterführende Literatur}

Bickley LS (2009) Bates Guide to physical examination and history taking, Lippincott Williams and Wilkins, 6. Aufl

Dahmer J (2006) Anamnese und Befund, Thieme, 10. Aufl

Fetzner UK, Hölscher AH (2009) Diagnose? Leicht gemacht!, Springer CME 6(12): 7-14

Grüne, Schölmerich (2007) Anamnese - Untersuchung - Diagnose, Springer

Hölscher AH (2006) Ösophagus. In: Becker, Encke, Röher: Viszeralchirurgie, Urban \& Fischer, 2. Aufl

Hölscher AH, Bäumler D, Bernhardt J (2000) Transkutane Sonographie: Systembezogene, organübergreifende Untersuchung und 
sonographische Leitbefunde. In: Weiser HF (Hrsg) Visceralchirurgische Sonographie. Springer, Heidelberg, S 319-355

Prosiegel (2010) Weber. Dysphagie, Springer

Siewert JR, Bumm R, Hölscher AH, Dittler HJ (1989) Obere gastrointestinale Ulkusblutung - Letalitätssenkung durch früh-elektive chirurgische Therapie von Risikopatienten. Dtsch Med Wochenschr 114:447-452

Siewert JR, Hölscher AH, Bumm R (1990) Chirurgische Therapie der gastroduodenalen Blutung. In: Siewert JR, Harder F, Allgöwer M et al. (Hrsg) Chirurgischer Gastroenterologie, 2. Aufl. Springer, Heidelberg, S 821-832

Siewert, Rothmund, Schumpelick (2006) Praxis der Viszeralchirugie, Band: Gastroenterologische Chirurgie. Springer, 2. Aufl

Troidl H, Vestweber KH, Kusche J, Bouillon B (1986) Die Blutung beim peptischen Gastroduodenalulkus: Daten als Entscheidungshilfe für ein chirurgisches Therapiekonzept. Chirurg 57:372-380

\subsection{Indikationen und Kontraindikationen zum operativen Eingriff}

\section{J. R. Siewert, R. Bumm}

Ohne eine korrekte Operationsindikation darf naturgemäß kein chirurgischer Eingriff erfolgen. Der Prozess der Indikationsstellung beginnt in der Regel beim Hausarzt des Patienten, der aufgrund einer Verdachtsdiagnose eine Krankenhauseinweisung vornimmt. Dabei hat er häufig bereits die Entscheidung zu treffen, welcher Art der Therapie (z. B. operativ oder konservativ) der Patient bedarf. Dies wird bei der heute gegebenen Therapievielfalt für den Hausarzt immer schwerer zu entscheiden, obwohl therapeutische Leitlinien inzwischen global verfügbar sind. Die Kliniken - derzeit noch methodisch und organbezogen orientiert - werden künftig den neuen Anforderungen durch Schaffung sog. problemorientierter Zentren gerecht werden müssen. Die Voraussetzungen und Bedingungen für die chirurgische Indikationsstellung bleiben davon unberührt.

\subsubsection{Rechtliche Aspekte}

(.) Cave

Jeder chirurgische Eingriff erfüllt den formalen Tatbestand der Körperverletzung. Er darf deshalb nur mit ausdrücklicher Einwilligung des Patienten ausgeführt werden.

Die Einwilligung des Patienten ist nur dann wirksam, wenn der Patient über den geplanten Eingriff aufgeklärt ist und diesem zugestimmt hat (sog. informed consent).

\section{Aufklärung}

Die Aufklärung über einen chirurgischen Eingriff soll den Patienten in die Lage versetzen, sich in Kenntnis der für ihn wesentlichen Umstände (Prognose seiner Erkrankung ohne Behandlung, Erfolgsaussichten des chirurgischen Eingriffs, nachteilige Folgen und Risiken des Eingriffs, Behandlungs- alternativen) für oder gegen die Operation zu entscheiden (- Abb. 1.8).

$>$ Ohne oder gegen den Willen eines Patienten darf der Arzt auch eine dringende, vital indizierte Behandlung nicht durchführen.

Ist der Patient nicht willens oder fähig, so bedarf es der Einwilligung seines gesetzlichen Vertreters. Bei unaufschiebbaren Notfalleingriffen entscheidet der Arzt entsprechend dem mutmaßlichen Willen des Patienten (z. B. beim Bewusstlosen nach einem Verkehrsunfall).

Die Rechtssprechung stellt an die Aufklärung über die allgemeinen Operationsgefahren (z.B. Infektionsrisiko, Thrombose- oder Emboliegefahr, etc.) geringere Anforderungen. Sehr viel strengere Anforderungen stellt die Rechtssprechung dagegen an die Aufklärung über die eingriffsspezifischen sog. typischen Risiken. Dies gilt auch für die Aufklärung über sehr seltene Risiken (Wahrscheinlichkeit des Eintritts: 1:10.000-1:20.000). So ist z. B. bei einer beidseitigen subtotalen Schilddrüsenresektion über die Möglichkeit einer doppelseitigen Stimmbandlähmung mit Notwendigkeit der Tracheotomie aufzuklären.

\section{$>$ Die Intensität der Aufklärungspflicht reduziert sich beim vital indizierten Notfalleingriff.}

Die wesentliche forensische Bedeutung der Aufklärungspflicht liegt in der Verschiebung der Beweislast (Weißauer 1980, 1985): Der Kläger, der seinen Schadensanspruch auf einen schuldhaften Behandlungsfehler stützt, muss diesen und seine Ursächlichkeit für den Schaden beweisen. Macht der Kläger aber geltend, er wäre nicht adäquat aufgeklärt worden, muss der Arzt die Aufklärung beweisen.

( Es empfiehlt sich daher dringend, eine sorgfältige Dokumentation des Aufklärungsgespräches vorzunehmen.

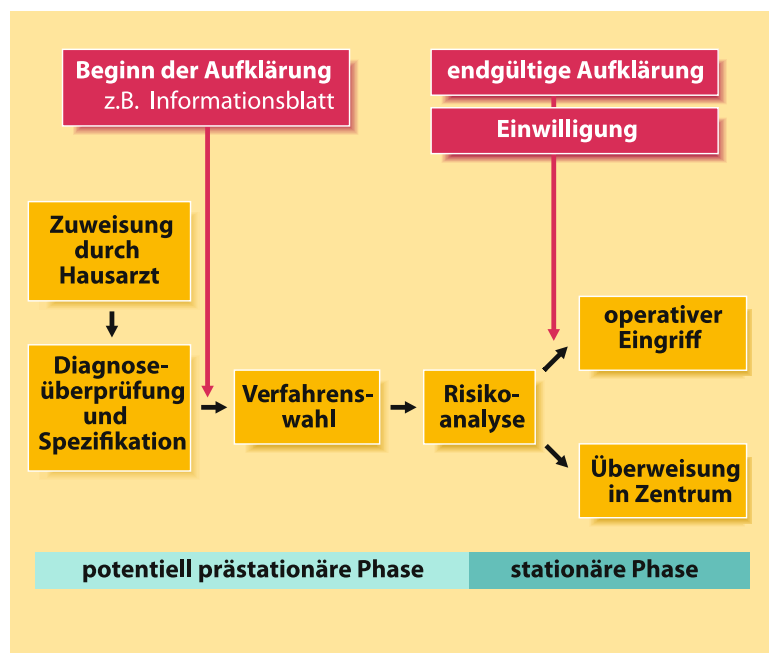

- Abb. 1.8 Indikationsstellung und Patientenaufklärung in der Chirurgie 


\section{Stufenaufklärung}

Darunter versteht man eine Kombination von schriftlicher Aufklärung (z.B. durch Merkblätter über den betreffenden Eingriff) und mündlicher Aufklärung durch den Arzt. Diese Aufklärungsschritte sollten idealerweise zeitlich gestaffelt erfolgen.

\section{Erweiterung des Eingriffs}

Ist aufgrund einer präoperativen sorgfältigen Diagnostik erkennbar, dass möglicherweise eine Erweiterung des eigentlich geplanten Eingriffs erforderlich werden kann, so muss der Arzt den Patienten präoperativ darüber aufklären und seine Einwilligung auch dazu einholen.

Ergibt sich erst während der Operation die Indikation für eine Änderung oder Erweiterung des Eingriffes und ist der Abbruch des Eingriffes sowie ein späterer erneuter Eingriff mit zusätzlichen Belastungen und Risiken für den Patienten verbunden, muss der Arzt nach dem mutmaßlichen Willen des Patienten handeln.

\section{Simultaneingriffe}

Wenn sich durch die Verbindung zweier oder mehrerer Eingriffe kein höheres medizinisches Risiko ergibt und der Patient darüber aufgeklärt ist, sind Simultaneingriffe erlaubt.

\subsubsection{Fachliche Grundlagen}

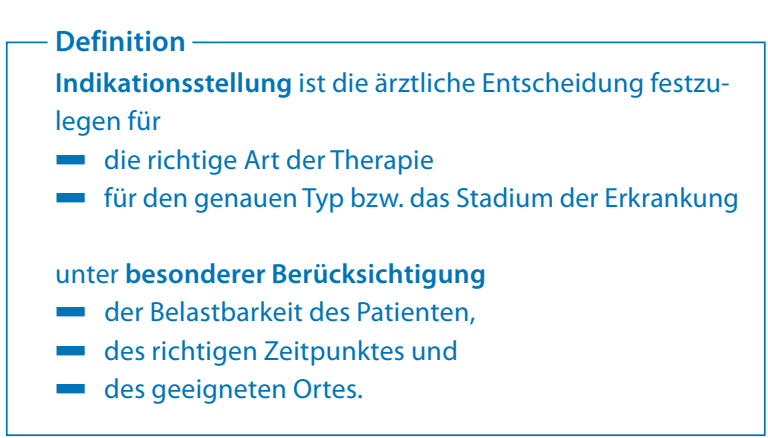

Die Indikationsstellung ist die wichtigste ärztliche Entscheidung in der Chirurgie. Sie entscheidet in hohem Maße über den Erfolg der Therapiemaßnahme. Die Indikationsstellung muss objektivierbar und nachvollziehbar sein, ggf. durch eine Second opinion überprüfbar sein. Im Notfall kommt der subjektiven Beurteilung eines erfahrenen Chirurgen besondere Bedeutung zu. Sie setzt eine exakte Diagnose voraus.

Im Einzelnen erfolgt die Abwägung der verschiedenen Punkte wie folgt.

\section{Art der Therapie}

Die ärztliche Entscheidung, aus dem verfügbaren Verfahrensspektrum - beinhaltend sowohl operative wie konservative Therapieprinzipien - die richtige Verfahrenswahl zu treffen, ist besonders wichtig.
Hierbei ist es von Bedeutung, dass der Chirurg das bewährte Verfahrensspektrum kennt und bewerten kann. Er hat den Patienten darüber aufzuklären. Stehen konservative, z. B. endoskopische Verfahren gleichrangig neben chirurgischen Verfahren, muss der Patient auch über diese Möglichkeiten aufgeklärt werden. Die Vor- und Nachteile der einzelnen Verfahren abschätzen zu können, setzt eine stets aktuelle Fortbildung voraus.

In die Verfahrenswahl gehen nicht nur objektive Fakten, sondern auch persönliche Erfahrungen ein. So spielt die Tatsache, welches Verfahren ein Chirurg besonders gut beherrscht, naturgemäß eine große Rolle. Gegebenenfalls muss aber auch eine Weiterverlegung des Patienten in ein Zentrum mit größerer Erfahrung erfolgen.

\section{Typ und Stadium der Erkrankung}

Erkrankung und Patient spielen die entscheidende Rolle in der Indikationsstellung. Grundsätzlich muss zwischen gutartigen und bösartigen Erkrankungen im Rahmen der Indikationsstellung unterschieden werden.

\section{Gutartige Erkrankungen}

$>$ Für die richtige Therapieentscheidung ist die Individualdiagnose bzw. der spezielle Typ der Erkrankung entscheidend.

In aller Regel wird ein Patient sich aufgrund seiner Symptome an den Hausarzt wenden. Dieser hat die Aufgabe, orientiert am Leitsymptom eine Arbeitshypothese für die weitere Diagnostik abzuleiten und den Patienten mit einer chirurgischen Diagnose ggf. zur Operation in das Krankenhaus einzuweisen. Inzwischen stehen für viele Krankheitsbilder therapeutische Leitlinien der Fachgesellschaften zur Verfügung ( Abschn. 1.10). Im Krankenhaus muss dann eine Individualdiagnose bzw. der Typ der Erkrankung festgelegt werden, die für die weitere Verfahrenswahl prägend ist.

Praxisbox

Beispiele zur Therapieentscheidung

- Im Rahmen der Ulkuskrankheit muss z. B. festgelegt werden, ob es sich um ein Ulcus ventriculi, ein präpylorisches Ulkus oder um ein Ulcus duodeni handelt. Die therapeutischen Konsequenzen sind unterschiedlich ( $\triangleright$ Abschn. 7.6).

- Im Rahmen der Ulkuskomplikationen, z. B. bei der Blutung, bestimmen Blutungsaktivität, Blutungsintensität und Blutungslokalisation die Therapieentscheidung ( $\triangleright$ Abschn. 1.1).

- Im Rahmen des Gallensteinleidens prägt die Tatsache, ob es sich um einen Gallensteinträger oder um einen Gallensteinkranken handelt, alle weiteren Überlegungen. Gallenblasensteine mit begleitender Entzündung oder begleitenden Komplikationen sind anders zu bewerten als blande Gallensteine. 
Insgesamt kann nur auf dem Boden einer sorgfältigen Individualdiagnose und in Kenntnis des genauen Typs der Erkrankung die richtige Therapieentscheidung getroffen werden.

\section{Bösartige Erkrankungen}

( Bei Malignomen muss zwischen Eingriffen mit palliativer Intention (Verbesserung der Lebensqualität) und Eingriffen mit kurativer Intention (Verbesserung der Prognose) unterschieden werden.

Um präoperativ entscheiden zu können, mit welcher Intention der Eingriff ausgeführt werden kann, ist die Erfassung sog. Prognosefaktoren wichtig. Derartige Prognosefaktoren sind für die verschiedenen Organtumoren erarbeitet worden und werden in den spezifischen Kapiteln dargestellt. Grundsätzlich lässt sich sagen, dass das Tumorstadium zum Zeitpunkt der Diagnose die Prognose am meisten prägt. Hier kommt unter allen Prognosefaktoren dem sog. nodulären Status (Lymphknotenmetastasen) die größte Bedeutung zu.

$>$ Durch ein sorgfältiges präoperatives Staging können viele Prognosefaktoren erfasst werden und in die Therapieentscheidung eingehen. Dieses Staging ist heute obligat. Es ermöglicht eine individuelle Indikationsstellung, die in jedem Fall anzustreben ist.

Die Erfassung des wichtigsten Prognosefaktors, nämlich das Ausmaß der Lymphknotenmetastasierung ist bei vielen Tumoren schwierig. Besser erfassbar ist die Ausdehnung des Primärtumors. Es besteht in den meisten Fällen eine gute Korrelation zwischen T-Kategorie und N-Kategorie.

\section{Belastbarkeit des Patienten}

Die Belastbarkeit eines Patienten klärt man am besten durch eine Risikoanalyse ab.

Dafür stehen verschiedene Risiko-Scores zur Verfügung (ASA, Appache II, - Abschn. 1.4.2), die jedoch nur eine sehr globale Erfassung des Risikos erlauben. Geeigneter für die Erfassung des Risikos erscheint die präoperative Analyse der wichtigsten Organfunktionen. Dabei stehen für die verschiedenen Eingriffe unterschiedliche Funktionen im Vordergrund (z. B. bei geplanter Ösophagektomie Störungen in der kardialen und in der Leberfunktion). Eine der Ursachen dafür ist, dass ein Versagen von Herz oder Leber postoperativ nur sehr schwer behandelt werden kann. Entsprechend werden Lungenfunktionsstörungen in Anbetracht der Verfügbarkeit suffizienter Beatmungstechniken geringer eingeschätzt. Einer eingeschränkten Nierenfunktion kommt in Anbetracht wirksamer Therapiemöglichkeiten eine nur untergeordnete Bedeutung zu.

Wesentlichster Gesichtspunkt der präoperativen Risikoabgrenzung ist der Gesamtzustand des Patienten, der sich z. B. im sog. Karnofsky-Index ( $\triangleright$ Abschn. 1.4.2) erfassen lässt und die mentale Kooperationsbereitschaft. Diese Kooperationsbereitschaft wird am nachhaltigsten durch Alkoholismus und zerebrale Durchblutungsstörungen negativ beeinflusst.
Das Alter eines Patienten allein gilt in der Regel nicht als isolierter Risikofaktor.

In jedem Fall muss sich der Umfang der präoperativen Risikoanalyse am Schweregrad des geplanten Eingriffs orientieren.

\section{Dringlichkeit des operativen Eingriffs}

( Absolute Indikation: Der Eingriff muss unverzüglich durchgeführt werden, anderenfalls ist mit dem Tod des Patienten zu rechnen.

Hier unterscheidet man zwischen:

- Eingriffen mit hoher Dringlichkeit, z. B. konservativ nicht zu stoppende Blutung $\rightarrow$ Notfalloperation und

- Eingriffen mit relativer Dringlichkeit, z. B. Dickdarmileus.

Bei Eingriffen von absoluter Indikation tritt der Stellenwert der detaillierten Aufklärung zurück, da ein Unterlassen der Operation unmittelbar zum Tode des Patienten führen würde.

Frühelektiv durchgeführte Operationen sind dringliche Eingriffe, die aber auf einen günstigen Zeitpunkt (z.B. im Routineoperationsprogramm am nächsten Morgen) verschoben werden können mit Verfügbarkeit aller technischen Modalitäten und einem geeigneten Operationsteam.

$>$ Relative Indikation: Der operative Eingriff kann durchgeführt werden, weil er für den Patienten einen quantifizierbaren Vorteil bringt.

Er führt potenziell

- zur Heilung eines Patienten (z. B. Cholezystektomie bei Cholezystolithiasis),

- zu einer deutlichen Prognoseverbesserung (z. B. gut resektables Magenkarzinom) oder

- zu einer deutlichen Verbesserung der Lebensqualität (z. B. operative Beseitigung einer Magenausgangsstenose).

Derartige Eingriffe haben in aller Regel Zeit und können elektiv durchgeführt werden. $\mathrm{Zu}$ diesen relativen Indikationen zählen auch sog. kosmetische Indikationen (z. B. Narbenkorrekturen) und auch sog. prophylaktische Indikationen: Die Operation beseitigt vorsorglich einen Herd, der mit großer Wahrscheinlichkeit zu einer Gefährdung des Patienten führen wird, z. B. Präkanzerose.

Bei allen relativen Indikationen muss die Aufklärung besonders sorgfältig durchgeführt werden, um dem Patienten eine echte Entscheidungsfreiheit bezüglich Ort, Operationszeitpunkt und Operateur einzuräumen.

\section{Geeigneter Ort}

Dieser Gesichtspunkt ist in den letzten Jahren zunehmend zu größerer Bedeutung gelangt, weil durch die Patientenmobilität und das flächendeckende Krankenhausnetz innerhalb Deutschlands oder auch Europas keine Notwendigkeit besteht, operative Eingriffe vor Ort, d.h. in unmittelbarer Nähe des Wohnortes durchzuführen. 
Der geeignete Ort meint,

- dass die entsprechende Klinik über eine dem geplanten Eingriff adäquate Ausstattung apparativer und personeller Art verfügt (z. B. Verfügbarkeit einer postoperativen Intensivpflegestation),

- dass der Chirurg über eine ausreichend große Erfahrung für den Eingriff verfügt. Der Chirurg ist für das Ergebnis einer Operation der prägende Prognosefaktor.

Für alle operativen Eingriffe ist in Deutschland der sog. Facharztstandard Voraussetzung, d.h. ein Facharzt für Chirurgie muss die Operation durchführen oder sie als Assistent überwachen.

\section{Second Opinion (Zweitmeinung)}

Die Einholung einer Second opinion ist in Deutschland vor gewichtigen Eingriffen als Recht der Patienten gesetzlich vorgegeben (SGBV). Als Second-opinion-Instanz eignet sich ein im betreffenden Krankheitsbild erfahrenes unabhängiges Zentrum. Voraussetzung ist eine abgeschlossene Erstmeinung des behandelnden Arztes. Welchen Einfluss die Second opinion auf die Therapieentscheidung des Patienten nimmt, ist derzeit noch offen. Möglicherweise wird sie aber Voraussetzung für die Kostenübernahme durch die Kassen.

\section{Kontraindikation}

Eine Kontraindikation zu einer Operation kann sich aus allen genannten Faktoren ergeben. Meist resultiert sie aus einer schweren Zweiterkrankung des Patienten (z.B. einem frischen Herzinfarkt), die einen operativen Eingriff nur mit höchstem Risiko zulassen würde. Kontraindikationen können sich aber auch aus der Erkrankung selbst (z. B. weit fortgeschrittene systemisch metastasierte Tumorerkrankung), aber auch durch den Operateur (z.B. mangelnde Erfahrung) ergeben.

\section{Inoperabilität/Irresektabilität}

$>$ Inoperabilität bezieht sich immer auf den Patienten, Irresektabilität auf seine Erkrankung.

Ergibt die Risikoanalyse eines Patienten ein extrem hohes Operationsrisiko, kann daraus eine Inoperabilität resultieren. Ist ein Tumor technisch nicht mehr mit vertretbarem Risiko resezierbar, resultiert daraus Irresektabilität.

\section{Spontanverlauf einer Erkrankung (sog. natürlicher Verlauf)}

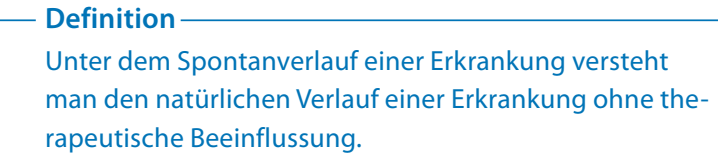

Das Wissen um den Spontanverlauf verschiedener gutartiger Erkrankungen ist gering, da derzeit fast jede diagnostizierte Erkrankung irgendwann therapeutisch beeinflusst wird. Dennoch liegen $\mathrm{zu}$ verschiedenen Erkrankungen epidemiolo- gische Studien vor, die den Spontanverlauf abschätzen lassen. Der Spontanverlauf maligner Erkrankungen ist dagegen besser abschätzbar.

Die Kenntnis des Spontanverlaufs einer Erkrankung ist von großer Bedeutung für die Entscheidung zu einem chirurgischen Eingriff.

\section{Multimodale Therapie}

Multimodale Therapieprinzipien kommen in erster Linie bei bösartigen Tumoren zum Einsatz. Dabei werden neben der Chirurgie v. a. die Chemotherapie und die Strahlentherapie eingesetzt. Bei allen onkologisch-chirurgischen Eingriffen muss die Frage nach der Sinnhaftigkeit eines multimodalen Vorgehens geprüft werden. Derartige multimodale Therapieprinzipien können präoperativ (neoadjuvant) zum Einsatz kommen, aber auch intraoperativ und postoperativ (adjuvante Therapie nach R0-Resektion; additive Therapie nach R1- oder R2-Resektion).

Überlegungen zur multimodalen Therapie müssen deshalb so früh wie möglich, d.h. bereits bei der primären Indikationsstellung in die Therapieplanung einbezogen werden, insbesondere muss die Indikation $\mathrm{zu}$ einer neoadjuvanten Therapie bereits initial getroffen werden. In diesem Zusammenhang sind die folgenden Definitionen wichtig:

\section{- Definition \\ Neoadjuvante Therapie: Präoperativer Einsatz einer Che- motherapie oder Strahlentherapie zum Zwecke der Tu- morreduktion mit dem Ziel, nach Vorbehandlung chirur- gisch doch noch eine komplette Tumorentfernung (sog. R0-Resektion) zu erreichen. \\ Adjuvante Therapie: Postoperative Therapie nach kom- pletter Tumorentfernung (sog. R0-Resektion) zur Prophy- laxe der systemischen Metastasierung. \\ Additive Therapie. Postoperativer Einsatz von Strahlen- oder Chemotherapie nach inkompletter Tumorentfer- nung (sog. R1- oder R2-Resektion).}

\section{Intraoperative Zusatztherapie}

Intraoperativ kann z. B. die Strahlentherapie zur Verbesserung der lokalen Radikalität im Tumorbett oder auch die Applikation verzögert freigesetzter Chemotherapeutika, z. B. als intraperitoneale Therapie zum Einsatz kommen.

\section{Problemorientierte Zentren}

Die Notwendigkeit der Festlegung der adäquaten Therapie unter interdisziplinärer Abwägung macht das organisierte Gespräch zwischen den verschiedenen medizinischen Disziplinen mehr und mehr notwendig (z. B. Tumorboard bei Krebspatienten). Darüber hinaus muss die Krankenhausstruktur künftig mehr den Patienten und sein Problem ins Zentrum seiner Operation stellen. Dies wird zur Bildung sog. problemorientierter Zentren führen, die unter Nutzung moderner Telekommunikationsmöglichkeiten neben die klassischen Klinikstrukturen treten werden. 


\section{In Kürze}

Indikationen und Kontraindikationen zum operativen Eingriff

Rechtliche Aspekte: Ohne rechtswirksame Einwilligung ist ein chirurgischer Eingriff formal als Körperverletzung anzusehen. Voraussetzung für die Einwilligung: korrekte Patientenaufklärung (allgemeine Operationsgefahren und eingriffsspezifische, typische Risiken), sorgfältige Dokumentation.

Fachliche Grundlagen: Indikationsstellung: ärztliche Entscheidung (nachvollziehbar, Second opinion)

- Richtige Art der Therapie: Voraussetzung: Kenntnis der Individualdiagnose im Kontext der aktuellen wissenschaftlichen Erkenntnisse (Fortbildung), konservative und operative Therapiemaßnahmen und deren objektive Darstellung gegenüber dem Patienten.

- Typ (therapeutische Leitlinien der Fachgesellschaften) bzw. Stadium der Erkrankung: gut-, bösartig, Staging, Prognosefaktoren, Eingriffe mit palliativer und kurativer Intention, multimodale Therapie: (neo)adjuvante bzw. additive Therapie.

- Belastbarkeit des Patienten: Risikoanalyse, KarnofskyIndex.

- Richtiger Zeitpunkt: absolute Indikation mit hoher oder relativer Dringlichkeit, relative Indikation.

- Geeigneter Ort: Klinik mit adäquater Ausstattung, erfahrener Chirurg, problemorientierte Zentren.

\section{Weiterführende Literatur}

Weißauer W (1980) Die ärztliche Aufklärungspflicht und das Konzept der Stufenaufklärung. Notfallmedizin 6:719-721

Weißauer W (1985) Der prozessuale Umweg über die Aufklärungspflicht und die Stufenaufklärung. Klinikarzt 14:748

Problemorientiertes Zentrum: http://www.cancercenter.de/

Therapeutische Leitlinien: http://www.awmf-online.de/

\subsection{Grundprinzipien der Operationstechnik}

\section{H. Feußner, B. Detter, J. R. Siewert}

\footnotetext{
Die Operationsverfahren der Allgemeinchirurgie setzen eine genaue Kenntnis der zur Verfügung stehenden Instrumente und Nahtmaterialien voraus. Ein optimaler Zugang zum Operationsfeld wird durch eine suffiziente Lagerung des Patienten und standardisierte Operationszugänge und Schnittführungen erreicht. Von besonderer Bedeutung ist die Kenntnis der möglichen Nahttechniken, die sich an den anatomischen Gegebenheiten der zu vereinigenden Gewebe orientiert. Der Nahtvorgang wird mit einem manuell oder instrumentell sicher ausgeführten Knoten komplettiert. Des Weiteren soll auf die zur Verfügung stehenden Drainagen und deren Indikation eingegangen werden.
}

\subsubsection{Grundbegriffe}

Additive Therapie Zusätzlich zu einer Tumorresektion durchgeführte onkologische Behandlung (z. B. Chemotherapie, Strahlentherapie), wobei nach dem chirurgischen Eingriff Tumoranteile im Patientenorganismus zurückgelassen werden mussten. Eine klassische Indikation für eine additive Therapie ist z. B. die Durchführung einer Chemotherapie bei Zustand nach reseziertem Kolonkarzinom und bekannten, nichtresektablen Lebermetastasen.

Adjuvante Therapie Zusätzlich zu einer Tumorresektion durchgeführte onkologische Behandlung (z. B. Chemotherapie, Strahlentherapie), wobei der Tumor zuvor nach Befund des Pathologen mikroskopisch und makroskopisch komplett entfernt werden konnte. Eine klassische, in kontrollierten Studien abgesicherte Indikation ist z. B. die Durchführung einer adjuvanten Chemotherapie bei Z.n. komplett reseziertem Kolonkarzinom und dem Nachweis von tumorbefallenen Lymphknoten im Resektionspräparat.

Amputation Spontanes, traumatisches oder operatives Abtrennen eines endständigen Körper- oder Organabschnittes (Extremitätenamputation, Rektumamputation etc.).

Anastomose Angeborene oder erworbene (z. B. operativ geschaffene) Verbindung zweier Hohlorganlumina. Man unterscheidet zwischen End-zu-End-Anastomosen, End-zu-SeitAnastomosen und Seit-zu-Seit-Anastomosen.

Anus praeter (A. p.) Künstlicher Darmausgang, der fast immer an der vorderen Bauchwand angelegt wird. Man unterscheidet permanente A. p. (z. B. zur Behandlung eines Darmverschlusses durch ein nichtresektables Rektumkarzinom) und temporäre (protektive) A. p. (z. B. vorgeschaltetes Ileostoma zum »Schutz« einer tiefen Rektumanastomose). Der A. p. bezeichnet sich nach dem ausgeführten Darmanteil (Ileostoma, Kolostoma, Aszendostoma, Deszendostoma) und wird weiterhin in endständige Stomata (endständiges Ausführen des Darmanteils aus der Bauchwand) und doppelläufige A. p. (Ausführen eines Darmschenkels mit zu- und abführendem Anteil, häufig verwendet bei protektiven A. p., z. B. Ileostoma) unterteilt.

Bride Strangförmige intraabdominelle Verwachsung, die zumeist im Gefolge von abdominellen Eingriffen auftritt und die Ursache eines postoperativen Ileuszustandes sein kann. Die Durchtrennung der Bride ist bei frühzeitiger Erkennung die kausale Therapie des Ileuszustandes.

Bypass Umgehungsanastomose im engeren Sinne: der künstliche, vorübergehend oder auf Dauer angelegte Umgehungsweg, meist im Sinne des Kollateralkreislaufs verwendet.

Dissektion Zerteilung von Gewebe zur Freilegung von Organstrukturen meist entlang eines vorgegebenen anatomischen »Operationspfades«. Die sachgerechte Dissektion trägt 
wesentlich zur Erhöhung der Operationsradikalität und zum blutsparenden Präparieren bei.

Ektomie Vollständiges Herausschneiden eines Organs (z. B. Gastrektomie, Cholezystektomie; $>$ Exstirpation).

Endoskopische Operation Eingriffe innerhalb von Hohlorganen mittels eines durch physiologische Körperöffnungen eingeführten Endoskopes (z. B. Papillotomie, Polypenabtragung). Im weiteren Sinne werden auch Eingriffe in Körperhöhlen, die über entsprechende Trokare durch artifizielle $\mathrm{Zu}$ gänge (z. B. laparoskopische, thorakoskopische oder arthroskopische Operation) ausgeführt werden, unter diesem Begriff zusammengefasst.

Enterostomie Operative Darmausleitung oder Fistelung zur Körperoberfläche (meist der Bauchwand) zum Zwecke der künstlichen Ernährung oder der Ableitung von Darminhalt. Im weiteren Sinne auch für interne Verbindung zwischen verschiedenen Hohlorganen zum Zwecke der Wiederherstellung oder Verbesserung der Intestinalpassage (z. B. Gastroenterostomie, Ileotransversostomie) benutzt.

Enterotomie Artifizielle, meist operative Eröffnung des Gastrointestinaltraktes (z.B. zur Fremdkörperentfernung, zum Zwecke der Diagnostik, zur Tumorentfernung, zum Darmabsaugen).

Enukleation "Ausschälen« eines abgekapselten Fremdkörpers oder Tumors ohne Mitentfernung benachbarten Gewebes.

Exhairese Herausziehen einer anatomischen Struktur (z. B. Nerv oder Vene).

Exploration Damit ist die z. T. tastende, z. T. visuelle»Erkundung « der Bauchhöhle bei einer Laparotomie zum Ausschluss pathologischer Organveränderungen gemeint. Zur kompletten Exploration bewährt es sich, nach einem festgeschriebenen Schema vorzugehen. Die Eröffnung der Bursa omentalis ist sinnvoll, um retroperitonale Prozesse zu erkennen. Die intraoperative Sonographie eröffnet eine neue Möglichkeit zur Verbesserung der intraoperativen Exploration.

Exstirpation Entfernung eines umschriebenen Gebildes (z. B. Tumor), wobei der Defekt der Spontanheilung überlassen bleibt. Aber auch Entfernung eines ganzen Organs (z. B. Gallenblasenexstirpation).

Exzision Entfernung eines Gewebe- oder Organteils mit einem scharfen Instrument ( $\downarrow$ Probeexzision), auch die Entfernung eines Tumors zum Zwecke der histologischen Untersuchung.

Gefäßdesobliteration Wiedereröffnung eines Gefäßlumens durch Entfernung von meist atheromatösen Plaques inklusive der Intima aus ganz oder teilweise verschlossenen Blutge- fäßen mittels spezieller Instrumente nach Inzision des Gefäßes.

Gewebeersatz Ersatz körpereigenen Gewebes durch artifizielle Ersatzstoffe oder körpereigenen Gewebetransfer, aber auch durch autologe oder heterologe Gewebetransplantation.

Implantation Einbringen eines Implantates in den Körper (z. B. Einpflanzung einer Gelenk-, Gefäß- oder Herzklappenprothese, eines künstlichen Herzschrittmachers).

Injektion Relativ rasches Einbringen einer Flüssigkeit (Arzneimittel, Infusionslösung, Blut etc.) in den Körper. Aber auch »kapilläre Gefäßinjektion« (

Inzision Chirurgisches Einschneiden in das Gewebe, meist im Sinne einer Eröffnung (z. B. eines Abszesses oder Hohlorganes).

Minimalinvasive Operationsverfahren Der Begriff minimalinvasiv bezieht sich in erster Linie auf den Zugangsweg zur jeweiligen Körperhöhle. Hier werden im Gegensatz zu den Zugängen der offenen Chirurgie nur kleine Stichinzisionen verwendet, über die Trokare eingebracht werden, um auf diese Weise endoskopisches Operieren in Körperhöhlen zu ermöglichen.

Neoadjuvante Therapie Vor einer Tumorresektion durchgeführte onkologische Behandlung (z. B. Chemotherapie, Strahlentherapie) mit dem Ziel, den Tumor des Patienten vor einer geplanten Resektion zu verkleinern bzw. eine bessere Gesamtprognose des Patienten zu erzielen. Eine klassische Indikation für eine neoadjuvante Therapie ist z. B. die präoperative Chemotherapie bei einem Patienten mit fortgeschrittenem Magenkarzinom.

Osteosynthese Vereinigung reponierter Knochenfragmente durch Verschraubung, Nagelung, Plattenanlagerung etc.

Punktion Einführen einer Kanüle in einen präformierten (Gelenk, Pleura, Bauchhöhle, Liquor, Blutgefäß etc.) oder pathologischen Hohlraum (z.B. Abszess) zur diagnostischen Analyse des Inhaltes oder aber auch Punktion eines Gewebes zur Gewinnung einer Gewebeprobe (z. B. Abklärung der Dignität bei Tumoren).

\section{Rekonstruktion Wiederherstellung.}

Reposition "Zurückführen« eines pathologisch verlagerten Organanteils in seine ursprüngliche anatomische Lage. Die gekonnte Reposition ist eine wesentliche Voraussetzung der konservativen Knochenbruchbehandlung. Aber auch pathologisch intraabdominell verlagerte Organe (z. B. Darmstrukturen in einem Bruchsack bei Leistenhernie) können geschlossen (ohne Operation) oder offen (operativ) reponiert werden. 
Resektion Operative partielle oder komplette Entfernung eines Organs (z. B. Darmresektion).

En-bloc-Resektion Entfernung eines Organs oder eines Anteils eines Organs im Zusammenhang mit umgebendem Gewebe, insbesondere der Lymphabflusswege in einem Stück.

Sklerosierung Verhärtung entsprechend einer Sklerose, aber auch Erzeugung einer Sklerosierung durch Injektion sklerosierender Substanzen (z. B. Ösophagusvarizensklerosierung).

Transplantation Verpflanzung lebender Zellen (z.B. Bluttransfusion), von Gewebe oder von Organen ( $\triangleright$ Organtransplantation):

- Autotransplantation: Verpflanzung körpereigenen Gewebes

- Heterotransplantation: Verpflanzung körperfremden Gewebes

- Xenotransplantation: Verpflanzung von Gewebe einer anderen Spezies

Trepanation Operative Eröffnung einer Mark- oder der Schädelhöhle oder des pneumatisierten Warzenfortsatzes oder einer Nasennebenhöhle. Osteoklastische Trepanation mit permanentem Defekt, osteoplastische Trepanation mit nur temporärer Entfernung eines Knochenstückes.

\subsubsection{Instrumentarium}

\section{Instrumente}

( Die souveräne Beherrschung des chirurgischen Instrumentariums allein garantiert noch nicht den Erfolg eines Eingriffs. Sie ist aber die Voraussetzung für jede langfristig erfolgreiche chirurgische Tätigkeit.

Erforderlich sind im Einzelnen nicht nur genaue Kenntnisse über die für spezifische Zwecke in Frage kommenden Instrumente, sondern auch ihre sichere technische Beherrschung, insbesondere von Spezialinstrumenten. Darüber hinaus muss der Chirurg zumindest prinzipielle Vorstellungen über die Vor- und Nachbereitung sowie über den spezifischen finanziellen Aufwand der einzelnen Verfahren haben.

Diese Forderungen sind bei der fast unübersehbaren Zahl heute verfügbarer Instrumente schwer zu erfüllen. Dennoch sind sie unumgänglich und müssen daher im Rahmen der Aus- und Weiterbildung berücksichtigt werden. Am sinnvollsten wird die Beschreibung des Instrumentariums nach seinen Hauptfunktionen strukturiert.

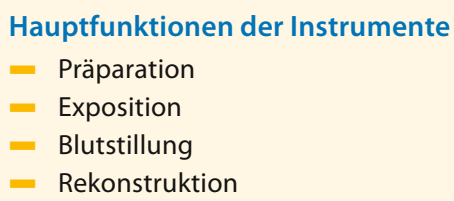

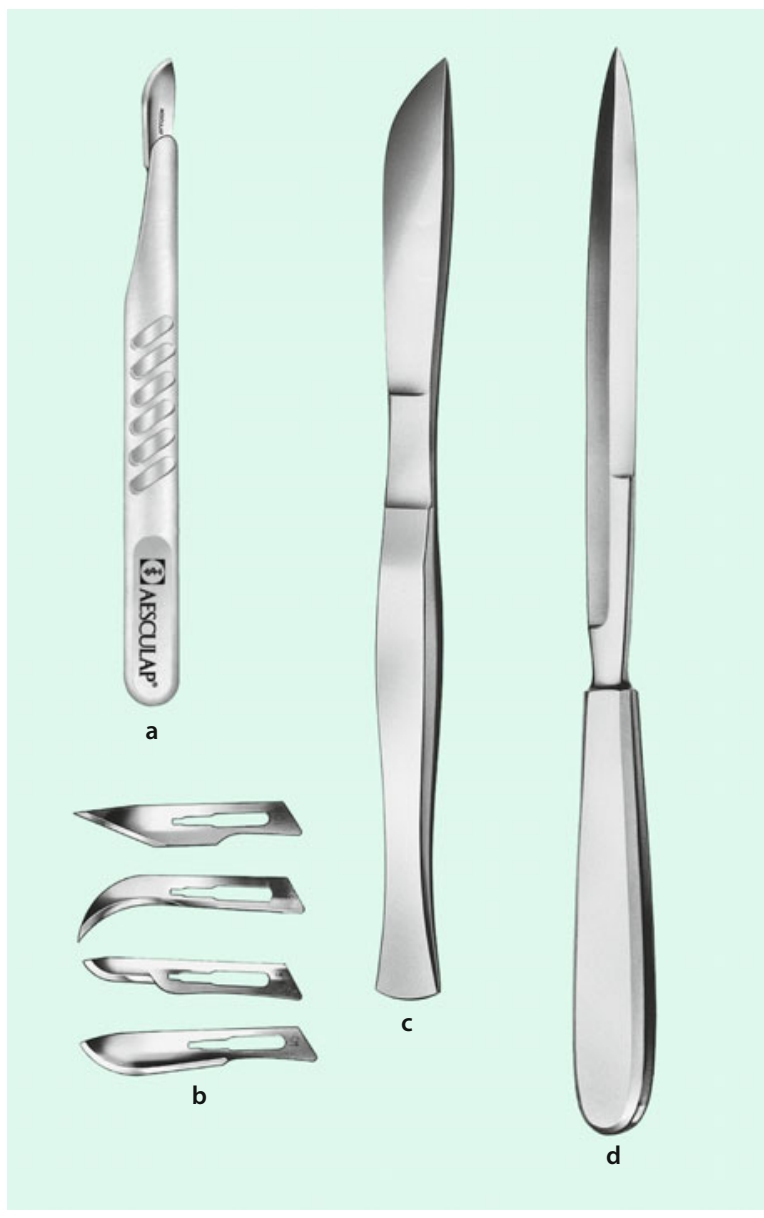

- Abb. 1.9 a Skalpell, b Skalpellklingen, 4 verschiedene Grundformen; c Seziermesser nach Virchow, d Amputationsmesser (Instrumente: Aesculap)

Diese prinzipielle Einteilung gilt auch für die laparoskopische Chirurgie. Hier muss jedoch zusätzlich die erforderliche apparative Zusatzausrüstung mit einbezogen werden, die ein integraler Bestandteil der minimalinvasiven Chirurgie ist.

\section{Präparation \\ Skalpell}

Das klassische Dissektionsinstrument der Chirurgie ist das Skalpell (• Abb. 1.9a). Aus Sicherheitsgründen werden heute fast nur noch Einwegskalpelle eingesetzt, die prinzipiell in 4 verschiedenen Klingenformen angeboten werden (• Abb. 1.9b). Die unterschiedlichen Größen sind nach einem Nummernsystem kodiert. Eine Ausnahme ist nur das Skalpell des Pathologen (• Abb. 1.9c). Eine besondere Form des chirurgischen Messers ist das sog. Amputationsmesser, das in unterschiedlichen Größen aus der ursprünglichen Form des Amputationsmessers von Virchow ${ }^{8}$ entwickelt wurde (• Abb. 1.9d).

8 Rudolf Virchow, Begründer der modernen Pathologie, 1821-1902 


\section{Schere}

Die Schere ist das vielseitigste Dissektionsinstrument, das neben einer gezielten Gewebedurchtrennung auch eine gleichzeitige Kontrolle der für die Dissektion notwendigen Kraft (Erfassung der Gewebequalität) erlaubt. Gleichzeitig ermöglicht die Schere ein Auseinanderspreizen des zu durchtrennenden Gewebes, so dass auch sehr feine Strukturen selektiv durchtrennt werden können. Es werden folgende Hauptgruppen unterschieden:

- Präparationsscheren: Sie werden in unterschiedlichen Längen und Biegungen verwendet und dienen der Gewebepräparation und Durchtrennung. Ein typischer Vertreter aus dieser Gruppe ist die Metzenbaumschere (• Abb. 1.10a).

- Sog. bipolare Scheren ermöglichen gleichzeitig mit dem Schneiden auch die Applikation von Koagulationsstrom zur Blutstillung.

- Gefäßscheren: Für die speziellen Anforderungen des Schneidens kanalikulärer Strukturen, insbesondere von Gefäßen, wurde eine Reihe Spezialscheren entwickelt (- Abb. 1.10b).

- Mikro- und Federscheren: Für das mikrochirurgische Anwendungsgebiet werden sog. Federscheren verwendet. Diese Scheren werden gegen den Federdruck betätigt, so dass die Schere nach dem Schnitt wieder selbsttätig öffnet (- Abb. 1.10c).

- Rippenscheren: Es handelt sich um besonders kräftige, gewinkelte Scheren, mit denen durch eine geeignete Übersetzung die nötige Kraft zum Absetzen von Rippen aufgebracht werden kann (- Abb. 1.10d).

- Faden- und Ligaturscheren: Sie sind besonders robust gearbeitet. Häufig weist eine Branche einen Wellenschliff auf, der das Ausweichen des Fadens beim Schnitt verhindern soll.

- Verbandscheren: Hier handelt es sich um abgewinkelte Scheren, deren untere Branche in einer besonderen Lippe ausläuft. Diese soll beim Unterfahren des Verbandes Führung geben und Hautverletzungen vermeiden (• Abb. $1.10 \mathrm{e})$.

\section{Diathermieapplikatoren}

Die Dissektion mit dem sog. elektrischen Messer beruht auf der Applikation von Schneidstrom über die differente Elektrode. Diese kann als Nadel, Schwert, Stichel oder Lanzette ausgebildet sein (• Abb. 1.11).

\section{Ultraschalldissektor}

Für die Dissektion von parenchymatösem Gewebe steht heute der Ultraschalldissektor zur Verfügung: Ein Metallstössel wird mit Frequenzen im Bereich von $20 \mathrm{MHz}$ in axiale Schwingung versetzt, wodurch weiches Gewebe (z.B. Parenchymzellen oder Fett) zerschlagen wird. Die Gewebetrümmer werden gleichzeitig durch koaxialen Sog unter kontinuierlicher Spülung entfernt. Da kanalikuläre Strukturen (Blutgefäße, Gallengänge) intakt bleiben, können sie gezielt umstochen oder unterbunden werden. Auf diese Weise kann sehr blutsparend und gezielt disseziert werden (• Abb. 1.12).

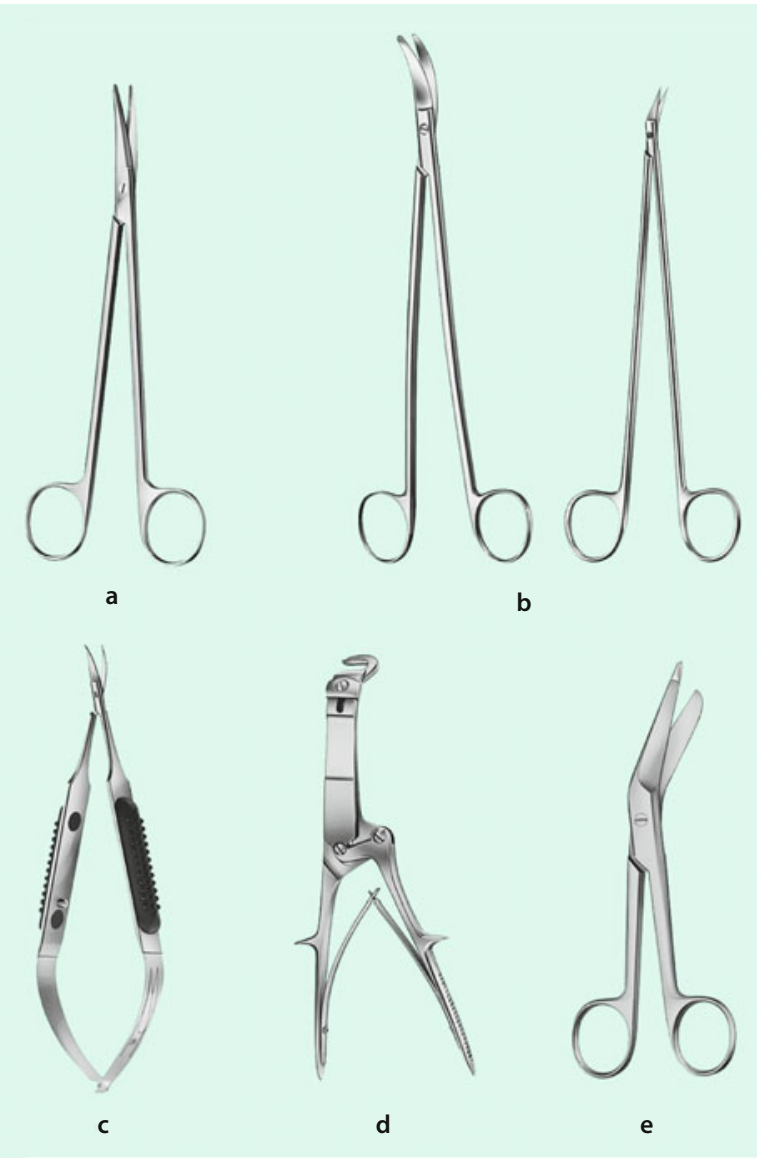

- Abb. 1.10 a Präparierschere nach Metzenbaum, b Gefäßscheren, c Mikro- und Federscheren am Beispiel einer Federschere, d Rippenschere nach Brummer, e Verbandschere nach Lister (Instrumente: Aesculap)

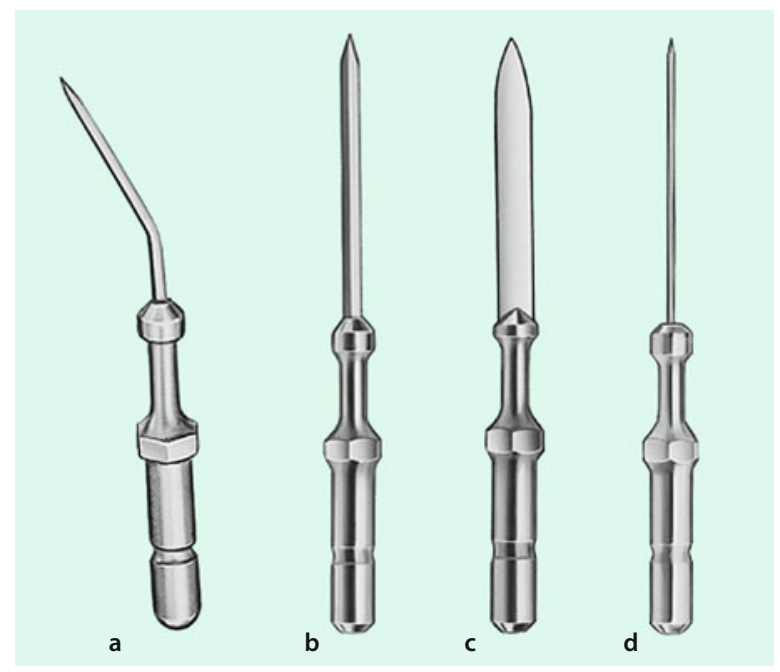

- Abb. 1.11 Diathermie-Applikatoren: a Nadelelektrode gebogen, b Lanzettelektrode, c Messer- oder Schwertelektrode, d Nadelelektrode (Instrumente: Aesculap) 


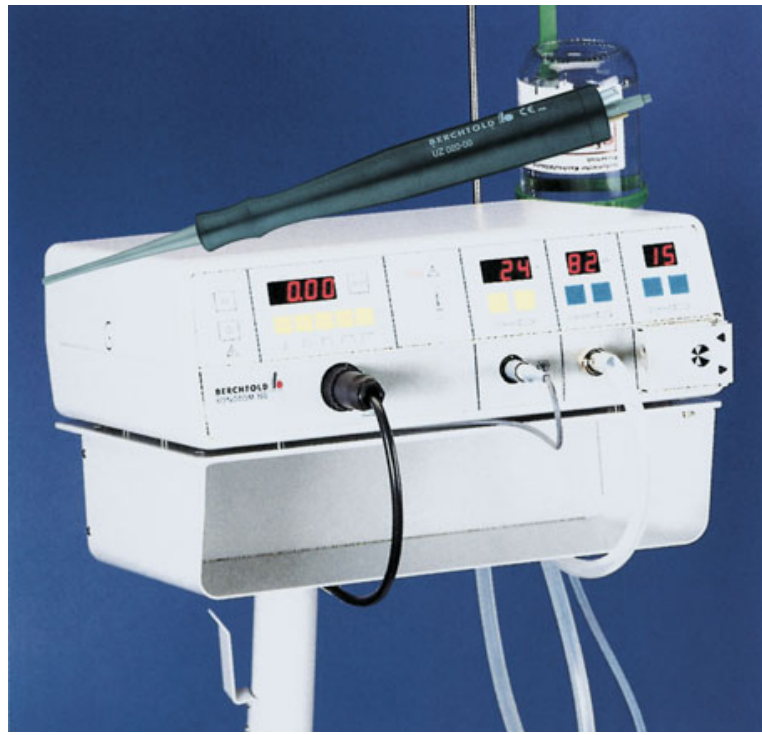

- Abb. 1.12 Ultraschallaspirator mit Handstück (Gerät: Berchtold Medizin-Elektronik)

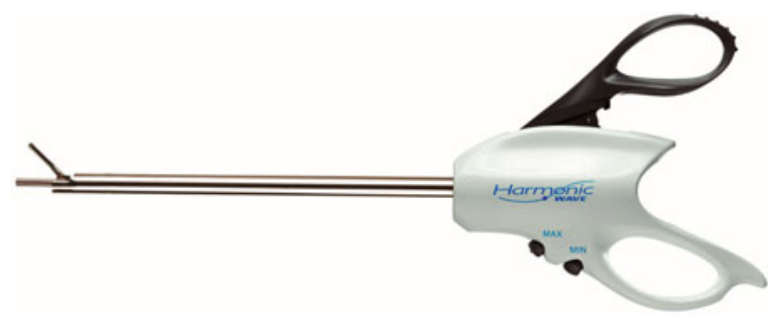

- Abb. 1.13 Ultraschallschere für die offene Chirurgie: Wenn Gewebe mit der beweglichen Branche gegen die mit sehr hoher Frequenz oszillierende gerade Branche gedrückt wird, kommt es zunächst zur Denaturierung (Koagulation) und daraufhin zur Durchtrennung (Gerät: Fa. Ethicon)

Das Prinzip wurde für die Entwicklung von Ultraschallscheren weiterentwickelt: In dem scherenartig ausgeformten Instrument wird die zu durchtrennende Gewebsschicht mit der beweglichen Branche gegen den vibrierenden Stössel gedrückt. In kürzester Zeit kommt es zur Eiweißdenaturierung in dem komprimierten, hochgradig dynamisch belasteten Gewebsbereich, die schließlich zur Dissektion führt (•Abb. 1.13).

\section{Laser}

Eine Gewebedurchtrennung kann auch durch gebündelte elektromagnetische Wellen (Laser) erreicht werden. Abhängig von der Art, in der die optische Strahlung erzeugt und gebündelt wird, unterscheidet man zwischen Gas- (Helium, Krypton, $\mathrm{CO}_{2}$ ), Festkörper- (Rubin, Neodym-Yag, Neodym-Gas) und Flüssigkeitslaser (z. B. Dye-Laser). Die Energie wird entweder gepulst oder kontinuierlich abgegeben.

Der Schneideffekt wird durch die Verdampfung des vom Laserstrahl getroffenen Gewebes erzielt. Je nach Typ des Lasers kommt es dabei auch zu einer mehr oder weniger ausgeprägten Koagulation des angrenzenden Nachbargewebes.

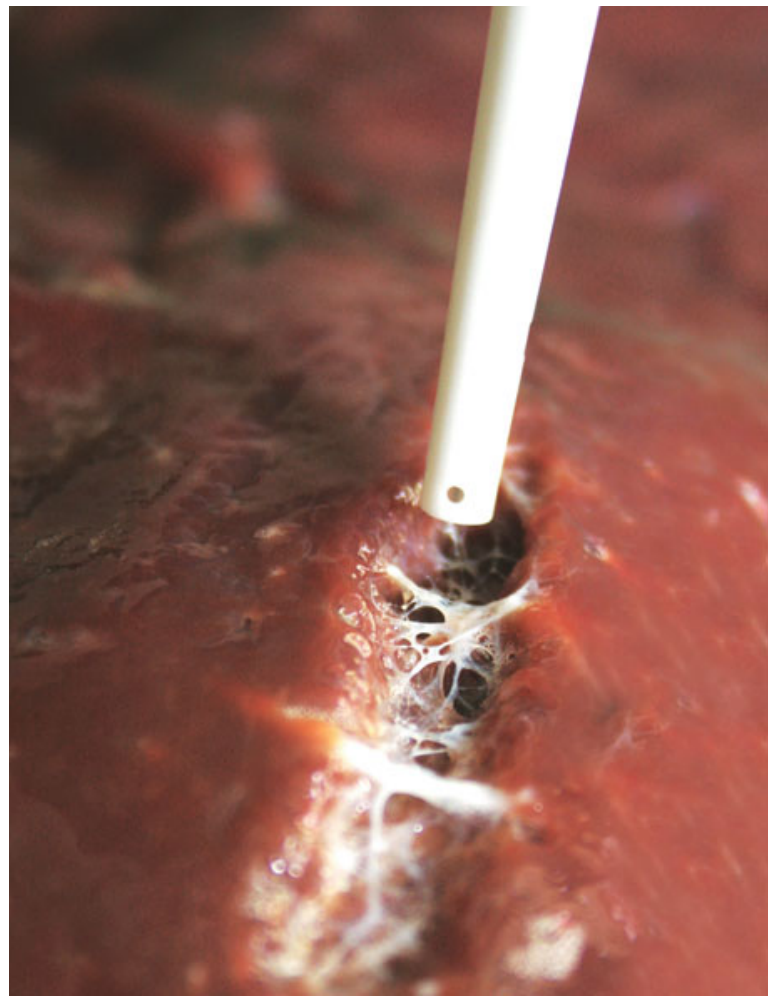

- Abb. 1.14 Durch den unter hohem Druck stehenden, sehr feinen Wasserstrahl werden die Parenchymzellen abgeräumt. Bindegewebige und vaskuläre Strukturen bleiben erhalten und können gezielt durch Elektrokoagulation oder Unterbindung/Clipping versorgt werden

\section{Wasserstrahl-Dissektion}

Bei der Wasserstrahl-Dissektion wird Wasser mit sehr hohem Druck durch eine Düse gepresst, so dass der dadurch entstehende scharfe Strahl Gewebe durchtrennen kann. Durch entsprechende Anpassung des Druckes können dabei Strukturen wie stärkere Gefäße geschont werden und selektiv mittels Umstechung, Clips, usw. versorgt werden. Die Wasserstrahl-Dissektion eignet sich besonders für parenchymatöse Organe (• Abb. 1.14).

\section{Stumpfe Gewebedurchtrennung}

Für die stumpfe Gewebedurchtrennung werden Stieltupfer, Präparationsklemmen oder Ligaturklemmen benutzt (• Abb. 1.15).

\section{Exposition und Halten Pinzetten}

Man unterscheidet nach der Maulform zwischen chirurgischen und atraumatischen (anatomischen) Pinzetten (• Abb. 1.16).

\section{Wundhaken}

Man unterscheidet zwischen Ein- bzw. Mehrzinken- sowie flächigen Wundhaken (•Abb. 1.17). Selbsthaltende Wundhaken halten die Wunde entweder durch Zug (z. B. Stuhler-Haken) oder durch Spreizen offen (• Abb. 1.18). 


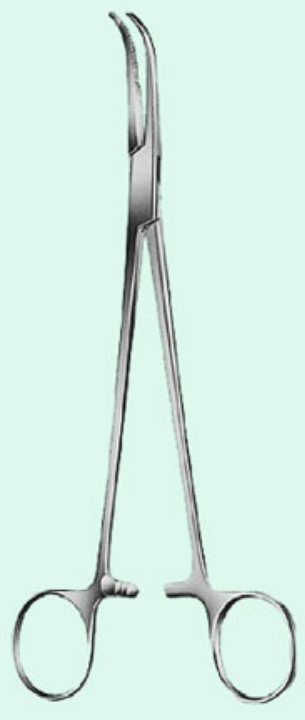

- Abb. 1.15 Ligatur- und Präparationsklemme nach Overholt (Instrumente: Aesculap)

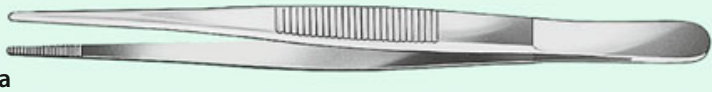

a

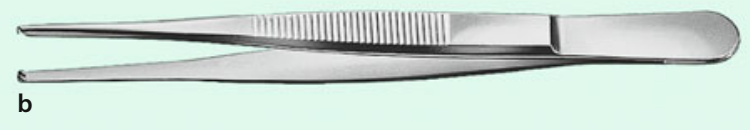

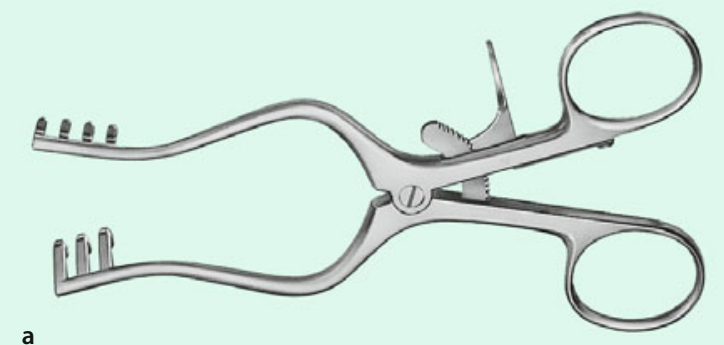

a

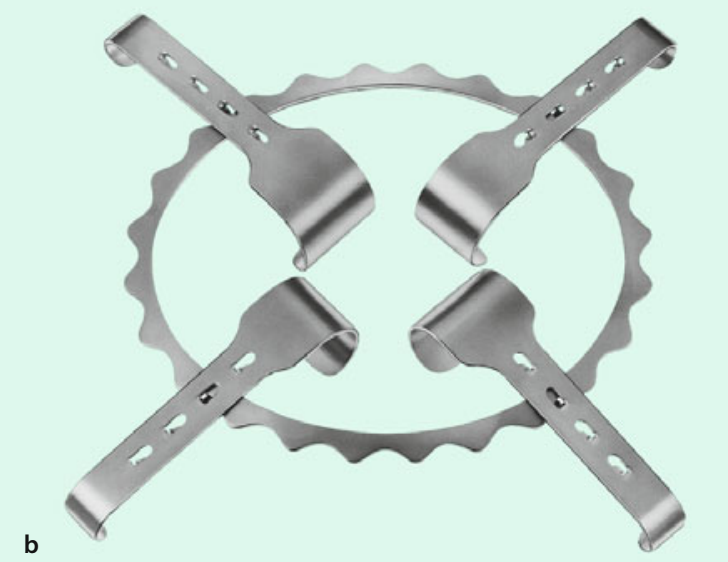

- Abb. 1.18 Selbsthaltende Wundhaken und -spreizer nach a Weitlaner, b Zenker (Instrumente: Aesculap

- Abb. 1.16 a Atraumatische (anatomische) und b chirurgische Pinzetten (Instrumente: Aesculap)

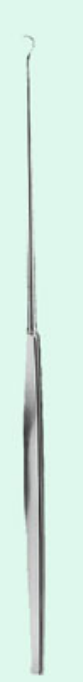

a

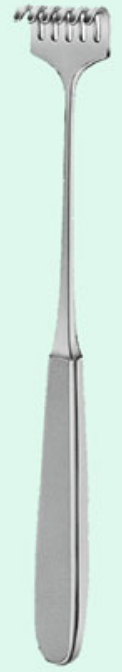

b

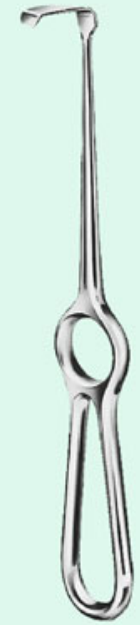

c
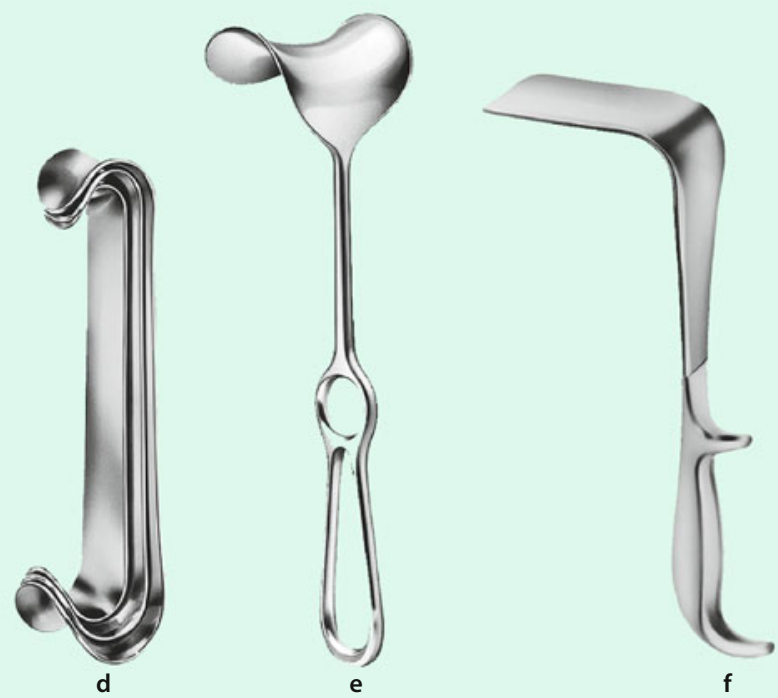

f

- Abb. 1.17 Wundhaken nach a Gillies, b Volkmann, c Langenbeck, d Roux, e Fritsche, f Doyen (Instrumente: Aesculap) 


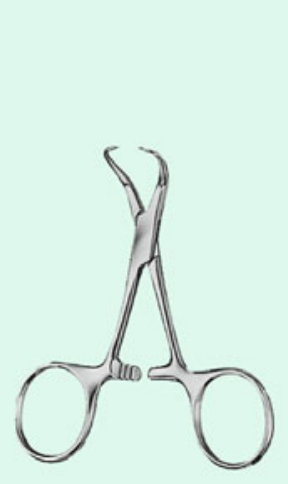

a

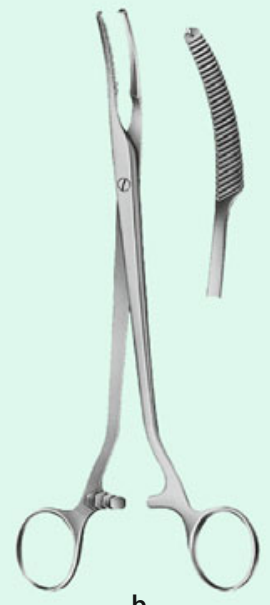

b

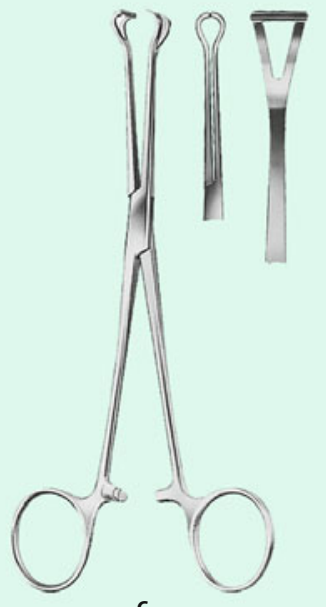

c
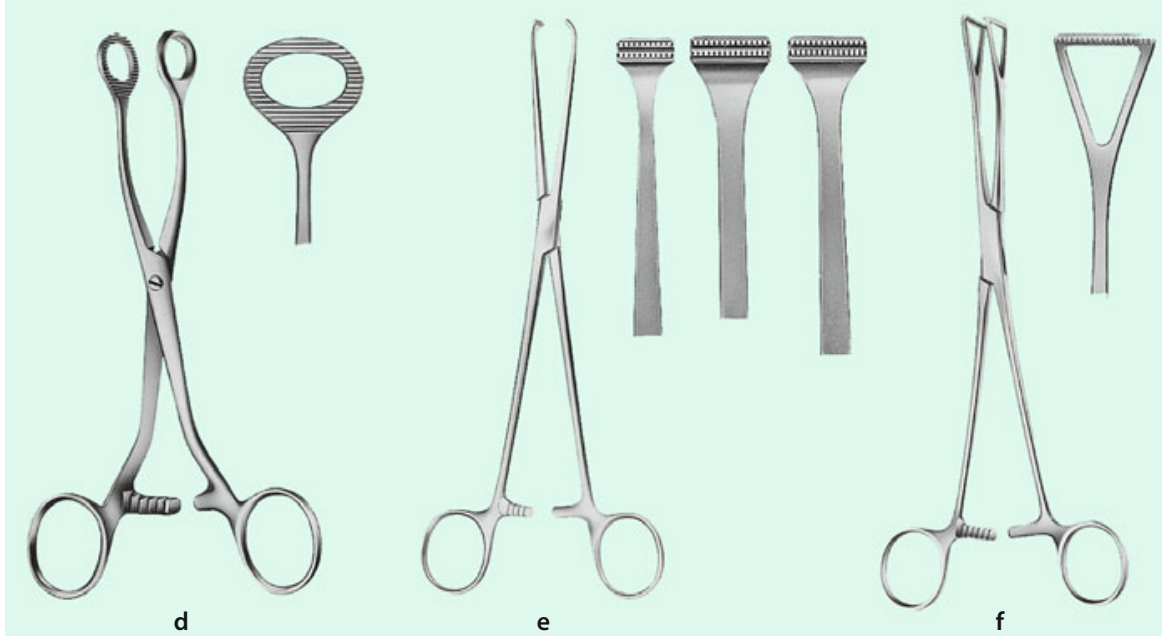

- Abb. 1.19 Organ- und Gewebefasszangen nach a Backhaus, b Mikulicz, c Babcock, d Collin, e Allis, f Duval (Instrumente: Aesculap)

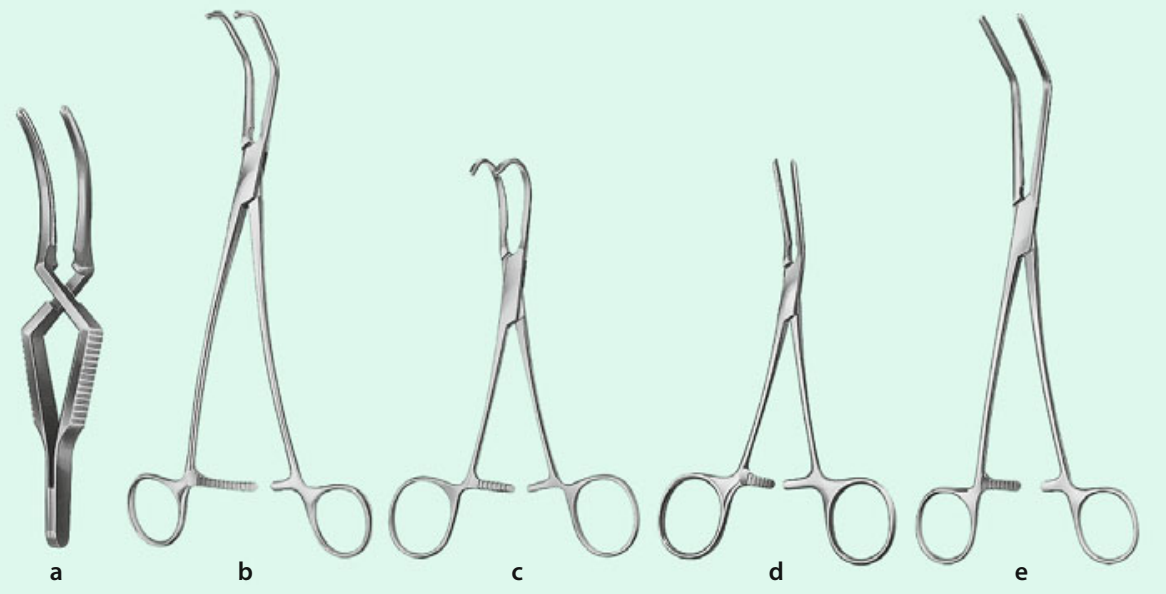

- Abb. 1.20 Gefäßklemmen: a Bulldog, b nach Satinsky, c nach Cooley, d nach Dardik, e nach DeBakey (Instrumente: Aesculap) 

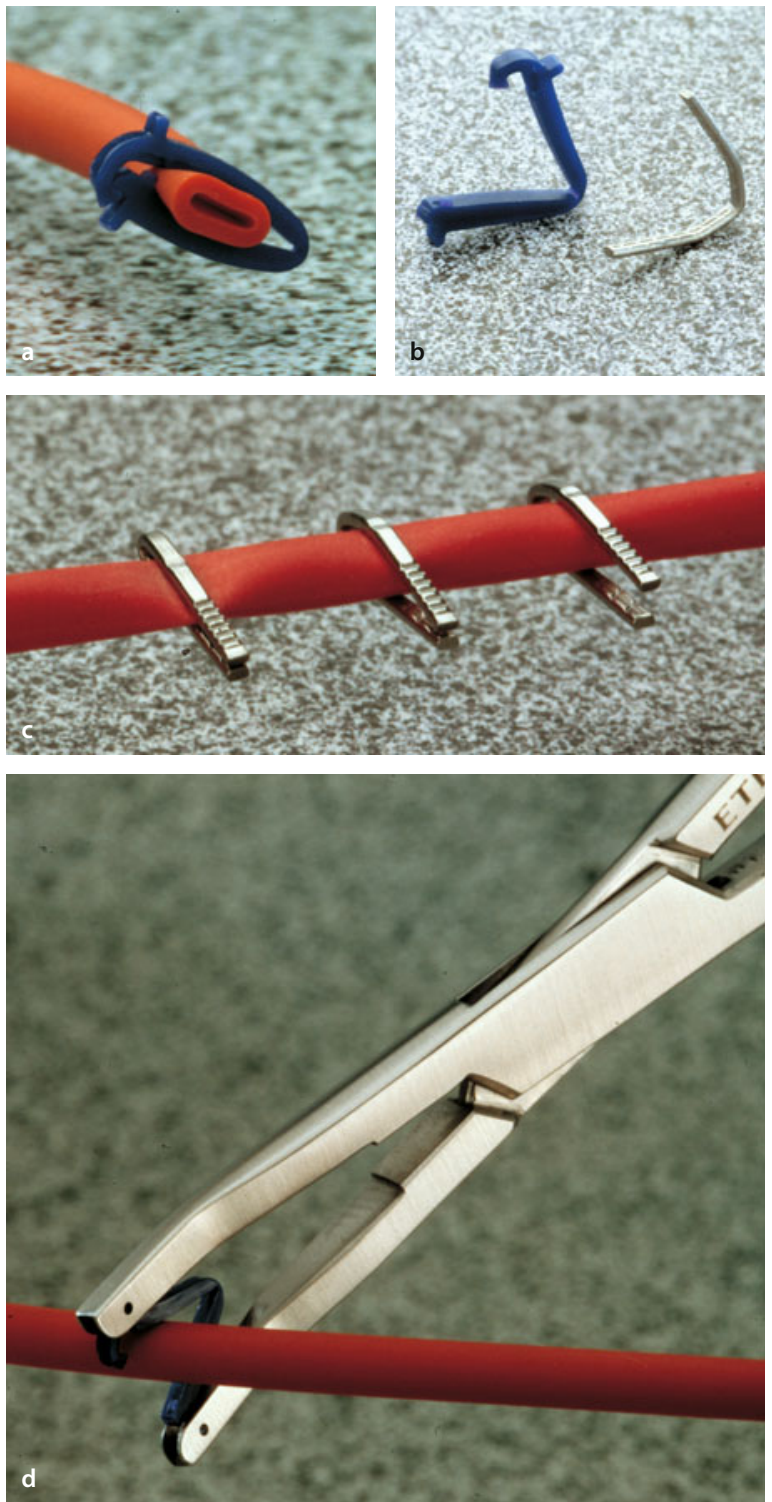

- Abb. 1.21a-d Clips und Applikationszange. (Instrumente: Ethicon)

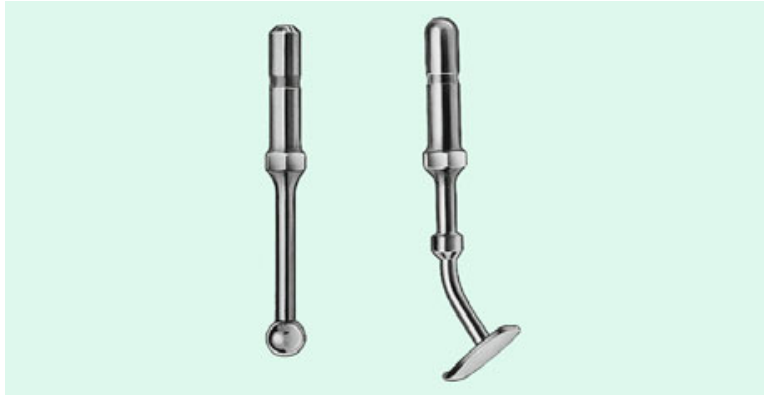

- Abb. 1.22 Verschiedene Koagulationselektroden (Instrumente: Aesculap)
Darmschlingen können auch mittels sog. versenkbarer Retraktoren aus dem OP-Gebiet gehalten werden.

\section{Organ- und Gewebefasszangen}

Für jede Gewebeart wurden spezielle Fasszangen entwickelt (-Abb. 1.19, zeigt eine Auswahl). Besonders hohe Anforderungen werden an Gefäßklemmen gestellt, die zwar sicher fixieren, aber nur minimal traumatisieren dürfen (• Abb. 1.20).

\section{Blutstillung}

Die klassische Form der Blutstillung ( $\triangleright$ Abschn. 1.3.3) ist nach wie vor die Ligatur bzw. die Umstechung mit geeignetem Nahtmaterial. Sog. Gefäßclips können vorteilhaft sein, wenn es auf Zeitersparnis ankommt oder der zu versorgende Stumpf sehr zart oder sehr kurz ist.

In der Regel werden heute Titan- oder resorbierbare Clips verwendet, die mit entsprechenden Zangen appliziert werden (- Abb. 1.21).

Eine sehr wesentliche Rolle spielt die Thermokauterisation. Der Koagulationsstrom wird bei der monopolaren Koagulation entweder direkt mit der Spitze des Handstückes, die als Kugel-, Flächen- oder Hakenelektrode ausgebildet ist, über die haltende Pinzette oder berührungslos via Spraykoagulation appliziert (• Abb. 1.22).

Eine sehr wichtige Weiterentwicklung dieses Prinzips ist die impedanzgesteuerte Koagulation. Durch die computergesteuerte Leistungsabgabe wird bewirkt, dass es während des Koagulationsvorganges im Gewebe nicht zu Karbonisationsvorgängen kommt, die bei der konventionellen Elektrokoagulation die Koagulationsleistung stets begrenzen. Es wird also möglich, sehr viel höhere Energiedichten lokal zu erzeugen, so dass es zu einem regelrechten »Verschweißen" des Gewebes und auch größerer Gefäße kommt. Meist sind in die Applikatoren auch Klingen eingebracht, so dass das koagulierte Gewebe auch durchtrennt werden kann. Mittels impedanzgesteuerter Elektrokoagulation können auch größere Gefäße zuverlässig und schnell disseziert werden (• Abb. 1.23).

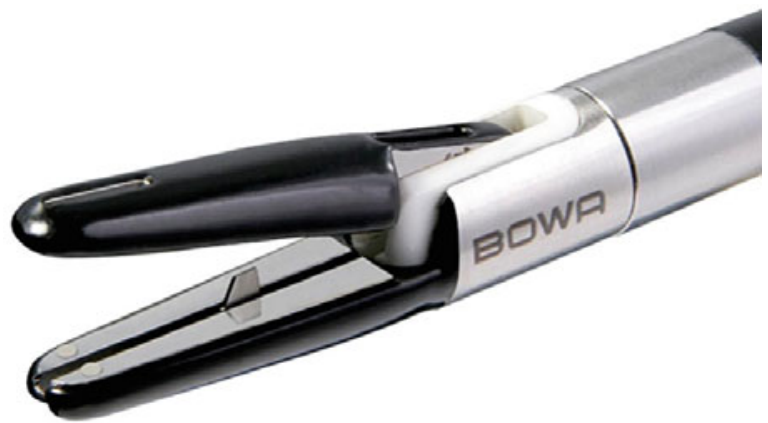

- Abb. 1.23 Maulteil eines impedanzgesteuerten Elektrodissektionsgerätes. Das koagulierte Gewebe wird durch Vorschieben der Klinge (hier in der Mitte der unteren Backe zu sehen) durchtrennt (Gerät: Fa. Bowa) 


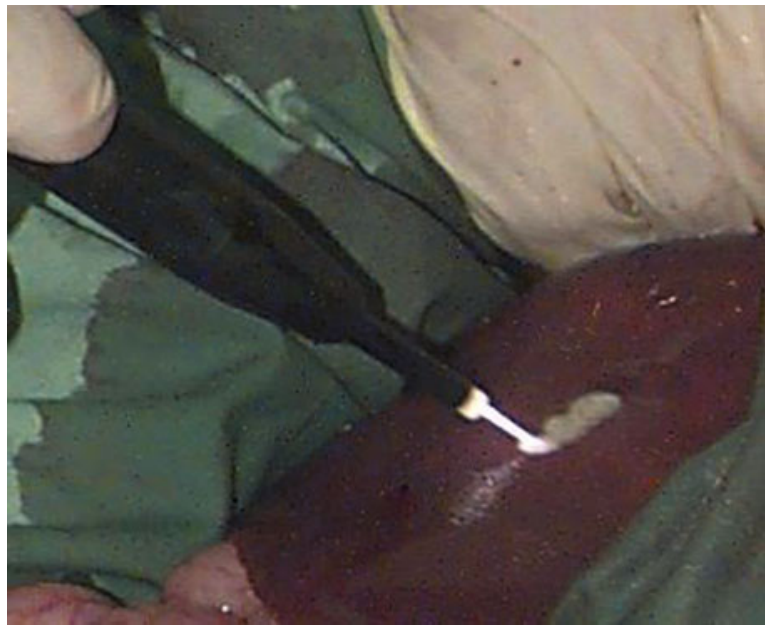

- Abb. 1.24 Berührungsfreie Koagulation unter Schutzgas (Argonbeaming)

Für die Blutstillung an parenchymatösen Organen (Flächenhämostase) steht die Schutzgaskoagulation zur Verfügung: Dieses Verfahren (z. B. Argon-Beamer) verwendet ionisiertes Inertgas (meist Argon). Die ionisierten Gaspartikel führen bei Gewebekontakt zu einer festen Nekrosebildung, wobei die Verdrängung des Luftsauerstoffes zusätzlich eine Verbrennung des Gewebes verhindert. Da der Gasstrom das Austreten von Blut erschwert, kann eine sog. trockene Koagulation erreicht werden (• Abb. 1.24).

\section{Resektion und Rekonstruktion}

Neben der Resektion des Präparates mit dem Messer/der Schere oder dem Diathermieapplikator und der Anastomosierung von Hand, d. h. mit Wundnähten, können bei bestimmten Indikationen diese Schritte auch maschinell erfolgen. Mit Hilfe sog. Stapler wird Gewebe geklammert und ggf. auch mit einem integrierten Messer durchtrennt (• Abb. 1.25).

\section{Klammernahtapparate}

Zur Herstellung von Darmanastomosen werden zirkuläre Klammernahtapparate verwendet (• Abb. 1.25a). Für andere Anwendungsbereiche (z.B. Duodenalstumpfverschluss) gibt es lineare Apparate, die nur eine einseitige Klammernahtreihe setzen (• Abb. 1.25c).

\section{Klammernahtapparate}

Sie besitzen ein gerades oder kreisrundes Magazin, das zahlreiche Titanklammern in 2 oder 3 Reihen angeordnet enthält. Zur Anlage der Gewebeverbindung bzw. Anastomose werden die Klammern durch die miteinander zu verbindenden Wundränder gegen eine Andruckplatte gedrückt. Durch entsprechende Auskehlungen der Andruckplatte werden die Spitzen der Klammern in Form eines B umgebogen und vereinigen so die Geweberänder. Die Größe des B trägt der Mikrodurchblutung Rechnung. In der Regel wird eine dop-

\section{$\nabla$}
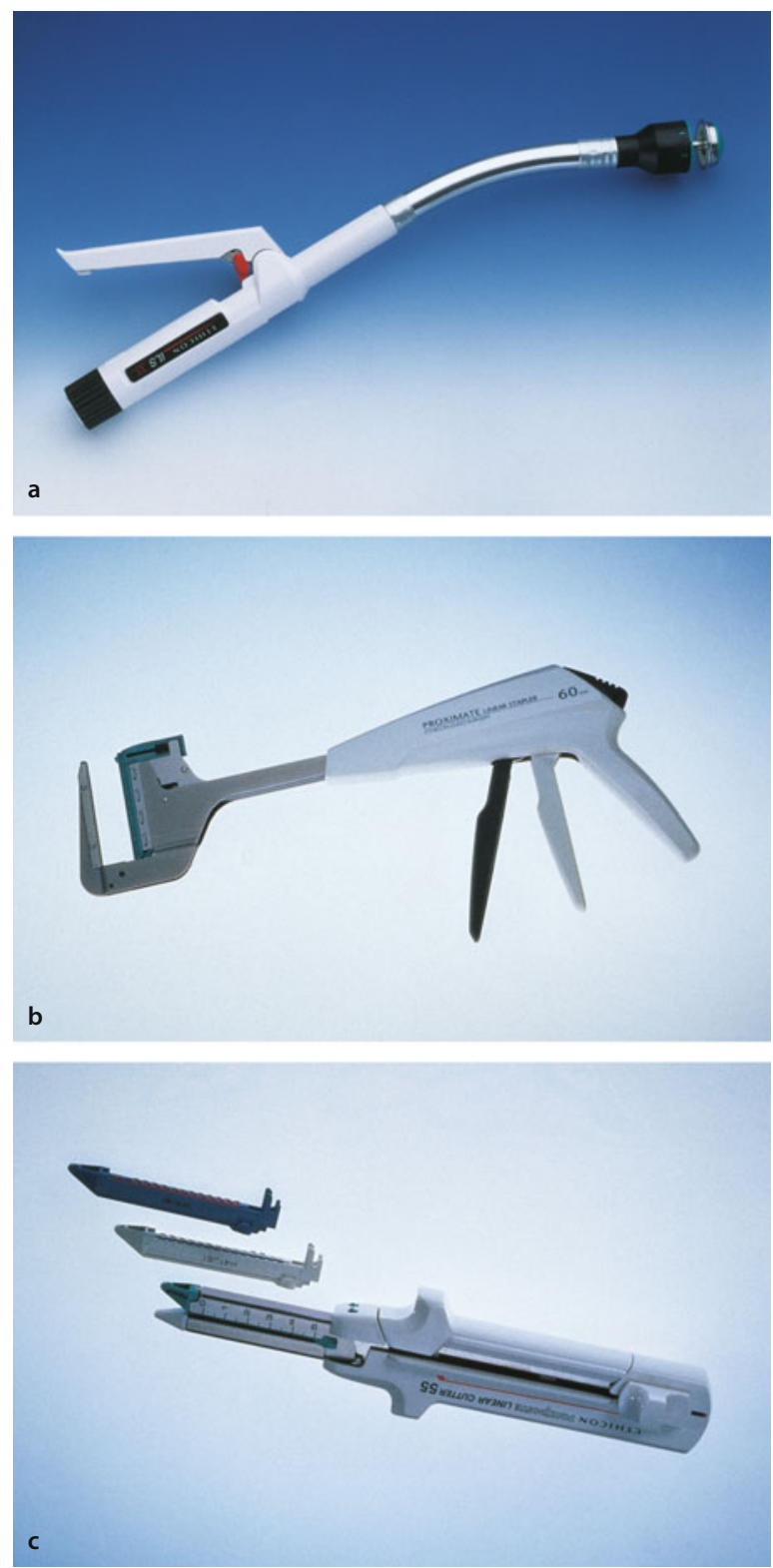

- Abb. 1.25 a Zirkuläres Klammernahtinstrument, CDH. b Linearstapler, TX. c Linearschneider, PLC (Instrumente: Ethicon)

pelte oder 3-fache, zueinander versetzte Klammernahtreihe angelegt. Im gleichen Arbeitsgang schiebt das Gerät eine Schneidevorrichtung nach vorn, so dass überstehendes Gewebe abgeschnitten wird.

\section{Instrumentarium für die laparoskopische Chirurgie}

Neben dem eigentlichen Operationsinstrumentarium ist für die Laparoskopie eine Reihe von speziellen technischen Geräten erforderlich, die zweckmäßigerweise in einem sog. Turm zusammengefasst werden (• Abb. 1.26). 
8 Die wichtigsten Grundgeräte sind das Kamerasystem mit Lichtquelle und Monitor, ohne die ein laparoskopischer Eingriff nicht durchführbar wäre. Zusätzlich wird eine Pumpe zur $\mathrm{CO}_{2}$-Insufflation für die Erzeugung des Pneumoperitoneums und eine SaugSpül-Pumpe für die intraoperative Reinigung des Operationsgebietes benötigt.

In entsprechender Modifikation sind heute nahezu alle Instrumente der offenen Chirurgie auch für die laparoskopische Chirurgie verfügbar. Zum Zweck der Kraftübertragung über eine relativ lange Strecke (durchschnittlich ca. $50 \mathrm{~cm}$ ) sind lange Instrumentenschäfte mit den entsprechenden Winkelübertragungen und Handstücken erforderlich.

Als wesentliches zusätzliches Instrument kommt der Trokar hinzu, der bei der Applikation der Instrumente auch die Gaszufuhr ermöglichen muss und gleichzeitig durch entsprechende Ventil-Dichtungssysteme Gasverluste vermeiden soll.

Für die Anlage des Pneumoperitoneums ist die sog. Veress-Kanüle erforderlich. Die Bildübertragung erfolgt über Stablinsenoptiken ( Abschn. 1.3.3, $\bullet$ Abb. 1.27).

\section{Navigationssysteme, Vernetzungssysteme}

Es steht außer Zweifel, dass wir derzeit an der Schwelle von bedeutenden Innovationen stehen, die die gesamte technologische Ausrüstung im Operationssaal ändern und erweitern werden. Als Stichwort soll hier nur der Begriff der computerassistierten Chirurgie (CAS) genannt werden. Wesentliche Voraussetzung dafür ist die leistungsfähige, interne und externe Vernetzung, der Einsatz von Navigationssystemen und u. U. der Einsatz von Telemanipulatoren.

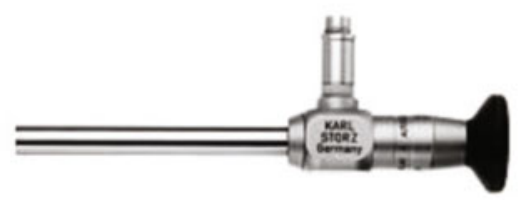

a

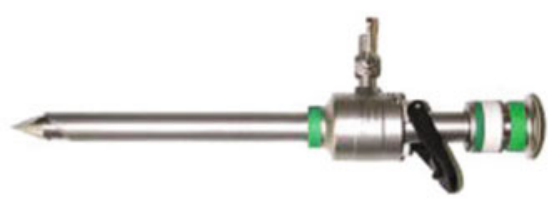

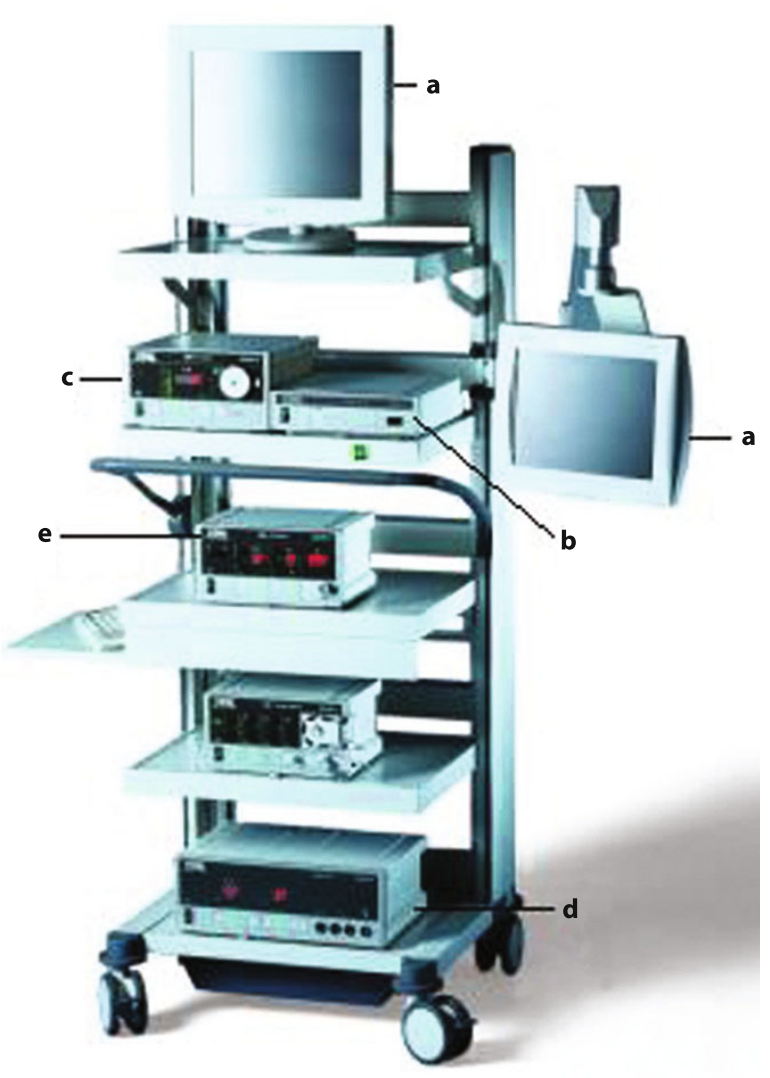

- Abb. 1.26 Laparoskopie-Turm. Alle erforderlichen Geräte sind in einer mobilen Arbeitseinheit zusammengefasst: a Monitor, b Kamerasteuerteil, c Lichtquelle, d Video, e Insufflator (Fa. Storz)

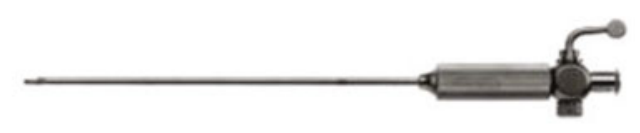

b

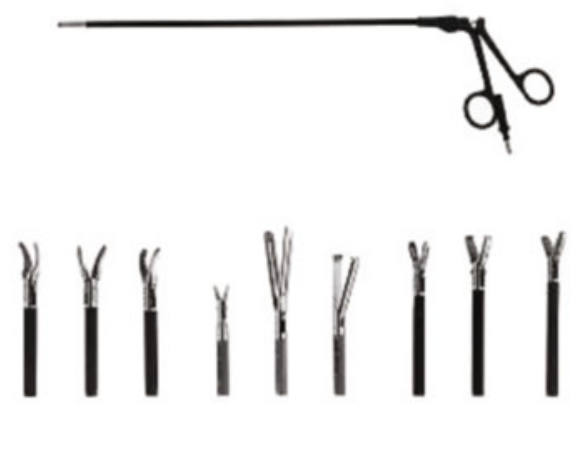

- Abb. 1.27 Laparoskopiespezifisches Instrumentarium: a Optik, b Veress-Nadel, c Trokar, d Fasszange mit verschiedenen Maulformen 


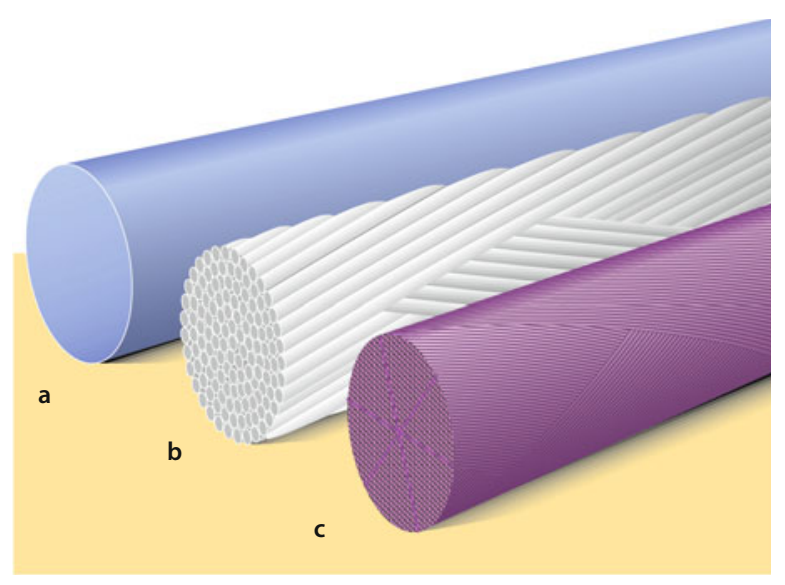

- Abb. 1.28 a Mono, b, c geflochtenes Nahtmaterial

\section{Nahtmaterialien}

Nahtmaterialien sind entweder resorbierbar oder persistieren im Gewebe (nicht resorbierbar). Nach der Fadenbeschaffenheit unterscheidet man zwischen monofilem und geflochtenem Faden (• Abb. 1.28).

Diese Eigenschaften beeinflussen die Reißkraft, den Knotensitz, die Handhabung, die Sägewirkung und das Gewebeverhalten. Heute dominieren eindeutig resorbierbare Nahtmaterialien, deren ursprünglicher Vertreter das Katgut, ein

- Tab. 1.4 Gebräuchliche Fadenstärken nach USP (United States Pharmakopoc) und metrischem Maß

\begin{tabular}{|l|l|l|}
\hline $\begin{array}{l}\text { USP- } \\
\text { Stärke }\end{array}$ & $\begin{array}{l}\text { Sterildurchmes- } \\
\text { ser (in } 0,01 \mathrm{~mm})\end{array}$ & Anwendungsbeispiele \\
\hline $10 / 0$ & $1,3-2,5$ & $\begin{array}{l}\text { Mikrochirurgie (Verwendung } \\
\text { von Lupenbrillen bzw. } \\
\text { Op-Mikroskopen erforderlich) }\end{array}$ \\
\hline $9 / 0$ & $2,5-3,8$ & Mikrochirurgie \\
\hline $8 / 0$ & $3,8-5,1$ & Neurochirurgie \\
\hline $7 / 0$ & $5,1-7,5$ & Ophthalmologie \\
\hline $6 / 0$ & $7,5-10,2$ & Gefäßchirurgie \\
\hline $5 / 0$ & $10,2-15,2$ & Gefäßchirurgie \\
\hline $4 / 0$ & $15,2-20,3$ & Gallenwege \\
\hline $3 / 0$ & $20,3-25,4$ & Darmnähte, Standardligatur \\
\hline $2 / 0$ & $25,4-33,0$ & Magenwand, grobe Ligatur \\
\hline 0 & $33,0-40,6$ & Haltefäden \\
\hline 1 & $40,6-48,3$ & Faszie an Extremitäten \\
\hline 2 & $48,3-55,9$ & Bauchfaszie \\
\hline 3 & $55,9-63,5$ & Extrem belastete Gewebe \\
\hline & & \\
\hline
\end{tabular}

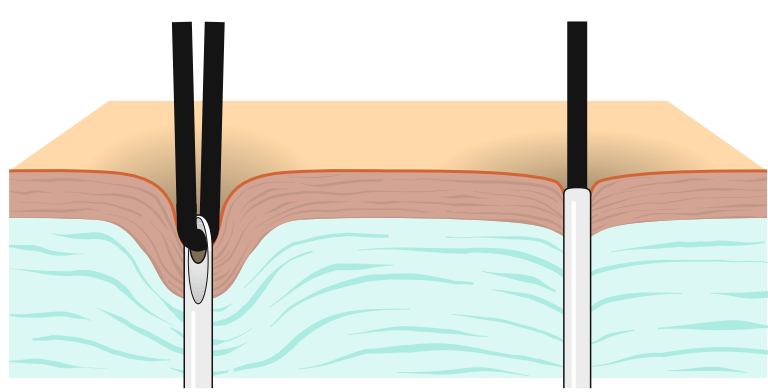

- Abb. 1.29 Vorteil der Nadel-Faden-Kombination (rechts)

aus der Submukosa des Schafdarmes gewonnener Faden, war. Heute werden fast ausschließlich synthetische Polymere (z.B. Polidioxanon) verwendet, die durch Hydrolyse innerhalb von etwa 180 Tagen vollständig abgebaut werden (z. B. Vicryl, Dexon).

\section{$>$ Nichtresorbierbare Fäden (z. B. Stahl, Seide, Poly- ester) werden heute nur noch für Spezialindika- tionen (Haut, Gefäße, Sehnen) verwendet.}

Geflochtenes Nahtmaterial lässt sich meist besser handhaben und knüpfen, weist jedoch eine unerwünschte Dochtwirkung für Keime auf, so dass es z. B. für Hautnähte nicht verwendet wird. Von praktischer Bedeutung ist es zu wissen, dass die Fadenstärke im Allgemeinen nicht metrisch, sondern nach USP (United States Pharmakopoc) angegeben wird (•Tab. 1.4).

\section{Nadeln}

Prinzipiell unterscheidet man hier zwischen Rundkörperund schneidenden Nadeln. Variationen und Kombinationen gibt es für fast alle Gewebearten. In praxi werden immer häufiger vorfabrizierte Nadel-Faden-Kombinationen verwendet, bei denen der Nadelkörper ohne Kalibersprung in den Faden übergeht. Sog. Abziehnadeln können nach Setzen der Naht ohne Verwendung einer Schere vom Faden abgezogen werden (-Abb. 1.29). Neben der Arbeitsersparnis ist der kleinere Wundkanal bei Nadel-Faden-Kombinationen vorteilhaft.

\section{Nadelhalter}

Im Wesentlichen sind 2 Grundtypen von Nadelhaltern gebräuchlich, die sich nach Formgebung und Art des Arretiermechanismus unterscheiden (• Abb. 1.30).

\subsubsection{Operationstechnik}

\section{Lagerung}

Die Lagerung eines anästhesierten Patienten auf einem Operationstisch soll einerseits einen optimalen Zugang zum Operationsfeld, aber auch ein bequemes Herantreten und Stehen von Operateur und Assistenten ermöglichen. Ggf. müssen Lagerungswechsel berücksichtigt werden. 


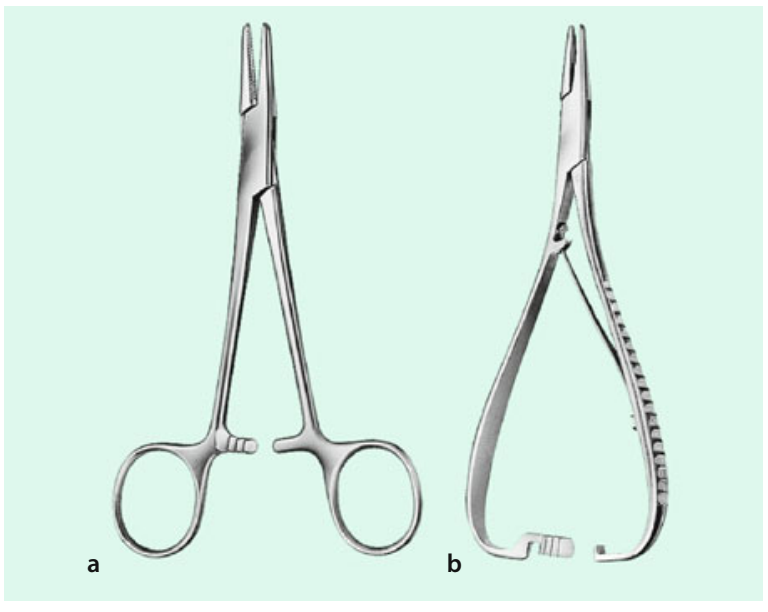

- Abb. 1.30 Zwei Grundtypen von Nadelhaltern: a Hegar, b Matthieu (Instrumente: Aesculap)

C Cave

Die Lagerung muss so sorgfältig vorgenommen werden, dass auch während lang dauernder Eingriffe keine Lagerungsschäden für den Patienten entstehen. Insbesondere ist die Schädigung peripherer Nerven zu vermeiden.

Die Regeln der Dekubitus- wie der Hypothermieprophylaxen müssen beachtet werden. Die Lagerung erfolgt vor Desinfektion und steriler Abdeckung, aber nach Einleitung der Anästhesie. Die Lagerung muss darüber hinaus dem Anästhesisten einen Zugang zum Nasen-Rachen-Raum und zu wenigstens einem Arm (Blutdruckmessung, Pulskontrolle, Zugang zum Venensystem etc.) freihalten. Typische Lagerungen sind:

- die Rückenlagerung, ggf. mit Überstreckung des Abdominalbereiches (• Abb. 1.31),
- die Seitenlagerung, ggf. mit Überstreckung des Thorax für laterale Thorakotomien (• Abb. 1.32),

- die sog. Steinschnittlage mit angewinkelten und gespreizten Beinen für proktologische oder gynäkologische Eingriffe, wenn gleichzeitig auch vom Abdomen her operiert wird (• Abb. 1.33),

- die Bauchlagerungen wie z. B. die sog. Heidelberger Lage, wobei der Patient auf dem Bauch liegt und die Analregion unter Abbeugung der Hüftgelenke angehoben ist (proktologische Eingriffe, • Abb. 1.34).

Für unfallchirurgische Eingriffe werden je nach Art und Lokalisation der Läsion besondere Lagerungen notwendig, z. B. in Form der Lagerung auf einem Extensionstisch.

Für die laparoskopische Chirurgie sind bei der Lagerung spezielle Besonderheiten zu beachten, die sich einerseits aus der Art des Zugangs und andererseits aus der Notwendigkeit ergeben, den Monitor möglichst ergonomisch sinnvoll zu platzieren. Dabei muss die korrekte optische Achse beachtet werden. Blickrichtung des Operateurs, das operative Arbeitsfeld und der Monitor müssen in einer optischen Achse liegen. Bei Eingriffen im Bereich des Oberbauchs steht dementsprechend der Monitor (meist inklusive des Turmes) im Bereich der rechten oder linken Schulter, bei Eingriffen im Unterbauch etwa in Höhe der rechten oder linken Hüfte. Der Monitor steht auf der Seite des pathologischen Befundes, während der Operateur und sein 1. Assistent im Allgemeinen auf der kontralateralen Seite stehen.

C Cave

Der Operateur ist immer persönlich für die richtige Lagerung seines Patienten verantwortlich und hat klare Anweisungen schon bei der Operationsanmeldung festzulegen.

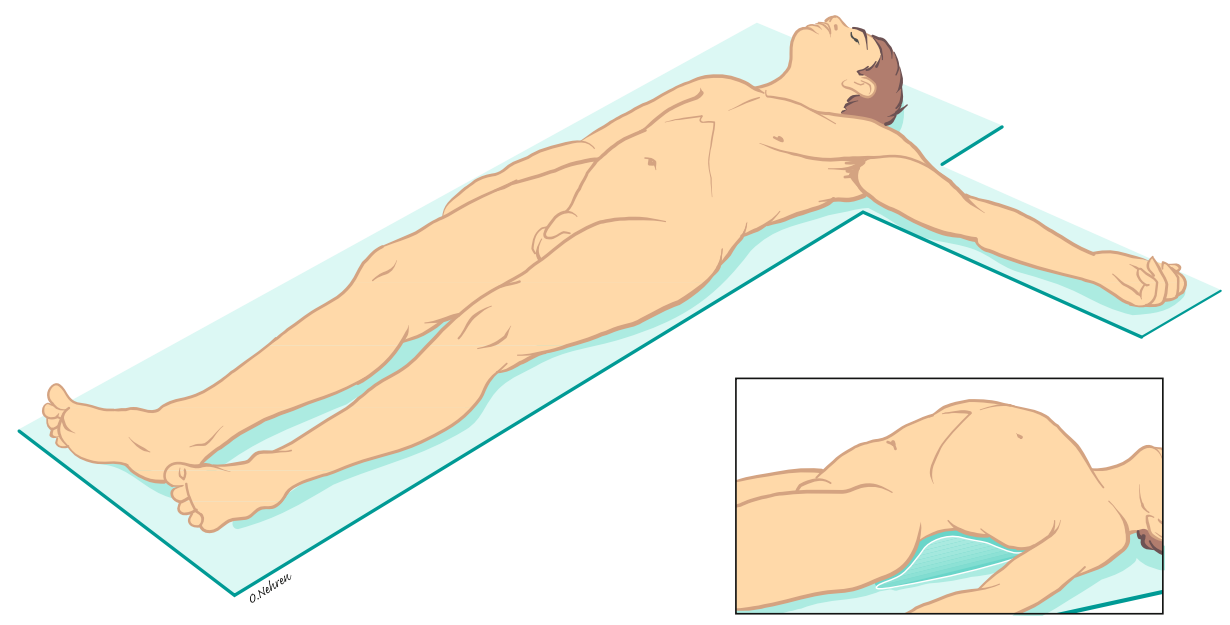

- Abb. 1.31 Standard-Rückenlage. Bei Oberbaucheingriffen ist ggf. eine Überstreckung des Abdominalbereichs sinnvoll (kleines Bild) 


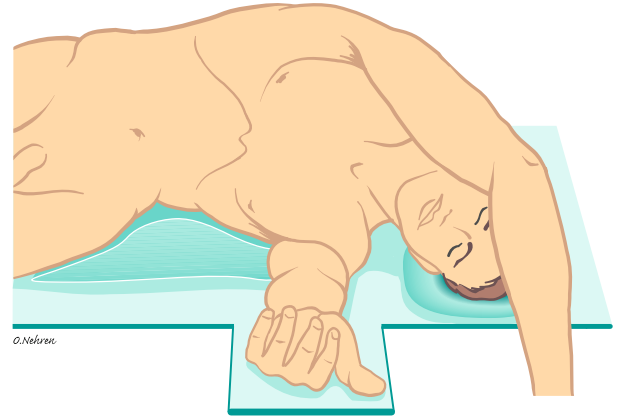

- Abb. 1.32 Seitenlagerung
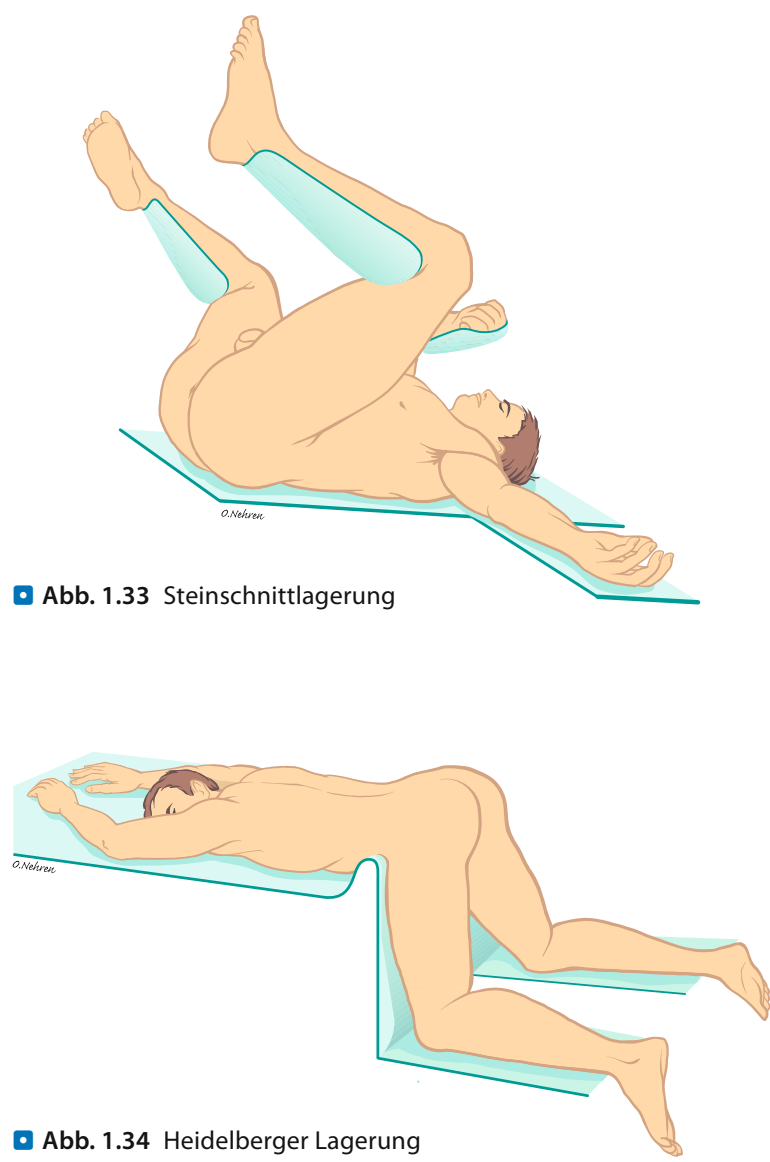

\section{Desinfektion (Asepsis)}

Nach vollendeter Lagerung wird das Operationsfeld sorgfältig desinfiziert. Im Bereich der Haut erfolgt dies meist mit kombinierten Alkohol-lod-Präparaten (Schleimhäute ohne Alkohol, bei Allergien und Strumen ohne Iod).

Die ganze Umgebung des desinfizierten Hautbereiches, der Patient und die notwendigen Gerätetische werden, soweit sie mit dem Patienten in Berührung kommen, mit sterilen Tüchern abgedeckt. Für die Dauer des Eingriffes muss das
Abdeckmaterial eine Penetration von Keimen zuverlässig verhüten.

Das Operationsteam selbst hat Hände und Unterarme sorgfältig desinfiziert und wird dann »steril« eingekleidet. Als letzter Schritt der Operationsvorbereitung werden sterile Operationshandschuhe angezogen. Selbstverständlich ist das Tragen einer Kopfbedeckung und eines Mundschutzes für jede Person, die sich im Operationsbereich aufhält.

\section{Schnittführung/Zugänge}

Die Probleme der Zugangswege zum jeweiligen Operationsfeld schienen über Jahrzehnte gelöst. Nach Einführung des endoskopischen Operierens sind sie jedoch neu in die Diskussion gekommen. Retrospektiv muss man feststellen, dass die Belastungen für den Patienten durch aufwändige Zugänge mit Durchtrennung mehr oder weniger großer Anteile, z. B. der Bauchdecke, lange unterschätzt wurden.

Ein Großteil der Hospitalisierungsdauer dient aus-
schließlich der Abheilung dieser Zugangswunden.

Je kleiner der vorzunehmende operative Eingriff, desto mehr zählen die Belastungen durch den Zugangsweg. Auf der anderen Seite ist jeder Patient gewillt, auch große $\mathrm{Zu}$ gänge im Rahmen z. B. der onkologischen Chirurgie hinzunehmen, wenn sie zur Verbesserung der Prognose beitragen können.

\section{Hautschnitte}

Diese werden möglichst in die Hautfalten oder entsprechend dem Verlauf der sog. Spaltlinien der Haut gelegt. Bei der Durchtrennung von Muskeln versucht man, die versorgenden Blutgefäße und Nerven zu schonen. Faszien durchtrennt man möglichst in der Hauptfaserrichtung. Bei der späteren Wiedervereinigung finden Nähte quer zur Hauptfaserrichtung besseren Halt.

\section{Anatomische Voraussetzungen der Laparotomie}

Die Bauchmuskulatur ist paarig angelegt. Ihre Ausläufer vereinen sich in der sehr straffen Aponeurose der Linea alba bzw. in den Rektusscheiden, wobei letztere oberhalb des Nabels bzw. der Linea alba semizirkulär ein vorderes und hinteres Blatt aufweist, unterhalb davon dagegen nur ein vorderes Blatt. Während die Blutversorgung der Bauchwand netzartig und reichlich ausgebildet ist, erfolgt die Innervation der Bauchdeckenmuskulatur nur segmental über Ausläufer der Interkostalnerven Th5-12 sowie über die Nn. ileohypogastricus und ileoinguinalis.

Diese anatomischen Gegebenheiten lassen unschwer erkennen, dass schräge bzw. quere, d. h. parallel zur Muskelfaser und zur Innervationsrichtung verlaufende Inzisionen besonders sicher sind und für den Patienten postoperativ mit geminderten Schmerz verbunden. Zugleich erweisen sich quere Schnitte als kosmetisch günstiger. Der mediane Längsschnitt in der Linea alba ist ebenfalls nervenschonend, hingegen ist die Wiedervereinigung (Bauchdeckennaht) größeren Zugkräften ausgesetzt. Im Folgenden seien die wichtigsten Zugänge kurz aufgeführt (• Abb. 1.35). 


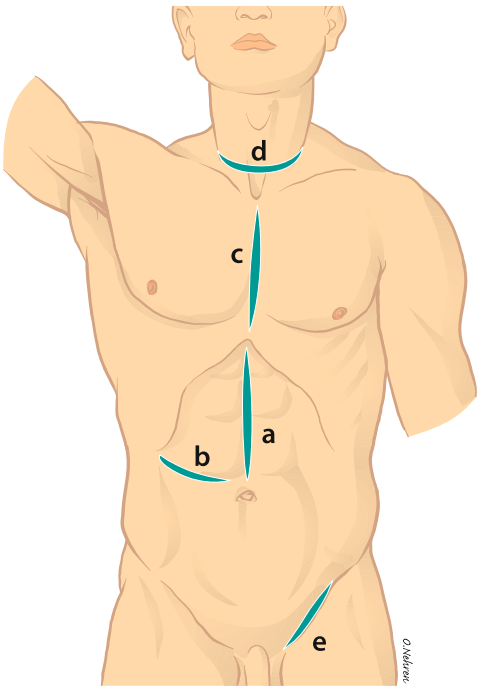

- Abb. 1.35 a Medianer Längsschnitt, b Kostoumbilikalschnitt, c mediane Längssternotomie, d Kragenschnitt nach Kocher, e Inguinalschnitt

\section{Medianer Längsschnitt}

Das Abdomen ist bei dieser Schnittführung besonders rasch zu öffnen und es ergibt sich eine gute Übersicht über die gesamte Bauchhöhle. Die Erweiterungsmöglichkeiten reichen von der Symphyse bis zum Xyphoid. Bei der Schnittführung links am Nabel vorbei bleibt die Corda umbilicalis erhalten.

Dies ist der Wahlzugang bei den allermeisten abdominellen Eingriffen, insbesondere bei Notfalleingriffen. Als Nachteil muss die relative Häufigkeit von Narbenhernien in Anbetracht der Zugwirkung auf die mediane Bauchdeckennaht genannt werden.

\section{Quere Bauchschnitte}

In Hinblick auf Sicherheit der Wundheilung und postoperativen Wundschmerz sowie Kosmetik sind diese Schnitte zu bevorzugen. Für Eingriffe am rechten Hemikolon sind sie besonders geeignet. Kommen sie im Oberbauch zum Einsatz (Operationen an Pankreas, am Magen oder an der Leber), müssen sie häufig durch eine kleine mediane Inzision erweitert werden, so dass ein umgekehrtes $\mathrm{T}$ entsteht. Dieser $\mathrm{Zu}$ gang eröffnet dann allerdings die beste Übersicht im Bereich des Oberbauches und ist für alle großen Oberbaucheingriffe gleichermaßen geeignet.

\section{Kostoumbilikalschnitt rechts}

Dieser Zugang schont die Innervation sowohl der seitlichen Muskulatur wie die des M. rectus und ist kosmetisch günstig, da er entlang der Spaltlinien der Haut verläuft. Beste Indikation ist die Gallenwegschirurgie.

\section{Thorakotomie}

Die laterale Thorakotomie stellt den Standardzugang dar. Eingriffe an Lunge und Ösophagus sind übersichtlich ausführbar. Er kann rechts wie links ausgeführt werden. Der Hautschnitt erfolgt in der Regel unterhalb der Mamille und der Skapulaspitze. Der Zugang zum Thorax erfolgt an der Oberkante der 5. oder 6. Rippe unter Schonung der Interkostalgefäße und -nerven.

\section{Mediane Längssternotomie}

Dies ist Standardzugang zum vorderen Mediastinum und zum Herzen. Das Sternum wird mit der oszillierenden Säge in ganzer Länge median gespalten.

\section{Weitere Zugänge}

Folgende Zugänge sind speziellen Indikationen vorbehalten:

- Kragenschnitt nach Kocher: Der Hautschnitt wird 12 Querfinger oberhalb der Schlüsselbeine bogenförmig und symmetrisch ausgeführt. Zugang zur Schilddrüse, aber auch zu schwierigen Tracheotomien und in das vordere Mediastinum.

- Typischer Wechselschnitt: Der Hautschnitt erfolgt quer, z. B. geeignet für Appendektomien. Faszien und Muskeln können dagegen median und parallel zur Längslinie durchtrennt werden.

- Chirurgie der weiblichen Brustdrüse:

- Schnittführung nach Pattey (radikale Mastektomie mit Ausräumung der Achsellymphknoten): Quer ovale, spindelförmige Umschneidung der Mamma. Die Schulterkulisse bleibt unberührt.

- Periareolärschnitte: Parallel zum Mamillenhof verlaufende quere, bogenförmige Schnitte, die für diagnostische Exstirpationen von Mammatumoren geeignet sind.

- Inguinalschnitt: Schnittführung verläuft schräg zwischen Spina iliaca anterior superior und Symphyse (Leistenhernienoperation, diagnostische Lymphknotenexstirpation etc.).

\section{Laparoskopische Zugänge}

Im Gegensatz zur konventionellen Chirurgie wird in der sog. minimalinvasiven Chirurgie das Operationsfeld nicht offen exponiert, sondern der Eingriff erfolgt im Allgemeinen in einem geschlossenen Hohlraum.

\section{Praxisbox}

\section{Minimalinvasive Chirurgie}

Durch Insufflation von Gas $\left(\mathrm{CO}_{2}\right)$ in den Peritonealspalt wird intraabdominell der nötige Raum für den Eingriff geschaffen. Instrumente werden dabei über gasdichte Trokare durch die Bauchdecke geführt. Meistens wird das Pneumoperitoneum über eine kleine periumbilikale Inzision angelegt. An der gleichen Stelle erfolgt das Einführen des 1. Trokares. Im Gegensatz zur Veress-Nadeltechnik kann jedoch auch der sog. halboffene Zugang (Hasson) gewählt werden, bei dem mittels einer Minilaparotomie das Peritoneum geöffnet und dann ein selbstabdichtender Trokar eingeführt wird. Diese Technik empfiehlt sich insbesondere dann, wenn intraabdominelle Verwachsungen zu erwarten sind. 


\section{Blutstillung}

$(7$ Die chirurgische Blutstillung kann primäres Operationsziel (epidurales Hämatom, Ösophagusvarizen, Milzruptur etc.) oder technische Notwendigkeit (Durchtrennung blutversorgter Gewebe) zum Erreichen eines bestimmten Operationszieles sein.

Erstmaßnahme zur Verhütung eines Blutverlustes ist meist die Kompression. Sie kann am Ort der Blutung selbst oder im Gefäßverlauf proximal und distal der Blutungsquelle erfolgen.

An den großen Gefäßen erfolgt die definitive Versorgung einer Blutungsquelle durch Verschluss mittels Naht. Defekte können durch autologes Gewebe (z.B. Venenwand) oder künstliche Prothesen überbrückt werden. Die Wiedervereinigung kleiner Gefäße bedarf der Methoden der Mikrochirurgie. Gefäße, die für die Organdurchblutung entbehrlich oder nach Beendigung des Eingriffes (z. B. nach Resektion eines Organes) nicht mehr notwendig sind, werden mit einem $\mathrm{Fa}-$ den (Ligatur) abgebunden. Befürchtet man ein Abrutschen des Fadens bei kurzem Gefäßstumpf oder großem Gefäßquerschnitt, kann der Faden im Gewebe oder im Gefäß durch eine Naht verankert werden (Durchstechungsligatur). Bei großen Arterien kann nicht resorbierbares Nahtmaterial zweckmäßig sein. Gezielte Elektrokoagulation vermag kleine Gefäße ausreichend zu verschließen.

Mit Hilfe von Clips aus Titanlegierung oder resorbierbarem Kunststoff kann ein blutendes Gefäß ebenfalls verschlossen werden, sofern es gut isolierbar und nicht zu groß ist. Entsprechende Applikatoren sind allerdings wesentlich teurer als Fadenmaterial und es besteht die Gefahr, dass diese Hämoclips im weiteren Verlauf der Operation infolge von Manipulationen wieder abgerissen werden oder abrutschen. In der endoskopischen Operationstechnik haben Clips dagegen eine große Bedeutung erlangt.

Die Esmarch-Blutleere erlaubt, an den Extremitäten ohne Blutverlust und anatomisch exakt zu operieren. Hierzu wird die Extremität zunächst hochgelagert, sodann das Blut mittels breiter Gummibinde von peripher nach zentral aus den Gefäßen herausgepresst. Danach wird eine Blutsperre angelegt und dann die Gummibinde entfernt. Die Dauer der Blutleere ist zu protokollieren. An den Extremitäten sind Ischämien von mehr als 45 min zu vermeiden.

Das Prinzip lässt sich auch bei Operationen an der Leber (Abklemmen des Lig. hepatoduodenale, sog. Pringle-Manöver) oder an der Milz (Abklemmen des Milzhilus) anwenden. Hier sollte eine Ischämiezeit von mehr als 30 min nicht überschritten werden.

Für großflächige diffuse Blutungen an parenchymatösen Geweben stehen Hämostyptika zur Verfügung (Zellulose- oder Kollagenvliese u. U. auch mit Gewebekleber beschichtet).

In Ausnahmefällen müssen Blutungen durch Kompression mit Tamponade gestillt werden: Blutung aus Abszessinzisionen z. B. mit Jodoformgaze (nach 2-3 Tagen entfernen, evtl. erneuern), Sengstaken-Sonde bei Ösophagusvarizen (36$48 \mathrm{~h}$ ), sehr unzugängliche Blutungsquellen bei schlechtem Allgemeinzustand des Patienten durch Tamponade bis zum granulomatösen Verschluss der Blutungsquelle (8-14 Tage) und bei Leberruptur in Form des perihepatischen "packing" (36-48 h).

\section{Nahttechnik}

Die Gewebenaht soll die zu vereinigenden Gewebe:

- "Stoß-auf-Stoß" (Vereinigung beider Wundkanten im gleichen Niveau) dauerhaft adaptieren und

- eine ausreichende Durchblutung garantieren.

Beste Bedingungen für die Wundheilung werden erreicht, wenn zueinander gehörende Gewebe exakt, spannungsfrei und unter Vermeidung von Hohlraumbildung vereinigt werden. Die Haut muss aus kosmetischen Gründen genau adaptiert werden. Die Unterfütterung mit Subkutanfett ist möglichst wiederherzustellen, damit die Narbe verschieblich bleibt und z. B. bei zunehmender Adipositas später keine tief eingezogene Grube bildet.

\section{Reihen- und Schichtennaht}

$(7$ Reihig bezieht sich auf die Nahtreihen, schichtig auf die Gewebeschichten.

Auch bei der Naht von Hohlorganen (z. B. Darm, Blutgefäße) ist die Adaptierung Stoß-auf-Stoß wünschenswert, weil sie prinzipiell die schnellste Heilung ermöglicht. Um eine separate Vereinigung einzelner Wandschichten zu erreichen, kann der Chirurg mehrreihig nähen, also z. B. die Schleimhaut mit einer Naht adaptieren und dann Serosa und Muskularis zusätzlich mit einer 2. Naht fassen. Diese letztere seromuskuläre Naht ist dann eine zweischichtige Naht. Sie ist heute weitgehend verlassen. Besser führt die Allschichtennaht zum Erfolg.

\section{In- und evertierende Nahttechnik}

Am Darm fürchtet man bei evertierenden Nähten eine Schleimhautinterposition, die zu Fistelbildung führen könnte. Sie wird durch prinzipiell invertierende Nahttechnik oder durch zusätzliche Serosanaht (Lembert) vermieden. Allerdings beweist der Erfolg moderner Klammernahtgeräte, dass bei entsprechender Dauerkompression der Wundränder ein dichter Abschluss auch bei evertierender Adaptierung der Schleimhaut erreicht wird.

$(8$ Bei Gefäßen hat andererseits außer der Dichtigkeit des Verschlusses auch eine glatte Intimavereinigung für die Thromboseprophylaxe große Bedeutung, so dass hier eine Evertierung angestrebt wird.

\section{Fortlaufende und Einzelknopfnähte}

Längere Wundränder kann man entweder mit fortlaufender Naht oder durch zahlreiche Einzelknopfnähte vereinigen. Prinzipiell ist eine fortlaufende Naht dichter und ist schneller auszuführen. Die Einzelknopfnaht beeinträchtigt die Blutversorgung der genähten Wundränder weniger und bietet bei schwer erkennbaren Gewebeschichten insbesondere in der Tiefe des Abdomens den Vorteil, dass man alle Fäden zunächst 


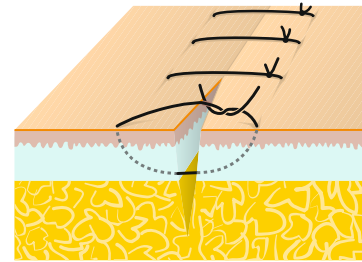

a

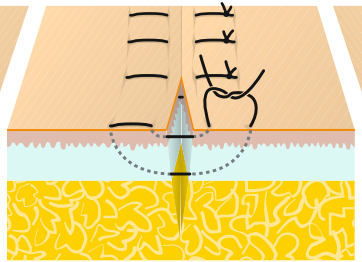

b

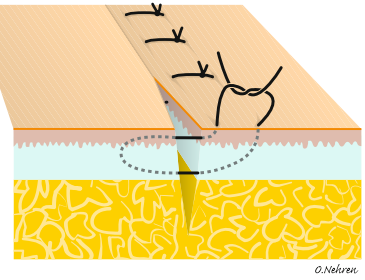

c

- Abb. 1.36 Hautnähte: a Einzelknopfnaht, b Donati-Naht, c Allgöwer-Naht

legen und dann erst in einem 2. Arbeitsgang knoten kann (sog. Klöppeltechnik).

\section{Nahtgeräte}

Für den Verschluss von Hohlorganen durch gerade Naht gibt es seit langem Nahtgeräte (Petz, Friedrich, $>$ Abschn. 1.3.2). Moderne Ausführungen arbeiten mit sehr feinen Einzelklammern aus Titanlegierungen in gegeneinander versetzten Doppelreihen. Sie ermöglichen auch die Anastomosierung mit gerader oder zirkulärer Naht. Es gibt auch Klammergeräte für die Naht der Faszie und der Haut (Stapler-Instrumentarium, - Abb. 1.25).

\section{Nahtfehler und Gefahren}

\author{
Nahtfehler \\ - Mangelnde Wundfestigkeit durch technische Fehler \\ - Zu großer Fadenabstand \\ - Zu wenig gefasstes Gewebe in Relation zur mecha- \\ nischen Beanspruchung \\ - Unregelmäßige Stichfolge \\ - Zu enge Stichfolgen können zu einem Durchreißen \\ des Gewebes führen (Briefmarkenphänomen) \\ - Zu dünnes Nahtmaterial schneidet bei Belastung \\ (z. B. Husten oder Erbrechen bei Nähten der Bauch- \\ wand) leichter durch das Gewebe \\ - Schlechte Knotentechnik ist besonders bei Fäden mit \\ glatter Oberfläche (monofile Fäden) oder mit Nei- \\ gung zum Quellen (Gore) gefährlich \\ - Zu hohe Spannung des Fadens führt zur Ischämie \\ des gefassten Gewebes
}

Bei der Vereinigung der äußeren Haut hat die Beeinträchtigung der Durchblutung durch zu festes Anziehen der Fäden gravierende kosmetische Nachteile, indem es durch ischämische Schädigung der Basalschicht der Epidermis zu quer zur eigentlichen Narbe verlaufenden Fadennarben kommt. Bei Keloidneigung kann sogar jeder Einstich der Nadel zu einem störenden Granulom führen. Eine Infektion der Stichkanäle verschlimmert die Narbenbildung.

Zur Vermeidung einer bleibenden Schädigung des Stratum germinativum kann man versuchen, die Fäden frühzeitig (2. postoperativer Tag, wenn eine Schwellung des Gewebes die Fadenspannung erhöht) durch Klebstreifen zu ersetzen. Die fortlaufende Naht kann besonders bei lose geknüpftem Endknoten ein zu festes Anziehen einzelner Schlingen und die Wundschwellung ausgleichen. Versenkte Fäden (Intrakutannaht) bringen die besten kosmetischen Ergebnisse. Das Einrollen der Hautränder z. B. an konkaven Körperoberflächen kann auch durch spezielle Rückstichnähte (Donati) verhindert werden (• Abb. 1.36).

Zur Vermeidung von Sekundärschäden sind vielfältige spezielle Nahttechniken und ausgewähltes Nahtmaterial im Gebrauch. Zur Vermeidung einer Steinbildung werden z. B. am Choledochus und Ureter resorbierbare Fäden verwendet.

\section{Naht- und Wundheilung}

Auch mit optimaler Nahttechnik (gleichmäßiger Fadenabstand, genügend weitgreifende Nähte) kann bei künstlicher Verbindung von Faszien, Bändern oder Knochen primär nur ein Bruchteil der normalen Festigkeit des natürlichen Gewebes erreicht werden (ca. 20-30\%): Der Kraftanteil konzentriert sich punktförmig auf die Durchtrittsstellen der verwendeten Nahtmaterialien durch das Gewebe. Eine Ruhigstellung der genähten Strukturen für die Zeit der Wundheilung ist daher anzustreben, im Falle der Bauchdecken aber nicht möglich. Husten und Erbrechen sind daher besonders in der Aufwachphase soweit wie möglich zu vermeiden.

\section{Wundheilung}

- Hautfäden können nach 7-8 Tagen entfernt werden

- Ausreichende Festigkeit für alltägliche Belastungen (z. B. Duschen, Gymnastik) hat die Hautnaht nach 12-14 Tagen

- Die Bildung, Ausrichtung und Vernetzung der Kollagenfasern in Faszien und Bändern hat nach 6 Wochen $80 \%$ der endgültigen Narbenfestigkeit erreicht

\section{Prinzipien der Nahttechnik am Gastrointestinaltrakt}

ᄀ Grundsätzlich strebt man auch am Gastrointestinaltrakt eine allschichtige, einreihige Stoß-auf-StoßNaht an.

Dieses Ziel der Nahttechnik ist überall da zu erreichen, wo die Darmwand von außen zugängig ist und dieses Ziel durch Wenden der Anastomose auch im Bereich der Hinterwand 
erreicht werden kann. Ein solches Wenden der Anastomose, d. h. Naht von außen sowohl im Bereich der Vorder- wie auch der Hinterwand ist an allen beweglichen Teilen des Gastrointestinaltraktes möglich (intraperitoneale Lage). An nur partiell beweglichen Organen (retroperitoneale Lage, z. B. Ösophagus, Duodenum, Rektum) muss die Hinterwand von innen genäht werden.

Naht von außen: Die Standardnahttechnik ist die allschichtige, einreihige Naht!

Praxisbox
Allschichtige, einreihige Naht
Dabei werden alle Wandschichten des Gastrointestinal-
traktes mit Ausnahme der Mukosa gefasst. Die meisten
Kollagenfasern, die allein der Naht ausreichend Halt
bieten, befinden sich in der Submukosa. Diese muss
deswegen großzügig tangential mit gefasst werden. Die
Mukosa wird nicht durchstochen, um eine Kommunika-
tion des Nahtmaterials mit dem Lumen des Gastrointes-
tinaltrakts zu vermeiden ( Abb. 1.37a).
Diese allschichtige Nahttechnik kann in Form von
Einzelknopfnähten, aber auch fortlaufend ausgeführt
werden. Immer beginnt eine Naht am Gastrointestinal-
trakt mit dem Legen der sog. Eckfäden mesenterial und
antimesenterial. Dann wird die Wiedervereinigung der
Wundlefzen im Bereich der Vorderwand und nach Wen-
den der Anastomose auch im Bereich der Hinterwand
durchgeführt. Mit dieser Nahttechnik können alle Be-
reiche des Gastrointestinaltrakts sicher versorgt werden.
Wesentliche Voraussetzung für eine ungestörte Wund-
heilung ist die ausreichende Durchblutung der zu ver-
einigenden Anteile des Gastrointestinaltrakts. Hierauf ist
ebenso besonderer Wert zu legen wie auf eine spannungs-
lose Vereinigung. Eine besondere Deckung der Anasto-
mose ist im Regelfall nicht notwendig.

Bei nicht wendbarer Anastomose (retroperitoneal gelegene Anteile des Gastrointestinaltrakts) muss die Hinterwand vom Lumen her versorgt werden. Dafür bedient man sich sog. Rückstichnähte (- Abb. 1.37b), die zunächst allschichtig beide Wundlefzen erfassen und dann im Sinne eines Rückstiches noch einmal tangential Mukosa und Submukosa ergreifen, um eine exakte Schleimhautadaptation der Hinterwand zu erreichen. Bei schwer zugänglichen Anastomosen können diese Nähte zunächst vorgelegt und erst später geknüpft werden (sog. Klöppeltechnik, - Abb. 1.38). Mit dieser relativ simplen Nahttechnik können alle Anastomosen im Bereich des Gastrointestinaltrakts sicher ausgeführt werden. Spezielle Nahttechniken insbesondere bei der Vereinigung parenchymatöser Organe mit dem Gastrointestinaltrakt werden in den entsprechenden Organkapiteln dargestellt.
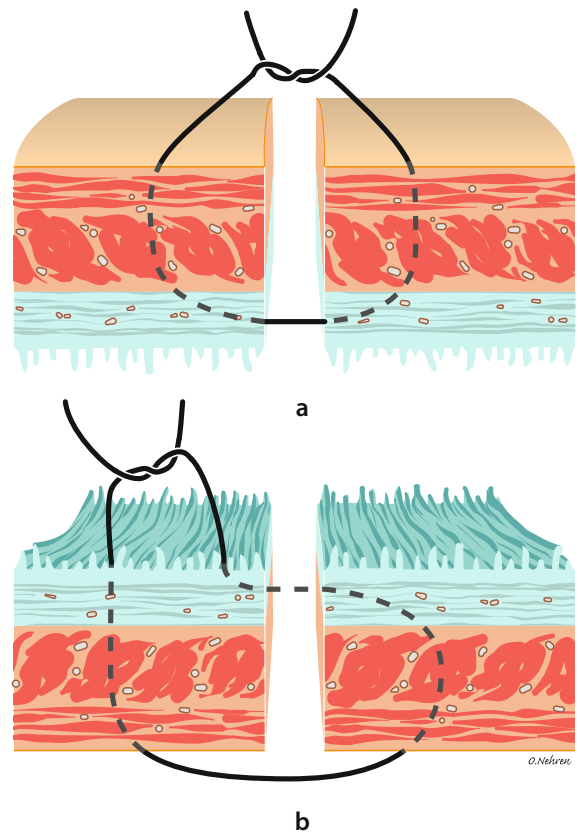

- Abb. 1.37 a Seromuskuläre Naht auf Stoß, b Rückstichnaht (Hinterwandnaht)

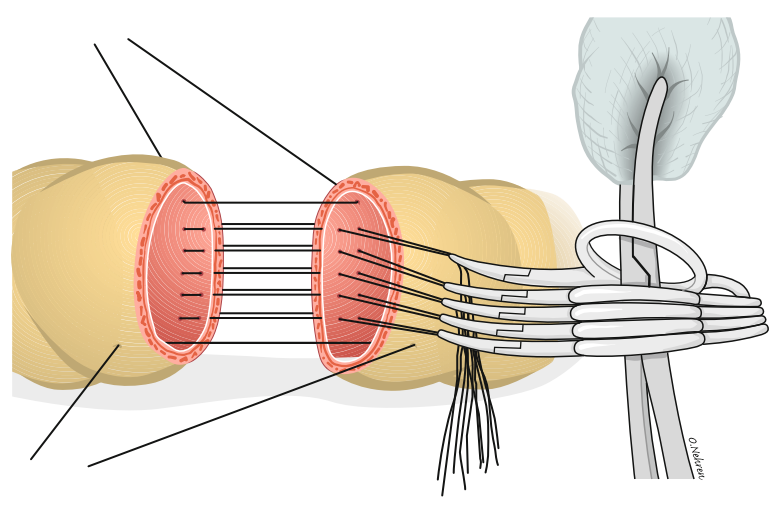

- Abb. 1.38 Sog. Klöppeltechnik

\section{Knotentechnik}

In der Chirurgie kommen im Regelfall 3 unterschiedliche Knotentechniken zur Anwendung, die allerdings durch eine große Zahl an individuellen Modifikationen ergänzt werden können. Die grundsätzlichen sind folgende:

- Einfacher Knoten: Gegenseitige Umschlingung der beiden zu vereinigenden Fäden (• Abb. 1.39). Dieser Knoten alleine ist nicht ausreichend sitzfest, so dass er in der Regel durch weitere 2 gegenläufige einfache Knoten ergänzt werden muss.

- Doppelter, sog. chirurgischer Knoten: Dieser beinhaltet eine doppelte Umschlingung der beiden Fadenenden. Dadurch wird eine etwa doppelt so ausgeprägte Reibung zwischen beiden Fäden erreicht. Der primäre Sitz ist entsprechend fester. Muss eine Naht z. B. unter Spannung des 

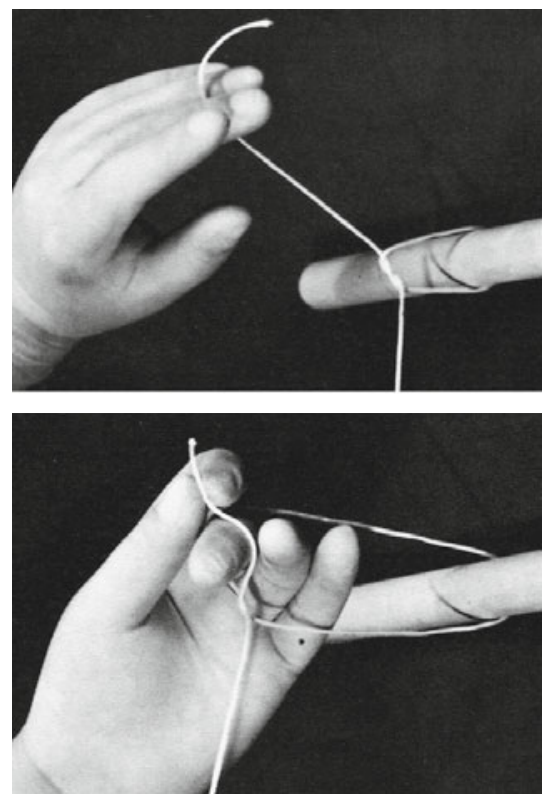

- Abb. 1.39 Wird beim einhändigen Knüpfen der Faden in Laufrichtung aus dem Knoten geführt und abwechselnd über den Zeigefinger und den Kleinfinger in die Handfläche gebracht, werden die Knoten mit Sicherheit gegenläufig (aus Braun-Dexon GmbH Melsungen 1975, Der Wundverschluss im OP)

Gewebes, wie bei der Fasziennaht, geknüpft werden, ist es günstiger, mit einem chirurgischen Knoten zu beginnen. Dieser kann leicht in der gewünschten Position gehalten werden. Er wird durch einen weiteren einfachen Knoten abgesichert.

- Sog. Schifferknoten: Dieser stellt einen doppelten, einfachen, gegenläufig geschlungenen Knoten dar und ist somit die Weiterentwicklung des einfachen Knotens.

Fäden können auch instrumentell, d.h. mit dem Nadelhalter, geknüpft werden. Das Prinzip der Fadenführung ist identisch (- Abb. 1.40).
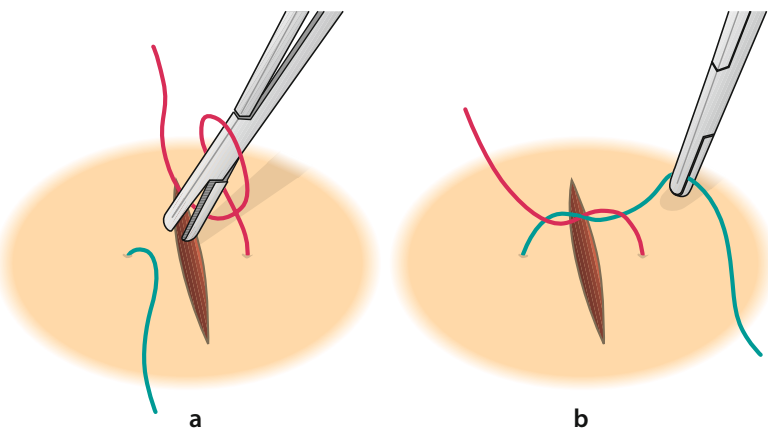

- Abb. 1.40 Bei Werfen des Fadens im wechselndem Drehsinn um die Spitze des Instruments entstehen beim Instrumentenknoten von

\section{Drainagen}

- Definition

Drainagen sollen Blut und Sekret aus natürlichen oder pathologischen Hohlräumen nach außen ableiten (Pleura, Peritoneum, Gallenwege, Abszesse).

Da Gummi die Bildung von Granulationsgewebe stark stimuliert, wird dieses Material für Gallenwegsdrainagen verwendet, weil eine sichere Verklebung des Drainagekanals gleich nach der Entfernung des T-Drains erwünscht ist. Als möglichst reizarmes Material findet andererseits Silikon in der Pleura- oder Peritonealhöhle Verwendung. Der Drain kann auf natürlichem Wege (transnasale Magensonde, transurethraler Dauerkatheter) oder durch entsprechende Inzisionen (Wunde, Gastrostomie, suprapubische Blasendrainage) eingebracht werden. Der Flüssigkeitstransport kann durch Absaugung beschleunigt werden. Drainagen können auch zur Spülung Verwendung finden.

Drainiert werden grundsätzlich alle Abszesshöhlen, soweit man sie nicht ganz breit spalten kann. Spülungen mit Antibiotikalösungen haben sich bei Osteomyelitis bewährt.

\section{Subkutanbereich}

Im schlecht durchbluteten Fettgewebe bleiben längere Zeit Hohlräume bestehen. In Zysten oder Hämatomen können aber schon sehr kleine Bakterienkolonien zu einer Abszessbildung führen, weil die körpereigene Abwehr schlecht angreifen kann. Daher versucht man, mit Redon-Drainagen, die aus sehr festem Kunststoff bestehen, zahlreiche Abflusslöcher aufweisen und unter starkem negativem Druck stehen, die Hohlraumbildung zu verhindern. Die gleiche Technik wird in der Extremitätenchirurgie und auch nach Strumaresektion zur Ableitung von Hämatomen und zur Früherkennung von Nachblutungen verwendet. Sie werden nach weitgehender Erfüllung dieser Aufgaben, also nach 2-3 Tagen, entfernt. Aus Gründen der Infektionsprophylaxe werden fast nur noch geschlossene Systeme verwendet (• Abb. 1.41).
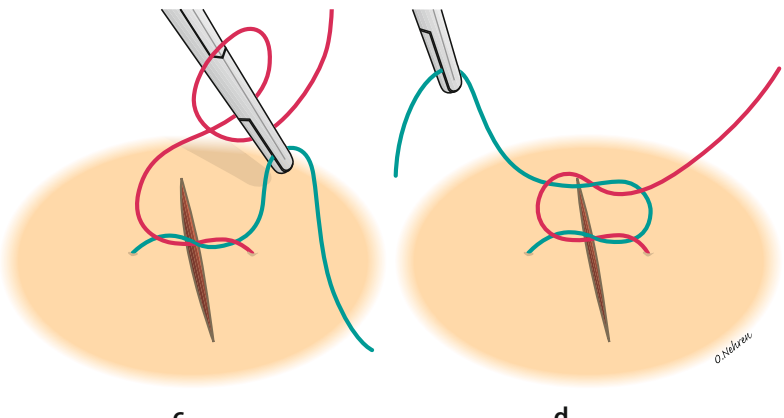

d

selbst gegenläufige Knoten (aus Braun-Dexon GmbH Melsungen 1975, Der Wundverschluss im OP) 


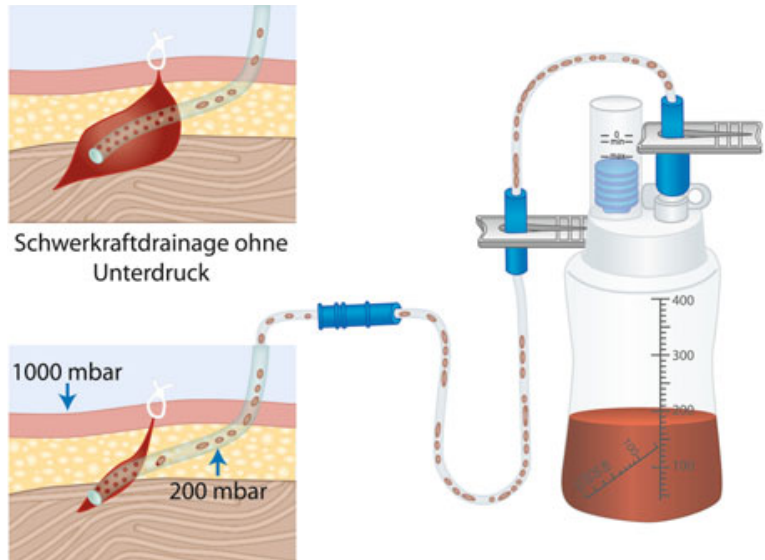

- Abb. 1.41 Redon-Drainage

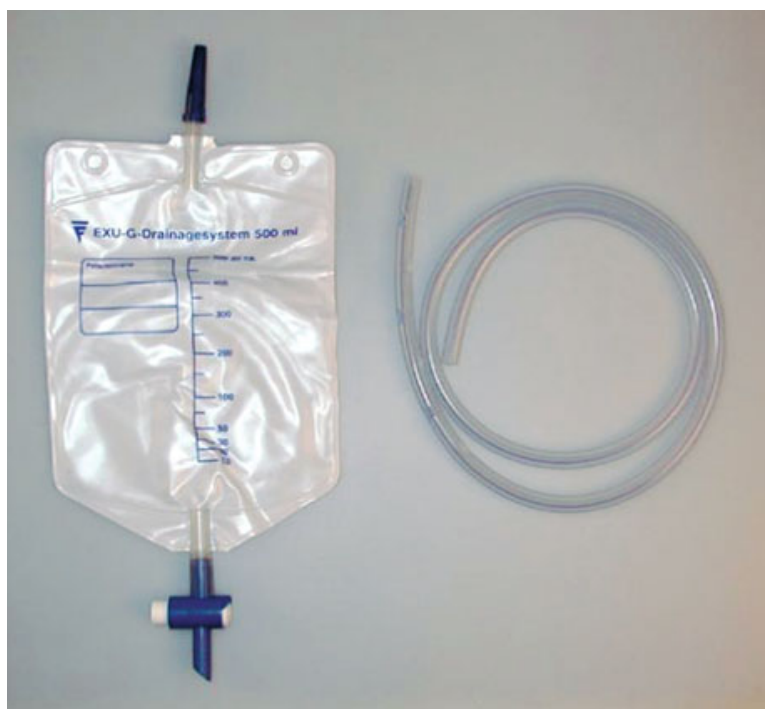

- Abb. 1.42 Sog. Robinson-Drainage: rechts die Drainage (das perforierte Ende wird in den Situs platziert); links Auffangbeutel

\section{Abdomen}

$($ Im Peritonealbereich dienen Drainagen neben der Ableitung postoperativen Sekretes in erster Linie der Erkennung von Anastomoseninsuffizienzen ("Spion im Bauch«).

Diese werden bei Nahtfehlern in den ersten 3 Tagen, bei Insuffizienzen durch Nekrosebildung (Ischämie) bis zum 7. postoperativen Tag offenbar. Nach dieser Zeit können die Drainagen entfernt werden (• Abb. 1.42).

Wird die Drainage nur eingelegt, um Nachblutungen oder parenchymatöse Sekretaustritte zu erkennen, kann sie früher (nach 48 h) gezogen werden. Zur Behandlung einer Peritonitis können die Drainagen auch als Zugangsweg für eine intermittierende Peritonealspülung benutzt werden.

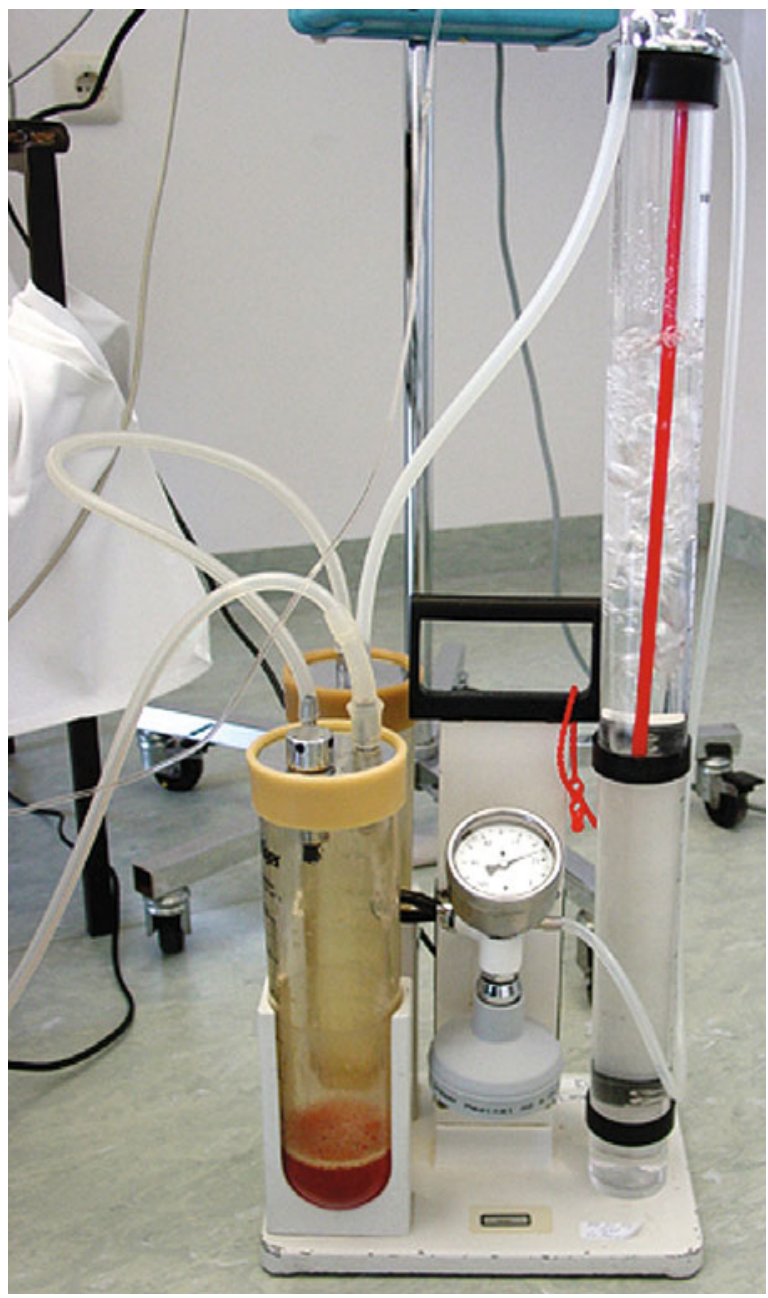

- Abb. 1.43 Bülau-Drainage: In dem Standzylinder (rechts) wird ein Unterdruck erzeugt, der durch Verschieben der mit der freien Atmosphäre kommunizierenden zentralen Röhre (rot) eingestellt werden kann. Zwischen Wasserschloss und Patient ist ein Sekretauffangbehälter zwischengeschaltet

\section{Pleurahöhle}

Drainagen in der Pleurahöhle erfordern zur Aufrechterhaltung des negativen Druckes eine konstante Saugung (hydrostatisch oder durch Pumpe), solange durch Stichkanäle und Ähnliches noch Luft aus der Lunge in die Pleurahöhle eintreten kann. Ist dies nicht der Fall (z. B. nach Entleerung eines Pleuraergusses oder -empyems), ist die Absicherung des negativen Druckes durch ein Ventil (Wasserschloss: Bülau-Drainage, $\bullet$ Abb. 1.43) notwendig.

\section{Magensonde und Blasendrainage}

Die transnasale Magensonde entlastet den Magen, der auf große intraperitoneale Eingriffe mit einer Atonie reagieren kann. Zur Ableitung des Urins dient die suprapubische Blasendrainage. 


\section{In Kürze}

Grundprinzipien der Operationstechnik

Die erfolgreiche Durchführung eines chirurgischen Eingriffes erfordert:

- Exakte anatomische Kenntnisse

- Sichere Operationstechniken: Lagerung (Vermeidung von Nervenschädigung), Asepsis, Schnittführung, Zugänge, Blutstillung, Naht- und Knotentechnik, Drainagen

- Subtile Kenntnis und souveräne Beherrschung des chirurgischen Instrumentariums:

- Operationsinstrumente (Präparation, Exposition, Blutstillung, Rekonstruktion)

- Technische Hilfsmittel (v. a. minimalinvasive Technik)

\subsection{Pathophysiologische Folgen, Vorbe- handlung und Nachbehandlung bei operativen Eingriffen und Traumen}

\section{H. Bartels}

Die Stoffwechselveränderungen nach großen operativen Eingriffen sind heute messbar geworden. Eine detaillierte Kenntnis dieser ganz spezifischen Reaktionsmuster ist unerlässlich zur Durchführung adäquater perioperativer und postoperativer Therapiemaßnahmen.

Die Risikoabschätzung des Patienten vor geplanten Operationen hat das Ziel, präexistente Erkrankungen aufzudecken. Sie bietet die Möglichkeit, durch funktionelle Vorbehandlung gestörte Organfunktionen zu stabilisieren und das Risiko des Eingriffes zu senken. Sie nimmt damit Einfluss auf die Indikationsstellung und auch Verfahrenswahl und ist Voraussetzung für jedes problemorientierte postoperative Management.

Die postoperative Therapie umfasst Infusions- und Ernährungsregime, die sich an den aktuellen Flüssigkeitsverlusten und der Notwendigkeit, den Organismus mit genügend Bauund Nährstoffen zu versorgen, orientieren. Besondere Bedeutung kommt einer ausreichenden Schmerzmedikation zu und physikalischen Therapiemaßnahmen zur Vermeidung vor allem pulmonaler Komplikationen.

Zur Absicherung des postoperativen Verlaufes sind das Monitoring vitaler Organfunktionen und die Überwachung des Operationssitus unerlässlich. Nach viszeralchirurgischen Eingriffen sind postoperative Komplikationen ganz überwiegend auf Störungen im Bereich des Operationssitus zurückzuführen. Dabei stellt die septische Komplikation die häufigste und schwerste Belastung des postoperativen Verlaufs dar. Ziel aller Überwachungsmaßnahmen ist es, solche Störungen frühestmöglichst zu erkennen und entsprechende diagnostische und therapeutische Maßnahmen einzuleiten, bevor sekundäre Organversagen auf die bereits eingetretene Komplikation hinweisen.

\subsubsection{Pathophysiologische Folgen von Traumen und operativen Eingriffen}

\section{- Definition \\ Als Stressantwort werden alle endokrinen, metabolischen und immunologischen Reaktionen des Organismus auf Trauma und operativen Eingriff verstanden.}

Der chirurgische Patient reagiert auf Trauma und operativen Eingriff mit einer ganz spezifischen Stressantwort. Ist der Insult (Trauma, Operation) nur gering ausgeprägt, erfolgt in der Regel in kurzer Zeit die Wiederherstellung der metabolischen und immunologischen Homöostase. Ist der Insult aber massiv und länger anhaltend, kann dies zu ausgeprägten Veränderungen der endogenen Regulationsprozesse führen mit lebensbedrohlicher Rückwirkung auf den Gesamtorganismus. Immunologisch zeigen sich dann eine systemische Hyperinflammation und metabolisch typische Veränderungen, die als Postaggressionssyndrom (Postaggressionsstoffwechsel) bezeichnet werden.

\section{Definition}

Die Überaktivierung des unspezifischen Immunsystems wird als systemische Hyperinflammation (»systemic inflammatory response syndrome«, SIRS) bezeichnet.

Beide Phänomene können in einem Netzwerk sich gegenseitig regulierender Feed-back-Mechanismen über die Aktivierung zahlreicher zellulärer Komponenten zu Mikrozirkulationsstörungen auch in initial nicht betroffenen Organsystemen führen oder in eine progrediente Eiweißkatabolie münden (• Abb. 1.44).

$\checkmark$ Vorrangig sind daher Therapiemaßnamen gefordert, die die systemische Hyperinflammation (z. B. effektive Schocktherapie) und die Begrenzung des Eiweißkatabolismus beeinflussen (z. B. Ernährungsregime).

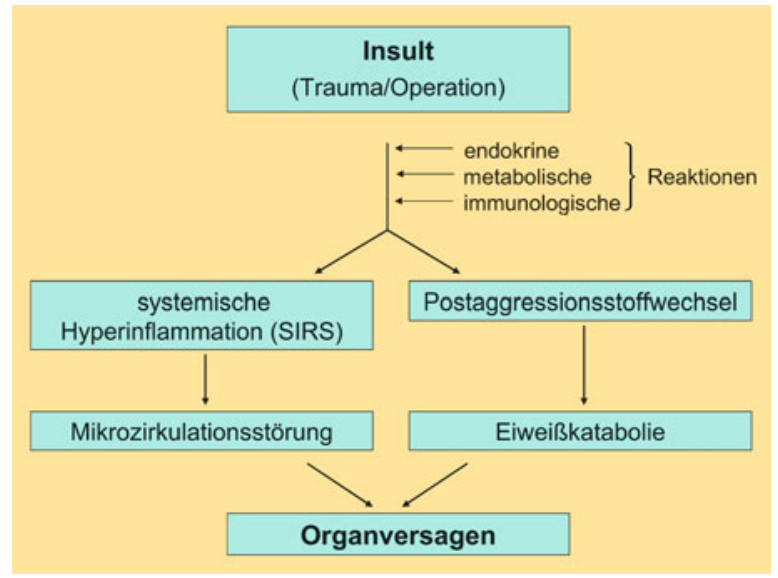

- Abb. 1.44 Pathophysiologische Folgen nach chirurgischem Trauma 


\section{Kausale Faktoren}

$(7$ Als auslösende Faktoren der ausgeprägten Homöostasestörung nach Trauma und großen operativen Eingriffen werden heute die initiale Gewebeschädigung/Verletzung, der Ischämie (Reperfusionsschaden nach Hypoxämie) und Schockphasen und die intestinale Translokation diskutiert.

Bei der Translokation können als Folge einer passageren Minderdurchblutung (z.B. Blutungsschock) Mikroorganismen und deren Toxine die intestinale Mukosabarriere überwinden, aus dem Darmlumen austreten und dann systemisch oder auch in der Darmwand selbst immunologische Vorgänge auslösen.

Durchdiegenannten Mechanismenwerden Immunmediatoren (z. B. Zytokine) freigesetzt, neuronale (z. B. Schmerz, Angst) und systemische Reaktionen (z. B. Tachykardie) getriggert und Barorezeptoren beispielsweise durch intravasale Flüssigkeitsverschiebungen stimuliert. Die Folge ist eine reaktive Ausschüttung von Hormonen, die der sympathoadrenalen Achse (autonomes Nervensystem, Nebenniere) und der hypothalamohypophysären Achse zuzuordnen sind.

\section{Sympathoadrenale Reaktion}

$(>$ Die sympathoadrenale Reaktion ist als zentraler Mechanismus zur schnellen Aktivierung von kardiovaskulären, respiratorischen und metabolischen Reaktionen entscheidend für das Überleben des Organismus.

Bereits sehr früh, d.h. unmittelbar nach einem Trauma oder noch während einer Operation werden Katecholamine, Glukokortikoide und Glukagon freigesetzt. Neben den direkten kardiopulmonalen Effekten der Katecholamine (z. B. Steigerung von Herzzeitvolumen und Energieumsatz) führt die synergistische Wirkung der Stresshormone zu charakteristischen Veränderungen im Kohlehydrat-, Eiweiß- und Fettstoffwechsel. Dabei wird die Konzentration aller Substrate des Intermediärstoffwechsels im Serum erhöht und Glukose, Aminosäuren und freie Fettsäuren frei verfügbar. Teleologisch ist diese Reaktion des Organismus im Sinne einer Akutreaktion auf Aggression durchaus sinnvoll.

Diese Regulationsprozesse sind zur afferenten Signalübertragung auf ein intaktes peripheres Nervensystem angewiesen. Deshalb sind z. B. bei Patienten mit Querschnittläsion oder bei spinalen bzw. epiduralen Anästhesieverfahren Stresshormone in deutlich geringerer Konzentration nachweisbar.

\section{Hypothalamohypophysäre Reaktion}

Ebenfalls innerhalb von Minuten nach chirurgischem Trauma kommt es auch zur Aktivierung der hypothalamohypophysären Achse. Dabei setzt der Hypothalamus stimulierende Substanzen (z. B. CRH, ACTH, TRH) frei, die ihrerseits die Hypophyse zur Ausschüttung von trophischen Hormonen für bestimmte Zielorgane anregt. Bei dieser endokrinen Akut- reaktion, die eine enge Korrelation zum jeweiligen Ausmaß der Homöostasestörung aufweist, sind u. a. Glukokortikoide, Schilddrüsenhormone, Wachstumshormone, Prolaktin, Testosteron und Vasopressin (antidiuretisches Hormon, ADH) in einer um ein Vielfaches erhöhten Konzentration im Serum nachweisbar.

Vasopressin als potenter Vasokonstriktor bewirkt eine Blutdrucksteigerung. Gleichzeitig sind erhöhte Vasopressinund Aldosteronspiegel für eine Natrium- und Wasserretention verantwortlich, jeweils im Austausch gegen Kalium- und Wasserstoffionen (Transmineralisation). Hierdurch wird ein effektiv zirkulierendes Plasmavolumen wiederhergestellt.

\section{Postaggressionsstoffwechsel}

- Definition -

Der Postaggressionsstoffwechsel ist gekennzeichnet

durch Katabolie aller im Organismus vorhandenen

Substratdepots. Besondere Bedeutung kommt dabei dem

Eiweißabbau zu.

Die Reaktionsmuster im Postaggressionsstoffwechsel sind durch das Zusammenspiel der aufgezeigten hormonellen Veränderungen geprägt und stellen eine zunächst sinnvolle physiologische Reaktion dar, um den Organismus mit Bausteinen zur Energiegewinnung und zum Aufbau wichtiger Funktionsproteine zu versorgen.

$(7$ Vereinfacht dargestellt führt der Anstieg von Adrenalin und Noradrenalin zur Glykogenolyse, Lipolyse und - in Kombination mit Glukokortikoiden - auch zur Proteolyse.

Damit steht die Katabolie aller im Körper vorhandener Substratdepots im Zentrum der Veränderungen. Durch diese Mechanismen werden bei gleichzeitiger peripherer Insulinresistenz ausreichend hohe Glukosespiegel sichergestellt, die in den glukoseabhängigen Geweben (z. B. zentrales Nervensystem, immunkompetente Zellen, Fibroblasten) die Glukoseaufnahme und den Energiestoffwechsel aufrechterhalten.

Darüber hinaus werden freie Fettsäuren als alternative Substrate in den nicht obligat kohlehydratabhängigen Geweben verfügbar, ebenso Aminosäuren zur Synthese wichtiger Funktionsproteine (z. B. Wundheilung, Akute-Phase-Proteine) und als Voraussetzung für die hepatogene Glukoneogenese. Die Aktivierung der hepatogenen Glukoneogenese wird wiederum durch Adrenalin und Glukagon vermittelt und die Synthese von Akute-Phase-Proteinen durch Immunmediatoren und Wachstumshormone stimuliert.

Die für die Glukoneogenese endogen freigesetzten Aminosäuren bedingen aber zwangsläufig einen Stickstoffverlust. $1 \mathrm{~g}$ Stickstoff entspricht 6,25 g Eiweiß und $30 \mathrm{~g}$ Muskelmasse. Die tägliche Stickstoff(Harnstoff)-Ausscheidung eines gesunden Erwachsenen beträgt $12 \mathrm{~g}$. Sie ist im Postaggressionsstoffwechsel aber um den Faktor 3 und beim polytraumatisierten Patienten sogar um den Faktor 4 erhöht. 
Die negative Stickstoffbilanz führt zu einer Abnahme des Körpereiweißbestandes und zum Verlust von Funktionsproteinen (z. B. Muskulatur, Enzyme, Strukturelemente) mit klinisch relevanten Auswirkungen auf den Gesamtorganismus.

Das Postaggressionssyndrom weist einen charakteristischen Zeitverlauf auf:

- In der Akutphase sind die Stresshormone Adrenalin und Noradrenalin maximal stimuliert und die Insulinsekretion gehemmt. Die Zytokinfreisetzung zeigt sich $u$. a. in Fieber und Tachykardie (SIRS).

- In der 2. Phase (1.-3. Tag) steht eine ausgeprägte Insulinresistenz im Vordergrund. Die erhöhte Zytokinexpression unterhält eine Akute-Phase-Reaktion mit Steigerung des Energieverbrauches und negativer Stickstoffbilanz.

- Die Insulinresistenz klingt ab dem 4. Tag langsam ab, allerdings bleiben Energieverbrauch und Stickstoffausscheidung für weitere Tage erhöht.

Im Postaggressionszustand kommt es zu einer erheblichen intestinalen Minderdurchblutung und damit auch $\mathrm{zu}$ einer Schädigung der Darmmukosa (Translokation), die durch Nahrungskarenz noch verstärkt wird.

Schweregrad und zeitliche Dauer des Postaggressionsstoffwechsels korrelieren mit dem Ausmaß des chirurgischen Eingriffes. Die Eiweißkatabolie als biochemisches Korrelat für die progrediente Abnahme von Muskelmasse hat erst nach 2 Wochen ihr Maximum erreicht. Erst nach 3-6 Monaten kann mit einer Wiederauffüllung des Körpereiweißbestandes gerechnet werden. Auch das Körpergewicht erreicht dann erst wieder den präoperativen Ausgangswert.

\section{Therapiemaßnahmen}

$\checkmark$ Für die Prognose des Patienten ist in der Initialphase die aggressive Behandlung der systemischen $\mathrm{Hy}$ perinflammation von vorrangiger Bedeutung. Damit steht eine effektive Schocktherapie mit Volumensubstitution und ausreichender Oxygenierung ganz im Vordergrund.

Ziel dabei ist es, eine ausreichende nutritive Perfusion aller Organe wiederherzustellen und Hypotonie- und Hypoxämiephasen auch im weiteren Verlauf zu vermeiden. Die Wirksamkeit einer effektiven Schocktherapie ist heute gut belegt. Neben dieser eigentlichen Kausaltherapie hat der Versuch, die negative Stickstoffbilanz zu beeinflussen, zunächst eher nachgeordnete Bedeutung. $\mathrm{Zu}$ entsprechendem Infusions- und Ernährungsregime, systemischem Schmerzmanagement und physikalischen Therapiemaßnahmen (z. B. Frühmobilisation), - Abschn. 1.4.3.

\section{In Kürze}

Pathophysiologische Folgen von Traumen und operativen Eingriffen

- Reaktion auf Trauma und operativen Eingriff mit ganz spezifischen endokrinen, metabolischen und immunologischen Reaktionsmustern (Stressantwort).

- Bei massivem Insult keine Rückkehr zur Homöostase, sondern endogene Regulationsprozesse mit lebensbedrohlicher Rückwirkung auf den Gesamtorganismus: systemische Hyperinflammation (SIRS) und Postaggressionssyndrom.

- Sympathoadrenale und hypothalamohypophysäre Reaktionen verändern Hormonspiegel und Stoffwechsel: Katabolie aller im Körper vorhandenen Substratdepots, Mobilisierung der körpereigenen Energie- und Proteinreserven mit Abnahme des Körpereiweißbestandes (negative Stickstoffbilanz).

- Therapiemaßnahmen müssen neben der initialen effektiven Schockbehandlung spezifisches Infusionsund Ernährungsregime berücksichtigen.

\subsubsection{Voruntersuchung und Vorbehandlung bei operativen Eingriffen}

\footnotetext{
Definition

Risikofaktoren sind Gesundheitsstörungen oder Erkrankungen, die den Patienten bei chirurgischen Eingriffen zusätzlich gefährden.
}

Die präoperative Risikoabschätzung gewinnt heute bei immer umfangreicheren Operationen in der Chirurgie zunehmend an Bedeutung. Ihre Zielsetzung dabei ist, die Patienten zu selektionieren, bei denen große und größte Eingriffe noch mit vertretbarem Risiko durchgeführt werden können und einen Operationszeitpunkt zu wählen, mit dem geringsten Risiko für den Patienten und der niedrigsten Komplikationswahrscheinlichkeit. Damit dient die präoperative Risikoabschätzung als Entscheidungshilfe bei der Therapieplanung (z. B. Vorbehandlung), nimmt Einfluss auf die Verfahrenswahl (z.B. Sicherheitschirurgie), ermöglicht ein problemorientiertes postoperatives Management (z. B. Nachbeatmung) und hilft die perioperative Morbidität und Mortalität zu senken.

\footnotetext{
Ziele der präoperativen Risikoabschätzung

- Patientenselektion: Eingriff noch mit vertretbarem Risiko durchführbar?

- Therapieplanung: Vorbehandlung bei funktionellen Störungen

- Einfluss auf die Verfahrenswahl: limitierte Chirurgie, Sicherheitschirurgie beim Hochrisikopatienten

- Problemorientiertes postoperatives Management, z. B. Nachbeatmung, Antikoagulation

- Senkung der perioperativen Mortalität
} 
Bei Notfalleingriffen müssen die Rahmenbedingungen, die der Patient mitbringt, akzeptiert werden. Diktiert durch den Zeitdruck ist eine sorgfältige Evaluation der Risikosituation in der Regel nicht möglich. Es gelingt bestenfalls, grob orientierend Organfunktionsstörungen abzuklären und nur in Ausnahmefällen, sie auch zu beeinflussen.

Bei Elektiveingriffen muss aber die Chance einer gezielten Operationsvorbereitung genutzt werden. Notwendige Voraussetzung dafür ist, relevante Begleiterkrankungen mit möglichem Einfluss auf den postoperativen Verlauf zu identifizieren und ggf. durch funktionelle Vorbehandlung zu bessern oder sogar auszuschalten.

\section{Risikoabschätzung}

Der traditionelle Weg des Versuchs einer präoperativen Risikoabschätzung ist die subjektive Beurteilung des Patientenzustandes durch den Operateur, ggf. unterstützt durch konsiliarärztliche Stellungnahme von Spezialisten für die einzelnen Organfunktionen. Dieser »klinische Eindruck« des Operateurs, der in jedem Fall eine große Erfahrung voraussetzt, kann aber in der Regel eine objektive Evaluation nicht ersetzen. So hat sich in der Vergangenheit gezeigt, dass Chirurgen präoperativ den Zustand ihrer Patienten zu positiv beurteilen. Das gilt in besonderem Maße für die Einschätzung von Hochrisikopatienten.

Am weitesten verbreitet ist heute die präoperative Risikoabschätzung anhand der ASA-Klassifikation (American Society of Anaesthesiology), die Patienten entsprechend ihres klinischen Status 5 Risikogruppen zuordnet (•Tab. 1.5). Die ASA-Klassifikation fasst den objektiven Befund, den subjektiven Eindruck und das abschließende klinische Urteil zusammen. Ihre Zielsetzung ist die Anwendbarkeit unter anästhesiologischen Gesichtspunkten für ein großes Eingriffsspektrum. Bezogen auf das individuelle Risiko, z. B. eines Patienten mit Ösophaguskarzinom, ist die ASA-Klassifikation aber wenig hilfreich, zumal Art und Größe des geplanten Eingriffs als wesentliche Kriterien keine Berücksichtigung finden.

- Tab. 1.5 Risikoklassifikation nach ASA (American Society of Anaesthesiology)

Klasse Zustand des Patienten

I Normaler, gesunder Patient

II Patient mit leichter Allgemeinerkrankung

III Patient mit schwerer Allgemeinerkrankung und Leistungsminderung

IV Patient mit inaktivierender Allgemeinerkrankung, die eine ständige Lebensbedrohung darstellt

V Moribunder Patient, von dem nicht erwartet wird, dass er die nächsten $24 \mathrm{~h}$ überlebt

\begin{abstract}
Definition
Risikoerfassung ist die Identifizierung von operationsbezogenem und patientenbezogenem Risiko.
\end{abstract}

Andere Versuche, z. B. anhand des Patientenalters, des Ernährungszustandes (anthropometrische Messungen), des Alkoholkonsums oder eines aus mehreren dieser Faktoren zusammengesetzten Klassifikationssystems, Risikogruppen zu definieren, haben sich im klinischen Alltag nicht durchgesetzt. Es bleibt somit festzuhalten, dass z. Zt. das präoperative Risiko für ein breites Spektrum chirurgischer Eingriffe nicht allgemein verbindlich erfasst werden kann. Daher sind bei der Risikoevaluation und zur Erstellung effektiver Präventionsstrategien in gleichem Maße das operationsbezogene Risiko und das patientenbezogene Risiko zu berücksichtigen.

\section{Operationsbezogenes Risiko}

Richtlinien zur perioperativen Evaluation für nicht kardiochirurgische Eingriffe sind heute klar definiert. Ein operationsbezogenes hohes Risiko (perioperative Mortalität $>5 \%$ ) liegt vor bei Notfalloperationen v. a. bei älteren Menschen, bei chirurgischen Eingriffen an der Aorta und den großen Gefäßen und bei allen ausgedehnten und lang andauernden Operationen mit hohen Flüssigkeitsverschiebungen, Blutverlust und damit verbundener systemischer Entzündungsreaktion. Zu dieser Kategorie gehören zweifelsfrei auch alle Eingriffe am oberen und unteren Gastrointestinaltrakt.

In der Ösophaguschirurgie kommt es darüber hinaus bedingt durch die Obstruktion des rechten Ventrikels durch das Interpositionsorgan - postoperativ zum Abfall des Cardiac-Index und in 90\% der Fälle zu hartnäckigen supraventrikulären Rhythmusstörungen. Damit sind v. a. Patienten mit eingeschränkten kardialen und koronaren Reserven in hohem Maße gefährdet. Um aber auch diesen Patienten einen potentiell kurativen Eingriff mit vertretbarem Risiko zu ermöglichen, bieten sich die Konzepte der limitierten Chirurgie und Sicherheitschirurgie an.

\section{Limitierte Chirurgie}

Limitierte Chirurgie bedeutet, wenn onkologisch vertretbar, z. B. bei Hochrisikopatienten mit Adenokarzinom des Ösophagus eine transhiatale Resektion anstelle der transthorakalen Ösophagektomie oder bei Patienten mit frühem Adenokarzinom im Barrett-Ösophagus eine Resektion des distalen Ösophagus mit Jejunuminterposition anstelle der radikalen Ösophagektomie. Mit diesen attraktiven chirurgischen Alternativen konnte bei spezieller Indikationsstellung die postoperative Morbidität deutlich gesenkt werden.

\section{Sicherheitschirurgie}

Sicherheitschirurgie trägt v. a. der besonderen Gefährdung von Patienten nach neoadjuvanter Radio-/Chemotherapie Rechnung. Immunologische Daten zeigen, dass die T-Lymphozyten, von entscheidender Bedeutung für die körpereigene Infektabwehr, durch die Vorbehandlung supprimiert werden. Diese exogene Immunsuppression bietet eine hinrei- 
chende Erklärung für den schlechten Verlauf und die hohe Mortalität bei Eintreten von postoperativ septischen Komplikationen.

Etabliert ist die Sicherheitschirurgie heute beim tief sitzenden Rektumkarzinom nach neoadjuvanter Radio-/Chemotherapie. Das Vorschalten eines protektiven Ileostomas minimiert die negativen Folgen einer potentiellen Anastomosenkomplikation.

In der Ösophaguschirurgie bietet sich als Sicherheitskonzept das zweizeitige Vorgehen mit "Splitting « der Resektionsphase von der Rekonstruktionsphase an. Nach Resektion des Ösophagus und Anlage einer endständigen zervikalen Speichelfistel ist das Risiko einer Kontamination des Mediastinums durch Speichel und Gastrointestinalinhalt ausgeschaltet. Das Ösophagusbett im hinteren Mediastinum kann verkleben, so dass bei Durchführung einer retrosternalen Rekonstruktion zum späteren Zeitpunkt, selbst bei Auftreten einer zervikalen Anastomoseninsuffizienz, eine Mediastinitis unwahrscheinlich wird (Mediastinitisprophylaxe). Damit können die häufig deletären Folgen einer Anastomoseninsuffizienz gerade beim Hochrisikopatienten verhindert werden.

$(8$ Beim Ösophaguskarzinom sollte ein zweizeitiges Vorgehen als Präventionsstrategie bei Patienten mit neoadjuvanter Radio-/Chemotherapie zur Anwendung kommen und auch bei nicht vorbehandelten Patienten, die aber auf dem Boden von präexistenten Begleiterkrankungen eine eingeschränkte Leistungsreserve und damit ein stark erhöhtes Risiko aufweisen.

\section{Patientenbezogenes Risiko}

Das patientenbezogene Risiko erwächst aus der allgemeinen Leistungsfähigkeit sowie Anzahl und Schwere vorhandener Begleiterkrankungen. Bei der Abklärung dieser Risikofaktoren ist die quantitative Erfassung der Organfunktionen, die unmittelbar Einfluss auf den postoperativen Verlauf nehmen, von vorrangiger Bedeutung.

\section{Pulmonale Funktion}

$(8$ Chirurgischer Eingriff und Allgemeinanästhesie führen zu charakteristischen Veränderungen der respiratorischen Funktion. Ursache dafür sind Störungen des Atemantriebs, der Lungenmechanik, des Ventilations-Perfusions-Verhältnisses und des pulmonalen Gasaustausches.

Oberbauch- und Zweihöhleneingriffe bedeuten darüber hinaus ein zusätzliches Risiko. Es kommt zu einer drastischen Reduktion sämtlicher Lungenvolumina und zur Abnahme der pulmonalen Compliance. Vitalkapazität und funktionelle Residualkapazität sind bis zu 70\% reduziert und erreichen erst nach 10-12 Tagen ihr Ausgangsniveau.

Diese auch beim Lungengesunden zwangsläufig auftretenden Veränderungen sind aber bei Patienten mit pulmonaler Vorerkrankung umso stärker ausgeprägt und von ungleich höherer klinischer Bedeutung. Der pulmonale Risikopatient ist postoperativ sehr viel schlechter in der Lage, ausreichend tief einzuatmen und damit auch effektiv abzuhusten. Folgen dieser Veränderungen können dann Hypoxämie, Sekretretention und Pneumonie sein.

$\checkmark$ Damit ergeben sich bei der präoperativen Abklärung durch

- Anamnese (Nikotinabusus, COPD, Asthma bronchiale),

- körperliche Untersuchung (Adipositas, Kyphoskoliose, Muskelerkrankungen),

- Auskultationsbefund der Lunge und/oder einer Dyspnoe

jeweils Indikationen für eine schrittweise Evaluation der Lungenfunktion.

\section{Kardiovaskuläre Funktion}

Perioperativ treten eine Reihe von Veränderungen mit negativer Rückwirkung auf die kardiovaskuläre Funktion auf. Kältezittern (Erhöhung des Sauerstoffverbrauchs), Restwirkung von Anästhetika (negativ inotrope Wirkung), Angst, Schmerz, Hypoxämie, erhöhte Atemarbeit und Blutdruckabfall sind Faktoren, die eine kardiale Dekompensation auslösen können.

(. Cave

Grundsätzlich stellt die kardiale Komplikation eine der schwersten Belastungen des postoperativen Verlaufs dar. Die Gefährdung ist aber ungleich höher bei Patienten mit spezifischen Vorerkrankungen und eingeschränkter kardialer und koronarer Leistungsreserve.

Hauptprädiktoren für erhöhtes kardiovaskuläres Risiko sind entsprechend heute gültigen Richtlinien instabile Koronarsyndrome, dekompensierte Herzinsuffizienz, signifikante Rhythmusstörungen und schwere Herzklappenfehler. Diese Patienten und auch Patienten mit stabiler Angina pectoris, stattgehabtem Herzinfarkt und Diabetes mellitus benötigen präoperativ Spezialuntersuchungen und daraus resultierend eine Optimierung ihrer funktionellen Leistungsfähigkeit bis hin zur koronaren Revaskularisation.

8

Insofern erfordert ein erfolgreiches perioperatives Management des kardialen Risikopatienten schon im Vorfeld eine sorgfältige Kommunikation zwischen Chirurgen, Anästhesisten und Kardiologen hinsichtlich eingriffsspezifischer Besonderheiten (z. B. Ösophagusresektion), Dringlichkeit des geplanten Eingriffes und Notwendigkeit einer spezifischen Vorbehandlung.

\section{Hepatorenale Funktion}

Bei Patienten mit Leberfunktionsstörungen ist im Vergleich $\mathrm{zu}$ »lebergesunden" Kontrollkollektiven die postoperative Morbidität und Mortalität deutlich erhöht. Die zugrunde liegenden Pathomechanismen sind neben einer Prädisposition für septische Komplikationen durch Immunsuppression und 
verminderte Infektabwehr kardiale Probleme (Rhythmusstörungen, toxische Kardiomyopathie), zirrhosebedingte Störungen (Aszites, Enzephalopathie) und erhöhte Blutungsneigung auf dem Boden eingeschränkter Thrombozyten- und Gerinnungsfunktion.

Als häufigste Ursache für eine Leberschädigung muss heute der chronische Alkoholismus gelten. Alkoholabusus beeinflusst den postoperativen Verlauf auch dahingehend, dass bei Entzugssymptomatik und dabei zwangsläufig eingeschränkter Kooperation (z.B. Abhusten) die Inzidenz postoperativer Pneumonien ansteigt.

$\checkmark$ Präexistente Leberfunktionsstörungen können sich einer laborchemischen Routinediagnostik entziehen.

Der hepatische Metabolismus ist charakterisiert durch seine hohe Funktionsreserve. Erst bei Vorliegen einer Zirrhose werden spezifische Muster einer fortgeschrittenen Insuffizienz transparent. Die Leberzirrhose reflektiert damit das Endstadium einer hepatischen Funktionsstörung und gilt heute allgemein als Kontraindikation für große elektive Chirurgie.

\section{Nierenfunktion}

Im Gegensatz zu einer Leberfunktionsstörung ist der Einfluss einer eingeschränkten Nierenfunktion auf den postoperativen Verlauf eher gering. Unter der Voraussetzung, dass prärenale Störungen (z.B. Hypovolämie) adäquat behoben werden, gelingt es in der Regel, eine präexistente Niereninsuffizienz im Stadium der Kompensation zu halten. Ein isoliertes akutes Nierenversagen tritt postoperativ heute nur noch in Ausnahmefällen auf und ist therapeutisch sehr viel besser beeinflussbar als z. B. die akute kardiale oder hepatische Dekompensation.

Beim bereits dialysepflichtigen Patienten muss der Zeitpunkt eines elektiven Eingriffes die gegebenen Dialyseintervalle berücksichtigen, um eine Überwässerung des Patienten am Operationstag oder postoperative Blutungen auf dem Boden einer dialyseinduzierten Koagulopathie zu verhindern.

\section{Allgemeinzustand und Kooperation}

Nach großen viszeralchirurgischen Eingriffen wird den Patienten ein Höchstmaß an Disziplin und Mitarbeit abverlangt.

Zur Prophylaxe von pulmonalen und thromboembolischen Komplikationen müssen Therapiemaßnahmen wie Atemtraining, Abhusten, Frühmobilisation u. a. immer wieder durchgeführt werden. Grundvoraussetzung dafür sind aber somatische Belastbarkeit und mentale Kooperationsfähigkeit des Patienten.

Derzeit stehen noch keine Methoden zur Verfügung, die präoperativ die Mitarbeit des Patienten nach dem Eingriff vorhersagen lassen. Ganz sicher ist diese Kooperation aber eingeschränkt beim alten Patienten, bei Demenz/Alzheimer, bei Vorerkrankungen aus dem psychiatrischen Formenkreis (z. B. Depression) und Medikamenten-, Drogen- und Alkoholabusus.

Somit ist die Bemessensgrundlage für die Einschätzung desAllgemeinzustandesdes Patientenund seiner Kooperations- fähigkeit weiterhin der »klinische Eindruck « des erfahrenen Operateurs, der entscheiden muss, ob dem Patienten der entsprechende Eingriff zugemutet werden kann.

\section{Umfang und Spektrum obligater Voruntersuchungen}

\section{( Grundvoraussetzung für jede präoperative Risiko- abschätzung ist die ausführliche Anamnese und ge- wissenhafte körperliche Untersuchung.}

Nur durch die genaue Erhebung der Anamnese lassen sich bisherige Medikation, Unverträglichkeiten, Allergien und Konsumgewohnheiten (z. B. Nikotin, Alkohol) erfassen. Diese Informationen liefern auch entsprechende Hinweise für ein problemorientiertes postoperatives Management.

Die körperliche Untersuchung kann bisher nicht bekannte Störungen aufdecken, aus denen sich durchaus Konsequenzen für den geplanten Eingriff ergeben mögen. So ist eine periphere arterielle Verschlusskrankheit nicht nur ein lokales, auf die Extremitäten beschränktes Problem, sondern signalisiert auch erhöhtes kardiales Risiko. Viele Risikofaktoren der arteriellen Verschlusskrankheit (z. B. Nikotin, Diabetes) sind auch Risikofaktoren für die koronare Herzerkrankung. Die Angina pectoris als Leitsymptom der koronaren Herzerkrankung kann klinisch verschleiert sein, weil der Patient z. B. wegen hohen Lebensalters oder intermittierender Claudicatio bisher nicht grenzwertig belastbar war.

Somit können streng genommen erst nach Vorliegen der aus Anamnese und körperlicher Untersuchung erhobenen Befunde Umfang und Spektrum obligater Voruntersuchungen bestimmt werden. Aus organisatorischen Gründen empfiehlt es sich aber, routinemäßig eine Basisdiagnostik durchzuführen, die heute ohnehin vor chirurgischen Eingriffen gefordert wird und deren Ergebnisse dann in Ergänzung zu Anamnese und Untersuchungsbefund zur Verfügung stehen.

\section{Basisdiagnostik}

Ziel der Basisdiagnostik ist es, Erkrankungen aufzudecken, die den Patienten über das eingriffsspezifische Risiko hinaus gefährden können. Dies gilt in gleichem Maße für kardiopulmonale Störungen, Leberschädigung (Bilirubin, GPT, alkalische Phosphatase), Niereninsuffizienz (Harnstoff, Kreatinin), Diabetes (BZ), Elektrolytentgleisung (Natrium, Kalium), Anämie (Hb, Hk), Blutungsneigung (Quick, PTT, Thrombozyten) oder latente Infektionen (Leukozyten, CRP).

Basisdiagnostik

- Anamnese, körperliche Untersuchung

- EKG, Röntgen-Thorax

- Blutbild (Hb, Hk, BZ, Leukozyten, Thrombozyten)

- Gerinnung (Quick, PTT, Fibrinogen)

- Serum-Elektrolyte (Natrium, Kalium)

- Bilirubin, GPT, alkalische Phosphatase

- Harnstoff, Kreatinin 
Nur wenn sich aus Anamnese, Untersuchungsbefunden und der Basis-Labordiagnostik Hinweise auf spezifische Organerkrankungen ergeben, werden nach Rücksprache mit den Spezialisten der entsprechenden Fachgebiete Zusatzuntersuchungen erforderlich.

\section{Erweiterte Diagnostik}

Art und Umfang der erweiterten Diagnostik richten sich nach den Erfordernissen des Einzelfalls, insbesondere in Abhängigkeit vom Alter und Allgemeinzustand des Patienten und Art und Größe des vorgesehenen Eingriffs.

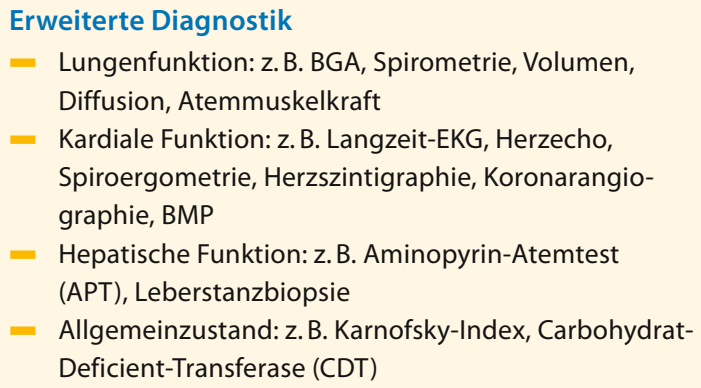

\section{Lungenfunktion}

So ist die Spirometrie als Routinemaßnahme zur präoperativen Abklärung der Lungenfunktion nicht erforderlich. Nur bei begründetem Verdacht auf Vorliegen einer pulmonalen Störung und vor thoraxchirurgischen Eingriffen werden spezifische Lungenfunktionstests benötigt. Dann muss der Pneumologe auch Stellung nehmen, ob ggf. eine funktionelle Vorbehandlung die pulmonale Leistungsfähigkeit präoperativ steigern kann.

\section{Herzfunktion}

Die kardiale Leistungsfähigkeit wird heute in metabolischen Äquivalenzstufen (MET) angegeben. Das perioperative Risiko, eine kardiale Komplikation zu erleiden, steigt, wenn 4 MET unter Belastung nicht mehr möglich sind. In grober Annäherung bedeuten $4 \mathrm{MET}$ eine symptomfreie Leistungsfähigkeit von mindestens 2 Stockwerken Treppensteigen oder zügigem Gehen in der Ebene.

Ist diese funktionelle Mindestkapazität nicht gegeben, sind BNP (»brain natriuretic peptide«) als neue kardiale Marker zur Risikostratifizierung bei der Herzinsuffizienz erhöht oder finden sich andere Hinweise auf ein erhöhtes kardiales Risiko, muss ein Kardiologe konsiliarisch hinzugezogen werden. Seine Aufgabe ist es dann, Spezialuntersuchungen zu veranlassen und Therapieempfehlungen auszusprechen bis hin zur koronaren Revaskularisation, auch wenn dies den Zeitpunkt der geplanten Operation hinausschiebt. Und er muss aus seiner Sicht das kardiale Gesamtrisiko des Patienten beurteilen, jeweils in Kenntnis über Art des Engriffes, voraussichtliche Eingriffsdauer und eingriffsspezifische Besonderheiten.

\section{Leberfunktion}

Ein hepatisches Äquivalent zum Harnstoff- und Kreatininanstieg bei Nierenerkrankungen ist laborchemisch leider nicht verfügbar. Die konventionelle Leberdiagnostik ist nur aussagekräftig bei bereits fortgeschrittenen Störungen. Die ChildPugh-Klassifikation mit zusätzlichen Parametern (z. B. CHE, $\mathrm{NH}_{3}$, Albumin) ist ein speziell auf Lebertransplantationen zugeschnittener Score.

Zur quantitativen Erfassung der Leistungsreserve bieten sich spezielle Leberfunktionsuntersuchungen, wie z.B. der Aminopyrin-Atemtest (APT) an, mit dem die hepatische Zytochrom-p450-Funktion gemessen wird. Diese Tests erlauben es in der Regel, präoperativ Risikopatienten zu identifizieren. Als Ultima Ratio bleibt bei begründetem Verdacht auf Leberzirrhose, die anders nicht diagnostiziert oder ausgeschlossen werden kann, die histologische Sicherung durch Leberstanzbiopsie.

\section{Allgemeinzustand}

Die Beurteilung des Allgemeinzustandes des Patienten, seiner Kooperation und Leistungsfähigkeit ist weiterhin der schwierigste Teilaspekt der präoperativen Risikoabschätzung, da objektive Parameter nicht verfügbar sind. Hilfestellung bei der Beurteilung liefert der Karnofsky-Index, der bereits in früheren Untersuchungen der relevante Risikofaktor bei der Abschätzung des postoperativen Verlaufes war.

Entscheidende Bedeutung kommt auch der Beurteilung des Alkoholkonsums zu. Anamnestische Angaben von Patienten hinsichtlich ihrer Trinkgewohnheiten sind z. T. unzuverlässig und Bestimmungen der Blut- bzw. Urin-Alkoholkonzentrationen als Screening-Methode wertlos. Alternativ bietet sich die Bestimmung des Carbohydrat-Deficient-Transferrins (CDT) an, die bisher vor allem bei forensischen Fragestellungen zur Anwendung gekommen ist.

\section{Funktionelle Vorbehandlung}

$\checkmark$ Ein wesentlicher Teilaspekt des Risikomanagements ist die sich daraus ergebende Möglichkeit, durch funktionelle Vorbehandlung präexistente Erkrankungen in ihrem Schweregrad zu beeinflussen oder sogar auszuschalten (- Abb. 1.45). Das gilt in besonderem Maße für pulmonale und kardiale Störungen.

\section{Vorbehandlung bei pulmonalen Erkrankungen}

Die Möglichkeiten Patienten mit restriktiven Ventilationsstörungen (z. B. Lungenfibrose) durch Vorbehandlung funktionell zu bessern, sind gering. Eine medikamentöse Therapie ist in der Regel nicht wirksam, nur in Ausnahmefällen profitieren diese Patienten von Steroiden. Durch gezielte Atemgymnastik kann aber die Kooperation des Patienten verbessert, die Muskelfunktion gestärkt und seine »emotionale« Dyspnoe gesenkt werden. Damit erlernt der Patient bereits präoperativ Techniken (z. B. Vertiefung der Spontanatmung), die postoperativ zur Prophylaxe pulmonaler Komplikationen notwendig werden. Dies erhöht auch seine Bereitschaft postoperativ Atemtraining selbstständig durchzu- 


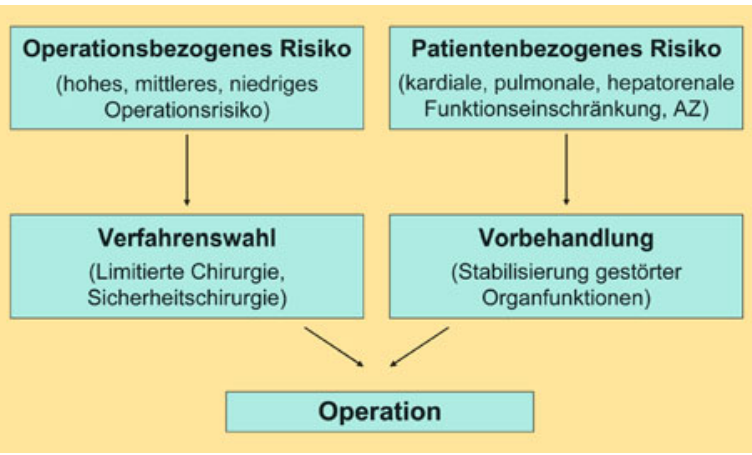

- Abb. 1.45 Risikomanagement in der Viszeralchirurgie (AZ: Allgemeinzustand)

führen, unabhängig von der Anwesenheit eines Physiotherapeuten.

Im Gegensatz dazu kann bei obstruktiven Lungenerkrankungen (z.B. Asthma, COPD) häufig eine funktionelle Verbesserung erzielt werden. Ziel einer antiobstruktiven, mukolytischen und antiinflammatorischen Therapie ist es, Sekrete zu lösen, Superinfektionen zu beherrschen und Atemwiderstand, Lungenvolumina sowie Gasaustausch zu bessern. Die Therapiedauer beträgt in der Regel 1-2 Wochen. Anhand der Lungenfunktionskontrolle entscheidet dann der Pneumologe, ob der Patient ausreichend rekompensiert ist oder ob eine weitere Vorbehandlung angezeigt erscheint.

\section{Vorbehandlung bei kardiovaskulären Erkrankungen}

Ein elektiver, nicht kardiochirurgischer Eingriff kann bei Vorliegen von instabiler Angina, dekompensierter Herzinsuffizienz, symptomatischen Rhythmusstörungen und schweren Herzklappenfehlern so lange nicht durchgeführt werden, bis eine klinische Besserung, ggf. erst nach herzchirurgischer Intervention, herbeigeführt ist.

\section{Eine präoperative koronare Revaskularisation ist grundsätzlich bei allen Patienten mit koronarer Ischämie in Erwägung zu ziehen.}

Die zur Anwendung kommenden Verfahren (z. B. PTCA, koronare Stents oder primäre Bypass-Chirurgie) richten sich nach angiographisch gesicherten anatomischen und funktionellen Kriterien. Es kann heute davon ausgegangen werden, dass nach erfolgreicher koronarer Revaskularisation das kardiale Risiko nicht mehr höher ist, als bei Patienten ohne koronare Herzerkrankung. Allerdings müssen eine Zeitverzögerung für den geplanten Elektiveingriff bis zu 6 Wochen und postoperativ spezielle Probleme durch konventionelle Antikoagulation bzw. Thrombozytenaggregation in Kauf genommen werden.

Tachykarde Rhythmusstörungen erfordern präoperativ eine elektrische oder pharmakologische Kardioversion.
Eine präoperative Sanierung von Karotisstenosen wird bei hochgradigen und v. a. symptomatischen Karotisstenosen notwendig. Das erforderliche Zeitintervall zwischen Karotischirurgie und geplantem viszeralchirurgischen Eingriff beträgt heute nur noch einige Tage.

Bei Patienten mit korrekturbedürftigen Klappenvitien sollte der kardiochirurgische Eingriff, wenn immer vertretbar, vor der Elektivoperation erfolgen. Postoperativ sind dann allerdings Endokarditisprophylaxe und ggf. eine dauerhafte Antikoagulation zu berücksichtigen.

Bezüglich der medikamentösen Therapie bei koronarer Herzerkrankung, Herzinsuffizienz, Rhythmusstörungen und arterieller Hypertonie sei auf spezielle Lehrbücher der Kardiologie und Pharmakologie verwiesen. Grundsätzlich muss aber gelten, dass eine spezifische Medikation konsequent bis zum Zeitpunkt der Operation weitergeführt und auch postoperativ fortgesetzt werden muss. Dies gilt heute in besonderem Maße für die Medikation mit $\beta$-Blockern als »Koronarprophylaxe«.

\section{Risikoanalyse}

- Definition

Risikoanalyse ist die Bewertung der präoperativen Risikosituation des Patienten in Korrelation zum geplanten chirurgischen Eingriff.

Auf dem Boden der dargestellten Basisuntersuchung und erweiterten Diagnostik wird eine präoperative Risikoerfassung möglich. Durch die Messung einzelner Parameter, orientiert an »Cut off-points«, die normale und eingeschränkte Organfunktionen differenzieren, und unterstützt durch Stellungnahmen der jeweiligen Fachspezialisten können einzelne Organfunktionen beurteilt werden.

Eine quantitative Aussage über die präoperative Risikosituation des Patienten gelingt dann, wenn die Einzelorganfunktionen ihrer klinischen Bedeutung entsprechend in Regressionsanalysen bewertet werden. Damit sind die Voraussetzungen für einen organbezogenen Risikoscore erfüllt.

Am Modell der Ösophaguskarzinomchirurgie wurde gezeigt, dass das Risiko anhand präoperativ verfügbarer Daten objektiviert und mit einem Summations-Score auch quantifiziert werden kann. Dieses Scoring-System ermöglicht die Klassifikation von Patienten mit Ösophaguskarzinom in verschiedene Risikogruppen und erlaubt eine Vorhersage der postoperativen Mortalität. Das Einbeziehen dieses Risikoscores in Entscheidungsprozesse bei der Indikationsstellung zur Resektion und auch zur Verfahrenswahl hat an der eigenen Klinik zu einer Senkung der postoperativen Mortalität von Patienten mit Ösophaguskarzinom auf Werte unter 2\% geführt. 
In Kürze

Voruntersuchungen und Vorbehandlung bei operativen Eingriffen

- Ziele der präoperativen Risikoabschätzung: Patientenselektion, Therapieplanung (funktionelle Vorbehandlung), problemorientiertes postoperatives Management und Senkung der perioperativen Morbidität und Mortalität.

- Operationsbezogenes Risiko: mögliche Einflussnahme durch limitierte Chirurgie und Sicherheitschirurgie.

- Patientenbezogenes Risiko erwächst aus der Anzahl und Schwere vorhandener Begleiterkrankungen.

- Risikoerhöhung, v. a. bei Störungen der kardiopulmonalen und hepatogenen Funktion, bei reduziertem Allgemeinzustand und eingeschränkter Kooperationsfähigkeit.

- Obligate Voruntersuchungen: ausführliche Anamnese, körperliche Untersuchung, Basisdiagnostik und ggf. erweiterte Diagnostik.

- Funktionelle Vorbehandlung zur Besserung oder sogar Ausschaltung präexistenter Erkrankungen, speziell bei pulmonalen und kardiovaskulären Störungen.

\subsubsection{Postoperative Therapie}

$\checkmark$ Der manifeste Flüssigkeitsverlust nach Trauma und nach großen chirurgischen Eingriffen muss initial durch eine aggressive Volumentherapie aufgefangen werden.

Ziel dieser Maßnahme in der Akutphase ist die möglichst rasche Wiederherstellung einer ausreichenden nutritiven Perfusion aller Organsysteme und Beeinflussung der systemischen Hyperinflammation ( $\triangle$ Abschn. 1.4.1). Die sich daran anschließenden Infusions- und Ernährungsregime haben den Basisbedarf an Wasser und Elektrolyten, die Korrektur zusätzlicher Verluste, die Bereitstellung notwendiger Bau- und Nährstoffe sowie den gesteigerten Energiebedarf im Postaggressionsstoffwechsel zu berücksichtigen.

\section{Infusionstherapie}

Volumendefizit, erhöhtes Serumkalium und gesteigerte ACTH-Produktion beeinflussen den aldosteronvermittelten Wasser- und Elektrolythaushalt. Die Folgen sind eine Natriumverschiebung in den Intrazellulärraum (Transmineralisation) und Wasserverluste im funktionellen Extrazellulärraum. Diese Verluste können allein durch gesteigerte endogene Wasserproduktion (z. B. Lipolyse, Glykogenolyse) nicht therapiert werden.

Der Basisbedarf von freiem Wasser liegt postoperativ bei 30-40 ml/kgKG/Tag. Natrium sollte mit 2-3 mval/kgKG/Tag und Kalium mit 1-1,5 mval/kgKG/Tag in Form von Elektro-
- Tab. 1.6 Dosierungsrichtlinien für postoperative Infusionstherapie und parenterale Ernährung (70 kg schwerer Patient)

\begin{tabular}{|l|l|}
\hline Infusionen & Dosis \\
\hline Wasser & $30-40 \mathrm{ml} / \mathrm{kgKG} / \mathrm{Tag}$ \\
\hline $\mathrm{Na}^{+}$ & $2-3 \mathrm{mval} / \mathrm{kgKG} / \mathrm{Tag}$ \\
\hline $\mathrm{K}^{+}$ & $1-1,5 \mathrm{mval} / \mathrm{kgKG} / \mathrm{Tag}$ \\
\hline Kalorien & $25-30 \mathrm{kcal} / \mathrm{kgKG} / \mathrm{Tag}$ \\
\hline Glukose & $5 \mathrm{~g} / \mathrm{kgKG} / \mathrm{Tag}$ \\
\hline Aminosäuren & $1,5 \mathrm{~g} / \mathrm{kgKG} / \mathrm{Tag}$ \\
\hline Fette & $1-2 \mathrm{~g} / \mathrm{kgKG} / \mathrm{Tag}$ \\
\hline
\end{tabular}

lytlösungen substituiert werden (• Tab. 1.6). Unabhängig davon sind zusätzliche Verluste (z. B. Magensonde, Wunddrainage) entsprechend ihrer qualitativen und quantitativen $\mathrm{Zu}$ sammensetzung als Korrekturbedarf mit adaptierten Elektrolytlösungen zu ersetzen.

Da infolge der katabolen Vorgänge im Postaggressionsstoffwechsel die Aminosäuren-, Glukose- und Fettsäurespiegel nach operativem Eingriff ohnehin stark ansteigen, muss in dieser Phase die Infusionstherapie lediglich den Basisbedarf und Korrekturbedarf an Wasser und Elektrolyten abdecken.

Bei normalem Ernährungszustand des Patienten und einer erwarteten Nahrungskarenz bis zu 7 Tagen ist diese Infusionstherapie ausreichend. Bei bereits präoperativ reduziertem Ernährungszustand und einer erwarteten Nahrungskarenz $>7$ Tagen werden darüber hinaus parenterale und enterale Ernährungsregime erforderlich.

\section{Parenterale Ernährung}

\section{- Definition \\ Aufgabe der postoperativen Ernährungstherapie ist es, den Organismus bei gesteigertem Energiebedarf mit aus- reichenden Bau- und Nährstoffen zu versorgen.}

Eine parenterale Ernährung ist immer dann indiziert, wenn die gastrointestinale Funktion eine enterale Ernährung (noch) nicht zulässt. Die Planung der parenteralen Ernährung muss den Basisbedarf an Wasser und Elektrolyten, den Energieumsatz, das Ausmaß der erwarteten Katabolie (negative Stickstoffbilanz) und die Höhe der jeweiligen Kohlehydrat-, Fettund Eiweißzufuhr berücksichtigen.

Aus dem Fettgewebe als größtem Energiespeicher des Organismus werden postoperativ Fettsäuren freigesetzt, die in der Peripherie zur Energieabdeckung dienen. Die geringen hepatischen Glykogenreserven spielen als Energiequelle nur in kurzfristigen Akutsituationen eine Rolle. Glukose muss als 
lebenswichtige Substanz für das zentrale Nervensystem, immunkompetente Zellen und Fibroblasten in der Leber immer neu synthetisiert werden. Vorläufer dieser Glukoneogenese sind Aminosäuren, die aus den Proteinspeichern der Muskulatur stammen ( $\triangleright$ Abschn. 1.4.1).

$\checkmark$ Neuere Untersuchungen haben gezeigt, dass die Steigerung des Energieumsatzes postoperativ nur das 1-2-Fache des Ruheumsatzes beträgt.

Der Kalorienbedarf nach Trauma und großen Operationen liegt zwischen 25 und $35 \mathrm{kcal} / \mathrm{kgKG}$ und entspricht damit für einen $70 \mathrm{~kg}$ schweren Patienten etwa $1.750-2.450 \mathrm{kcal} / \mathrm{Tag}$. Glukose ist das Infusionskohlehydrat der Wahl. Der Mindestbedarf, um die Versorgung glukoseabhängiger Zellen sicherzustellen und Aminosäuren bzw. Körperprotein einzusparen, liegt bei 100-150 g Glukose/Tag. Eine höhere Zufuhr induziert gesteigerte Fettneubildung in der Leber.

Als Alternative bietet sich der Einsatz von den Nicht-Glukose-Kohlehydraten Sorbit und Xylit an. Der wesentliche Nachteil dieser Zuckeraustauschstoffe liegt aber darin, dass bei vollständiger parenteraler Ernährung eine ausreichende Kalorienzufuhr damit nicht mehr gewährleistet ist.

D Cave

Fruktose darf in der Ernährungstherapie wegen der Gefahr einer induzierten Fruktoseintoleranz bei Patienten mit hereditärem Fruktose-1-Phosphataldolasemangel nicht mehr zur Anwendung kommen.

\section{Eiweiß}

$\checkmark$ Bei der postoperativen Ernährungstherapie sind v. a. die Proteolyse und negative Stickstoffbilanz zu berücksichtigen.

Das Ausmaß der Katabolie, definiert als Differenz zwischen dem gleichzeitig stattfindenden Eiweißabbau und der Eiweißneosynthese, ist abhängig vom präoperativen Ernährungszustand des Patienten und der Größe des chirurgischen Traumas. Dabei hat sich gezeigt, dass der Eiweißabbau (Proteolyse) postoperativ nicht beeinflusst werden kann. Durch Aminosäurenzufuhr gelingt es lediglich, die Eiweißneosynthese zu steigern. Einen maximalen Effekt weisen dabei 1,5 g Aminosäurelösungen/kgKG/Tag auf. Eine höhere Aminosäurenzufuhr bewirkt vermehrte Stoffwechselbelastung und Anstieg der harnpflichtigen Substanzen.

Nach großen Eingriffen mit einer mehrtägigen postoperativen Nahrungskarenz ist eine Aminosäurensubstitution in den ersten postoperativen Tagen bereits sinnvoll, auch wenn eine vollständige Deckung des kalorischen Bedarfes nicht möglich ist. Dabei sollten die Aminosäuren zur optimalen Verwertung immer zusammen mit den Energielieferanten Kohlehydrate und Fette infundiert werden.

\section{Fette}

Die Lipolyse, d.h. der Abbau von Triglyzeriden in freie Fettsäuren und Glyzerol ist in der Stressantwort beschleunigt.
Fettsäuren sind neben Glukose die wichtigsten Energielieferanten. $1 \mathrm{~g}$ Fett liefert 9,1 kcal.

Fettemulsionen sind als integrierter Bestandteil der parenteralen Ernährung bisher überwiegend unter dem Aspekt »Energieträger « gesehen worden. Sie sollen bei Ernährungsregimen 30-60\% des täglichen Energiebedarfes abdecken. Die empfohlene Dosierung für Erwachsene liegt damit bei 1-2 g Fettemulsion/kgKG/Tag.

Die nichtenergetische Bedeutung von Fettemulsionen besteht darin, dass essenzielle Fettsäuren für den Aufbau von Zellmembranen, Prostaglandinen und Leukotrienen erforderlich sind. Bei primärer Fettstoffwechselstörung mit Hypertriglyzeridämien $>300$ mg\% sollte die Fettzufuhr auf die essenziellen Fettsäuren beschränkt bleiben.

\section{Vitamine, Spurenelemente}

Vitamine sind bei der parenteralen Ernährung ebenso unverzichtbar wie bei normaler Nahrungsaufnahme. Bei Patienten, die bereits präoperativ fehl- oder mangelernährt sind, kann nicht mit ausreichenden Vitaminreserven im Organismus gerechnet werden. Bei diesen Patienten sollte eine Vitaminsubstitution mit im Handel verfügbaren Präparaten von Anfang an erfolgen- sonst erst ab der 2. postoperativen Woche.

Der Bedarf an Spurenelementen bei der intravenösen Ernährung ist nicht vollständig geklärt. Eine Substitution erscheint aber zumindest im Rahmen langfristiger Ernährungstherapie erforderlich. Der Bedarf wird ebenfalls mit industriell hergestellten Komplettlösungen abgedeckt.

\section{Praktische Durchführung}

Das Spektrum der postoperativen Ernährungstherapie wird vom präoperativen Ernährungszustand, der Dauer der Nahrungskarenz und dem Ausmaß der Operation bestimmt.

\section{Praxisbox \\ Parenterale Ernährung}

Bei der praktischen Durchführung der parenteralen Ernährung hat sich folgendes Vorgehen bewährt:

- Bei normalem Ernährungszustand des Patienten und einer erwarteten Nahrungskarenz $<7$ Tage kann auf die parenterale Ernährung ganz verzichtet werden. Es wird lediglich der Wasser- und Elektrolytbedarf abgedeckt.

- Ist die orale Nahrungsaufnahme nach 7 Tagen noch nicht möglich, wird eine hypokalorische Ernährung mit handelsüblichen Präparaten durchgeführt.

Derartige Lösungen enthalten Aminosäuren (1 g AS/kgKG/ Tag), Kohlenhydrate (2 g KH/kgKG/Tag) und Elektrolyte in einer Mischung, die z. B. als 3-Liter-Konzept eine nahezu ausgeglichene Stickstoffbilanz garantiert. Der nicht exogen abgedeckte Energiebedarf wird dabei aus der endogenen Lipolyse sichergestellt. Eine Fettsubstitution ist nicht erforderlich. Der Vorteil der hypokalorischen Ernährung liegt in seiner einfachen Handhabung. Ernsthafte metabolische Nebenwirkungen sind nicht zu erwarten. Der niedrige Kohlenhydratan- 
teil bedingt eine Gesamtosmolarität $<800 \mathrm{mosm} / \mathrm{l}$, die eine peripher-venöse Applikation zulässt.

$(7$ Ist von einer Nahrungskarenz $>7$ Tage auszugehen oder befindet sich der Patient präoperativ in reduziertem Ernährungszustand, wird eine normokalorische Ernährung über zentralvenöse Zugänge erforderlich.

Auch hierfür stehen vorgefertigte Komplettlösungen zur Verfügung. Als additive Energiezufuhr dienen dabei 20\%ige Fettemulsionen. Darüber hinaus ist eine Substitution von Vitaminen und Spurenelementen in Erwägung zu ziehen. Der Aufbau der normokalorischen Ernährung erfolgt schrittweise, wobei in den ersten 2 Tagen ein hypokalorisches Konzept zur Anwendung kommen sollte. Für die praktische Durchführung sind Infusionspumpen und engmaschige Kontrollen von Laborparametern (z. B. Glukose, Harnstoff, Triglyzeride) unverzichtbar.

Die parenterale Zufuhr von Bau- und Nährstoffen ist aber unphysiologisch. Die Reduktion der Proteinsyntheserate als verantwortlicher Mechanismus für den Eiweißverlust kann nicht vollständig kompensiert werden. Die Gefahr metabolischer Komplikationen wie Überernährung und Fettleber lässt sich durch stufenweise Steigerung der Energiezufuhr zwar eingrenzen, aber nicht ganz verhindern. Darüber hinaus belasten katheterassoziierte Komplikationen (z. B. Thrombose, Infektion, Septikämie) diese Ernährungsregime.

C Cave

Als besonders schwerwiegend gilt heute, dass die parenterale Langzeiternährung zur morphologischen und funktionellen Atrophie der Darmschleimhaut führt und damit der Gefahr einer intestinalen Translokation Vorschub leistet.

\section{Enterale Ernährung}

$(7$ Die enterale Ernährung erhält die Integrität und Funktionsfähigkeit der Intestinalmukosa.

Aus diesem Grunde sollte postoperativ der enteralen Nahrungszufuhr, wenn immer möglich, der Vorzug gegeben werden. Weitere Argumente für eine enterale Nährstoffzufuhr sind:

- Die Ernährung ist physiologischer.

- Im Vergleich zur normokalorischen parenteralen Ernährung kann der Eiweißverlust über einen Zeitraum von 10 Tagen nahezu halbiert werden.

- Sie ist in Abhängigkeit von der jeweiligen Kostform preisgünstiger (25-30\% der Kosten einer parenteralen Ernährung).

- Die Zugangswege bergen im Vergleich zu zentralvenösen Kathetern ein deutlich geringeres Risiko.

$(8$ Bei der enteralen Ernährung sollte die kalorische Zusammensetzung den Empfehlungen der Deutschen Gesellschaft für Ernährung entsprechen (Kohlenhydrate : Fette : Eiweiß = 50:30:20). Die Kalorienmenge der handelsüblichen Sondenkost ist auf $1 \mathrm{kcal} / \mathrm{ml}$ begrenzt.
Damit wird ein tägliches Angebot von $2000 \mathrm{kcal}$ entsprechend $2000 \mathrm{ml}$ Volumenbelastung möglich. Grundsätzlich sind hochmolekulare nährstoffdefinierte Diäten und niedermolekulare chemisch definierte Diäten zu unterscheiden, die jeweils spezielle Zugangswege und Anwendungstechniken erfordern.

\section{Hochmolekulare Diät}

Hochmolekulare oder nährstoffdefinierte Diäten (NDD) werden aus natürlichen Nährstoffen hergestellt, erfordern die Verdauungskapazität des gesamten Intestinaltraktes und sind deshalb das geeignete Substrat für eine gastrale Sondenernährung. Neben der standardisierten Sondenkost werden von der Industrie auch proteinreiche und hyperkalorische Varianten angeboten.

\section{Niedermolekulare Diät}

Niedermolekulare oder chemisch definierte Diäten (CDD) enthalten Hydrolysate natürlicher Eiweiße als Proteinkomponente sowie Oligo- bis Polysaccharide und Fette als Energiekomponenten. Es handelt sich um "vorverdaute « natürliche Nährstoffe, die das geeignete Substrat für Jejunalsonden darstellen. Die Standardpräparate sind ballaststoffreich.

\section{Praktische Durchführung}

Praxisbox

Enterale Ernährung

- Für die gastrale Ernährung stehen Magen- bzw. Duodenalsonden zur Verfügung. Diese Sonden werden transnasal »blind« eingeführt oder endoskopisch platziert. Die Ernährung erfolgt mit hochmolekularen Diäten, entweder als Bolus (z. B. 500-ml-Portionen) oder kontinuierlich.

- Die gastrale Ernährung nutzt den fermentativen und resorptiven Apparat des gesamten Intestinaltraktes. Voraussetzung dafür ist eine ungestörte gastrointestinale Funktion, die nach großen viszeralchirurgischen Eingriffen wegen der postoperativen Atonie aber in der Regel erst ab dem 3. postoperativen Tag gegeben ist.

Wird eine Sondenernährung über die 2. Woche hinaus erforderlich, bietet sich als Alternative die perkutane endoskopische Gastrostomie (PEG) an. Dabei wird in speziellen Techniken nach perkutaner Punktion des Magens eine Ernährungssonde transgastral eingeführt und fixiert.

Für eine enterale Langzeiternährung (z. B. Ösophagektomie ohne primäre Rekonstruktion der Speisepassage) wird intraoperativ eine Ernährungsfistel in das Jejunum eingenäht (Katheter-Jejunostomie) und perkutan ausgeleitet. Die Ernährung wird mit niedermolekularen Diäten kontinuierlich und pumpengesteuert durchgeführt. In Hinblick auf Patientenkomfort, Resorptionsbedingungen und Komplikationsrate (z. B. Dislokation, Druckulzera) ist dieser Zugangsweg anderen enteralen Ernährungsformen überlegen. 
Der Aufbau der enteralen Ernährung muss schrittweise erfolgen (Adaptationsphase). Innerhalb von 3-4 Tagen kann die tägliche Zufuhr auf das angestrebte Gesamtvolumen von $2000 \mathrm{ml}$ gesteigert werden. Zwischenzeitlich bietet sich eine Kombination mit hypokalorischer parenteraler Ernährung an. Eine initiale Verdünnung der Sondennahrung ist heute nicht mehr erforderlich. Die Dauer der Adaptationsphase ist abhängig von der individuellen Toleranz des Patienten. Bei spärlicher Peristaltik, abdomineller Distension oder auch Diarrhö kann durch passagere Reduktion der Substratzufuhr eine Toleranzverbesserung erreicht werden. In dieser Phase ist aber die klinische und sonographische Überwachung des Abdomens anspruchsvoll und die Diagnostik postoperativer Komplikationen häufig erschwert. Als Kontraindikationen für die Fortführung einer enteralen Ernährung müssen heute gelten: Darmobstruktion mit relevanter Passagestörung, paralytischer Ileus, schwerer Schockzustand mit Kreislaufinstabilität und gastrointestinale Blutung.

\section{Schmerztherapie}

Das subjektive Schmerzerlebnis des Patienten ist individuell stark unterschiedlich und hängt nicht regelhaft vom Ausmaß des vorangegangenen chirurgischen Traumas ab. Einflussnehmende Größen sind aber im Allgemeinen Operationsdauer, intraoperative Lagerung und auch der gewählte chirurgischer Zugang. So werden nach Cholezystektomien über einen Oberbauchlängsschnitt weniger Schmerzen angegeben als nach Transversal- oder Rippenbogenrandschnitten. Für endoskopische Operationstechniken ist gesichert, dass der Analgetikabedarf postoperativ deutlich abnimmt.

Das Schmerzereignis wird auch wesentlich durch psychische Faktoren des Patienten wie Erwartungshaltung, Motivation und Emotionslage beeinflusst. Auf diese emotionalen und affektiven Komponenten ist zurückzuführen, dass bei Elektiveingriffen durch ein ausführliches präoperatives Gespräch und entsprechende medikamentöse Narkosevorbereitung (Prämedikation) eine signifikante Reduktion des postoperativen Analgetikaverbrauchs erzielt werden kann.

Der Einfluss einer suffizienten postoperativen Analgesie wurde lange unterschätzt. Heute gilt als gesichert, dass postoperative Schmerzen u. a.

- die körperliche Aktivität des Patienten einschränken (Risiko: Thromboembolien),

- die Stressantwort des Organismus unterhalten und verstärken ( $>$ Abschn. 1.4.1),

- durch Schonatmung (Hypoventilation) v. a. nach thorakalen und abdominellen Eingriffen pulmonalen Komplikationen Vorschub leisten (• Abb. 1.46),

- und emotionale Veränderungen bis hin zu psychischen Krisen und Depressionen induzieren können.

\ Die Schmerztherapie ist heute mit entscheidender Bestandteil jeder postoperativen Behandlung.

Das Spektrum der postoperativen Schmerzbeeinflussung umfasst allgemeine nichtmedikamentöse Maßnahmen und die eigentliche medikamentöse Therapie.

\section{Nichtmedikamentöse Maßnahmen}

$\mathrm{Zu}$ den Allgemeinmaßnahmen gehört eine schonende Lagerung des operierten Patienten unter weitgehender Entlastung der Operationswunde. Nach viszeralchirurgischen Eingriffen hat sich eine Erhöhung des Oberkörpers um $30^{\circ}$ bei leichter Beugestellung in den Hüft- und Kniegelenken bewährt. Mobilisationsmaßnahmen müssen sorgfältig vorbereitet und behutsam durchgeführt werden. Abrupte Bewegungen, die immer ein relevantes Schmerzereignis verursachen, sind $\mathrm{zu}$ vermeiden. Sonden und Drainagen beeinflussen postoperativ ganz erheblich den Patientenkomfort. Sie sollten so früh wie möglich entfernt werden. Darüber hinaus sollte die Möglichkeit einer physikalischen Schmerztherapie durch Kälte-oder Wärmeanwendung genutzt werden.

\section{Medikamentöse Therapie}

Voraussetzung für die medikamentöse Therapie akuter perioperativer und posttraumatischer Schmerzen entsprechend den Leitlinien der Deutschen Interdisziplinären Vereinigung für Schmerztherapie (DIVS) ist die Messung der Schmerzintensität. Zuverlässige Angaben zur Schmerzintensität und damit auch zur Einschätzung des Analgetikabedarfes und auch des Therapieerfolges kann aber nur der Patient selbst machen.

Idealerweise sollte die Schmerzmessung in regelmäßigen Abständen - mindestens alle $8 \mathrm{~h}$ - anhand einer visuellen Analogskala von 0-10 erfolgen. Als behandlungsbedürftig gelten im Allgemeinen Schmerzen ab einer Intensität von 3-4 (in Ruhe) oder 5 (bei Belastung).

Grundlage eines Stufenschemas, das bei der medikamentösen Therapie den interindividuellen Unterschieden hinsichtlich Schmerzerleben, Schmerzstärke und Analgetikabedarf Rechnung trägt, sollte die Gabe eines Nichtopioidanalgetikums (z.B. Paracetamol 4-mal $1 \mathrm{~g} / 24 \mathrm{~h}$ ) zu festen Zeiten sein (Stufe1).

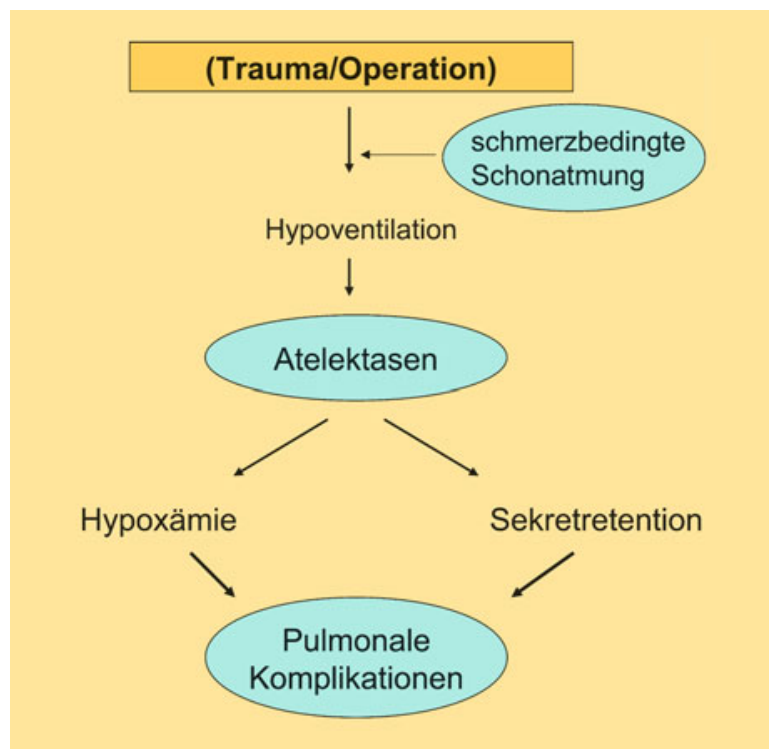

- Abb. 1.46 Pathogenese postoperativer Lungenfunktionsstörungen 
Ein Nichtopioidanalgetikum kann bei kleineren Eingriffen als alleiniges Analgetikum ausreichen, um Schmerzen auf ein adäquates Niveau (Ruheschmerz $<3$, Belastungsschmerz <5) zu reduzieren.

Bei mittelgroßen bis großen Eingriffen ist in Stufe 2 die zusätzliche Gabe eines schwachen Opioides (z. B. Tramadol) und in Stufe 3 die zusätzliche Gabe eines starken Opioides (z. B. Morphin, Fentanyl) angezeigt.

$>$ Opioide sind laut S3-Leitlinie heute zentraler Bestandteil der postoperativen Schmerztherapie und dürfen den Patienten nicht aus Angst vor einer möglichen Suchtreaktion vorenthalten werden.

Die generelle Empfehlung ist, im Rahmen eines balancierten Analgesieregimes zusätzlich zur Opioidtherapie immer Nichtopioide als Basismedikation einzusetzen. Dadurch können der tägliche Opioidverbrauch um bis zu 20\% gesenkt und Opioidnebenwirkungen (z. B. Übelkeit, Erbrechen, Darmparalyse, Sedierung, Atemdepression) bis zu 30\% gemindert werden.

Die systemische Pharmakotherapie, die der großen Variabilität von Schmerzintensität und Schmerzmittelverbrauch am besten gerecht wird, ist die intravenöse patientenkontrollierte Analgesie (patient controlled analgesia, PCA).

( Als Goldstandard gilt heute die patientenkontrollierte Analgesie (PCA): Sie sollte gegenüber kontrollierten Applikationsformen bevorzugt werden.

Dabei verabreicht sich der Patient selbst mittels eines Knopfdruckes eine vorgegebene Dosis des Schmerzmittels (Bolus). Handelsübliche PCA-Pumpen ermöglichen eine Programmierung der Bolusgröße, der Lock-out-Zeit, innerhalb derer trotz Anforderung kein weiterer Bolus appliziert wird und der Basalrate (kontinuierliche Dosierung des Analgetikums). Dank der programmierten Kontrollmechanismen ist die i.v.PCA ein sicheres Verfahren. Bereitstellung, Wartung und Kontrolle der i.v.-PCA erfordern allerdings einen hohen Zeitund Personalaufwand.

$\checkmark$ Die intravenöse patientenkontrollierte Analgesie hat die Qualität der postoperativen Schmerztherapie entscheidend verbessert. Im Vergleich zu anderen Verfahren ermöglicht sie eine individuell angepasste Schmerzbekämpfung.

Ein weiterer großer Fortschritt in der Schmerztherapie vor allem nach großen viszeralchirurgischen Eingriffen stellt die thorakale Periduralanalgesie (tPDA) dar. In Abhängigkeit von der exakten segmentalen Platzierung des Katheters und auch ausreichend langer postoperativer Nutzungsdauer liegen ihre günstigen Effekte neben der analgetischen Wirkung v. a. in einer verbesserten Koronarperfusion (kardialer Risikopatient!), Blockierung sympatischer Reflexe (Darmparalyse!) und Reduktion der Stressantwort auf das chirurgische Trauma.

Gemeinsames Ziel der nichtmedikamentösen Maßnahmen und der eigentlichen systemischen Analgesie ist es, das aktuelle Wohlbefinden und die Zufriedenheit des Patienten zu verbessern (Patientenkomfort) und die Voraussetzung dafür zu schaffen, dass der Patient schmerzfrei mobilisiert und notwendigen postoperativen Behandlungsmaßnahmen (z. B. physikalische Therapie) zugeführt werden kann.

\section{Physikalische Therapie}

Bei den physikalischen Behandlungsmaßnahmen stehen die postoperative Atemtherapie und die Frühmobilisation des $\mathrm{Pa}$ tienten ganz im Vordergrund. Zur Pathogenese postoperativer Lungenfunktiosstörungen, - Abb. 1.46. Vor allem nach Oberbauch- und Zweihöhleneingriffen und verstärkt noch durch schmerzbedingte Schonatmung ist der Patient nicht mehr in der Lage, ausreichend tief einzuatmen und effektiv abzuhusten. Zwangsläufige Folgen sind dann Minderbelüftung von Alveolarbezirken und Atelektasen. Das bewirkt auf der einen Seite eine Hypoventilation noch perfundierter Lungenabschnitte mit Erhöhung des Rechts-Links-Shunts und Hypoxämie, und auf der anderen Seite Sekretretention, Infektion und Pneumonie. Somit gelten als vorrangige Behandlungsziele der postoperativen Atemtherapie die Ventilationsverbesserung, Sekretmobilisation und das Erlernen spezieller Hustentechniken.

\section{Praxisbox \\ Praxisbox: Postoperative Atemtherapie \\ Beim intubierten Patienten wird eine Sekretmobilisation durch entsprechende Lagerungsbehandlung und Thorax- kompression mit Unterstützung der Ausatmung erreicht. Das gelockerte Bronchialsekret kann anschließend »blind " durch Katheterabsaugung oder »unter Sicht" durch flexible Bronchoskopie entfernt werden. Damit wird eine Wiedereröffnung vorher nicht ausreichend ventilierter Lungenbezirke möglich. \\ Ist der Patient bereits extubiert, werden apparative Techniken zur Atemvertiefung eingesetzt, die einen exspiratorischen Kollaps der Alveolen verhindern und damit einen Gasaustausch über den gesamten Atemzyklus ermöglichen (z. B. "continuous positive airway pressure", (PAP). Ein sehr einfaches Trainingsgerät für postoperative Atemübungen ist der sog. Coach. Der Patient muss ge- gen einen vorgegebenen Widerstand langsam einatmen und kann dabei selbst das Atemzugvolumen als Thera- piekontrolle auf einer Skala ablesen. \\ Medikamentöse Maßnahmen zur Ventilationsvertie- fung sind u. a. Inhalation mit Bronchodilatatoren oder Substanzen zur Senkung des Atemwegswiderstandes. \\ Hustentechniken, die pulmonale Risikopatienten bereits präoperativ erlernen sollten, werden in entspre- chender Lagerung (Kopfteil erhöht, Hüften gebeugt) und unter vorsichtiger Kompression der Operationswunden durchgeführt. Unterstützend wirkt auch der »Flutter«, ein Kugelventil, das exspiratorisch angeblasen wird und os- zillierende Bewegungen in das Trachealsystem überträgt.}

Grundvoraussetzung für die adäquate Durchführung der postoperativen Atemtherapie ist wiederum der schmerzfreie und kooperationsfähige Patient. Dies gilt auch in besonderem 
Maße für die Frühmobilisation. Gerade bei alten und behinderten Patienten (z. B. Paresen, Amputationen) muss die Immobilisationsphase so kurz wie möglich gehalten werde, d.h. postoperativ müssen die Patienten zum frühestmöglichen Zeitpunkt aufgesetzt, vor das Bett gestellt und ggf. mit krankengymnastischer Unterstützung zum Gehen angehalten werden.

$\checkmark$ Diese ersten Rehabilitationsschritte sind wesentlich zur Vermeidung von hypostatischer Pneumonie, Dekubitalulzera und - zusammen mit der medikamentösen Antikoagulation - die entscheidende Maßnahme zur Thromboembolieprophylaxe.

\section{In Kürze}

\section{Postoperative Therapie}

- Infusionstherapie orientiert sich an dem Basisbedarf von Wasser und Elektrolyten und dem Korrekturbedarf bei zusätzlich aufgetretenen Verlusten. Bei normalem Ernährungszustand des Patienten und einer erwarteten Nahrungskarenz $<7$ Tagen ist diese Infusionstherapie alleine ausreichend.

- Parenterale Ernährung: bei bereits präoperativ reduziertem Ernährungszustand, einer erwarteten Nahrungskarenz $>7$ Tagen.

- Enterale Ernährung ist heute frühzeitig anzustreben. Sie ist im Vergleich zu parenteralen Regimen physiologischer (Intestinalmukosa), effektiver, sicherer (Zugangswege) und preiswerter.

- Physikalische Therapie mit postoperativer Atemtherapie und Frühmobilisation des Patienten.

- Schmerztherapie mit nichtmedikamentösen Maßnahmen (Lagerung!) und systemisch applizierten Analgetika anhand eines Stufenschemas (Nichtopioide, schwache Opioide, starke Opioide). Bevorzugt heute: patientenkontrollierte Analgesie (PCA).
Heute sind die Hauptursachen für postoperative Morbidität und Mortalität chirurgische (OP-bedingte) Komplikationen. Ziel aller Überwachungsmaßnahmen ist es, Störungen im postoperativen Verlauf frühestmöglich zu erfassen und dann umgehend eine zielgerichtete Diagnostik einzuleiten.

\section{Überwachung der Vitalfunktionen}

( Die postoperative Überwachung hat grundsätzlich die Risikosituation des Patienten, mit den sich daraus ergebenden möglichen Veränderungen und Komplikationen zu berücksichtigen.

Darüber hinaus sind nach großen chirurgischen Eingriffen in der Regel die vitalen Organfunktionen des Patienten unmittelbar postoperativ gestört:

- Einschränkungen der Lungenfunktion resultieren aus Veränderungen der Atemmechanik (z.B. restriktive Ventilationsstörung) und der schmerzbedingten Schonatmung des Patienten.

- Häufigste Ursache für Herz-Kreislauf-Instabilität sind Restwirkungen von Anästhetika (negativ inotrope Wirkung), Tachykardie (Hypovolämie, Rhythmusstörung), Schmerz, Agitation, Kältezittern (erhöhter Sauerstoffverbrauch) und Imbalanzen im Säure-Basen- und WasserElektrolythaushalt.

- Darüber hinaus ist die Niere postoperativ Zielscheibe einer Reihe von neuroendokrinen Reaktionen mit negativer Rückwirkung auf die glomeruläre und tubuläre Funktion.

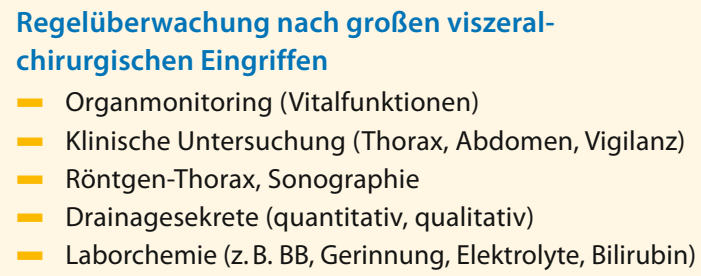

Kommen zur Unterstützung und Aufrechterhaltung der gestörten Funktionen invasive Verfahren der Intensivmedizin zur Anwendung (z. B. Beatmung, Volumentherapie, Kardiaka) beinhaltet das Organmonitoring auch immer gleichzeitig die Kontrolle der jeweils durchgeführten Therapie. Bezüglich Indikationsstellung und Durchführung spezieller Therapieverfahren sei auf Lehrbücher der Intensivmedizin hingewiesen.

Lebertransplanta ist dabei das Monitoring vitaler Organfunktionen, die ggf. durch Maßnahmen der Intensivmedizin (z. B. Nachbeatmung, Kreislauftherapie) unterstützt werden müssen. Es gilt die schwere Belastung des Patienten durch Operation und Narkose schnellstmöglich überwinden zu helfen und damit die Voraussetzung für ein erfolgreiches Gelingen des Eingriffes zu sichern.

( Die eigentliche chirurgische Aufgabe ist die Überwachung des Operationssitus.
Vorrangiges Ziel im postoperativen Management ist die Vermeidung von Hypoxämie- und Hypotoniephasen.

Ein kontrolliertes Aufwärmen in Kombination mit ausreichender analgetischer Therapie hilft die Stressantwort zu minimieren. Für die postoperative Nachbeatmung gilt, dass zur Vermeidung von Sekundärkomplikationen (z. B. Pneumonie, Thromboembolie) der Patient schnellstmöglich auf assistierte Beatmungsformen und Spontanatmung zurückgeführt 
wird. Beim extubierten Patienten müssen alle Möglichkeiten der physikalischen Therapie mit dem Ziel einer effektiven Bronchialtoilette zur Anwendung kommen. Die Infusionstherapie hat den Basisbedarf an Wasser und Elektrolyten, den Korrekturbedarf bei eingetretenen Verlusten und darüber hinaus Ernährungsregime zu berücksichtigen, die dem jeweiligen Ausmaß der Katabolie angepasst sind ( $\triangleright$ Abschn. 1.4.3).

\section{Überwachung des Operationssitus}

Bei der Überwachung des Operationssitus kommt der wiederholten physikalischen Untersuchung eine zentrale Bedeutung zu. So können durch Inspektion, Palpation und Auskultation wesentliche Befunde wie Nachblutung, Abwehrspannung, Distension des Abdomens, Peristaltik, Wundinfektion, Hautemphysem u. a. erhoben werden. Darüber hinaus ist der Patient regelmäßig hinsichtlich seiner Atemmechanik, Bewusstseinslage, Kooperationsfähigkeit und Belastbarkeit zu beurteilen.

C Cave

Die Menge und Zusammensetzung von Drainagesekreten muss immer wieder überprüft werden. Auf eine mögliche Dislokation oder Verstopfung durch Blutkoagel ist zu achten.

Dabei geben laborchemische Analysen Hinweise auf pathologische Veränderungen wie Blutung $(\mathrm{Hb})$, intestinale Leckage (a-Amylase) oder Gallefistel (Bilirubin). Ein gesteigerter oder blutiger Reflux über die Magensonde lässt eine intestinale Motilitätsstörung erfassen oder kann beweisend für eine intraluminale Blutung sein.

Die Sonographie steht weiterhin im Mittelpunkt der Überwachung des operierten Abdomens. Sie erlaubt Beurteilung und Verlaufskontrolle bei Veränderungen an parenchymatösen Organen (z. B. Leberhämatom, Milzläsion) und macht intraabdominelle und intrathorakale Flüssigkeitsansammlungen sichtbar. Die Differenzierung dieser Flüssigkeit (z. B. Blut, Erguss, Intestinalsekret) gelingt durch schallgezielte Punktion.

Die Röntgenthoraxaufnahme kann neben der Beurteilung von Herz und Lunge wesentliche Zusatzinformationen liefern wie Zwerchfellhochstand, Erguss, Mediastinalemphysem oder Überblähung des Interpositionsorgans nach Ösophagusersatz.

Spezielle Fragestellungen lassen sich angiographisch bzw. duplexsonographisch (z. B. Transplantatdurchblutung), endoskopisch (z. B. Anastomoseninsuffizienz) oder bronchoskopisch (z. B. tracheale Läsion) überprüfen.

Bei klinisch nicht eindeutigen Situationen müssen die Untersuchungen und Analysen in kurzen Zeitabständen wiederholt werden. Nur so lassen sich Veränderungen rasch erfassen und objektivieren. Häufig liefern Zusatzinformationen wie Temperaturverlauf, metabolische Azidose, gesteigerter Insulinbedarf, Laktat-Erhöhung, Kreislaufinstabilität oder OilgoAnurie entscheidende Hinweise.

8 Die Kontrolle von Vitalfunktionen und Operationssitus ist nicht voneinander zu trennen und sollte im Idealfall in der gemeinsamen Verantwortung eines erfahrenen Chirurgen liegen.

\section{Postoperative Komplikationen}

In der Viszeralchirurgie sind postoperative Komplikationen nicht vermeidbar, auch wenn es wünschenswert wäre, sie zu vermeiden.

\section{Der intraoperative Situs gibt die besten Hinweise auf mögliche postoperative Komplikationen. Der erfahrene Chirurg weiß das und informiert darüber.}

Ziel aller Überwachungsmaßnahmen ist es, die Komplikation frühzeitig zu erkennen, bevor sekundäres Organversagen auf die bereits eingetretene Katastrophe hinweist. Das bedeutet, dass schon beim ersten Verdacht eine zielgerichtete Diagnostik eingeleitet werden muss.

- Cave

In der Regel entstehen Probleme nicht aus der Komplikation selbst, sondern aus dem Umgang mit ihr, d.h. aus der zu spät erfolgten Diagnostik und einem unzureichenden Komplikationsmanagement.

Das Vorliegen einer Komplikation wird bei jedem Abweichen vom erwarteten (normalen) postoperativen Verlauf wahrscheinlich. Solche Warnhinweise oder Symptome, die es immer zu beachten gilt, sind in folgender Übersicht zusammengefasst.

Symptome postoperativer Komplikationen

- Klinische Veränderungen, z. B. Schmerz, Fieber, Paralyse, Compliance, Belastbarkeit (»Der Patient hat immer Recht!«)

- Organinsuffizienz

- Laborchemie, z. B. BB, CRP, Laktat, PCT

- Veränderung der Drainagesekrete (»Spion im Bauch«)

Voraussetzung für eine zielgerichtete Diagnostik ist die Kenntnis, welche Komplikationen häufig und welche selten sind (Inzidenz der Komplikation), und wann mit welcher Komplikation zu rechnen ist (Prävalenz der Komplikation).

\section{Definition \\ Allgemeine Komplikationen sind Störungen der Vital- funktionen bei regelrechtem Operationssitus. Opera- tionsbedingte Komplikationen werden definiert als Störungen im Bereich des Operationssitus und benach- barter Areale (eigentliche chirurgische Komplikation).}

\section{Eigene Untersuchungen}

Eine prospektive Dokumentation und Analyse des postoperativen Verlaufs von über 9.000 Patienten im eigenen Krankengut hat gezeigt, dass nach großen viszeralchirurgischen Eingriffen Komplikationen in ca. 10\% der Fälle auftreten (• Abb. 1.47). Dabei handelt es sich aber nur in $15 \%$ um allgemeine Komplikationen. Dies ist offensichtlich Ausdruck einer heute verbesserten präoperativen Risikoabschätzung und Folge modifizierter Strategien im postoperativen Management. 


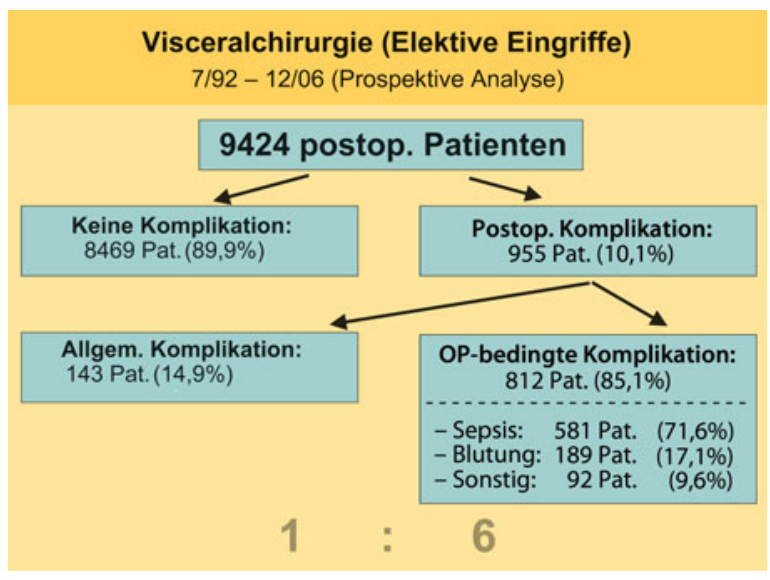

- Abb. 1.47 Postoperative Komplikationen nach großen viszeralchirurgischen Eingriffen (eigene Ergebnisse)

Im Gegensatz dazu finden sich chirurgische Komplikationen (OP-bedingte Komplikationen) 6-mal häufiger. Dabei sind septische Komplikationen mit 72\% zahlenmäßig absolut führend, vor Blutungen (17\%) und sonstigen Störungen wie Ileus, Platzbauch u. a. (11\%). Bei der abdominellen Sepsis steht wiederum die Anastomoseninsuffizienz mit Prädilektionsterminen am 7. und 12. postoperativen Tag in $72 \%$ der Fälle ganz im Vordergrund. Seltenere Ursachen sind Nachbarorganverletzungen, Galleleckagen und Pankreasfisteln.

\section{Zielgerichtete Diagnostik}

Als Konsequenz daraus muss gelten, dass bei jedem Ereignis, das vom erwarteten glatten postoperativen Verlauf abweicht, immer und zuerst eine chirurgische Komplikation ausgeschlossen werden muss, bevor seltenere Differenzialdiagnosen in Erwägung gezogen werden. Das gilt auch nach technisch problemlosen Eingriffen, erst recht aber bei schwierigen oder technisch unbefriedigenden Operationsabläufen.

$>$ Die Diagnostik orientiert sich an der Art des Eingriffes, dem Zeitpunkt des Auftretens der Komplikation und damit an der Wahrscheinlichkeit des zugrunde liegenden Problems.

Grundsätzlich bieten bettseitige Diagnoseverfahren den Vorteil, dass sie einfach durchführbar sind, beliebig oft wiederholt werden können und eine rasche Information liefern. Damit entfällt der häufig aufwändige und risikoreiche Transport in Diagnoseeinheiten mit der Schwierigkeit, Überwachungsund Therapiemaßnahmen kontinuierlich weiter zu führen. Diese Überlegungen dürfen aber nicht dazu führen, dass notwendige Diagnostik unterbleibt, nur weil sie außerhalb der Intensivstation erfolgen muss.

$(>$ Der einfachste Nachweis einer Anastomoseninsuffizienz gelingt über die Differenzierung von Wundsekreten und Drainageflüssigkeiten.

Die Diagnose ist gesichert, wenn sich Intestinalsekret direkt oder als Marker ein Farbstoff über die Zieldrainage entleert.
Darüber hinaus kann die laborchemische Analyse mit Bestimmung der $\alpha$-Amylase Hinweise auf die Höhenlokalisation der Leckage im Gastrointestinaltrakt geben.

Der »Blauschluck« und auch die Gastrografindarstellung als bettseitige Untersuchungsmethode können lediglich im Sinne einer "Ja-Nein-Antwort« das Vorliegen einer Leckage oder Anastomoseninsuffizienz beweisen bzw. ausschließen. Sie stellen aber keine echte Alternative zur Endoskopie dar, zumal die lokale Durchblutungssituation als entscheidender Gesichtspunkt nicht beurteilt werden kann.

Die Endoskopie liefert die wesentliche Information über die Vitalität von Anastomosen. Es kann die Schleimhautdurchblutung direkt beurteilt werden, wie ausgedehnt eine Anastomoseninsuffizienz oder -dehiszenz ist und welche Heilungstendenz sie im Verlauf zeigt. Darüber hinaus kann endoskopisch eine innere Wundtoilette, z. B. durch Abziehen von Belägen oder Nekrosen erfolgen und in gleicher Sitzung Ernährungssonden oder Sonden/ Drainagen zum Absaugen von Intestinalinhalt aus dem Insuffizienzbereich platziert werden.

Die Bedeutung der Ultraschallsonographie liegt darin, dass in Kenntnis des Operationssitus gezielt nach freier Flüssigkeit und freier Luft gefahndet werden kann und bei konservativem Behandlungsversuch eine Verlaufskontrolle möglich wird.

Für die Computertomographie gilt die gleiche Fragestellung wie bei der Sonographie. Der Vorteil dieses Verfahrens liegt aber in der von der Erfahrung des Untersuchers unabhängigen objektiven Befunddokumentation, semiquantitativen Dichtemessung (DD: Hämatom, Abszess) und darin, dass eine Beurteilung auch dann möglich ist, wenn die sonographische Befundung (z.B. Adipositas, Bauchwanddefekt) nicht gelingt.

Die Angiographie ist die Untersuchungsmethode der Wahl bei Blutungskomplikationen. Neben der genauen Blutungslokalisation bietet sie v. a. die Möglichkeit der gleichzeitigen interventionellen Blutstillung durch Embolisation oder Überbrückung der entsprechenden Gefäßabschnitte mit gecoverten Stents.

Wenn es aber nicht gelingt, mit den angegebenen Diagnoseverfahren ein morphologisches Korrelat für die klinische Situation des Patienten zu liefern, bleibt als Ultima Ratio die diagnostische Laparotomie.

$(8$ Die Relaparotomie ist eines der wichtigsten diagnostischen und/oder therapeutischen Prinzipien in der Viszeralchirurgie: Sie anzuwenden bedarf keiner Entschuldigung. Vielmehr kann die unterlassene Relaparotomie ein Problem sein.

\section{Eigene Untersuchungen}

In dem dargestellten Krankengut konnte bei 497 Patienten mit abdomineller Sepsis im postoperativen Verlauf allein durch bettseitige chirurgische Diagnostik in 69\% der Fälle die genaue Ursache der vorliegenden Störung gesichert werden (• Abb. 1.48). Nur in 35\% der Fälle waren dazu als externe Untersuchungen CT und Angiographie erforderlich. Knapp 


\begin{tabular}{|c|c|}
\hline \multicolumn{2}{|c|}{$\begin{array}{l}\text { Chirurgische Diagnostik bei } \\
\text { abdomineller Sepsis (497 Patienten) } \\
\text { 7/92-12/06 (Prospektive Analyse) }\end{array}$} \\
\hline Bettseitige Diagnostik & \\
\hline $\begin{array}{l}\text { Sekret aus Drainage (Intestinalsekret ?) } \\
\text { Ultraschall (Flüssigkeitsnachweis ?) }\end{array}$ & \multirow{3}{*}{301 Pat. $(60,6 \%)$} \\
\hline Endoskopie (Vitalität ? Fistel ?) & \\
\hline Anastomosenkontrolle m. Gastrografin & \\
\hline \multicolumn{2}{|l|}{ Externe Diagnostik } \\
\hline $\begin{array}{l}\text { CT (Flüssigkeitsnachweis ?) / Punktion } \\
\text { Interventionelle Angiographie }\end{array}$ & $\begin{array}{l}149 \text { Pat. }(35,4 \%) \\
27 \text { Pat. }\end{array}$ \\
\hline Diagn. Laparotomie & 20 Pat. $(4,1 \%)$ \\
\hline
\end{tabular}

- Abb. 1.48 Diagnostisches Vorgehen bei abdomineller Sepsis (eigene Ergebnisse)

5\% der Patienten mussten zur Diagnosesicherung relaparotomiert werden. Diese Zahlen unterstreichen einmal mehr die Notwendigkeit des chirurgischen Know-how bei der Überwachung des postoperativen Verlaufes.

$(8$ Nur der Chirurg kennt die eigentlichen Schwachstellen seiner Operation. Er weiß, was an möglichen Komplikationen passieren kann und wann diese $\mathrm{Er}$ eignisse erfahrungsgemäß auftreten. Er beherrscht die geeigneten Diagnoseverfahren und verfügt auch über entsprechende Therapieoptionen.

\section{Komplikationsmanagement}

Die Anastomoseninsuffizienz stellt die häufigste, weitaus schwerwiegendste und am meisten gefürchtetste Komplikation in der Viszeralchirurgie dar. Sie ist unverändert die häufigste Ursache der postoperativen Morbidität und Mortalität. Bedingt durch die Besonderheiten im GI-Trakt mit seinen vor allem tryptischen und infektiösen Eigenschaften führt eine Anastomoseninsuffizienz, verzögert diagnostiziert und nicht adäquat interveniert, zwangsläufig zur Kontamination des Mediastinums und der Bauchhöhle. Die therapeutischen Konsequenzen sind meist »selbst evident«, wenn die Diagnose gestellt ist. Das Spektrum der Therapieoptionen hat sich heute durch Fortschritte in der interventionellen Radiologie und Endoskopie grundsätzlich erweitert. Je nach Lokalisation der Anastomoseninsuffizienz sind perkutane Abszessdrainagen, intraluminale Zieldrainagen, Galleableitung nach außen (z. B. nasobiliäre Sonden), Fibrinklebung, Anastomosen-ClipVerschluss, Stentplatzierung und bei septischen Arrosionsblutungen die Angiographie mit interventioneller Blutstillung verfügbar.

$>$ Primäres Behandlungsziel die rasche und suffiziente Drainage aller Verhalte nach außen und Vermeidung einer weiteren Kontamination durch Ableitung von Gastrointestinalinhalt aus dem Bereich der Insuffizienz.
Tab. 1.7 Anastomoseninsuffizienz: Klinische Klassifikation und therapeutische Konsequenzen

\begin{tabular}{|l|l|l}
\hline Insuffizienz & Befund & Konsequenz \\
\hline Grad I & $\begin{array}{l}\text { Gut drainiert, } \\
\text { ohne Sepsis }\end{array}$ & $\begin{array}{l}\text { Konservative } \\
\text { Therapie }\end{array}$ \\
\hline Grad II & $\begin{array}{l}\text { Ausreichend drai- } \\
\text { niert, aber mit Sepsis }\end{array}$ & $\begin{array}{l}\text { Ausschaltung aus der } \\
\text { Intestinalpassage }\end{array}$ \\
\hline Grad III & $\begin{array}{l}\text { Unzureichend/nicht } \\
\text { drainiert, mit Sepsis }\end{array}$ & $\begin{array}{l}\text { Revision zur Herd- } \\
\text { sanierung }\end{array}$ \\
\hline
\end{tabular}

Das ist geradezu die Voraussetzung für ein erfolgreiches Komplikationsmanagement. Gelingt diese Drainageableitung aber nicht und kommt es zu einer permanenten Reinfektion des Mediastinums oder der Bauchhöhle sind lokale Komplikationen wie Mediastinitis, Peritonitis, Arrosionsblutungen und systemisch die Entwicklung bis hin zum septischen Multiorganversagen nur schwer zu beeinflussen.

Eine allgemein akzeptierte Definition oder Klassifikation der Anastomoseninsuffizienz im Gastrointestinaltrakt liegt bis jetzt nicht vor. In der eigenen Erfahrung hat sich eine einfache Klassifikation bewährt, die nur die beiden wesentlichen Fragen berücksichtigt:

- Ist die Insuffizienz gut drainiert oder drainierbar?

- Liegen Zeichen einer Sepsis vor?

Daraus ergeben sich dann unmittelbar therapeutische Konsequenzen (•Tab. 1.7):

- Eine Insuffizienz Grad I liegt vor, wenn die Leckage gut drainiert ist, eine wesentliche Kontamination von Mediastinum oder Bauchhöhle nicht stattfindet und damit auch Zeichen einer Sepsis fehlen. In dieser Situation ist der Versuch eines konservativen (nicht operativen) Vorgehens gerechtfertigt.

- Eine Insuffizienz Grad II ist gekennzeichnet durch eine ausreichende Drainagesituation, aber klinische und laborchemische Zeichen einer Sepsis. Hier besteht Handlungsbedarf, da von einer persistierenden Infektion und Flüssigkeitsretention im Mediastinum/Abdomen ausgegangen werden muss. Es wird damit eine Neutralisation der Insuffizienz mit Ausschaltung aus der Intestinalpassage (z. B. protektives Stoma) erforderlich.

- Eine Insuffizienz Grad III, charakterisiert durch unzureichend drainierte oder nicht drainierbare Insuffizienz und dementsprechend mit Sepsis, bedarf immer einer operativen Revision zur chirurgischen Herdsanierung und Ausschaltung der primären Infektionsquelle, wenn erforderlich sogar auf Kosten einer Diskontinuitätsresektion.

Mit dieser klinischen Klassifikation sind die Behandlungsziele, Therapieprinzipien und Lösungsmöglichkeiten grundsätzlich aufgezeigt. Bezüglich besonderer Gesichtspunkte, die sich in Abhängigkeit von der jeweiligen Lokalisation der In- 
suffizienz im oberen/unteren GI-Trakt oder biliopankreatischen Bereich ergeben, sei auf spezielle Lehrbücher der Chirurgie hingewiesen.

\section{In Kürze}

Postoperativer Verlauf und seine Störungen Große viszeralchirurgische Eingriffe sind ohne unterstützende Intensivmedizin nicht durchführbar.

- Überwachung von Vitalfunktionen und Operationssitus:

- Ziel: Komplikationen frühzeitig erkennen, bevor sekundäre Organversagen auf die bereits eingetretene Katastrophe hinweisen.

- Überwachung des Operationssitus (Inspektion, Auskultation, Kontrolle von Drainagesekreten, Sonographie) als eigentliche chirurgische Aufgabe.

- Postoperative Komplikationen:

- Bei den geringsten Anzeichen zielgerichtete Diagnostik (abhängig von der vorangegangenen Operation und dem Zeitpunkt des Auftretens der Komplikation) einleiten.

- Anastomoseninsuffizenz mit abdomineller Sepsis häufigste und schwerste Belastung des postoperativen Verlaufes.

- Komplikationsmanagement: rasche und suffiziente Drainage aller Verhalte nach außen und Verhinderung einer weiteren Kontamination durch Ableitung von Gastrointestinalinhalt aus dem Bereich der Insuffizienz (klinische Klassifikation der Anastomoseninsuffizienz).

\section{Weiterführende Literatur}

American Society of Anaesthesiology (2002) Task force on preanaesthesia evaluation. Anaesthesiology 96/2:485-496

Bartels H (2006) Identifizierung von Hochrisiko-Patienten mit abdomineller Sepsis. Visceralchirurgie 41:18-23

Bartels H (2009) Spezielle Gesichtspunkte postoperativer Komplikationen in der Visceralchirurgie. Chirurg 80: 780-789

Bartels H, Stein HJ, Siewert JR (1998) Preoperative risk analysis and postoperative mortality of oesophagectomie for resectable oesophageal cancer. Br J Surg 85:840-844

Bartels H, Lägle F, Kührer I (2008) Perioperative Ernährung. In: Gnant M, Schlag MP (Hrsg) Chirurgische Onkologie. Strategien und Standards für die Praxis. Springer-Verlag Wien/New York, S. 55-66

Eagle KA, Berger PB, Calkins HH et al. (2002) American College of Cardiology (ACC)/American Heart Association (AHA) Guideline update for perioperative cardiovascular evaluation for noncardiac surgery - executive summary. Circulation 105/10:1257-1267

Grass JA (2005) Patient-controlled analgesia. Anaesth Analg 101: 44-61

Heidecke CD, Weighart H, Feith M et al. (2002) Neoadjuvant treatment of oesophageal cancer: immunosuppression following combined radiochemotherapy. Surgery 132:495-501

Leitlinien der Deutschen Interdisziplinären Vereinigung für Schmerztherapie, DIVS (2007) Behandlung akuter perioperativer und posttraumatischer Schmerzen. AWMV-Leitlinien-Register Nr.041/001
Rivers E, Nguyen B, Harstad S et al. (2001) Early GOAL - directed therapy in the treatment of severe sepsis and septic shock. N Engl J Med 345/19:1368-1372

Siewert JR, Stein HJ, Feith M (2003) Surgical approach to invasive adenocarcinoma of the distal Esophagus (Barrett- cancer). World J Surg 27:1058-1061

Siewert JR, Stein HJ, Bartels H (2004) Insuffizienzen nach Anastomosen im Bereich des oberen Gastro-Intestinaltraktes. Chirurg 75 1063-1070

Siewert JR, Bartels H, Stein HJ (2005) Abdomino-rechts-thorakale Oesophagusresktion mit intrathorakaler Anastomose beim Barrett-Carcinom. Chirurg 76: 588-594

Stein HJ, Feith M, Mueller J (2000) Limited resection for early adenocarcinoma in Barretts Esophagus. Ann Surg 232:733-742

Stein HJ, Bartels H, Siewert JR (2001) Oesophaguscarcinom: Zweizeitiges Operieren als Mediastinitisprophylaxe beim Risikopatienten. Chirurg 72:881-886

Theissen J, Bartels H, Weiss W et al. (2005) Current concept of percutaneous abscess drainage in postoperative retention. J Gastrointest Surg 9/2:280-283

\subsection{Wunde, Wundheilung und Wundbehandlung}

\section{O. Jannasch, H. Lippert}

Jegliche Zerstörung oder Zusammenhangstrennung von Geweben wird als Wunde bezeichnet. Die Unterscheidung erfolgt in akute oder chronische Wunden sowie hinsichtlich ihrer Genese. Die Behandlung akuter Wunden berücksichtigt primär das ursächliche Trauma und erfolgt nach standardisierten chirurgischen Prinzipien. Die Heilung verläuft idealerweise in typischen Wundheilungsphasen. Therapie und Verlauf chronischer Wunden differieren hiervon. Der Schwerpunkt liegt auf der Beurteilung und Behandlung der Grunderkrankung, der Wundbettsanierung sowie der konsequenten Umsetzung des Prinzips der idealfeuchten Wundbehandlung. Für ein optimales Wundmanagement ist eine sorgfältige Wunddokumentation unverzichtbar.

\subsubsection{Geschichtlicher Hintergrund}

Die Behandlung von Wunden gehört zu den ältesten medizinischen Tätigkeiten überhaupt. Zunächst wurden verschiedene Blätter und Kräuter als Wundauflage verwendet und Extremitäten mit einfachen Ästen ruhig gestellt. Laut dem Edwin-Smith'-Papyrus (ca. 1700 v. u. Z.) setzten bereits die alten Ägypter mit Öl und Honig getränkte Leinentücher ein. Spätestens seit dieser Zeit wurden auch verschiedene Arten von Wunden, entsprechend ihrer Entstehung, unterschieden. Im klassischen Griechenland entwickelte sich die eigentliche medizinische Wissenschaft. Insbesondere die Behandlung von Wunden und Knochenbrüchen zählt zu den größten Leis-

9 Edwin Smith, amerikanischer Antikenhändler, 1822-1906, erwarb 1862 den nach ihm benannten Papyrus in Luxor 
tungen der griechischen Heilkunde. Aus dieser Zeit sind auch Berichte über die Bedeutung der Wundspülung bekannt, wofür beispielsweise Wein und abgekochtes Regenwasser verwendet wurden.

Während unter Hippokrates ${ }^{10}$ das offene Zuheilen der Wunde als Dogma galt, führte Galen ${ }^{11}$ bei verletzten Gladiatoren den primären Verschluss von Wunden ein. Ebenso wird ihm das Ausbrennen der Wunden zur Blutstillung und Desinfektion zugeschrieben. Danach folgte eine lange Zeit des Stillstandes. Im Mittelalter oblag die Behandlung von Wunden, zumindest in Europa, ausschließlich Barbieren und Wundchirurgen. Eine ausführliche Zusammenfassung des damaligen Wissensstandes findet sich in der "Wund-Artzney « von Lorenz Heister ${ }^{12}$ aus dem Jahre 1719.

Erst Mitte des 18. Jahrhunderts begann die moderne Erforschung der Wundheilung mit den Beobachtungen von James Lind ${ }^{13}$ zum Wundheilungsverlauf bei Skorbut-Erkrankten. Mit der Einführung der Antiseptik ab Mitte des 19. Jahrhunderts konnte endlich die Rate der Wundinfektionen gesenkt werden. Die Entdeckung der Mikroorganismen lieferte später die Erklärung dafür. Im 20. Jahrhundert wurden durch die fortschreitende Technisierung der Verbandmittelherstellung, die Einführung der Antibiotika, die Umsetzung des Konzeptes der feuchten Wundbehandlung und die Ausbreitung von Biotechnologien die Grundlagen der modernen Wundbehandlung geschaffen.

\subsubsection{Wunde}

Definition
Der Begriff Wunde umfasst jegliche Zerstörung oder
Zusammenhangstrennung von Geweben an inneren oder
äußeren Körperoberflächen mit oder ohne Gewebsver-
lust.

Die häufigste Ursache ist ein einwirkendes Trauma. Insbesondere bei chronischen Wunden sind jedoch Erkrankungen mit Auswirkungen auf die Zellregeneration kausal verantwortlich.

\section{Epidemiologie}

In Deutschland wird die Zahl der Patienten mit chronischen Wunden auf 2,5-4 Mio. geschätzt. Für die gesetzlichen Krankenkassen bedeutet dies eine jährliche Belastung von 22,5 Mrd. Euro. Etwa 80\% der Wunden weisen eine vaskuläre

10 Hippokrates von Kos, berühmtester Arzt des griechischen Altertums, 460-370 v.u.Z.

11 Galenos von Pergamon, antiker griechischer Arzt und Anatom, 129-199

12 Lorenz Heister, deutscher Feldarzt, Anatom und Botaniker, 16831758

13 James Lind, britischer Arzt, Pionier der Schiffshygiene, Edinburgh, 1716-1794
Ursache auf. Der Anteil von stationären Patienten in Krankenhäusern und Rehabilitationseinrichtungen mit chronischen Wunden wird auf ca. $5 \%$ geschätzt.

Hinsichtlich der Häufigkeit akuter Wunden gibt es keine verlässlichen Daten. Dies liegt vor allem daran, dass ein Großteil der leichteren Verletzungen nicht ärztlich versorgt und somit zahlenmäßig nicht erfasst wird. Kleinste Verletzungen wie Nadelstiche, Schnitt-, Riss- und Schürfwunden gehören zum täglichen Leben, so dass davon ausgegangen werden kann, dass nahezu jeder Mensch, teilweise mehrmals pro Jahr, eine akute Wunde davonträgt. Die Anzahl der Betroffenen, die eine ärztliche Behandlung auf Grund akuter oberflächlicher Verletzungen und Verbrennungen erhalten, wird jährlich auf mindestens 2,18 Mio. geschätzt. Hinzu müssen die Patienten mit iatrogenen Verletzungen (Operationswunden) gerechnet werden.

\section{Wundarten}

Für die Einteilung von Wunden können verschiedene Kriterien verwendet werden.

1. Zeitrahmen der Heilung: Wunden, die durch ein Trauma entstanden sind und nach adäquater Versorgung innerhalb von ca. 4 Wochen abheilen, werden als akute Wunden bezeichnet. Die Wundheilung läuft dabei typischerweise in nacheinander verlaufenden Phasen ab. Als Sonderform der akuten Wunden gelten die iatrogenen Wunden, d. h. unter sterilen Bedingungen gesetzte Verletzungen wie Punktionen, Inzisionen, Laserbehandlungen, Spalthautentnahmen oder Amputationen.

Wunden die innerhalb von 4 Wochen bis 3 Monaten, trotz adäquater kausaler und lokaler Behandlung, nicht abheilen, werden als chronische Wunden bezeichnet. In der genannten Interimsphase werden Defekte daher auch als komplizierte Wunden bezeichnet. Chronischen Wunden liegt meist eine Erkrankung zu Grunde, die die Heilung verhindert. Oft kommt es zu Wundkomplikationen und die physiologische Abfolge der Wundheilung wird gestört.

2. Genese der Wundentstehung: Diese Einteilung wird primär für die Differenzierung akuter Wunden verwendet. Hierbei werden mechanische, chemische, thermische und radiogene Wunden unterschieden. Innerhalb dieser Gruppen werden weitere Unterteilungen hinsichtlich des genauen Entstehungsmechanismus und des typischen Gewebedefektes vorgenommen (•Tab. 1.8).

3. Zugrunde liegende Erkrankung: Bei chronischen Wunden liegen in der Regel eine oder mehrere Grunderkrankungen vor, die die Heilung behindern. Hauptursachen sind die chronisch venöse Insuffizienz (Ulcus cruris venosum), die periphere arterielle Verschlusskrankheit - paVK (Ulcus cruris arteriosum), ein Diabetes mellitus und seine Folgeerscheinungen (diabetische Ulzera), persistierender Druck auf exponierte Körperstellen (Dekubitalulzera). Mischformen treten in mehr als 20\% der Fälle auf. Auch Wunden, die durch eine radiogene Ursache entstanden sind, neigen durch die Veränderung des Zellstoffwechsels zur Chronifizierung. 
- Tab. 1.8 Genese und Klassifizierung akuter Wunden

\begin{tabular}{|c|c|}
\hline Genese & Wundform \\
\hline $\begin{array}{l}\text { Mechanische } \\
\text { Wunden }\end{array}$ & $\begin{array}{l}\text { Schürfwunden } \\
\text { Schnittwunden } \\
\text { Risswunden } \\
\text { Platzwunden } \\
\text { Stichwunden (Sonderform: Pfählung) } \\
\text { Quetschwunden } \\
\text { Oberflächliche Ablederung (Perga- } \\
\text { ment- oder Kortisonhaut) } \\
\text { Décollement } \\
\text { Bisswunden } \\
\text { Schusswunden } \\
\text { Traumatische Amputation } \\
\text { Hautblasen }\end{array}$ \\
\hline $\begin{array}{l}\text { Thermische } \\
\text { Wunden }\end{array}$ & $\begin{array}{l}\text { Verbrennungen (I.-IV. Grades) } \\
\text { Erfrierungen (I.-III. Grades) } \\
\text { Wunden nach Stromunfällen }\end{array}$ \\
\hline Chemische Wunden & $\begin{array}{l}\text { Verätzungen durch Säuren oder } \\
\text { Laugen }\end{array}$ \\
\hline Radiogene Wunden & Strahlenulkus \\
\hline
\end{tabular}

4. Grad der Keimbesiedlung: Hier wird entsprechend des mikrobiologischen und des klinischen Befundes eine Fünfteilung vorgenommen.

- Saubere oder aseptische Wunden weisen keine Keimbelastung auf.

- In kontaminierten Wunden lassen sich Mikroorganismen nachweisen, die sich jedoch (evtl. noch) nicht vermehren.

- Kolonisierte Wunden enthalten Mikroorganismen, die sich vermehren, ohne jedoch eine immunologische und klinische Wirtsreaktion hervorzurufen.

- In kritisch kolonisierten Wunden kommt es zur Vermehrung potenziell pathogener Keime, wobei kritische Mengen überschritten werden können. Es fehlen jedoch die typischen lokalen Zeichen einer Infektion. Andererseits können eine fehlende Heilungstendenz, eine verstärkte Schmerzempfindlichkeit oder eine verstärkte Exsudation auftreten und auf eine beginnende Infektion hinweisen.

- Infizierte Wunden weisen Mikroorganismen im Gewebe auf, die sich vermehren und eine entsprechende immunologische und klinische Wirtsreaktion hervorrufen. Als Schwellenwert gilt eine Zahl von $10^{5} \mathrm{Kei}-$ $\mathrm{men} / \mathrm{mm}^{3}$ bzw. g Gewebe. Die Wirtsreaktion ist jedoch sehr stark von der Pathogenität der Erreger und der Immunlage des Wirtes abhängig. Unterschieden wird zwischen lokal begrenzten Infektionen und solchen mit systemischer Ausbreitung/Auswirkung.

\subsubsection{Wundheilung}

\section{- Definition}

Der Wiederaufbau von zerstörtem bzw. die Vereinigung von durchtrenntem Gewebe wird als Wundheilung bezeichnet.

Diese verläuft in einer typischen Abfolge, den Wundheilungsphasen.

\section{Wundheilungsphasen}

Die Wundheilung ist ein dynamischer, kaskadenartiger Ablauf, in dem katabole und anabole Stoffwechselvorgänge den Fortgang bestimmen. Die einzelnen Etappen werden als Wundheilungsphasen bezeichnet und überlappen sich teilweise. Die Unterteilung ist daher willkürlich, was sich in einer Vielzahl von Bezeichnungen und Zeitzuordnungen wiederspiegelt. Eines der häufig verwendeten Systeme verwendet 4 Phasen.

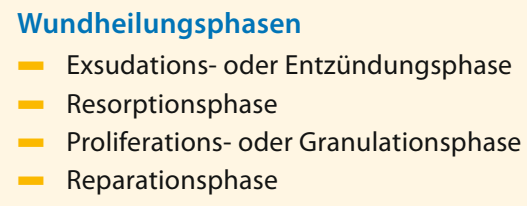

Der physiologische Ablauf dieser 4 Phasen dauert bei primär verschlossenen Wunden ca. 2 Wochen und ist mit der vollständigen Epithelisierung abgeschlossen. Die Reißfestigkeit der Hautnarbe beträgt dann ca. 20\% des Endzustandes. Erst der sich anschließende Maturations- bzw. Remodelingprozess beendet die Wundheilung. Er dauert Monate bis Jahre. In diesem Zeitraum wird das gefäßreiche Granulationsgewebe (rote Narbe) durch ein kapillar- und zellarmes Bindegewebe (weiße Narbe) ersetzt. Eine schrittweise Umstrukturierung der Kollagenfasern ermöglicht die Anpassung des Narbengewebes an die mechanischen Belastungen der betroffenen Körperregion.

\section{Exsudationsphase}

Die Exsudations- oder Entzündungsphase umfasst die ersten 8-12 h nach dem Trauma. Die Hämostase im Bereich der Wundfläche und der Austritt eiweißreicher Flüssigkeit führen zum 1. Wundverschluss (Thrombozyten, Thrombin, Fibronektin, Kollagen). Unterstützt wird dies durch Vasokonstriktoren wie Thromboxane und Prostaglandine. Thrombozyten geben chemotaktische Faktoren ab und locken vor allem Granulozyten und Monozyten in das Wundgebiet. Das primär entstandene Blutkoagel stabilisiert sich und bildet einen widerstandsfähigen Schutz für die Wundoberfläche. Mit zunehmender Exsudation von Gewebeflüssigkeit und der Ausschüttung von Zytokinen und Wachstumsfaktoren beginnt die eigentliche Entzündungsreaktion. Mit fortschreitender Diapedese großkerniger Zellen und Granulozyten wird die resorptive Phase eingeleitet. 


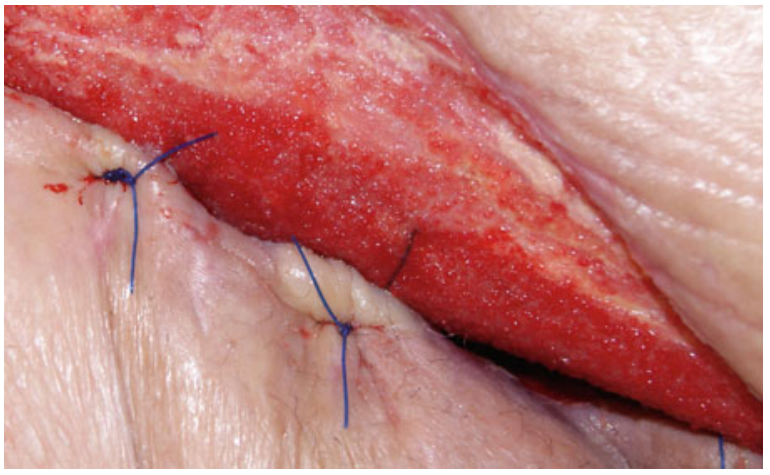

- Abb. 1.49 Granulationsgewebe

\section{Resorptionsphase}

In der resorptiven Phase (0.-4. Tag) übernehmen vor allem Makrophagen die wichtige Aufgabe der Infektionsabwehr. Sie werden durch eine Transformation aus Monozyten ca. $48 \mathrm{~h}$ nach Entstehung der Wunde gebildet. Durch Freisetzung verschiedener Enzyme wie Hydrolasen und Proteasen wird nekrotisches Gewebe aufgelöst. Der Abtransport von Zelldebris und Mikroorganismen erfolgt via Phagozytose. Neben der Aktivierung von T-Lymphozyten zu zellvermittelten Immunreaktionen wird die Proliferation und Migration von Fibroblasten sowie deren Umwandlung in Fibrozyten angeregt. Die Ausschüttung von Interleukinen, Tumornekrosefaktor und "activated macrophage growth factor « (»platelet factor») leitet die Neovaskularisation ein.

\section{Proliferationsphase}

Etwa ab dem 4. Tag beginnt die proliferative Phase, die durch die Bildung des Granulationsgewebes bestimmt wird. Dieses gut vaskularisierte Gewebe wird initial durch Fibroblasten und Myofibroblasten gebildet und durch Extrazellulärmatrix verstärkt (•Abb. 1.49). Entlang des primären Fibrinnetzes lagern sich Kollagenfasern zu Bündeln an und verstärken die mechanische Stabilität der Wunde. Verschiedene Zytokine und der "transforming growth factor « regulieren die Bildung dieses Fasernetzes. Durch Myofibroblasten wird die Wundkontraktion eingeleitet.

\section{Reparationsphase}

In der reparativen Phase, ca. 6.-28. Tag, kommt es zur Ausreifung der Kollagenfasern und dem Umbau des Granulationsgewebes in Bindegewebe. Die Wundkontraktur setzt sich fort und wird durch einen zunehmenden Flüssigkeitsverlust unterstützt. Keratinozyten leiten vom Wundrand kommend die Epithelisierung ein (• Abb. 1.50). Dies wird durch ein komplexes Zusammenspiel von Zell-Zell- und Zell-Matrix-Interaktionen koordiniert. Eine Vielzahl von Wachstumsfaktoren und -inhibitoren übernimmt dabei die Regulation. Durch den Abbau zellulärer Bestandteile bildet sich eine gefäßarme, kollagenreiche Narbe. Die sauber granulierende Wunde des Menschen verkleinert sich im Durchmesser täglich um 1-2 mm vom Wundrand her. In manchen Systematiken umfasst die
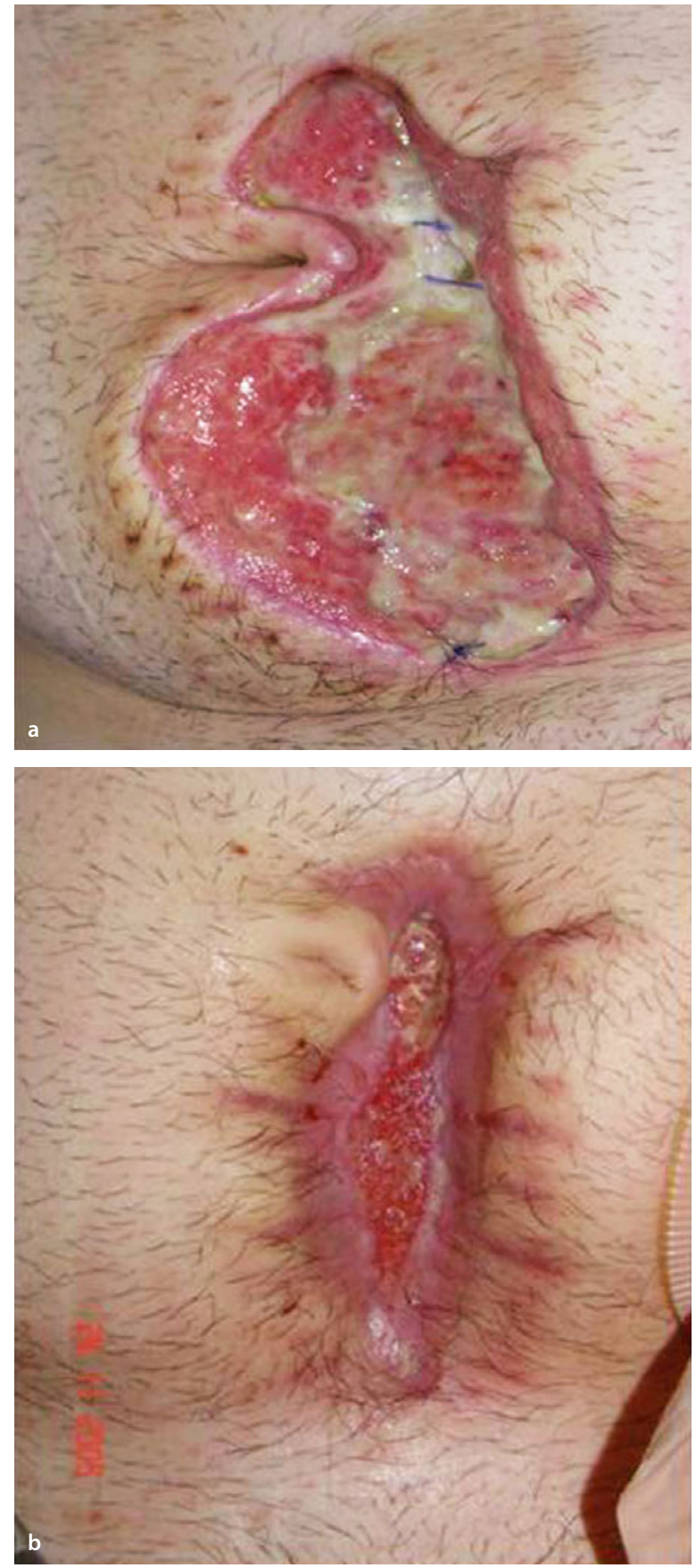

- Abb. 1.50 a Abdominale, sekundär heilende Wunde. b Wundkontraktion und beginnende Epithelisierung nach 12 Wochen

Reparationsphase die Maturation der Wunde. Dieser Vorgang kann allerdings Monate bis Jahre dauern.

\section{Wundheilungsformen}

Es lassen sich 2 grundlegende Mechanismen der Wundheilung unterscheiden: 
- Regeneration: stellt einen gewebespezifischen Ersatz dar.

- Reparation: entspricht einem unspezifischen Gewebsersatz, d. h. einer Narbe.

Eine Regeneration findet sich bei der epithelialen Wundheilung. Voraussetzung ist die Erhaltung des Stratum basale, d. h. der untersten Schicht der Epidermis. Die epitheliale Wundheilung lässt sich daher fast ausschließlich bei oberflächlichen Hautwunden beobachten, z. B. Schürfwunden. Sie kann auch unter Krusten (Schorf) stattfinden. Eine Ausnahme bildet die fetale Wundheilung (Wundheilung im Gestationsalter), die auch bei tiefer gehenden Verletzungen narbenfrei verlaufen kann. Dies ist u. a. auf eine nahezu fehlende Entzündungsreaktion, einen geringeren Differenzierungsgrad der Hautzellen sowie ein anderes Zytokin-Wachstumsfaktoren-Profil zurückzuführen.

Eine reparative Wundheilung ist meist Folge einer tiefer gehenden Verletzung, d.h. über die Epidermis hinausgehend. Das entscheidende Merkmal ist die Bildung von Narbengewebe.

Im chirurgischen Alltag werden die primäre Wundheilung (sanatio per primam intentionem) und die sekundäre Wundheilung (sanatio per secundam intentionem) voneinander unterschieden. Der Heilungsverlauf unterscheidet sich dabei nur quantitativ (•Tab. 1.9).

Eine primäre Wundheilung erfolgt bei der Vereinigung von 2 glatten Wundrändern bzw. Wundflächen, typischerweise ohne Bildung größerer Mengen von Narbengewebe. Dies schließt fast alle chirurgisch verschlossenen Wunden mit komplikationslosem Heilungsverlauf ein.

Eine sekundäre Wundheilung findet bei den meisten offen belassenen Wunden statt. Pathognomonisch ist die Auffüllung des Defektes mit reichlich Granulationsgewebe. Die Phasen der Wundheilung benötigen einen längeren Zeitraum als bei der primären Wundheilung, laufen prinzipiell aber in der gleichen Reihenfolge ab. Insbesondere in chronischen Wunden können diese Phasen in verschieden Wundbereichen auch parallel ablaufen.

Ausgang für die Narbenbildung ist das Granulationsgewebe. Es deckt den Wundgrund ab und dient nach Auffüllung des Gewebedefektes als Grundlage für die Epithelisation. Mak- roskopisch erscheint die Oberfläche des himbeergeleeroten Gewebes körnig (granuliert) strukturiert (• Abb. 1.49). Bestandteile des Granulationsgewebes sind Fibroblasten, neu gebildete Kapillaren und Extrazellulärmatrix (Kollagen, Proteoglykane). Im Verlauf verdichtet sich die Extrazellulärmatrix und ersetzt das Granulationsgewebe, vornehmlich durch Kollagen. Es bildet sich eine zug- und druckfeste, gefäßarme bzw. gefäßfreie Narbe. Die Reifung, d.h. der vollständige Umbau dauert durchschnittlich 6 Monate. Trotz gleicher biochemischer Zusammensetzung unterscheidet sich die entstandene Narbe strukturell von normaler Haut. Dies bewirkt eine verminderte Festigkeit der Narbe. Zusätzlich fehlen Hautanhangsgebilde wie Talg- und Schweißdrüsen.

\subsubsection{Störungen der Wundheilung}

Der physiologische Ablauf der Wundheilung kann durch allgemeine (systemische) und/oder lokale Faktoren behindert werden. Die hemmenden Wirkungen auf die Wunde sind sehr unterschiedlich und betreffen die initiale Hämostase, die Bildung des Granulationsgewebes, die Epithelisation sowie das anschließende Remodeling der Narbe. Zu den systemischen Faktoren zählen u. a. Alter, Ernährungszustand, Immun- und Hormonstatus, Infektionserkrankungen, Pharmaka und Durchblutungsstörungen.

Anatomische Variationen, Wundkomplikationen und -infektionen sowie direkte Auswirkungen ungenügender Operationstechniken stellen Beispiele für lokale Störfaktoren dar (- Tab. 1.10). Je nach Phase der Wundheilung ist die Wirkung der einzelnen Störfaktoren unterschiedlich stark ausgeprägt. Hinsichtlich des zeitlichen Einflusses betreffen einzelne Faktoren nur bestimmte Phasen, während andere einen hemmenden Einfluss über die gesamte Heilungsdauer ausüben (- Tab. 1.11)

\section{Wundkomplikationen}

Störungen des natürlichen Ablaufs der Wundheilung werden als Wundkomplikationen bezeichnet.

- Tab. 1.9 Merkmale der Wundheilungsarten

\begin{tabular}{|l|l|l|l|}
\hline Stadium & Merkmal & Wundheilungsart \\
\hline Granulation & $\begin{array}{l}\text { Hellrotes, vulnerables zell- und gefäßreiches Gewebe, seröse } \\
\text { Wundsekretion }\end{array}$ & Epithelial & Primär \\
\hline Epithelisation & $\begin{array}{l}\text { Wundverschluss durch Migration von Keratinozyten über das } \\
\text { Granulationsgewebe }\end{array}$ & +++ \\
\hline Kontraktion & $\begin{array}{l}\text { Kontinuierliche zentripetale Wundverkleinerung, Abblassen des } \\
\text { Gewebes durch Rückbau der Gefäße }\end{array}$ & - & + \\
\hline & Sele & + \\
\hline
\end{tabular}


- Tab. 1.10 Allgemeine und lokale Störfaktoren der Wundheilung

\begin{tabular}{|c|c|}
\hline Allgemeine Faktoren & Lokale Faktoren \\
\hline Hohes Lebensalter (>60 Jahre) & $\begin{array}{l}\text { Wundumgebung: } \\
\text { Ödem, Schorf, Nekrose }\end{array}$ \\
\hline $\begin{array}{l}\text { Grund- und Begleiterkrankungen: } \\
\text { Herz-Kreislauf-Erkrankungen, Organerkrankungen, Blut- } \\
\text { erkrankungen, Urämie, Gefäßerkrankungen, hormonelle } \\
\text { Erkrankungen, Autoimmunerkrankungen, dermatologische, } \\
\text { neurologische und psychiatrische Erkrankungen, Malignome }\end{array}$ & $\begin{array}{l}\text { Wundzustand: } \\
\text { Genese, Lokalisation, Ausdehnung, Weichteiltrauma, Begleit- } \\
\text { verletzungen, Verschmutzungsgrad, Wundumgebung }\end{array}$ \\
\hline $\begin{array}{l}\text { Stoffwechselerkrankungen: } \\
\text { Diabetes mellitus, Hyperbilirubinämie }\end{array}$ & Infektion \\
\hline $\begin{array}{l}\text { Infektionserkrankungen: } \\
\text { Tuberkulose, Syphilis, HIV, Sepsis }\end{array}$ & $\begin{array}{l}\text { Störungen der Durchblutung und/oder Nervenversorgung: } \\
\text { Gefäßerkrankungen, Stoffwechselstörungen, neurologische } \\
\text { Störungen, Strahlenfolgen }\end{array}$ \\
\hline $\begin{array}{l}\text { Systemische Bindegewebserkrankungen: } \\
\text { Marfan-Syndrom, Ehlers-Danlos-Syndrom }\end{array}$ & Tumoren \\
\hline Posttraumatische und postoperative Allgemeinfolgen & $\begin{array}{l}\text { Postoperative Störungen und Komplikationen: } \\
\text { Serome, Hämatome, Ödeme, Nekrosen, Nahtmaterial, Naht } \\
\text { unter Spannung, Elektrokoagulation, postoperative Wund- } \\
\text { infektion, Wunddehiszenz }\end{array}$ \\
\hline $\begin{array}{l}\text { Ernährungszustand: } \\
\text { Eiweißmangel, Vitaminmangel, Mangel an Mineralstoffen und } \\
\text { Spurenelementen, Kachexie, Adipositas }\end{array}$ & $\begin{array}{l}\text { Fehlerhafte Behandlung, artifizielle Störungen: } \\
\text { Lokaltherapeutika, Austrocknung, Druck, niedrige Temperatur, } \\
\text { mangelnde Ruhigstellung, Artefakte, Sauerstoffmangel, Dener- } \\
\text { vierung, Strahlung }\end{array}$ \\
\hline $\begin{array}{l}\text { Pharmaka: } \\
\text { Kortikosteroide, Zytostatika, Immunsuppressiva, Psycho- } \\
\text { pharmaka, Antikoagulantien, NSAR, Antibiotika, Fibrinolytika }\end{array}$ & \\
\hline \multicolumn{2}{|l|}{ Rauchen, Drogen } \\
\hline Psychosoziale Aspekte & \\
\hline
\end{tabular}

- Tab. 1.11 Einfluss von Störfaktoren während unterschiedlicher Wundheilungsphasen

\begin{tabular}{|c|c|c|}
\hline Wundheilungsphase & Beispiele für Störfaktoren & Effekt \\
\hline $\begin{array}{l}\text { Hämostase und } \\
\text { exsudative Phase }\end{array}$ & $\begin{array}{l}\text { Mangel an Gerinnungsfaktoren, Thrombopenie, } \\
\text { Antikoagulantien, Leber- und Nierenerkrankungen }\end{array}$ & $\begin{array}{l}\text { Verzögerte Blutgerinnung, Behinderung des ini- } \\
\text { tialen Wundverschlusses }\end{array}$ \\
\hline Resorptive Phase & $\begin{array}{l}\text { Chemotherapeutika, Kortikoide, hämatologische } \\
\text { und Autoimmunerkrankungen, Diabetes mellitus } \\
\text { und Infektionskrankheiten }\end{array}$ & $\begin{array}{l}\text { Hemmung der Einwanderung von neutrophilen } \\
\text { Granulozyten, Monozyten und Lymphozyten, } \\
\text { verminderte Infektabwehr, Angiogenese und } \\
\text { Wundreinigung }\end{array}$ \\
\hline Proliferative Phase & $\begin{array}{l}\text { Mangelernährung, Minderperfusion des Gewebes, } \\
\text { Rauchen sowie Gefäßerkrankungen, mechanische } \\
\text { Störungen, stärkere Sekretion, Hautspannung, } \\
\text { Wundrupturen und systemische Bindegewebser- } \\
\text { krankungen, Alter }>60 \text { Jahre }\end{array}$ & $\begin{array}{l}\text { Verminderte Fibroblasteneinwanderung und } \\
\text { Kapillarendotheleinsprossung, verminderte Infek- } \\
\text { tabwehr, Störung der Remodulation der Kollagen- } \\
\text { fasern, Unterbrechung der Reepithelisation der } \\
\text { Oberfläche }\end{array}$ \\
\hline Reparative Phase & $\begin{array}{l}\text { Systemische Bindegewebserkrankungen, } \\
\text { Pharmaka, Mangelernährung, Alter }>60 \text { Jahre }\end{array}$ & $\begin{array}{l}\text { Behinderung der vollständigen Epithelisierung, } \\
\text { fehlende oder verminderte Wundkontraktion }\end{array}$ \\
\hline
\end{tabular}



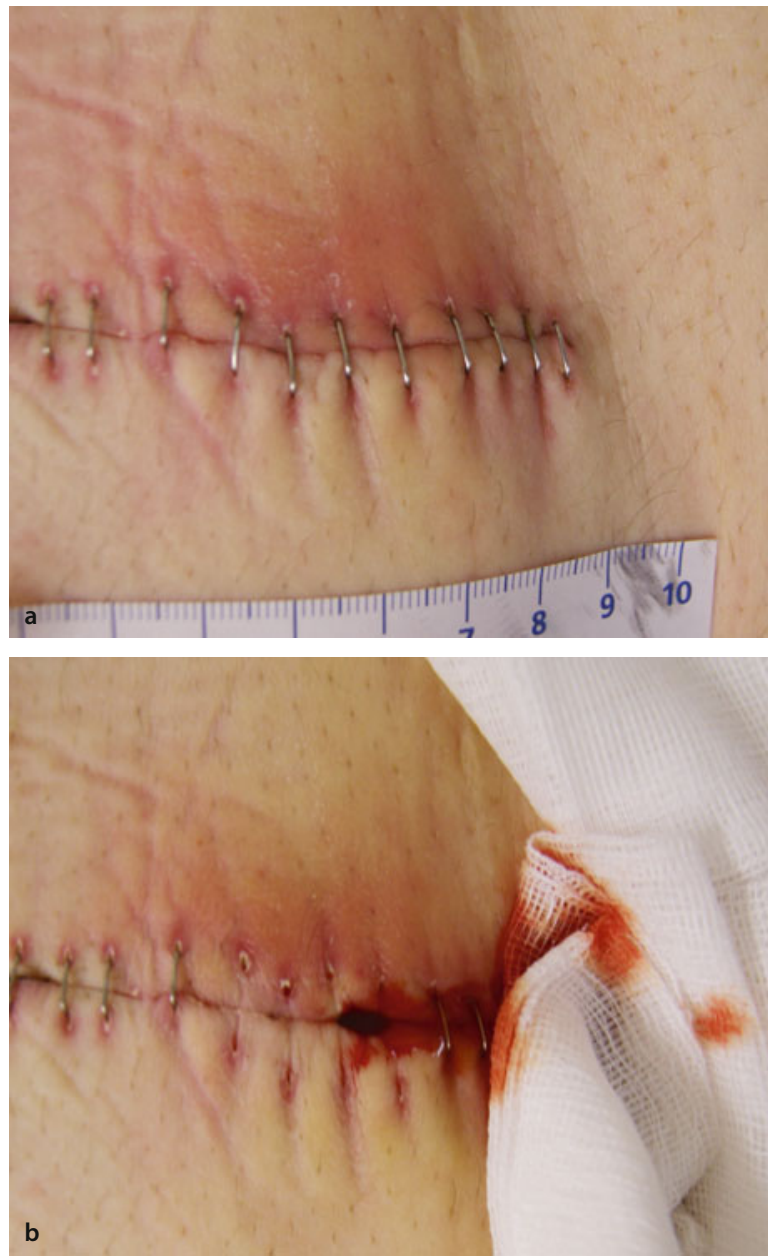

- Abb. 1.51 a Rötung und Schwellung der Haut durch Wundhämatom. b Spontane Entlastung des Wundhämatoms nach Klammerentfernung

Sie manifestieren sich in typischen Formen. Serome, Hämatome, Wundrand- und Weichteilnekrosen, Dehiszenzen sowie Infektion treten vor allem in frühen Abschnitten der Wundheilung auf. Hypertrophe Narbenbildung, Keloide oder eine maligne Entartung zählen zu den späteren Komplikationen. Eine genaue zeitliche Zuordnung ist jedoch nicht möglich, insbesondere bei chronischen Wunden.

\section{Definition}

Serome und Hämatome sind Ansammlungen von

Lymph- und Gewebsflüssigkeit bzw. Blut in meist präformierten Hohlräumen.

Häufige Ursachen sind traumatische bzw. iatrogene Gewebsschäden, Fremdkörperreize, Nekrosen, unzureichende Blutstillung oder Eiweißmangel. Erste klinische Hinweise bestehen meist in einer zunehmenden Druckschmerzhaftigkeit sowie Schwellung und Rötung des betroffenen Areals. Durch die Ge-

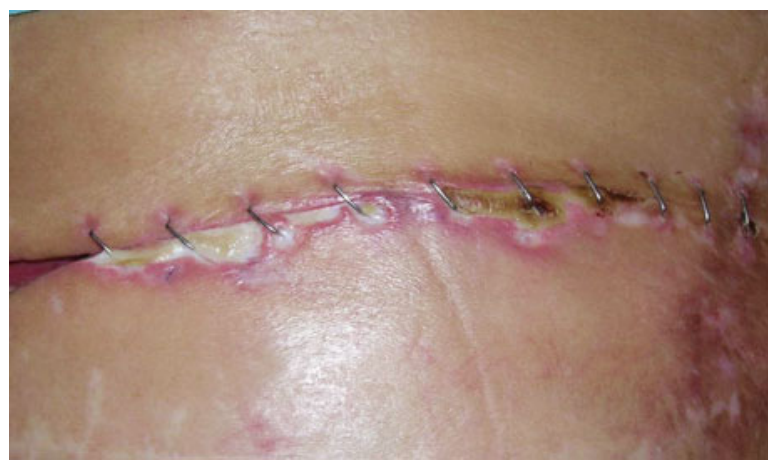

- Abb. 1.52 Wundrandnekrose

webespannung erscheint die Hautoberfläche oft sehr glatt bzw. spiegelnd. Dunkle Hautverfärbungen können auf ein Hämatom hinweisen. Bei noch nicht verklebten Wundrändern ist eine beginnende oder zunehmende Sekretion oft 1. Symptom eines darunterliegenden Seroms oder Hämatoms. Mittels Sonographie lassen sich bereits kleine Flüssigkeitsverhalte sicher darstellen. Die Therapie besteht in der Entlastung durch sterile Punktion oder Drainage bzw. der Wunderöffnung oder -revision bei ausgedehnten Befunden (• Abb. 1.51).

Wundrand- oder Weichteilnekrosen entstehen als Folge einer Minderperfusion des betroffenen Areals. Neben einer primären Ischämie können schlechte Nahttechnik, eine iatrogene Traumatisierung und auch eine inadäquate Schnittführung weitere Ursachen sein. Lokal sind Serome und Hämatome häufige Ursachen für ein Ansteigen des Gewebedruckes und einer folgenden Minderdurchblutung des Kapillarbettes. Systemisch stellen Diabetes mellitus und Arteriosklerose die wichtigsten Risikofaktoren dar. Initial fällt eine Hautverfärbung oder Wundsekretion auf, bis sich eine Nekrose abgrenzt (• Abb. 1.52). Bei geringfügigen trockenen Nekrosen kann vor einer operativen Sanierung eine Demarkation abgewartet werden.

D Cave

Feuchte Nekrosen sind stark infektionsgefährdet und sollten sofort exzidiert werden.

Die weitere Behandlung richtet sich nach Zustand und Größe des resultierenden Defektes.

Definition

Wunddehiszenz bedeutet das sekundäre Auseinanderweichen der Ränder einer durch Naht verschlossenen Wunde.

Die Ausprägung kann von einer Dehiszenz der Haut bis zur kompletten Wundruptur reichen (• Abb. 1.53).

\footnotetext{
- Definition

Die Wunddehiszenz nach operativen Eingriffen am Abdomen wird Platzbauch genannt (• Abb. 1.54).
} 


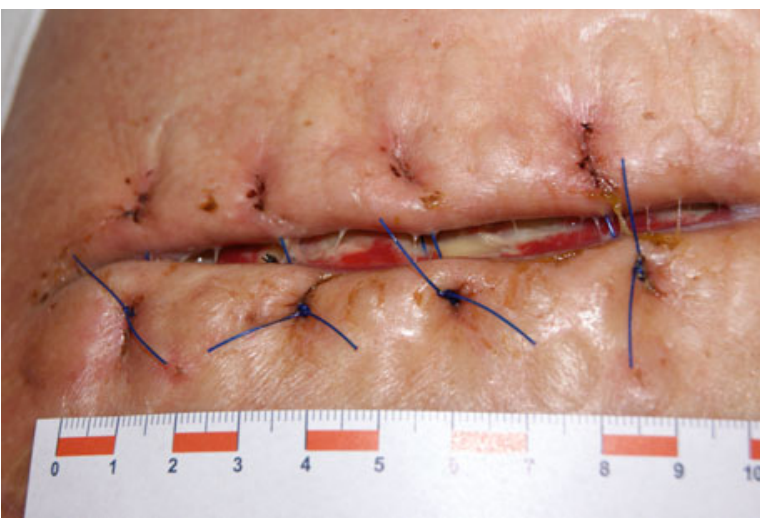

- Abb. 1.53 Wunddehiszenz nach Lebersegmentresektion bei HCC in Leberzirrhose

Unterschieden werden 3 Formen:

- inkomplett: Haut eröffnet, stehende Fasziennaht

- komplett: alle Schichten betroffen

- inapparent: Hautnaht geschlossen, dehiszente Fasziennaht

Neben zu engen oder vorzeitig entfernten Nähten, erhöhtem intraabdominellen Druck, lokalen Flüssigkeitsverhalten sowie Wundinfektionen spielen eine Vielzahl systemischer Störfaktoren wie beispielsweise Kachexie, schlecht eingestellter Diabetes mellitus, Urämie und Medikamente eine ursächliche Rolle. Klinisch finden sich eine, meist ab dem 3. postoperativen Tag einsetzende, Wundsekretion sowie zunehmende Schmerzen im Operationsgebiet. Solange tiefe Schichten bzw. die Bauchfaszie intakt sind und sich die Dehiszenz verhältnismäßig klein darstellt, scheint ein konservatives Vorgehen mit sekundärer Wundheilung gerechtfertigt. Große Wunddehiszenzen bzw. ein kompletter oder inapparenter Platzbauch werden chirurgisch revidiert. Ist eine Wundinfektion die Ursache, muss diese saniert werden.

\section{Definition \\ Eine Wundinfektion ist als Versagen der humoralen und zellulären Infektabwehr bei gleichzeitiger Zunahme einer Keimbesiedlung definiert.}

Die chirurgische Wundinfektion (»surgical site infection«) wird laut der Definition der Centers for Disease Control and Prevention in 3 Gruppen eingeteilt: oberflächlich, tief oder organbezogen. Sie stellen derzeit mit $25 \%$ die zweithäufigste Ursache nosokomialer Infektionen dar. Die Inzidenz nach chirurgischen Eingriffen wird mit ca. 7\% angegeben, am höchsten ist sie nach bauchchirurgischen Operationen. Im Allgemeinen gilt eine Zahl von $10^{5} \mathrm{Keimen} / \mathrm{g}$ Gewebe als therapiebedürftige Infektion, wobei die Virulenz der Erreger und die immunologische Reaktion des Wirtes eine wichtige Rolle spielen. Verschiedene spezifische Risikofaktoren für chirurgisch-postoperative Wundinfektionen sind zu beachten (•Tab. 1.12).
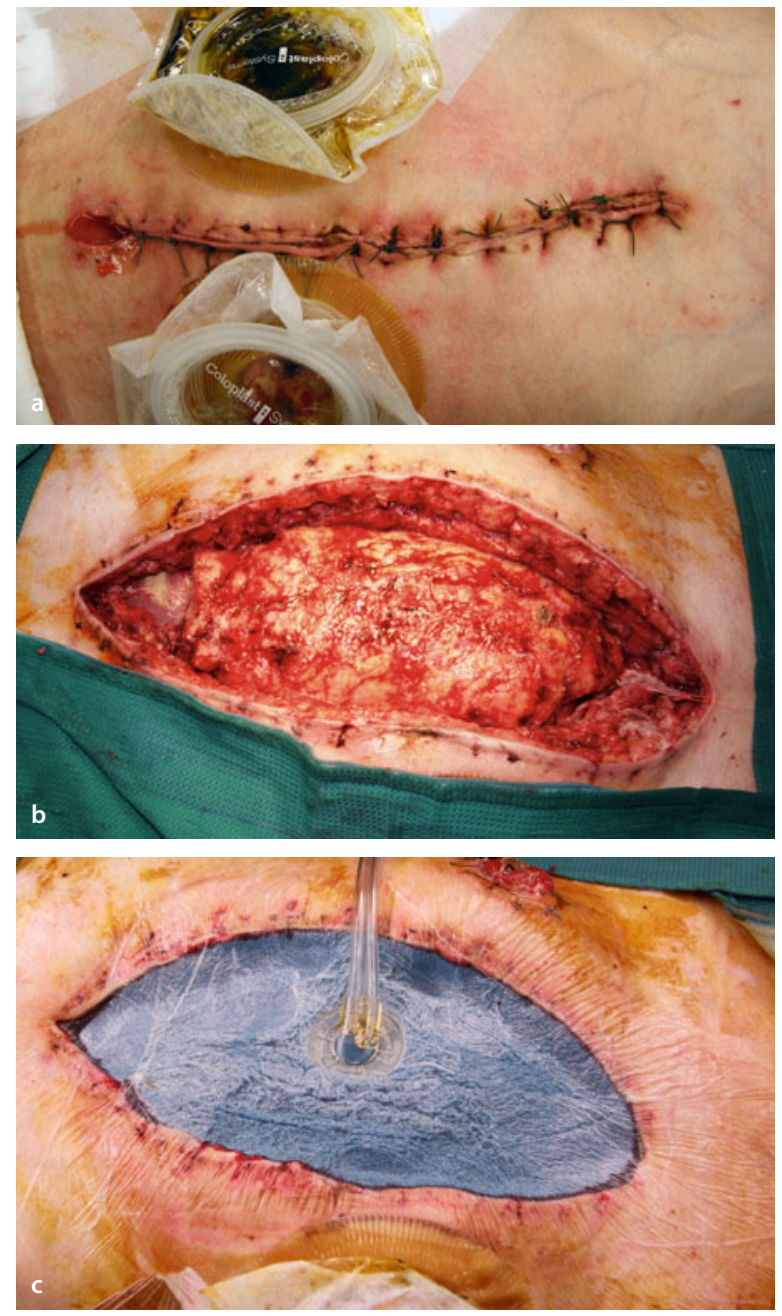

- Abb. 1.54 a Putride Wundsekretion als Zeichen eines Platzbauches. b Platzbauch nach chirurgischer Revision. c Platzbauch mit temporärem Bauchdeckenverschluss durch Vakuumtherapie

Die Behandlungsnotwendigkeit wird meist an Hand des klinischen Bildes getroffen (• Abb. 1.55).

\section{$(D$ Die lokale Entzündungsreaktion ist durch die klas- sischen Zeichen Rötung, Überwärmung, Schmerzen, Schwellung und Funktionsbeeinträchtigung gekennzeichnet.}

Weiterhin sind Geruchsbildung oder Sekretion möglich. Temperaturanstieg oder Schüttelfrost, erhöhte Entzündungsparameter sowie positive Blutkulturen deuten auf eine systemische Ausbreitung hin. Das Keimspektrum variiert je nach Lokalisation und Alter der Wunde. An Extremitäten, Thorax und im Gesichts- und Halsbereich finden sich meist Staphylokokken, während am Abdomen häufiger Mischinfektionen mit Enterobakterien auftreten (•Tab. 1.13). Mit zunehmendem Wundalter kann ein Wechsel der Flora eintreten. Gefürchtet ist das Auftreten von gramnegativen Keimen mit einem erweiterten Spektrum an $\beta$-Laktamasen (ESBL) sowie multiresistenten 


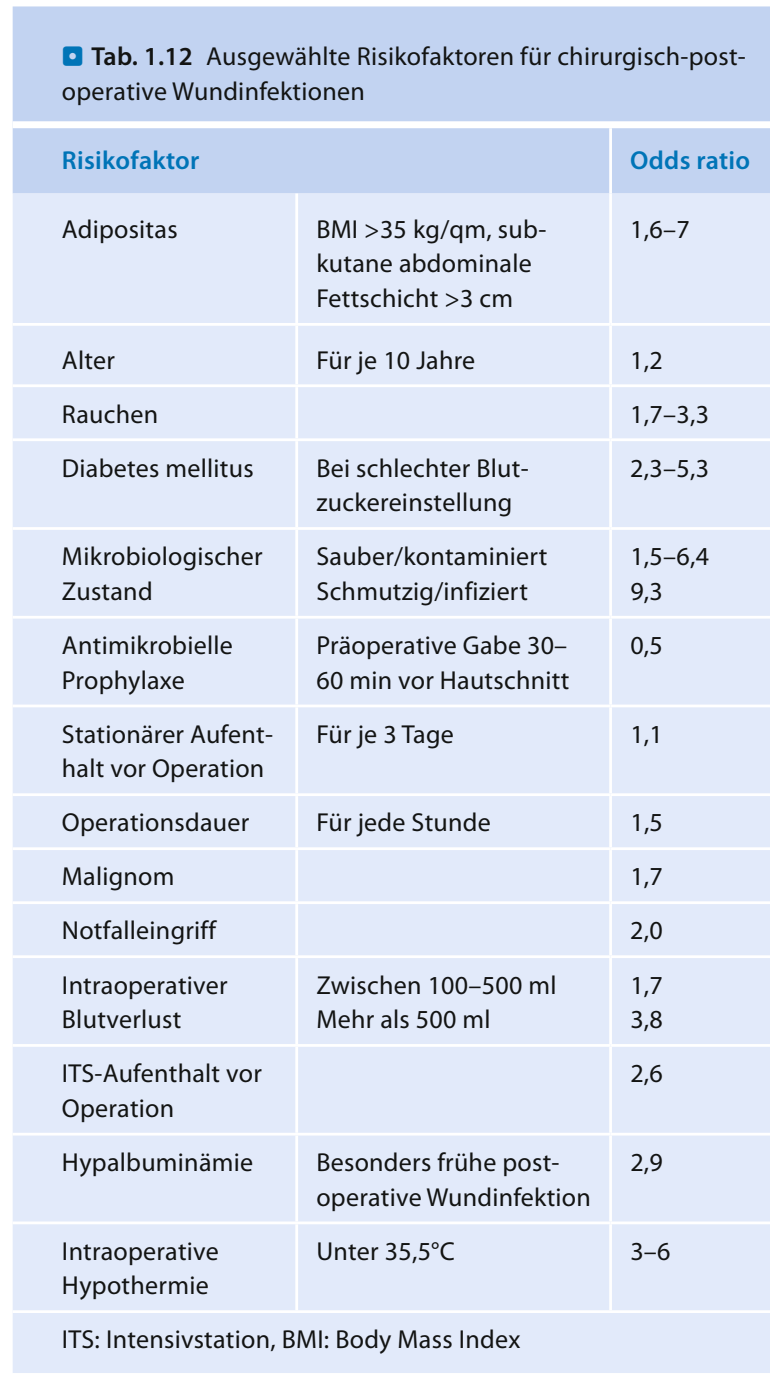

grampositiven Keimen (Methicillin-resistenter Staphylococcus aureus oder epidermidis-MRSA, MRSE sowie Vancomycin-resistente Enterokokken-VRE).

Die effektivste Behandlung der manifesten Wundinfektion besteht in der operativen Wundrevision. Sollte ein chirurgisches Wunddebridement nicht möglich sein, können autolytische, enzymatische, biologische (Fliegenlarven) oder mechanische (Jet-Lavage) Verfahren sowie silber- oder antiseptikahaltige Wundauflagen zum Einsatz kommen. Eine intravenöse oder orale Antibiotikatherapie sollte bei einem fortgeschrittenen lokalen Befund, einer systemischen Ausbreitung oder zusätzlichen Risikofaktoren (z. B. Immunsupression) erfolgen. Für einen routinemäßigen Einsatz gibt es hingegen keine ausreichende Evidenz. Die Entnahme eines mikrobiologischen Abstriches zur resistenzgerechten Antibiotikaauswahl ist Standard. Für die Initialtherapie ist die Kenntnis des typischen Erregerspektrums hilfreich (• Tab. 1.13). Begleitend ist eine Ruhigstellung und Entlastung der Wunden durchzuführen.

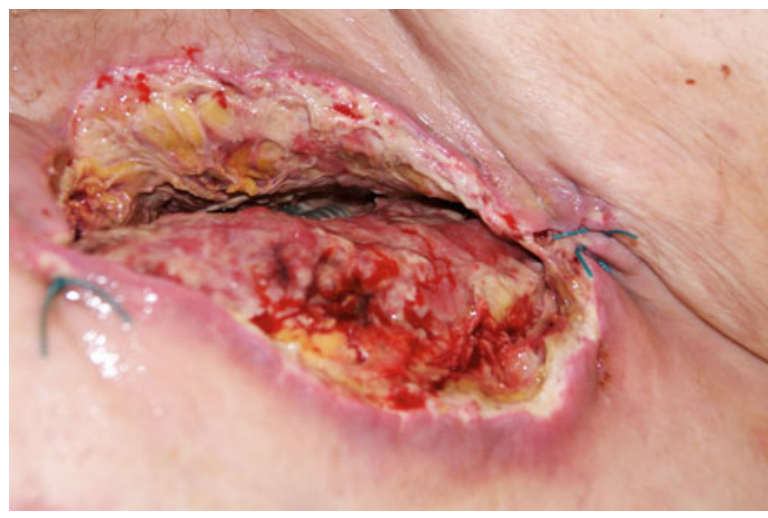

- Abb. 1.55 Wundinfektion in der Leiste mit freiliegenden Gefäßprothesen

Hypertrophe Narben sind Folge einer vermehrten Bildung an Granulationsgewebe sowie einer Störung der Kollagensynthese und -differenzierung. Die entstehende Narbe erhebt sich als wulstige, erythematöse Verdickungen über das Hautniveau. Sie bleibt jedoch auf die eigentliche Wunde beschränkt und bildet sich häufig über Monate oder Jahre zurück. Dieses Phänomen kann oft bei ausgedehnten Verbrennungswunden beobachtet werden. Problematisch sind folgende Narbenkontrakturen mit teilweise erheblichen funktionellen Einschränkungen.

Keloide sind klinisch oft schwer von hypertrophen Narben $\mathrm{zu}$ unterscheiden. Histologisch lassen sich jedoch eine differente Kollagenfaserstruktur und extrazelluläre Matrix nachweisen. Keloide überwuchern die Grenze der ehemaligen Wunde und zeigen selten eine Rückbildungstendenz.

Allgemeine Risikofaktoren einer überschießenden Narbenbildung sind jugendliches Alter, weibliches Geschlecht, schwarze Hautfarbe, Wundheilungsstörungen sowie bestimmte Körperregionen und Medikamente. Symptome wie Jucken, Brennen, Rötung und Schmerzen treten bei Keloiden häufiger als bei hypertrophen Narben auf. Es gibt derzeit keine standardisierte Behandlungsmethode der Wahl. Etabliert sind die frühzeitige intraläsionale Infiltration von Kortikosteroiden, Radiatio sowie Kryo- und Drucktherapie. Eine chirurgische Exzision sollte nur in therapieresistenten Fällen vorgenommen werden. Ohne medikamentöse Nachbehandlung liegt die Rezidivrate jedoch bei ca. 50\%. Wichtig scheint die Prophylaxe durch eine adäquate chirurgische Technik beim Primäreingriff. Die Behandlung mit Imiquimod, Interferonen, topischen Retinoiden, Silikongel oder Laser zeigt vielversprechende Erfolge, größere Studien stehen jedoch aus.

Narbenkarzinome sind selten und vornehmlich auf der Körperoberfläche lokalisiert. Eine chronische Irritation der Narbe wird ursächlich verantwortlich gemacht. Dementsprechend werden Narbenkarzinome vermehrt bei instabilen Narben, Brandwunden, chronischen Fisteln und Ulzera sowie Strahlenschäden festgestellt. Hauptsächlich handelt es sich um Plattenepithelkarzinome, seltener um Basaliome. Das chirurgische Vorgehen richtet sich nach onkologischen Kriterien. 
- Tab. 1.13 Erregerspektrum postoperativer Wundinfektionen (KISS, Krankenhaus-Infektions-Surveillance-System, Berechnungszeitraum: Januar 2006-Dezember 2010)

\begin{tabular}{|c|c|c|c|c|}
\hline Fachrichtung & Sehr häufige Erreger & $\%$ & Häufige Erreger & $\%$ \\
\hline Allgemeinchirurgie & $\begin{array}{l}\text { Staphylococcus aureus } \\
\left(\text { MRSA* }^{*}\right)\end{array}$ & $\begin{array}{l}34,0 \\
16,1\end{array}$ & $\begin{array}{l}\text { KNS } \\
\text { Streptococcus spp. } \\
\text { Enterococcus spp. }\end{array}$ & $\begin{array}{l}6,3 \\
5,9 \\
3,4\end{array}$ \\
\hline Abdominalchirurgie & $\begin{array}{l}\text { Escherichia coli } \\
\text { Enterococcus spp. }\end{array}$ & $\begin{array}{l}29,8 \\
24,8\end{array}$ & $\begin{array}{l}\text { Bacteroides spp. } \\
\text { Pseudomonas aeruginosa } \\
\text { Enterobacter spp. } \\
\text { Klebsiella spp. } \\
\text { Proteus spp. } \\
\text { Staphylococcus aureus } \\
\text { (MRSA*) }^{*} \text { KNS }\end{array}$ & $\begin{array}{r}6,0 \\
6,0 \\
4,8 \\
4,7 \\
4,3 \\
4,1 \\
28,5 \\
3,2\end{array}$ \\
\hline Traumatologie/Orthopädie & $\begin{array}{l}\text { Staphylococcus aureus } \\
\text { (MRSA*) } \\
\text { KNS } \\
\text { Enterococcus spp. }\end{array}$ & $\begin{array}{l}35,5 \\
19,1 \\
16,2 \\
12,8\end{array}$ & $\begin{array}{l}\text { Escherichia coli } \\
\text { Enterobacter spp. }\end{array}$ & $\begin{array}{l}4,6 \\
3,4\end{array}$ \\
\hline Gefäßchirurgie & $\begin{array}{l}\text { Staphylococcus aureus } \\
\text { (MRSA*) }^{*} \\
\text { Enterococcus spp. } \\
\text { Escherichia coli } \\
\text { KNS }\end{array}$ & $\begin{array}{l}39,0 \\
29,0 \\
17,9 \\
12,2 \\
11,2\end{array}$ & $\begin{array}{l}\text { Pseudomonas aeruginosa } \\
\text { Proteus spp. } \\
\text { Enterobacter spp. }\end{array}$ & $\begin{array}{l}7,3 \\
5,2 \\
3,3\end{array}$ \\
\hline Herzchirurgie & $\begin{array}{l}\text { Staphylococcus aureus } \\
\left(\text { MRSA*) }^{*}\right. \\
\text { KNS }\end{array}$ & $\begin{array}{l}30,3 \\
18,7 \\
26,1\end{array}$ & $\begin{array}{l}\text { Enterococcus spp } \\
\text { Escherichia coli } \\
\text { Enterobacter spp. } \\
\text { Pseudomonas aeruginosa }\end{array}$ & $\begin{array}{l}8,4 \\
5,0 \\
5,0 \\
3,6\end{array}$ \\
\hline Gesamt & $\begin{array}{l}\text { Staphylococcus aureus } \\
\left(\text { MRSA*) }^{*}\right. \\
\text { Enterococcus spp. } \\
\text { Escherichia coli } \\
\text { KNS }\end{array}$ & $\begin{array}{l}21,4 \\
20,2 \\
16,3 \\
15,3 \\
11,7\end{array}$ & $\begin{array}{l}\text { Pseudomonas aeruginosa } \\
\text { Enterobacter spp. } \\
\text { Proteus spp. }\end{array}$ & $\begin{array}{l}4,2 \\
4,0 \\
3,3\end{array}$ \\
\hline
\end{tabular}

\subsubsection{Behandlung akuter Wunden}

Für die Behandlung akuter Wunden ist es sinnvoll zwischen

- oberflächlichen,

- penetrierenden und

- komplexen Wunden zu unterscheiden.

Einen Sonderfall stellen die Wunden bei polytraumatisierten, d. h. lebensgefährlich verletzten Patienten dar.

Die Wunden müssen hinsichtlich ihrer Genese, der Lokalisation, des Alters und Zustandes sowie evtl. vorliegender Begleitverletzungen und Grunderkrankungen evaluiert werden.

Hinsichtlich des Wundverschlusses werden 4 Vorgehensweisen unterschieden.

- Primärnaht: Die Wunde wird im Intervall von $8 \mathrm{~h}$ nach ihrer Entstehung verschlossen.

- Verzögerte Primärnaht: Die Wunde wird innerhalb der Resorptionsphase, noch vor der Bildung von Granulationsgewebe verschlossen (etwa bis zum 5. Tag).
- Sekundärnaht: Die Wunde wird erst nach Beginn der Proliferationsphase und Bildung von Granulationsgewebe verschlossen (etwa ab dem 6. Tag).

- Offene Sekundärheilung: Die Wunde wird offen belassen und der Defekt durch Bildung von Granulationsgewebe und Epithel geschlossen.

Für die Behandlung akuter Wunden sollten einige Grundregeln beachtet werden.

Voraussetzung für einen primären Wundverschluss ist das Einhalten der 8-Stunden-Grenze nach dem Trauma. Abweichungen hiervon sind Einzelfallentscheidungen, z. B. in kosmetisch anspruchsvollen Regionen wie dem Gesicht. Weiterhin sollten kein stärkeres Weichteiltrauma, Verschmutzungen oder gar Zeichen einer Infektion vorliegen. Ebenfalls ausgeschlossen sind Wunden mit einem hohen Infektionsrisiko wie Biss- und Schussverletzungen.

Die chirurgische Wundbehandlung erfolgt immer unter sterilen Bedingungen. Eine suffiziente Schmerzbehand- 
lung, z. B. durch eine Lokalanästhesie, ist Voraussetzung für eine ausgiebige Wundexploration. Initial sollte eine Desinfektion und je nach Ausmaß der Verschmutzung ein Debridement vorgenommen werden. Eine Wundspülung ist ebenfalls zu erwägen. Ob hierbei sterile Kochsalzlösung, Leitungswasser oder andere physiologische Spüllösungen verwendet werden, scheint für das spätere Auftreten von Infektionen irrelevant. Bei stärker traumatisierten Wundrändern wird die Wundrandausschneidung nach Friedrich ${ }^{14}$ (1-2 mm im Gesunden) vorgenommen. Ausnahme ist wiederum das Gesicht. Auf Grund der guten Durchblutungsverhältnisse sollte hier auf eine Wundrandausschneidung verzichtet werden. Die Blutstillung sollte akribisch betrieben werden, um späteren Komplikationen vorzubeugen.

Den Abschluss bildet die Wundrandadaptation, die z. B. mittels Naht, Klammerung oder Klebung erfolgen kann. Bei unklarer Situation kann ggf. eine adaptierende Naht erfolgen, um einen Sekretabfluss zu ermöglichen. Dieses Prozedere wird auch bei der verzögerten Primär- bzw. bei der Sekundärnaht verwendet.

Bei jedem Patienten mit einer frischen Verletzung ist der Impfstatus abzuklären. Je nach Impfschutz und Art der Verletzungen erfolgt die Tetanusprophylaxe nach den geltenden Empfehlungen der ständigen Impfkommission des Bundesgesundheitsamtes (STIKO). Ebenfalls ist an Tollwut, eine HIVoder Hepatitiskontamination zu denken.

\section{Oberflächliche Wunden}

\section{- Definition - \\ Oberflächliche Wunden sind auf die Epidermis begrenzt.}

Meist handelt es sich um Schürf- oder tangentiale Schnittwunden. Aufgrund der ausgezeichneten Regenerationsfähigkeit der Epidermis heilen diese Wunden oft ohne Narbenbildung. Eine einfache Wundspülung und Abdeckung sind meist ausreichend für die Behandlung. Bei Schürfwunden an mechanisch beanspruchten Arealen sind Hydrokolloide sehr beliebt, die in der Werbung gerne als Blasenpflaster angepriesen werden.

\section{Penetrierende Wunden \\ - Definition \\ Penetrierende Wunden reichen mindestens bis in die Dermis.}

Typische Beispiele sind Stich-, Schnitt-, Riss-, Biss-, Quetsch-, Platz- und Schusswunden. Die Versorgung sauberer Schnitt-, Riss- und Platzwunden erfolgt in der Regel, nach sorgfältiger Inspektion, durch einen primären Wundverschluss. Je nach Unfallhergang können auch stärkere Weichteiltraumata oder ein erhöhtes Infektionsrisiko vorliegen. In diesem Fall wird

14 Paul Leopold Friedrich, Chirurg, Greifswald, Marburg, Königsberg, 1864-1916 die Wunde zunächst offen belassen und täglich kontrolliert und gereinigt. Pflicht ist dies für Biss- und Schusswunden. Die Wunde muss feucht gehalten werden, wofür sich flüssigkeitsgetränkte Kompressen oder Salbengazen eignen. Moderne okklusive Wundauflagen weisen, mit Ausnahme der Hydrokolloide, keine oder nur gering bessere Heilungsraten auf. Andererseits bieten sie Vorteilen hinsichtlich Schmerzreduktion, Patientenkomfort und Pflegeaufwand. Zusätzlich sollte die Wundregion durch einen Verband oder eine Schienung ruhig gestellt werden. Bleiben Infektionszeichen aus, kann eine verzögerte Primärnaht oder später eine Sekundärnaht erfolgen. Bei manchen Verletzungen wie Stich- und Schussverletzungen können jedoch auch innere Organe in Mitleidenschaft gezogen werden. In diesem Fall liegt eine komplexe Wunde vor.

\section{Komplexe Wunden}

\section{Definition \\ Komplexe Wunden zeichnen sich durch ein hohes Maß an Sekundärschäden aus.}

Beispielhaft sind traumatische Amputationen, Décollement, Pfählung, offene Frakturen und Verletzungen mit Organ- und Gefäßbeteiligung. Nicht die Wundöffnung, sondern die Folgen von Minderperfusion, Muskeltrauma und Organversagen bestimmen den weiteren Verlauf der Behandlung. Ähnliches gilt für Verletzungen im Rahmen eines Polytraumas, bei dem der Erhalt der Vitalfunktionen entscheidend ist.

\section{Verbrennungen}

Verbrennungen werden je nach Tiefe der Verletzung in die Schweregrade 1, 2a, 2b, 3 und 4 eingeteilt (•Tab. 1.14). Der Verbrennungsgrad ist initial meist schwer einzuschätzen. Bei ausgedehnten Verbrennungen sollte immer eine Abschätzung der betroffen Körperoberfläche (KOF), z. B. anhand der Neunerregel vorgenommen werden. Sind mehr als $\mathbf{5} \%$ der KOF betroffen, sollte eine Krankenhauseinweisung erfolgen. Da die meisten Verbrennungen sehr schmerzhaft sind, gehört eine ausreichende Gabe von Schmerzmedikamenten zur Grundbehandlung. Um ein »Nachbrennen«, d. h. eine fortschreitende Schädigung tieferer Schichten zu vermeiden, sollten Verbrennungen zunächst gekühlt werden. Bei eröffneter Haut, d. h. ab Schweregrad 2, wird die Wunde steril abgedeckt. Um Verklebungen mit dem Wundgrund und folgende schmerzhafte Verbandswechsel zu vermeiden, haben sich hierfür Salbengazen, Hydrokolloide oder bei stärkerer Sekretion Schaumverbände etabliert. Ab Schweregrad 2b ist mindestens die komplette Epidermis zerstört. Nach Abtragung der Gewebsnekrose muss hierbei über eine mögliche Defektdeckung entschieden werden. Gefürchtet sind die ausgedehnten Narbenbildungen nach tieferen Verbrennungen. Insbesondere im Gelenkbereich oder bei großflächigen Verbrennungen drohen Narbenkontrakturen.

Stromverletzungen werden prinzipiell wie Verbrennungsverletzungen behandelt. Betroffene Patienten bedürfen jedoch einer intensiven Diagnostik und Kontrolle, um mög- 
- Tab. 1.14 Schweregrade von Verbrennungen und Erfrierungen

\begin{tabular}{|c|c|c|c|}
\hline Schweregrad & Klinisches Bild & Gewebeschaden & Besonderheiten \\
\hline \multicolumn{4}{|l|}{ Verbrennungen } \\
\hline I & Rötung, leichte Hautschwellung & Epidermis, vollständig reversibel & Schmerzhaft \\
\hline Ila & \multirow[t]{2}{*}{ Blasenbildung } & $\begin{array}{l}\text { Epidermis und obere Dermis, } \\
\text { vollständig reversibel }\end{array}$ & \multirow[t]{2}{*}{ Starke Schmerzen } \\
\hline Illb & & $\begin{array}{l}\text { Epidermis und tiefe Dermis, } \\
\text { narbige Ausheilung }\end{array}$ & \\
\hline III & Schwarz-weiße Nekrosen & Dermis und Subkutis, irreversibel & $\begin{array}{l}\text { Keine Schmerzen durch } \\
\text { Zerstörung der Nervenenden }\end{array}$ \\
\hline IV & Verkohlung & $\begin{array}{l}\text { Alle Hautschichten, Faszien, } \\
\text { Gefäße, Nerven, Muskeln, } \\
\text { Knochen, irreversibel }\end{array}$ & Keine Schmerzen \\
\hline \multicolumn{4}{|l|}{ Erfrierung } \\
\hline I & $\begin{array}{l}\text { Blass-gefühllose Haut, nach Erwärmung } \\
\text { Rötung und leichte Schwellung, Juckreiz }\end{array}$ & Epidermis, vollständig reversibel & $\begin{array}{l}\text { Initial stechender Schmerz } \\
\text { (Ischämie) }\end{array}$ \\
\hline II & $\begin{array}{l}\text { Blasse, kalte Haut, später teils Rötung und } \\
\text { Schwellung, Blasenbildung }\end{array}$ & $\begin{array}{l}\text { Epidermis und Dermis, } \\
\text { vollständig reversibel }\end{array}$ & \\
\hline III & $\begin{array}{l}\text { Gangrän mit Induration und blauer oder } \\
\text { schwarzer Verfärbung, Krusten- oder Bla- } \\
\text { senbildung, teils Mumifizierung }\end{array}$ & $\begin{array}{l}\text { Kann alle Hautschichten und } \\
\text { tiefer liegende Strukturen betref- } \\
\text { fen, irreversibel }\end{array}$ & $\begin{array}{l}\text { Tatsächlicher Schaden } \\
\text { teilweise erst nach Tagen } \\
\text { oder Wochen erkennbar, } \\
\text { keine Schmerzen }\end{array}$ \\
\hline
\end{tabular}

liche sekundäre Verletzungen zu erkennen und zu behandeln.

\section{Erfrierungen}

Erfrierungen (- Tab. 1.14) werden in Anlehnung an die Verbrennungen in 3 Schweregrade eingeteilt. Sie sollten immer sehr schonend erwärmt werden. Neben der Schmerztherapie gehören eine sterile Abdeckung sowie die Polsterung der betroffenen Extremität zur Grundversorgung. Bei Auftreten von Nekrosen sollte, wenn möglich, vor der Amputation eine sichere Demarkierung abgewartet werden.

\section{Chemische Verletzungen}

Chemische Verletzungen treten durch Kontakt mit Säuren oder Laugen auf. Bei Säuren kommt es zur Eiweißgerinnung (Koagulationsnekrose), d. h. es bildet sich ein mehr oder weniger stabiles Gerinnsel, das der Ausbreitung der Verletzung in die Tiefe entgegensteht. Bei Laugen löst sich das Gewebe auf (Kolliquationsnekrose). Der Ausbreitung des Schadens in tiefere Schichten wird Vorschub geleistet.

\section{$\checkmark$ Die 1. Maßnahme sollte immer eine ausgiebige Spülung mit Wasser sein.}

Nur wenn sicher bekannt ist, um welches chemische Agens es sich handelt, kann eine spezifische Neutralisation versucht werden.

\subsubsection{Chronische Wunden}

Die Chronifizierung einer Wunde kann eine Wundkomplikation darstellen. Im Unterschied zu den o. g. Komplikationen liegen den chronischen Wunden meist eine oder mehrere Erkrankungen zu Grunde. Dies führt zur Unterbrechung der normalen Abfolge der Wundheilung.

$>$ Eine venöse Insuffizienz, Makroangio-, Mikroangiound Neuropathie im Rahmen diabetischer Stoffwechselstörungen oder eine chronische arterielle Verschlusskrankheit sind die Ursachen für den überwiegenden Teil chronischer Wunden.

Chronische posttraumatische oder postoperative Wunden entstehen bei unzureichender Primärbehandlung des Traumas oder dessen Komplikationen. Eine weitere Gruppe bilden die Druckgeschwüre.

Die Behandlung der zugrunde liegenden Erkrankungen ist entscheidend für den Therapieerfolg. Eine detaillierte Anamnese und Klassifizierung der Grunderkrankung sind daher unverzichtbar ( Tab. 1.15). Die lokale Wundbehandlung ordnet sich dem unter, ist aber wichtig für die Lebensqualität des Patienten und oft sehr langwierig. Die durchschnittliche Behandlungszeit bei leitliniengerechter Therapie betrug in einer großen Studie mit mehr als 7000 Patienten 433 Tage (Range 14-1867 Tage). 
- Tab. 1.15 Einteilung der Grunderkrankung von chronischen Wunden

\begin{tabular}{|c|c|c|c|}
\hline $\begin{array}{l}\text { Chronisch venöse } \\
\text { Insuffizienz (nach Widmer) }\end{array}$ & $\begin{array}{l}\text { Diabetisches Fußsyndrom } \\
\text { (nach Arlt) }\end{array}$ & $\begin{array}{l}\text { Diabetisches Fußsyndrom } \\
\text { (nach Armstrong) }\end{array}$ & pAVK (nach Fontaine) \\
\hline $\begin{array}{l}\text { Stadium I } I^{\mathrm{a}} \text { : reversible } \\
\text { Ödeme, Corona phlebectatica }\end{array}$ & $\begin{array}{l}\text { Typ A: ischämisch-angio- } \\
\text { pathische Form }\end{array}$ & $\begin{array}{l}\text { Stadium 0: Z. n. Ulkus, Fußfehl- } \\
\text { stellungen, Hyperkeratosen }\end{array}$ & Stadium I: asymptomatisch \\
\hline $\begin{array}{l}\text { Stadium II: persistierende } \\
\text { Ödeme, Induration, Atrophie, } \\
\text { Hyperpigmentierung }\end{array}$ & Typ B: neuropathische Form & $\begin{array}{l}\text { Stadium 1: oberflächliche } \\
\text { Läsion }\end{array}$ & $\begin{array}{l}\text { Stadium II: Claudicatio inter- } \\
\text { mittens } \\
\text { Illa: Gehstrecke }>250 \mathrm{~m} \\
\text { Ilb: Gehstrecke }<250 \mathrm{~m}\end{array}$ \\
\hline \multirow[t]{4}{*}{ Stadium III: Ulcus cruris } & Typ C: Mischform A + B & $\begin{array}{l}\text { Stadium 2: tiefergehende } \\
\text { Wunde (Muskel, Sehnen) }\end{array}$ & Stadium III: Ruheschmerz \\
\hline & & $\begin{array}{l}\text { Stadium 3: tiefer, infizierter } \\
\text { Defekt bis auf den Knochen }\end{array}$ & Stadium IV: Gangrän \\
\hline & & $\begin{array}{l}\text { Stadium 4: erste Teilnekrosen } \\
\text { des Fußes }\end{array}$ & \\
\hline & & $\begin{array}{l}\text { Stadium 5: großflächige Nekro- } \\
\text { se oder Gangrän }\end{array}$ & \\
\hline
\end{tabular}

Lokale (z. B. Debridement, Infektionsmanagement, feuchte Wundbehandlung) und systemische Behandlung (z. B. medikamentöse Einstellung, Revaskularisation, Patientenschulung) müssen aufeinander abgestimmt werden (• Abb. 1.56). Ein interdisziplinärer Ansatz ist oft der Schlüssel zum Erfolg. Für die Kontrolle des Heilungsverlaufes ist eine regelmäßige Wunddokumentation und Reevaluation notwendig. $\checkmark$ Die wichtigste Maßnahme zur Verhinderung von Rezidiven ist die Sekundärprävention durch ein geeignetes Screening bei Risikopatienten sowie die engmaschige Nachsorge.

Leider ist die Evaluation einzelner Therapiemaßnahmen weiterhin lückenhaft. So gehört beispielsweise die Lagerungsthe-

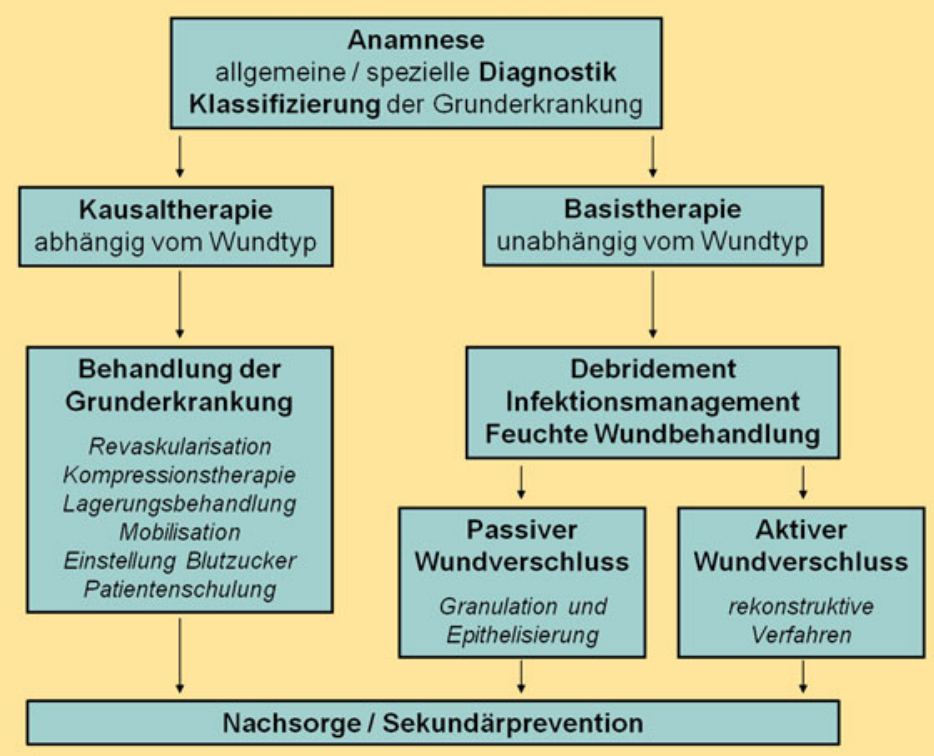

- Abb. 1.56 Schema der Behandlung chronischer Wunden 
rapie zum Standard der Dekubitusbehandlung, randomisierte Untersuchungen über den Effekt dieser Maßnahme fehlen aber.

\subsubsection{Behandlung des Wundbettes nach dem TIME-Prinzip}

Unter dem Begriff der »wound bed preparation « hat sich ein Behandlungskonzept etabliert, das unter Beachtung der pathophysiologischen Besonderheiten chronischer Wunden, eine optimale Vorbereitung des Wundbetts auf den Wundverschluss zum Ziel hat.

Das sog. TIME-Prinzip setzt 4 Schwerpunkte.

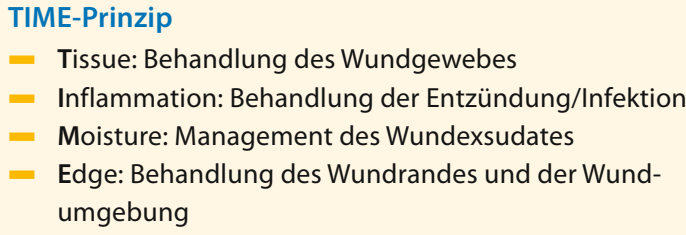

Durch die Entfernung von Nekrosen wird Mikroorganismen der Nährboden entzogen und die Entzündungsreaktion verkürzt. Das Wunddebridement muss ggf. mehrmals durchgeführt werden. Die Verfahrenswahl konservativ oder operativ ist von Wundart, -größe und -ausdehnung abhängig. Weitere beeinflussende Faktoren sind die Wundheilungsphase, der $\mathrm{Zu}$ stand des Patienten und die vorliegende Grunderkrankung.

Chronische Wunden sind immer von Mikroorganismen besiedelt.

$>$ Der alleinige Keimnachweis ist jedoch keine Indikation für eine antiseptische oder antibiotische Behandlung.

Ein regelmäßiges mikrobiologisches Screening gehört aber zum Standard der Wundevaluation. In Abhängigkeit von der lokalen Wundsituation und ggf. vorhandenen systemischen Zeichen einer Infektion kann dann ein zielgerichtetes Infektionsmanagement durchgeführt werden. Dies umfasst u. a. Wundspülungen, antiseptische Verbände und Wunddebridement.

Das Sekret chronischer Wunden weist qualitative Unterschiede zu dem akuter Wunden auf. Dies betrifft u. a. Veränderungen von extrazellulären Matrixproteinen und Wachstumsfaktoren und einer Dysbalance von Matrix-Metalloproteinasen (MMPs) und ihrer Inhibitoren (TIMPs). Das Exsudatmanagement richtet sich daher neben der Keimreduktion, der Förderung der Mikrozirkulation und der Herstellung eines idealfeuchten Wundklimas auch auf die Korrektur des biochemischen Ungleichgewichtes.

Die Epithelisierung der Wunde geht in der Regel von den Wundrändern aus. Veränderungen der Wundumgebung im Sinne von Mazerationen, Ödemen oder Hyperproliferationen können daher den Wundverschluss behindern. Ähnlich prob- lematisch wirken sich allergische Reaktionen, z. B. durch Verbandsklebstoffe, aus.

( Der Evaluation und Pflege der Wundumgebung sollte daher die gleiche Aufmerksamkeit geschenkt werden wie der eigentlichen Wunde.

\section{Ulcus cruris venosum}

- Pathogenese

Das Ulcus cruris venosum ist Folge einer chronisch venösen Insuffizienz oder eines postthrombotischen Syndroms. Der venöse Blutstau führt zu einer Mikrozirkulationsstörung. Der Gipfel der Prävalenz des Ulcus cruris venosum liegt jenseits des 70. Lebensjahres.

\section{- - Symptomatik}

Klinisch finden sich die Ulzera meist am distalen Unterschenkel, medial häufiger als lateral. Gelegentlich treten zirkuläre Ulzera als sog. Gamaschenulkus auf. Neben Pigmentstörungen und einer Stauungsdermatitis findet sich im fortgeschrittenen Stadium eine Dermatolipofasziosklerose (• Abb. 1.57).

\section{- Diagnostik}

Standard zum Nachweis der venösen Insuffizienz ist die Duplexsonographie. Differenzialdiagnostisch ist das Ulcus cruris venosum vom Ulcus cruris arteriosum, Vaskulitiden, Kollagenosen, malignen Erkrankungen und seltenen Infektionen wie Pyodermien, Lepra oder Leishmaniosen abzugrenzen.

\section{- Therapie}

Grundlage der Behandlung sind die Kompressionstherapie und Mobilisation. Zusätzlich sollte eine Sanierung des extrafaszialen Venensystems und der Vv. perforantes erfolgen. Eine Fasziotomie bzw. Fasziektomie verbessert den Blutabstrom bei Vorliegen einer Dermatolipofasziosklerose. Nach erfolgreicher Therapie treten in bis zu 70\% der Fälle Rezidive auf.

\section{Ulcus cruris arteriosum \\ - Pathogenese}

Etwa 20\% der Unterschenkelgeschwüre entfallen auf das Ulcus cruris arteriosum. Ursache ist eine Arteriosklerosis obliterans großer und mittlerer Gefäße.

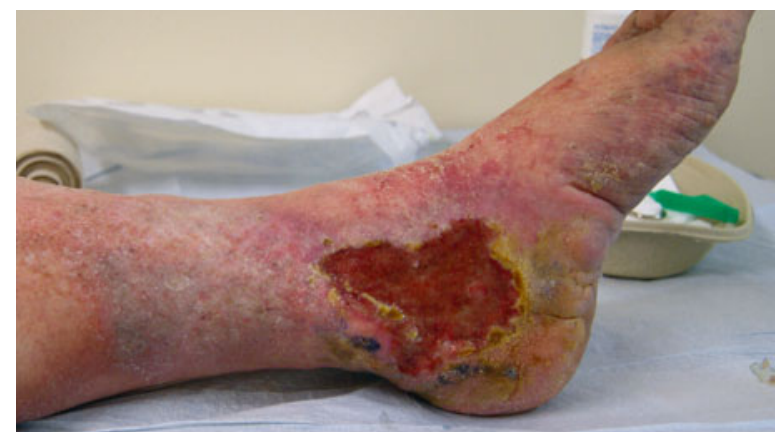

- Abb. 1.57 Ulcus cruris venosum 


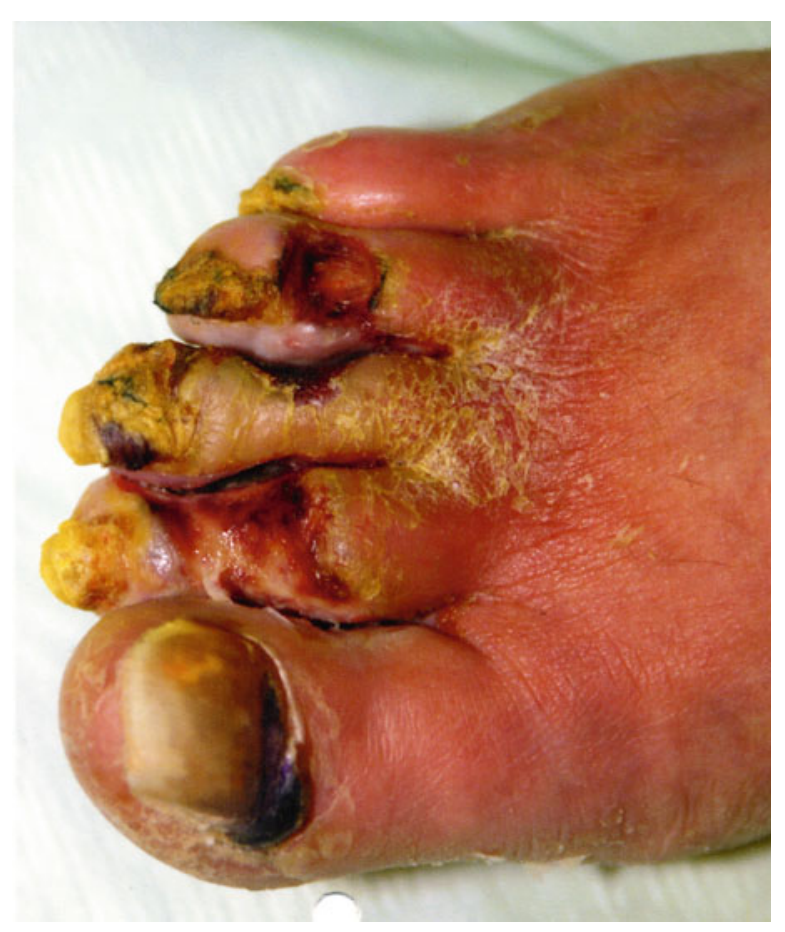

- Abb. 1.58 Ulcus cruris arteriosum mit Infektion

\section{- Symptomatik}

Die typische Lokalisation findet sich im Vergleich zum venösen Ulkus weiter distal, d.h. an den Endphalangen und den Köpfchen der Metatarsalia, seltener am lateralen Fußrand, der Ferse, den Interdigitalräumen und den Unterschenkelstreckseiten. Diese Ulzera sind meist schmerzhaft und von Nekrosen begleitet, die bis auf Sehnen und Knochen reichen können (- Abb. 1.58). Fast immer finden sich ein pathologischer Pulsstatus, eine Claudicatio intermittens sowie eine Befundprogredienz im Verlauf.

\section{- Diagnostik}

In der Diagnostik steht daher eine ausführliche Gefäßdiagnostik im Vordergrund (Pulsstatus, arterielle Verschlussdrücke, Ermittlung des arteriellen brachio-tibialen-Indexes, Doppler- und Duplexsonographie sowie Angiographie).

Die Differenzialdiagnose gleicht der des Ulcus cruris venosum, umfasst aber auch neurologische und orthopädische Erkrankungen. Eine Mischform des Unterschenkelgeschwürs - Ulcus cruris mixtum - kommt in ca. 10-15\% aller Fälle vor.

\section{- ". Therapie}

Konservative Maßnahmen umfassen die Ausschaltung von Risikofaktoren, ein Gehtraining, Prostaglandintherapie und Gabe von gerinnungshemmenden Medikamenten. Ein signifikant positiver Effekt der hyperbaren Oxygenierung konnte nicht festgestellt werden. Interventionsradiologische Techniken wie Ballondilatation oder Stentimplantation können in vielen Fällen die Durchblutung wieder herstellen. Die chirur- gische Therapie folgt dem I-R-A-N-Schema (Infektionsmanagement - Revaskularisation/Gefäßrekonstruktion - Amputation - Nachsorge).

\section{Diabetische Ulzera}

\section{- - Pathogenese}

Als Folge eines chronisch schlecht eingestellten Blutzuckers treten bei ca. 10-15\% aller Diabetiker Ulzerationen, insbesondere der unteren Extremitäten, auf. Neben einer arteriellen Angiopathie ist vor allem die diabetische Polyneuropathie für den meist schweren Krankheitsverlauf verantwortlich.

Je nach primär vorliegender Störung wird zwischen der neuropathischen und der neuroischämischen Form unterschieden. Bei neuropathischen Ulzera liegt eine schwere Störung der Sensibilität vor. Das Vollbild des diabetischen Fußsyndroms mit Knochenbeteiligung wird als Charcot-Fuß bezeichnet.

\section{- - Symptomatik}

An der Haut finden sich initial eine Purpura, Pigmentstörungen und ein Erythem. Später folgen atrophische Hautdefekte und flache Ulzera. Eine der bekanntesten Manifestationen ist das Malum perforans am Os metatarsale I.

Die neuropathischen Ulzera finden sich oft an der Fußsohle und sind wenig schmerzhaft. Die umgebende Haut ist rosig und warm.

Neuroischämische Ulzera finden sich eher an den Zehen, der Ferse und dem Fußrücken. Auf Grund der ungestörten Sensibilität sind sie schmerzhaft. Neben den abgeschwächten oder fehlenden Pulsen findet sich eine blasse, kühle Haut. Die Knochenstruktur ist erhalten.

\section{( Das vermehrte Auftreten von Infektionen bei dia- betischen Ulzera erklärt auch die hohe Rate an not- wendigen Amputationen.}

\section{- Diagnostik}

Die Diagnostik umfasst vaskuläre und neurologische Störungen. In der radiologischen Bildgebung wird primär die Frage nach einer Knochenbeteiligung (Osteitis) gestellt. Differenzialdiagnostisch müssen Läsionen durch arterielle Gefäßerkrankungen, venöse Ulzera, Raynaud-Syndrom, Panaritium, Gicht, Mykosen, Epidermiolysen, alkoholische Polyneuropathie, Malabsorptionsstörungen und Kollagenosen abgeklärt werden.

\section{- Therapie}

Essentiell sind die Kontrolle und Einstellung des Blutzuckers. Ziel der Patientenschulung ist vor allem eine Stoffwechseloptimierung. Haut- und Fußpflege sind für die lokale Wundkontrolle wichtig. Begleitend sollte die Versorgung mit orthopädischem Schuhwerk erfolgen, um eine Druckentlastung zu gewährleisten. Bei der neuroischämischen Form lehnt sich die Therapie an die Behandlung des Ulcus cruris arteriosum an. Eine hyperbare Oxygenierung scheint die Abheilungschancen zu verbessern und das Amputationsrisiko zu vermindern. 


\section{Dekubitalulzera}

- - Pathogenese

Die 3 wichtigsten pathogenetischen Faktoren für die Entstehung eines Dekubitalulkus (kurz Dekubitus) sind Auflagedruck, Druckverweildauer und Disposition. Je größer der Druck auf ein bestimmtes Hautareal wirkt und je länger der Druck anhält, desto schwerer ist die resultierende Minderperfusion. Daher finden sich Dekubitalulzera vor allem bei bettlägerigen und immobilen Patienten sowie an Körperregionen, an denen Knochen direkt unter der Haut liegen (z. B. Sakralund Fersenbereich, - Abb. 1.59). Nach Schätzungen leiden in Krankenhäusern und Pflegeeinrichtungen ca. 5-14\% der Patienten an Dekubitalgeschwüren, bei Menschen in häuslicher Pflege sind es bis zu $40 \%$.

\section{- Symptomatik}

Die Klassifizierung der Tiefenausdehnung des Dekubitus erfolgt in 4 Stadien.

\section{Stadieneinteilung des Dekubitalulkus \\ Stadium 1 Nicht wegdrückbare Rötung: Bei Fingerdruck nicht abblassende, umschriebene Hautrötung bei intakter Haut, ggf. Ödembildung, Induration, lokale Überwärmung und Verfärbung der Haut \\ Stadium 2 Teilverlust der Haut: Epidermis und ggf. Teile der Dermis sind geschädigt. Klinisch als Erosion, Haut- blase oder flaches Geschwür imponierend \\ Stadium 3 Verlust der Haut: Verlust aller Hautschichten und Schädigung oder Nekrose des subkutanen Gewebes, die bis auf den darunter liegenden Muskel reichen kann. Klinisch tiefes, offenes Geschwür \\ Stadium 4 Vollständiger Haut- und Gewebeverlust: Ver- lust aller Hautschichten mit ausgedehnter Zerstörung, Gewebsnekrose oder Schädigung von Muskeln, Knochen oder unterstützenden Strukturen (Sehnen, Gelenkkapsel)}

Initial findet sich meist eine Rötung oder livide Verfärbung. Später kommt es zur Ausbildung einer mehr oder weniger scharf begrenzten Hautnekrose bis sich dann das eigentliche Ulkus zeigt.

\section{( Typischerweise reicht die Ausdehnung in der Tiefe weiter, als das betroffene Hautareal ahnen lässt.}

\section{- Diagnostik}

Finden sich die Ulzera im Bereich der Extremitäten sollte neben der laborchemischen und mikrobiologischen Untersuchung eine Gefäßdiagnostik erfolgen. Differenzialdiagnostisch kommen vor allem im Fußbereich diabetische und gefäßbedingte Ulzera in Frage.

\section{- Therapie}

Wichtigste Therapiemaßnahmen sind Druckentlastung, Lagerungstherapie, Mobilisation und Hautpflege. Unterstützend sollte die Ernährung optimiert werden. Die lokale Behandlung umfasst das Wunddebridement, das Infektions-
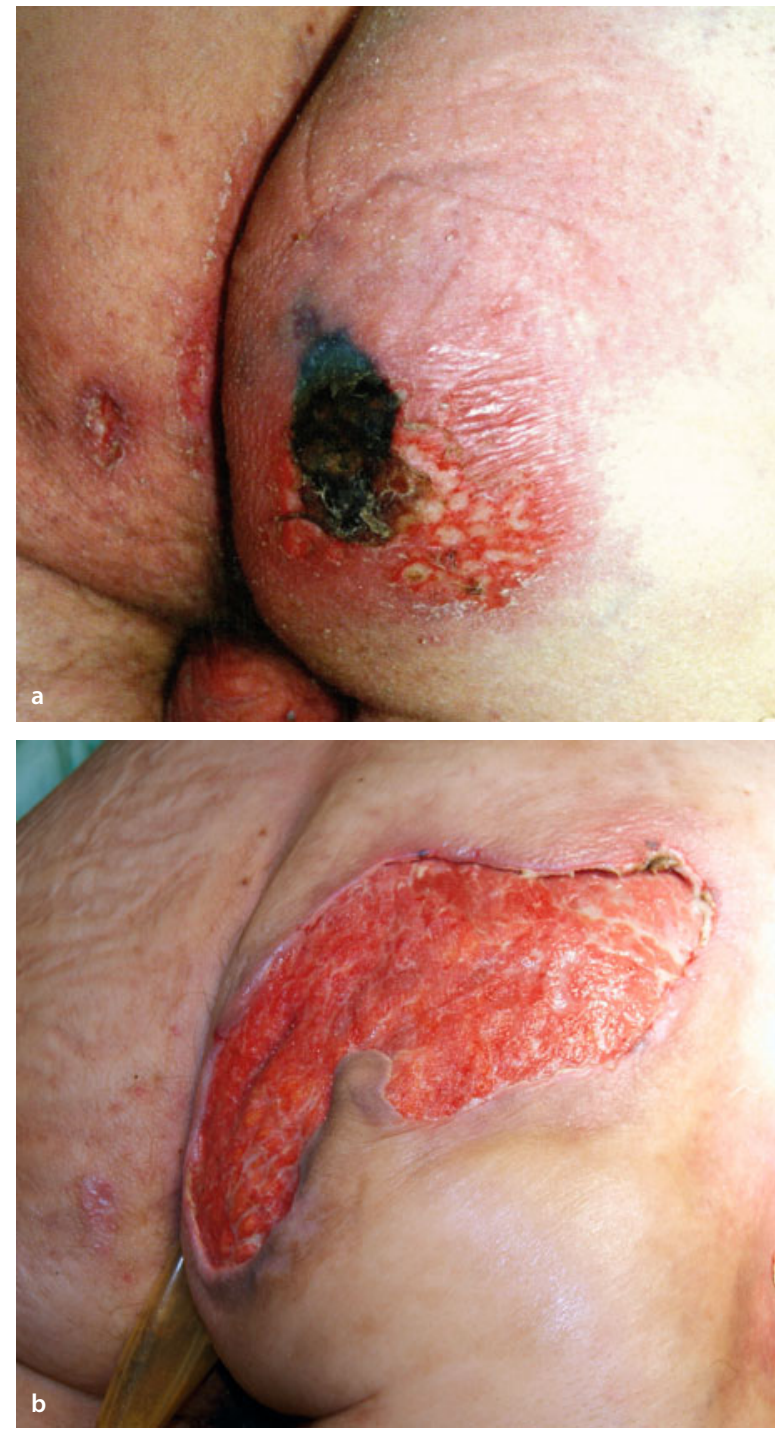

- Abb. 1.59 a Dekubitus vor Debridement. b Dekubitus nach Debridement

management und eine feuchte Wundbehandlung. Eine Wundspülung wird für tiefe oder zerklüftete Ulzera empfohlen. Welche Spüllösung oder -technik optimal ist bleibt unklar. Je nach Ausdehnung des Befundes kommt eine sekundäre Wundheilung oder eine plastisch rekonstruktive Deckung des Gewebedefektes in Frage.

\section{Strahlenulzera und Tumornekrosen}

Radiogene oder aktinische Wunden werden im Allgemeinen zu den akuten Wunden gezählt. In den meisten Fällen besteht jedoch zwischen der ursächlichen Wirkung und der Entstehung der eigentlichen Wunde ein längerer Zeitraum (Wochen bis Monate). Durch die lange Nachwirkung der Strahlung heilen diese Wunden nur über einen längeren Zeitraum ab und neigen zu Rezidiven. Der klinische Verlauf ähnelt daher eher dem chronischer Wunden. 
Tumoren der Haut bzw. hautnaher Regionen (z. B. Analkarzinom) sowie Narbenkarzinome können bei Ausbildung von Nekrosen zu schwer oder nicht heilenden Wunden führen. Eine ursächliche Behandlung ist chirurgisch, chemotherapeutisch oder mittels Strahlentherapie möglich. Falls diese Optionen nicht in Frage kommen, bleibt eine auf den Einzelfall abgestimmte Wundbehandlung übrig. Kontraindikationen bei Tumorwunden, wie sie beispielsweise für die Vakuumtherapie gelten, sollten sich in der palliativen Situation der Lebensqualität des Patienten unterordnen.

\subsubsection{Wundauflagen}

Der Einsatz von Wundauflagen richtet sich nach:

- der Menge des Wundexsudates,

- dem Wundtyp bzw. der Beschaffenheit des Wundgrundes,

- der Wundgröße,

- der Wundlokalisation.

Die Materialien können dabei in inaktive, interagierende und bioaktive Wundauflagen unterteilt werden.

\section{Inaktive Wundauflagen}

Inaktive Auflagen sind typischerweise Textilien. Am häufigsten werden Mullkompressen verwendet. In Verbindung mit Ringer- oder Kochsalzlösung kommen sie vor allem zum Feuchthalten von akuten Wunden zum Einsatz. Ähnliches gilt für infizierte Wunden, bei denen sie mit Antiseptika getränkt werden. Trockene Textilkompressen sind weiterhin die häufigste Wundauflage für unauffällige primär oder sekundär verschlossene Wunden.

\section{Interagierende Wundauflagen}

$\mathrm{Zu}$ den interagierenden Verbänden zählt die große Gruppe der modernen Wundauflagen, die ein idealfeuchtes Wundmilieu gewährleisten.

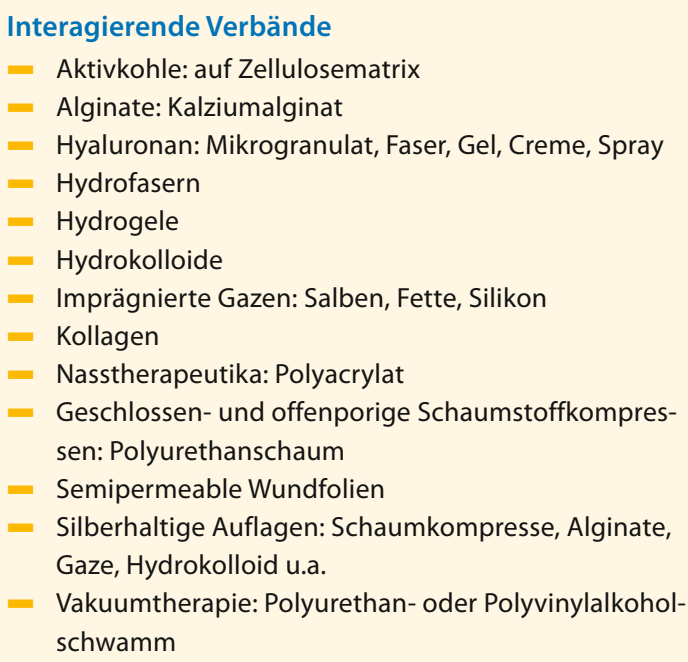

Das Prinzip der idealfeuchten Wundbehandlung wurde 1962 von George Winter ${ }^{15}$ inauguriert, der nachweisen konnte, dass Wunden unter okklusiven Folienverbänden schneller abheilen. In größerer Menge wurden anfänglich nur Folienund Hydrokolloidverbände verwendet. Die Produktliste ist jedoch stark angewachsen und füllt heute alleine ganze Bücher. Die unterschiedlichen Eigenschaften der einzelnen Produkte ermöglichen teilweise eine gezielte Beeinflussung der Wundheilungsphasen. Durch die Einbindung von Silber oder Antiseptika ist der Einsatz bei infizierten oder bakteriell belasteten Wunden möglich. Das Spektrum umfasst auch Wunden mit Methicillin-resistenten Staphylokokken (MRSA, MRSE) und Vancomycin-resistenten Enterokokken (VRE). Eine eindeutige Empfehlung für den Einsatz silberhaltiger Produkte bei infizierten Wunden lässt die Datenlage derzeit nicht zu. Gleiches gilt für die Infektionsprophylaxe gefährdeter Wunden. Nasstherapeutika (TenderWet ${ }^{\circledR}$ ) ermöglichen eine kontinuierliche Spülung und Reinigung der Wunde und eignen sich gut zum Lösen von Nekrosen. Die Vakuumtherapie besitzt mittlerweile ein großes Einsatzspektrum, insbesondere bei der Versorgung größerer Wunden mit extremer Sekretionsmenge, wie dem offenen Abdomen. Obwohl Hinweise für die Verbesserung der Wundheilung existieren, reicht die Evidenz nicht für eine allgemeine Empfehlung aus. Durch die Herstellung von Wundauflagen mit besonderer Passform und unterschiedlicher Größe wurde die Versorgung von Wunden an schwierigen Körperregionen (z. B. Fersen, Handbereich, Sakrum) erleichtert.

Zum Überblick über verschiedene Wundauflagen und ihre Einsatzgebiete, • Tab. 1.16.

Obwohl sich in Zentren der Einsatz moderner Wundauflagen durchgesetzt hat, werden im ambulanten, häuslichen Bereich nur 7-28\% der Patienten mit chronischen Wunden mittels feuchter Wundtherapie versorgt. Ein kontroverser Punkt bleibt die Kostensituation. Den höheren Kosten für die einzelnen Wundauflagen stehen ein besserer Patientenkomfort und ein geringerer Pflegeaufwand entgegen. Trotz vielversprechender einzelner Studien konnte anhand der Datenlage in Metaanalysen keine eindeutige Empfehlung für bestimmte feuchte Wundauflagen ausgesprochen werden. Dies liegt zum größten Teil an der Qualität der durchgeführten Studien. Im Vergleich mit konventionellen textilen Verbänden konnte für Hydrokolloide eine beschleunigte Wundheilung nachgewiesen werden.

\section{Bioaktive Wundauflagen}

Bioaktive Wundauflagen verwenden u. a. Wachstumsfaktoren und Proteasemodulatoren, die aus den Verbänden in die Wunde abgegeben werden und die Granulation fördern sollen. Die Applikation von Wachstumsfaktoren bereitet jedoch aus verschiedenen Gründen Schwierigkeiten. Klinisch wurde bisher lediglich rekombinantes PDGF-BB in größerem Umfang eingesetzt (Regranex ${ }^{\circledR}$ ).

15 George D. Winter, englischer Mediziner und Biologe, Pionier der feuchten Wundheilung, London, 1927-1981 
- Tab. 1.16 Einsatz moderner Wundauflagen nach Indikation (Wundtyp und Exsudatmenge)

\begin{tabular}{|c|c|c|}
\hline Indikation & Wundauflage & Besonderheiten \\
\hline \multirow{6}{*}{$\begin{array}{l}\text { Infektion, kritische } \\
\text { Kolonisation }\end{array}$} & Alginate, Hydrofasern-Silber & Bei Taschenbildungen und tiefen Wunden, bei multiresistenten Keimen \\
\hline & Aktivkohle, ggf. mit Silber & Bei multiresistenten Keimen, gute Geruchsabsorption \\
\hline & Gaze-Silber & $\begin{array}{l}\text { Bei oberflächlichen Wunden, bei multiresistenten Keimen, meist Kombina- } \\
\text { tion mit Saugkompresse notwendig }\end{array}$ \\
\hline & Schaumverband-Silber & Bei multiresistenten Keimen, bei mäßig starker Exsudation \\
\hline & Hydrokolloid-Silber & Bei multiresistenten Keimen, bei geringer bis mäßiger Exsudation \\
\hline & Nasstherapeutika & Saug-Spülwirkung \\
\hline \multirow{2}{*}{$\begin{array}{l}\text { Trockene Beläge, } \\
\text { Nekrosen }\end{array}$} & Gele, Hydrogele & Lösung durch Feuchtigkeit oder enzymatische Wirkung \\
\hline & Nasstherapeutika & Saug-Spülwirkung \\
\hline \multirow{3}{*}{$\begin{array}{l}\text { Höhlen- und } \\
\text { Taschenbildung }\end{array}$} & Hydrofasern, Alginate & Gut formbar, Alginate mit blutstillenden Eigenschaften \\
\hline & Gele & Optimale Formanpassung \\
\hline & Vakuumtherapie & $\begin{array}{l}\text { Schwamm formt sich optimal an, aktive Gewebeverformung, umgekehrte } \\
\text { Gewebeexpansion }\end{array}$ \\
\hline \multirow[t]{3}{*}{ Starke Exsudation } & Hydrofasern, Alginate & $\begin{array}{l}\text { Alginate mit blutstillenden Eigenschaften, ggf. in Kombination mit Saug- } \\
\text { kompressen }\end{array}$ \\
\hline & Schaumstoffe & Teilweise Anwendung unter Kompressionsverbänden möglich \\
\hline & Vakuumtherapie & Auch bei größten Sekretionsmengen \\
\hline \multirow{2}{*}{$\begin{array}{l}\text { Mäßige bis geringe } \\
\text { Exsudation }\end{array}$} & Hydrokolloide & Gut anformbar \\
\hline & Schaumstoffe & Teilweise Anwendung unter Kompressionsverbänden möglich \\
\hline
\end{tabular}

Die Haupteinsatzgebiete bioaktiver Wundauflagen sind gegenwärtig die Verbrennungsmedizin und die Behandlung chronischer Wunden. Insbesondere bei ausgedehnten Verbrennungen muss zur temporären Deckung auf Hautersatzmaterialien zurückgegriffen werden. Zur Anwendung kommen allogener (konservierte Leichenhaut), xenogener (Schweinehaut) oder künstlicher Hautersatz (z. B. Epigard ${ }^{\circledR}$, Biobrane $\left.{ }^{\circledR}\right)$. Künstliche Hautersatzmaterialien minimieren das Infektionsrisiko. Das Wechselintervall ist abhängig vom Produkt. Im Vergleich mit inaktiven und interagierenden Wundauflagen konnte für einige bioaktive Produkte (z. B. Apligraf ${ }^{\circledR}$, Injektion von "granulocyte-macrophage colony-stimulating factor «, OASIS ${ }^{\circledR}$ Schweinekollagen Wundmatrix) eine höhere Rate an kompletten Abheilungen bzw. eine kürzere Heilungsdauer nachgewiesen werden. Eine andere Möglichkeit stellt die Nutzung von Keratinozytenkulturen dar. Diese werden meist aus patienteneigenem Material gezüchtet und dienen als Epidermis-Ersatz. Die Herstellung ist technisch anspruchsvoll, teuer und erfordert einen hohen Aufwand. Die Einheilungsrate variiert zwischen 20-60\%. Im weiteren Sinne können auch Spalthauttransplantation, lokale Lappenplastiken oder ein freier Lappentransfer als biologische Wunddeckung aufgefasst werden.

\section{Gentherapie}

Mithilfe moderner DNS-Chiptechnologie werden Genexpressionmuster im Rahmen der Wundheilung untersucht. Dies soll den Einsatz gentechnischer Wundtherapeutika ermöglichen. Eine gezielte Gentherapie könnte die Wunde wieder in die Lage versetzen, benötigte Wirkstoffe selbst herzustellen. Mittels Gentransfer werden Desoxyribonukleinsäure (DNS) oder Ribonukleinsäure (RNS) in die Zielzelle eingeschleust. Hierfür steht eine breite Palette an Vektoren zur Verfügung. Bisher wird die Gentherapie in der klinischen Praxis noch nicht eingesetzt, u. a. wegen bestehender Sicherheitsbedenken.

\subsubsection{Wunddokumentation}

Im Rahmen der Zunahme an Patienten mit chronischen Wunden sowie als forensisch geforderter schriftlicher Nachweis, ist die Wunddokumentation essentieller Bestandteil der Wundbehandlung.

$>$ Eine exakte Wunddokumentation sollte dabei alle relevanten Kriterien erfassen, die die Therapieplanung und Prognoseabschätzung sowie die Kontrolle der Therapie und den Heilungsverlauf betreffen. 
Gerade bei chronischen Wunden kann so, durch die oft komplexen und langwierigen Behandlungsverläufe, eine objektive und effektive Verlaufskontrolle durchgeführt werden. Für die Beurteilung und Interpretation von Wunden wurden verschiedene Klassifikationen entwickelt und eingesetzt. Gemeinsam ist ihnen eine standardisierte Beurteilung der Wunde, die topographische, tektonische und inflammatorische Verhältnisse einschließt. In der Praxis ermöglicht die Fotodokumentation zusammen mit einem standardisierten Beurteilungsbogen eine optimale Charakterisierung der Wunde, insbesondere bei wechselndem ärztlichem und pflegerischem Personal. Die Verwendung EDV-gestützter Dokumentationssysteme ermöglicht den Aufbau von Wundnetzwerken. Im Deutschen Wundnetz ist es so erstmals gelungen mehr als 7.000 Patienten mit chronischen Wunden leitliniengerecht zu behandeln und dies zu dokumentieren.

\section{In Kürze}

Wunde, Wundheilung und Wundbehandlung Beurteilung und Behandlung von Wunden stellt eine Kernkompetenz aller chirurgischen Fächer dar. Klassifizierung kann u. a. hinsichtlich Genese, Zeitrahmen der Heilung oder der Belastung mit Keimen erfolgen.

- Therapie der akuten Wunden orientiert sich primär an der Genese und erfolgt nach klassischen chirurgischen Prinzipien. Die Heilung verläuft idealerweise in den typischen Wundheilungsphasen.

- Bei chronischen Wunden steht die Evaluierung und Behandlung der Grunderkrankung an 1. Stelle.

- Lokaltherapie sollte Prinzipien der Wundsanierung und idealfeuchten Wundbehandlung folgen. Das große Spektrum an modernen Wundauflagen bietet die Möglichkeit eines individuell angepassten Verbandes. Die Wunddokumentation ist essentieller Bestandteil des Wundmanagements.

\section{Weiterführende Literatur}

Dissemond J (2006) Moderne Wundauflagen für die Therapie chronischer Wunden. Hautarzt 57: 881-887

Falanga V (2000) Classifications for wound bed preparation and stimulation of chronic wounds. Wound Rep Reg 8: 347-352

Jannasch O, Tautenhahn J, Dalicho S, Lippert H (2007) Die schwierige Wunde. Ther Umsch 64: 485-94

Kramer A, Daeschlein G, Kammerlander G et al. (2004) Konsensusempfehlung zur Auswahl von Wirkstoffen für die Wundantiseptik. Hyg Med 5: 147-157

Lippert H, (ed.) (2006) Wundatlas: Kompendium der komplexen Wundbehandlung. 2. Aufl., Georg Thieme Verlag, Stuttgart

Riedel K, Ryssel H, Koellensperger E et al. (2008) Pathophysiologie der chronischen Wunde, Chirurg 79: 526-534

Vasel-Biergans A, Probst W (2010) Wundauflagen für die Kitteltasche. 3. Auflage. Stuttgart: Wissenschaftliche Verlagsgesellschaft

\subsection{Chirurgische Infektionslehre}

\author{
T. Miethke, H. Wagner
}

Trotz Asepsis und Antisepsis sowie eindrucksvoller Fortschritte in der Antibiotikatherapie und in der perioperativen Chemoprophylaxe sind Infektionen in der Chirurgie von großer klinischer Bedeutung. Dies gilt in erster Linie für die primär chirurgisch behandlungsbedürftigen Infektionen wie Abszess, Phlegmone, Empyem, Peritonitis, Gasbrand und Leberbefall bei Echinokokkose oder Amöbiasis. Darüber hinaus kann der Erfolg von lebensrettenden Operationen aufgrund von induzierter Abwehrschwäche durch Infektionen zunichte gemacht werden. Infolge Infektionsbahnung durch langliegende Katheter (Venen, Harnwege) sowie Langzeitbeatmung gehören Pneumonie, Harnwegsinfektionen und Sepsis zu den häufigen Manifestationen der Nosokomialinfektion. Zudem wird heute die antibiotische Therapie durch bakterielle Resistenzentwicklungen zunehmend erschwert. Unter den virusbedingten Krankheiten hat neben den parenteral übertragbaren Hepatitiden die HIV-Infektion den von menschlichem Blut und Körpersekreten für Arzt und Patient ausgehenden Gefahren eine neue Dimension verliehen.

\subsubsection{Allgemeine Infektionslehre}

\section{Infektionen}

- Definition

Unter Infektionen versteht man das Eindringen von Mikroorganismen durch innere oder äußere Oberflächen des menschlichen Körpers und krankhafte (klinisch manifeste) lokalisierte oder generalisierte Reaktionen desselben.

Exogene Erreger Typische Erreger von Infektionskrankheiten, z.B. Mycobacterium tuberculosis, kommen stets von außen (exogene Infektion).

Endogene Erreger Bei einer Schädigung der natürlichen Resistenz- und Immunitätslage des Makroorganismus (z.B. durch Trauma, Operation, Karzinom u. a.) können Mikroorganismen aus der normalerweise harmlosen Oropharyngeal-, Intestinal- oder Genitalflora invasiv werden und Infektionen auslösen (endogene Infektion).

Obligat pathogene Erreger Dieser Begriff beschreibt Mikroorganismen, die nicht zur physiologischen Flora gehören und relativ unabhängig von der Abwehrleistung des Wirts eine Infektion auslösen, z. B. Salmonella typhi und Typhus.

Fakultativ pathogene Erreger Diese Erreger gehören in der Regel zur physiologischen Kolonisationsflora. Die Erreger werden erst pathogen, wenn infektionsbegünstigende Faktoren des Wirtsorganismus vorliegen. Der Nachweis dieser Mikroorganismen kann, muss aber nicht, mit einer Erkrankung des Wirts zusammenhängen. Escherichia coli ist physiologischerweise im Kolon zu finden, erst bei Austritt in die 
Bauchhöhle, z. B. bei einer Anastomoseninsuffizienz, wird dieser Erreger pathogen.

Opportunistische Erreger Als opportunistische Erreger werden manche als lediglich fakultativ pathogen einzuschätzende Erreger meist exogener Herkunft bezeichnet. Krankheitserscheinungen werden nur bei lokaler/systemischer Abwehrschwäche hervorgerufen.

Ein klassisches Beispiel für opportunistische Erreger ist der Befall von Verbrennungswunden durch Pseudomonas aeruginosa.

Ausbreitung der Erreger im menschlichen Körper Bei der Lokalinfektion bleibt der Erreger zunächst auf die Eintrittspforte und deren Umgebung beschränkt (Staphylokokkenabszess, Erysipel). Bei der systemischen oder Allgemeininfektion gelangen Erreger in die Lymphbahnen und Lymphknoten, die die Region der Eintrittspforte drainieren. Nach der Vermehrung im lymphatischen Gewebe (während der Inkubationszeit) treten die Erreger in die Blutbahn über (Generalisation) und gelangen anschließend in Organe (Organmanifestation). $\mathrm{Zu}$ den Allgemeininfektionen gehören Tuberkulose und Syphilis.

D Cave

Der Einbruch der Erreger in die Blutbahn verläuft in seiner klinisch schwersten Form als Sepsis (Septikämie, $>$ Abschn. 1.6.8).

\section{Resistenz und Immunität}

Die Abwehrleistung des Makroorganismus gegen Infektionen setzt sich aus den bereits vor der Infektion vorhandenen Immunmechanismen (angeborene Resistenz) als auch aus der sich im Lauf der Infektion entwickelnden, spezifischen Immunantwort zusammen.

\footnotetext{
- Definition

Immunität ist eine Abwehrleistung des Organismus, die durch eine antigenspezifische Reaktion von T- und B-Zellen gekennzeichnet ist und in vielen Fällen zu einem dauerhaften Schutz gegenüber der ursprünglichen Infektion führt. Der Aufbau der spezifischen, adaptiven Immunität wird durch das angeborene Immunsystem entscheidend beeinflusst.
}

\footnotetext{
- Definition

Das angeborene Immunsystem besteht aus phagozytierenden Zellen wie Makrophagen und Granulozyten und den für die Antigenpräsentation besonders wichtigen dendritischen Zellen sowie einer Fülle weiterer Komponenten wie dem Komplementsystem, antibakteriellen Peptiden (z. B. Defensinen), Lysozym, Epithelbarrieren, Selbstreinigungsmechanismen und der Infektionsverhütung durch die bestehende Normalflora. Zusammengefasst stellen diese Mechanismen die natürliche Resistenz gegenüber Infektionen dar.
}

Neueste Erkenntnissen zeigen, dass das angeborene Immunsystem über mehrere Familien von Rezeptoren, wie z. B. den Toll-like- und den NOD-like Rezeptoren verfügt, über die essenzielle Strukturkomponenten von Mikroorganismen (z. B. Endotoxin) erkannt werden.

Nach der Phase der unspezifischen Abwehr von Krankheitserregern, die sofort gegenüber einem Infektionserreger wirksam ist, folgt die spezifische Immunantwort. Diese ist gekennzeichnet durch die Expansion von antigenspezifischen T- und B-Zellen und deren Differenzierung in Effektorzellen wie zytokinsezernierende $\mathrm{CD} 4^{+}$-T-Helfer-Zellen, zytolytische $\mathrm{CD}^{+}$-T-Zellen und antikörpersezernierende B-Zellen. Die Bedeutung der einzelnen Komponenten dieses Systems variiert bei unterschiedlichen Infektionen.

$>$ Das Zusammenspiel von angeborener Resistenz und adaptiver Immunität ist entscheidend für eine effektive Abwehr von Infektionen.

\section{Morphologisch unspezifische und spezifische Infektionen}

Bei nicht zu zahlreichen in Gewebe oder Blutbahn eingedrungenen Erregern bzw. bei nur gering virulenten Erregern finden Phagozytose und schnelle intrazelluläre Abtötung durch polymorphkernige Granulozyten (PMN) statt und der Mensch bleibt klinisch gesund. Ist die intrazelluläre Erregerabtötung erschwert oder die Erregerzahl zu groß, so tritt trotz Anlockung exzessiv hoher PMN-Zahlen (Chemotaxis) Zelltod (Gewebenekrose) ein und es bilden sich Eiterherde (bestehend aus Erregern, PMN und Detritus).

\section{$>$ Eiterherde können in Form von Abszess, Phlegmone oder Empyem ( $\triangleright$ Abschn. 1.6.8) auftreten.}

Mit entscheidend für Manifestation und Verlauf sind infektionsbahnende Faktoren. Die Summe der infektionsbahnenden Faktoren fasst man unter den Begriff Prädisposition zusammen.

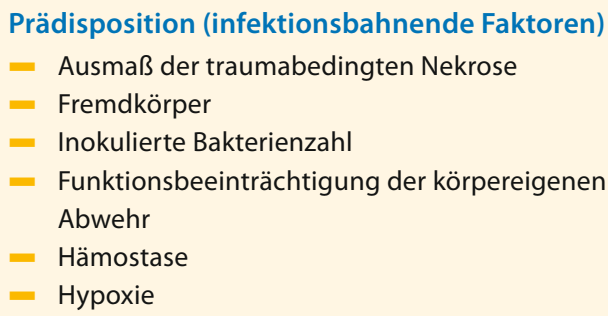

$\mathrm{Zu}$ den morphologisch spezifischen Infektionskrankheiten gehören die toxisch determinierten Krankheiten Gasbrand und Wunddiphtherie sowie durch Granulombildung gekennzeichnete Infektionskrankheiten wie Tuberkulose und Aktinomykose, aber auch bestimmte Parasitosen, Virosen und Mykosen, - Tab. 1.17). 
- Tab. 1.17 Differenzierung von Infektionserkrankungen nach morphologischen Kriterien

\begin{tabular}{|l|l|l}
\hline Unspezifische Morphologie & Spezifische Morphologie & Intoxikationen mit spezifischer Morphologie \\
\hline Abszess (S. aureus) & Granulom (M. tuberculosis) & Gasbrand (C. perfringens) \\
\hline Phlegmone (S. pyogenes) & Gumme (T. pallidum) & Diphterie (C. diphteriae) \\
\hline Empyem (Mischflora) & Drusen (A. israelii) & \\
\hline
\end{tabular}

\section{Klinikbezogene mikrobiologische Grundlagen}

Infektionen haben für den Chirurgen mehrfache Bedeutung:

- Es gibt eine Reihe von Infektionserkrankungen, die primär chirurgisch zu behandeln sind.

- Komplikationen sind im Bereich von Operationswunden oder Traumen chirurgisch relevante Infektionsprozesse.

- Nosokomiale, operationsferne Infektionen bedrohen regelmäßig den Erfolg chirurgischer Heilmaßnahmen (• Tab. 1.18).

\section{Nosokomiale Infektionen}

Sie entstehen während oder anlässlich eines Krankenhausaufenthaltes. Ein Zusammenhang mit dem primären chirurgisch behandlungsbedürftigen Leiden kann bestehen oder fehlen. Schwer kranke Laparotomierte sind stark gefährdet, Harnwegsinfektionen oder/und Infektionen der tiefen Atemwege zu akquirieren. Zu den vorherrschenden Krankheitsmanifestationen der nosokomialen Infektion gehören außerdem Venenkatheterinfektionen, postoperative Wundinfektionen und Sepsis.

\section{Erreger}

Die genannten Krankheitsbilder haben manchmal einen einzigen Erreger, viel häufiger aber mehrere Erreger gleichzeitig (z.B. polybakterielle aerob/anaerobe Mischinfektion) oder

- Tab. 1.18 Chirurgisch relevante Infektionen

\begin{tabular}{|l|l|l|}
$\begin{array}{l}\text { Primär chirurgisch } \\
\text { zu behandelnde } \\
\text { Infektionen }\end{array}$ & $\begin{array}{l}\text { Komplikationen } \\
\text { im Bereich der } \\
\text { Operationswunde }\end{array}$ & $\begin{array}{l}\text { Operationsferne } \\
\text { Infektionen }\end{array}$ \\
\hline Panaritium & $\begin{array}{l}\text { Bauchdecken- } \\
\text { abszess }\end{array}$ & Pneumonie \\
\hline $\begin{array}{l}\text { Furunkel, } \\
\text { Karbunkel }\end{array}$ & $\begin{array}{l}\text { Anastomosen- } \\
\text { insuffizienz }\end{array}$ & $\begin{array}{l}\text { Harnwegs- } \\
\text { infektion }\end{array}$ \\
\hline Organabszesse & $\begin{array}{l}\text { Osteitis/Osteo- } \\
\text { myelitis (nach } \\
\text { Osteosynthese) }\end{array}$ & \\
\hline Appendizitis & & \\
\hline Spontane & & \\
\hline Peritonitis & &
\end{tabular}

sind durch Erregerwechsel gekennzeichnet. Die in pyogenen und putriden Infektionsprozessen vorherrschenden Arten kann man als Leitkeime auffassen, v. a. wenn sie sich nach ihrer Herkunft (exogen bzw. endogen) und nach ihrer bevorzugten klinischen Manifestation unterscheiden.

\section{$>$ Die 3 wichtigsten Erreger nosokomialer Infektionen sind Staphylococcus aureus (grampositiv) und die beiden aus der Darmflora stammenden gramnega- tiven Stäbchen Escherichia coli (aerob) und Bacteroi- des fragilis (anaerob).}

Als Leitkeime der nosokomialen Infektion gelten neben $\beta$ Laktamase-bildenden und daher penicillinresistenten Staphylococcus-aureus-Stämmen v. a. Enterobacteriaceae, die z. T. hochresistent gegenüber einer Reihe von Antibiotika sind oder während der Therapie werden, als auch Pseudomonas aeruginosa, der nur mit Reserveantibiotika therapierbar ist.

Viele postoperative Infektionen werden durch die physiologische mikrobielle Flora des Magen-Darmtrakts, des Mund-Rachen-Raums sowie der Haut ausgelöst. Die Zusammensetzung der bakteriellen Flora an einem Infektionsort kann daher Aufschluss auf die Infektionsquelle geben (•Tab. 1.19).

\section{Erregernachweis}

Bei Infektionen durch schnell wachsende Bakterien (Aerobier mit Ausnahme der Tuberkuloseerreger, außerdem Anaerobier) eröffnet der kulturelle Erregernachweis aus signifikantem Untersuchungsmaterial, d.h. aus dem Infektionsprozess selbst, die Möglichkeit der Erregeridentifizierung und Resistenzbestimmung und damit einer gezielten Antibiotikatherapie. PCR-Verfahren erlauben den kulturunabhängigen Erregernachweis. Diese Methodik besitzt große Bedeutung bei nicht oder schwer anzüchtbaren sowie langsam wachsenden Erregern, wie z. B. Mykobakterien. Aus der großen Fülle von Immunreaktionen besitzen nur einige ausgewählte Methoden krankheitsdiagnostische Bedeutung (Antitoxinnachweis, Nachweis des Legionellen-Antigens im Urin, Nachweis antiviraler Antikörper mit ELISA u. a., Nachweis von Antikörpern gegen Parasiten- und Helminthenantigene).

\section{Meldepflichtige Infektionen}

Unter Meldepflicht ist Anzeigepflicht - in der Regel gegenüber dem Gesundheitsamt - für bestimmte Infektionskrankheiten wie Tuberkulose, Syphilis, Milzbrand, Diphtherie, Tollwut 
- Tab. 1.19 Physiologische Keimflora

\begin{tabular}{|l|l|l|}
\hline Mund-Rachen-Raum & Haut & Kolon \\
\hline $\begin{array}{l}\text { Vergrünende Streptokokken } \\
\text { Koagulasenegative Staphylokokken }\end{array}$ & Koagulasenegative Staphylokokken & Verschiedene Anaerobier, z. B. Bacteroides fragilis \\
\hline $\begin{array}{l}\text { Apathogene Neisserien } \\
\text { Verschiedene Anaerobier }\end{array}$ & Corynebacterium & Enterobacteriaceae, z. B. Escherichia coli \\
\hline Apathogene Treponemen & & Enterokokken \\
\hline Candida & & Streptokokken \\
\hline
\end{tabular}

und Virushepatitis zu verstehen. Sie wird durch das Gesetz zur Verhütung und Bekämpfung von Infektionskrankheiten beim Menschen, das Infektionsschutzgesetz (IFSG), geregelt.

\section{In Kürze}

\author{
Allgemeine Infektionslehre \\ Erreger: exogen, endogen; obligat oder fakultativ patho- \\ gen, opportunistisch. \\ Symptomatik: Lokalinfektion, Eiterherde (Abszess, Phleg- \\ mone, Empyem), Allgemeininfektion bis hin zur Sepsis, \\ Prädisposition (infektionsbahnende Faktoren), Resistenz, \\ Immunität. \\ Diagnostik: Erregernachweis durch Kultur, PCR-Verfah- \\ ren, Immunreaktionen. \\ Komplikationen: Operationsferne nosokomiale Infek- \\ tionen wie Pneumonie nach bauchchirurgischen Eingrif- \\ fen bedrohen nicht selten den Erfolg chirurgischer Heil- \\ maßnahmen, nicht zuletzt aufgrund der häufig hohen \\ Antibiotikaresistenz der beteiligten Erreger.
}

\subsubsection{Endogene Infektionen durch Entero- bakteriazeen und Anaerobier}

\footnotetext{
Definition

Bei endogen eitrigen Infektionen handelt es sich um Entzündungen durch fakultativ pathogene, obligat wie fakultativ anaerobe Bakterien. Putride Infektionen werden durch obligat anaerobe Bakterien verursacht. In beiden Fällen liegen häufig Mischinfektionen vor.
}

Befallen sind Extremitäten, Stamm sowie Organe der großen Körperhöhlen (z. B. Abdominal-, Lungen-, Hirn-, Leberabszesse). Die hier diskutierten fakultativ anaeroben Erreger gehören zur Gruppe der Enterobacteriaceae (Escherichia coli, Klebsiella, Enterobacter usw.), während Bacteroides fragilis, Bacteroides melaninogenicus, Fusobacterium nucleatum und Peptostreptococcus zu den obligat anaeroben Erregern gehören.

\section{- Symptomatik}

Lokaler Krankheitsprozess Klinisch sind eitrige oder putride Infektionen gekennzeichnet durch

- Abszess,

- faulig stinkendes, dünnflüssiges Wundsekret, z. T. mit Gasbildung,

- flächenhaften, nekrotisierenden Gewebezerfall,

- fehlende leukozytäre Abgrenzung zum gesunden Gewebe.

Allgemeinreaktion Je nach Ausdehnung und Sitz des Infektionsprozesses sowie nach Virulenz der Erreger kommt es zu Allgemeinreaktionen wie Fieber, Gewichtsverlust u. a. Die Infektionen erstrecken sich von der einfachen Zystitis bis hin zur Sepsis (- Tab. 1.20). Mit Anaerobiersepsis ist v. a. bei Darmkarzinompatienten mit intraabdominellen Infektionsprozessen zu rechnen.

\section{- Differenzialdiagnose}

Bei Extremitätenbefall und Prozessen am Körperstamm sind obige Infektionen gegen Gasbrand (akute Myositis durch Clostridium perfringens $\mathrm{u}$. a.) abzugrenzen.

. Cave

Der Übergang von putrider Infektion zu Gasbrand, z. B. an infizierten Amputationsstümpfen kein seltenes Ereignis, muss durch häufige klinische und bakteriologische Kontrolle rechtzeitig erkannt werden.

\section{- Diagnostik}

Klinisch wird der Verdacht auf eine Infektion mit endogenen Erregern durch typische Infektionslokalisationen wie Peritonitis, perityphlitischer Abszess, Lungen- und Hirnabszess etc., durch fötiden Eiter, septische Thrombophlebitis, sowie generell bei Malignom nahe gelegt.

( Im Wesentlichen beruht die Diagnose einer aerob/ anaeroben Mischinfektion auf dem Erregernachweis mittels Anlage einer Kultur und zwar aus geeignetem (signifikantem) Untersuchungsmaterial. 
- Tab. 1.20 Aerob/anaerobe Mischinfektion

\begin{tabular}{|l|l|l|}
\hline Art der Infektion & Häufigste Erregergruppe & Leitkeim \\
\hline Cholangitis & Enterobacteriaceae/Enterokokken/obligate Anaerobier & E. coli/Enterococcus faecalis/B. fragilis \\
\hline Akute Cholezystitis & Enterobacteriaceae & E.coli \\
\hline Infizierte Pankreaspseudozysten & Enterobacteriaceae & E.coli \\
\hline Gangränös perforierte Appendizitis & Obligate Anaerobier & B. wadsworthia \\
\hline Peritonitis & Enterobacteriaceae/obligate Anaerobier & E.coli/B. fragilis \\
\hline Sepsis & Enterobacteriaceae/selten obligate Anaerobier & E.coli \\
\hline Hirnabszess & Obligate Anaerobier & B. fragilis/Peptostreptococcus \\
\hline Zystitis & Enterobacteriaceae & E.coli \\
\hline
\end{tabular}

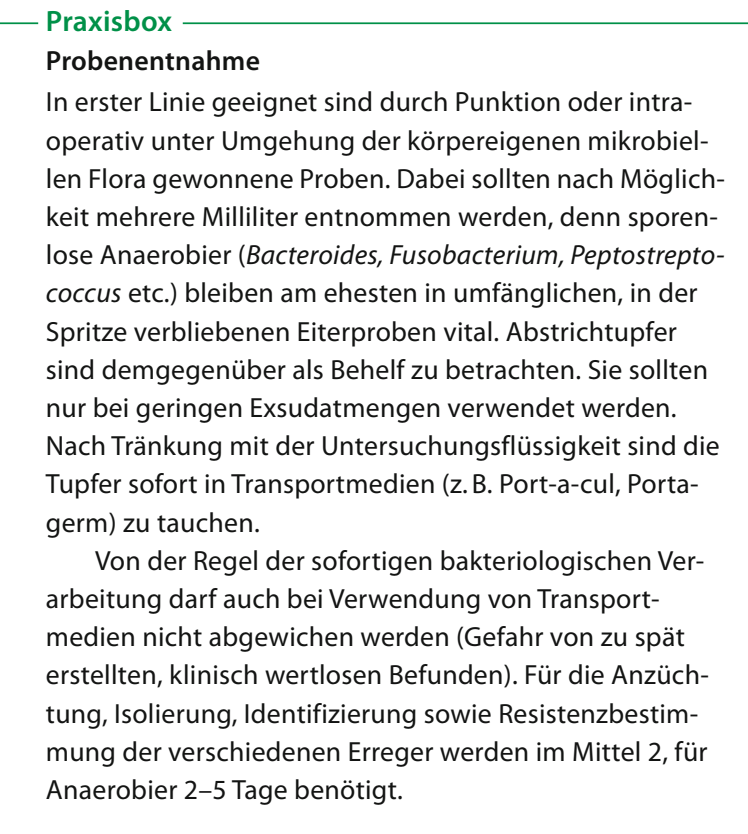

\section{- Komplikationen}

Bei eitrigen oder putriden Wundinfektionen, Anaerobierinfektionen im Kopf-Hals-Bereich, Peritonitis nach Darmperforation und Infektionen bei Karzinompatienten kommt ein Übertritt der Erreger ins Blut mit Fieber, Schüttelfrost und weiteren Zeichen der akut lebensbedrohlichen Sepsis ( $\triangleright$ Abschn. 1.6.8) vor. Diagnostisch ist hierbei die Beimpfung eines aeroben sowie anaeroben Blutkultursystems mit Kubitalvenenblut der Patienten erforderlich. Häufigster Erreger der Sepsis ist Escherichia coli, unter den Anaerobiern Bacteroides fragilis.

\section{- Bakteriologische Befunde}

Die Leitkeime der aerob/anaeroben Mischinfektion finden sich in den verschiedenen Lokalisationen und klinischen Manifestationen mit unterschiedlicher Häufigkeit.
Escherichia coli Dieser Erreger wird innerhalb der Enterobacteriaceae am häufigsten isoliert. Wie alle Enterobacteriaceae ist E. coli ein gramnegatives Stäbchen mit anspruchslosen Wachstumsbedingungen. Es ist der häufigste Erreger der gramnegativen Sepsis, innerhalb der Enterobacteriaceae wird er am häufigsten bei Peritonitis, Gallengangs- und Harnwegsinfektionen isoliert (•Tab. 1.20).

Klebsiella Von medizinischer Bedeutung sind K. pneumoniae und K. oxytoca. Beide Arten (häufiger K. pneumoniae) sind für nosokomiale Pneumonien, Harnwegsinfektionen als auch intestinale Infektionen verantwortlich.

Enterobacter Insbesondere E. cloacae als auch E. aerogenes werden regelmäßig aus relevanten Proben chirurgischer Patienten isoliert. Die Erreger zeichnen sich häufig durch mehrfache Antibiotikaresistenzen aus.

Citrobacter C. freundii und C. koseri finden sich als Erreger von Harnwegsinfektionen als auch intestinaler Infektionen.

Proteus P. vulgaris, P. mirabilis und P. penneri lösen insbesondere Harnwegsinfektionen aus, sind jedoch auch bei intestinalen Infektionen vorzufinden.

Bacteroides fragilis Dieses Bakterium ist der bekannteste Vertreter aus der Gruppe der intestinalen, strikt anaeroben gramnegativen sporenlosen Stäbchen. Als vorherrschender anaerober Erreger findet sich die Spezies bei (sekundärer) Peritonitis, bei gangränösen Appendizitisstadien mit Perforation sowie nachfolgender postappendizitischer Peritonitis bzw. bei perityphlitischen Abszessen, außerdem bei Gallenwegsinfektionen und subphrenischen Abszessen. Extraabdominelle Infektionen treten im Bereich der Extremitäten als Gangrän, diabetische Ulzera, Amputationsstumpfinfektionen u. a. auf. Otogene Hirnabszesse sind fast stets durch Bacteroides fragilis hervorgerufen. 
Bilophila wadsworthia Das gramnegative anaerobe Stäbchenbakterium wird bei Appendizitis sowie bei Anaerobierinfektionen unterschiedlicher Lokalisation (z. B. Skrotalabszess, Schweißdrüsenabszess, mandibuläre Osteomyelitis, Leberabszess mit septischer Aussaat) gefunden. Aufgrund von $\beta$-Laktamase-Bildung liegt Resistenz gegen Penicilline und bestimmte Cephalosporine vor.

Fusobacterium nucleatum Diese oropharyngeale Anaerobierspezies bildet Buttersäure ( $\rightarrow$ Geruch von Kultur und infiziertem pathologischen Material) und herrscht in Infektionsprozessen im Kopf-Hals-Bereich sowie in der Lunge vor. Die meisten Isolate sind penicillinempfindlich. Zusammen mit oralen Treponemen sind Fusobakterien für die Angina PlautVincent verantwortlich, einer meist einseitigen, nekrotisierenden Tonsillitis.

Peptostreptokokkusarten Peptostreptococcus anaerobius und andere Spezies dieser Gattung von strikt anaeroben grampositiven Kettenkokken sind bei putriden Infektionen in praktisch allen Körperregionen beteiligt (Hirn-, Lungen- und Leberabszesse, Schweißdrüsenabszesse, intraabdominale und pelvine Infektionsprozesse). Im befallenen Gewebe (wie in der Kultur) führen sie zu starker Gasbildung.

Peptostreptokokkusinfektionen sind daher eine wichtige Differenzialdiagnose gegenüber Gasbrand durch Clostridium perfringens u. a.

Peptostreptokokken sind penicillinempfindlich und die meisten Stämme sind auch gegenüber Metronidazol empfindlich, wobei Resistenzen beschrieben worden sind.

Prevotella bivia Dieser gramnegative sporenlose stäbchenförmige Anaerobier ist Leitkeim der putriden Genitalinfektionen (parametrane Abszesse, Pelveoperitonitis) und - ähnlich Bacteroides fragilis - ein häufiger $\beta$-Laktamasebildner.

Prevotella melaninogenica Ein anaerobes gramnegatives, sporenloses Stäbchenbakterium, das in der Kultur durch schwarzbraune Pigmentbildung auffällt. Es findet sich häufig bei Infektionen im Kopf-Hals-Bereich und bei Lungenabszes- sen, seltener in anderen Körperregionen. Die Spezies ist penicillinempfindlich.

\section{- Therapie}

$>$ Die chirurgische Sanierung von eitrigen oder putriden Infektionen ist Voraussetzung für eine erfolgreiche Therapie.

Operative Therapie Im Vordergrund der therapeutischen Maßnahmen steht die unverzügliche operative Sanierung der Infektionsquelle. Dies erfolgt mittels Inzision, Entfernung von Nekrosen sowie Drainage und Spülung von Abszesshöhlen. Durch offene Wundbehandlung wird dabei die weitere Ausbreitung der Infektion verhindert und der Heilungsvorgang beschleunigt. Solitäre Abszesse in den großen Körperhöhlen (intraabdominell u. a.) können ggf. unter sonographischer Kontrolle durch perkutane Punktion und Drainage behandelt werden.

Antibakterielle Chemotherapie Bei progredientem Verlauf sowie bei Prozessen, bei denen eine chirurgische Intervention unmöglich ist, und bei allen lebensbedrohlichen Verlaufsformen wie Sepsis, Meningitis, Endokarditis, anaeroben Lungeninfektionen und Peritonitis hängt das Schicksal des Patienten von einer wirksamen, d.h. nach Möglichkeit gezielten Chemotherapie ab.

Die antibiotische Therapie der Enterobacteriaceae wird zunehmend durch Antibiotikaresistenzen erschwert. E. coli erweist sich heute nicht selten resistent gegenüber Erst- und Zweitgenerationscephalosporinen als auch Ampicillin, Mezlocillin und Piperacillin. Insbesondere Klebsiella-Arten und E. coli können durch Bildung von $\beta$-Laktamasen gegen Drittgenerationscephalosporine (sog. Extended-spectrum- $\beta$-Laktamasen, ESBL) gegen alle Penicilline und Cephalosporine resistent werden. Hinzukommen seit kurzem Carbapenemase-bildende Stämme beider Bakterienarten, die dann panresistent sind. Mehrere häufig vorkommende Anaerobierarten sind penicillinempfindlich, andere wie Bacteroides fragilis erfordern den Einsatz von Nitroimidazolpräparaten (z. B. Metronidazol) oder $\beta$-Laktamase-festen Anaerobiermitteln (• Tab. 1.21).

- Tab. 1.21 Kalkulierte Antibiotikatherapie bei eitrigen oder putriden Infektionen

Antibiotika
$\begin{aligned} & \text { Piperazillin/Sulbactam } \\ & \text { oder Tazobactam }\end{aligned}$
Imipenem
Cephalosporine
3. Generation
Metronidazol
Penicillin G

Empfindliche Erreger

Nahezu alle Enterobacteriaceae, Entercoccus faecalis, alle Anaerobier. Cave: ESBL-bildende E. coli und Klebsiella spp. können resistent sein.

Alle Enterobacteriaceae, Entercoccus faecalis, alle Anaerobier. Cave: Carbapenemasen bei E. coli, Klebsiella spp., Pseudomonaden, rasche Resistenzentwicklung bei Pseudomonas aeruginosa unter Therapie

Nahezu alle Enterobacteriaceae, keine Enterokokken, Anaerobier (außer B. fragilis). Cave: ESBL-Bildner

Nahezu alle Anaerobier (inkl. B. fragilis), nicht wirksam bei Enterobacteriaceae, keine Enterokokken

Peptostreptococcus, Prevotella, Fusobacterium, Bacteroides (außer B. fragilis), keine Enterobacteriaceae, keine Enterokokken 
> Die kalkulierte Antibiotikatherapie besteht daher aus einem breitwirksamen Penicillin wie Mezlocillin oder Piperacillin in Kombination mit Sulbactam oder Tazobactam. Alternativen bestehen in der Gabe eines Drittgenerationscephalosporins zusammen mit Metronidazol oder der alleinigen Gabe eines Carbapenems, letzteres insbesondere bei Hinweis auf ESBL-positive Enterobactericeae. Um das Risiko der Entwicklung von Resistenzen gegenüber Antibiotika zu minimieren, sollte die kalkulierte Therapie durch eine gezielte Antibiotikatherapie sobald wie möglich ersetzt werden.

\section{In Kürze}

\section{Endogene Infektionen durch Enterobacteriaceae} und Anaerobier

Pathogenese: endogen eitrige Infektionen durch Enterobacteriaceae (E. coli, Klebsiella, Enterobacter usw.); putride Infektionen durch Anaerobier.

Symptomatik: lokal: Abszess, faulig, evtl. mit Gas, nekrotisch, ohne leukozytäre Abgrenzung. Allgemeinreaktion von fieberhafter Entzündung bis hin zur Sepsis.

Diagnostik: Lokalisation, Anamnese (Karzinom?), Leitkeime. Cave: Differenzialdiagnose Gasbrand. Therapie: unverzügliche operative Sanierung der Infektionsquelle, evtl. zusätzlich antibakterielle Chemotherapie.

\subsubsection{Gasbrand}

- Einteilung, Erreger

Gasbrand bzw. Gasödem gehören zu den »klassischen « clostridialen Toxininfektionen. Neben Clostridium perfringens sind als Erreger dieser Erkrankungen - wenn auch seltener - Clostridium novyi, Clostridium septicum und Clostridium histolyticum von Bedeutung. Das Vorkommen bzw. der Nachweis dieser Clostridien bedeutet jedoch keineswegs immer die klinische Diagnose Gasbrand: Da z. B. Clostridium perfringens in der Darmflora jedes Patienten vorkommt, ist Kontamination von Haut, oberflächlichen Wundschichten usw. häufig.

\section{Definition \\ Nur Clostridiennachweis zusammen mit Myositis/Myo- nekrose entspricht dem Befund Gasbrand (clostridialer Myositis, Abb. 1.60).}

Bei den genannten Erregern Clostridium perfringens, Clostridium novyi, Clostridium septicum, Clostridium histolyticum (-Tab. 1.22) handelt es sich um obligat anaerobe Bakterien, die im Boden und mit unterschiedlicher Häufigkeit im menschlichen Darm vorkommen. Im Grampräparat stellen sie sich als relativ große plumpe grampositive Stäbchen dar, die mit Ausnahme von Clostridium perfringens beweglich sind

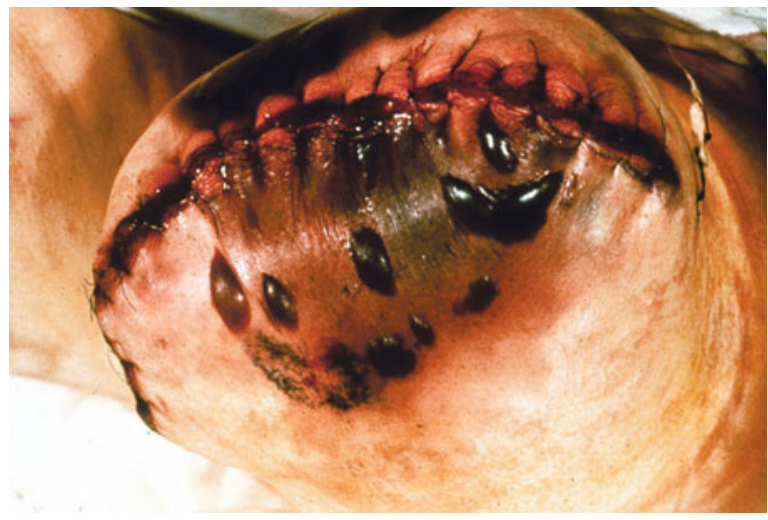

- Abb. 1.60 Gasbrand des linken Oberschenkels nach Amputation mit deutlicher Schwellung, rötlich bis livider Verfärbung der Haut und z. T. blasiger Ablösung (mit freundlicher Genehmigung von Prof. Dr. Disko, München)

und häufig Sporen (subterminal) bilden. Clostridium perfringens ist von einer polysaccharidhaltigen Kapsel umgeben und ist der häufigste Erreger des Gasbrandes, während die anderen Clostridien (C. novyi, C. septicum, C. histolyticum) nur eine geringere Rolle spielen.

Clostridium perfringens kann mindestens 12 lösliche Antigene, die als Toxine wirksam sind, bilden. Anhand des differenten Bildungsvermögens dieser Toxine werden die Clostridium-perfringens-Typen A, B, C, D und E unterschieden. In der menschlichen Infektionspathologie sind fast ausschließlich Typ-A-Stämme bedeutsam. Bei der Ätiopathogenese von Wundinfektionen durch Clostridium perfringens Typ A ist das wichtigste Toxin - da letal wirksam - eine Lezithinase. Diese kalziumabhängige Phospholipase C, ein Zinkmetalloenzym mit einem Molekulargewicht von 53.000, ist in der Lage, membranständiges Lezithin zu spalten und damit die Struktur von Zellmembranen zu zerstören. Daneben sind noch andere Toxine, zu denen eine Kollagenase, ein Hämolysin, eine Hyaluronidase und eine Desoxyribonuklease gerechnet werden, von Bedeutung. Unter der Einwirkung all dieser Toxine und der weiteren Vermehrung des Erregers kommt es zur Zerstörung aller Gewebestrukturen, insbesondere der Muskulatur (Myonekrose), mit Verflüssigung und Gasbildung. Auch andere Körperzellen, z. B. Leukozyten, Erythrozyten, werden von den Toxinen zerstört.

\section{- Pathogenese, Klinik}

Die Wundinfektion durch Clostridium perfringens, C. novyi, C. septicum und C. histolyticum setzt anaerobe Bedingungen für die Vermehrung und die damit einhergehende Toxinbildung der Erreger voraus. Dies ist insbesondere in stark gequetschtem und nekrotischem Gewebe, in dem keine adäquate Blutversorgung und damit keine Sauerstoffversorgung mehr gewährleistet sind, und bei in der Wunde liegenden Fremdkörpern der Fall. Auf Grund des in der Umwelt ubiquitären Vorkommens der Erreger und ihrer saprophytären Existenz im menschlichen Darm kommt die Kontamination von 
- Tab. 1.22 Erreger des Gasbrands

\begin{tabular}{|l|l|}
\hline Erreger & Eigenschaften \\
\hline C. perfringens & $\begin{array}{l}\text { Anhand des Toxinbildungsvermögens wer- } \\
\text { den Typ A-E unterschieden: Typ A, häufigs- } \\
\text { ter Erreger des menschlichen Gasbrandes, } \\
\text { stärkstes Toxin Phosholipase C, eine Lezithi- } \\
\text { nase, führt zu Permeabilitätstörungen phos- } \\
\text { pholipidhaltiger Membranen, zerstört Lyso- } \\
\text { somenmembran, Freisetzung von Enzymen, } \\
\text { Inkubationszeit 5-48 h, bei den anderen } \\
\text { Clostridien bis zu 6 Tagen }\end{array}$ \\
\hline C. novyi & $\begin{array}{l}\text { 4 verschiedene Toxintypen A-D, Toxine sind } \\
\text { nicht identisch zu denen von C. perfringens, } \\
\text { für 10-20\% der Gasbrandfälle verantwortlich }\end{array}$ \\
\hline C. histolyticum & $\begin{array}{l}\text { Seltenste, aber gefährlichste Form des } \\
\text { Gasbrandes }\end{array}$ \\
\hline C. septicum & $\begin{array}{l}\text { Verantwortlich für Gasgangrän, tödliche } \\
\text { Enterokolitis }\end{array}$ \\
\hline
\end{tabular}

Wunden häufig vor. In den meisten Fällen tritt jedoch keine Invasion in tiefere Gewebeschichten ein. Die so auf primär nekrotische Bezirke beschränkte Zellulitis zeigt in der Regel kaum Ausbreitungstendenzen. In seltenen Fällen kann sich allerdings die stets lebensbedrohliche perakute Myonekrose, d. h. der Gasbrand, entwickeln mit Ausbreitung der Infektion in gesundes, nicht durch ein Trauma oder andere Einflüsse vorgeschädigtes Muskelgewebe. Gleichzeitig kommt es über die Toxinämie und die Clostridiämie zu Fieber und Schocksymptomatik.

Das klinische Bild ist recht charakteristisch: Mehrere Stunden bis Tage nach einem Trauma treten heftiger Wundschmerz, verbunden mit lokaler Schwellung und Blässe, und später Rotfärbung der gespannten umgebenden Haut auf. Allmählich treten Blasen, serosanguinöses Wundexsudat mit charakteristischem Geruch und häufig Krepitationen bei der Palpation auf. Die Patienten sind akut schwer krank. Im Vergleich zur Körpertemperatur besteht eine unverhältnismäßig hohe Tachykardie.

( Cave

Schließlich kommt es zu Schock und ohne Behandlung in $100 \%$ der Fälle zum Exitus letalis unter dem Bild multipler Organinsuffizienzen (Koma, respiratorische Insuffizienz, Hämolyse mit Ikterus, Leber- und Niereninsuffizienz).

Die Prognose hängt von der Lokalisation der Primärinfektion ab. An den Extremitäten ist der Gasbrand meist beherrschbar, am Rumpf sehr häufig letal.

D Cave

Bei foudroyantem Verlauf kann der Gasbrand bereits innerhalb von $5 \mathrm{~h}$ zum Tode führen.

Neben der Infektion von stark traumatisiertem Gewebe (Verkehrsunfall, Kriegsverletzungen u. a.) können die Erreger

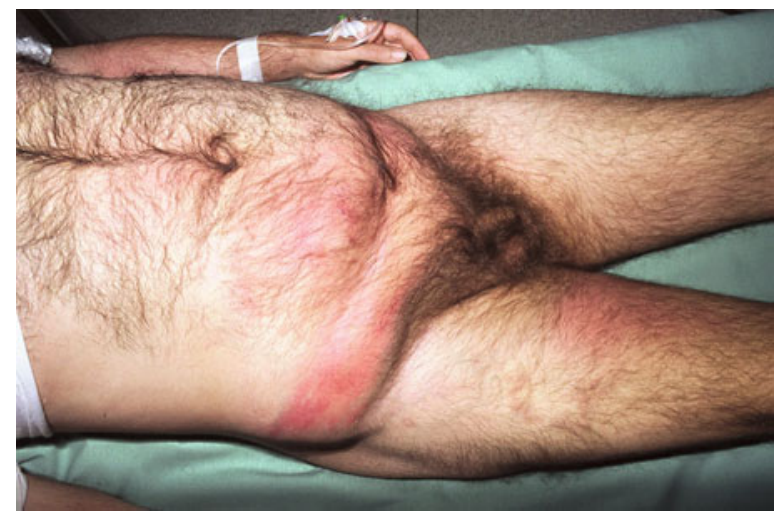

- Abb. 1.61 Rechtseitige Gasphlegmone der Bauchwand mit Rötung und deutlich tastbarer Crepitatio, hinweisend auf Gasbildung im Gewebe. Das klinische Bild wurde von einem in die Bauchwand perforierten Zäkumkarzinom verursacht

auch nach abdominalchirurgischen Eingriffen Bedeutung erlangen (Gasbrand der Bauchwandmuskulatur, nahezu immer tödlich endend). Darüber hinaus sind »darmferne« endogene Gasbrandfälle ohne vorherige Gewebeläsion beschrieben, z. B. an den Extremitäten, wobei die Erreger (u. a. auch Clostridium septicum) über ulzeröse Veränderungen in der Darmwand in die Blutbahn gelangen und hämatogen-metastatisch zur Infektion führen.

\section{Vom Gasbrand (clostridialer Myositis) ist klinisch und ätiologisch die Gasphlegmone (aerob/anaerobe Mischinfektion), d. h. eine eitrige, gasbildende Infek- tion ohne progrediente Myositis/Myonekrose, zu unterscheiden.}

Ätiologisch beteiligt sind - meist in Mischinfektionen - gasbildende aerobe und/oder anaerobe Bakterien, z. B. Klebsiella, Peptostreptococcus, Bacteroides. Sogar Clostridium perfringens kann an dieser polybakteriellen Infektion beteiligt sein. Die Prognose der Gasphlegmone ist bei wirksamer chirurgischer und antibiotischer Behandlung - im Gegensatz zum Gasbrand - meist gut (• Abb. 1.61).

\section{- Diagnostik}
( Der mikroskopische Erregernachweis von reichlich clostridialen Zellen im gramgefärbten Muskel- quetschpräparat ist pathognomonisch.

Umgekehrt liegt beim mikroskopischen Nachweis von gramnegativen Stäbchen und grampositiven Kokken, evtl. in Kombination mit clostridialen Zellen, eine aerob/anaerobe Mischinfektion oder Gasphlegmone vor. Die Bestätigung erfolgt durch die kulturelle Erregeranzucht und -identifizierung aus den entsprechenden Muskelgewebeproben.

Bei Verdacht auf Gasbrand, d.h. progrediente Myonekrose/Myositis, besteht das Untersuchungsmaterial aus frisch vom marginalen Bezirk des progredienten Krankheitsprozesses entnommener Muskulatur. 
Der Transport des Untersuchungsmaterials ins Labor muss so schnell wie möglich und in für Anaerobier geeigneten Transportmedien erfolgen. Bei längerer Exposition gegenüber Luftsauerstoff und langen Transportzeiten sterben die Clostridien, v. a. Clostridium novyi, schnell ab und lassen sich kulturell nicht mehr nachweisen. Neben der Untersuchung von Gewebeproben ist der Erregernachweis in Blutkulturen diagnostisch wertvoll. Auch hier ist die richtige Entnahme der anaeroben Blutkultur (kein Zutritt von Luftsauerstoff) von großer Bedeutung.

Die kulturelle Bestätigung der Gattung Clostridium erfordert einen Zeitraum von 1-2 Tagen, die Speziesidentifizierung benötigt weitere 3-5 Tage mit konventionellen Methoden. Allerdings erlaubt die heute in vielen Laboren zur Verfügung stehende Massenspektrometrie die Clostridienidentifizierung in wenigen Minuten.

\section{- Therapie}

Blande Wundinfektionen bedürfen der üblichen chirurgischen Behandlung und - ggf. in Abhängigkeit von sonstigen aeroben und anaeroben Mischinfektionserregern - einer wirksamen antibakteriellen Chemotherapie.

D Cave

Der Erfolg einer Gasbrand- bzw. Myonekrosetherapie hängt vom frühen Beginn des chirurgischen Eingriffes ab. Die mögliche Applikation hyperbaren Sauerstoffs ( 3 bar) darf den chirurgischen Eingriff nicht verzögern.

Neben der chirurgischen Behandlung besitzt die antibakterielle Chemotherapie (20 Mio. IE Penicillin-G/Tag) einen hohen Stellenwert.

Chirurgisch wird das gesamte nekrotische Gewebe entfernt und durch Fasziotomie für eine zusätzliche Dekompression gesorgt. Alle Wunden bleiben offen. Frühzeitige Amputation vermindert das Risiko des Auftretens einer Allgemeinsymptomatik. Lokale Spülungen mit $\mathrm{H}_{2} \mathrm{O}_{2}$ (desinfizierend und $\mathrm{O}_{2}$-Entwicklung in der Wunde) werden durchgeführt. Der Einsatz der hyperbaren Sauerstofftherapie ist umstritten. Möglicherweise kann das Debridement bei zusätzlicher hyperbarer Sauerstoffbehandlung weniger verstümmelnd gehalten werden und die Letalität gesenkt werden.

Der therapeutische Effekt des polyvalenten Gasbrandantitoxins ist bei Clostridium-perfringens- und bei Clostridiumsepticum-Gasbrand als fraglich einzuschätzen. Da der Clostridium-novyi-Gasbrand durch schnell eintretende Toxinämie gekennzeichnet ist, wird hier die frühzeitige Antitoxingabe nach wie vor für obligatorisch gehalten. Zusätzliche therapeutische Maßnahmen müssen den Gefahren der Hyperkaliämie infolge Gewebenekrose, der Hämolyse und evtl. der Niereninsuffizienz Rechnung tragen.

\section{- Prophylaxe}

Das ubiquitäre Vorkommen (Darm, Erdboden) der Erreger erschwert die Prophylaxe von Gasbrandinfektionen. Hauptgrundlage der Prophylaxe ist neben obligater Asepsis und Antisepsis die frühzeitige chirurgische Wundbehandlung mit dem Ziel, den Clostridien kein Milieu zur Vermehrung und Toxinbildung zu bieten.

\section{In Kürze}

\section{Gasbrand}

Pathogenese: clostridiale Toxininfektion, obligat anaerob. Symptomatik: charakteristisches Bild, perakute Myonekrose. Unbehandelt tödlicher Verlauf.

Diagnostik: mikroskopischer Erregernachweis, Blutkulturen.

Therapie: Der Erfolg hängt vom frühen Beginn des chirurgischen Eingriffs ab. Penicillin, evtl. hyperbarer Sauerstoff.

\subsubsection{Tetanus}

\section{- Erreger}

Clostridium tetani, der Erreger des Tetanus (Wundstarrkrampf), kommt im Darm von Mensch und Tier sowie im Erdboden vor. Nach Schätzungen der Weltgesundheitsorganisation sterben jährlich Hunderttausende von Menschen, v. a. durch den in Entwicklungsländern häufigen Tetanus neonatorum ( $\rightarrow$ Nabelwunde), an dieser Krankheit. Infolge von Präventivmaßnahmen (Wundchirurgie, Immunprophylaxe) ist der Tetanus in den Industrieländern eine seltene Erkrankung geworden.

Es handelt sich um ein obligat anaerobes, relativ großes $(5 \mu \mathrm{m} \times 1 \mu \mathrm{m})$ grampositives Stäbchenbakterium, das beweglich ist und terminale Sporen bildet, wodurch die sporentragende Zelle eine sog. Trommelschlägerform erhält. Die Sporen gehören zu den widerstandsfähigsten biologischen Einheiten (die Überlebenszeit bei feuchter Hitze von $100^{\circ} \mathrm{C}$ - entspricht dem früher häufig durchgeführten Auskochen von Spritzen - beträgt bis $\mathrm{zu} 2 \mathrm{~h}$ ). Clostridium tetani bildet verschiedene Exotoxine, u. a. das Tetanospasmin, ein aus 2 Untereinheiten bestehendes Protein, das im ZNS Muskelkrämpfe bewirkt.

\section{- Pathogenese, Klinik}

Die ubiquitär vorkommenden Sporen von Clostridium tetani können potenziell in alle Wunden gelangen und dort in Nekrosebezirken oder bei gleichzeitigem Vorliegen von aeroben, sauerstoffzehrenden, anaerobioseerzeugenden Bakterien auskeimen und Tetanospasmin bilden. Von der Wunde aus gelangt das Tetanospasmin, v. a. durch retrograden axonalen Transport und nur z. T. auf dem Blutwege, ins ZNS zu den Vorderhörnern des Rückenmarks. Es kann sich in der gesamten grauen Substanz des Rückenmarks und im Hirnstamm anreichern (generalisierter Tetanus). Die Wirkung des Tetanospasmins beruht im Wesentlichen auf einer Blockade der Freisetzung inhibitorischer Transmittersubstanzen. In der Folge kommt es zur unkontrollierten Entladung der motorischen Neurone, was sich klinisch als Krämpfe äußert.

Nach einer Inkubationszeit von wenigen Tagen bis mehreren Wochen entsteht das charakteristische klinische Bild. 


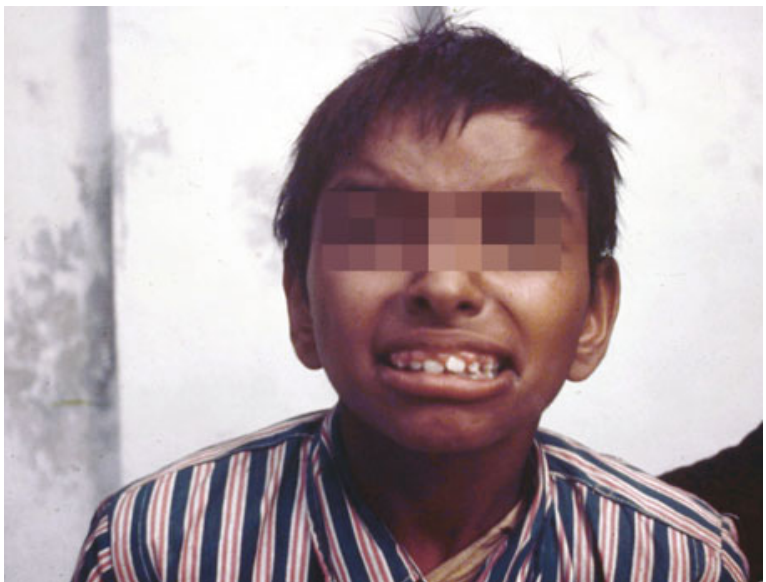

- Abb. 1.62 Trismus und Risus sardonicus (mit freundlicher Genehmigung von Prof. Dr. Disko, München)

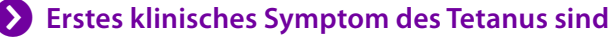
Spasmen in der Kau- und Gesichtsmuskulatur.

Es kommt zur Kiefersperre (Trismus) und zum Risus sardonicus (• Abb. 1.62).

Die Krämpfe können weitere Muskelgruppen des Körpers erfassen und bei voll ausgebildeter spastischer Paralyse durch das Überwiegen der Rückenstreckmuskulatur zum Opisthotonus führen (• Abb. 1.63).

Die Krämpfe, die bei erhaltenem Bewusstsein als quälend schmerzhaft erlebt werden, lassen sich über alle Sinnesmodalitäten auslösen (Berührung, Licht, Schall usw.), wobei die Reizschwelle sehr niedrig liegt. Bei schwerem Verlauf treten auch Spontankrämpfe auf. Der Tod tritt infolge Asphyxie durch Lähmung der Schlund- und Atemmuskulatur ein. Leichte lokalisierte Tetanusfälle zeigen lediglich Muskelstarre ohne Krämpfe.

$(7$ Unbehandelt führt der generalisierte Tetanus meist zum Tode. Das Überstehen des Tetanus lässt keine schützende Immunität zurück, d. h. Zweiterkrankungen sind möglich.

\section{- Diagnostik}

Bei Vorliegen typischer Zeichen kann die Diagnose zweifelsfrei klinisch gestellt werden. Ätiologisch hat die größte Bedeutung der Tetanospasminnachweis aus menschlichem Gewebe, in der Regel Wundexzidat. Blut ist als Untersuchungsmaterial weniger geeignet.

\section{Tetanospasminnachweis}

Zwei Mäusen wird Gewebematerial implantiert, ein Tier erhält Tetanusantitoxin. Im positiven Fall diffundiert Tetanospasmin aus dem Gewebematerial. Die hoch empfindliche, auf geringste Toxinmengen reagierende Maus entwickelt aszendierenden Tetanus. Das antitoxinbehandelte Tier bleibt erscheinungsfrei. Dadurch ist die Tetanospasminnatur des Toxins aus menschlichem Gewebe bewiesen.

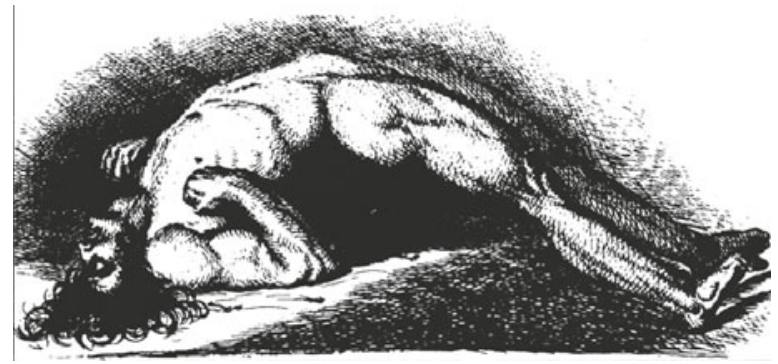

- Abb. 1.63 Generalisierter, die gesamte Skelettmuskulatur betreffender Tetanus mit charakteristischem Opisthotonus des Erkrankten, nach einer Zeichnung von C. Bell, 1832

Eine Erregerkultur ist ebenfalls möglich, allerdings gelingt die Anzucht der Bakterien nur selten.

\section{- Therapie}

Die großzügige Wundexzision schafft aerobe Verhältnisse, und die weitere Vermehrung des Erregers sowie die Toxinbildung werden gestoppt. Neben lokalen Desinfektionsmaßnahmen wird zusätzlich Penicillin-G systemisch appliziert. Bei Vorliegen einer begleitenden Mischinfektion muss die Antibiotikatherapie entsprechend erweitert werden. Die Gabe von humanem Antitoxin bindet im Blut zirkulierendes und in der Wunde vorhandenes Tetanospasmin, kann aber das schon im ZNS fixierte Tetanospasmin nicht mehr neutralisieren. Die symptomatische Behandlung der Krämpfe durch Muskelrelaxanzien sowie die künstliche Langzeitbeatmung in speziellen intensivmedizinischen Einrichtungen schaffen die Voraussetzungen für das Überleben des Patienten. Wichtig sind noch:

- aktive Immunisierung des Kranken mit Tetanustoxoid zum Aufbau einer Immunität,

- Bekämpfung einer bakteriellen Infektion der tiefen Atemwege (Beatmungspneumonie) durch Antibiotika.

8 Auch bei Einsatz modernster Behandlungsmethoden beträgt die Letalität noch $10-30 \%$.

\section{- Prophylaxe}

Durch das ubiquitäre Vorkommen der Sporen ist jede Wunde als potenziell mit Clostridium tetani kontaminiert zu betrachten. Daher ist die chirurgische Wundbehandlung - auch bei sog. Bagatellverletzungen - von großer Bedeutung zur Verhütung des Tetanus.

\section{$($ Die wichtigste Tetanusprophylaxe stellt die aktive Immunisierung dar.}

Der Effekt beruht auf der antitoxischen, d.h. toxinneutralisierenden Wirkung der vom Organismus rechtzeitig bereitgestellten Antikörper. Die aktive Immunisierung hat entscheidend zur Abnahme der Tetanusmorbidität und -mortalität beigetragen. Dies trifft auch für den Tetanus neonatorum zu: Die von der immunen Schwangeren - die aktive Immunisierung kann ggf. auch während der Schwangerschaft durchge- 
- Tab. 1.23 Tetanusprophylaxe im Verletzungsfall, nach Robert Koch-Institut, Epidemiologisches Bulletin 30, 2010

\begin{tabular}{|c|c|c|c|c|}
\hline \multirow{2}{*}{$\begin{array}{l}\text { Vorgeschichte der Tetanus- } \\
\text { impfung (Anzahl der Impfungen) }\end{array}$} & \multicolumn{2}{|c|}{ Saubere, geringfügige Wunden } & \multicolumn{2}{|c|}{ Alle anderen Wunden ${ }^{a}$} \\
\hline & DTaP/Tdap ${ }^{b}$ & TIGc & DTaP/Tdap ${ }^{b}$ & TIGc \\
\hline Unbekannt & $\mathrm{Ja}$ & Nein & $\mathrm{Ja}$ & $\mathrm{Ja}$ \\
\hline $0-1$ & Ja & Nein & Ja & Ja \\
\hline 2 & $\mathrm{Ja}$ & Nein & $\mathrm{Ja}$ & Nein ${ }^{d}$ \\
\hline 3 und mehr & Nein & Nein & Nein $^{f}$ & Nein \\
\hline \multicolumn{5}{|c|}{$\begin{array}{l}\text { Tiefe und/oder verschmutzte (mit Staub, Erde, Speichel, Stuhl kontaminierte) Wunden, Verletzungen mit Gewebszertrümmerung } \\
\text { und reduzierter Sauerstoffversorgung sowie Eindringen von Fremdkörpern (z. B. Quetsch-, Riss-, Biss-, Stich-, Schusswunden), schwe- } \\
\text { re Verbrennungen und Erfrierungen, Gewebenekrosen, septische Aborte }\end{array}$} \\
\hline \multicolumn{5}{|c|}{$\begin{array}{l}\text { b Kinder unter } 6 \text { Jahren erhalten einen Kombinationsimpfstoff DTaP (Diphterie-, Tetanus-, azellulärer Pertussis-Impfstoff), ältere Kinder } \\
\text { Tdap (d. h. Tetanus-Diphtherie-Impfstoff mit verringertem Diphtherietoxoid-Gehalt und verringerter azellulärer Pertussis-Komponen- } \\
\text { te). Erwachsene erhalten ebenfalls Tdap, wenn sie noch keine Tdap-Impfung im Erwachsenenalter ( } \geq 18 \text { Jahre) erhalten haben oder } \\
\text { sofern eine aktuelle Indikation für eine Pertussis-Impfung besteht }\end{array}$} \\
\hline \multicolumn{5}{|c|}{$\begin{array}{l}\text { c TIG = Tetanus-Immunglobulin, im Allgemeinen werden } 250 \text { IE verabreicht, die Dosis kann auf } 500 \text { IE erhöht werden. TIG wird simul- } \\
\text { tan mit DTaP/Tdap-Impfstoff angewendet }\end{array}$} \\
\hline \multicolumn{5}{|c|}{ d Ja, wenn die Verletzung länger als $24 \mathrm{~h}$ zurückliegt } \\
\hline \multicolumn{5}{|c|}{ e Ja (1 Dosis), wenn seit der letzten Impfung mehr als 10 Jahre vergangen sind } \\
\hline \multicolumn{5}{|c|}{ f Ja (1 Dosis), wenn seit der letzten Impfung mehr als 5 Jahre vergangen sind } \\
\hline
\end{tabular}

führt werden - gebildeten plazentagängigen IgG-Antikörper verleihen dem Neugeborenen einen mehrwöchigen Schutz bis zum Aufbau einer eigenen (Impf-) Immunität.

\section{Praxisbox \\ Tetanus-Immunisierung \\ Die Tetanus-Immunität wird üblicherweise durch die im 2. Lebensmonat begonnene Grundimmunisierung, be- stehend aus 3 Einzelinjektionen Tetanustoxoid im Mindest- abstand von 4 Wochen sowie einer 4. Injektion im Alter von 11-14 Monaten, erreicht. Der Impfschutz stellt sich hierbei ca. 1 Woche nach der 2. Injektion ein. Durch Auf- frischimpfungen im 1. und 2. Lebensjahrzehnt entsteht eine langjährige Immunität. Danach werden Auffrisch- impfungen in 10-jährigen Abständen empfohlen. Eine Grundimmunisierung ist in jedem Lebensalter möglich - und nötig, falls kein entsprechender Schutz besteht (Ro- bert Koch-Institut Epidemiologisches Bulletin 30, 2010).}

Im Falle einer Verletzung ist ein differenziertes Vorgehen bei der Tetanusimmunprophylaxe erforderlich, die aufgrund der häufig unzureichenden Immunität gegen Diphtherie mit einer entsprechenden Immunisierung verbunden werden sollte (- Tab. 1.23).

( Besonders wichtig ist die im Verletzungsfall ggf. durchzuführende Simultanimpfung, d.h. die gleichzeitige Applikation von humanem Tetanus-Immunglobulin (Antikörper zum Sofortschutz) und - an anderer Körperstelle - von Tetanustoxoid (Aufbau einer aktiven Immunität zum zukünftigen Schutz).
Bis zum Eintreten des Tetanusschutzes durch die neu aufgebaute aktive Immunität vergeht allerdings ein Zeitraum von mehreren Wochen. Dieses Intervall wird durch die im Rahmen der Simultanimpfung applizierten Immunglobuline überbrückt, deren Serumspiegel durch Metabolisierung über Wochen hinweg zwar kontinuierlich abfällt, jedoch während der kritischen Aufbauphase der aktiven Immunität ausreichend antitoxisch wirksam bleibt.

\section{Fallbeispiel}

Ein 53-jähriger Diabetiker schnitt sich bei der Gartenarbeit mit der Rosenschere durch den Handschuh in das Grundglied des linken Zeige- und Mittelfingers. Da die Wunde kaum schmerzte und nur wenig Blut austrat, säuberte er sie erst nach Beendigung der Gartenarbeit mit Leitungswasser und Seife. In den nächsten 2 Tagen entwickelte sich im Wundbereich eine leichte Schwellung und ein Hämatom: Wegen der geringfügigen, nicht konstanten Schmerzen wurde kein Arzt konsultiert. Nach weiteren 4 Tagen bemerkte der Patient plötzlich auftretende »Anspannungen« und Schmerzen im Kieferwinkel mit intermittierender Kiefersperre. Beim nun erfolgten Arztbesuch zeigte sich eine mäßig gereizte, z. T. geschlossene Schnittwunde. Der Wundbereich war nahezu schmerzfrei. Dagegen wurde die Palpation der Kau- und Gesichtsmuskulatur als äußerst unangenehm empfunden. Zum Stand seiner Tetanusimmunisierung konnte der Patient keine Angaben machen. 


\section{Weiteres Vorgehen:}

A. Kurze Inspektion der Wunde und gegebenenfalls Säuberung wegen eines Verdachts auf Wundinfektion.

B. Hyperbare Sauerstofftherapie wegen der Möglichkeit eines Gasbrandes.

C. Chirurgische Wundbehandlung und Tetanussimultanimpfung.

Antwort: Trotz sofortiger chirurgischer Wundbehandlung und Tetanussimultanimpfung entwickelte sich binnen $48 \mathrm{~h}$ eine schwere Tetanussymptomatik, die eine 8-tägige intensivmedizinische Behandlung (komplette Muskelrelaxation, Beatmung, tiefe Sedierung u. a.) erforderlich machte. Erst eine weitere 3-wöchige Nachbehandlung erlaubte es dem Patienten schließlich, sein gewohntes Leben wieder aufzunehmen.

\section{In Kürze}

\section{Tetanus (Wundstarrkrampf)}

Clostridium tetani, obligat anaerob, ubiquitär. In Entwicklungsländern häufig Tetanus neonatorum.

Symptomatik: Trismus, Risus sardonicus, Opisthotonus, Spontankrämpfe bis Atemlähmung.

Diagnostik: klinisch, Tetanospasminnachweis.

Therapie: großzügige Wundexzision, Penicillin, humanes Antitoxin.

Prophylaxe: aktive Immunisierung, Grundimmunisierung und Auffrischung nach 10 Jahren. Die ubiquitäre Tetanusbedrohung von Wunden und Verletzungen jeder Art wird durch die chirurgische Wundversorgung plus spezifische Immunprophylaxe minimiert.

\subsubsection{Aktinomykose}

\footnotetext{
Definition

Die Aktinomykose kommt mit Ausnahme der Inokulation über menschliche Bisse endogen (die Erreger existieren als Saprophyten vorwiegend in der Mundhöhle und im Darm) zustande, z. B. nach Verletzungen (Zahnextraktion) oder in Folge von Durchblutungsstörungen.
}

Nach Sitz und Verlauf werden die zervikofaziale und die seltener vorkommenden thorakale (meist nach Aspiration erregerhaltigen Materials aus der Mundhöhle) und intestinale Form unterschieden.

\section{- Pathogenese, Klinik}

Pathologisch-anatomisch ist die Aktinomykose durch chronisch-destruktive Abszesse sowie durch spezifische Granulome charakterisiert. Typisch sind indurierte, von fibrösem Wall umgebene Massen mit eitrigem Zentrum. Diese Eiterherde können konfluieren und Fisteln bilden. Aus diesen ent- leert sich im typischen Fall Eiter mit stecknadelkopfgroßen gelben Granula, sog. Drusen. Die Drusen bestehen aus Ballen von fadenförmigen verzweigten Bakterien, die wallförmig von Leukozyten umgeben sind.

\section{$>$ Fisteln und Drusen gelten als pathognomonisch für} die Aktinomykose.

Unbehandelt verläuft diese Erkrankung chronisch-progredient, wobei sie sich über Organgrenzen hinweg in benachbartes Gewebe ausbreitet. Durch Einbruch in lebenswichtige Organstrukturen sowie durch (seltene) hämatogene Streuung kann die Aktinomykose zum Tode führen.

\section{- Erreger}

Als Erreger der menschlichen Aktinomykosen, die zusammenfassend als Aktinomyzeten bezeichnet werden, findet man v. a. Bakterien der Gattung Actinomyces (am häufigsten Actinomyces israelii, seltener A. gerenscreriae), sowie seltener andere fadenförmig und verzweigt wachsende grampositive Stäbchenbakterien. Aktinomyzeten bilden keine Exotoxine oder andere toxische Substanzen. Zur Etablierung der Infektion ist einerseits die Zerstörung der mukosalen Barriere (z. B. durch chirurgische Eingriffe) als auch Begleitflora (Streptococcus species, Staphylococcus aureus; Aggregatibacter, früher Actinobacillus actinomycetemcomitans; Anaerobier der Gattung Prevotella u. a.) von Bedeutung.

\section{$>$ Echte Aktinomykosen sind nahezu immer misch-} infiziert.

Die Begleitflora begünstigt einerseits durch Verbrauch von Sauerstoff anaerobe Verhältnisse, andererseits bahnt sie durch eigene Virulenzfaktoren die Ausbreitung der Aktinomyzeten.

\section{- Diagnostik}

Bei mikroskopischem Nachweis sich verzweigender, fadenförmiger grampositiver Bakterien in Eiter/Exsudaten und Gewebeproben werden Kulturen angelegt und unter anaeroben Bedingungen sowie parallel in einer $\mathrm{CO}_{2}$-angereicherten Atmosphäre bebrütet. Aufgrund der langen Generationszeit kann die Erregeridentifizierung und Empfindlichkeitsprüfung 14 Tage oder mehr erfordern.

\section{- Therapie}

\section{Am wirksamsten erweisen sich chirurgische Maßnahmen in Kombination mit antibakterieller Chemotherapie.}

Aktinomyzeten sind gegen Penicillin-G und vergleichbare Antibiotika gut empfindlich. Jedoch versagt die klassische Penicillin-G-Therapie häufig, vermutlich in Folge der $\beta$-Laktamaseaktivität bestimmter Begleitbakterien. Deshalb kommen in erster Linie $\beta$-Laktamase-geschützte Penicilline bzw. $\beta$ Laktamase-feste Cephalosporine zur Anwendung. Die eingehende bakteriologische Untersuchung unter Einschluss der aeroben und anaeroben Begleitbakterien mit Erstellung spezifischer Antibiogramme ermöglicht schließlich das »Umstellen« der kalkulierten Chemotherapie auf eine die jeweils ätio- 
logisch bedeutsamen Erreger erfassenden antibiotischen Behandlung.

\section{In Kürze}

\section{Aktinomykose}

Pathogenese: meist endogene Infektion, Aktinomyzeten u. a.

Symptomatik: Abszesse, Fisteln, Drusen; chronisch-progredient.

Diagnostik: mikroskopischer Nachweis, Kultur.

Therapie: chirurgische Maßnahmen mit antibakterieller Chemotherapie.

\subsubsection{Tuberkulose}

\section{- Epidemiologie}

Die Tuberkulose ging nach dem Ende des Zweiten Weltkrieges in den Industrieländern durch Verbesserung der Lebensumstände und durch Entwicklung antituberkulotisch wirksamer Chemotherapeutika stark zurück. Bedingt durch die weiter ungebremste Ausbreitung von HIV in den Entwicklungsländern als auch durch die sozialen und wirtschaftlichen Umwälzungen in diesen Ländern und insbesondere in den Staaten der ehemaligen Sowjetunion steigen die Krankheitszahlen in den letzten Jahren wieder (in Deutschland sind die Erkrankungszahlen allerdings rückläufig). Die bei HIV-Infizierten reduzierte T-Zellimmunität ermöglicht $u$. a. die Exazerbation alter tuberkulöser Herde, da Mykobakterien als intraphagozytäre Krankheitserreger nur durch die zellvermittelte Immunität kontrolliert werden können und die »Ausheilung « einer Tuberkulose meist nur durch den Einschluss persistierender Erreger in Granulomen (Tuberkulomen) möglich ist.
- - Pathogenese

Mykobakterien, schlanke stäbchenförmige Bakterien, zeichnen sich v. a. durch den hohen Lipid- und Wachsgehalt ihrer Zellwand aus, der für viele typische Eigenschaften dieser Bakterien verantwortlich ist, $u$. a. für die Fähigkeit innerhalb von Makrophagen zu überleben oder für die enorme Resistenz gegen Umwelteinflüsse sowie gegen Laugen und Säuren.

\section{$>$ Bedingt durch den meist aerogenen Infektionsweg (Tröpfcheninfektion) ist bei der Tuberkulose am häufigsten die Lunge betroffen.}

Je nach Zahl der eingedrungenen Erreger und der Immunitätslage des Wirtsorganismus wird dieses Organ in unterschiedlichem Ausmaß befallen. Neben den typischen Granulomen, die später meist verkalken (auch Hiluslymphknoten), kann es bei schlechter Immunitätslage zur lymphogenen/hämatogenen Streuung (Miliartuberkulose) kommen oder es können ausgedehnte Nekrosebezirke mit Kavernenbildung entstehen (• Abb. 1.64, • Abb. 1.65).

Bei sekundärer hämatogener Aussaat der Erreger ist Befall prinzipiell aller Organe möglich (Meningitis tuberculosa; Skeletttuberkulose, Urogenitaltuberkulose, Tuberkulose peripherer Lymphknoten u. a.). Die früher häufige Darmtuberkulose, die durch die Aufnahme erregerhaltiger (Mycobacterium bovis) Milch tuberkulosekranker Kühe erworben wurde, ist nach Einführung der Pasteurisierung der Milch und der Sanierung der Rinderbestände in den Industrieländern praktisch verschwunden.

\section{- Diagnostik}

Die Diagnostik der Tuberkulose stützt sich neben klinischen Befunden (Tuberkulin-Hauttest, TB-spezifische Interferon- $\gamma$ Release Teste, Thoraxröntgen $u$. a.) in erster Linie auf den Nachweis der Erreger - in Westeuropa fast ausnahmslos Mycobacterium tuberculosis. Mycobacterium africanum wird vor-

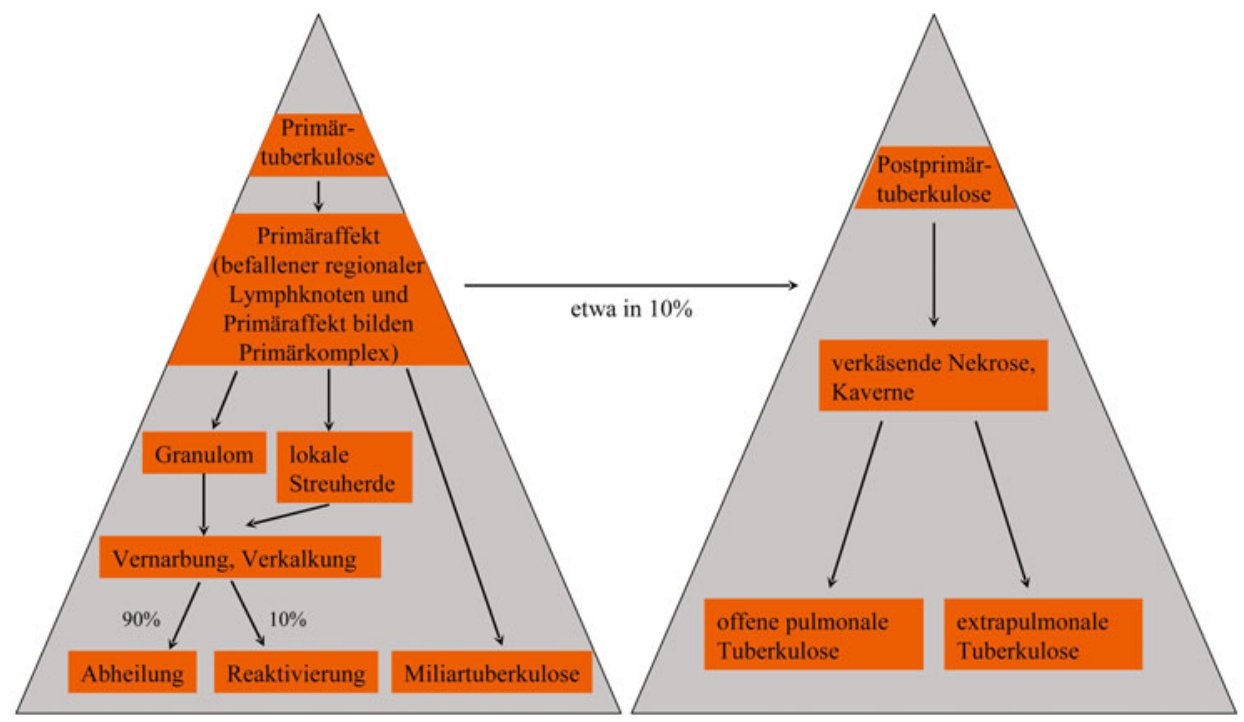

- Abb. 1.64 Stadien der Tuberkulose 

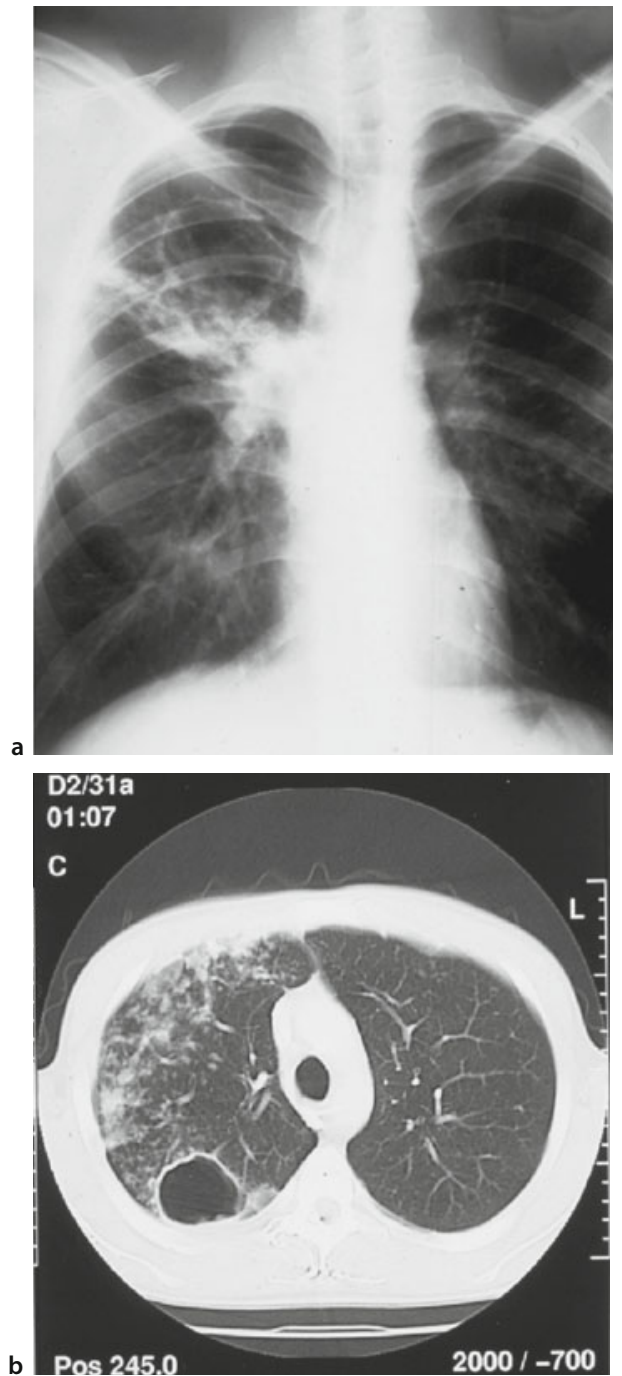

- Abb. 1.65a,b Tuberkulose mit Kavernenbildung, mit freundlicher Genehmigung von Prof. Dr. Disko, München

wiegend in Westafrika gefunden, Mycobacterium bovis in Entwicklungsländern mit infizierten Rindern. Bei der Lungentuberkulose werden zum Erregernachweis morgendliches Sputum, Bronchiallavage und Nüchternmagensaft eingesetzt, bei Befall anderer Organe entsprechende Gewebeproben. Das mikroskopische Präparat auf säurefeste Stäbchen (ZiehlNeelsen-Färbung), das innerhalb von 30 min erste Hinweise liefern kann, ermöglicht allerdings keine Speziesidentifizierung (•Abb. 1.66).

C Cave

Ein negativer mikroskopischer Befund schließt (wegen der geringen Sensitivität der Methode) die Tuberkulose nicht aus. Die Speziesidentifizierung, die bei der üblichen kulturellen Anzucht der Bakterien nach 2-8 Wochen vorliegt, darf zur Einleitung einer Therapie nicht abgewartet werden.

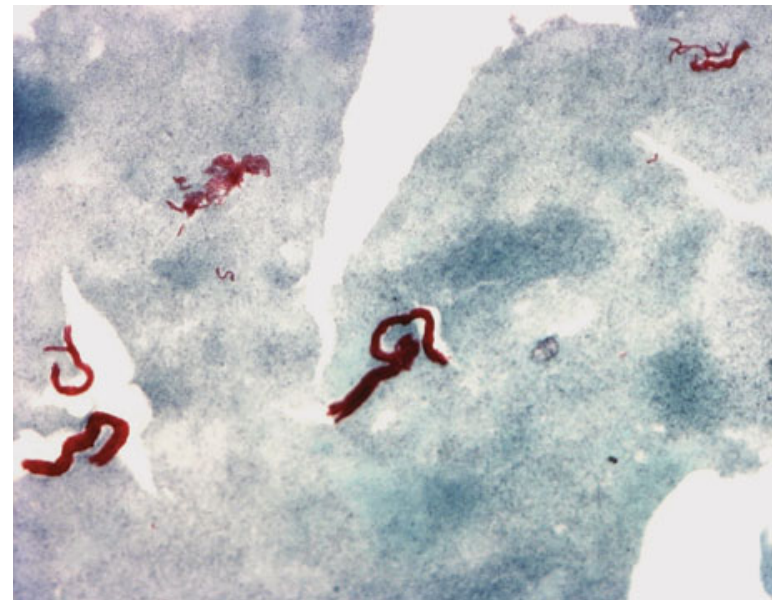

- Abb. 1.66 Säurefeste Stäbchen

Die Erregeranzucht, die auch heute als Goldstandard für den Erregernachweis gilt, wurde mit Einführung von Flüssigkulturen (Bactec) wesentlich beschleunigt. Die bisher übliche biochemische Identifikation der Erreger wird immer häufiger mit molekularbiologischen Methoden durchgeführt, z. B. mithilfe von sog. Gensonden, die spezifisch mit Nukleinsäuren von Mykobakterien hybridisieren und dadurch den Nachweis der verschiedenen Mykobakterien erlauben. Ein anderes Verfahren ist die PCR, die auch ohne Anzucht der Erreger diese in verschiedenen klinischen Materialien schnell nachweist. Eine Resistenztestung setzt in Kultur vermehrte Erreger voraus und erfordert einen Zeitaufwand von bis zu mehreren Wochen.

\section{- - Therapie}

Die Behandlung der Tuberkulose erfolgt durch Gabe antimykobakterieller Chemotherapeutika.

(C) Cave

Bei der langen Behandlungsdauer (mindestens ein halbes Jahr) ist zur Verhinderung der Selektion resistenter Mutanten sowie zur Minimierung von Rezidiven eine Kombinationstherapie unerlässlich.

Meist wird eine Dreier-/Viererkombination der Antituberkulotika Rifampicin, Isoniazid, Ethambutol, Pyrazinamid und Streptomycin eingesetzt. Leider werden weltweit multiresistente Isolate (d.h. gleichzeitige Rifampicin- und Isoniazidresistenz) sowie »extended drug resistant (XDR) « Mycobacterium-tuberculosis-Stämme (diese sind zusätzlich gegenüber weiteren wirksamen Antibiotika resistent) immer häufiger nachgewiesen, eine Entwicklung, die mit großer Aufmerksamkeit verfolgt wird.

$(8$ Eine operative Behandlung, die nur zusammen mit einer antimykobakteriellen Chemotherapie durchgeführt wird, hat lediglich bei medikamentös alleine nicht beherrschbaren Krankheitsprozessen eine Indikation. Dies kann v. a. befallene Knochen und Gelenke sowie Lungenkavernen betreffen. 


\section{In Kürze}

\section{Tuberkulose}

Pathogenese: Mykobakterien (in Westeuropa Mycobacterium tuberculosis), Tröpfcheninfektion (Lunge), sekundäre hämatogene Aussaat.

Symptomatik: Lunge (Granulome, Miliartuberkulose), Hiluslymphknoten und verschiedene Organe.

Diagnostik: klinisch, Röntgen, Erregernachweis (ZielNeelsen-Färbung. säurefeste Stäbchen).

Therapie: Antituberkulotikakombination, evtl. zusätzliche chirurgische Maßnahmen.

\subsubsection{Syphilis}

\section{- . Klinik}

Die Syphilis hat für den Chirurgen im Wesentlichen differenzialdiagnostische Bedeutung. Die hierfür wichtigen Organveränderungen manifestieren sich im Tertiärstadium dieser Infektionskrankheit nach jahre- bis jahrzehntelangem nicht oder nur ungenügend therapiertem Krankheitsverlauf.

Von besonderem Interesse ist die Mesaortitis luica, die zur Ausbildung eines Aortenaneurysmas führen kann. Betroffen ist in erster Linie die Aorta ascendens, seltener die anderen Abschnitte der Aorta. Bei Befall der Aortenklappe kann sich eine Aorteninsuffizienz entwickeln, bei Übergreifen des Entzündungsprozesses auf die Abgänge der Koronararterien eine Koronarinsuffizienz.

Weitere chirurgisch wichtige Manifestationsformen stellen die potenziell in allen Organen auftretenden Granulome (Gumma) dar, die meist zu ausgedehnten Organzerstörungen Anlass geben. Knochenbefall kann zu Deformitäten und Spontanfrakturen führen, Gelenkaffektionen sind durch chronische Ergüsse und Schwellungen charakterisiert. An der Haut kann es durch Aufbrechen der Granulome zu Geschwüren kommen.

\section{( Ausbildung von Gummen in inneren Organen} (z. B. Leber) wirft stets das Problem der differenzialdiagnostischen Abgrenzung gegen Tumore/ Metastasen auf.

\section{- Diagnostik}

Die Diagnose der Syphilis erfolgt serologisch, d.h. durch den Nachweis von Antikörpern gegen das Bakterium Treponema pallidum, den Erreger der Syphilis. Zur Anwendung kommen der TPPA (Treponema-pallidum-Partikelagglutinationstest) als sog. Suchtest, sowie - bei positivem Ausfall des TPPA - der FTA-Abs-Test («fluorescent treponemal antibody absorption test«) zur Bestätigung der Antikörperspezifität gegen Treponema pallidum und damit zur Sicherung der Diagnose. Weitere serologische Parameter dienen der Unterscheidung zwischen aktiver und inaktiver Syphilis: Bei aktiver Syphilis gelingt der Nachweis von 19S-IgM-Antikörpern und von hochtitrigen (unspezifischen) Kardiolipinantikörpern.

\section{- Therapie}

Behandelt wird die Syphilis durch Gabe von Penicillin-G. Bei Penicillinallergie werden Cephalosporine, Tetrazykline und Erythromycin verwendet.

$\checkmark$ Eine Therapie ist nur bei aktivem Krankheitsprozess erforderlich - die inaktive Syphilis wird nicht behandelt.

Der Therapieerfolg wird anhand serologischer Aktivitätsparameter beurteilt: Bei erfolgreicher Therapie kommt es zu einem deutlichen Titerabfall der Kardiolipinantikörper und der 19SIgM-Antikörper.

\section{In Kürze}

Syphilis

Symptomatik: Organveränderungen im Tertiärstadium, Mesaortitis luica, Granulome (Gummen).

Diagnostik: serologisch (TPPA, FTA-Abs-Test), Differenzialdiagnose zu Tumoren/Metastasen.

Therapie: Penicillin.

\subsubsection{Sonstige bakterielle Infektionen}

\section{Grundlagen Lokale Infektion}

Bakterielle Infektionen mit Eiterbildung können lokalisiert als Abszess (• Abb. 1.67), Phlegmone oder Empyem verlaufen. Das jeweilige Erscheinungsbild hängt vom Erreger, dem befallenen Organ sowie der Abwehrleistung des Organismus ab.

\section{Definition}

Bei einem Abszess handelt es sich um eine eitrige Gewebeeinschmelzung, die von den umgebenden Organstrukturen durch eine Membran abgegrenzt ist.

Ein typischer Abszesserreger ist Staphylococcus aureus, der z. B. mittels seines Exotoxins Plasmakoagulase Fibrinpolymere erzeugen und damit eine Membran induzieren kann. Abszesse bilden sich häufig unter Beteiligung der lokalen Bakterienflora, z. B. als Schweißdrüsenabszess, Schwielenabszess, periproktitischer Abszess. Sie können aber auch durch exogen eingedrungene Krankheitserreger und auf hämatogenem Weg in inneren Organen entstehen.

\section{- Definition \\ Als Phlegmone wird eine nicht abgegrenzte, sich diffus ausbreitende eitrige Entzündung bezeichnet.}

Typische - aber nicht alleinige - Erreger sind $\beta$-hämolysierende Streptokokken, deren gewebedestruierende Exotoxine die Voraussetzung zur Ausbreitung in den befallenen Organen schaffen. Phlegmonöse Entzündungen können dramatisch 


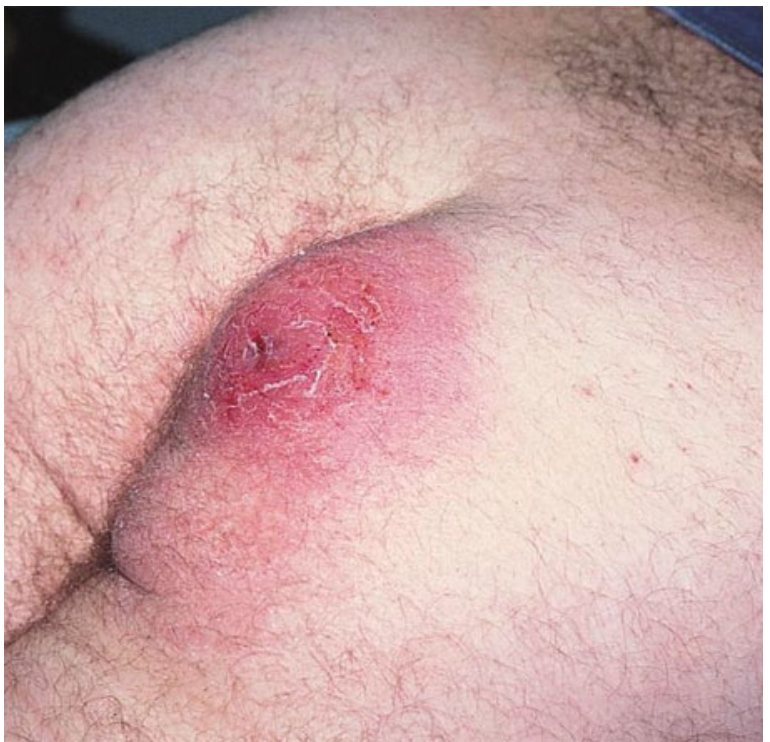

- Abb. 1.67 Abszess der Glutealregion

verlaufen, z. B. als Hohlhandphlegmone, bei der die Entzündung sehr schnell die Beugesehnenscheiden befallen und sich so rasch eine Unterarmphlegmone entwickeln kann. Definition
Ein Empyem ist eine Eiteransammlung in natürlichen
präformierten Körperhöhlen.

Derartige Entzündungen können z. B. als Pleura-, Gallenblasen- oder Gelenkempyem verlaufen. Die Erreger gelangen auf dem Blut- und Lymphweg, kanalikulär oder auch direkt fortgeleitet in diese Organstrukturen. Häufig liegen bakterielle Mischinfektionen (Aerobier/Anaerobier) vor.

\section{- Symptomatik}

Die Symptomatik wird v. a. durch die klassischen Entzündungszeichen sowie ggf. durch Allgemeinreaktionen geprägt.

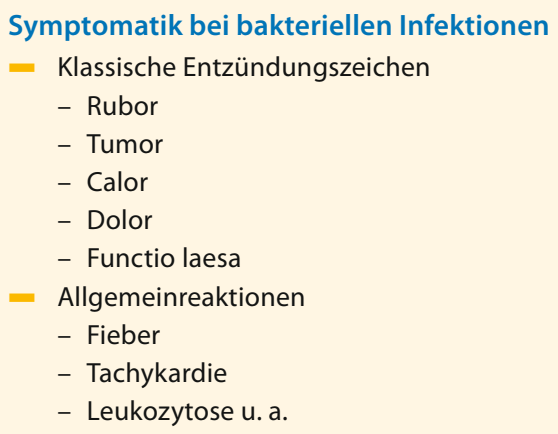

- Therapie

( Therapeutisch kommen in erster Linie chirurgische Maßnahmen (Inzision, Eiterdrainage u. a.) entsprechend der Regel »ubi pus, ibi evacua« zur Anwendung.

Eine zusätzliche antibiotische Behandlung ist meist nur bei tiefen, ausgedehnten Prozessen und bei Komplikationen erforderlich. Die Indikation zur ausschließlichen antibiotischen Behandlung ist auf wenige Krankheitsbilder beschränkt.

\section{Ausbreitung der Infektion}

Nach Einbruch der Erreger in Lymphgefäße entwickelt sich eine Lymphangitis (rote Streifen in der Haut) und eine regionäre Lymphadenitis (geschwollene, schmerzhafte Lymphknoten). Bei weiterer lymphogener Fortleitung gelangen die Erreger in die Blutbahn, die auch durch direkte Invasion der Blutgefäße erreichbar ist. Mit dem Blut können die Erreger schließlich im gesamten Organismus »ausgestreut « werden.

\section{Allgemeininfektion, Sepsis \\ - - Pathogenese}

In den Blutkreislauf gelangte Bakterien und Pilze können bei guter Abwehrlage des Organismus und bei geringer Zahl und Virulenz der Erreger symptomlos eliminiert werden - Bakteriämie, Fungämie. Bei schlechter Abwehrlage jedoch und/ oder hoher Zahl und Virulenz der Erreger kann sich daraus eine Sepsis (septische Allgemeininfektion) entwickeln.

Definition

Bei der Sepsis handelt es sich um ein akutes, mit hoher Letalität einhergehendes Krankheitsbild, das durch in den Blutkreislauf gelangte Mikroorganismen und klassischen Entzündungszeichen evtl. deren metastatischer Absiedlung bzw. deren Bestandteile und Toxine hervorgerufen wird.

Bei gleichzeitigem Versagen des Kreislaufs liegt ein septischer Schock vor.

Verursacht werden die Symptome der Sepsis durch die aus verschiedensten Körperzellen, u. a. aus Makrophagen, freigesetzten Zytokine. Dies geschieht im Wesentlichen unter der Einwirkung bakterieller Substanzen wie Endotoxin von gramnegativen Bakterien, Peptidoglykan, oder Exotoxine mit Superantigenwirkung, z. B. dem Toxic-shock-Toxin von Staphylococcus aureus. Im Rahmen einer Sepsis können sich die Erreger auch in einzelne Organe absiedeln und eitrige Entzündungen, oftmals in Form von Abszessen (metastatische Abszesse), auslösen.

Häufigster Sepsiserreger

- im gramnegativen Bereich ist Escherichia coli,

- im grampositiven Bereich Staphylococcus aureus,

- unter den obligat anaeroben Bakterien Bacteroides fragilis,

- bei den Pilzen Candida albicans. 
- - Symptomatik

Klinisch ist die Sepsis durch hohes Fieber, Leukozytose, aber auch Leuko- und Thrombopenie gekennzeichnet.

D Cave

Unbehandelt versterben die Patienten meist inner-

halb kurzer Zeit im Multiorganversagen - Herz-,

Kreislauf-, Lungen-, Nierenversagen, Koma, disseminierte intravasale Blutgerinnung (DIC) u. a.

\section{- Diagnostik}

Zur Diagnostik werden mehrfach (mindestens 3) - am aussichtsreichsten in der Phase des Fieberanstieges - aerobe/anaerobe Blutkulturen zum Erregernachweis entnommen.

\section{- Therapie}

Zur Anwendung kommen primär bakterizide Substanzen (in Kombination), die gegen ein breites Erregerspektrum wirksam sind, im Allgemeinen $\beta$-Laktame in Kombination mit einem $\beta$-Laktamasehemmer, Aminoglykoside, Gyrasehemmer oder Carbapeneme. Nach Vorlage des Antibiogrammes wird die Chemotherapie ggf. umgestellt. Bei Verdacht auf eine Pilzsepsis werden Antimykotika, u. a. Azole wie Flucoanzol, Itraconazol, Voriconazol, Posaconazol oder Echinocandine wie Caspofungin, Micafungin, Anidulafungin und das Polyen Amphotericin B eingesetzt.

$>$ Die antibiotische Therapie der Sepsis muss sofort nach Probennahme eingeleitet werden. Die chirurgische Behandlung/Beseitigung des Sepsisherdes ist von größter Wichtigkeit.

Als Sepsisherd fungieren nicht nur lokale Infektionen, sondern eine Sepsis kann auch von primär mit Bakterien bzw. mit Pilzen besiedelten Regionen des Organismus (z. B. vom Darm, bei Ileus) ihren Ausgang nehmen. Intensivmedizinische Maßnahmen zur Stützung der Organfunktionen sind entsprechend den aktuellen Erfordernissen durchzuführen.

\section{Follikulitis, Furunkel, Karbunkel \\ - Definition}

Alteration der Haut, Sekretstau in den Ausführungsgängen der Talgdrüsen, Abwehrschwäche (v. a. bei Diabetes mellitus) begünstigen die Entstehung von eitrigen Entzündungen des Haarbalges und der Talgdrüsen. Der verantwortliche Erreger ist fast immer Staphylococcus aureus.

\section{Definition}

Bleibt die Infektion auf die Haarstrukturen beschränkt, liegt eine Follikulitis vor.

Bei Ausbreitung in das angrenzende Gewebe der Haut bildet sich um den Haarbalg herum ein wenige Millimeter durchmessender Abszess, ein Furunkel.

Prädilektionsstellen hierfür sind Nacken, Gesicht, Extremitäten und Gesäß.
Definition

Durch Konfluieren mehrerer benachbarter Furunkel entsteht v. a. am Nacken, Rücken und Gesäß eine mehrere Zentimeter große Hautnekrose, ein Karbunkel.

\section{- Symptomatik}

Furunkel und Karbunkel äußern sich lokal durch Rötung, Schwellung und erhebliche Schmerzen. Das Allgemeinbefinden kann beeinträchtigt sein (u. a. Fieber) und es besteht, v. a. beim Karbunkel, die Gefahr der Entwicklung einer Sepsis.

\section{- Therapie}

Die Behandlung besteht - je nach klinischem Bild - in lokal desinfizierenden Maßnahmen, Ruhigstellung, Abszessspaltung. Antibiotika kommen lediglich bei Komplikationen zum Einsatz.

D Cave

Ein Gesichtsfurunkel wird stets konservativ therapiert. Sämtliche Manipulationen können hier zur Erregerverschleppung in die Hirnsinus (Gesichtsvenen $\rightarrow$ Venen der Augenhöhle $\rightarrow$ Sinus cavernosus) mit septischer Thrombose und Meningitis führen.

Die Therapie eines Gesichtsfurunkels umfasst: Gabe eines penicillinasefesten $\beta$-Laktams (z. B. Cefazolin, Flucloxacillin), Bettruhe, Sprech- und Kauverbot, Flüssignahrung.

\section{Panaritium, Paronychie}

\section{- Definition}

Als Panaritien bezeichnet man eitrige Infektionen der Beugeseiten von Finger und Zehen sowie des Nagelbettes, als Paronychie (Umlauf) Eiterprozesse am Nagelwall.

\section{- Pathogenese}

Die Erreger, in den meisten Fällen Staphylococcus aureus, seltener $\beta$-hämolysierende Streptokokken und andere Bakterien, dringen über Verletzungen, Fremdkörper in die Haut ein und verursachen primär lokalisierte Eiterungen (• Abb. 1.68).

Im weichen Gewebe ist die Tendenz zur Ausbreitung jedoch groß und bei Erreichen vorgegebener »Schienen « (z. B. Sehnenscheiden) entwickeln sich rasch fortschreitende phlegmonöse Entzündungen. Bei Einbruch in Lymph- und Blutgefäße kann eine Sepsis entstehen. Je nach Verletzung bzw. Ausbreitung im Gewebe sind unterschiedliche Strukturen betroffen: Panaritium cutaneum, P. subcutaneum, P. tendinosum, P. ossale, P. articulare, P. subunguale u. a.

\section{- Symptomatik}

Die Symptomatik besteht hauptsächlich in heftigen, pochenden Schmerzen. Rötung und Schwellung können gering ausgeprägt sein, z. T. nur kontralateral (Handrückenödem bei volaren Abszessen). 


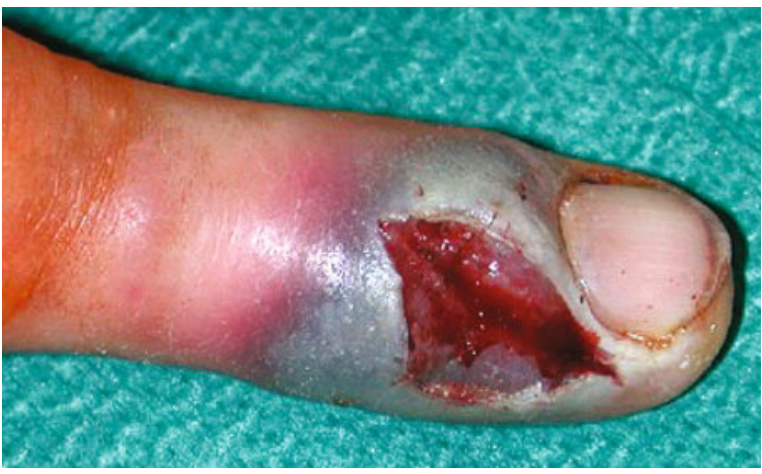

- Abb. 1.68 Panaritium nach Infektion mit S. aureus nach Tierbiss, mit freundlicher Genehmigung von Dr. Werber, München

\section{- Therapie \\ $>$ Therapeutisch muss sofort inzidiert und für Eiter- ableitung gesorgt werden.}

Eine zusätzliche antibiotische Behandlung erfolgt bei tiefen Panaritien und bei Komplikationen - primär mit Fusidinsäure (lokal) bzw. staphylokokkenwirksamen $\beta$-Laktamantibiotika (systemisch), nach Vorlage von Erregeridentifizierung (aus Eiter, Gewebeproben) und Antibiogramm mit den im Einzelfall indizierten Chemotherapeutika, z. B. beim Nachweis von MRSA-Stämmen mit Resistenz gegen Oxacillin Therapie mit Vancomycin.

\section{Erysipel, nekrotisierende Fasziitis und Myositis - Definition}

Beim Erysipel dringt Streptococcus pyogenes ( $\beta$-hämolysierende Streptokokken der Serogruppe A) über Epitheldefekte in die Haut ein und breitet sich mithilfe seiner gewebezerstörenden Exoenzyme (z. B. Hyaluronidase, Desoxyribonuklease) phlegmonös in den tieferen Schichten der Haut aus.

Bei foudroyantem Krankheitsverlauf entstehen erhebliche Nekrosen im Bereich der Faszie (nekrotisierende Fasziitis) sowie in weiten Bereichen der Muskulatur (nekrotisierende Myositis, - Abb. 1.69).

\section{- Klinik}

Durch den starken Gewebezerfall als auch durch eine massive Toxinämie (Toxic-shock-Syndrom, TSS) kann es hierbei zum tödlichen Multiorganversagen, insbesondere zum Nierenversagen, kommen, das eine intensivmedizinische Behandlung des Patienten erfordert. Das Toxic-shock-Syndrom ist als toxische Komplikation von der durch Erregereinschwemmung verursachten Sepsis eindeutig abgegrenzt. Pathogenetisch bedeutsam sind neben den Exotoxinen v. a. die oberflächlichen M-Proteine der A-Streptokokken, die sie vor Phagozytose durch polymorphkernige Granulozyten schützen.

\section{- Diagnostik}

Die Diagnose erfolgt durch das typische klinische Bild: An den Prädilektionsstellen (Unterschenkel, Gesicht) entwickelt sich eine schmerzhafte gezackte, scharf begrenzte Hautrötung,

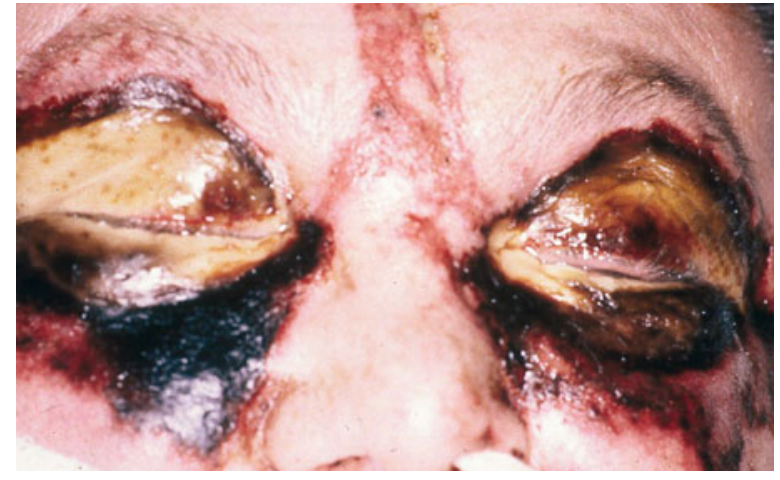

- Abb. 1.69 Nekrotisierende Myositis

die sich rasch ausbreitet. Meist treten Allgemeinsymptome (hohes Fieber u. a.) hinzu. Nach wenigen Tagen beginnt bei unkompliziertem Verlauf mit zentraler Abblassung der Rötung die Heilung. Als Spätfolgen können sich durch obliterierte Lymphgefäße chronische Ödeme (Elephantiasis nostras) entwickeln bzw. - selten - Glomerulonephritiden. Der mikrobiologische Erregernachweis aus dem betroffenen Hautgebiet gelingt meist nicht. Als Rachenabstrich ist er von geringem diagnostischem Wert. Die Bildung von Antikörpern (Antistreptolysin, Antihyaluronidase, Anti-DNAse-B) kann für die Therapieeinleitung nicht abgewartet werden, vermag jedoch retrospektiv die Diagnose zu stützen.

- Therapie

Das Erysipel wird antibiotisch mit hoch dosierter PenicillinG-Gabe behandelt. Weitere Therapiemaßnahmen umfassen Ruhigstellung und Bettruhe.

( Bei foudroyantem Verlauf (nekrotisierende Fasziitis, Myositis) ist zusätzlich zur hochdosierten Penicillintherapie in Kombination mit Clindamycin eine chirurgische Spaltung der Faszie als auch Abtragung aller Nekrosen erforderlich.

\section{Erysipeloid}

- Definition

Bei Erysipelothrix rhusiopathiae, dem Erreger des Erysipeloids des Menschen, handelt es sich um ein kurzes schlankes grampositives Stäbchenbakterium, das in erster Linie Erkrankungen bei Schweinen (Rotlauf), seltener bei anderen Tieren verursacht. Beim Umgang mit infizierten Tieren/Fleisch (Landwirte, Metzger, Fischer u. a.) können die Erreger über kleine Läsionen in die Haut eindringen.

\section{- - Symptomatik, Diagnostik}

Vor allem an Fingern und Händen entwickelt sich eine eitrige Entzündung mit schmerzhafter blau-roter, scharf begrenzter Schwellung und Arthritis der benachbarten Gelenke. Fieber und andere Allgemeinsymptome treten nicht auf. Innerhalb von 2 Wochen heilt die Erkrankung meist spontan ab, doch ist wegen der Gefahr der (seltenen) Endokarditis Chemotherapie indiziert. 
$(8$ Die Diagnose, auch die Abgrenzung zum Erysipel, wird primär klinisch anhand der Anamnese, der Symptomatik und der Lokalisation gestellt.

Die Isolierung des Erregers aus Wundsekret gelingt nicht immer.

\section{-" Therapie}

Therapeutisch wird Penicillin-G in hoher Dosierung verabreicht und die betroffene Hand ruhig gestellt.

\section{Osteomyelitis \\ Endogene Form}

\section{- Pathogenese}

Die akute hämatogene Osteomyelitis manifestiert sich hauptsächlich im Kindes- und Jugendalter und betrifft hier v. a. Femur, Tibia und Humerus.

Im Rahmen einer von Furunkel, Tonsillitis, Wundinfektion und anderen bakteriellen Erkrankungen ausgehenden Sepsis gelangen die Erreger - in der überwiegenden Mehrzahl der Fälle Staphylococcus aureus, seltener $\beta$-hämolysierende Streptokokken der Serogruppe A und andere Bakterien - in die Metaphysen der langen Röhrenknochen und infizieren die Markhöhle (Markphlegmone). Von hier aus durchdringt die Infektion die Knochensubstanz bis zum Periost (subperiostaler Abszess) und kann auch die angrenzenden Gelenke (Empyem) erreichen. Der nekrotische Knochenabschnitt wird durch Demarkierung zum Knochensequester. Bei abgeschwächtem Krankheitsverlauf entsteht lediglich eine abgekapselte Eiterung (Brodie-Abszess) in der Meta-/Epiphysenregion. Unbehandelt hat die Erkrankung eine hohe Letalität bzw. führt bei Überstehen häufig zu Defektheilungen oder geht in eine chronische Osteomyelitis mit Fisteleiterung über.

\section{- Diagnostik}

Diagnostisch wegweisend sind Sepsissymptomatik zusammen mit Knochenschmerzen/Gelenkschmerzen.

Der Verdacht kann durch szintigraphische Untersuchungen erhärtet werden. Röntgenologische Veränderungen (Entkalkungen, Sequester u. a.) treten erst nach 2-3 Wochen auf. Die Erregerisolierung erfolgt aus Blutkulturen, Abszesspunktaten und Gewebeproben.

\section{- Therapie}

Die Therapie besteht in hochdosierter Gabe gut in den Knochen penetrierender Antibiotika über mindestens 6 Wochen.

Bis zur Vorlage des Antibiogrammes kommen in erster Linie staphylokokkenwirksame Substanzen in Frage, bei Kenntnis des septischen Herdes primär eine entsprechend kalkulierte Chemotherapie. Daneben erfolgen Ruhigstellung der Extremität und ggf. chirurgische Maßnahmen (Abszesspunktion, Sequesterentfernung u. a.).

\section{Exogene Form}

- Pathogenese

Die exogene Osteomyelitis/Osteitis entsteht posttraumatisch, fortgeleitet (z.B. Zahnwurzeleiterung) oder postoperativ.

$>$ Das Erregerspektrum ist vielgestaltig, nicht selten findet man Mischinfektionen unter Beteiligung obligat anaerober Bakterien.

Die Erkrankung verläuft häufig chronisch-schleichend mit progredienter Knochendestruktion, kann jedoch durch septische Streuung der Erreger jederzeit einen hochakuten, lebensgefährlichen Verlauf nehmen.

\section{- Diagnostik, Therapie}

Die Diagnose ergibt sich aus der Anamnese, dem Lokalbefund und dem Erregernachweis aus dem Wundgebiet. Differenzialdiagnostisch ist - wie bei allen Knochendestruktionen - neben der Tuberkulose an einen malignen Prozess (primär bzw. metastatisch) zu denken.

Therapeutisch kommen lokale Sanierung mit Sequesterentfernung, Ruhigstellung der Extremität sowie lokale und systemische Antibiotikagabe (entsprechend der Empfindlichkeit der isolierten Erreger) zur Anwendung.

\section{Milzbrand}

\section{- Definition}

Der Milzbrand, eine vorwiegend bei Tieren (Rinder, Scha-

fe, Schweine u. a.) auftretende Erkrankung, wird durch

Bacillus anthracis, ein grampositives zentral sporenbildendes unbewegliches Stäbchenbakterium, hervorgerufen.

\section{- Pathogenese}

Pathogenetisch bedeutsam sind zum einen der Phagozytoseschutz durch die die Bakterien umschließende Kapsel, zum anderen verschiedene lokal gewebeschädigende Enzyme sowie der aus 3 Proteinen bestehenden Anthrax-Toxin-Komplex. Die Infektion des Menschen verläuft am häufigsten als Hautmilzbrand, bei dem die Erreger bzw. ihre Sporen durch Hautverletzungen eindringen - meist beim Umgang mit infizierten Tieren (z.B. Scheren von Schafen) oder mit Fellen/ Häuten.

\section{- Symptomatik}

Aus einer Rötung entsteht nach 1-3 Tagen ein Bläschen mit dunklem bis schwarzem Inhalt (Pustula maligna), das nach Austrocknung eine schwarze Hautnekrose (Milzbrandkarbunkel, • Abb. 1.70) hinterlässt. Durch Demarkierung und Abstoßung der Nekrose erfolgt die Heilung des meist lokal verlaufenden Hautmilzbrandes.

D Cave

Bei septischer Streuung, die sehr häufig bei Lungenmilzbrand (Einatmung der Sporen) und Darmmilzbrand (Aufnahme der Sporen mit der Nahrung) eintritt, sterben die Patienten rasch unter hohem Fieber, Schock und Atemlähmung (ZNS-Schäden). 


\section{- Diagnostik}

Diagnostisch hilfreich sind v. a. die Anamnese (u. a. berufliche Exposition) und bei Hautmilzbrand die typische Pustula maligna (• Abb. 1.70). Der Erregernachweis aus Bläscheninhalt/Exsudat, aus Sputum (Lungenmilzbrand), aus Stuhl (Darmmilzbrand) und bei Verdacht auf Sepsis aus Blutkulturen sichert die Diagnose.

\section{- Therapie}

Die Therapie bestand bislang in der Gabe von Penicillin-G sowie in der Ruhigstellung der betroffenen Extremität bei Hautmilzbrand. Allerdings schränkt die Resistenz des Erregers die Bedeutung von Penicillin-G ein, daher wird heute Ciprofloxacin oder Doxycyclin zur Therapie empfohlen. Gleiches gilt bei Penicillinallergie.

D Cave

Wegen der möglichen Entwicklung einer Sepsis sind chirurgische Maßnahmen beim Milzbrand kontraindiziert.

\section{Wunddiphtherie}

\section{- Definition \\ Diphtherie ist eine auf den Menschen beschränkte Infek- tionskrankheit, durch toxinogenes Corynebacterium diph- theriae hervorgerufen, die sich lokal in typischer Weise als Tonsillitis/Pharyngitis mit pseudomembranösen Auflage- rungen manifestiert. \\ Bei der Wunddiphtherie, die durch Resorption von Diphtherietoxin ebenfalls zur Parese motorischer Nerven sowie zur toxischen Myokarditis führen kann, liegen schmerzhafte, tief nekrotisierende Wunden mit blau-vio- letter Verfärbung und Pseudomembranen ohne Heilungs- tendenz vor.}

\section{- Diagnostik}

Die Diagnose wird durch den Nachweis der Erreger aus der Wunde und durch den Nachweis des Toxinbildungsvermögens der isolierten Corynebakterien gestellt.

$\checkmark$ An Wunddiphtherie ist v. a. bei nicht geimpften Rückkehrern aus Endemiegebieten (tropische Regionen, Russland und GUS-Staaten, Asien u. a.) zu denken.

\section{- Therapie}

Die Therapie besteht in der Gabe von antitoxischem Serum, offener Wundbehandlung und im Versuch der antibiotischen Erregereliminierung (Penicillin-G, Erythromycin).

\section{Eitrige Meningitis}

\footnotetext{
Definition

Bei der eitrigen Meningitis liegt eine bakterielle Entzündung der harten oder weichen Hirnhaut oder der Rückenmarkhäute vor, meist kombiniert (Meningitis cerebrospinalis).
}

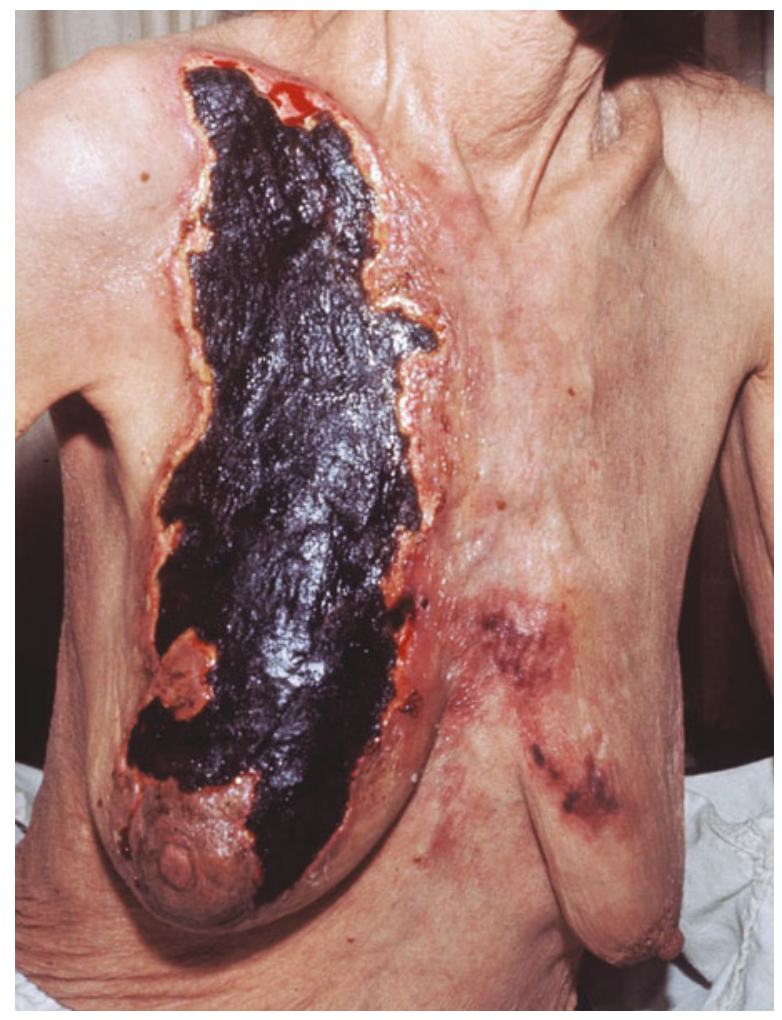

- Abb. 1.70 Ausgedehnter Milzbrand der Haut, mit freundlicher Genehmigung von Prof. Dr. Disko, München

Chirurgisch bedeutsam sind

- die aus einem Gesichtsfurunkel entstehende Meningitis,

- die posttraumatische Meningitis (offene Schädel-HirnVerletzungen),

- die postoperative Meningitis (HNO-, Schädel- und Gehirnoperationen, auch als Infektion über eine liegende Liquordrainage),

- die Meningitis bei Osteomyelitis des Schädels,

- die hämatogen entstandene Meningitis, z. B. bei Wundinfektionen oder bei Beatmungspneumonien.

\section{- Diagnostik}

Die Diagnose ergibt sich aus der klinischen Symptomatik (u. a. Fieber, Nackensteifigkeit, Bewusstseinstrübung) und aus dem Liquorbefund (Trübung, Zellzahl, Bakteriennachweis, Glukose, Laktat, Eiweiß). Der Erregernachweis muss auch von dem für die Meningitis als Ursache vermuteten »Ausgangsherd «bzw. aus Blutkulturen versucht werden.

\section{- Therapie}

Die Therapie besteht in der systemischen Gabe von liquorgängigen Antibiotika, primär kalkuliert entsprechend dem jeweils zu erwartendem Erregerspektrum, gezielt nach Vorlage von Erregeridentifizierung und Antibiogramm. Zusätzliche intensivtherapeutische Maßnahmen sind entsprechend den Erfordernissen durchzuführen. 
( Begleitend zur antibakteriellen Chemotherapie muss schnellstmöglich die Behandlung/Beseitigung der Meningitisursache in Angriff genommen werden.

\section{Wundinfektion nach Tierbiss- und Kratz- verletzungen \\ - Pathogenese}

Nach Tierbiss- und Kratzverletzungen kann es typischerweise nach wenigen Stunden zu einer akuten Entzündung ausgelöst durch Pasteurella multocida kommen. Im Bereich der Verletzung entwickelt sich eine serös-blutige oder eitrige Sekretion, die regionären Lymphknoten sind entzündlich vergrößert.

Die seltene Erkrankung betrifft vorzugsweise Tierhalter und -händler, Landwirte, Schlachthauspersonal. Pasteurellae sind kleine sporenlose, gramnegative Stäbchenbakterien. Neben Pasteurellen sind oft auch Erreger wie Staphylococcus aureus und Anaerobier bei dieser Art von Wundinfektion beteiligt.

\section{- - Therapie}

Bei alleiniger Infektion durch Pasteurellen gilt Penicillin G als Mittel der Wahl. Die Wunde wird sofort desinfiziert und chirurgisch mit einer offenen Wundtoilette behandelt. Häufig liegen Mischinfektionen vor, die, abhängig von der Wundsituation, mit einer das Keimspektrum erfassenden Antibiose (z. B. Amoxicillin/Clavulansäure) behandelt werden müssen.

$\checkmark$ Bei Wunden durch Tierbiss- und Kratzverletzungen muss immer mit einer Wundinfektion gerechnet werden und eine entsprechende chirurgische Therapie als auch die mikrobiologische Untersuchung des Wundsekrets veranlasst werden

\section{In Kürze}

Sonstige bakterielle Infektionen

Symptomatik: Klassische Entzündungszeichen: Rubor, Tumor, Calor, Dolor, Functio laesa. Erscheinungsbild abhängig vom Erreger, befallenem Organ und Abwehrleistung des Organismus: Follikulitis, Furunkel, Karbunkel, Panaritium, Erysipel, Erysipeloid, Osteomyelitis, Milzbrand, eitrige Meningitis $u$. a.

Therapie: Bei Krankheiten wie Abszessen, Phlegmonen, Empyemen und eitrigen/putriden Infektionen stellen chirurgische Maßnahmen (u. a. »ubi pus, ibi evacua«) die Basistherapie dar. Antibiotikatherapie hat ihren Platz bei chirurgisch allein nicht beherrschbaren, v. a. sepsisbedrohten Verläufen.

\subsubsection{Virusinfektionen}

\section{Tollwut}

- Pathogenese

Der Erreger der Tollwut (Rabies, Lyssa, Hydrophobie), das zu den Rhabdoviren gehörige Tollwutvirus, wird durch den Biss infizierter, das Virus im Speichel ausscheidender Tiere (Hunde, Katzen, Füchse u. a.) übertragen.
Nach kurzer Vermehrungsphase in den Zellen der Wunde (z.B. Muskulatur) gelangt das Virus in periphere nervöse Strukturen und innerhalb dieser ins ZNS, wo sich durch Befall der Nervenzellen eine Enzephalitis mit den charakteristischen Negri-Körperchen entwickelt.

( Die sehr variable Inkubationszeit (Wochen bis Monate) ist umso kürzer, je näher die Viruseintrittsstelle zum ZNS lokalisiert ist.

\section{- - Symptomatik}

Nach uncharakteristischen Prodromi (z.B. lokales Jucken, Brennen im Bereich der Bisswunde, Fieber) treten die typischen Symptome auf: Spasmen im Pharynx-Larynx-Bereich, generalisierte Krämpfe, Hyperventilation, Unruhe, Halluzinationen u. a., aber auch vereinzelt Paresen und Aphasie. Innerhalb weniger Tage kommt es zu zunehmender Bewusstseinstrübung, schließlich zum Koma und zum Tod (oft durch Atemstillstand).

D Cave

Sobald die Symptomatik begonnen hat, sterben die Patienten - trotz aller therapeutischer Bemühungen.

\section{- Diagnostik}

Erreger- und Antikörpernachweis sind diagnostisch nur bedingt verwertbar: Ein negativer Erregernachweis schließt die Tollwut nicht aus. Antikörper werden erst sehr spät im Krankheitsverlauf gebildet.

\section{- Prophylaxe}

Die chirurgische Versorgung tollwutverdächtiger Verletzungen besteht in der ausgiebigen Spülung der Wunde mit Wasser und in der Reinigung mit Seife/Detergens (Inaktivierung des lipidhaltigen Virus). Anschließend wird wie üblich desinfiziert. Danach werden die Wunde und die Umgebung mit homologem Rabies-Immunglobulin infiltriert, ggf. exzidiert und nicht geschlossen. Eine intramuskuläre passive Immunisierung sowie die postexpositionelle aktive Immunisierung sind anzuschließen. Stark gefährdete Personen (Jäger, Waldarbeiter, Tierärzte u. a.) werden präexpositionell aktiv immunisiert.

D Cave

Schon bei Verdacht auf eine Tollwutinfektion müssen entsprechende Maßnahmen ergriffen werden.

\section{Hepatitis}

- - Definition

Die infektiöse Hepatitis wird durch verschiedene Viren hervorgerufen:

- Die durch das Hepatitis-A-Virus und das Hepatitis-E-Virus bedingten Erkrankungen, die fäkal-oral übertragen werden, heilen meist folgenlos aus.

- Die parenteral übertragenen Hepatitiden, verursacht durch das Hepatitis-B-Virus, Hepatitis-D(Delta)-Virus und Hepatitis-C-Virus, können neben einem überwiegend gut- 
artigen Verlauf aber auch einen letalen Ausgang nehmen und bei chronischem Verlauf zur Entwicklung einer Leberzirrhose oder eines hepatozellulären Karzinoms führen.

Die Bedeutung des Hepatitis-G-Virus als Auslöser einer Hepatitis ist bislang unklar. Obwohl bei bis zu $2 \%$ aller Blutspender nachweisbar, scheint es nach derzeitigem Wissen bestenfalls in Einzelfällen für eine Hepatitis verantwortlich zu sein.

\section{- Diagnostik}

Durch serologische Untersuchungen kann im Falle der Hepatitis B (HBs-Antigen, anti-HBs, HBe-Antigen, anti-HBe) die chronische von der akuten Verlaufsform unterschieden werden. Zusätzlich stehen für die Diagnostik der Hepatitis B als auch der Hepatitis C PCR-Verfahren zur Verfügung, um zwischen akuter und chronischer Verlaufsform zu unterscheiden, sowie den Erfolg therapeutischer Interventionen (z. B. PEG Interferon- $\alpha$-Ribavirintherapie bei Hepatitis C) zu beurteilen.

\section{- - Bedeutung im Rahmen des Hospitalismus}

Die Erreger gelangen über die Schleimhäute und kleinste Hautläsionen in den Organismus, wobei schon geringste Mengen Blut (z.B. Blutreste an Kanülen) eine ausreichende Infektionsdosis enthalten können. Unter Berücksichtigung dieser Erkenntnisse ergeben sich entsprechende Konsequenzen für den Umgang mit Blut/Blutprodukten und infizierten Patienten, die denen bei Aids bzw. HIV-infizierten Patienten gleichen. Eine zusätzliche Schutzmaßnahme gegen Hepatitis B (und damit nachfolgend auch gegen Hepatitis D) stellt die aktive Immunisierung und die nach Virusaufnahme in den Organismus ggf. erforderliche passive Immunisierung (als passive/aktive Simultanimpfung) dar. Gegen Hepatitis C gibt es derzeit keine Immunprophylaxe. Zum Vorgehen bei Stichverletzungen, - Tab. 1.24.

Bedingt durch die Übertragbarkeit mittels Blut und Blutprodukten sind Patienten, wie die in der Krankenversorgung Tätigen, in besonderem Maße gefährdet an Hepatitis B und D oder an Hepatitis C zu erkranken. Deswegen ist die Impfung gegen Hepatitis B empfohlen.

\section{Aids}

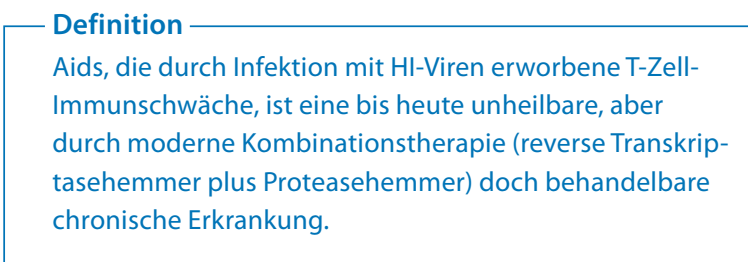

Wegen dieser Prognose, wegen der Übertragbarkeit durch Blut und Blutprodukte (daneben auch durch Genitalsekrete und andere Körperflüssigkeiten) und wegen der fehlenden Immunprophylaxe (keine Schutzimpfung) hat diese Infektionskrankheit für Patienten wie für die im medizinischen Bereich Tätigen eine besondere Bedeutung.

\section{( $)$}

Umsichtiges - nicht hysterisches - Verhalten beim Umgang mit HIV-positiven Patienten und mit Blut/Blutprodukten sowie eine zuverlässige Diagnostik dieser Erkrankung sind von größter Wichtigkeit.

- Tab. 1.24 Vorgehen bei Stichverletzungen

\begin{tabular}{|c|c|c|}
\hline Verdacht auf & \multicolumn{2}{|l|}{ Maßnahmen } \\
\hline HIV & $\begin{array}{l}\text { Sofort nach Verletzung } \\
\text { umgehende Abklärung des } \\
\text { Infektionsrisikos }\end{array}$ & $\begin{array}{l}\text { Blutfluss durch Druck auf das umliegende Gewebe fördern ( } \geq 1 \mathrm{~min} \text { ) } \\
\text { Intensive antiseptische Reinigung der Wunde } \\
\text { HIV-Status des Patienten ermitteln } \\
\text { Ggf. systemische, medikamentöse Postexpositionsprophylaxe des Stichverletzten } \\
\text { (z.B. empfohlen bei perkutaner Verletzung mit Injektions- oder Hohlraumnadel) } \\
\text { Serologischer Antikörpernachweis beim Stichverletzten }{ }^{\text {a }}\end{array}$ \\
\hline \multirow[t]{2}{*}{$\mathrm{HBV} / \mathrm{HCV}$} & $\begin{array}{l}\text { Sofort nach Verletzung } \\
\text { umgehende Abklärung des } \\
\text { Infektionsrisikos }\end{array}$ & $\begin{array}{l}\text { Wie bei möglicher HIV-Exposition } \\
H B V / H C V \text {-Status des Patienten ermitteln, HBV-Impfstatus des Stichverletzten } \\
\text { ermitteln } \\
\text { Sofortige aktive/passive Immunisierung gegen HBV bei nicht vorhandenem oder } \\
\text { unklarem Impfschutz des Stichverletzten }\end{array}$ \\
\hline & Serologische Bestimmung & $\begin{array}{l}\text { Anti-HBs bei geimpften Stichverletzten, aber unklaren Angaben zum Impferfolg } \\
\text { Anti-HBc bei fehlender Impfung des Stichverletzten }{ }^{\mathrm{a}} \\
\text { Bestimmung von Anti-HCV }{ }^{a} \text { sowie der Transaminasen }{ }^{\text {b }} \\
\text { Bei } H C V \text {-positiven Patienten } H C V \text {-PCR beim Stichverletzten } 2 \text { Wochen nach Verlet- } \\
\text { zung zur Einleitung einer möglichen Frühtherapie }\end{array}$ \\
\hline
\end{tabular}


- - Symptomatik

Die Erkrankung verläuft zunächst inapparent oder mononukleoseähnlich. Nach einer bis zu Jahren dauernden Phase der Latenz, in der der Infizierte klinisch gesund ist, zeigt sich eine Periode der Lymphadenopathie und allgemeiner Symptome, gefolgt von Infektionen durch opportunistische Erreger, wie Pneumocystis carinii, Toxoplasmen, Mykobakterien usw. Der Erkrankte hat nun das Vollbild von Aids entwickelt.

\section{- - Diagnostik}

Methodisch kommt meist ein ELISA zum Nachweis von Antikörpern gegen das HI-Virus zur Anwendung. Mit den neuesten Tests lassen sich die ersten Antikörper häufig bereits 3 Wochen nach Infektion nachweisen (Serokonversion). Während dieses Zeitraumes fällt beim infizierten Patienten, der die Erkrankung schon jetzt übertragen kann, der Test negativ aus (falsch-negatives Untersuchungsergebnis).

( Die Diagnostik der HIV-Infektion erfolgt routinemäßig durch Nachweis von Antikörpern im Patientenserum.

Aufgrund der enormen Bedeutung, die der Nachweis von $H I V$-Antikörpern für den Patienten hat, muss die Untersuchung durch Wiederholung bestätigt werden. Deshalb wird im positiven Fall das Ergebnis mithilfe eines weiteren Verfahrens, dem Western-Blot, überprüft. Durch Bestätigung des Antikörpernachweises aus einer 2. Serumprobe wird die Möglichkeit der Serumverwechslung (ungenügende Beschriftung der Probe, Vertauschung im Labor u. a.) ausgeschlossen. Führen alle Untersuchungen zu übereinstimmenden Ergebnissen, kann die Diagnose HIV-Infektion gestellt werden.

Der direkte Virusnachweis durch Anzucht des Virus oder die Messung des p24-Antigens ist zwar in vielen Fällen möglich, ist heute aber durch die PCR ersetzt, die durch semiquantitativen Aufbau eine Messung der Virusmenge oder Viruslast im Serum des Patienten ermöglicht.

$\mathrm{Zu}$ Verhaltensregeln gegenüber $H I V$-positiven Patienten, Abschn. 1.7.2. Zu Maßnahmen bei Stichverletzungen, - Tab. 1.24.

\section{In Kürze}

\section{Virusinfektionen}

Tollwut (Rabies): durch Biss infizierter Tiere, Spasmen, Krämpfe, Tod. Diagnostik nur bedingt verwertbar. Deswegen schnellste chirurgische Wundbehandlung plus passive/aktive Tollwutimmunisierung schon bei Verdacht auf Tollwut.

Hepatitis, Aids: große Gefahren für Patient und Arzt durch parenteral (Blut, Sekrete) übertragbare Viruskrankheiten wie Hepatitiden (B, D, C) und HIV-Infektionen. Bei Hepatitis B (und D) Schutzimpfung empfohlen, bei Hepatitis C und HIV-Infektion/Aids fehlende Immunprophylaxe. Nach Stichverletzung sofortige Reaktion mit umgehender Abklärung des Infektionsrisikos.

\subsubsection{Parasitäre Erkrankungen}

\section{Echinokokkose}

\section{Definition}

Bei der Infektion des Menschen unterscheidet man die zystische Echinokokkose, verursacht durch Echinococcus granulosus (Hundebandwurm), von der alveolären Echinokokkose, verursacht durch Echinococcus multilocularis (Fuchsbandwurm).

\section{- Pathogenese}

Nach oraler Aufnahme der Eier (kontaminierte Lebensmittel, Kontakt mit infizierten Tieren) dringen die im Darm ausschlüpfenden Larven in die Schleimhaut und in Blutgefäße ein.

Bei Echinococcus granulosus entwickeln sich aus den Larven vorwiegend in der Leber (• Abb. 1.71), z. T. auch in der Lunge (in anderen Organen seltener) bis zu kindskopfgroße, flüssigkeitsgefüllte Blasen (Hydatiden), die von Bindegewebe eingekapselt werden. Durch Verdrängung angrenzender Strukturen entstehen je nach Lokalisation der Blasen unterschiedliche Symptome (Oberbauchschmerzen, Ikterus u. a.).

D Cave

Eine Ruptur der Hydatiden kann zum allergischen Schock und/oder zur metastatischen Absiedlung (sekundäre Hydatidose) führen.

Die Larven von Echinococcus multilocularis befallen primär fast ausschließlich die Leber. Es kommt zu einem infiltrativdestruierenden Wachstum - ähnlich einem malignen Tumor - mit schleichender progredienter Zerstörung der Leber unter Ausbildung multipler kleiner Bläschen. Ein Einbruch in die Blutgefäße führt zur Metastasierung in alle Organe. Die Symptomatik besteht v. a. in Oberbauchschmerzen, Ikterus und zunehmender Leberinsuffizienz.

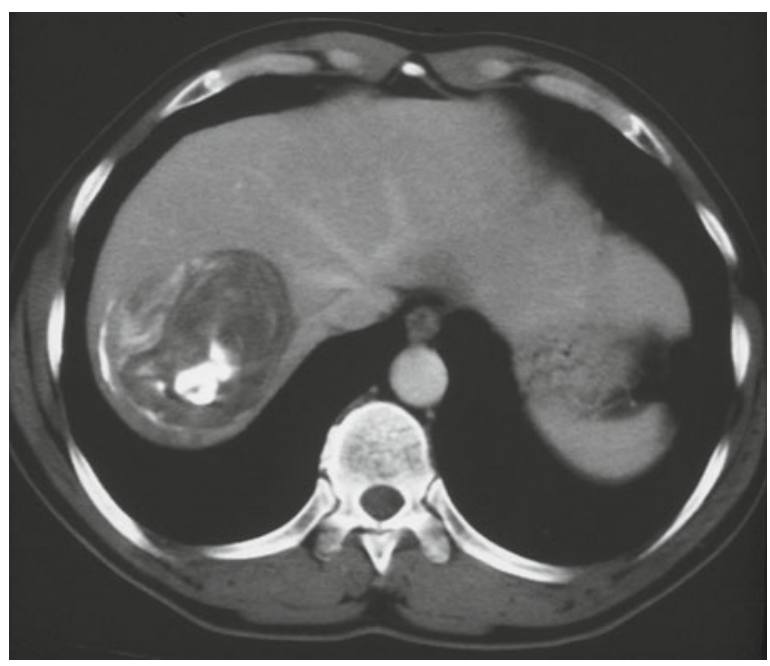

- Abb. 1.71 Solitäre Leberzyste durch Echinococcus granulosus (mit freundlicher Genehmigung von Prof. Dr. Disko, München) 
( Unbehandelt endet diese Erkrankung nach mehreren Jahren fast immer tödlich.

\section{- Diagnostik}

Zur Diagnose werden neben klinischen Befunden in erster Linie bildgebende Verfahren (Sonographie, Computertomographie u. a.) kombiniert mit Antikörpernachweis im Patientenserum herangezogen. Die Feinnadelbiopsie (Gewinnung von Erregerbestandteilen zum DNA-Nachweis mittels PCRMethodik) wird wegen der möglichen Erregeraussaat kontrovers beurteilt und deshalb nicht generell empfohlen.

\section{- Therapie}

Alleinige Chemotherapie mit Albendazol, alternativ Mebendazol führt in seltenen Fällen zum Absterben des Parasitengewebes, meist wird jedoch lediglich eine Wachstumshemmung erreicht.

Bei der zystischen Echinokokkose kann durch Exstirpation der Hydatide(n) in toto häufig eine Heilung erreicht werden.

D Cave

Die Ruptur der Blase(n) muss dabei unbedingt vermieden werden.

Bei der alveolären Echinokokkose ist nur die radikale Leberteilresektion im Gesunden kombiniert mit einer Chemotherapie (Albendazol oder Mebendazol) kurativ wirksam. Bei ausgedehnter Leberzerstörung kann ggf. eine Lebertransplantation erfolgen. Die bei inoperablen Fällen als alleinige Maßnahme verbleibende Chemotherapie kann bei Echinococcus multilocularis in den meisten Fällen das Parasitenwachstum stoppen, eine Heilung ist jedoch nicht möglich.

\section{Amöbiasis}

\section{- Definition}

Das Protozoon Entamoeba histolytica, der Erreger der menschlichen Amöbiasis, kann nach oraler Aufnahme eine schwere Kolitis mit tiefen Darmwandgeschwüren (Komplikation: Peritonitis) verursachen, die sich durch blutig-schleimige Diarrhöen (Amöbenruhr) äußert.

\section{- Klinik}

Die Amöben penetrieren in die Blutgefäße der Darmwand und gelangen mit dem Blutstrom in die Leber (sehr viel seltener in andere Organe), wo sie über fokale Nekrosen Abszesse verursachen (• Abb. 1.72).

Diese äußern sich v. a. durch Oberbauchschmerzen und Lebervergrößerung. Unbehandelt können derartige Abszesse in benachbarte Organe (z. B. Lunge) oder in Blutgefäße einbrechen, woraus eine hämatogene Aussaat der Erreger mit Besiedlung weiterer Organe resultiert.

Bei schwerem Verlauf kann die Amöbiasis zum Tode führen.

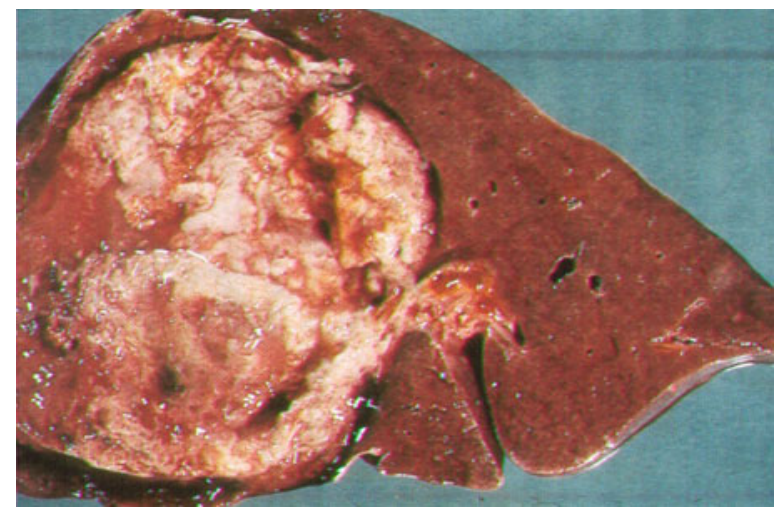

- Abb. 1.72 Leberabszess durch Entamoeba histolytica (mit freundlicher Genehmigung von Prof. Dr. Disko, München)

\section{- Diagnostik}

Der mikroskopische/immunologische Erregernachweis, durch den bei der intestinalen Amöbiasis die Diagnose aus Stuhl gestellt wird, gelingt bei der Untersuchung von Abszesspunktaten meist nicht. Leberabszesse und andere extraintestinale Manifestationen werden durch Antikörpernachweis im Patientenserum verifiziert. Mittels bildgebender Verfahren (Sonographie, Computertomographie u. a.) wird die Abszesslokalisation ermittelt. Eine Amöbiasis ist in erster Linie bei Tropenrückkehrern differenzialdiagnostisch zu bedenken.

\section{- Therapie}

Die Behandlung erfolgt durch Gabe amöbenwirksamer Chemotherapeutika, v. a. durch Nitroimidazole (z. B. Metronidazol).

( Bei großen Leberabszessen und bei Komplikationen (z. B. Perforation, Ruptur) ist ein entsprechendes chirurgisches Vorgehen (Punktion, Inzision, Drainage u. a.) erforderlich.

\section{Askariasis \\ - Definition}

Die Askariasis, der Befall mit dem zu den Nematoden gehörenden Parasiten Ascaris lumbricoides (Spulwurm), ist weltweit verbreitet, in den Tropen eine der häufigsten Helminthiasen.

\section{Entwicklung}

Aus den oral aufgenommenen Eiern des Ascaris lumbricoides schlüpfen im Dünndarm Larven, die in die Blutgefäße des Darmes einbrechen und mit dem Blutstrom zunächst zur Leber, schließlich in die Lungen gelangen. Die Askariden verlassen das Kapillarsystem der Lunge und wandern, in den Alveolen beginnend, den Bronchialbaum aufwärts. Hierbei können sich bei begleitender Bluteosinophilie entzündliche Infiltrate bilden (eosinophiles Lungeninfiltrat). Über die Trachea und den Ösophagus erreichen die Larven den Dünndarm, wo sie zu adulten Nematoden heranreifen. 


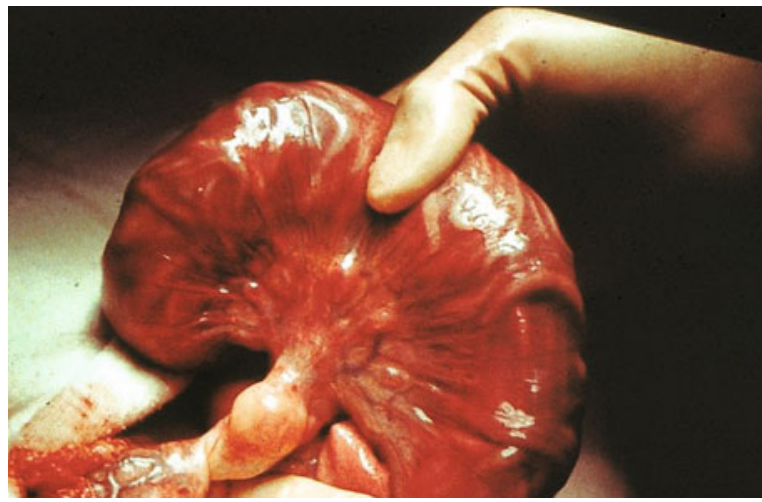

- Abb. 1.73 Befall des Darms durch Ascaris lumbricoides (mit freundlicher Genehmigung von Prof. Dr. Disko, München)

\section{- Symptomatik}

Symptomatisch stehen Abdominalschmerzen, Durchfall und Erbrechen im Vordergrund. Gelegentlich entwickeln sich bei massivem Befall ein Askaridenileus (• Abb. 1.73), bei Einwandern in die Gallenwege ein Verschlussikterus, bei Eindringen in den Pankreasgang eine Pankreatitis, bei Perforation der Dünndarmwand eine Peritonitis mit in der Bauchhöhle vorhandenen Würmern und andere Komplikationen.

\section{- Diagnose}

Die Diagnose erfolgt durch mikroskopischen Nachweis der Eier im Stuhl, bei Komplikationen durch die jeweils geeigneten Methoden (z. B. Röntgen).

\section{- - Therapie}

Primär wird die antihelminthische Chemotherapie angewendet, in erster Linie unter Verwendung von Albendazol, alternativ Mebendazol.

( Abdominelle Komplikationen wie Askaridenileus, Verschlussikterus, Pankreatitis oder Perforation des Dünndarmes bedürfen in der Regel der chirurgischen Behandlung.

\section{In Kürze}

\section{Parasitäre Erkrankungen}

Echinokokkose: Hundebandwurm (E. granulosus) oder Fuchsbandwurm (E. multilocularis). Hydatiden in Lunge und v. a. Leber, nach Möglichkeit Exstirpation, Cave: Ruptur der Blasen.

Amöbiasis: Entamoeba histolytica (v. a. Tropen), Kolitis, sog. Amöbenruhr, hämatogene Aussaat, Leberabszess. Chemotherapie, evtl. chirurgische Maßnahmen.

Askariasis: Ascaris lumbricoides, eosinophiles Lungeninfiltrat, gastroenterologische Symptome. Mikroskopischer Nachweis der Eier im Stuhl. Chemotherapie, bei Komplikationen chirurgische Therapie.

\section{Weiterführende Literatur}

Bundesministerium für Gesundheit (2000) Gesetz zur Verhütung und Bekämpfung von Infektionskrankheiten beim Menschen (Infektionsschutzgesetz, IFSG)

Köhler W, Eggers HJ, Fleischer B et al. (2001) Medizinischen Mikrobiologie, 8. Aufl. Urban \& Fischer, München

Mandell GL, Bennett JE, Dolin R (2010) Principles and practice of infectious diseases, 7. Aufl. Churchill Livingstone, Philadelphia

Robert Koch-Institut (2010) Empfehlungen der Ständigen Impfkommission (STIKO) - Stand: Juli 2010. Epidemiologisches Bulletin Nr. 30

Simon C, Stille W (2006) Antibiotika-Therapie Klinik und Praxis der antiinfektiösen Behandlung, 11. Aufl. Schattauer, Stuttgart

Thomas L (2005) Labor und Diagnose, 6. Aufl. TH-Books, Frankfurt

\subsection{Ursachen und Prävention postoperativer Wundinfektionen}

\section{Kappstein}

Postoperative Infektionen im Operationsgebiet (sog. Wundinfektionen) gehören zu den häufigsten nosokomialen (krankenhauserworbenen) Infektionen. Sie können je nach ihrer anatomischen Lokalisation lediglich oberflächlich und harmlos sein oder bis in die Tiefe des Operationsgebietes reichen und mit schwerer, langwieriger Erkrankung des Patienten verbunden sein. In diesem Kapitel werden die wichtigsten pathogenetischen Prinzipien bei der Entstehung sowie etablierte Maßnahmen zur Prävention (sog. Hygienemaßnahmen) von Wundinfektionen erörtert.

\subsubsection{Entstehung von Wundinfektionen}

( Infektionen im Zusammenhang mit diagnostischen und therapeutischen medizinischen Maßnahmen (nosokomiale oder krankenhauserworbene Infektionen) sind auch bei einem - im Sinne der Infektionsprävention - einwandfreien Arbeiten nicht immer zu verhüten und sind somit nicht an sich beweisend für einen Fehler bei der Behandlung des Patienten.

Infektionen sind immer möglich. Daraus folgt, dass man die Patienten aufmerksam beobachten und bei Wundinfektionszeichen (Rötung, Schwellung, Überwärmung Schmerzen, Wundheilungsstörung, Sekretion und/oder sog. Spannungsblasen, als möglicher Hinweis auf Staphylococcus aureus-Infektion) die erforderliche Diagnostik einleiten muss: Bestimmung von Körpertemperatur und unspezifischen Entzündungsparametern (insbesondere C-reaktivem Protein, Leukozytenzahl, Differenzialblutbild) sowie Veranlassung von mikrobiologischen Untersuchungen und ggf. bildgebende Verfahren. Auf diese Weise kann man schwere infektiöse Komplikationen verhüten, die sich in vielen Fällen erst aus primär relativ harmlosen und begrenzten Infektionen entwickeln, deren Verlauf keineswegs 
"schicksalhaft" vorbestimmt ist. Von Anfang an foudroyant verlaufende Infektionen, auf die man therapeutisch gar nicht schnell genug reagieren kann, sind sehr selten.

$(7$ Die meisten postoperativen Infektionen im Operationsgebiet werden während des Eingriffs erworben.

Notwendige Bedingung für die Entstehung postoperativer Infektionen im Operationsgebiet ist die perioperative bakterielle Kontamination des Operationsgebietes. Darüber hinaus ist es entscheidend, inwieweit ein Missverhältnis zwischen den natürlichen lokalen und systemischen Abwehrfunktionen auf der einen Seite und dem Erreger mit seiner durch Keimzahl und/oder Virulenz gegebenen aktuellen Pathogenität auf der anderen Seite besteht. Bei Vorhandensein von Fremdkörpern sind wesentlich geringere Keimzahlen ausreichend, um eine Infektion zu erzeugen. Insbesondere im Zusammenhang mit großen Fremdkörpern, wie Gelenkimplantaten, können auch Bakterien zu Infektionen führen können, deren natürliche Virulenz eher gering ist und die deshalb früher als apathogen eingestuft wurden (v. a. koagulasenegative Staphylokokken).

Bei Auftreten gehäufter Infektionen mit dem gleichen Erreger - im Fall von Streptokokken-A-Infektionen aber auch schon bei Einzelfällen wegen der potenziellen ausgeprägten Virulenz dieser Erreger - muss sofort die Ursache geklärt werden, um die Entwicklung eines Ausbruchs so frühzeitig wie möglich zu erkennen.

$($ Die wichtigste Maßnahme zum Schutz vor operationsassoziierten Ausbrüchen ist die kontinuierliche sorgfältige Beobachtung des Erregerspektrums postoperativer Wundinfektionen.

\section{Erregerspektrum}

In den meisten Fällen werden postoperative Wundinfektionen von Bakterien verursacht, aber auch Pilze, v. a. C. albicans, kommen vor. Insgesamt am häufigsten sind in allen operativen Fachgebieten Staphylokokken, in erster Linie S. aureus. Auch koagulasenegative Staphylokokken (z. B. S. epidermidis) können - besonders im Zusammenhang mit großen Fremdkörpern - postoperative Infektionen im Operationsgebiet verursachen. Abhängig vom operativen Fachgebiet spielen auch Enterobakterien, wie E. coli, ferner Enterokokken und gramnegative Anaerobier, v. a. Bacteroidesspezies, eine Rolle.

\section{Erregerreservoire}

\section{$(7$ Die körpereigene Flora des Patienten stellt das Haupterregerreservoir dar.}

Exogene Reservoire, wie die Körperflora des Operationspersonals oder Keime aus der unbelebten Umgebung im Operationssaal, sind sehr viel seltener die Ursache endemischer postoperativer Infektionen. Bei Ausbrüchen jedoch sind diese exogenen Reservoire ggf. von Bedeutung.

\section{Endogene perioperative Erregerreservoire Körpereigene Flora}

Die meisten Wundinfektionen entstehen durch Keime der körpereigenen Flora des Patienten. So lässt sich die Hautflora auch bei sorgfältiger präoperativer Desinfektion des Operationsfeldes nicht vollständig eliminieren. Dies gilt besonders für die tieferen Hautschichten. Bei Darmoperationen ist meist die typische Mischflora aus gramnegativen Enterobakteriazeen, Enterokokken und gramnegativen Anaerobiern für Infektionen im OP-Gebiet verantwortlich.

\section{Systemische Streuung}

Die Erreger können auch aus einer vom Ort des operativen Eingriffs entfernt liegenden Infektion stammen. Von dort können sie auf hämatogenem (oder lymphogenem) Weg in die Wunde gelangen, wo sie intra- oder postoperativ günstige Bedingungen für Absiedlung und Wachstums finden.

\section{Nasale Besiedlung mit S. aureus}

Eine nasale Besiedlung mit $S$. aureus kann Ursache für eine postoperative Wundinfektion sein.

Die Nase gilt als Hauptreservoir des Menschen für S. aureus, von wo die restliche Körperhaut besiedelt wird.

Daneben ist eine weitere Hypothese, dass es im Rahmen von Intubationsnarkosen bei Patienten, die nasopharyngeal besiedelt sind, durch die Manipulationen an der Schleimhaut bei In- und Extubation zu einer Einschwemmung von S. aureus in die Blutbahn kommen und anschließend intra- oder postoperativ eine Absiedlung im Operationsgebiet als Locus minoris resistentiae stattfinden kann.

\section{Exogene perioperative Erregerreservoire Luft}

Als Erregerreservoir ist die Luft im Operationssaal nach heutiger Auffassung ohne Bedeutung. Die Luftkontamination (mit normalerweise sehr niedrigen Keimzahlen) wird heute auch in der Implantationschirurgie in Anbetracht der physiologischen endogenen Erregerreservoire des Patienten (mit im Gegensatz zur Luft sehr hohen Keimzahlen) als nicht relevant für die Entstehung postoperativer Infektionen angesehen.

In sehr seltenen Fällen wurden Ausbrüche postoperativer Infektionen auf eine aerogene Übertragung der ursächlichen Erreger zurückgeführt. Dabei fanden sich Personen, die unbemerkt und trotz Beachtung der Regeln der Asepsis potenziell pathogene Keime streuten. Es gibt jedoch keine Möglichkeit, diese in den meisten Fällen asymptomatischen Streuer präventiv zu ermitteln (z. B. durch routinemäßige Personaluntersuchungen).

\section{Hautflora des Personals}

Durch die ständige Abgabe von abgeschilferten Epithelien, insbesondere bei körperlicher Bewegung oder durch Reibung der Kleidung an der Haut, stellt die Haut des Personals in der Operationsabteilung ein potenzielles Erregerreservoir dar. Hautschuppen sind sehr klein (Durchmesser ca. $<20 \mu \mathrm{m}$ ) und 
deshalb so leicht, dass sie zu den schwebenden Partikeln gehören. Da die Haut mikrobiell besiedelt ist, werden häufig mit den Epithelien auch Mikroorganismen in die Luft freigesetzt.

\section{$>$ Die meisten Keime in der Luft eines Operationssaales stammen von den anwesenden Personen und die Luftkeimzahl ist maßgeblich von der Anzahl und der körperlichen Aktivität dieser Personen abhängig.}

\section{Nasopharyngealflora des Personals}

Die Abgabe potenziell kontaminierter Tröpfchen aus dem Nasen-Rachen-Raum wird durch die chirurgische Maske (Mund-Nasen-Schutz) zwar reduziert, aber nicht vollständig aufgehoben. So ist aus verschiedenen Untersuchungen bekannt, dass das Ausmaß der Freisetzung von Nasopharyngealflora des Operationsteams davon abhängig ist, wie viel gesprochen wird. Dabei kommt es vorwiegend zur Abgabe großer respiratorischer Tröpfchen und nicht zu einer Aerosolbildung. Das bedeutet, dass eine Erregerübertragung aus dem Nasen-Rachen-Raum, wenn sie überhaupt stattfindet, nicht aerogen erfolgt, sondern durch Sedimentation von Tröpfchen aus dem Nasen-Rachen-Raum des Operationsteams in den Operationssitus.

\section{Hände des Personals}

Transiente und residente Flora der Hände sind wegen der unmittelbaren Nähe der Hände zum Operationssitus als Erregerreservoir von großer Bedeutung. Die präoperative Händedesinfektion hat deshalb das Ziel, die transiente Flora zu eli- minieren und die residente Flora weitgehend zu reduzieren. Die sterilen OP-Handschuhe leisten einen zusätzlichen Beitrag zur Senkung des Kontaminationsrisikos der Wunde.

\section{Haare des Personals}

Das Haar wird durch die Kopfhaut kontaminiert, spielt aber bei der Streuung von Mikroorganismen in die Luft des OPSaales wahrscheinlich keine Rolle.

\section{Flächen und Gegenstände}

Die sog. unbelebte Umgebung im Operationssaal kommt als Erregerreservoir für postoperative Infektionen nur in Betracht, wenn Gegenstände, die nicht regelrecht sterilisiert oder die anschließend rekontaminiert wurden, in direkten oder indirekten Kontakt mit dem Operationssitus kommen. Flächen in größerer Distanz (z. B. Wände, Fußboden, Geräte) spielen bei der Entstehung postoperativer Infektionen keine Rolle, weil eine Aufwirbelung bereits sedimentierter Mikroorganismen unter normalen Bedingungen einer Operation nicht zustande kommt.

\section{Risikofaktoren Kontaminationsklassen operativer Eingriffe}

Seit Jahrzehnten werden je nach Art des Eingriffs verschiedene Kontaminationsklassen operativer Eingriffe unterschieden, die lange Zeit allein zur Stratifizierung der Patienten in Gruppen mit unterschiedlichem postoperativen Wundinfektionsrisiko verwendet wurden (• Tab. 1.25).

- Tab. 1.25 Kontaminationsklassen operativer Eingriffe

Kontaminationsklasse

Sauberer (aseptischer) Eingriff

Sauber-kontaminierter (bedingt aseptischer) Eingriff

Kontaminierter Eingriff

Schmutziger oder infizierter (septischer) Eingriff
Keine physiologische mikrobielle Besiedlung und keine Entzündung oder Infektion im Operationsgebiet, weder Respirations- noch Gastrointestinal- oder Urogenitaltrakt eröffnet

Primärer Wundverschluss und, falls erforderlich, geschlossene Drainagen

Keine Kontamination des Operationsgebietes durch ortsständige Flora oder Infektion (z. B. Schilddrüsen-, Herz-, Gelenkoperation)

Operationsgebiet mit physiologischer mikrobieller Besiedlung, z. B. Eröffnung des Respirations-, Gastrointestinal- oder Urogenitaltraktes unter kontrollierten Bedingungen ohne ungewöhnliche Kontamination

Kontamination des Operationsgebietes mit wenig virulenter Flora in mäßiger Keimzahl (z. B. Oropharynx-, Gallenwegs-, vaginale Operation)

Größerer Bruch in der aseptischen Technik oder deutlicher Austritt von Darminhalt oder Vorliegen einer akuten, aber nichteitrigen Entzündung im Operationsgebiet oder frischer Verletzungswunde

Erhebliche Kontamination des Operationsgebietes durch endogene Standortflora oder exogene Erreger (z. B. Dickdarmoperation, Operation bei frischer Unfallwunde), Eingriffe mit Eröffnung des Urogenitaltraktes bei kolonisiertem Urin oder mit Eröffnung der Gallenwege bei kolonisierter Gallenflüssigkeiten

Eitrige Infektion im Operationsgebiet, Perforation im Gastrointestinaltrakt oder ältere Verletzungswunde mit devitalisiertem Gewebe

Massive Kontamination des Operationsgebietes durch endogene Standortflora oder exogene Erreger (z. B. Operation nach Darmperforation, bei eitriger Cholezystitis, operative Versorgung einer älteren Verletzungswunde) 
- Tab. 1.26 CDCa-Risiko-Index für postoperative Wundinfektionen

\begin{tabular}{|c|c|}
\hline Ermittelt aus & Risikopunkte \\
\hline \multirow[t]{3}{*}{$\begin{array}{l}\text { 1. } \text { ASA }^{b_{-}} \\
\text {Klassifikation }\end{array}$} & $\begin{array}{l}\text { Klasse } 3=\text { schwere systemische Störung } \\
(\rightarrow 1 \text { Risikopunkt) }\end{array}$ \\
\hline & $\begin{array}{l}\text { Klasse } 4=\text { schwere und lebensbedrohliche } \\
\text { systemische Störung ( } \rightarrow 1 \text { Risikopunkt) }\end{array}$ \\
\hline & $\begin{array}{l}\text { Klasse } 5=\text { moribunder Patient }(\rightarrow 1 \text { Risiko- } \\
\text { punkt) }\end{array}$ \\
\hline \multirow{2}{*}{$\begin{array}{l}\text { 2. OP-Kontami- } \\
\text { nationsklasse }\end{array}$} & Kontaminiert ( $\rightarrow 1$ Risikopunkt) \\
\hline & Septisch ( $\rightarrow 1$ Risikopunkt) \\
\hline $\begin{array}{l}\text { 3. Operations- } \\
\text { dauer }\end{array}$ & Operation $>\gg \mathrm{T}^{\mathrm{c}}$, Stunden $(\rightarrow 1$ Risikopunkt) \\
\hline \multirow{4}{*}{$\begin{array}{l}\text { Bestehend aus } \\
4 \text { Risiko- } \\
\text { kategorien }\end{array}$} & Risiko-Score 0 = kein erhöhtes Risiko \\
\hline & Risiko-Score 1 = mäßiges Risiko \\
\hline & Risiko-Score 2 = mittleres Risiko \\
\hline & Risiko-Score 3 = hohes Risiko \\
\hline \multicolumn{2}{|c|}{$\begin{array}{l}\text { a CDC: Centers for Disease Control and Prevention (Atlanta, } \\
\text { USA); }{ }^{b} \text { ASA: American Society of Anesthesiologists; }{ }^{c}>T_{<}: \text {Zeit, } \\
\text { nach der } 75 \% \text { der entsprechenden Eingriffe beendet sind ( } z \text {. B. } \\
\text { Hysterektomie: } 2 \text { h, Kolonoperation: } 3 \text { h, koronare Bypass-OP } \\
5 \text { h) }\end{array}$} \\
\hline
\end{tabular}

\section{CDC-Risiko-Index}

Die Centers for Disease Control and Prevention (CDC, Atlanta, USA) haben Anfang der 1990er-Jahre einen Risikoindex vorgestellt, der zusätzlich zu den Kontaminationsklassen weitere Risikofaktoren berücksichtigt (•Tab. 1.26).

Er ermöglicht durch die Stratifizierung in 4 verschiedene Risikokategorien einen aussagefähigen Vergleich der Wundinfektionsraten zwischen den Operateuren einer Klinik sowie mit anderen Abteilungen und Krankenhäusern. Generell kann man die Risikofaktoren in endogene und exogene Faktoren unterteilen (•Tab. 1.27) wobei es sich überwiegend um potenzielle - also nicht in kontrollierten Studien gesicherte - Risikofaktoren handelt.

\section{Multiresistente Erreger (MRE)}

In den vergangenen Jahrzehnten hat die Häufigkeit multiresistenter Erreger, insbesondere Methicillin-(Oxacillin-)resistenter S. aureus-Stämme (MRSA), weltweit sehr zugenommen. Heute wird dafür vorwiegend der Selektionsdruck durch (Breitspektrum-)Antibiotika verantwortlich gemacht. Ein weiterer Faktor für die Verbreitung von MRE ist eine mangelhafte Umsetzung der Infektionspräventionsmaßnahmen bei der direkten Patientenversorgung, wodurch es zu Erregerübertragungen zwischen den Patienten kommen kann.
- Tab. 1.27 Risikofaktoren für postoperative Wundinfektionen

Endogene Höheres Lebensalter: reduzierte AbwehrRisiko- funktionen

faktoren

Extremes Übergewicht: Infektionen im Bereich der Inzision durch reduzierte Durchblutung, größeres Wundgebiet, größere operationstechnische Probleme durch das adipöse Gewebe

Begleitkrankheiten: mehrere schwere Krankheiten

Nasale Besiedlung mit $\mathrm{S}$. aureus

Infektion entfernt vom OP-Gebiet an einer anderen Körperstelle

Kontaminationsklasse des Eingriffs

Hypothermie während des Eingriffs

Exogene Dauer des präoperativen Aufenthaltes: Je Risiko- länger, umso schwerer die Erkrankungen und

faktoren umso größer die Möglichkeit der Besiedlung mit potenziell-pathogenen, auch (multi-)resistenten Erregern

Präoperative Haarentfernung durch konventionelle Rasur am Abend vor der Operation

Spezielle Operationstechniken, z. B. erhöhtes Sternuminfektionsrisiko bei koronarer Bypassoperation unter Verwendung der A. mammaria interna, möglicherweise wegen daraus resultierender schlechterer Sternumdurchblutung

Dauer der Operation: Je länger die Operation, umso höher das Expositionsrisiko für die Wunde und umso größer die Möglichkeit der Gewebetraumatisierung wegen längerer Manipulationen am Gewebe

Allogene Bluttransfusionen, wenn die Leukozyten nicht weitgehend durch Filtration eliminiert sind

$\checkmark$ Nosokomiale Erregerübertragungen kommen überwiegend durch Kontakt (v. a. über die kontaminierten Hände des Personals und über kontaminierte Gegenstände bzw. Instrumente im weiteren Sinne) zustande.

Dies gilt für alle MRE, die zwar nicht virulenter als empfindliche Bakterienstämme sind, aber für die u. U. nur wenige (und v. a. keine Basis-)Antibiotika bei einer ggf. erforderlichen antimikrobiellen Behandlung wegen einer Infektion zur Verfügung stehen. Für MRSA trifft dies heute allerdings weniger zu als für Enterobakteriazeen (z. B. Extended-Spektrum-Betalaktamase-Bildner [ESBL]), weil es für die Behandlung von MRSA-Infektionen inzwischen mehrere neue Antibiotika gibt (z. B. Linezolid, Tigecyclin). 


\section{Isolierung bei MRSA-Patienten}

Nationale und internationale Leitlinien empfehlen meist immer noch strikte Isolierungsmaßnahmen: Unterbringung in einem Einzelzimmer, das der Patient nicht verlassen soll, sowie umfangreiche Schutzkleidung für das Personal bei Betreten des Zimmers. Angesichts der Bedeutung, die der »lsolierung « von Patienten mit MRSA zugemessen wird, tritt jedoch in den Hintergrund, dass die Grundlage für die Prävention jeder Erregerübertragung eine gute Standardhygiene, also v. a. Händehygiene ist. Denn die strikten Regeln, die im Falle von MRSA angeblich unverzichtbar sind, haben vorrangig das Ziel, das Personal ständig daran zu erinnern, dass eine Übertragung des Erregers verhindert werden muss. Es sind also an sich supportive Maßnahmen, mit denen die aus zahlreichen Untersuchungen bekannte mangelnde Beachtung der Händehygiene kompensiert werden soll. Mit diesen Barrieremaßnahmen soll sichergestellt werden, dass der MRSA des Patienten nach Ablegen der Schutzkleidung im Zimmer des Patienten bleibt und nicht mit dem Personal, v. a. an dessen Händen, zu anderen Patienten gelangen kann. Die Forderung nach strikter Isolierung von Patienten mit MRSA ist also nicht stringent, sondern vielmehr Ausdruck der Resignation vor der fehlenden sog. Compliance eines Teils des medizinischen Personals, die Standards der Infektionsprävention adäquat zu erfüllen, und darf nicht so verstanden werden, als sei die Effektivität dieser Maßnahmen bei der Prävention von MRSA im Vergleich zu einer guten Standardhygiene belegt.

\section{Konzept "Standardhygiene statt Isolierung"}

Isolierungsmaßnahmen können nur bei dem Teil der Patienten angewendet werden, der als MRSA-besiedelt identifiziert ist. Ein wesentlicher Teil der Patienten mit MRSA wird jedoch a) bereits unerkannt besiedelt stationär aufgenommen, b) hat einen solchen Stamm unbemerkt via Übertragung während des Aufenthaltes erworben oder c) weist unter dem Selektionsdruck von Antibiotika im Verlauf der Behandlung unerwartet einen positiven Befund auf. Somit muss unter dem Aspekt der Infektionsprävention die Qualität der Versorgung aller Patienten während der gesamten Behandlung geeignet sein, Erregerübertragungen zu verhindern. Dies gilt natürlich nicht nur für MRSA, sondern für jeden Erreger.

\section{$\checkmark$ Auf eine gute Standardhygiene muss im Umgang mit jedem Patienten zu jeder Zeit Wert gelegt werden.}

Wie bei der Prävention von HBV-, HCV- und HIV-Übertragungen muss das Konzept Anwendung finden, dass jeder Patient als potenziell besiedelt angesehen werden muss und dass demzufolge die Prävention von Erregerübertragungen schon beginnen muss, wenn ein Patient in die (ambulante oder stationäre) Behandlung kommt, und nicht erst, nachdem ein MRE nachgewiesen wurde. Dem Personal muss vermittelt werden, dass Erregerübertragungen in den meisten Fällen durch einfache Maßnahmen vermeidbar sind und dass die Standardhygiene - auch bei Ausbrüchen - die größte Bedeutung hat. Demzufolge ist bei Nachweis von MRSA der Einsatz von situationsbezogenen patientennahen Barrieremaßnahmen (Händedesinfektion, Einmal-Handschuhe, Schutzkittel und ggf. Mund-Nasen-Schutz), abhängig von den individuellen Gegebenheiten, wie bei der Versorgung anderer Patienten auch sinnvoll. Mit anderen Worten: Das Personal kann Patienten mit MRSA in der normalen Arbeitskleidung versorgen und legt spezielle Schutzkleidung erst dann an, wenn es die am
Patienten beabsichtigte Tätigkeit erfordert: z. B. Ablegen des Arztkittels und Anlegen einer Schürze sowie von EinmalHandschuhen vor einem Wundverbandswechsel oder zusätzlich Anlegen eines Mund-Nasen-Schutzes vor dem endotrachealen Absaugen eines intubierten, beatmeten Patienten. Es gelten demnach die Regeln der Standardhygiene wie bei jedem Patienten, also v. a. die häufige Händedesinfektion.

Personaluntersuchungen (z. B. Nasenabstriche) sollten speziellen epidemiologischen Situationen vorbehalten bleiben (z. B. bei Verdacht auf einen Ausbruch). Der Patient seinerseits kann sich, wenn er mobil ist, frei im Krankenhaus bewegen und braucht keinen Mund-Nasen-Schutz zu tragen, wenn er nasal mit MRSA besiedelt ist. Zur Dekolonisierung bei nasaler Besiedlung werden die Patienten mit Mupirocin-Nasensalbe behandelt. Antiseptische Körperwaschungen sind sehr zeitund personalintensiv und hinsichtlich ihrer mittel- oder langfristigen Effektivität nicht belegt. In der OP-Abteilung sind die gleichen Maßnahmen wie bei allen anderen Eingriffen adäquat. Alle darüber hinaus gehenden Maßnahmen (z. B. Einteilung der Eingriffe bei Patienten mit MRSA immer am Ende des OP-Tages) sind nicht plausibel: Da die Wahrscheinlichkeit einer Übertragung von MRSA im Operationssaal nicht größer ist als bei empfindlichen Stämmen von S. aureus (oder anderen Erregern, wie z.B. E. coli), sind zusätzliche Maßnahmen nicht gerechtfertigt.

\section{$\checkmark$ Wichtig ist auch ein psychologischer Effekt: Der Verzicht auf strikte Isolierungsmaßnahmen im Um- gang mit Patienten, bei denen MRSA nachgewiesen wurde, führt zur Entängstigung der Patienten, deren Angehöriger sowie des Personals.}

Für das Personal ist dies beispielsweise auch mit der Erfahrung verbunden, dass jeder dazu beitragen kann, die Qualität der Patientenversorgung zu verbessern, und dass man mit einfachen Mitteln einen für alle sichtbaren Erfolg haben kann, und der Patient erfährt, dass er keine Angst vor einem "gefährlichen « Erreger haben muss. Hinweise (oder gar Belege) dafür, dass durch das Konzept "Standardhygiene statt Isolierung« das Risiko für die Mitpatienten steigen würde, MRSA zu erwerben, gibt es nicht.

\section{In Kürze}

\section{Entstehung von Wundinfektionen}

Entstehungsmechanismen nosokomialer Infektionen wichtig für effektive Präventionsmaßnahmen. Auch bei optimaler Praktizierung der Maßnahmen der Infektionsprävention bei der Krankenversorgung nur ein (kleinerer) Teil der Krankenhausinfektionen vermeidbar.

- Erregerspektrum: Bakterien (v. a. Staphylokokken wie S. aureus und S. epidermidis, E. coli), Pilze (C. albicans). Besondere Probleme mit multiresistenten Erregern (MRSA).

- Erregerreservoir: Patient (körpereigene Flora), exogen (Personal, Gegenstände, Luft).

Zu Risikokategorien, • Tab. 1.25, • Tab. 1.26, • Tab. 1.27. 


\subsubsection{Prävention von Wundinfektionen}

\section{Maßnahmen beim Personal}

Das Personal muss je nach Aufgabengebiet verschiedene teils organisatorische, teils konkrete Maßnahmen beachten, die der Infektionsprävention dienen sollen (sog. Hygienemaßnahmen), von denen aber die meisten in ihrer Effektivität nicht durch aussagefähige Untersuchungen belegt sind
(• Tab. 1.28). Viele dieser Maßnahmen sind Rituale, die dem Personal von Generation zu Generation weitergegeben, aber nie wirklich hinterfragt wurden bzw. werden.

\section{Chirurgische Händedesinfektion}

Mit der chirurgischen (oder präoperativen) Händedesinfektion soll die Elimination der transienten und eine weitgehende Reduktion der residenten Hautflora erreicht werden. Sie wird

- Tab. 1.28 Maßnahmen beim OP-Personal

Bereichskleidung

Schmuck und Armbanduhren

Händedesinfektion

Kopfschutz

Mund-NasenSchutz (Maske)

Sterile Operationskleidung
Vor Betreten der Operationsabteilung in der Umkleide Kasak, Hose, Haube und Bereichsschuhe anziehen (verdeckt darunter getragene saubere private Kleidung, z. B. T-Shirt mit kurzen Ärmeln, möglich)

Nach Verschmutzung wechseln

Vor Verlassen der Abteilung ausziehen (soll sehr sauber sein, weil sie unmittelbar unter dem sterilen OP-Kittel getragen wird, und soll deshalb nicht außerhalb der Operationsabteilung getragen werden)

Bereichsschuhe aus praktischen Erwägungen (nicht aus Gründen der Infektionsprävention) erforderlich, weil sie häufig während der Eingriffe kontaminiert werden und maschinell gewaschen werden können

Schmuck an Händen und Unterarmen nicht mit den Anforderungen an die Infektionsprävention im OP zu vereinbaren (beeinträchtigt ebenso wie Nagellack und künstliche Fingernägel die Händedesinfektion und muss vor dem Operieren ohnehin abgelegt werden)

Halsketten, Ohrringe und auch Nasenringe (sowie sonstiges Bodypiercing) aus der Sicht der Infektionsprävention irrelevant und deshalb - ebenso wie Brillen - auch im OP möglich

Vor Betreten des OP-Flurs, d. h. noch im Umkleideraum, durchführen

Als wichtigste Regel der Standardhygiene auch bei der (prä- und postoperativen) Patientenversorgung in der OP-Abteilung von großer Bedeutung

Muss vom gesamten Personal (also auch der Anästhesie oder der Kardiotechnik) berücksichtigt werden

Soll das Haar vollständig bedecken (für Vollbartträger zusammenhängender Kopfbartschutz)

Soll verhindern, dass Haare in das Operationsfeld gelangen

Kein Einfluss auf die Luftkeimzahl im OP-Saal

Außerhalb der OP-Säle ohne konkreten Nutzen im Sinne der Infektionsprävention (trägt aber dazu bei, dass das Personal immer ordentlich aussieht)

Nur im Operationssaal während der Operation bei allen anwesenden Personen sinnvoll, auf dem Flur und in den Nebenräumen nicht erforderlich (Bedeutung von Masken für die Infektionsprävention in aller Regel bei weitem überschätzt)

Masken für das Operationsteam sinnvoll, um den Operationssitus so gut wie möglich zu schützen (außerdem bieten sie Schutz vor verspritzendem Blut)

Muss dicht am Gesicht anliegen und Mund und Nase vollständig bedecken

Masken müssen während der Operation nicht routinemäßig, z. B. alle $2 \mathrm{~h}$, gewechselt werden, denn das Risiko einer Kontamination des steril gekleideten OP-Personals und/oder des offenen OP-Situs beim Maskenwechsel ist größer als der postulierte Nutzen frischer Masken

Zwischen 2 Eingriffen entweder anbehalten oder ablegen und entsorgen. Nicht herunterhängen lassen, da die Innenseite durch die Nasen-Rachen-Flora kontaminiert ist. Nach längerem, aber nicht notwendigerweise nach jedem kurzen Eingriff wechseln

Für das Reinigungspersonal, das zwischen den Eingriffen den Operationssaal säubert, nicht erforderlich

OP-Team erhält sterile Kittel und Handschuhe nach der chirurgischen Händedesinfektion

Bei Kittelwechsel während der Operation, erst den Kittel, dann die Handschuhen ausziehen, um Kontamination der Hände zu vermeiden (nach kurzer Händedesinfektion neuen Kittel und Handschuhe anziehen lassen) 
- Tab. 1.28 (Fortsetzung)

Sterile Bei starker Beanspruchung der Handschuhe (z. B. erhöhte Perforationsgefahr in der Traumatologie) grundsätz-

Handschuhe

lich mit doppelten Handschuhen operieren)

Tragen von doppelten Handschuhen reduziert das Risiko einer Kontamination mit bzw. Inokulation von Blut

Wechsel der Handschuhe nach Perforation und ggf. nach septischem Teil einer Operation (dazwischen kurze Händedesinfektion)

Verhalten während der Türen des Operationssaales während der Operation möglichst immer geschlossen lassen, weil sonst die Operation RLT-Anlage ihre Funktion nicht erfüllen kann

Während der Operation Anzahl der im OP-Saal anwesenden Personen soweit wie möglich reduzieren und unnötigen Personaldurchgang vermeiden

Ablegen der OP-Kleidung Nach dem Eingriff Kittel, Handschuhe und Maske im OP-Saal in die jeweiligen Entsorgungsbehälter ablegen Schuhe bei sichtbarer Kontamination ebenfalls im OP-Saal ausziehen

von allen steril gekleideten Personen des unmittelbaren Operationsteams vor Betreten des Operationssaales durchgeführt (-Tab. 1.29). Die Dauer der chirurgischen Händedesinfektion ist von 5 min noch in den 1980er Jahren über 3 min seit Beginn der 1990er Jahre auf mittlerweile nur noch 1,5 min zurückgegangen. Dies beruht darauf, dass die längeren Desinfektionszeiten nicht mit einer signifikant höheren Keimzahlreduktion verbunden sind. Aber nur sukzessive war es offenbar möglich, kürzere Zeiten für denkbar zu halten und zu untersuchen. Klinische Studien über den Einfluss unterschiedlicher Zeiten bei der chirurgischen Händedesinfektion auf die Häufigkeit von postoperativen Wundinfektionen gibt es nicht, weil derartige Studienprotokolle nicht realisierbar wären. Die kürzeren Desinfektionszeiten stellen eine wesentliche Erleichterung für das OP-Team dar, nicht nur, weil dadurch Zeit gespart wird, sondern vor allem weil die Haut langfristig weniger belastet wird.

- Tab. 1.29 Chirurgische Händedesinfektion

Erster operativer Eingriff

Verwendung von alkoholischen Einreibepräparaten
1 min Waschen der Hände und Unterarme bis zum Ellenbogen mit Flüssigseife (nur vor dem 1. Eingriff des Tages bzw. bei Verschmutzung oder Resten von Hautpflegemitteln)

Nur die Fingernägel und Nagelfalze, nicht die Haut mit der Nagelbürste reinigen

Haut mit einem sauberen Einmal- oder Baumwolltuch gründlich abtrocknen

Danach das Händedesinfektionsmittel während 1,5 min in der angegebenen Reihenfolge in ausreichender Menge in die Haut einreiben, so dass die Haut gut benetzt ist:

- $30 \mathrm{sec}$ Hände und Unterarme bis unterhalb der Ellenbogen

- $30 \mathrm{sec}$ Hände und unteres Drittel der Unterarme (Handschuhbereich)

- $30 \mathrm{sec}$ nur noch Hände und Handgelenke

- Desinfektionsmittel einreiben, bis die Haut trocken ist

Verwendung antiseptischer Seifen (z. B. Polyvidon-lodseife)
1 min Waschen der Hände und Unterarme bis zum Ellenbogen (Nagelbürste s. oben)

Danach z. B. weitere 3 min Waschen mit antiseptischer Seife (Dauer nicht untersucht, Schema s. oben)

Zum Schluss die Seife unter fließendem Wasser abspülen

Mit sauberem Baumwolltuch gründlich abtrocknen

Aufeinanderfolgende Eingriffe

Händewaschen

Händedesinfektion
In der Regel nicht erforderlich (nur bei Verschmutzung bzw. deutlichen Resten von Hautpflegemitteln) s. oben 


\section{Maßnahmen beim Patienten}

Im Rahmen der Operationsvorbereitung werden noch auf der Station (in der Regel am Tag vor der Operation) sowie unmittelbar präoperativ in der OP-Abteilung verschiedene Vorkehrungen getroffen, mit denen die Voraussetzungen für die Operation unter dem Aspekt der Infektionsprävention erfüllt werden sollen (•Tab. 1.30, • Tab. 1.31).

Die Maßnahmen bei Operationen von Patienten mit sog. septischen Eingriffen (• Tab. 1.25) sowie von Patienten mit meldepflichtigen übertragbaren Krankheiten gemäß $\$ \$ 6,7$ Infektionsschutzgesetz (z. B. Salmonellose, Tuberkulose) oder von Patienten mit Kolonisierung bzw. Infektion durch multiresistente Erreger (z. B. MRSA, ESBL-Bildner) unterscheiden sich davon nicht. Insbesondere ist weder die Durchführung solcher Eingriffe am Ende des OP-Tages zwingend noch müs- sen postoperativ spezielle Desinfektionsmaßnahmen vorgenommen werden. Die während des Eingriffs verwendeten Materialien und Gegenstände werden, wie nach jedem Eingriff üblich, entweder entsorgt oder für den Transport zur Aufbereitung bereitgestellt (• Tab. 1.32).

\section{Maßnahmen bei blutassoziierten Virusinfektionen}

\section{Schutz des Personals vor infizierten Patienten}

$\checkmark$ Auch Patienten, von denen man (noch) nicht weiß, dass eine mit Blut und Körperflüssigkeiten übertragbare Infektion (Hepatitis-B/C- oder HIV-Infektion) vorliegt, können infektiös sein Daher ist es notwendig, bei allen Patienten die gleichen Vorsichtsmaßnahmen zu beachten.

- Tab. 1.30 Präoperative Vorbereitung des Patienten auf der Station

Körperpflege Am Vortag baden oder duschen, dabei auf gründliche Reinigung bestimmter Körperregionen wie Nägel oder Bauchnabel achten sowie ggf. farbigen Nagellack entfernen (Beurteilung der peripheren Durchblutung)

Verwendung antimikrobieller Seife ohne Einfluss auf die Häufigkeit postoperativer Infektionen, so dass für die Körperwaschung am Tag vor dem Eingriff normale Seife verwendet werden kann

Bettzeug Bett nur frisch beziehen, wenn die Bettwäsche nicht mehr sauber ist

Gilt auch für sog. septische Patienten und Patienten mit MRSA und anderen MRE

Verbände Evtl. vorhandene Verbände erneuern, wenn sie nicht mehr frisch sind

Haarentfernung Haare lassen sich ebenso gut desinfizieren wie die Haut, deshalb möglichst keine Haarentfernung durchführen Wenn konventionelle Rasur, dann unmittelbar präoperativ, da minimale, d. h. nicht notwendigerweise sichtbare, Hautläsionen unvermeidbar sind

Am besten Haarschneidemaschine verwenden, dann auch Haarentfernung am Vortag möglich, da dabei kurze Stoppeln stehen bleiben und keine Hautläsionen entstehen

Auch Anwendung von Haarentfernungscreme am Vortag möglich (evtl. zuvor Allergietestung durchführen)

Transport in die Operationsabteilung
Patient in der Regel nur mit frischem Operationshemd ohne Unterwäsche bekleidet (saubere persönliche Unterwäsche möglich, wenn sie bei der OP nicht stört)

Nach Umlagerung vom Bett auf den OP-Tisch über mechanische Hebevorrichtung die Auflagefläche ringsum wischdesinfizieren (z. B. mit alkoholischem Flächendesinfektionsmittel)

- Tab. 1.31 Maßnahmen beim Patienten in der Operationsabteilung

Nach Übergabe an das OP-Personal

Hautdesinfektion

Abdecken des Patienten
In der Regel Haarschutz und bei Regionalanästhesie meist auch Maske (beides verzichtbar, denn zum Infektionsschutz nicht erforderlich)

Meist vom Operateur nach der chirurgischen Händedesinfektion, aber vor Anziehen des Operationskittels und der Handschuhe vorgenommen

Wenn erforderlich (z. B. bei Notfalloperation), die Haut über dem Operationsgebiet zuvor abwaschen (z. B. mit Polyvidon-lodseife)

Großflächige Desinfektion des Operationsfeldes mit einem geeigneten Hautdesinfektionsmittel, z. B. Polyvidonlod-Alkohol-Lösung, während z. B. 3 min, dabei das Desinfektionsmittel mit reichlich getränkten Tupfern auf der Haut verreiben und Tupfer mehrfach wechseln (Dauer nicht untersucht)

Sterile Tuchabdeckung durchgeführt von 2 Personen, die schon den sterilen Kittel und die sterilen Handschuhe angezogen haben (die Handschuhe müssen anschließend nicht notwendigerweise gewechselt werden)

Mehrweg- oder Einwegtücher möglich 
- Tab. 1.32 Maßnahmen nach der Operation

\begin{tabular}{|c|c|}
\hline \multirow{2}{*}{$\begin{array}{l}\text { Instrumenten- } \\
\text { entsorgung }\end{array}$} & Instrumente trocken in die Entsorgungscontainer legen \\
\hline & $\begin{array}{l}\text { Routinemäßiges Einlegen in Desinfektions- oder Reinigungslösung nicht erforderlich und auch hinsichtlich der } \\
\text { Lebensdauer der Instrumente nicht empfehlenswert }\end{array}$ \\
\hline $\begin{array}{l}\text { Wäsche- und } \\
\text { Abfallentsorgung }\end{array}$ & $\begin{array}{l}\text { Wäsche und Abfall noch im Operationssaal in die entsprechenden Transportsäcke bzw. -behälter geben (ggf. } \\
\text { bei meldepflichtigen übertragbaren Krankheiten Wäsche, die mit infektiösem Patientenmaterial kontaminiert } \\
\text { ist, zur sog. infektiösen Wäsche bzw. entsprechenden Abfall zum sog. infektiösen Abfall) }\end{array}$ \\
\hline Extubation & Meist in der Ein-/Ausleitung durchgeführt, aber auch im Operationssaal möglich \\
\hline \multirow[t]{2}{*}{$\begin{array}{l}\text { Transport in den } \\
\text { Aufwachraum }\end{array}$} & $\begin{array}{l}\text { Transport in den Aufwachraum (auch bei Patienten mit MRSA und anderen MRE) durch Anästhesiepersonal in } \\
\text { der OP-Bereichskleidung }\end{array}$ \\
\hline & $\begin{array}{l}\text { Umkleiden vor der Rückkehr in die Operationsabteilung nur erforderlich, wenn die Bereichskleidung ver- } \\
\text { schmutzt wurde }\end{array}$ \\
\hline \multirow{4}{*}{$\begin{array}{l}\text { Transport auf die } \\
\text { Station }\end{array}$} & Für den Rücktransport des Patienten nicht notwendigerweise frisches Bett erforderlich \\
\hline & $\begin{array}{l}\text { Nur wenn das Patientenbett beim Transport in die Operationsabteilung nicht mehr sauber war, die Bettwäsche } \\
\text { teilweise oder vollständig erneuern, bevor der frischoperierte Patient wieder in sein Bett kommt }\end{array}$ \\
\hline & Auch das Bettgestell nur dann reinigen, wenn es verschmutzt ist \\
\hline & $\begin{array}{l}\text { Zum Umlagern das saubere Bett z. B. in den Aufwachraum schieben, ohne dass zuvor Desinfektionsmaßnahmen, } \\
\text { z. B. an den Rädern, durchgeführt werden müssen }\end{array}$ \\
\hline
\end{tabular}

Das Tragen von doppelten Handschuhen reduziert das Risiko einer Kontamination mit bzw. Inokulation von Blut: Bei Beschädigungen ist nicht immer auch der innere Handschuh betroffen und im Falle eines Nadelstichs wird durch das Abstreifen des Blutes am Handschuhmaterial die inokulierte Blutmenge vermindert. Schnitt- und Stichverletzungen müssen durch umsichtiges und konzentriertes Arbeiten im Umgang mit scharfen und spitzen Gegenständen vermieden werden. Anstelle des manuellen Fassens und Führens der Nadel muss eine Operationstechnik mit vermehrtem instrumentellen Arbeiten angewendet werden. Wenn mit Verspritzen von Blut in die Umgebung zu rechnen ist, müssen Schutzbrillen getragen werden, um Bindehautkontakt zu vermeiden.

\section{Schutz der Patienten vor infizierten Operateuren \\ D Cave}

Übertragungen von HBV oder HCV von infizierten Operateuren auf Patienten sind wiederholt publiziert worden.

Meist wurden dafür intraoperative Verletzungen der Operateure verantwortlich gemacht, wodurch es zu einem Kontakt ihres Blutes mit Blut bzw. Gewebe der Patienten gekommen ist und damit eine Virusübertragung wahrscheinlich wurde. Teilweise sind derartige Verletzungen durch eine modifizierte Operationstechnik vermeidbar, manche Eingriffe sind aber auch besonders verletzungsträchtig.

In einigen Fällen war es jedoch nicht möglich, Übertragungen auf intraoperative Verletzungen der Operateure zurückzuführen. Stattdessen scheinen unbemerkte und nicht blutende Hautschäden sowie - ebenfalls nicht sichtbare - Beschädigungen der OP-Handschuhe ursächlich gewesen zu sein, die z. B. beim sehr festen Knüpfen oder beim Verschluss von Sternotomien entstanden sind. Als entscheidender Risikofaktor wurden in diesen Fällen sehr hohe Viruskonzentrationen der Operateure - bis $\mathrm{zu} 10^{9}$ Genomäquivalenten $/ \mathrm{ml}$ (Gäq/ml) Serum - betrachtet, deren Blut bzw. Gewebsflüssigkeit somit sehr infektiös war.

( Infiziertes Personal muss v. a. bei sog. übertragungsträchtigen Eingriffen besondere Vorsichtsmaßnahmen beachten.

Übertragungsträchtige operative Eingriffe bzw. intraoperative Situationen

- Operationen in beengtem Operationsfeld

- Operationen mit unterbrochener Sichtkontrolle

- Lang dauernde Operationen (mit dadurch bedingten Handschuhschäden)

- Sternotomieverschluss (und vergleichbare Situationen mit starker Beanspruchung der Hände beim Knüpfen)

In manchen Fällen sind (vorübergehende) Einschränkungen des Tätigkeitsspektrums erforderlich. Da Infektionen mit HBV oder HCV häufig klinisch inapparent verlaufen, müssen Operateure regelmäßig (z.B. einmal jährlich) die diagnostischen Marker untersuchen lassen, um eine Serokonversion so früh wie möglich zu entdecken und nicht unbemerkt $\mathrm{zu}$ einem vermeidbaren Risiko für die Patienten zu werden. Bei Viruskonzentrationen $<10^{3} \mathrm{Gäq} / \mathrm{ml}$ ist das Übertragungsrisiko erfahrungsgemäß gering. Eine HBV-Infektion ist allerdings durch die aktive Impfung vermeidbar und somit für jeden Operateur als Pflicht zu betrachten. 


\section{Perioperative Antibiotikaprophylaxe}

Ziel der perioperativen Antibiotikaprophylaxe ist die Keimzahlreduktion und die Wachstumshemmung potenziell pathogener Bakterien im Operationsgebiet, um das Risiko einer Infektion im Operationsgebiet zu reduzieren.

Jede Antibiotikagabe hat Auswirkungen auf die Normalflora und kann zur Entwicklung bzw. Selektion resistenter Erreger führen. Außerdem erhöht ein unangemessener Gebrauch von Antibiotika zur perioperativen Antibiotikaprophylaxe (zu lang und/oder zu breit) die Antibiotikakosten beträchtlich. Die perioperative Antibiotikaprophylaxe sollte möglichst kurz und "schmal" sein. Es sollen Basisantibiotika mit Wirksamkeit gegen S. aureus und normale Enterobakteriazeen (z. B. E. coli) sowie ggf. Anaerobier verwendet und möglichst nur eine einzige Dosis (und keine Antibiotikagabe mehr nach Ende der Operation) verabreicht werden.

. Cave

Breitspektrumantibiotika sind ungeeignet, da sie keine ausreichende Wirksamkeit gegen $\mathrm{S}$. aureus haben, dem häufigsten Erreger von Wundinfektionen unabhängig von der chirurgischen Fachdisziplin.

\section{Praxisbox}

Anwendungshinweise für die perioperative Antibiotikaprophylaxe

Intraoperativ müssen hohe Serumspiegel vorhanden sein, weil nur so hohe interstitielle Spiegel erreicht werden. Die Antibiotikagabe muss somit vor der Bildung von Koageln und Hämatomen erfolgen, weshalb die Gabe vor Beginn der Operation erforderlich ist, da Antibiotika bei späterer Gabe nicht sicher, wenn überhaupt, in Koagel etc. penetrieren können. Außerdem müssen dauerhaft hohe Serumspiegel während des gesamten Eingriffs aufrecht erhalten werden. Deshalb sind bei langen Operationen oder bei hohem Blutverlust wiederholte Gaben notwendig.

Die Antibiotikagabe muss unmittelbar vor Beginn der Operation erfolgen, $d$. h. vor einer potenziellen Kontamination des Gewebes. Die Gabe wird als Kurz$\nabla$ infusion vorgenommen, in der Regel über eine Dauer von 15-20 min. Es wird die übliche therapeutische Dosis verabreicht, in der Regel als Einmal-Gabe. Bei wiederholter Gabe soll das Dosierungsintervall der 2- bis 3-fachen Halbwertszeit entsprechen (z. B. bei Basiscephalosporinen alle $2-3 \mathrm{~h}$ ).

\section{Auswahl der Antibiotika}

( Für die Standardprophylaxe ist die Wirksamkeit gegen S. aureus und (normale) Enterobakteriazeen, wie z. B. E. coli erforderlich.

Insofern sind Basiscephalosporine oder Aminopenicillin- $\beta$ Laktamaseinhibitor-Kombinationen gut geeignet. Beispiele für die entsprechenden operativen Fachgebiete sind die Herzund Gefäßchirurgie, Thoraxchirurgie, Orthopädie, Unfallchirurgie und Neurochirurgie. Wenn eine Beteiligung von Anaerobiern möglich ist, kommt die Kombination mit Metronidazol, $\beta$-Laktamaseinhibitor oder Clindamycin in Frage, z.B. in der Allgemeinchirurgie, Gynäkologie/Geburtshilfe, Urologie, Hals-Nasen-Ohren-Chirurgie und Zahn-MundKiefer-Chirurgie.

Abhängig von der speziellen Resistenzsituation der Klinik bzw. Abteilung müssen ggf. andere als die Standardsubstanzen angewendet werden. Dies gilt ebenso bei Patienten mit $\beta$-Laktamallergie. Dann eignet sich z. B. Clindamycin (in Kombination mit einem Aminoglykosid, wenn Enterobakteriazeen berücksichtigt werden müssen).

\section{Reinigung, Desinfektion und Sterilisation}

Reinigung, Desinfektion und Sterilisation sind verschiedene Methoden der Dekontamination, die abhängig davon, welchen Grad der mikrobiellen »Reinheit« man erreichen muss, angewendet werden müssen.

\section{Risikokategorien für Gegenstände}

Die Wahl der Dekontaminationsmethode hängt davon ab, welches potenzielle Risiko für den Patienten von einem Gegenstand ausgeht. Unabhängig von der Methode muss für eine vollständige Trocknung gesorgt sein (•Tab. 1.33).

- Tab. 1.33 Risiko-Kategorien für Gegenstände

Nichtkritische Gegenstände: Reinigung

Semikritische Gegenstände: Reinigung und Desinfektion

Kritische Gegenstände: Reinigung und Sterilisation
Kontakt mit intakter Haut, aber nicht mit Schleimhäuten (z. B. Blutdruckmanschette, Stethoskop, Bettgestell, Möbel, Waschbecken, Wände, Fußboden)

Infektionsrisiko nicht vorhanden oder vernachlässigbar gering

Kontakt mit Schleimhäuten oder nicht intakter Haut (z. B. Beatmungs-, Narkosezubehör, Endoskope)

Infektionsrisiko bei Kontamination mit potenziell-pathogenen Mikroorganismen

Kontakt mit dem Blutgefäßsystem und/oder sterilem Gewebe (z. B. Kanülen, chirurgische Instrumente, intravasale Katheter, Blasenkatheter, Implantate)

Hohes Infektionsrisiko bei Kontamination mit Mikroorganismen aller Art 


\section{Reinigung}

\section{Definition}

Unter Reinigung versteht man die Beseitigung sichtbarer Verunreinigungen (z. B. Schmutz, Staub, organisches Material).

Dabei wird gleichzeitig ein großer Anteil an Mikroorganismen beseitigt.

( Eine gründliche Reinigung ist der erste und wichtigste Schritt bei der Dekontamination von Gegenständen, weil eine anschließend erforderliche Desinfektion oder Sterilisation nur erfolgreich sein kann, wenn zuvor alle Rückstände entfernt worden sind.

\section{Desinfektion}

\section{- Definition}

Als Desinfektion bezeichnet man die weitgehende oder vollständige Eliminierung potenziell pathogener Mikroorganismen (außer bakterieller Sporen).

Bei Instrumenten sollen wegen der höheren Sicherheit - und auch aus Gründen des Personalschutzes - vollautomatischthermische Verfahren bevorzugt werden, weil die mechanische Komponente mit intensiver Spülung zusätzlich einen wesentlichen Beitrag zur Reduktion der Erreger leistet ( $\bullet$ Abb. 1.74, - Tab. 1.34).

Für die Dekontamination von Flächen kommt nur die Wischdesinfektion in Frage, wobei Reinigung und Desinfektion in einem Arbeitsgang erfolgen.

D Cave

Das Versprühen von Desinfektionsmitteln oder das Verdampfen von Formaldehyd als "Raumdesinfektion « sind längst überholte Maßnahmen, die der Vergangenheit angehören müssen, weil sie ineffektiv und toxikologisch problematisch sind.

\section{Sterilisation}

- Definition

Sterilisation ist die vollständige Elimination aller mikrobiellen Zustandsformen (inkl. bakterieller Sporen), also sowohl der potenziell pathogenen Mikroorgansimen als auch apathogener Keime.

Abhängig von der Hitzeverträglichkeit des Materials kann eine Sterilisation mit verschiedenen Verfahren erreicht werden, von denen die Dampfsterilisation (Autoklavieren) die sicherste Methode ist.

\section{Flächendesinfektionsmaßnahmen in der OP-Abteilung} In den Operationssälen kommt es häufig zu einer Kontamination in der Umgebung des Operationstisches. Deshalb werden

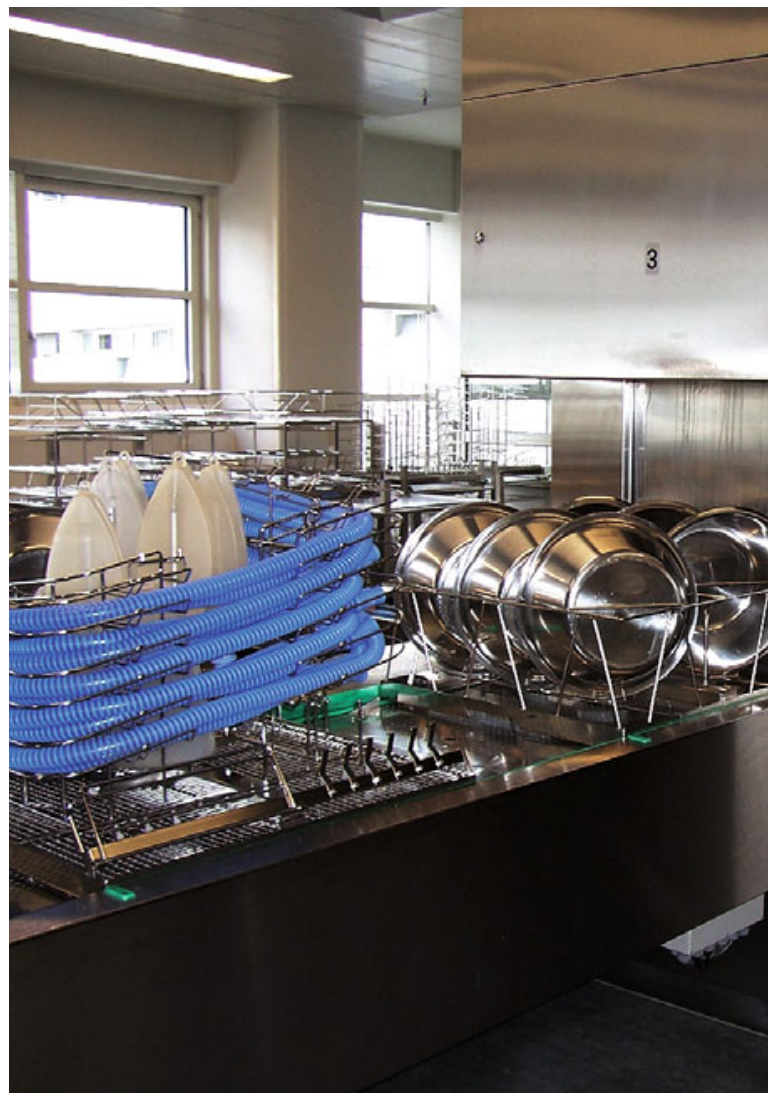

- Abb. 1.74 Taktbandanlage einer Zentralen Sterilgut-Versorgungsanlage (ZSVA). Vollautomatische Reinigung, thermische Desinfektion (z. B. bei $90^{\circ} \mathrm{C}$ für $5 \mathrm{~min}$ ) und Trocknung von chirurgischen Instrumenten, Beatmungsschläuchen, Waschschüsseln usw.

Flächendesinfektionsmaßnahmen durch Zusatz eines Desinfektionsmittels zum Wischwasser routinemäßig durchgeführt. In der Operationsabteilung werden dieselben Desinfektionsmittel und Anwendungskonzentrationen wie im übrigen Krankenhaus eingesetzt.

Dies gilt auch nach sog. septischen Eingriffen (inklusive bei MRE), nach Operationen bei Patienten mit blutassoziierten Virusinfektionen sowie bei meldepflichtigen übertragbaren Krankheiten (z. B. Tuberkulose, Salmonellose), bei denen über das übliche Maß hinausgehende Desinfektionsmaßnahmen nur durchgeführt werden müssen, wenn dies vom zuständigen Gesundheitsamt im konkreten Fall angeordnet wurde. Einwirkzeiten müssen nicht abgewartet werden: Sobald die Flächen getrocknet sind, können die Vorbereitungen für den nächsten Eingriff beginnen. 
- Tab. 1.34 Reinigung, Desinfektion, Sterilisation

Reinigung

Gründliche Reinigung erster und wichtigster Schritt bei der Dekontamination von Gegenständen und Flächen

Beseitigung sichtbarer Verunreinigungen (z. B. Schmutz, Staub, organisches Material) und eines großen Teils der vorhandenen Mikroorganismen

Reinigungseffekt durch Zusammenwirken von mechanischer Reinigung und schmutzlösender Wirkung der Reinigungsmittel

Anzahl an Mikroorganismen zusätzlich durch Trocknung reduziert

In vielen Fällen sind Reinigungsmaßnahmen für eine adäquate Dekontamination von Gegenständen oder Flächen ausreichend

Desinfektion

Ziel im klinischen Alltag: Reduktion der Zahl potenziell pathogener Keime auf einer Fläche oder einem Gegenstand in dem Maße, dass eine Erregerübertragung nicht mehr möglich ist

Thermostabile Materialien:

Physikalisch-thermische Verfahren in vollautomatischen Reinigungs- und Desinfektionsmaschinen

Seltener Dampfdesinfektion gereinigter und verpackter Gegenstände in Autoklaven

Thermolabile Gegenstände:

Vollautomatische maschinelle chemo-thermische oder rein chemische Verfahren

Manuelle Verfahren der Instrumentendesinfektion mit chemischen Desinfektionsmitteln

Wegen höherer Sicherheit (und Personalschutz) vollautomatische Verfahren bevorzugen

Sterilisation

Thermostabile Materialien:

Feuchte Hitze: Dampfsterilisation = Autoklavieren

Trockene Hitze: Heißluftsterilisation

Thermolabile Gegenstände:

Plasmasterilisation

Gassterilisation mit Formaldehyd- und Ethylenoxid

Sog. Kalt-Sterilisation:

Mit bestimmten chemischen Desinfektionsmitteln unter definierten Bedingungen ebenfalls Sterilisation möglich (d.h. Eliminierung aller vorhandenen Mikroorganismen bis hin zu bakteriellen Sporen)

Rekontamination möglich (fehlende Verpackung)

Erhöhte Störanfälligkeit

Möglichst nur dann anwenden, wenn die sicheren vollautomatischen Verfahren nicht zur Verfügung stehen

\section{In Kürze}

\section{Prävention von Wundinfektionen}

- Entscheidend für die Prävention ist die systematische Beachtung der Standardhygiene, also v. a. der Händehygiene, durch alle Personen, die in die Patientenversorgung involviert sind.

- Maßnahmen bei Patienten und Personal, v. a. bei blutassoziierten Virusinfektionen (doppelte Handschuhe, Verletzungen vermeiden, regelmäßige Blutuntersuchungen, HBV-Impfung).

- Perioperative Antibiotikaprophylaxe: »Kurz und schmal«, intraoperativ hohe Serumspiegel, z. B. Basis-

cephalosporine, Aminopenicillin- $\beta$-LaktamaseinhibitorKombinationen, bei Anaerobiern Kombination mit Metronidazol, $\beta$-Laktamaseinhibitor oder Clindamycin.

- Dekontamination von Gegenständen durch gründliche Reinigung, Desinfektion (für Instrumente vollautomatisch-thermische Verfahren, für Flächen Wischdesinfektion) und Sterilisation (Elimination aller mikrobiellen Zustandsformen v. a. durch Dampfsterilisation (Autoklavieren). 


\subsubsection{Wundverbandswechsel}

Da nicht jede Wunde primär heilt oder nicht primär verschlossen werden kann, müssen Ärzte in der chirurgischen Ausbildung frühzeitig darin unterrichtet werden, wann ein Wundverband sinnvoll ist und wie Wundverbände bei offenen und infizierten Wunden sowie in den unterschiedlichen Heilungsphasen so durchgeführt werden, dass Kontaminationen ausgeschlossen sind. Der Zustand der Operationswunde ist ein wichtiges Ergebnis von Operationen. Der Verbandswechsel gibt dem Operateur Gelegenheit, postoperativ mit dem Patienten in Kontakt zu bleiben, indem über den Zustand der Wunde und den Fortgang der Heilung gesprochen wird. Diese Kommunikation hilft dem Patienten auch, über eine unerwartet lange Phase der postoperativen Wundheilung hinwegzukommen.

\section{Primärer Wundverschluss}

Bei primär heilenden Operationswunden sind Verbandswechsel nicht mehr erforderlich, wenn der am Ende der Operation gelegte Verband $\mathbf{4 8} \mathrm{h}$ danach entfernt wird. Bei primärem Wundverschluss ist eine Wunde ohne Drainage nach spätestens $48 \mathrm{~h}$ nicht mehr kontaminationsgefährdet. Die Wunden können offen bleiben oder mit einem Pflasterstreifen bedeckt werden. Sie müssen aber weiterhin beobachtet und darauf kontrolliert werden, dass die Wundheilung ungestört abläuft und nicht z. B. sekundäre Dehiszenzen entstehen.

$>$ Jede Wunde jedoch, die, obwohl primär verschlossen, nicht an jeder Stelle primär verheilt, und alle Wunden, die bis zu einem sekundären Verschluss offen gelassen werden, benötigen einen Verband zum Auffangen des Wundsekrets und zum Schutz vor Kontamination.

Jede Flüssigkeit zum Spülen von Wunden muss steril sein. Leitungswasser ist nicht keimfrei und kann sog. Wasserbakterien, z. B. Pseudomonas spp., enthalten. Beim Duschen infizierter Wunden mit Leitungswasser kann es also zu einer sekundären Kontamination der Wunde kommen, wenngleich der damit erzielte mechanische Spüleffekt positiv ist, weil Sekretreste und nekrotisches Gewebe auf schonende Art gründlich entfernt werden.

\footnotetext{
Praxisbox

Wundverbandswechsel

- Wenn die Wundflächen groß sind und damit das Risiko der Kontamination der Arbeitskleidung besteht, Arztkittel vorher ablegen und z. B. Einmalschürze umbinden.

- Händedesinfektion durchführen und Einmal-Handschuhe anziehen.

- Verband bis auf die wundabdeckenden Kompressen entfernen und vorsichtig in einen gut erreichbaren Abfalleimer entsorgen.
}

- Danach die wundabdeckende Kompresse mit steriler Pinzette abnehmen und ebenfalls ohne Kontamination der Umgebung sofort entsorgen.

- Handschuhe ausziehen und Händedesinfektion durchführen, anschließend mit No-Touch-Technik weiterarbeiten, d.h. kein Kontakt der Wunde mit den Händen, sondern nur mit sterilen Instrumenten.

- Reinigung der Wunde wie im individuellen Fall erforderlich (z. B. Kompressen mit Kochsalzlösung tränken und die Umgebung der Wunde sauber wischen).

- Antiseptikum auf die Wundfläche auftragen und trocknen lassen.

- Frische Wundauflagen auflegen und geeignet fixieren.

- Arbeitsfläche des Verbandswagens z. B. mit alkoholischem Flächendesinfektionsmittel wischdesinfizieren.

- Abschließend nochmals Händedesinfektion und Dokumentation des Zustands der Wunde im Krankenblatt.

Nach Möglichkeit soll beim Verbandswechsel zu zweit gearbeitet werden, weil dadurch das aseptische Arbeiten erleichtert wird. Unabhängig davon, ob die Wunden infiziert sind oder nicht, soll der Verbandswagen zum Patienten mitgenommen werden. Denn man hat im Zimmer des Patienten praktisch nie eine geeignete Ablagefläche zur Verfügung, auf der man z. B. ein Tablett mit den notwendigen Materialien abstellen kann (wenn das Verbandsmaterial in diesen Fällen nicht ohnehin in die Kitteltaschen gesteckt und dann letztlich auf dem Patientenbett abgelegt wird). Diese Improvisation wird auf die Patienten eher unprofessionell wirken. Ein solches Vorgehen ist darüber hinaus mit den Erfordernissen eines unter aseptisch Kautelen durchzuführenden Verbandswechsels nicht zu vereinbaren.

\section{Aseptischer Verbandswagen}

Obwohl eine verbreitete Gepflogenheit, ist es dennoch nicht sinnvoll, für »aseptische« (nichtinfizierte) und »septische« (infizierte) Wunden 2 verschiedene Verbandswagen vorzuhalten. Denn dieses System impliziert die Möglichkeit der Kontamination der dort gelagerten Utensilien bei der Versorgung infizierter Wunden und die nachfolgende Übertragung der Erreger dieser Wunden auf andere Patienten. Eine Kontamination muss jedoch nicht nur bei nichtinfizierten Wunden vermieden werden, sondern kann selbstverständlich auch bei bereits infizierten Wunden nicht toleriert werden. Diese Zusammenhänge sind an sich unbestritten, dass aber dennoch vielerorts an einer Trennung zwischen »aseptischen« und »septischen« Patienten festgehalten wird, ist nur ein Beispiel für die mangelnde Folgerichtigkeit, die Empfehlungen von »Hygienemaßnahmen«zugrunde liegen kann ( $\downarrow$ Abschn. 1.7.1). Als Vertreter einer medizinischen Disziplin, die selten mit »harten « Daten (wie bei naturwissenschaftlich orientierten Fächern) argumentieren kann, sondern sich zu einem beträchtlichen Teil auf die meist als »weich « bezeichneten epidemiologischen Daten stützen muss, scheint die Krankenhaushygiene für Denkbarrieren und Fiktionen besonders anfällig zu sein. 


\section{Antiseptische Wundbehandlung}

Primär heilende Wunden müssen nicht in regelmäßigen Abständen mit einem Antiseptikum behandelt werden. Man entfernt also ca. $48 \mathrm{~h}$ postoperativ den noch im Operationssaal gelegten Verband, säubert die Wunde ggf. und kann anschließend noch einmal ein Antiseptikum auf die Wunde geben. Sind Drainagen vorhanden, ist eine regelmäßige antiseptische Behandlung an deren Austrittsstelle sinnvoll, bis die Hautdefekte nach ihrer Entfernung wieder verschlossen sind. Nahtmaterial und Hautklammern werden mit sterilen Instrumenten nach gründlicher Desinfektion der Naht entfernt.

\section{In Kürze}

\section{Wundverbandswechsel}

- Primärer Wundverschluss: nach $48 \mathrm{~h}$ kein Verband mehr nötig, aber weiterhin Kontrolle (Infektion, Dehiszenzen).

- Möglichst aseptischer Verbandswechsel: Verbandswagen (keine Trennung in septisch und aseptisch nötig), möglichst zu zweit, sterile Spülflüssigkeit für die Wunde (kein Leitungswasser), regelmäßige antiseptische Behandlung bei Drainagen.

\subsubsection{Surveillance postoperativer Wundinfektionen}

Das Infektionsschutzgesetz (IfSG) fordert im $\$ 23$ die sog. Surveillance nosokomialer Infektionen in der operativen Medizin (auch im ambulanten Bereich).

\section{Definition \\ Surveillance bedeutet Überwachung und hat im epidemi- ologischen Kontext von Krankenhausinfektionen eine er- weiterte Bedeutung, die man als kontinuierliche systema- tische Beobachtung, Analyse, Interpretation und Bericht- erstattung umschreiben kann.}

Aus den Ergebnissen der Surveillance können ggf. Maßnahmen zur Lösung von Infektionsproblemen abgeleitet werden. Für die Überwachung der postoperativen Infektionen im Operationsgebiet sollte ein typischer operativer Eingriff ausgewählt werden, der häufig durchgeführt wird und mit einem relevanten postoperativen Infektionsrisiko assoziiert ist. Die Auswahl einer solchen sog. Indikatoroperation kann jede chirurgische Abteilung individuell treffen. Es werden dann nur die Patienten beobachtet, bei denen dieser Eingriff vorgenommen wurde.

\section{Berechnung der Infektionsraten}

Für die Berechnung der postoperativen Wundinfektionsraten wird die Anzahl der Wundinfektionen nach bestimmten operativen Eingriffen (z. B. Cholezystektomie) auf alle Patienten
- Tab. 1.35 Stratifizierte Wundinfektionsraten

\begin{tabular}{|l|l|l|l|}
\hline Risiko-Score & $\begin{array}{l}\text { Anzahl der } \\
\text { Operationen }\end{array}$ & $\begin{array}{l}\text { Anzahl } \\
\text { der Wund- } \\
\text { infektionen }\end{array}$ & $\begin{array}{l}\text { Stratifizierte } \\
\text { Wundinfek- } \\
\text { tionsrate }\end{array}$ \\
\hline 0 & 42 & 1 & $2,4 \%$ \\
\hline 1 & 55 & 2 & $3,6 \%$ \\
\hline 2 & 37 & 3 & $8,1 \%$ \\
\hline 3 & 24 & 4 & $16,7 \%$ \\
\hline $\begin{array}{l}\text { Alle } \\
\text { Operationen }\end{array}$ & 158 & 10 & $6,3 \%$ \\
\hline
\end{tabular}

bezogen, bei denen dieser Eingriff während des Beobachtungszeitraumes (z. B. 1 Jahr) durchgeführt wurde: Die Rate gibt die Inzidenz von Wundinfektionen für alle Patienten an, bei denen die Indikatoroperation durchgeführt wurde, und wird in Prozent angegeben.

\section{Stratifizierung nach Risikokategorie}

Für einen aussagefähigen späteren Vergleich von Wundinfektionsraten mit den Ergebnissen zurückliegender Zeiträume oder mit Referenzdaten wird ebenfalls eine Inzidenzrate berechnet, aber nur auf die jeweilige Risikokategorie gemäß CDC-Risiko-Index (•Tab. 1.26) bezogen. Für diese sog. stratifizierte Wundinfektionsrate wird die Anzahl der Wundinfektionen bei den Patienten der einzelnen Risikokategorien durch die Gesamtzahl der Patienten mit der Indikatoroperation in der jeweiligen Risikokategorie dividiert. Für Vergleiche zieht man nur die Infektionsraten derselben Risikokategorie heran, um nur Patienten mit vergleichbarem Risiko einander gegenüber zu stellen (•Tab. 1.35).

\subsubsection{Baulich-technische Maßnahmen zur Prävention postoperativer Infektionen}

\section{Bauliche Konzeption von Operationsabteilungen}

Operationsabteilungen werden baulich und organisatorisch vom übrigen Krankenhausbereich durch Vorräume (sog. Schleusen für Personal-, Material- und Geräte) abgetrennt. Die bauliche Konzeption muss ein störungsfreies Ineinandergreifen der verschiedenen Organisationsabläufe ermöglichen. 
Raumlufttechnische Anlagen (RTL-Anlagen)

Moderne RLT-Anlagen in Operationsabteilungen führen keimarme bis nahezu keimfreie Luft in die angeschlossenen Räume. In Deutschland wurden RLT-Anlagen für OP-Abteilungen jahrzehntelang so geplant, dass sämtliche Räume der Abteilung (also auch Flure, Diktatkabinen und Aufenthaltsräume) 3-stufig gefiltert wurden, d. h. mit Grobfilter, Feinfilter und endständigem Schwebstofffilter, der 99,97\% aller schwebenden Partikel $(<5 \mu \mathrm{m})$ zurückhält. Dieser hohe lufttechnische Aufwand ist jedoch nur in den Operationssälen gerechtfertigt. Für die Notwendigkeit spezieller strömungstechnischer Vorkehrungen in OP-Sälen (LAF = Laminar Air Flow oder TAV = turbulenzarme Verdrängungsströmung) gibt es jedoch keine Grundlage. Mit der letzten Fassung der DIN 1946/4 (RLT-Anlagen in Gebäuden und Räumen des Gesundheitswesens) von 2008 wurde aber von dem zuständigen DIN-Ausschuss (fast ausschließlich bestehend aus Technikern und Vertretern der einschlägigen Industrie) ein RLT-Konzept vertreten, das eine solche aufwändige Technik für alle Operationen (im Gegensatz zu sog. Eingriffen) und damit für jeden OP-Saal (sog. Raumklasse la im Gegensatz zu Raumklasse Ib im sog. Eingriffsraum) fordert. Damit wird die DIN 1946/4 (2008) den heutigen wissenschaftlichen Erkenntnissen über die Rolle der Luft als Erregerreservoir für postoperative Wundinfektionen nicht gerecht. Aus diesem Grunde hat sich die Kommission für Krankenhaushygiene und Infektionsprävention (KRINKO) beim Robert-Koch-Institut von dieser DIN-Norm in einer Stellungnahme distanziert (Epidemiologisches Bulletin 4/2010; www.rki.de): "Die Studienlage zum infektionsprophylaktischen Effekt von (...) RLT-Anlagen mit (...) TAV zeigt gegenwärtig (Stand: 12/2009) keinen Vorteil in Bezug auf die Prävention von postoperativen Wundinfektionen/Infektionen im Operationsgebiet (Kategorie III, keine Empfehlung, ungelöste Frage). Eine Differenzierung in Raumklasse la und Ib ist somit unter diesem Gesichtspunkt nicht gerechtfertigt." Eine DIN-Norm ist keine Rechtsvorschrift, sondern eine Regel der Technik. Als solche muss sie zu den verschiedenen Fragestellungen darstellen, welche technischen Möglichkeiten vorhanden sind bzw. welche Gegebenheiten ggf. aktuell erforderlich sind, sofern der Sachverstand im DIN-Ausschuss dazu Stellung nehmen kann. Medizinische Sachverhalte gehören jedoch nicht zur Kompetenz eines Ausschusses für technische Regelwerke, und das bedeutet, dass die Frage, welche Art von RLT-Anlage (incl. Filterung und Strömungstechnik) ausreichend bzw. erforderlich ist, von Medizinern auf dem Boden der wissenschaftlichen Erkenntnisse beantwortet werden muss.

\section{Weiterführende Literatur}

Jarvis WR (Hrsg) (2007) Bennett \& Brachman's Hospital infections, 5. Aufl. Wolters Kluwer Lippincott Williams \& Wilkins, Philadelphia

Kappstein I (2009) Nosokomiale Infektionen - Prävention, Labor-Diagnostik, Antimikrobielle Therapie, 4. Aufl. Georg Thieme Verlag, Stuttgart

Mayhall CG (Hrsg.) (2004) Hospital epidemiology and infection control. 3. Aufl., Lippincott Williams \& Wilkins, Philadelphia

\subsection{Chirurgisch relevante Schockformen}

\author{
P. Krebs, J. Bail, A. Junger
}

In der Umgangssprache wird der Begriff »Schock« für sehr unterschiedliche körperliche und psychische Zustände gebraucht. Diese reichen vom körperlich schwer Verletzten bis hin zum psychisch »Schockierten «, aber körperlich Unversehrten, z. B. nach einem schweren psychischen Trauma (Verlust eines Angehörigen). Im Jahr 1737 beschrieb der französische Chirurg Le Dran ${ }^{16}$ die Symptomatik von Patienten mit schweren Schusswunden als »Choc«.

In medizinischen Sprachgebrauch versteht man unter Schock einen lebensbedrohlichen physischen Zustand unterschiedlicher Genese, der mit einer kritischen Beeinträchtigung der Organperfusion (Mikro- und Makrozirkulation) und konsekutivem Missverhältnis zwischen Sauerstoffangebot und Sauerstoffbedarf einhergeht.

Je nach Ursache können folgende Schockformen unterschieden werden:

- Hypovolämischer Schock

- Hämorrhagischer Schock

- Septischer Schock

- Neurogener Schock

- Anaphylaktischer Schock

- Kardiogener Schock

All diese Schockformen können im Zeitverlauf über das klinische Bild einer generalisierten inflammatorischen Reaktion, einem sog. Systemischen Inflammatorischen Response Syndrom (engl. Systemic Inflammatory Response Syndrome, SIRS), zu einem Multiorganversagen (MOV) führen, das mit einer sehr hohen Sterblichkeit einhergeht.

Am Anfang dieses Kapitels wird zunächst diese systemische inflammatorische Antwort (SIRS) und das daraus resultierende Multiorganversagen näher beschrieben, bevor die für das Fachgebiet der Chirurgie besonders relevanten Schockformen dargestellt werden.

Zu den unterschiedlichen Schockformen, • Tab. 1.36

\subsubsection{Systemisches inflammatorisches Response Syndrom (SIRS)}

\section{- Definition}

Im Jahre 1992 wurde im Rahmen einer Konsensuskonferenz des American College of Chest Physicians und der Society of Critical Care Medicine (ACCP/SCCM) eine Definition dieses klinischen Syndroms erarbeitet.

Ein SIRS wird rein deskriptiv beschrieben und liegt vor, wenn mindestens 2 der folgenden Bedingungen erfüllt sind. 
- Tab. 1.36 Schockformen

\begin{tabular}{|c|c|c|c|}
\hline Schockform & Ursache & Besonderheiten & Therapie \\
\hline Hypovolämisch & $\begin{array}{l}\text { Dehydratation, z. B. Durchfälle, } \\
\text { Verbrennungen }\end{array}$ & $\begin{array}{l}\text { Hypovolämie } \\
\text { periphere Vasokonstriktion und } \\
\text { Zentralisation } \\
\text { blasse, kühle Haut } \\
\text { Blässe, Kaltschweißigkeit }\end{array}$ & $\begin{array}{l}\text { Therapie der Grunderkrankung, } \\
\text { z. B. Ileus, Pankreatitis } \\
\text { Ausgleich des Volumenmangels } \\
\text { (Infusionen) }\end{array}$ \\
\hline Hämorrhagisch & $\begin{array}{l}\text { Starke Blutung, z. B. Trauma, } \\
\text { Operation }\end{array}$ & $\begin{array}{l}\text { s. o. } \\
\text { zusätzlich Anämie }\end{array}$ & $\begin{array}{l}\text { Chirurgische Blutungskontrolle } \\
\text { Volumentherapie, u. a. Blutprodukte } \\
\text { unterstützend Normalisieren der } \\
\text { Hämostase }\end{array}$ \\
\hline Septisch & Infektion (Bakterien, Viren, Pilze) & $\begin{array}{l}\text { Inflammatorische Effekte im Bereich } \\
\text { der Mikrozirkulation (Vasodilatation } \\
\text { und Ödembildung) mit relativer } \\
\text { Hypovolämie und Hypotonie } \\
\text { Störung der Gewebeoxygenierung }\end{array}$ & $\begin{array}{l}\text { Herdsanierung, antimikrobielle } \\
\text { Therapie (Antibiotika) sowie diffe- } \\
\text { renzierte Volumen- und Katechola- } \\
\text { mintherapie }\end{array}$ \\
\hline Neurogen & $\begin{array}{l}\text { Periphere oder zentrale neurolo- } \\
\text { gische Schädigung, z. B. Hirn- } \\
\text { stammschädigung oder akuter } \\
\text { Querschnitt }\end{array}$ & $\begin{array}{l}\text { Störung der Kreislaufregulation mit } \\
\text { Vasodilatation und konsekutiver } \\
\text { relativer Hypovolämie }\end{array}$ & $\begin{array}{l}\text { Therapie der neurologischen } \\
\text { Störung sowie differenzierte Volu- } \\
\text { men- und Katecholamintherapie }\end{array}$ \\
\hline Anaphylaktisch & $\begin{array}{l}\text { Anaphylaktische und anaphy- } \\
\text { laktoide Reaktion, z. B. Antibiotika, } \\
\text { Latexallergie, Röntgenkontrast- } \\
\text { mittel }\end{array}$ & $\begin{array}{l}\text { IgE-Antikörper-vermittelte oder } \\
\text { direkte Freisetzung von Histamin, } \\
\text { Serotonin, Bradykinin mit Vasodila- } \\
\text { tation und relativer Hypovolämie } \\
\text { Quaddelbildung und Gewebsödem } \\
\text { Bronchospasmus }\end{array}$ & $\begin{array}{l}\text { Entfernung der auslösenden Subs- } \\
\text { tanz (Allergen) und Stoppen der } \\
\text { überschießenden Immunreaktion } \\
\text { (Adrenalingabe, Antihistaminika), } \\
\text { differenzierte Volumen- und } \\
\text { Katecholamintherapie }\end{array}$ \\
\hline Kardiogen & $\begin{array}{l}\text { - Myokardiales Pumpversagen, } \\
\text { z.B. Myokardinfarkt, Myokarditis, } \\
\text { - } \text { rhythmogenes Pumpversagen, } \\
\text { z.B. Tachykardien, Asystolie, } \\
\text { - mechanische Pumpversagen, } \\
\text { z. B. Vitien, Lungenembolie }\end{array}$ & $\begin{array}{l}\text { Erniedrigter systolischer Blutdruck } \\
\text { (RR } \leq 90 \mathrm{mmHg} \text { ) } \\
\text { Vermindertes Herzzeitvolumen } \\
\text { (Herzindex } \leq 2,2 \mathrm{l} / \mathrm{min} / \mathrm{m}^{2} \text { Körper- } \\
\text { oberfläche) } \\
\text { Erhöhter linksventrikulärer Füllungs- } \\
\text { druck (LVEDP }>15 \mathrm{mmHg} \text { ) }\end{array}$ & $\begin{array}{l}\text { Therapie der Grunderkrankung, } \\
\text { z. B. Lyse bei Herzinfarkt } \\
\text { Wiederherstellen einer ausreichend } \\
\text { kardialen Pumpfunktion (Inotro- } \\
\text { pika, Diuretika) }\end{array}$ \\
\hline
\end{tabular}

Bedingungen für das Vorliegen eines SIRS

(SIRS; mindestens 2 Kriterien)

- Fieber $\left(\geq 38^{\circ} \mathrm{C}\right)$ oder Hypothermie $\left(\leq 36^{\circ} \mathrm{C}\right)$

- Tachykardie (Herzfrequenz $\geq 90 / \mathrm{min}$ )

- Tachypnoe (Frequenz $\geq 20 / \mathrm{min}$ ) oder Hyperventilation (paCO2 $\leq 4,3 \mathrm{kPa} / \leq 33 \mathrm{mmHg}$ )

- Leukozytose $\left(\geq 12.000 / \mathrm{mm}^{3}\right)$ oder Leukopenie $\left(\leq 4.000 / \mathrm{mm}^{3}\right)$ oder $\geq 10 \%$ unreife Neutrophile im Differenzialblutbild

\section{- - Ätiologie}

Während eine lokale Entzündungsreaktion auf eine bestimmte Körperregion beschränkt bleibt, handelt es sich bei dem SIRS um eine systemische Entzündungsreaktion des Körpers, also eine komplexe systemische inflammatorische Wirtsreaktion auf eine Noxe unterschiedlicher Genese.
Das SIRS kann u. a. durch folgende Erkrankungen getriggert werden: Neben lokalen Entzündungen (z. B. Pneumonien, Wundinfektionen, Darmperforation mit Peritonitis) kommen schwere Traumata (Polytraumen), Schock, Verbrennung, schwere Blutungen, Ischämien, große Operationen (z.B. Herzoperationen) und auch nekrotisierende Pankreatitiden in Frage.

\section{- " Pathophysiologie und Klinik}

Durch die jeweilige endogene oder exogene Noxe kommt es zur lokalen Aktivierung von zellulären Bestandteilen (Lymphozyten, Makrophagen) und humoralen Kaskadensystemen (Gerinnungssystem, Kinin-Kallikrein-System, Komplementsystem) und konsekutiv zur Freisetzung von inflammatorischen Mediatoren und Zytokinen (u. a. TNF, IL6, NO). Diese lokale Entzündung stellt eine physiologische Abwehrreaktion dar und dient der Wiederherstellung der Integrität des Organismus. 
Damit sich die Entzündungsreaktion nicht unkontrolliert ausbreitet, versucht der Körper nun mithilfe seiner anti-inflammatorischen Systeme, z. B. durch die Freisetzung von entzündungshemmenden Mediatoren (IL4, IL10) und Hormonen (Kortisol), dem kompensatorisch entgegenzuwirken um die Entzündung zu begrenzen. Diese generalisierte Immunreaktion wird als CARS (Compensatory Anti-inflammatory Response Syndrome) bezeichnet und birgt das Risiko der verminderten Immunkompetenz und Infektabwehr.

Versagt die Antiinflammation so kommt es zu einer überschießenden Entzündungsreaktion, die sich im gesamten Organismus ausbreitet, häufig mit Tachykardie, Fieber und Blutdruckabfall einhergeht und dann als SIRS bezeichnet wird. Diese generalisierte unkontrollierte Inflammation ist für den Organismus schädlich. Das gleichzeitige Ablaufen beider Reaktionen wird als MARS (Mixed Antagonistic Response Syndrome) bezeichnet.

$>$ Jegliche Inbalance zwischen diesen pro- und antiinflammatorischen Systemen ist potentiell gefährlich.

Proinflammatorische Mediatoren führen in der Mikrozirkulation u. a. zur Gerinnungsaktivierung und zur Leukozytenadhäsion im Bereich des Endothels. Durch die vermehrte Freisetzung und Synthese von NO kommt es zur Vasodilatation. Die gleichzeitig eintretende vaskuläre Permeabilitätsstörung hat ein perivaskuläres und interstitielles Ödem zur Folge. Dieser Flüssigkeit-Shift ins Gewebe und die weitgestellten Arteriolen führen zu einer relativen Hypovolämie auf Ebene der Makrozirkulation und zum Abfall des arteriellen Blutdrucks.

\section{- Diagnostik}

Die Diagnose wird anhand der oben beschriebenen 3 klinischen Zeichen und des Differenzialblutbildes gestellt.

$\checkmark$ Die SIRS-Kriterien sind sehr unspezifisch und müssen sehr sorgfältig im klinischen Kontext interpretiert werden.

Die Kriterien wurden primär entwickelt, um für zukünftige Studien kritisch Kranke objektiver klassifizieren zu können.

\section{-1 - Therapie}

Die Therapie hängt von der primären Noxe und Schockform ab und wird in den jeweiligen Unterkapiteln besprochen.

\subsubsection{Multiorganversagen}

\footnotetext{
Definition

Unter einem Multiorganversagen (MOV) oder auch Multi Organ Dysfunction Syndrome (MODS) versteht man das gleichzeitige oder sequentielle Versagen von mindestens 2 lebenswichtigen Organsystemen.
}

\section{- Ätiologie}

Meist geht dem Multiorganversagen ein schweres SIRS voraus, das durch eine primär lokal begrenzte Noxe getriggert wurde
( $\triangleright$ Abschn. 1.8.1). Im fortgeschrittenen Verlauf kann es dann zu einer Kreislaufinstabilität kommen und zu einer kritischen Minderperfusion verschiedener Organe mit einem Missverhältnis zwischen Sauerstoffangebot und Sauerstoffverbrauch. Wie bereits oben dargestellt, führt die generalisierte Entzündungsreaktion zu einer Endothelzellschädigung und Permeabilitätszunahme (capillar leak) in der Mikrozirkulation mit Entwicklung von interstitiellen Ödemen, welche die Sauerstoffversorgung weiter beeinträchtigen.

\section{- . Pathophysiologie und Klinik}

Die Klinik des Multiorganversagens hängt von den jeweils betroffenen Organen ab. Die Mortalität steigt mit der Anzahl der betroffenen Organe dramatisch an (bei 3 oder mehr Organsysteme über $80 \%$ !).

Herz und Kreislauf Zirkulierende Mediatoren und Endotoxine haben vasodilatatorische (z. B. NO) und direkt negativ inotrope (TNF) Effekte. Hieraus resultieren massive Blutdruckabfälle bis hin zur therapieresistenten Vasoplegie und eine erheblich eingeschränkte Pumpfunktion (septische Kardiomyopathie). Nicht nur die systolische Pumpfunktion ist dabei beeinträchtigt, sondern auch die diastolische Funktion (Relaxierung) ist durch das interstitielle intramyokardiale Ödem reduziert. Die Therapie gestaltet sich rein symptomatisch und besteht aus einer differenzierten Katecholamin- und Volumentherapie.

Lunge Das klassische Lungenversagen äußert sich durch eine akute respiratorische Insuffizienz mit Hypoxämie. Je nach Auswirkung der Hypoxämie unterscheidet man anhand des $\mathrm{p}_{\mathrm{a}} \mathrm{O}_{2} / \mathrm{FiO}_{2}$-Quotienten zwischen einem Acute Lung Injury (200-300 mmHg, ALI) und dem Acute Respiratory Distress Syndrome ( $\leq 200 \mathrm{mmHg}$, ARDS) mit morphologischem Umbau des Lungengewebes. Im Röntgenbild finden sich bilaterale Infiltrate und Zeichen eines intraalveolären Lungenödems. Die ödembedingten massiven Atelektasen führen zu einem erheblichen intrapulmonalen Shunt und zur Hypoxämie. Mit lungenprotektiven Beatmungsverfahren (niedrige Atemzugvolumina mit PEEP, positive end-expiratory pressure), negativer Bilanzierung und ggf. extrakorporalen Lungenersatzverfahren (ECMO) wird versucht die Funktion der Lunge bis zur Selbstheilung zu unterstützen.

Niere Das akute Nierenversagen (ANV) per se geht mit einer deutlich erhöhten Mortalität einher. Durch Vasodilatation, verminderten Blutdruck, Minderperfusion sowie durch verschiedene Mediatoren kommt es zum Abfall der renalen Filtrationsrate. Bei abnehmender Urinausscheidung steigen die nierenpflichtigen Substanzen im Plasma an (Kreatinin, Harnstoff). Durch den Einsatz von Nierenersatzverfahren (Hämofiltration bzw. -dialyse) kann der Funktionsausfall auch längerfristig kompensiert werden.

Leber und Gastrointestinaltrakt Im Splanchnikusgebiet führt die Perfusionsstörung mit Ödembildung und Gewebeischämie zur hepatischen Dysfunktion und Verlust der Darmintegrität. 
Vor allem der Gastrointestinaltrakt spielt im Rahmen des MOV eine wichtige Rolle. Durch die Darmischämie kommt es zur Schädigung der Mukosa und zur Translokation von Bakterien aus dem Darmlumen in das Gefäßsystem.

( Die daraus resultierende Bakteriämie oder Toxinämie kann sowohl für die Entstehung als auch für die Aufrechterhaltung eines Multiorganversagens verantwortlich sein.

Die Zeichen einer gestörten Leberintegrität (Plasmabilirubin $>2,0 \mathrm{mg} / \mathrm{dl}$, Gerinnungsstörungen, Hypoglykämien) sind meist erst relativ spät im Krankheitsverlauf zu beobachten und prognostisch ungünstig.

Therapeutisch ist die Optimierung des Sauerstoffangebotes durch eine zielgerichtete Kreislauftherapie entscheidend. Zudem wird eine frühe enterale Ernährung über entsprechende Sonden (Magensonde, Gastroduodenalsonde) angestrebt. Die Erwartungen an die in den letzten Jahren entwickelten Leberersatzverfahren (z. B. Albumindialyse) haben sich nur zum Teil erfüllt.

Gerinnung Im Rahmen der inflammatorischen Reaktion kommt es zur generalisierten überschießenden Aktivierung des Gerinnungssystems mit Verbrauch von Gerinnungsfaktoren und gesteigerter Fibrinolyse. Diese disseminierte intravasale Koagulopathie oder auch kurz DIC (Disseminated Intravascular Coagulation) genannt, führt zu einer verstärkten Blutungsneigung und endet schlussendlich in einem $\mathrm{Zu}$ sammenbruch der Blutgerinnung. Neben der Behandlung des ursächlichen Grundleidens spielt die Transfusions- und Hämotherapie v. a. mit Gerinnungspräparaten eine entscheidende Rolle.
Nervensystem Bereits früh im Rahmen einer kritischen Erkrankung kommt es zu einer zerebralen Dysfunktion mit Abnahme der kognitiven Leistung. Häufig sind zerebrale Symptome wie Verwirrtheit und Somnolenz die ersten Zeichen einer kritischen Erkrankung. Bei längerem intensivpflichtigen Krankheitsverlauf ist bei vielen Patienten zudem eine Critical IIIness Polyneuropathie (CIP) mit schlaffer Parese festzustellen, die schwierig zu therapieren ist und mit einer schlechten Prognose einhergeht. Neben der Vermeidung von Muskelrelaxantien und Glukokortikoiden spielt hier die möglichst flache Sedierung und die frühe Mobilisierung eine entscheidende Rolle.

\section{- Diagnostik}

Die Diagnose wird organspezifisch gestellt und ergibt sich aus dem Gesamtbild der Einzeldiagnosen. Als globaler Parameter für eine allgemeine Sauerstoffunterversorgung in den verschiedenen Organen (Hypoxämie) wird häufig die Serum-Laktatkonzentration bestimmt. Es muss allerdings bedacht werden, dass eine erhöhte Laktatkonzentration sowohl von einer gesteigerten Produktion in den verschiedenen Organen aufgrund eines gesteigerten anaeroben Stoffwechsels, als auch durch einen verminderten Laktatabbau in der Leber verursacht sein kann.

Zur Beurteilung von Schweregrad und Verlauf eines MOV werden verschiedene Score-Systeme eingesetzt. Von den verschiedenen existierenden Scoring-Systemen soll an dieser Stelle nur auf den Sequential Organ Failure Assessment (SOFA) Score näher eingegangen werden. Er beinhaltet mit nur 6 einfachen Parametern wesentlich weniger Variablen als sonstige Scores und ist somit relativ einfach anwendbar (- Tab. 1.37). Obwohl der SOFA-Score primär zur Beschreibung von Organdysfunktionen und -ausfällen entwickelt wur-

- Tab. 1.37 Bewertungssyteme des SOFA-Scores (Sequential Organ Failure Assessment Score)

\begin{tabular}{|c|c|c|c|c|}
\hline Parameter & 1 Punkt & 2 Punkte & 3 Punkte & 4 Punkte \\
\hline \multicolumn{5}{|l|}{ Respiration } \\
\hline $\mathrm{p}_{\mathrm{a}} \mathrm{O}_{2} / \mathrm{FiO}_{2}[\mathrm{mmHg}]$ & $<400$ & $<300$ & $<200^{1}$ & $<100^{1}$ \\
\hline \multicolumn{5}{|l|}{ Koagulation } \\
\hline Thrombozyten $\left[10^{3} \mathrm{~mm}^{3}\right]$ & $<150$ & $<100$ & $<50$ & $<20$ \\
\hline \multicolumn{5}{|l|}{ Leber } \\
\hline Bilirubin [mg/dl] & $1,2-1,9$ & $2,0-5,9$ & $6,0-11,9$ & $>12,0$ \\
\hline $\begin{array}{l}\text { Herz-Kreislauf-System } \\
\text { Hypotension }^{2}\end{array}$ & MAP $<70 \mathrm{mmHg}$ & $\begin{array}{l}\text { Dopamin } \leq 5 \text { oder } \\
\text { Dubutamin (jede Dosis) }\end{array}$ & $\begin{array}{l}\text { Dopamin }>5 \text { oder Adrenalin } \\
\leq 0,1 \text { oder Noradrenalin } \leq 0,1\end{array}$ & $\begin{array}{l}\text { Dopamin }>15 \text { oder Adrenalin } \\
>0,1 \text { oder Noradrenalin }>0,1\end{array}$ \\
\hline \multicolumn{5}{|l|}{ ZNS } \\
\hline Glasgow-Koma-Skala & $13-14$ & $10-12$ & $6-9$ & $<6$ \\
\hline \multicolumn{5}{|l|}{ Niere } \\
\hline Kreatinin [mg/dl] & $1,2-1,9$ & $2,0-3,4$ & $3,5-4,9$ & $>5,0$ \\
\hline oder Urinausfuhr [ml/Tag] & & & $<500$ & $<200$ \\
\hline
\end{tabular}


de, konnte eine gute Korrelation mit dem Outcome nachgewiesen werden.

\section{- " Therapie}

Die wesentlichen intensivmedizinischen Grundprinzipien in der Therapie des Multiorganversagens sind die Therapie der Grunderkrankung sowie die symptomatische Therapie der einzelnen Organversagen. Letzteres beinhaltet die verschiedenen organunterstützenden Maßnahmen (z.B. Beatmung, Katecholamintherapie) sowie die einzelnen Organersatzverfahren (z. B. Dialyse, ECMO). Ein weiterer wesentlicher Aspekt ist die Optimierung des globalen Sauerstoffangebots u. a. durch die frühzeitige und zielgerichtete Kreislauftherapie mit Volumengabe und medikamentöser Kreislaufunterstützung.

\subsubsection{Hypovolämischer Schock}

\section{- Definition}

Der Begriff hypovolämischer Schock (•Tab. 1.36) bezeichnet verschiedene Schockformen, denen ein intravasaler Flüssigkeitsverlust gemeinsam ist.

Beim Gesunden hat der Körper einen Wasseranteil von ca. 50-75\%:

- Kinder $60-75 \%$

- Frauen $50-55 \%$

- Männer 60-65\%

Das Körperwasser verteilt sich zu ca. 65\% auf den intrazellulären Raum, zu ca. 28\% auf das Interstitium und zu ca. 7\% auf den intravasalen Raum. Wasser kann zwischen diesen Räumen verschoben werden, so dass eine Änderung des Wasseranteils in einem der Kompartimente mit einer gewissen Verzögerung auch eine Änderung in den anderen Kompartimenten nach sich zieht. Der Körper kann auf unterschiedliche Art Flüssigkeit (sog. Volumen) verlieren.

\section{- Definition}

Unter einem hypovolämischen Schock versteht man einen Schockzustand, bei dem das zirkulierende Blutvolumen aufgrund eines Flüssigkeitsverlustes stark reduziert ist.

Unter den Begriff hypovolämischer Schock fallen

- der Dehydratationsschock durch fortgeschrittenen Flüssigkeitsmangel (z. B. Exsikkose, Ileus),

- der hämorrhagische Schock (durch Blutung),

- der traumatisch-hypovolämische Schock (traumatisch bedingter Flüssigkeitsverlust, z. B. bei Verbrennung).

- Ätiologie

Dehydratationsschock Verschiedene Krankheitsbilder können zu einer protrahierten Exsikkose führen:

- Äußere Flüssigkeitsverluste können durch Polyurie, Erbrechen und Durchfälle (Diabetes insipidus, Diuretikaüberdosierung, akutes Nierenversagen) und durch vermehrtes Schwitzen (Hyperthermie, Fieber) bedingt sein.
- Innere Flüssigkeitsverluste von durchaus mehreren Litern entstehen durch Sequestration (bei z. B. Ileus, Pankreatitis oder Leberzirrhose)

- Eine über längere Zeit zu geringe Flüssigkeitszufuhr ist einem Verlust gleich zu setzten. Neben Patienten mit gastrointestinalen Erkrankungen können hiervon besonders Kinder und Alte betroffen sein. Hierdurch kann es zu einer kritischen Reduktion des intravaskulären Volumens mit nachfolgendem Schock kommen.

\section{Hämorrhagischer Schock}

- Definition

Ein hämorrhagischer Schock ist auf eine akute Blutung zurückzuführen.

Sowohl bei traumatischer wie atraumatischer Blutung kann es sich um eine innere oder äußere Blutung handeln.

- Häufige nichttraumatische Blutungen sind: gastrointestinale Blutung, Gefäßruptur bei Aneurysma oder Dissektion, peripartale Blutung, Gefäßarrosion durch Tumore

- Traumatisch bedingte Blutungen entstehen durch spitze oder stumpfe Gewalteinwirkung. Hierbei kann die Blutung durch eine direkte Verletzung größerer Blutgefäße bedingt sein. Aber auch eine ausgedehnte Verletzung von Weichteilen und Knochen kann ohne direkte Verletzung großer Gefäße zu dramatischen Blutverlusten führen. Beim polytraumatisierten Patienten können gleichzeitig mehrere Blutungsquellen bestehen.

Traumatisch-hypovolämischer Schock Durch Verbrennungen, Verbrühungen oder Verätzungen können große Teile der Körperoberfläche verletzt werden. Über diese großflächigen Wunden der Haut und der darunter liegenden Gewebe können große Mengen an Flüssigkeit verloren gehen.

\section{- . Pathophysiologie und Klinik}

Beim Schock kommt es zu einer Minderdurchblutung und somit $\mathrm{zu}$ einem Sauerstoffmangel lebenswichtiger Organe. Zunächst führt der Sauerstoffmangel zur Störung der Zellfunktion, d.h. zu reversiblen Funktionsstörungen einzelner Organe. Bei fortbestehender Mangelversorgung mündet dies in einen Zelluntergang, also in irreversible strukturelle Organschädigungen.

Veränderung der Makrozirkulation im Schock Wie bei allen Schockarten haben wir es auch beim hypovolämischen Schock mit einem Abfall des Herzzeitvolumens zu tun.

Wenn das Herzzeitvolumen sinkt, so wird pro Minute weniger Sauerstoff durch den Körper gepumpt und es sinkt auch der systemarterielle Blutdruck.

Der Körper reagiert auf einen Schock initial über das Herzkreislaufsystem, das renale System und über das neuroendokrine System.

Beim Gesunden transportiert das arterielle Blut pro Zeit deutlich mehr Sauerstoff, als der Körper in dieser Zeit ver- 
stoffwechselt. Die Sauerstoffausschöpfung liegt normal unter 25-30\%, woraus eine zentralvenöse Sättigung $\left(\mathrm{ScvO}_{2}\right)$ von $>70 \%$ resultiert. Ein vermindertes Sauerstoffangebot führt zunächst zu einer erhöhten Sauerstoffextraktion, so dass die $\mathrm{ScvO}_{2}$ unter 70\% fällt. Die $\mathrm{ScvO}_{2}$ ist sicherlich ein Globalparameter, der keine Aussage über die Sauerstoffextraktion eines spezifischen Organs, sondern nur des Körpers als Ganzem zulässt. Jedoch kann damit ein generalisiertes Krankheitsbild wie ein Schock in seiner Schwere erfasst und ggf. die Therapie u. a. danach gesteuert werden.

Der Blutdruckabfall wird über Barorezeptoren in linkem Vorhof, Aortenbogen, Karotissinus und Lungenstrombahn registriert. Über den Nucleus tractus solitarii führt die geringere "Feuerrate « der Barorezeptoren zu einem Anstieg des Sympathotonus und gleichzeitig zu einer Aktivitätsminderung des Parasympathikus. Hierdurch schlägt das Herz schneller und kräftiger (positiv inotrope und positiv chronotrope Wirkung) wodurch sich das Sauerstoffangebot wieder erhöht. Über eine Gefäßengstellung im Splanchnikusgebiet, der Haut und Skelettmuskulatur wird das Blut innerhalb des Gefäßsystems zu den »lebenswichtigeren" Organen Herz, Lunge und Gehirn umverteilt. Durch die Vasokonstriktion im präkapillären und postkapillären Gefäßen sinkt nicht nur das im jeweiligen Organ befindliche Blutvolumen. Durch den verminderten hydrostatischen Druck im Kapillarbett wandert in begrenztem Umfang Flüssigkeit vom extravaskulären Raum in die Kapillaren, d.h. das Blutvolumen wird über eine Art Autotransfusion erhöht. Diese Erhöhung des intravasalen Volumens führt zu einem Anstieg der kardialen Vorlast und somit zu einem höheren Schlagvolumen, was das Herzzeitvolumen wieder erhöht. Durch die Vasokonstriktion im arteriellen Bereich wird der systemvaskuläre Widerstand gesteigert, was zu einer Stabilisierung des Blutdrucks führt.

In den Nieren wird im Schock vom juxtaglomerulären Apparat vermehrt Renin freigesetzt. Durch den hierdurch erhöhten Angiotensin-II Spiegel wird die arterioläre Vasokonstriktion weiter verstärkt und durch den höheren Aldosteronspiegel wird vermehrt Natrium und Wasser aus dem Primärharn rückresorbiert. Dies bewirkt ein erhöhtes Blutvolumen.

Über das neuroendokrine System wird aus der Hypophyse vermehrt antidiuretisches Hormon (ADH) ausgeschüttet. Auch hierdurch wird mehr Wasser aus dem Primärharn rückresorbiert und das intravaskuläre Volumen steigt.

Veränderung der Mikrozirkulation Bereits durch den Schock selbst, bei dem das Herzzeitvolumen reduziert ist, sind der systemische und somit auch der kapilläre Blutfluss verringert. Durch die kompensatorische Umverteilung des Blutes aus dem Splanchnikusgebiet, der Haut und Skelettmuskulatur wird dort der kapilläre Blutfluss zusätzlich gedrosselt. Bei fortbestehendem Schock und vermindertem Blutfluss im Kapillargebiet werden die Versorgung der Zellen mit Sauerstoff und die Entsorgung von Stoffwechselprodukten gestört. Die unterversorgten Zellen müssen die notwendige Energie für Ihren Stoffwechsel durch anaerobe Glykolyse bereitstellen. Die hierbei anfallenden sauren Valenzen werden bei verminderter Durchblutung nicht ausreichend abtransportiert, es entwickelt sich eine Gewebeazidose. In dieser Situation sind nicht nur die Zellen von z. B. Darm, Nieren oder Muskel in ihrer Funktion gestört, sondern auch die Zellen der Kapillaren selbst, hier v. a. die Endothelzellen. Die Störung der Endothelfunktion, die auch durch eine erhöhte Konzentration von Histamin, Bradykinin, Prostanoiden und anderen Zytokinen bedingt wird, führt zu einem Anschwellen der Endothelzellen und einem kapillären Leck. Dies hat 2 Folgen: Einerseits kommt es durch eine schlechtere Sauerstoffdiffusion aufgrund der längeren Diffusionsstrecke durch die Kapillarwand zu einer konsekutiv weiteren Verschlechterung der Sauerstoffversorgung der Organe. Andererseits entwickelt sich ein interstitielles Ödem und das intravaskuläre Volumen nimmt weiter ab. Durch die niedrige Fließgeschwindigkeit und die ödembedingte Hämokonzentration im Kapillarbett verschlechtern sich nun auch noch die Fließeigenschaften des Blutes, was bis zur Stase im Kapillargebiet führen kann.

Besonderheiten des Dehydratationsschocks Beim Verlust von Wasser kommt es durch Volumenverschiebung auch zu einem verminderten Plasmavolumen, jedoch gehen primär keine Blutzellen verloren. Somit kommt es zu einer Hämokonzentration mit einem Anstieg des Hämatokrit. Hierdurch verschlechtern sich die Fließeigenschaften des Blutes und die kapilläre Durchblutung wird zusätzlich verschlechtert.

Besonderheiten des hämorrhagischen Schocks Derhämorrhagische Schock (• Abb. 1.75) ist besonders dadurch gekennzeichnet, dass nicht nur Wasser, sondern auch Blutzellen und Gerinnungsfaktoren verloren gehen. Es verringert sich durch den Abfall der Hämoglobinkonzentration die Sauerstofftransportkapazität des Blutes. Bis zu einem gewissen Maß wird dies durch verbesserte Fließeigenschaften des Blutes bei niedrigem Hämatokrit kompensiert, führt jedoch im weiteren Verlauf zu einem verringerten zellulären Sauerstoffangebot (Diese Grenze kann von Patient zu Patient unterschiedlich sein. Sie liegt etwa bei einem Hämatokrit von 20-30\%).

Durch den Sauerstoffmangel im Gewebe entwickelt sich wie oben beschrieben eine metabolische Azidose.

Ein weiteres Problem ist die sich entwickelnde Gerinnungsstörung. Durch den Verlust von Blutzellen gehen nicht nur Erythrozyten verloren (Anämie), wodurch die Sauerstofftransportkapazität des Blutes sinkt, sondern auch Thrombo-

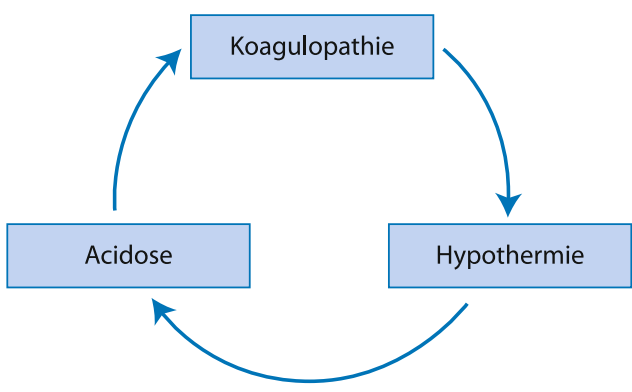

- Abb. 1.75 Koagulopathie - Azidose - Hypothermie 
- Tab. 1.38 Schockstadien (Erwachsene) nach dem ATLS-Konzept

\begin{tabular}{|c|c|c|c|c|}
\hline Parameter & Stadium 1 & Stadium 2 & Stadium 3 & Stadium 4 \\
\hline Blutverlust (ml) & $<750$ & $750-1.500$ & $1.500-2.000$ & $>2.000$ \\
\hline Blutverlust (\%) & $<15$ & $15-30$ & $30-40$ & $>40$ \\
\hline Puls (Schlag/min) & $<100$ & $100-120$ & $120-140$ & $>140$ \\
\hline Blutdruck & Normal & Normal & Erniedrigt & Erniedrigt \\
\hline Pulsdruck & Normal/erhöht & Erniedrigt & Erniedrigt & Erniedrigt \\
\hline Atemfrequenz (Zug/min) & $14-20$ & $20-30$ & $30-35$ & $>35$ \\
\hline Diurese (ml/h) & $<30$ & $20-30$ & $5-15$ & $<5$ \\
\hline Bewusstseinsstörung & Gering & Ängstlich & Ängstlich/verwirrt & Verwirrt/lethargisch \\
\hline Volumenersatz & \multicolumn{2}{|c|}{ Kristalloide/Kollloide } & \multicolumn{2}{|c|}{ Kristalloide/Kolloide und »Blutprodukte» } \\
\hline
\end{tabular}

zyten und Gerinnungsfaktoren und es kommt zu einer Verlustkoagulopathie. Durch die bestehende metabolische Azidose werden Gerinnungsmechanismen gehemmt und das Ausmaß der Gerinnungsstörung nimmt zu. Eine intakte Gerinnung ist jedoch essentiell, um die Schockursache, nämlich die Blutung selbst stillen zu können. Wenn dann, z. B. bedingt durch die gestörte Thermoregulation und meist auch die Infusionstherapie, zusätzlich die Körpertemperatur sinkt, verschlechtert dies wiederum die Gerinnung. Das Schockgeschehen selbst, aber auch die Gewebeschädigung (gerade bei ausgedehnten Knochen- oder Weichteilverletzungen) kann eine disseminierte intravasale Gerinnungsstörung auslösen, wie sie im Abschnitt Multiorganversagen dargestellt ist ( $\triangleright$ Abschn. 1.8.2).

Eine im ATLS-Konzept (Advanced Trauma Life Support, - Tab. 1.38) vom American College of Surgeons vorgestellte Einteilung erlaubt eine grobe Einschätzung der Schockschwere.

Besonderheiten des traumatisch-hypovolämischen Schocks Beim traumatisch-hypovolämischen Schock liegt durch eine sehr großflächige Verletzung der Haut durch Verbrennung oder Verätzung ein Mischbild der pathophysiologischen $\mathrm{Zu}-$ sammenhänge vor. Zum einen kann die ausgedehnte Gewebeverletzung einer Verbrennung durch Auslösung einer systemischen Entzündungsreaktion im Sinne eines SIRS einen Schock bedingen (traumatischer Anteil). Zum anderen wird die Permeabilität der kapillären Gefäßwände (kapilläres Leck) erhöht und es kommt sowohl durch eine Ödembildung als auch durch Flüssigkeitssequestration über die Wundfläche zu einem Verlust intravasalen Volumens (hypovolämischer Anteil).

\section{- Diagnostik}

Für die Diagnose eines Schocks muss man zuerst einmal daran denken, dass ein Patient einen Schock haben könnte. Wenn dann die Symptome eines Schocks erkannt sind und die Diagnose richtig gestellt ist, muss im Weiteren dann aber auch die
Ursachen des Schocks, also die zugrunde liegende Erkrankung oder Verletzung identifiziert werden.

\section{$($ Die Diagnose eines Schocks wird in der Regel bereits klinisch gestellt.}

Ergänzend kommen apparative und laborchemische Befunde hinzu, die die Diagnose bestätigen. Zentralvenöser Katheter, arterielle Kanüle und Blasenkatheter sind wichtige Instrumente sowohl für die Diagnostik als auch die Therapie bei einem Schock.

Die pathophysiologischen Veränderungen schlagen sich bei verschiedenen Organsystemen nieder.

Schockzeichen - Kreislauf Die Patienten entwickeln eine Tachykardie und eine verringerte Blutdruckamplitude. Später kommt es dann zum Blutdruckabfall. Es resultiert ein schneller, schwacher Puls.

D Cave

Bei Patienten unter Betablocker- oder Herzschrittmachertherapie kann, ebenso wie bei Ausdauersportlern, die Herzfrequenz auch im schweren Schock »normal« sein!

Durch die periphere Vasokonstriktion und Zentralisation haben die Patienten eine blasse, kühle Haut. Es kommt zu einer verstärkten Schweißbildung, auf der kühlen Haut ist auch der Schweiß kühl. Es resultieren Blässe und KaltschweiBigkeit.

B Cave

Wenn die periphere Sauerstoffsättigung einen zu niedrigen Wert (unter 90\%) anzeigt, kann dies einerseits Ausdruck einer Hypoxämie sein, andererseits kann der Wert durch die schlechte periphere Perfusion im Schock (Sättigungsmessclip am blassen, kalten Finger) bedingt sein, während die arterielle Sättigung ggf. noch normal ist. 
Die Bewertung einer zu niedrigen peripheren Sättigung kann nur im klinischen Kontext erfolgen. Im Zweifel muss zur Kontrolle eine arterielle Blutgasanalyse erfolgen.

Der Schockindex, welcher den Quotienten aus Herzfrequenz $(1 / \mathrm{min})$ und systolischem Blutdruck $(\mathrm{mmHg})$ beschreibt ist in der klinischen Praxis zur Beurteilung der Schockschwere von untergeordneter Bedeutung.

Im EKG bildet sich die Tachykardie ab, zudem können Rhythmusstörungen Ausdruck des kardialen Sauerstoffmangels sein.

Schockzeichen - Blut Im Labor zeigt sich im Schock häufig eine metabolische Azidose mit Laktatanstieg. Von besonderer Bedeutung für die Einschätzung der Schockschwere und zur Therapiesteuerung sind $\mathrm{pH}$-Wert, Basenüberschuss und Hämatokrit:

- Beim hämorrhagischen Schock ist der Hämatokrit erniedrigt, da Erythrozyten verloren gegangen sind und die übrigen Erythrozyten durch von extravasal nach intravasal umverteiltes Volumen verdünnt wurden. In der Frühphase einer starken Blutung, wenn diese Verdünnung noch nicht erfolgt ist, kann trotz eines großen Blutverlustes der Hämatokrit noch normal sein.

- Beim hypovolämischen Schock ohne Blutung kommt es zu einer Hämokonzentration, so dass der Hämatokrit ansteigt.

$($ Die zentralvenöse Sättigung fällt im Schock unter $70 \%$.

Analysen der Gerinnungsfunktion können eine Koagulopathie objektivieren und als Verlaufsuntersuchung helfen, die Therapie zu steuern.

Schockzeichen - Niere Durch die stärkere renale Wasserretention und der wegen der eingeschränkten Nierenperfusion niedrigeren Primärharnbildung kommt es im Schock zu einer Oligurie oder Anurie. Die Diurese muss bei einem Patienten im Schock zur Diagnostik und für die Therapiesteuerung erfasst werden. Hierzu wird meist ein Blasenkatheter gelegt.

Schockzeichen - Gehirn Als ein sehr frühes Zeichen eines Schocks kann die Gehirnfunktion beeinträchtigt sein. Unruhe, Angst, Aufregung, Verwirrtheit, Schläfrigkeit und Bewusstlosigkeit können Ausdruck eines kritisch reduzierten zerebralen Sauerstoffangebots sein.

Diagnose der Schockursache Für eine gezielte Behandlung der Schockursachen müssen diese zunächst diagnostiziert werden. Auf die Diagnose spezieller Krankheitsbilder, welche zu einem hypovolämischen Schock führen können, wird in den einzelnen Kapiteln gezielt eingegangen.
Beispiel

Ein Patient hat einen Verkehrsunfall erlitten. Er ist blass, kaltschweißig, hat einen Blutdruck von $90 / 50 \mathrm{mmHg}$, eine Herzfrequenz von 110/min, ist verwirrt und unruhig. Bei der klinischen Untersuchung wird ein instabiler Beckenring festgestellt.

Das beschrieben Bild eines Schocks könnte sich natürlich alleine durch die Beckenfraktur erklären. Es müssen aber auch weitere Blutungsquellen ausgeschlossen werden (externe Blutung oder innere Blutung in Thorax, Bauch, Retroperitoneum oder Extremitäten).

Die neurologischen Symptome Unruhe und Verwirrtheit könnten ebenfalls durch den hämorrhagischen Schock alleine erklärt werden, jedoch muss auch ein Schädel-Hirn-Trauma als Ursache in Erwägung gezogen werden.

$\checkmark$ Ein Schock als generalisiertes Krankheitsbild zieht Funktionsstörungen verschiedener Organe nach sich. Es muss aber bei jedem Patienten und jedem Symptom kritisch überlegt werden, ob wirklich »nur" der Schock oder evtl. auch noch eine weitere, organspezifische Ursache dahinter stecken.

Das Schockgeschehen muss immer im klinischen Gesamtzusammenhang gesehen und behandelt werden.

\section{- Therapie}

Die Therapie des Schocks hat stets 2 Anteile, die kausale Therapie und die symptomatische Therapie.

\section{Kausale Therapie}

- Definition -

Die kausale Therapie behandelt direkt die Schockursache.

Sie ist für den Patienten im Schock überlebenswichtig. Die Schockursache muss frühzeitig erkannt und dann sofort und gezielt behandelt wird. Hierdurch kann die Überlebenschance des Patienten maßgeblich erhöht werden.

Die Schockformen werden nach ihrer jeweiligen Ursache klassifiziert und erfordern hierdurch auch eine unterschiedliche kausale Therapie, welche in den jeweiligen Kapiteln genauer besprochen wird:

- Hypovolämischer Schock: Ausgleich des Volumenmangels, Therapie des Grunderkrankung (z. B. Ileus, Pankreatitis)

- Hämorrhagischer Schock: chirurgische Blutungskontrolle, unterstützend normalisieren der Hämostase

- Septischer Schock: Herdsanierung und Antibiose

- Neurogener Schock: Therapie der neurologischen Störung

- Anaphylaktischer Schock: Entfernung der auslösenden Substanz (Allergen) und Stoppen der überschießenden Immunreaktion

- Kardiogener Schock: Wiederherstellen einer ausreichenden kardialen Pumpfunktion 
Symptomatische Therapie

\section{- Definition}

Die symptomatische Therapie, soll unabhängig von der Schockursache die Sauerstoffversorgung des Gewebes wiederherstellen und den Patienten für die weitere Diagnostik und Therapie stabilisieren.

Die kausale Therapie darf aber nicht durch die symptomatische Behandlung verzögert werden. Je nach klinischer Situation setzt diese symptomatische Therapie an verschiedenen Punkten an:

Das im ATLS-Konzept vorgestellte Behandlungsprinzip »treat first what kills first « (Behandle zuerst die Störung, die am schnellsten zum Tod führt) hat sich in der Versorgung schwerverletzter Patienten im klinischen Alltag bewährt. Bei dieser standardisierten Form des prioritätenorientierten Vorgehens werden Störungen der Vitalfunktionen in einer festen Reihenfolge identifiziert und bei Bedarf sofort behandelt. Diese ursprünglich für Traumapatienten entworfene Behandlungsstrategie kann in ggf. angepasster Form, für alle Patienten im Schock, egal welcher Genese (auch bei nichtchirurgischen Erkrankungen) angewendet werden:

- A: Airway maintenance with cervical spine protection (Atemwegssicherung unter Halswirbelsäulenstabilisierung)

- B: Breathing and Ventilation (Atmung und Gasaustausch)

- C: Circulation with hemorrhage control (Kreislaufstabilisierung mit Blutungskontrolle)

- D: Disability: Neurologic status (»Behinderung«: neurologischer Zustand)

- E: Exposure/Environmental control: (Entkleidung/richtige Umgebungsbedingungen)

Wenn ein ausreichend großes und eingespieltes Behandlungsteam vor Ort ist, sollten die Punkte A-E nach Möglichkeit gleichzeitig abgearbeitet werden (Während z. B. noch der Patient intubiert wird, wird gleichzeitig eine Stabilisierung oder Kompression des Beckens zur Blutungskontrolle angelegt). Nach jedweder Intervention wird der Zustand des Patienten nach dem gleichen Schema umgehend reevaluiert und ggf. ein nicht adressiertes Problem reevaluiert.

- A: Airway maintenance with cervical spine protection (Atemwegssicherung unter Halswirbelsäulenstabilisierung: Da ein verlegter Atemweg innerhalb weniger Minuten zum Tod führen kann, muss sofort zu Beginn der Versorgung eine ungehinderte Luftpassage durch MundNasen-Rachenraum, Kehlkopf und tiefe Atemwege sichergestellt sein. Hier kann eine verbesserte Lagerung mit Anheben des Unterkiefers (Esmarch-Handgriff) oder verschieden Atemwegshilfsmittel (supraglottische Atemwegshilfen, Endotrachealtubus, Koniotomiekanüle) notwendig sein. Das zu bevorzugende Atemwegshilfsmittel ist hierbei der orotracheale Tubus und die Koniotomiekanüle ("patent airway«). Hierbei sind die Atemwege vor einer Aspiration oder einer mechanischen Verlegung weitge- hend geschützt. Ggf. muss der Patient hierfür narkotisiert werden.

- B: Breathing and Ventilation (Atmung und Gasaustausch): Allein ein gesicherter Atemweg garantiert nicht unbedingt eine suffiziente Atmung und Gasaustausch. Zur Erhöhung der inspiratorischen Sauerstoffkonzentration erhält der Patient z.B. eine Sauerstoffmaske mit $12 \mathrm{lO}_{2} / \mathrm{min}$ vor Mund und Nase. Dies ist eine schnelle, nebenwirkungsarme und billige Maßnahme bei allen Schockformen. Manche Patienten atmen jedoch nicht ausreichend. Der Sauerstoff aus der Maske kommt dann nicht in die Alveolen, auch wenn der Atemweg frei ist. Der Patient muss u. U. mechanisch ventiliert werden, wodurch Sauerstoff in die Alveole gelangt und $\mathrm{CO}_{2}$ heraus. Es ist sicherzustellen, dass dieser Gasaustausch in der Lunge stattfinden kann. Beim traumatischen Schock sollte in dieser Phase die Entlastung eines Pneumothorax oder Hämatopneumothorax erfolgen. Durch die Verbesserung der Füllung des Herzens hat diese Maßnahme auch eine Auswirkung auf die Zirkulation (siehe C).

- C: Circulation with hemorrhage control (Kreislaufstabilisierung mit Blutungskontrolle): Die Stillung der einem hämorrhagischen Schock zugrunde liegenden Blutung ist die überlebensnotwendige kausale Therapie. Hier können oft einfache Maßnahmen vorübergehend ausreichen (Kompression einer Wunde, grobe Reposition und Schienung von Frakturen, Verkleinerung des Beckenvolumens bei einer Beckenfraktur mit einer Beckenschlinge oder -zwinge). Andererseits kann aber auch eine sofortige Operation notwendig sein (v. a. bei intrathorakaler oder intraabdomineller Blutung).

- Die symptomatische Kreislauftherapie besteht im Wesentlichen aus Volumentherapie und ggf. medikamentöser Therapie.

D Cave

Bei einem hämorrhagischen Schock und einer noch aktiven, also ungestillten starken Blutung, sollte ein systolischer Blutdruck von $80-90$ mmHg nicht überschritten werden. Bei einer zu aggressiven Volumentherapie mit kristalloiden oder kolloidalen Lösungen wird die Blutung durch den Blutdruckanstieg verstärkt und die Blutgerinnung durch die Verdünnung von gerinnungsaktiven Blutbestandteilen (Dilutionskoagulopathie) weiter verschlechtert.

Um den Sauerstofftransport von der Alveole zu den Zellen zu verbessern, müssen Herzzeitvolumen und Blutdruck verbessert werden.

Durch Steigerung des zirkulierenden Blutvolumens wird die kardiale Vorlast erhöht, wodurch sich, außer bei kardialer Dekompensation, das Schlagvolumen und der Blutdruck erhöhen. Hierdurch wird der $\mathrm{O}_{2}$-Transport von den Alveolen zu den Körperzellen verbessert. Die schnellste und einfachste Methode dies, wenn auch nur kurzzeitig zu erreichen, ist die Schocklage (Trendelenburglage) bzw. das Hochlegen der Beine des Patienten. Hierdurch wird Blut aus der unteren Körperhälfte in Richtung Herz, Lun- 
ge und Gehirn umverteilt, wodurch sich dort das zirkulierende Blutvolumen erhöht. Eine weitere notwendige Volumengabe erfolgt intravenös (wenn dies nicht möglich ist intraossär). In der Regel sind balancierte kristalloide oder kolloidale Lösungen geeignet.

Der Einsatz hyperonkotischer, hyperosmolarer Infusionslösungen kann eine hilfreiche Option in der Behandlung des hämorrhagischen Schocks sein. Durch eine Wasserverschiebung von extravasal nach intravasal bedingen diese einen intravasalen Volumeneffekt, der das Infusionsvolumen deutlich übersteigt. Gerade Patienten mit begleitenden zerebralen Verletzungen scheinen durch einen antiödematösen und wahrscheinlich immunmodulierenden Effekt von dieser Behandlung zu profitieren. Bei einem hämorrhagischen Schock mit Anämie und Verlustkoagulopathie wird häufig die frühzeitige Transfusion von Blutprodukten (Erythrozyten, Thrombozyten, Plasma, Gerinnungsfaktoren) notwendig.

Beim schweren Volumenmangelschock kann, wie bei allen anderen Schockformen auch, der Einsatz von positiv inotropen Medikamenten (z. B. Dobutamin, Adrenalin) oder Vasopressoren (z. B. Noradrenalin) notwendig sein.

- D: Disability, Neurologic status (»Behinderung» Neurologischer Zustand):

Die orientierende neurologische Untersuchung ist bei Verletzten alleine schon notwendig, um evtl. SchädelHirn-Verletzungen zu erfassen und entsprechend zu behandeln. Unabhängig von solchen Verletzungen sollten aber alle Patienten im Schock regelmäßig neurologisch evaluiert werden, da der neurologische Status ein sehr guter Verlaufsparameter ist, um die Wirksamkeit der Schocktherapie einschätzen zu können.

- E: Exposure/Environmental control: (Entkleidung/Richtige Umgebungsbedingungen):

Die vollständige körperliche Untersuchung und die hierfür notwendige Entkleidung ist bei allen Schwerverletzten obligat.

Da eine Hypothermie die Überlebenswahrscheinlichkeit eines Patienten im hypovolämischen Schock deutlich senkt, muss bei der Behandlung durch entsprechende Wärmemaßnahmen konsequent eine Auskühlung vermieden werden (Wärmematten und -decken, Infusionswärmer, Zudecken des Patienten, sofern dies Diagnostik und Therapie nicht erschwert).

Besonderheiten der Therapie beim traumatisch-hypovolämischen Schock: Die Behandlung des traumatisch-hypovolämischen Schock, also bei ausgedehnten Verbrennungen oder Verätzungen ist im entsprechenden Kapitel ausführlich dargestellt.

Neben der chirurgischen Versorgung der betroffenen Hautareale ist eine ggf. notwendige, rechtzeitige Atemwegssicherung (bei Verbrennung im Gesicht oder Inhalationstrauma), eine suffiziente Schmerztherapie, sowie der Schutz vor Unterkühlung notwendig. Ebenso wichtig ist eine frühe (bereits präklinisch begonnene) intravenöse Flüssigkeitstherapie zur Vermeidung eines intravasalen Volumenmangels. Solange für die Steuerung dieser Flüssigkeitstherapie kein entsprechendes Monitoring zur Verfügung steht, kann der Flüssigkeitsbedarf nach der Parkland-Baxter-Formel abgeschätzt werden.

Der Flüssigkeitsbedarf in den ersten $24 \mathrm{~h}$ nach einer Verbrennung liegt bei $4 \mathrm{ml} / \mathrm{kgKG}$ pro Prozent verbrannter Körperoberfläche (hierbei werden nur Areale berücksichtigt, die 2.- und 3.-gradig verbrannt sind).

Für die Infusion soll körperwarme, balancierte kristalloide Lösung verwendet werden. Die Hälfte des errechneten Bedarfs soll gleichmäßig über die ersten $8 \mathrm{~h}$ nach Verbrennung verabreicht werden. Der Rest soll gleichmäßig über die weiteren $16 \mathrm{~h}$ gegeben werden. Diese Formel erlaubt jedoch nur eine grobe Abschätzung des Volumenbedarfs. Sobald es möglich ist, sollte die Volumentherapie nach der Diurese mit einem Zielwert von $0,5-1 \mathrm{ml} / \mathrm{kgKG} / \mathrm{h}$ gesteuert werden.

\subsubsection{Septischer Schock}

\section{- Definition}

Neben dem hypovolämisch-hämorrhagischen Schock ist in den operativen Fachgebieten der septische Schock (• Tab. 1.36) aufgrund einer generalisierten Inflammation als Folge einer primären oder sekundären Infektion (infektiöser Stimulus) von besonderer Bedeutung.

\section{Die Sepsis ist die häufigste Todesursache bei inten-} sivpflichtigen Patienten.

Laut den Leitlinien der Deutschen Sepsis-Gesellschaft e.V. (DSG) und der Deutschen Interdisziplinären Vereinigung für Intensiv- und Notfallmedizin (DIVI) wird empfohlen, die Sepsiskriterien des deutschen Kompetenznetzwerkes Sepsis (SepNet) für die klinische Diagnose der schweren Sepsis bzw. des septischen Schocks zu verwenden. Hierbei handelt es sich um modifizierte Diagnosekriterien für die Sepsis, die schwere Sepsis und den septischen Schock ACCP/SCCM-KonsensusKonferenz-Kriterien.

Kriterien für Sepsis, schwere Sepsis und septischen Schock

1. Nachweis der Infektion: Diagnose einer Infektion über den mikrobiologischen Nachweis oder durch klinische Kriterien.

2. Severe inflammatory host response (SIRS, mindestens 2 Kriterien):

- Fieber $\left(\geq 38^{\circ} \mathrm{C}\right)$ oder Hypothermie $\left(\leq 36^{\circ} \mathrm{C}\right)$ bestätigt durch eine rektale oder intravasale oder vesikale Messung

- Tachykardie (Herzfrequenz $\geq 90 / \mathrm{min}$ )

- Tachypnoe (Frequenz $\geq 20 / \mathrm{min}$ ) oder Hyperventilation $\left(\mathrm{p}_{\mathrm{a}} \mathrm{CO}_{2} \leq 4,3 \mathrm{kPa} / \leq 33 \mathrm{mmHg}\right)$

- Leukozytose $\left(\geq 12.000 / \mathrm{mm}^{3}\right)$ oder Leukopenie $\left(\leq 4.000 / \mathrm{mm}^{3}\right)$ oder $\geq 10 \%$ unreife Neutrophile im Differenzialblutbild 
3. Akute Organdysfunktion (mindestens 1 Kriterium)

- Akute Enzephalopathie: eingeschränkte Vigilanz, Desorientiertheit, Unruhe, Delirium

- Relative oder absolute Thrombozytopenie: Abfall der Thrombozyten um mehr als $30 \%$ innerhalb von $24 \mathrm{~h}$ oder Thrombozytenzahl $\leq 100.000 / \mathrm{mm}^{3}$. Eine Thrombozytopenie durch akute Blutung oder immunologische Ursachen muss ausgeschlossen sein.

- Arterielle Hypoxämie: $\mathrm{p}_{\mathrm{a}} \mathrm{O}_{2} \leq 10 \mathrm{kPa}(\leq 75 \mathrm{mmHg})$ unter Raumluft oder ein $\mathrm{p}_{\mathrm{a}} \mathrm{O}_{2} / \mathrm{FIO}_{2}$-Verhältnis von $\leq 33 \mathrm{kPa}$ ( $\leq 250 \mathrm{mmHg}$ ) unter Sauerstoffapplikation. Eine manifeste Herz- oder Lungenerkrankung muss als Ursache der Hypoxämie ausgeschlossen sein.

- Renale Dysfunktion: Eine Diurese von $\leq 0,5 \mathrm{ml} /$ $\mathrm{kgKG} / \mathrm{h}$ für wenigstens $2 \mathrm{~h}$ trotz ausreichender Volumensubstitution und/oder ein Anstieg des Serumkreatinins $>2$-fach oberhalb des lokal üblichen Referenzbereiches.

- Metabolische Acidose: base excess $\leq-5 \mathrm{mmol} / \mathrm{l}$ oder eine Laktatkonzentration >1,5-fach oberhalb des lokal üblichen Referenzbereiches

Sepsis: Kriterien 1 und 2

Schwere Sepsis: Kriterien 1, 2 und 3

Septischer Schock: Kriterien 1 und 2 sowie für wenigstens $1 \mathrm{~h}$ ein systolischer arterieller Blutdruck $\leq 90 \mathrm{mmHg}$ bzw. ein mittlerer arterieller Blutdruck $\leq 65 \mathrm{mmHg}$ oder notwendiger Vasopressoreinsatz, um den systolischen arteriellen Blutdruck $\geq 90 \mathrm{mmHg}$ oder den arteriellen Mitteldruck $\geq 65 \mathrm{mmHg}$ zu halten. Die Hypotonie besteht trotz adäquater Volumengabe und ist nicht durch andere Ursachen zu erklären.

\section{- Definition \\ Von einer Sepsis spricht man dann, wenn eine Infektion nachgewiesen wurde und zusätzlich ein SIRS besteht. \\ Unter einer schweren Sepsis versteht man eine Sep- sis mit Zeichen der Organdysfunktion. \\ Vom septischen Schock spricht man, wenn zusätzlich zur Sepsis trotz adäquater Volumentherapie eine signifi- kante Hypotonie vorliegt, die nur mit Hilfe von Vasopres- soren zu therapieren ist.}

\section{- - Ätiologie}

Häufige Ursachen im Bereich der Chirurgie sind Abszesse, intraabdominelle Infektionen (Cholezystitis, perforierender Sigmadivertikulitis, sekundär nach resezierenden Darmeingriffen) sowie nosokomiale Infektionen (Wundinfektionen, Pneumonien, Katheterinfektionen). Neben Bakterien (grampositiv und gram-negativ), und Pilzen (Candida, Aspergillen) können auch Toxine und Viren (Herpes, CMV) eine Sepsis auslösen.

\section{- " Pathophysiologie und Klinik}

Die durch die inflammatorischen Effekte im Bereich der Mikrozirkulation (Vasodilatation und Ödembildung) bedingte relative Hypovolämie führt zu einer profunden Hypotonie und diese wiederum zu einer Aktivierung des Sympathikus. Die mit der Sympathikusaktivierung einhergehende Ausschüttung von Katecholaminen (Adrenalin, Noradrenalin) verursacht eine kompensatorische Steigerung des Herzzeitvolumens ( $\beta$-Rezeptoren im Myokard) und führt häufig zu einer nicht effektiven Vasokonstriktion mit Zentralisation ( $\alpha$-Rezeptoren and den Gefäßen). Auf der anderen Seite können Bakterienbestandteile und Toxine direkt am Myokard eine negativ-inotrope Wirkung (septische Kardiomyopathie) entfalten und somit eine adäquate Steigerung des Herzzeitvolumens verhindern. Je nach Überwiegen der einzelnen Effekte können klinisch 2 Formen des septischen Schocks unterschieden werden:

- Hyperdyname Form (häufig): Diese Form ist häufig in der Frühphase einer Sepsis zu beobachten und geht mit einer hyperdynamen Kreislaufsituation (Tachykardie und moderate Hypotonie) einher. Ein niedriger peripherer Gefäßwiderstand und ein zum Teil extrem hohes Herzzeitvolumen (über 5 l/min) prägen diese Form des septischen Schocks. Die Haut ist meist warm, trocken und gut durchblutet. Im weiteren Verlauf kommt es zu weiteren massiven Flüssigkeitsverschiebungen in das Interstitium mit extremen Ödemen und Gewichtszunahme.

- Hypodyname Form: Ist das Herzkreislaufsystem z. B. aufgrund von kardialen Vorerkrankungen oder einer ausgeprägten septische Kardiomyopathie nicht in der Lage das Herzzeitvolumen adäquat zu steigern, kommt es zur Zentralisation. Die Haut ist in diesem Fall meistens blass, kühl und feucht. Diese klinische Form des septischen Schocks hat eine sehr ungünstige Prognose.

Ein weiterer wesentlicher Aspekt der systemischen Inflammation ist eine Störung der Gewebeoxygenierung, die gekennzeichnet ist durch eine verminderte Sauerstoffextraktion und Sauerstoffverwertungsstörung auf der Ebene der Mitochondrien mit Entkopplung der oxidativen Phosphorylierung. Bei nicht erfolgreicher Therapie führen beide Formen zu einem Multiorganversagen mit letalem Ausgang.

\section{- Diagnostik}

Im Wesentlichen wird die Diagnose einer Sepsis, schweren Sepsis und septischem Schock anhand klinischer und laborchemischer Parameter gestellt. Eine besondere Bedeutung kommt dem mikrobiologischen Keimnachweis (Blutkultur, Wundabstrich) zu, der allerdings nur in ca. 30\% der Fälle gelingt, da diese Patienten häufig antibiotisch vorbehandelt sind.

Als klinische Parameter spielen neben den SIRS-Kriterien (Temperatur, Tachykardie, Tachypnoe) der Wundbefund, die septische Enzephalopathie (Verwirrtheit und Somnolenz) und evtl. septische Hauterscheinungen eine wichtige Rolle. Hilfreiche Laborparameter sind Leukozyten- und Thrombozytenzahlen, C-reaktives Protein (CRP), Procalcitonin (PCT) und Serumlaktat. 
- Therapie

Die kausale und symptomatische Sepsistherapie umfasst folgende wesentliche Punkte, wobei die möglichst frühzeitige Therapieeinleitung absolut entscheidend ist und sich günstig auf die Mortalität auswirkt:

- Kausale Therapie der auslösenden Grunderkrankung: z.B. die chirurgische Sanierung des Fokus, die antimikrobielle Therapie einer Pneumonie oder der Wechsel eines infizierten Katheters.

- Adäquate antimikrobielle Therapie: Initial sofortige breite Abdeckung in hoher Dosierung mit einer Kombination verschiedener Antibiotika (kalkulierte Therapie). Nach Vorliegen eines Antibiogramms mit Resistenzprüfung Deeskalation und umstellen auf eine gezielte Therapie. Auch eine nur um wenige Stunden verzögerte Gabe führt zu einem signifikanten Anstieg der Mortalität!

- Zeitnahe auf Zielparameter gerichtete Kreislauftherapie zur Optimierung des Sauerstoffangebotes (sog. Early Goal Directed Therapy). Für die hämodynamische Stabilisierung werden folgende Zielkriterien empfohlen:

- Volumenzufuhr zur Einstellung eines ZVD von 8$12 \mathrm{mmHg}$

- Anheben des arteriellen Mitteldrucks auf $\geq 65 \mathrm{mmHg}$ durch Volumengabe und/oder Noradrenalin

- bei einer zentralvenöse Sauerstoffsättigung (aus dem ZVK) unter $70 \%$

- ggf. Transfusion von Erythrozytenkonzentraten bis zu einem Hämatokrit $>30 \%$

- Einsatz von positiv inotropen Substanzen (Dobutamin) zur Steigerung des Herzzeitvolumens

- Lungenprotektive Beatmung mit kleinen Tidalvolumina (6 ml/kg Körpergewicht) sowie einem adäquaten PEEP

- Frühzeitige enterale Ernährung über Sonden zur Vermeidung einer Zottenatrophie mit konsekutiver Translokation von Bakterien aus dem Darmlumen in die Blutbahn

- Bei sehr hohem Katecholaminbedarf evtl. 200-300 mg/d Hydrokortison

- Ein Abfall des Laktats und eine Anstieg der Diurese $(\geq 0,5 \mathrm{ml} / \mathrm{kgKG} / \mathrm{h})$ weisen auf ein Ansprechen der Therapie hin und sind prognostisch als günstig zu bewerten

\subsubsection{Neurogener Schock}

\section{- Definition}

Beim neurogenen Schock (• Tab. 1.36) kommt es, bedingt durch eine Störung der Kreislaufregulation zu einem Abfall des Tonus der glatten Gefäßmuskulatur und zu einer relativen Hypovolämie.

\section{n. Ätiologie}

$\mathrm{Zu}$ einer solchen Störung der Kreislaufregulation kann es im Wesentlichen durch 2 Mechanismen kommen:

- Eine direkte Schädigung der Zentren der Kreislaufregulation im Hirnstamm (Nucleus tractus solitarii, retikulärer Ventrolateralkern, transtegmentaler Tractus) durch
- Durchblutungsstörungen (z. B. bei Basilaristhrombose oder Vasospasmus)

- Druckerhöhung (durch Einblutung, Hirnödem oder Tumore)

- Entzündliche Prozesse (Enzephalitis)

- Eine Störung der Nervenleitung vom Hirnstamm zu Herz und Blutgefäßen. Diese Leitungsstörung im Bereich der Medulla oblongata oder des Rückenmarks kann bedingt sein durch

- Verletzungen (akuter Querschnitt, dies ist die häufigste Ursache eines neurogenen Schocks)

- Durchblutungsstörungen

- Totale Spinalanästhesie

\section{n - Pathophysiologie und Klinik}

Die Steuerung des Tonus der glatten Gefäßmuskulatur beim Gesunden erfolgt über den humoralen Weg und neurale vegetative Leitungsbahnen. Der normale Tonus der Gefäßmuskulatur ist von einem Gleichgewicht zwischen Sympathikus und Parasympathikus abhängig. Kommt es zu einer Störung der zentralen Kreislaufregulation und einer Inbalance zwischen sympathischem und parasympathischem Einfluss, so kann ein Abfall des Gefäßtonus bis hin zur Vasoplegie resultieren. Durch die Weitstellung der Blutgefäße entsteht eine relative Hypovolämie mit verringertem venösen Rückstrom und einem entsprechenden Abfall der kardialen Vorlast.

Wie bei allen Schockformen sinkt das zelluläre Sauerstoffangebot und es resultieren die klinischen Zeichen der Funktionsstörung verschiedener Organe (Vigilanzminderung, Verwirrtheit, verringerte Harnausscheidung, metabolische Azidose).

Da jedoch dem neurogenen Schock eine Dysregulation der Zirkulation zugrunde liegt, können manche klinischen Zeichen eines hypovolämischen Schocks fehlen.

Durch den Ausfall des Sympathikus kann die Herzfrequenz normal oder vermindert sein (fehlende Tachykardie) und die Gefäße der Haut stellen sich nicht eng (fehlende blasse, kaltschweißige Haut).

\section{- Diagnostik}

Die Diagnose des neurogenen Schocks wird klinisch und anhand der Anamnese gestellt. Bildgebende Verfahren wie Röntgen, Computertomographie und Kernspintomographie (ggf. auch eine Liquoruntersuchung) können die Diagnose erhärten und die Ursache der Funktionsstörung ggf. darstellen und so für die weitere Behandlung wegweisend sein.

\section{- Therapie}

Da ein neurogener Schock meist durch ein Wirbelsäulentrauma mit Beteiligung des Rückenmarks bedingt ist, stellt die chirurgische Entlastung des Myelons bei relevanter Einengung eine wichtige Maßnahme dar.

Die Stabilisierung der Vitalfunktionen im neurogenen Schock erfordert als sofortige Basismaßnahmen Sauerstoffgabe, Atemwegssicherung, ggf. künstliche Beatmung, die An- 
lage großlumiger venöser Zugänge (z.B. $2 \times 14-16$ G). Die Vasoplegie muss medikamentös, z. B. mit Noradrenalin, adressiert werden. Es kann (beim Erwachsenen) in Einzelboli von 5-10 $\mu$ g gegeben werden. Wegen der kurzen Wirkdauer muss es dann jedoch alle 2-5 min erneut verabreicht werden. Wenn es der Versorgungsablauf zulässt, sollte Noradrenalin kontinuierlich über eine Spritzenpumpe gegeben werden. Um eine Bradykardie zu behandeln, kann z. B. Atropin (0,5-1 mg i.v. beim Erwachsenen) eingesetzt werden.

Ein Patient im neurogenen Schock hat nicht zwingend Flüssigkeit verloren, jedoch sollte auch bei diesen Patienten eine Infusionstherapie erfolgen. Zum einen, weil evtl. bereits 500-1.000 ml kristalloide Lösung ausreichen, um den Kreislauf zu stabilisieren. Zum anderen bestehen bei Patienten, bei denen der neurogene Schock auf eine Wirbelsäulenverletzung zurück zu führen ist, oft begleitend weitere Verletzungen. Bei diesen Patienten muss also bis zum Beweis des Gegenteils davon ausgegangen werden, dass der Schock neben der neurogenen, auch eine hämorrhagische Komponente hat.

D Cave

Beim verletzungsbedingten neurogenen Schock muss immer nach weiteren Verletzungen gesucht und eine mögliche hämorrhagische Komponente des Schocks berücksichtigt werden.

\subsubsection{Anaphylaktischer Schock}

\section{- Definition}

Beim anaphylaktischen Schock (- Tab. 1.36) handelt es sich um eine akute schwere Verlaufsform einer anaphylaktischen oder einer anaphylaktoiden Überempfindlichkeitsreaktion.

\section{- Definition \\ Als anaphylaktische Reaktion wird eine humorale Aller- gie vom Soforttyp bezeichnet, der eine durch IgE-Antikör- per vermittelte Histamin- und Serotoninfreisetzung aus Mastzellen und basophile Granulozyten zugrunde liegt. Voraussetzung für diese Reaktion ist eine Sensibilisierung des Organismus durch bestimmte Allergene. \\ Hingegen erfolgt bei der anaphylaktoiden Reaktion die Ausschüttung der Mediatoren direkt durch den Kon- takt des Allergens mit den jeweiligen Zellen, also nicht antikörpervermittelt.}

\section{- Ätiologie}

Im chirurgischen Bereich spielen häufig folgende Allergene eine Rolle:

- Antibiotika

- Latexallergie (u. a. Handschuhe)

- Röntgenkontrastmittel

- Muskelrelaxantien

- Schmerzmittel (z. B. Lokalanästhetika)

- Insektengifte
- - Pathophysiologie und Klinik

Durch die Exposition mit dem jeweiligen Allergen kommt es im Rahmen einer Immunreaktion zur Bildung von IgE-Antikörper, die sich u. a. an Mastzellen, basophilen Granulozyten und Endothelzellen binden. Im Falle einer Reexposition findet eine Antigen-Antikörper-Reaktion statt und es werden verschiedene Mediatorsubstanzen wie Histamin, Serotonin, Bradykinin sowie Leukotriene aus den besetzten Zellen freigesetzt. Bei der anaphylaktoiden Reaktion erfolgt die Stimulation der Freisetzung direkt. Über entsprechende Rezeptoren (z. B. H1- und H2-Rezeptoren) wird die Wirkung an den verschiedenen Zielorganen ausgelöst. Folge ist die Vasodilatation der präkapillären Arteriolen bei gleichzeitiger Konstriktion postkapillärer Venolen. Gleichzeitig steigt die Gefäßpermeabilität, die mit erhöhten Flüssigkeits- und Proteinverlusten ins Interstitium einhergeht, was wiederum zur Quaddelbildung und Gewebsödem beiträgt. Am Ende steht eine relative Hypovolämie mit Tachykardie, die in einem Schockgeschehen enden kann. Weitere Symptome sind Angstzustände, generalisiertes Erythem, Quaddelbildung, Pruritus, Erbrechen, Diarrhö, Bronchospasmus sowie Schwellung der oberen Atemwege mit Erstickungsgefahr!

\section{- Diagnose}

Die Diagnose wird anhand der klinischen Symptome aus dem jeweiligen situativen Kontext heraus gestellt (z. B. Kreislaufzusammenbruch nach Lokalanästhetikagabe).

- " Therapie

D Cave

Der Schock kann sich in wenigen Minuten entwickeln. Aufgrund der unmittelbaren Lebensbedrohung stehen die Kreislauftherapie, sowie die Sicherung der Atemwege (frühe Intubation und Beatmung) absolut im Vordergrund.

Die weitere Antigenzufuhr muss unmittelbar gestoppt werden. Neben der Volumentherapie hat die intravenöse vorsichtige Gabe von Adrenalin absolute Priorität. Adrenalin hemmt die weitere Histaminausschüttung, wirkt bronchodilatativ, antiödematös, positiv inotrop und vasokonstriktiv. Die weitere symptomatische Therapie erfolgt dann mit Histaminrezeptorenblockern (H1: Dimetinden, H2: Cimetidin) und Glukokortikoiden (z. B. Dexamethason). Bei Bedarf kommen auch Bronchodilatatoren zum Einsatz (Beta-2-Mimetika).

\subsubsection{Kardiogener Schock (Lungenembolie, Fettembolie, Contusio cordis)}

\section{- - Definition}

Dem kardiogenen Schock (-Tab. 1.36) liegt ein akutes kardiales Pumpversagen zugrunde. Hierbei kann zwischen einem rechts- und linksventrikulären Pumpversagen, sowie einem systolischen und diastolischen Pumpversagen unterschieden werden. Eine weitere Einteilung unterscheidet das myokardiale (Myokardinfarkt, Myokarditis), rhythmogene (Tachy- 
kardien, Asystolie) und mechanische Pumpversagen (Klappenvitien, Herzbeuteltamponade).

\section{- . Ätiologie}

Relevante Ursachen für den kardiogenen Schock im Fachgebiet der Chirurgie sind der perioperative Herzinfarkt, die akut dekompensierte chronische Herzinsuffizienz, akute Rhythmus- und Reizleitungsstörungen sowie das akute Rechtsherzversagen im Rahmen einer Lungenembolie durch Thromben, Luft oder Fett. Seltenere Gründe sind Klappenvitien oder das diastolische Pumpversagen im Rahmen einer Herzbeuteltamponade. Ein stumpfes Thoraxtrauma kann mit einer Contusio cordis einhergehen, hingegen führt ein spitzes Trauma oft zu einer Perforation.

\section{- Pathophysiologie und Klinik}

Die verminderte kardiale Pumpleistung führt zu einem Abfall des Herzzeitvolumens und somit zu einer verminderten Perfusion der peripheren Organe. Durch die Aktivierung des Sympathikus und der konsekutiven vermehrten Ausschüttung von Katecholaminen versucht der Organismus die Pumpleistung zu steigern ( $\beta_{1}$-Rezeptoren) und den Blutdruck durch Vasokonstriktion ( $\alpha_{1}$-Rezeptoren) anzuheben. Es kommt zu einer Umverteilung des zirkulierenden Blutvolumens zugunsten der absolut vitalen Organe Herz und Gehirn. Durch den Abfall des Sauerstoffangebots mit zunehmender Gewebshypoxie stellt der Organismus in der Peripherie auf anaeroben Stoffwechsel um und es bilden sich vermehrt Laktat und saure Metaboliten, die zu einer metabolischen Azidose führen. Weitere Folgen sind Vasodilatation und Kapillarschaden mit Ödembildung. Durch die Organhypoperfusion wird v. a. bei der Myokardischämie die kardiale Funktion weiter beeinträchtigt und die Schockspirale weiter angetrieben. Es droht das Multiorganversagen.

Bei dem Linksherzversagen kommt es zu einem Anstieg des linksventrikulären enddiastolischen Füllungsdrucks und einem Blutrückstau in die Lunge mit einem Lungenödem. Beim Rechtsherzversagen, häufig durch eine akut erhöhte Nachlast (Embolie) verursacht, steigt der zentrale Venendruck und das Blut staut sich in der Leber und den Halsvenen. Eine Form des diastolischen Rechtsherzversagens stellt die Perikardtamponade dar, welche die adäquate diastolische Füllung des rechten Ventrikels verhindert. Ursache für die Perikardtamponade sind häufig pentrierende Verletzungen (z. B. Stichverletzungen). Wesentlich öfter wird in Mitteleuropa die mangelhafte diastolische Füllung jedoch durch einen Spannungspneumothorax verursacht. Dieser resultiert zumeist aus einem bei uns viel häufiger vorkommenden stumpfen Thoraxtrauma mit Rippenfraktur(en).

\section{- Diagnostik}

Entscheidend ist die Diagnostik der ursächlichen Störung:

- Myokardinfarkt: EKG, Troponin, Herz-Echokardiographie

- Herzinsuffizienz: Brain Natriuretic Peptide (BNP), Echokardiographie, Röntgenthorax

- Lungenembolie: transösophageale Echokardiographie (TEE), CT
- Spannungspneumothorax: Röntgenthorax, ggf. Sonographie, ggf. Schockraum-CT

- Perikardtamponade: Sonographie, ggf. TEE, ggf. Schockraum-CT

Der kardiogene Schock wird durch folgende Parameter beschrieben:

- erniedrigter systolischer Blutdruck ( $\mathrm{RR} \leq 90 \mathrm{mmHg}$ )

- vermindertes Herzzeitvolumen (Herzindex $\leq 2,2 \mathrm{l} / \mathrm{min} /$ $\mathrm{m}^{2}$ Körperoberfläche)

- erhöhter linksventrikulärer Füllungsdruck (LVEDP $>15 \mathrm{mmHg}$ )

Neben der möglichst invasiven Blutdruckmessung benötigt man zur Erhebung dieser Parameter einen Rechtsherzkatheter oder eine transösophageale Echokardiographie. Für die HZV-Messung stehen heute noch weitere Verfahren zur Verfügung (PICCO, Doppler). Eine erniedrigte zentralvenöse Sättigung (ZVD), eine metabolischen Azidose (arterielle Blutgasanalyse) und eine erhöhtes Serum-Laktat sind ebenfalls indirekte Hinweise auf ein insuffizientes Herzzeitvolumen.

\section{- Therapie}

Neben der kausalen Therapie erfolgt die symptomatische Behandlung durch die Gabe von positiv inotropen Substanzen wie Adrenalin, Dobutamin, Phosphodiesterasehemmer und Levosimendan. Eine verminderte Nachlast kann durch Noradrenalin angehoben werden, um den Perfusionsdruck in den Koronarien zu sichern. Eine weitere sehr effektive Möglichkeit besteht in der mechanischen Kreislaufunterstützung durch die intraaortale Ballonpumpe (IABP) oder extrakorporale Unterstützungssysteme (ECMO; Ventricular Assit Devices, VAD). Bei der IABP wird durch das aktive Kollabieren eines Ballons in der Aorta descendens in der Systole die Nachlast für den linken Ventrikel gesenkt und durch das Aufblasen in der Diastole die Koronarperfusion verbessert.

Bei traumatischer Ursache (Spannungspneumothorax, Perikardtamponade) ist die kausale Behandlung lebensrettend. Die sofortige Druckentlastung der Thoraxhöhle (z.B. Punktion nach Monaldi oder schnelle Einlage einer Thoraxdrainage beim Pneumothorax, Perikardiozentese oder sofortige Thorakotomie mit Perikardiotomie bei der Perikardtamponade) ist notwendig.

\section{In Kürze}

\section{Chirurgisch relevante Schockformen}

Schock bezeichnet lebensbedrohlichen physischen Zustand unterschiedlicher Genese, geht einher mit kritischer Beeinträchtigung der Organperfusion (Mikro- und Makrozirkulation) und konsekutivem Missverhältnis zwischen Sauerstoffangebot und Sauerstoffbedarf (metabolische Azidose und Laktatanstieg). Abhängig von Ursache zu unterscheiden (• Tab. 1.36):

$\nabla$ 

- Hypovolämischer Schock
- Hämorrhagischer Schock
- Septischer Schock
- Neurogener Schock
- Anaphylaktischer Schock
- Kardiogener Schock

Alle Formen können über das klinische Bild einer generalisierten inflammatorischen Reaktion (systemisches inflammatorisches Response Syndrom, engl. systemic inflammatory response syndrome, SIRS) zum Multiorganversagen (MOV) führen, welches mit hoher Sterblichkeit einhergeht.

Therapie: kausal (Behandlung der Schockursache) und symptomatisch (Wiederherstellung der Sauerstoffversorgung, Stabilisierung für weitere Diagnostik und Therapie). dan U, Pape HC, Piek J, Prange H, Roesner D, Roth B, Schürholz T, StandI T, Teske W, Vogt PM, Werner GS, Windolf J, Zander R, Zerkowski HR (2005) Empfehlungen zur Diagnostik und Therapie der Schockformen der IAG Schock der DIVI. Teil 6: Neurogener Schock. Intensivmedizin und Notfallmedizin 42: 615-619

American College of Surgeons (2008) ATLS: Advanced Trauma Life Support for Doctors: Student Course Manual. Eigenverlag ACS

Dellinger RP, Levy MM, Carlet JM et al. (2008) Surviving Sepsis Campaign: International guidelines for management of servere sepsis and septic shock. Intensive Care Med 34:17-60

Deutsche Sepsis-Gesellschaft, Deutsche Interdisziplinäre Vereinigung für Intensiv- und Notfallmedizin. Leitlinie: Prävention, Diagnose, Therapie und Nachsorge der Sepsis, AWMF online (http://www. awmf.org/uploads/tx_szleitlinien/079-001I_S2k_Sepsis_Leitlinientext_01.pdf)

Dutton RP (2008) Pathophysiology of Traumatic Shock, ITACCS 18 (1); $12-15$

Hagel S, Brunkhorste F (2011) Sepsis. Intensivmed 48:57-73

Sielenkämper A., Prien T., Van Aken H (2001) Der Patient im SchockPathophysiologie, Ursachen und therapeutische Grundsätze, Hessisches Ärzteblatt 9: 424-433

\subsection{Anästhesie}

Adams HA, Baumann G, Cascorbi I, Ebener C, Emmel M, Geiger S, Janssens U, Klima U, Klippe HJ, Knoefel WT, Marx G, Müller-Werdan U, Pape HC, Piek J, Prange H, Roesner D, Roth B, Schürholz T, Standl T, Teske W, Vogt PM, Werner GS, Windolf J, Zander R, Zerkowski HR (2004) Empfehlungen zur Diagnostik und Therapie der Schockformen der IAG Schock der DIVI. Teil 1: Vorbemerkung, Möglichkeiten und Grenzen des Diagnostischen Instrumentariums. Intensivmedizin und Notfallmedizin 41: 618-626

Adams HA, Baumann G, Cascorbi I, Ebener C, Emmel M, Geiger S, Janssens U, Klima U, Klippe HJ, Knoefel WT, Marx G, Müller-Werdan U, Pape HC, Piek J, Prange H, Roesner D, Roth B, Schürholz T, Standl T, Teske W, Vogt PM, Werner GS, Windolf J, Zander R, Zerkowski HR (2005) Empfehlungen zur Diagnostik und Therapie der Schockformen der IAG Schock der DIVI. Teil 2: Hypovolämischer Schock. Intensivmedizin und Notfallmedizin 42: 96-109

Adams HA, Baumann G, Cascorbi I, Ebener C, Emmel M, Geiger S, Janssens U, Klima U, Klippe HJ, Knoefel WT, Marx G, Müller-Werdan U, Pape HC, Piek J, Prange H, Roesner D, Roth B, Schürholz T, Standl T, Teske W, Vogt PM, Werner GS, Windolf J, Zander R, Zerkowski HR (2005) Empfehlungen zur Diagnostik und Therapie der Schockformen der IAG Schock der DIVI. Teil 3: Kardialer Schock. Intensivmedizin und Notfallmedizin 42: 196-210

Adams HA, Baumann G, Cascorbi I, Ebener C, Emmel M, Geiger S, Janssens U, Klima U, Klippe HJ, Knoefel WT, Marx G, Müller-Werdan U, Pape HC, Piek J, Prange H, Roesner D, Roth B, Schürholz T, Standl T, Teske W, Vogt PM, Werner GS, Windolf J, Zander R, Zerkowski HR (2005) Empfehlungen zur Diagnostik und Therapie der Schockformen der IAG Schock der DIVI. Teil 4: Anaphylaktischer Schock. Intensivmedizin und Notfallmedizin 42: 299-304

Adams HA, Baumann G, Cascorbi I, Ebener C, Emmel M, Geiger S, Janssens U, Klima U, Klippe HJ, Knoefel WT, Marx G, Müller-Werdan U, Pape HC, Piek J, Prange H, Roesner D, Roth B, Schürholz T, StandI T, Teske W, Vogt PM, Werner GS, Windolf J, Zander R, Zerkowski HR (2005) Empfehlungen zur Diagnostik und Therapie der Schockformen der IAG Schock der DIVI. Teil 5: Septischer Schock. Intensivmedizin und Notfallmedizin 42: 531-543

Adams HA, Baumann G, Cascorbi I, Ebener C, Emmel M, Geiger S, Janssens U, Klima U, Klippe HJ, Knoefel WT, Marx G, Müller-Wer-

\section{Kaufmann, A. Urwyler, W. Ruppen, D. Scheidegger}

Jeder chirurgische Assistent und chirurgisch interessierte Student sollte einige Aspekte der Anästhesie kennen, z. B. welche präoperativen Abklärungen für die Anästhesie von Wichtigkeit sind und welche Risiken bei der Operationsindikation berücksichtigt werden müssen. Genauere Kenntnisse der Lokalanästhetika muss jeder chirurgisch tätige Arzt haben, damit schwerwiegende Komplikationen vermieden werden können. Auch die modernen Überwachungsmethoden eines Patienten während einer Operation müssen allen Beteiligten bekannt sein. Die heutigen Formen der postoperativen Schmerzbekämpfung und die häufigen postoperativen Komplikationen muss jeder Chirurg kennen.

70-80\% aller großen Zwischenfälle im Operationssaal beruhen auf menschlichem Versagen. Davon sind etwa 90\% durch eine mangelhafte Kommunikation verursacht. Erst in den letzten Jahren wurde realisiert, dass viele Trainingsmethoden zur Erhöhung der Sicherheit, die heute in der zivilen Luftfahrt selbstverständlich sind, auch im Operationssaal angewendet werden können. Deshalb werden wir zum Schluss des vorliegenden Kapitels neue Wege des Trainings und der Kommunikation im Operationssaal aufzeigen.

\subsubsection{Präoperative Maßnahmen}

Die präoperativen Maßnahmen erfolgen in Zusammenarbeit zwischen Chirurgen und Anästhesisten. Die folgenden Punkte müssen dabei beachtet werden:

- Ambulante oder stationäre Behandlung

- Art der Operation

- Dringlichkeit der Operation 
- Gesundheitszustand des Patienten

- Möglichkeiten der Optimierung des Gesundheitszustandes des Patienten

- Postoperative Maßnahmen

Die Patienten sollen für die Operation in verschiedener Hinsicht optimal vorbereitet werden. Gezielt ist nach relevanten Krankheiten zu suchen, um den Gesundheitszustand präoperativ zu optimieren.

\section{( Außerdem gehört die umfassende Information des Patienten über den geplanten Eingriff, die vorgese- hene Anästhesietechnik und die postoperative Nachbetreuung zu den präoperativen Maßnahmen.}

Ebenso wichtig für einen erfolgreichen Behandlungsablauf ist die Erstellung einer auf die Bedürfnisse des Patienten ausgerichteten Planung der Anästhesie. Neben der Wahl des Anästhesieverfahrens und der Medikamente werden die notwendigen Überwachungsmaßnahmen (Monitoring) festgelegt. Falls benötigt, ist ein postoperativer Überwachungsplatz bereits vor dem Eingriff zu reservieren, um den Patienten nach erfolgter Operation nicht zu gefährden.

Perioperative Morbidität und Mortalität sind von verschiedenen Faktoren abhängig. Neben Art, Ausdehnung und Dringlichkeit des Eingriffes ist der Allgemeinzustand des Patienten von Bedeutung. Ein Abdominaleingriff stellt im Vergleich zu einer Wundversorgung an der Hand für den Patienten eine größere Belastung dar, weil bei Abdominaleingriffen die Atemmechanik postoperativ beeinträchtigt ist.

Eine Reduktion des Allgemeinzustandes oder eine vorbestehende Erkrankung stellt ein zusätzliches Operationsrisiko dar. Von besonderer Wichtigkeit für den perioperativen Verlauf sind vorbestehende kardiovaskuläre oder pulmonale Erkrankungen. Für die Planung einer Anästhesie sind die Anamnese und der Status die Basis des weiteren Vorgehens. Durch eine gezielte Befragung sowie eine korrekte Untersuchungstechnik können nahezu alle relevanten Probleme des Patienten erkannt werden. Sind Hinweise für Organpathologien oder systemische Erkrankungen vorhanden, müssen gezielte Laboranalysen oder bestimmte Zusatzuntersuchungen veranlasst werden. Bei elektiven Eingriffen ermöglicht eine präoperative Therapie häufig eine Verbesserung des präoperativen Gesundheitszustandes des Patienten. Dadurch können das Auftreten oder das Ausmaß perioperativer Komplikationen vermindert werden. Wegen der begrenzten finanziellen Ressourcen, die dem Gesundheitswesen heute zur Verfügung stehen, und einem ungenügenden Kosten-Nutzen-Verhältnis sind routinemäßige, präoperative Screening-Tests nicht empfehlenswert.

\section{( Klinisch gesunde Patienten benötigen keine Screening-Tests.}

Die Zahl der Operationen, die an älteren und polymorbiden Patienten durchgeführt werden, ist in den letzten Jahren kontinuierlich angestiegen. Bei diesem Patientengut ist die perioperative Morbidität und Mortalität erhöht. Deshalb werden höhere Ansprüche an die perioperative Betreuung gestellt.
Zur Abschätzung des Überwachungsaufwandes während und nach der Operation hat sich die Klassifikation nach der American Society of Anesthesiologists (ASA) in 6 Klassen weltweit etabliert.

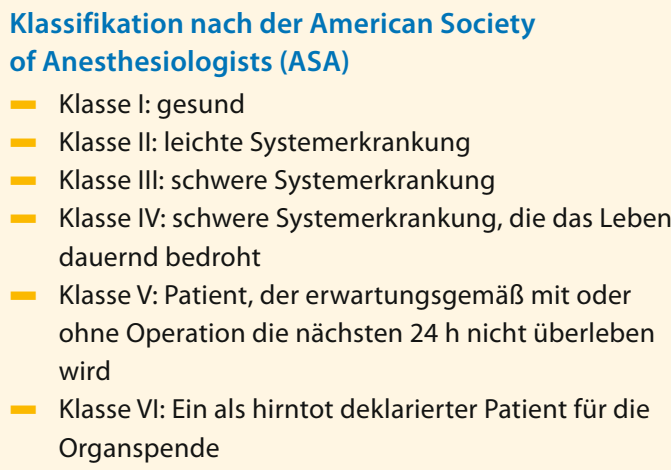

\section{$>$ Patienten mit einer ASA-Klasse III oder höher müssen präoperativ gezielt abgeklärt werden.}

Bei diesen Patienten soll der Anästhesist so früh wie möglich konsiliarisch hinzugezogen werden. Dadurch können Abklärungen, Änderungen der aktuellen Therapie und die Planung der postoperativen Betreuung in die Wege geleitet werden. Der mündige Patient oder seine Angehörigen müssen in die präoperativen Entscheidungsprozesse miteinbezogen werden.

\section{Anamnese}

Genau wie in anderen Spezialfächern der Medizin gibt die Anamnese die wichtigsten Anhaltspunkte über den Gesundheitszustand des Patienten wieder.

Ein systematisches Vorgehen verhindert, dass wichtige Aspekte vergessen werden.

Die Anamnese der wichtigen Organsysteme und weitere anästhesierelevante Informationen über den Patienten müssen erhoben werden.

Praxisbox

\section{Anästhesierelevante Anamnese}

- Herz/Kreislauf: Belastungsfähigkeit, Herzoperationen, Herzklappenerkrankungen, Myokardinfarkt, Angina pectoris und Hypertonie, Synkopen

- Lunge: Dyspnoe, Orthopnoe, Husten, Asthma, Nikotinabusus

- Leber: Status nach Hepatitis

- Blutgerinnung: starke Blutung nach dem Zähneputzen, unstillbare Blutungen nach Schnittverletzungen, Hämatome nach Bagatelltraumen

- Niere: Niereninsuffizienz, Status nach Nephrektomie

- Neurologie: ischämische Ereignisse, neurologische Erkrankungen, sensible und/oder motorische Ausfälle, Muskelkrankheiten, Synkopen 
- Stoffwechsel: Diabetes mellitus, Hypo- oder Hyperthyreose

- Aspirationsgefahr: gastroösophagealer Reflux, lleus, Hiatushernie

- Allergien: auf Medikamente, Jod, Pflaster, Latex, andere Auslöser

- Medikamente: aktuelle Therapie

- Anästhesiezwischenfälle aufgrund früherer Anästhesien beim Patienten und in der Familie (Intubationsprobleme, Porphyrie, maligne Hyperthermie, Todesfälle)

- Sonstiges: frühere Blutübertragungen, Zahnprothese/ lockere Zähne, Schwangerschaft, Alkohol/Drogenkonsum

Basierend auf den Befunden der Anamneseerhebung werden gezielte Laboruntersuchungen und andere Abklärungen angeordnet. Dadurch kann das Ausmaß von Krankheiten erfasst und der Effekt etwaiger therapeutischer Maßnahmen gemessen werden. Bei Spezialproblemen sind konsiliarisch andere Spezialisten hinzuzuziehen. Fragestellungen an Konsilarien sollen sich fokussiert auf die Durchführung und Beurteilung von speziellen Untersuchungen und auf die Möglichkeiten einer präoperativen Verbesserung eines pathologischen Organbefundes durch therapeutische Maßnahmen beschränken. Die Anästhesiefähigkeit und das Anästhesierisiko werden durch den Anästhesisten unter Einbeziehung sämtlicher Aspekte beurteilt.

\section{Status}

Der Status ergänzt die anamnestischen Erhebungen durch objektivierbare Befunde. Die folgenden Befunde sollen dabei erhoben werden:

- Herz/Kreislauf: Puls, Blutdruck, hepatojugulärer Reflux, Auskultation und Palpation, Punktionsstellen

- Lunge/Luftwege: Auskultation, anatomische Besonderheiten der oberen Luftwege,

- orientierender Neurostatus,

- Lokalstatus für Regionalanästhesien.

Das Ausmaß einer Herzinsuffizienz sowie der Erfolg etwaiger therapeutischer Maßnahmen können beurteilt werden. In der Anästhesie sind außer der Funktion des Herz-Kreislauf-Systems und der Lunge pathologische Befunde des Nervensystems von Bedeutung. Die Dokumentation neurologischer Ausfälle vor dem Anlegen einer Regionalanästhesie ist aus arztrechtlichen Gründen nötig. Der Lokalbefund im Bereiche der geplanten Punktionsstelle einer Regionalanästhesie ist von Bedeutung, wenn aufgrund der Anatomie oder wegen einer lokalen Infektion die Applikation einer Regionalanästhesie kontraindiziert ist.

\section{Screening-Tests}

In verschiedenen Kliniken werden routinemäßig ScreeningTests zur Erfassung evtl. vorhandener, aber dem Patienten nicht bekannter Erkrankungen durchgeführt. Weil mit zunehmendem Alter vermehrt pathologische Befunde zu erwarten sind, erfolgen in verschiedenen Krankenhäusern ScreeningTests nach Alterslimit. Ein weiterer Grund für derartige Routineuntersuchungen ist der medicolegale (haftpflichtrechtliche) Aspekt. Der Wert von solchen ungezielten ScreeningUntersuchungen ist jedoch gering, weil relevante Diagnosen bereits durch die Anamnese und den Status erhoben werden können. Deswegen genügt es, eine exakte Dokumentation der Anamnese und des Status zu erstellen.

In der Regel werden bei vorliegender Indikation Hämoglobin (Hb), Hämatokrit (Hk), Leukozyten, Thrombozyten, Prothrombin, Natrium, Kalium, Blutzucker, Kreatinin und/oder Harnstoff als Laborparameter bestimmt.

Auch in höheren Altersgruppen sind routinemäßige Screening-Tests bei altersentsprechend gesunden und leistungsfähigen Patienten nicht nötig. Die optimale präoperative Vorbereitung des Patienten sollte heute nach Möglichkeit nur noch mit gezielten Untersuchungen erfolgen.

\section{Gezielte Untersuchungen}

Je nach Ergebnis der Anamnese und des Status müssen gezielte Untersuchungen durchgeführt werden. Viele dieser Untersuchungen erfordern einen gewissen Zeitaufwand, so dass es sich gerade bei polymorbiden Patienten lohnt, den Anästhesisten frühzeitig hinzuzuziehen. Viele präoperative $\mathrm{Ab}$ klärungen können bereits anlässlich der 1. Planung der Operation ambulant oder durch den Hausarzt des Patienten erfolgen. Als Beispiele seien Elektrokardiogramm (EKG) oder selektive Laboruntersuchungen erwähnt.

Blutgerinnungsstörungen lassen sich durch eine gezielte Anamnese erheben. Gibt der Patient auffällige Blutungen beim Zähneputzen, eine verlängerte Blutungszeit nach Schnittwunden oder die Bildung von Suffusionen und Hämatomen nach Bagatelltraumen an, muss nach einer Blutgerinnungsstörung gesucht werden.

Einen 1. Anhaltspunkt auf eine mögliche Ätiologie erhält man durch die Bestimmung der Thrombozytenzahl und des Prothrombins. Es gilt zu beachten, dass die Wirkung von Thrombozytenaggregationshemmern wie Aspirin allerdings dadurch nicht erfasst werden kann. Will man den Einfluss von nichtsteroidale Antirheumatika auf die Blutgerinnung ausschließen, so müssen diese Medikamente 10 Tage vor dem elektiven Eingriff abgesetzt werden. Ist der Patient antikoaguliert, ist das Sistieren der Antikoagulation unter Laborkontrolle bei den meisten elektiven Eingriffen indiziert. Eine vorübergehende Gerinnungshemmung durch (evtl. niedermolekulares) Heparin kann notwendig sein.

Für komplexere Erkrankungen, wie manifeste koronare Herzkrankheit (KHK), Lungenfunktionsstörung mit ausgeprägter Einschränkung der Belastbarkeit und endokrine Erkrankungen, sind die entsprechenden Spezialisten rechtzeitig hinzuzuziehen, damit die notwendigen weiterführenden Untersuchungen durchgeführt werden können.

Die Notwendigkeit einer präoperativen kardiologischen Abklärung bei Patienten mit Verdacht auf KHK hängt im Wesentlichen von folgenden Faktoren ab: 


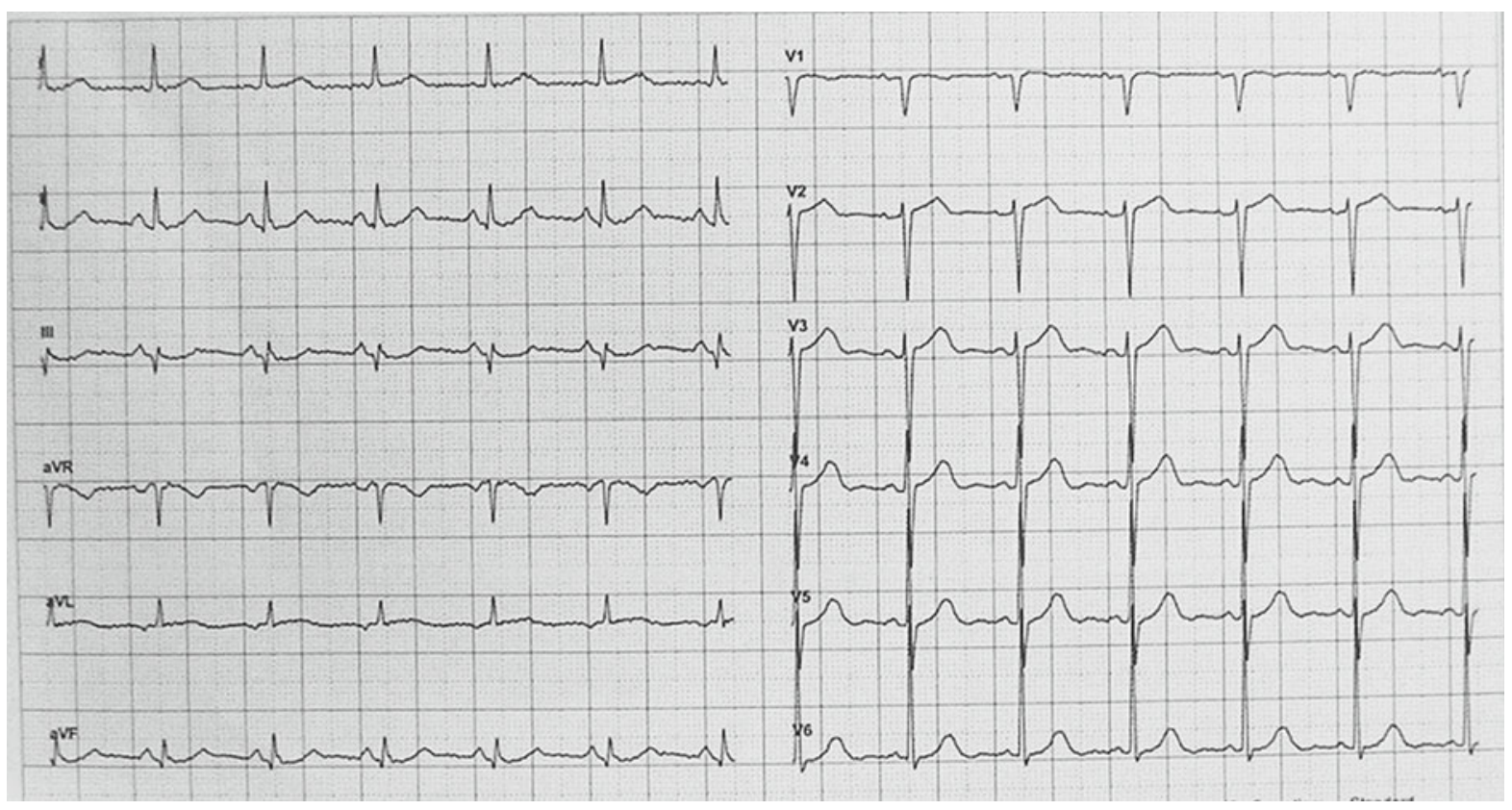

- Abb. 1.76 Normales EKG: Sinusrhythmus, Linkslage, unauffällige Repolarisation

- Dringlichkeit des Eingriffes: bei Notfalleingriff oft nicht möglich,

- Vorhandensein von klinischen Prädiktoren wie bekannte koronare Herzkrankheit, Herzinsuffizienz, zerebrovaskuläre Erkrankungen, Diabetes mellitus, Niereninsuffizienz,

- funktionelle Kapazität/Belastungsfähigkeit (Atemnot nach Steigen von weniger als 2 Stockwerken),

- Art des chirurgischen Eingriffes (z. B. Gefäßeingriffe, Thorakotomien, Laparatomien, große orthopädische Eingriffe).

Bei Patienten mit einer stabilen KHK und erhaltener Belastungsfähigkeit darf - außer vor großen Eingriffen - die kardiale Risikostratifizierung, definitive Abklärung und Therapieanpassung auch erst postoperativ erfolgen, z. B. bei einem abnormalen EKG, einem normokarden Vorhofflimmern, einer milden Angina pectoris oder einer suboptimal eingestellten Hypertonie.

Patienten nach perkutaner koronarer Intervention und Stenting sollten sich während den folgenden 1-2 Monaten (12 Monate bei beschichteten Stents) keinen elektiven Eingriffen unterziehen. Bestehen Hinweise auf gravierende Rhythmusstörungen, z. B. wegen Synkopen, ist ein 24 h-EKG indiziert (• Abb. 1.76).

Bei instabiler Angina pectoris oder schlechter funktioneller Kapazität sollten weiterführende Abklärungen wie Belastungselektrokardiogramm, Echokardiographie, Dipyridamolszintigraphie und evtl. eine Koronarangiographie durchgeführt werden (• Abb. 1.77).

Je nach Befund kann durch Anpassung der Therapie der kardiale Zustand des Patienten verbessert werden. Je nach Ausmaß und Lokalisation von Koronarstenosen ist eine PTCA (perkutane transluminale Koronarangioplastie) indiziert oder sogar eine Revaskularisierung durch einen aortokoronaren Bypass vor dem ursprünglich geplanten Eingriff nötig.

Bei Patienten mit einer limitierten Lungenfunktion - restriktive Lungenerkrankung, COLD (chronisch-obstruktive Lungenerkrankung), Asthma - lässt sich durch eine Testung

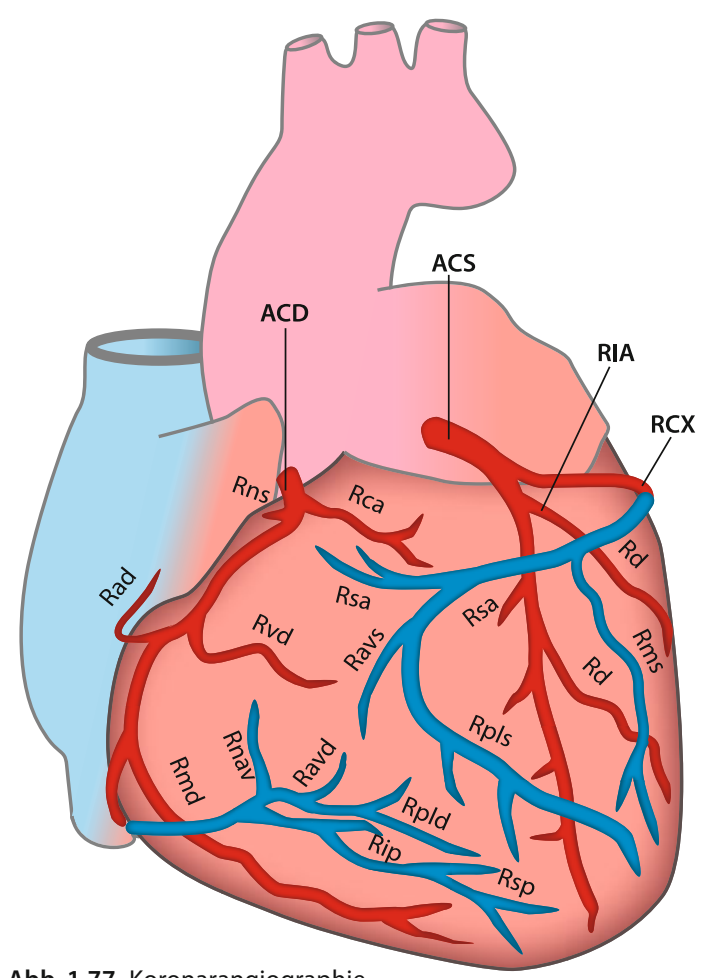

- Abb. 1.77 Koronarangiographie 


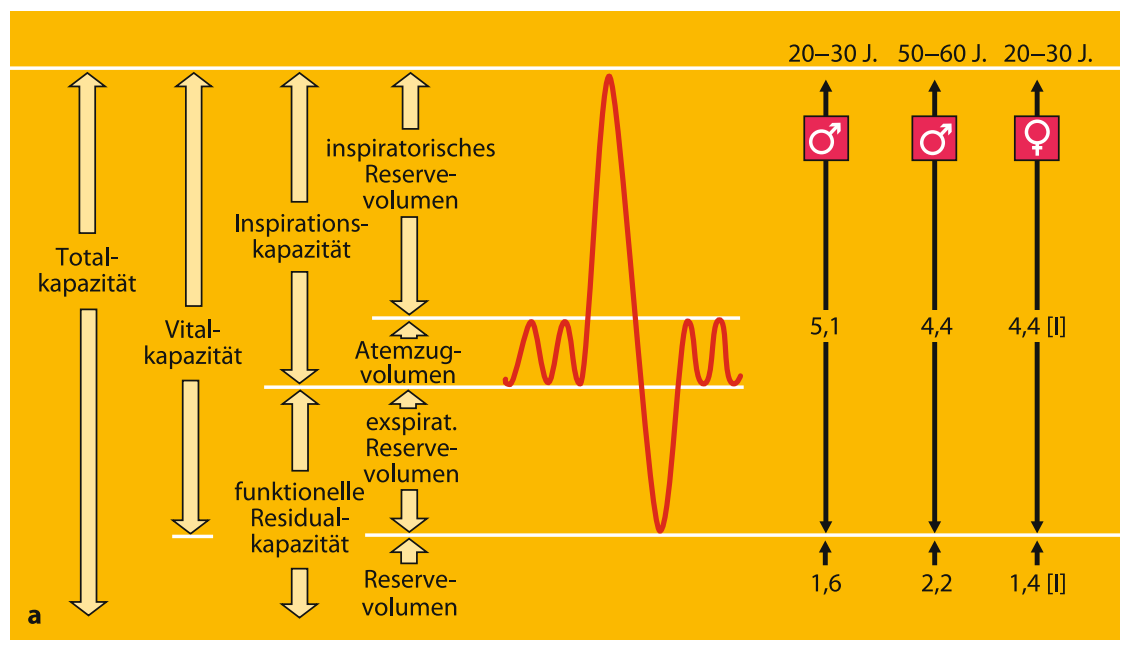

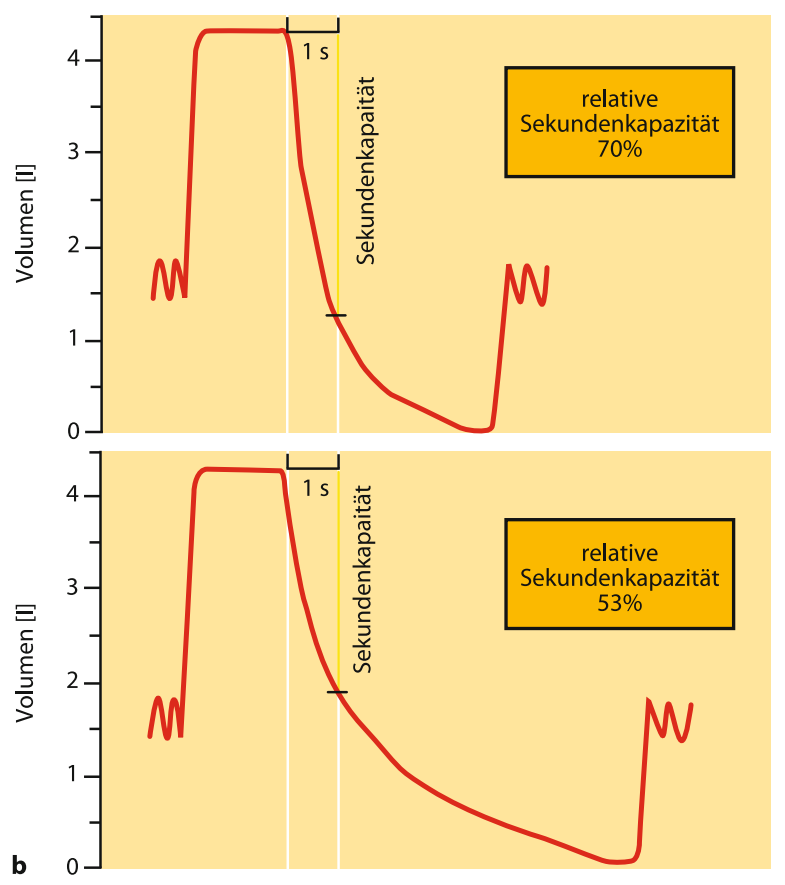

- Abb. 1.78 Schema Lungenfunktion. a Übersicht Lungenvolumina mit altersabhängigen Veränderungen. $\mathbf{b}$ Einsekundenkapazität (FEV1) in Relation zur Vitalkapazität Normal $>70 \%$, erniedrigt bei obstruktiven Lungenerkrankungen

der Lungenfunktion abschätzen, ob eine broncholytische Therapie (Inhalation mit $\beta_{2}$-Stimulanzien, Steroidtherapie) die pulmonalen Reserven des Patienten verbessern kann (• Abb. 1.78).

Eine präoperative Blutgasanalyse gibt Auskunft darüber, welche Werte postoperativ anzustreben sind. Besonders gefährdet sind Patienten mit Schlaf-Apnoe-Syndrom, weil sie durch einen geringen Überhang von Anästhetika postoperativ für eine Apnoe gefährdet sind. Derartige Patienten müssen deshalb während den ersten $24 \mathrm{~h}$ postoperativ mit der Puls- oxymetrie und entsprechend geschultem Personal kontinuierlich überwacht werden.

\section{In Kürze}

\section{Präoperative Maßnahmen}

- Zusammenarbeit von Chirurg und Anästhesist: Art und Dringlichkeit der OP, ambulant oder stationär, Zustand des Patienten, optimale Vorbereitung des Patienten, postoperative Maßnahmen, notwendige technische und apparative Ausrüstung.

- Zur Abschätzung der perioperativen Betreuung: Einteilung in ASA-Klassen, Anamnese (systematisches Vorgehen), Status, evtl. Screening-Test.

- Labor- und weitere präoperative Untersuchungen: gezielt nach pathologischen Befunden in der Anamnese und im Status sowie nach den Operationsindikationen.

- Verschiebung des Operationstermins bei elektiven Eingriffen, falls der Allgemeinzustand des Patienten durch therapeutische Maßnahmen verbessert und dadurch die Inzidenz von Komplikationen reduziert werden kann.

\subsubsection{Präoperative Verordnungen}

\section{Nüchternheit}

D Cave

Im Rahmen einer Allgemeinanästhesie verlieren die Patienten ihre Schutzreflexe, so dass bei vollem Magen die Gefahr einer Regurgitation und Aspiration besteht.

Untersuchungen haben gezeigt, dass Erwachsenen bis $3 \mathrm{~h}$ und Kindern bis $2 \mathrm{~h}$ vor der Operation die Einnahme von klarer Flüssigkeit (Tee, kohlenhydrathaltige klare Getränke, Mineralwasser) ohne Gefahr erlaubt werden kann. Bei Notfallein- 
griffen muss mit dem Chirurgen zusammen das Risiko einer Anästhesie beim nichtnüchternen Patienten mit möglicher Aspiration gegen die Gefahren einer Aufschiebung der Operation diskutiert und abgewogen werden. Auch der Patient muss über die Entscheidung und deren Folgen informiert werden.

Selbstverständlich müssen auch für Regionalanästhesieverfahren und sog. Stand-by-Überwachungen in Lokalanästhesie die gleichen Regeln eingehalten werden. Adverse Reaktionen auf das Anlegen einer Regionalanästhesie (allergische Reaktionen, Krampfanfall durch versehentliche intravasale Applikation eines Lokalanästhetikums, hohe Spinalanästhesie), unvollständige Regionalanästhesie oder eine unerwartete Verlängerung der Operation können direkt zum Verlust der Schutzreflexe des Patienten führen oder die Umstellung auf eine Allgemeinanästhesie mit entsprechender Gefahr zur Folge haben. Bei Nichteinhalten der NüchternRegel ist der Patient in derartigen Situationen unnötigerweise für eine Aspiration gefährdet. Für Notfälle mit vollem Magen ergeben sich Konsequenzen hinsichtlich besonderer Vorbereitung des Patienten. Der Magen kann durch die Einlage einer Magensonde vor der Einleitung der Anästhesie entleert werden.

\section{Nüchternzeit $6 \mathrm{~h}$ für feste Nahrung, 2-3 h für klare Flüssigkeit!}

\section{Medikamente}

Nach der präoperativen Visite verordnet der Anästhesist dem Patienten die präoperative Medikation. Herz- und Kreislaufmedikamente wie $\beta$-Blocker, Kalziumantagonisten, ACEHemmer und Nitrate werden je nach Befunden, geplanter Operation und Anästhesietechnik in einer angepassten Dosierung weiterverordnet.

\section{$(7$ Patienten mit Herz-Kreislauf-Erkrankungen sind auch intra- und postoperativ therapiebedürftig.}

Wird die Therapie unterbrochen, besteht die Gefahr einer perioperativen Exazerbation der Grundkrankheit, mit allen ihren Risiken. Eine bestehende Therapie mit $\beta$-Blockern sollte perioperativ unbedingt weitergeführt werden um die Inzidenz von koronaren Ereignissen zu reduzieren. Weil ein operativer Eingriff für den Patienten immer mit zusätzlichem Stress verbunden ist, wird im Allgemeinen präoperativ ein anxiolytisches Medikament verordnet. Benzodiazepine, z. B. Midazolam (7,5 mg oral für gesunde Erwachsene), haben sich bewährt.

$(7$ Kardiale Medikamente, insbesondere $\beta$-Blocker, sollten in der Regel perioperativ weitergegeben werden!

\section{Antikoagulation}

WeilRegionalanästhesieverfahren, insbesondererückenmarksnahe Anästhesien nur bei normaler Gerinnung appliziert werden dürfen, ist der Gerinnungssituation in der perioperativen Phase besondere Beachtung zu schenken. Die Einnahme von nichtsteroidalen, entzündungshemmenden Medikamenten (NSAID) stellt keine Kontraindikation zur Durchführung einer rückenmarksnahen Anästhesie dar. Wegen der erhöhten Blutungsgefahr soll hingegen unter Therapie mit Clopidogrel auf rückenmarksnahe Anästhesien verzichtet werden. Eine orale Antikoagulation wird gemäß Absprache zwischen dem Chirurgen und Anästhesisten aufgehoben, falls dies vom Patienten her möglich ist. Bei einer Therapie mit Kumarinderivaten wird die Antikoagulation durch Absetzen des Medikamentes über mehrere Tage oder durch Gabe von Vitamin K über mehrere Stunden, aufgehoben. Dies stellt das übliche Vorgehen für Wahleingriffe dar. Lediglich bei Notfalleingriffen kann die Kumarinwirkung durch die Applikation von Vitamin-K-abhängigen Gerinnungsfaktoren innerhalb von Minuten aufgehoben werden. Die Antikoagulation mit Heparin hat die Vorteile, dass mit Protamin ein sofort wirksames Antidot vorhanden ist, und dass nach Absetzen des Heparins die Gerinnung bereits 3-4 h später wieder im Normbereich liegt. Bei Herzklappenträgern oder Patienten mit kurz zurückliegender Thromboembolie, die eine dauernde Antikoagulation benötigen, ist deshalb präoperativ eine Umstellung von Kumarinderivaten auf Heparin parenteral oder alternativ eine Therapie mit niedermolekularem Heparin s.c. vorzusehen. Postoperativ kann die Heparinisierung nach Absprache mit den Chirurgen wieder begonnen werden.

Bei einer Vielzahl von Eingriffen ist eine perioperative Thromboseprophylaxe indiziert. Damit dem Patienten am Operationstag gefahrlos eine Regionalanästhesie appliziert werden kann, empfiehlt sich die Einmal-Thromboseprophylaxe mit niedermolekularem Heparin jeweils am Vorabend. Bei Notfalleingriffen soll der Zeitpunkt der Applikation der Thromboseprophylaxe mit dem Anästhesisten diskutiert werden. Während im Falle einer Allgemeinanästhesie Heparin sofort verabreicht werden kann, soll für Regionalanästhesien wegen der Gefahr einer Blutung die Thromboseprophylaxe erst nach der Applikation der Regionalanästhesie erfolgen. Zwischen der Gabe von niedermolekularen Heparinen in prophylaktischer Dosis und der Durchführung regionalanästhesiologischer Verfahren soll ein Mindestzeitraum von $12 \mathrm{~h}$ nicht unterschritten werden. Nach Verabreichung von Rivaroxaban beträgt dieser Zeitraum mindestens $18 \mathrm{~h}$.

\section{In Kürze}

Präoperative Verordnungen

- Nüchternzeit von 6 h für feste Nahrung, 2-3 h für klare Flüssigkeit.

- Herz- und Kreislaufmedikamente, insbesondere $\beta$-Blocker, sollten in der Regel perioperativ weitergegeben werden.

- Gerinnungssituation ist in der perioperativen Phase besonders zu beachten, v. a. bei rückenmarksnahen Anästhesien. Umstellen von Kumarinderivaten auf Heparin (z. B. bei Herzklappenträgern).

- Perioperative Thromboseprophylaxe. 


\subsubsection{Anästhesieverfahren}

\section{Stand-by-Anästhesie}

Bestimmte Eingriffe werden in Lokalanästhesie, jedoch in Anwesenheit eines Anästhesisten (Stand-by) durchgeführt. Diese Maßnahme kann sinnvoll sein, wenn der Allgemeinzustand des Patienten schlecht ist und er deshalb eine kontinuierliche Überwachung benötigt. Eine andere Indikation für einen Stand-by kann durch eine Erweiterung des Eingriffes gegeben sein, so dass auf eine allgemeine Anästhesie gewechselt werden muss. Deshalb gelten für jeden Stand-by die genau gleichen Vorbereitungsregeln wie für eine Allgemein- oder Regionalanästhesie (Nüchternzeit einhalten).

\section{Regionalanästhesie \\ Lokal- oder Leitungsanästhesie durch den Operateur}

Lokalanästhetika sind potenziell gefährliche Substanzen. Weil in der Chirurgie oft Eingriffe in Lokal- oder Leitungsanästhesie ohne Einbeziehung des Anästhesisten durchgeführt werden, sollen in diesem Kapitel wichtige Grundkenntnisse der Lokalanästhetika, Gefahren sowie Komplikationen und deren Therapie vermittelt werden.

Chemisch synthetisierte Lokalanästhetika weisen immer die gleiche Grundstruktur auf: Sie haben einen lipophilen aromatischen Teil und einen hydrophilen Aminorest (• Abb. 1.79).

Die beiden Teile sind durch eine Zwischenkette verbunden. Diese Zwischenkette ist in unterschiedlicher Weise an den aromatischen Teil gebunden, entweder durch eine Esteroder eine Amidbindung und bestimmt die Einteilung der Lokalanästhetika in Ester- und Amidtypen. Der Prototyp der Esterlokalanästhetika ist das Procain, derjenige des Amidtyps das Lidocain. Der Hauptunterschied zwischen einem Esterund Amidtyp-Lokalanästhetikum liegt nicht in seiner anästhetischen Wirkung, sondern in der Art, wie das Medikament metabolisiert wird. Die Esterverbindungen werden im Plasma durch die Pseudocholinesterase hydrolysiert. Dadurch entsteht u. a. der Metabolit Paraaminobenzoesäure, ein bekanntes Allergen. Die Amidverbindungen werden primär in der Leber durch mikrosomale Enzyme metabolisiert.

\section{Allergische Reaktionen sind für Lokalanästhetika vom Amidtyp extrem selten.}

Amidtyp-Lokalanästhetika werden langsamer abgebaut als Estertyp-Lokalanästhetika. Die Plasmakonzentration der Amidtyp-Lokalanästhetika bleibt somit länger hoch und eine systemische Toxizität ist häufiger als bei Estertyp-Lokalanästhetika. Die Gefahr einer Kumulation ist bei Amidtyp-Lokalanästhetika ebenfalls größer als beim Estertyp.

Die Wirkung der Lokalanästhetika erfolgt durch die Beeinflussung der Ionenpermeabilität der Zellmembran der Nervenzelle. Um diesen Effekt auszuüben, muss das Lokalanästhetikum zuerst in das Axoplasma eindringen, um die Natrium- und Kaliumkanäle von innen reversibel zu blockieren. Die wirksame Form des Medikamentes am Rezeptor ist der ionisierte Zustand, während zur Durchdringung der nichtionisierte Zustand vorliegen muss. Der $\mathrm{pK}_{\mathrm{a}}$-Wert des Lokal-

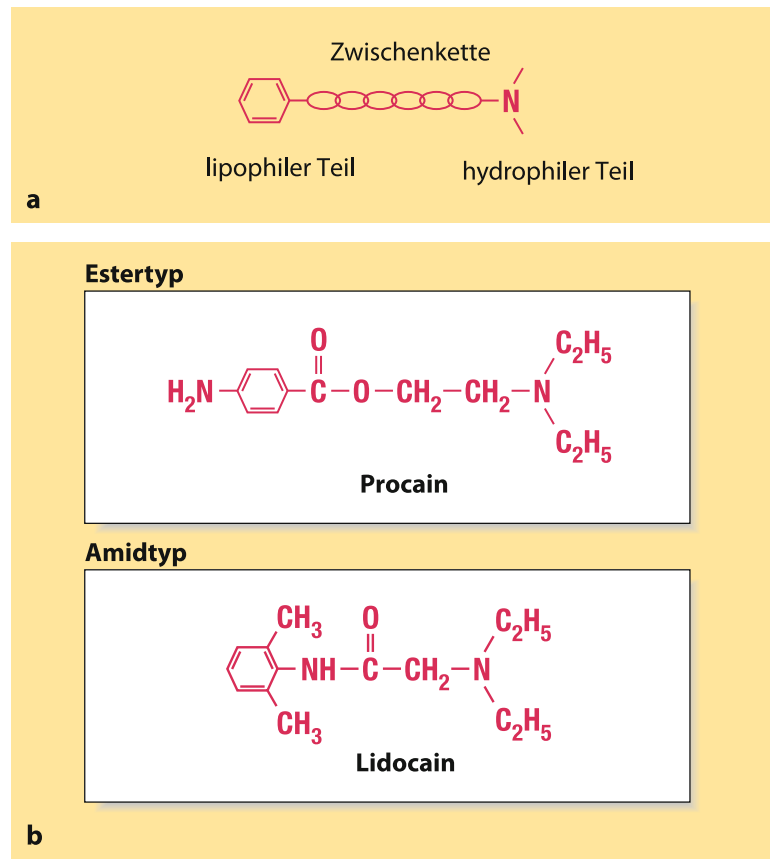

- Abb. 1.79 Molekulare Grundstruktur der Lokalanästhetika. Strukturformel von Procain (Estertyp) und von Lidocain (Amidtyp)

anästhetikums, der angibt, wie viel der aktiven Form eines Lokalanästhetikums (Kation, $\mathrm{K}_{\mathrm{a}}$ ) in Abhängigkeit vom Gewebe-pH vorhanden ist, und der $\mathrm{pH}$-Wert des Gewebes bestimmen, wie viele Moleküle durch die Zellmembran dringen und die Ionenkanäle besetzen.

Zusammenfassend ergibt sich folgende Wirkungsweise: Das Lokalanästhetikum wird zunächst an den Rezeptor in der Nervenmembran gebunden. Dadurch werden die Natriumkanäle verschlossen und der Einstrom für Natriumionen herabgesetzt. Durch den Verlust der Membrandurchlässigkeit für Natrium kann keine Zellmembrandepolarisation mehr erfolgen. Es setzt eine Nervenblockade ein. Die Wahl des Lokalanästhetikums hängt vom Operationsort, von der Dauer der Operation, der Art der Regionalanästhesie, der Patientengröße und vom Zustand des Patienten ab.

D Cave

Außer den seltenen allergischen Reaktion können toxische Reaktionen durch eine versehentliche intravasale Injektion, schnelle Resorption oder durch Überdosierung verursacht werden.

Sie sind gekennzeichnet durch Reaktionen des zentralen Nervensystems (Taubheitsgefühl perioral, metallischer Geschmack auf der Zunge, Benommenheit, Schwindel, Sehstörungen, Ohrensausen, tonisch/klonische Krämpfe, Atemstillstand) und des Herz-Kreislauf-Systems (Blutdruckabfall, Rhythmusstörungen). 
D Cave

ZNS-Reaktionen treten vor den lebensbedrohlichen kardialen Wirkungen auf und sind deshalb als Warnzeichen einer Intoxikation zu werten.

Praxisbox

Technik der Injektion von Lokalanästhetika

Toxische Reaktionen können durch richtige Technik weitgehend vermieden werden. Bei der Injektion muss unbedingt eine intravenöse oder intraarterielle Applikation vermieden werden, da sonst innerhalb Sekunden toxische Blutspiegel erreicht werden können. Deshalb sollte vor jeder Injektion eine Aspiration auf Blut durchgeführt werden. Findet die Injektion des Lokalanästhetikums in blutreiches Gewebe statt, können ebenfalls durch schnelle Resorption hohe Blutspiegel erreicht werden. Durch die Zugabe von Vasokonstriktoren, wie z. B. Adrenalin in einer Konzentration von 1:200.000 kann die Resorption vermindert sowie die Wirkungsdauer der Nervenblockade verlängert werden. Dabei ist zu beachten, dass für die Lokalanästhesie im Versorgungsgebiet einer Endarterie, wie z. B. Finger wegen der Gefahr einer Gewebsnekrose auf den Zusatz eines Vasokonstriktors verzichtet werden muss. Eine weitere wichtige Maßnahme zur Verhinderung einer toxischen Reaktion ist die Einhaltung der Maximaldosierung (•Tab. 1.39).

\section{Intravenöse Regionalanästhesie}

Dabei wird das Lokalanästhetikum in das Gefäßsystem zu dessen Verteilung in der Körperregion gespritzt. Da dafür eine Blutleere notwendig ist, ist die Anwendung auf den Arm und den Unterschenkel begrenzt. Für den Erfolg der Anästhesie ist sowohl ein genügendes Volumen zur Auffüllung und Verteilung im Gefäßsystem, als auch eine genügende Konzentration notwendig, um zumindest die sensorischen Nervenfasern zu blockieren.

\section{Praxisbox}

\section{Technik der intravenösen Regionalanästhesie}

Zuerst wird eine dünne Verweilkanüle in eine Vene nahe des Operationsgebietes eingelegt (• Abb. 1.80). Danach wird die Extremität durch Elevation und Auswickeln mit einer Esmarch-Binde entleert. Am Oberarm wird dann eine vorher angelegte pneumatische Blutsperremanschette $100 \mathrm{mmHg}$ über dem systolischen Blutdruck aufgeblasen. Für die untere Extremität wird die Manschette am Unterschenkel angelegt und muss auf $350-400 \mathrm{mmHg}$ aufgeblasen werden. Vorteilhaft ist die Verwendung einer 2-kammerigen Manschette. Zuerst wird jeweils die proximale Kammer unter Druck gesetzt. Nach Entfernung der Esmarch-Binde wird das Venensystem über die Verweilkanüle mit dem Lokalanästhetikum (Prilocain 0,5\% ohne Zusätze) aufgefüllt. Bei Erwachsenen sind am Arm 40 ml, am Bein $60 \mathrm{ml}$ notwendig. Bei Schmerzhaftigkeit der
Manschette wird nach 30-45 min die distale Kammer aufgeblasen und anschließend die proximale Kammer entlüftet. Der Manschettendruck verschiebt sich dann in das bereits anästhesierte Gebiet. Etwa 5-10 min nach der Injektion kann mit der Operation begonnen werden. Bei dieser Technik sollte die Operation nicht viel länger als $1 \mathrm{~h}$ dauern.

D Cave

Beim Ablassen der Manschette muss der Patient genau beobachtet werden, um toxische Reaktionen sofort zu erkennen und zu behandeln. Der Beobachtungszeitraum nach Ablassen der Manschette muss mindestens 10 min betragen, da viele Symptome wie Bradykardie, Übelkeit oder Blutdruckabfall erst nach einigen Minuten auftreten.

Bei der Anwendung der intravenösen Anästhesie besteht die Gefahr der Manschettenruptur mit der Folge der sofortigen Freisetzung des Lokalanästhetikums bevor eine Diffusion ins Gewebe erfolgt ist. Deshalb muss vor der Applikation des Lokalanästhetikums immer ein 2. intravenöser Zugang gelegt werden, damit etwaige toxische Reaktionen sofort behandelt werden können.

\section{Blockade des Plexus brachialis}

Die Plexusblockade bietet sich als Methode der Wahl bei Operationen und Manipulationen der Schulter, des Armes und der Hand an (• Abb. 1.81).

Der Plexus brachialis wird klassischerweise mit 3 verschiedenen Zugängen blockiert:

- Für Schultereingriffe wird der interskalenäre Zugang am Hals gewählt,

- für Eingriffe am Arm der Supra- oder Infraklavikulärblock

- und für Eingriffe am Vorderarm oder auch der Hand wird die axilläre Plexusblockade verwendet.

Die Ultraschall-basierte Nervenidentifikation führt zu rascherer und zuverlässigerer Blockade. Die Technik des axillären Zugangs wird auch oft von Chirurgen selbst eingesetzt. Dabei

- Tab. 1.39 Maximaldosen der meist verwendeten Lokalanästhetika

Lokalan-

ästhetikum

Maximal Dosierung

Ohne Adrenalinzusatz

Mit Adrenalinzusatz

\begin{tabular}{l|l|l}
\hline Lidocain & $4 \mathrm{mg} / \mathrm{kgKG}$ & $7 \mathrm{mg} / \mathrm{kgKG}$ \\
\hline Mepivacain & $4 \mathrm{mg} / \mathrm{kgKG}$ & $7 \mathrm{mg} / \mathrm{kgKG}$ \\
\hline Bupivacain & $2 \mathrm{mg} / \mathrm{kgKG}$ & $3 \mathrm{mg} / \mathrm{kgKG}$ \\
\hline Prilocain & $8 \mathrm{mg} / \mathrm{kgKG}$ & $8 \mathrm{mg} / \mathrm{kgKG}$
\end{tabular}




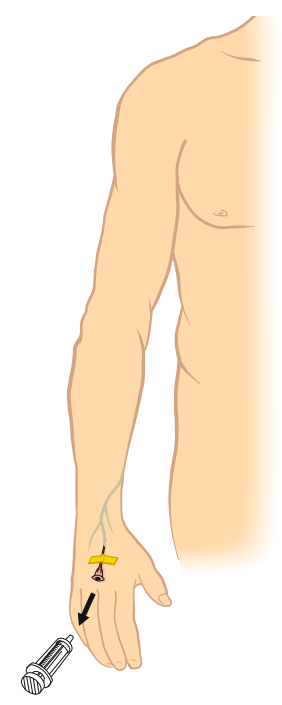

a

- Abb. 1.80 Intravenöse Regionalanästhesie. a Legen der intravenösen Verweilkanüle am Handrücken. $\mathbf{b}$ Emporheben des Armes mit angelegter, lockerer Doppelmanschette, Auswickeln der Gefäße von

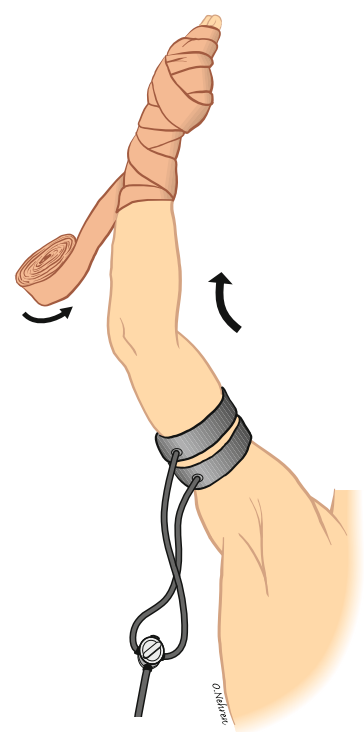

b

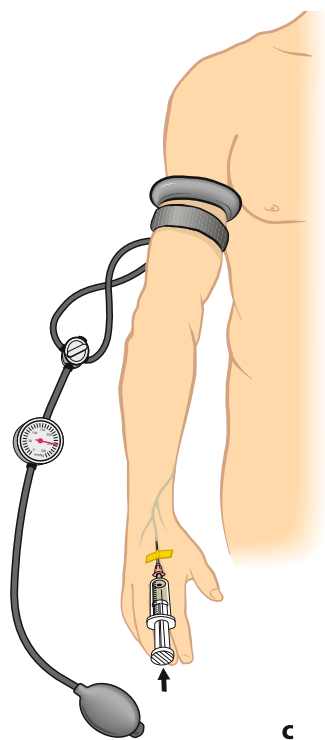

distal nach proximal mit Esmarch-Binde, Aufblasen der proximalen Manschette. c Füllen des Venensystems distal der aufgeblasenen proximalen Manschette mit dem Lokalanästhetikum

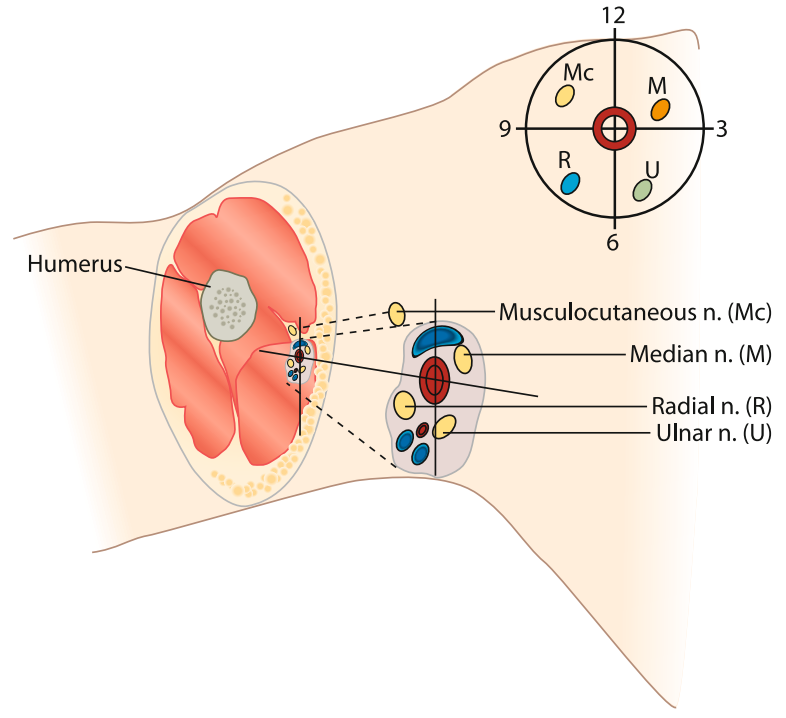

- Abb. 1.81 Anatomie Plexusblockade (aus Döberl u. Eriksson, 1980)

\section{Patientenüberwachung}

Zur Überwachung des Patienten ist ein der Situation angepasstes Monitoring notwendig.

sind Barbiturate oder Benzodiazepine zur Therapie ein Krampfanfalles sowie Adrenalin und Atropin zur Therapie schwerer Kreislaufzwischenfälle auf Vorrat zu halten. Bei einem refraktären kardiotoxischen Herzkreislaufstillstand kann zusätzlich zur kardiopulmonalen Reanimation die i.v.-Gabe einer 20\%-Lipidlösung erwogen werden (Bolus von $1,5 \mathrm{ml} / \mathrm{kgKG}$.

$(>$ Bei Infiltrationsanästhesien und Nervenblockaden mit kleinem Volumen (Faustregel: $<25 \%$ der Maximaldosierung) ist eine spezielle Patientenüberwachung beim gesunden Patienten (ASA-Klassen I und II) nicht indiziert. 
Werden große Mengen Lokalanästhetika infiltriert, wie z.B. bei einer axillären Plexusblockade, ist ein Monitoring, bestehend aus EKG, Pulsoxymetrie und nichtinvasiver Blutdruckmessung, angezeigt. Bei polymorbiden Risikopatienten ist eine Überwachung durch den Anästhesisten zu erwägen (Stand-by).

\section{Spinalanästhesie, Periduralanästhesie}

Bei der periduralen Anästhesie erfolgt eine Blockade von Spinalwurzeln durch Injektion eines Lokalanästhetikums in den Periduralraum. Davon abzugrenzen ist die Spinalanästhesie, durch die eine Blockade des Rückenmarks durch Injektion eines Lokalanästhetikums in den Subarachnoidalraum erfolgt (- Abb. 1.82, A Abb. 1.83).

Der Wirkungseintritt der Periduralanästhesie ist in der Regel langsam, die Wirkungsdauer mittellang bis lang. Die Spinalanästhesie wirkt in der Regel schnell und die Wirkungsdauer ist kurz. Die Spinalanästhesie führt zu einer ausgeprägten Muskelrelaxierung. Es werden relativ geringe Mengen an Lokalanästhetika benötigt, so dass systemische Reaktionen auf Lokalanästhetika vernachlässigt werden können. Die Periduralanästhesie erreicht die Blockade von jeweils 1-2 spinalen Dermatomen/ml Lokalanästhetikum. Es sind höhere Volumina an Lokalanästhetikum zu verabreichen.

Bei beiden Anästhesieformen müssen Blutdruck, Herzfrequenz, EKG und Anästhesieausdehnung kontinuierlich überprüft werden.

B Cave

Neurologische Ausfälle nach rückenmarksnahen Anästhesien (schwere Rückenschmerzen, Blasendarmfunktionsstörungen, progressive Sensibilitätsstörungen oder zunehmende motorische Schwäche) müssen zum Ausschluss eines raumfordernden Hämatoms frühzeitig $(<6 \mathrm{~h})$ radiologisch abgeklärt werden!

\section{Allgemeinanästhesie}

Dem Anästhesisten steht ein ganzes Armentarium verschiedener Medikamente für Mono- oder Kombinationsanästhesien zur Verfügung. Die Überwachung des Patienten wird entsprechend seinem Gesundheitszustand und der geplanten Operation festgelegt. Ebenso richtet sich die Wahl der Medikamente nach dem Gesundheitszustand des Patienten und nach der Art der Operation. Wenn für die Operation eine Muskelrelaxation nötig ist, ist eine Intubationsanästhesie durchzuführen. In geeigneten Situationen kann die Ventilation auch über eine konventionelle Maske oder durch die Verwendung einer Larynxmaske sichergestellt werden. Die so im Alltag erworbene hohe Professionalität im Umgang mit dem Luftweg des Patienten, die Fertigkeiten im Kreislaufmanagement (Zugangsverfahren, Schockbehandlung, Reanimation) und die teamorientierte Patientenversorgung qualifizieren Anästhesisten auch für den präklinischen Notarztbereich (- Abb. 1.84).

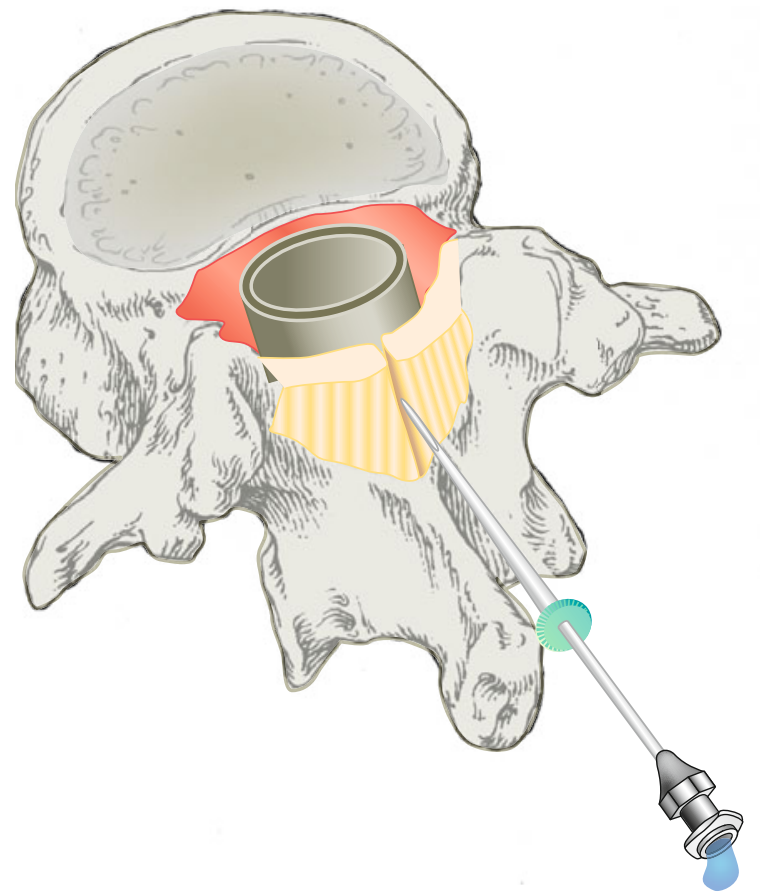

- Abb. 1.82 Anatomie Spinalanästhesie (aus Döberl u. Eriksson, 1980)

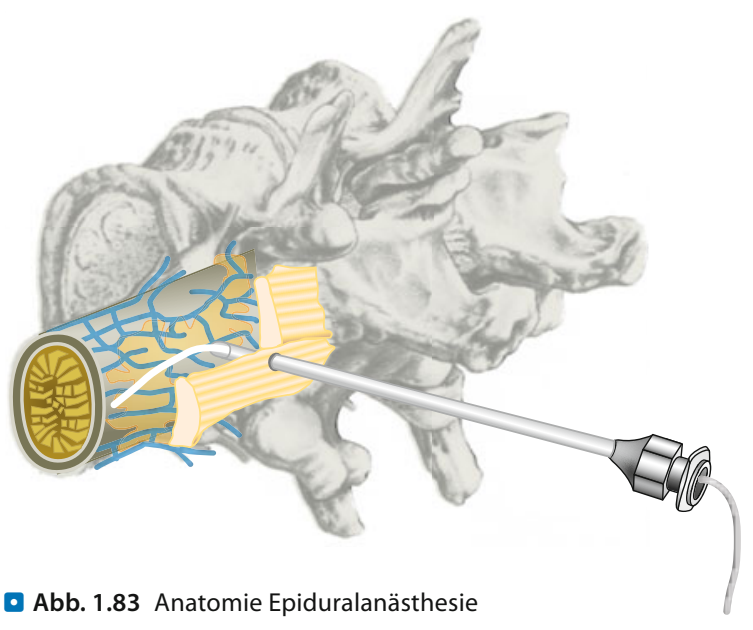

\section{Kombinierte Anästhesietechniken}

In bestimmten Fällen ergeben sich günstige Synergieeffekte durch die Kombination einer Regional- mit einer Allgemeinanästhesie. Für Oberbaucheingriffe kann z. B. eine thorakal eingelegte Periduralanästhesie bereits intraoperativ für die Analgesie eingesetzt werden.

$>$ Kombinationsanästhesien haben den Vorteil, dass der Patient postoperativ durch das Fortführen der Regionalanästhesie analgetisch therapiert werden kann ( $\triangleright$ Abschn. 1.9.5). 

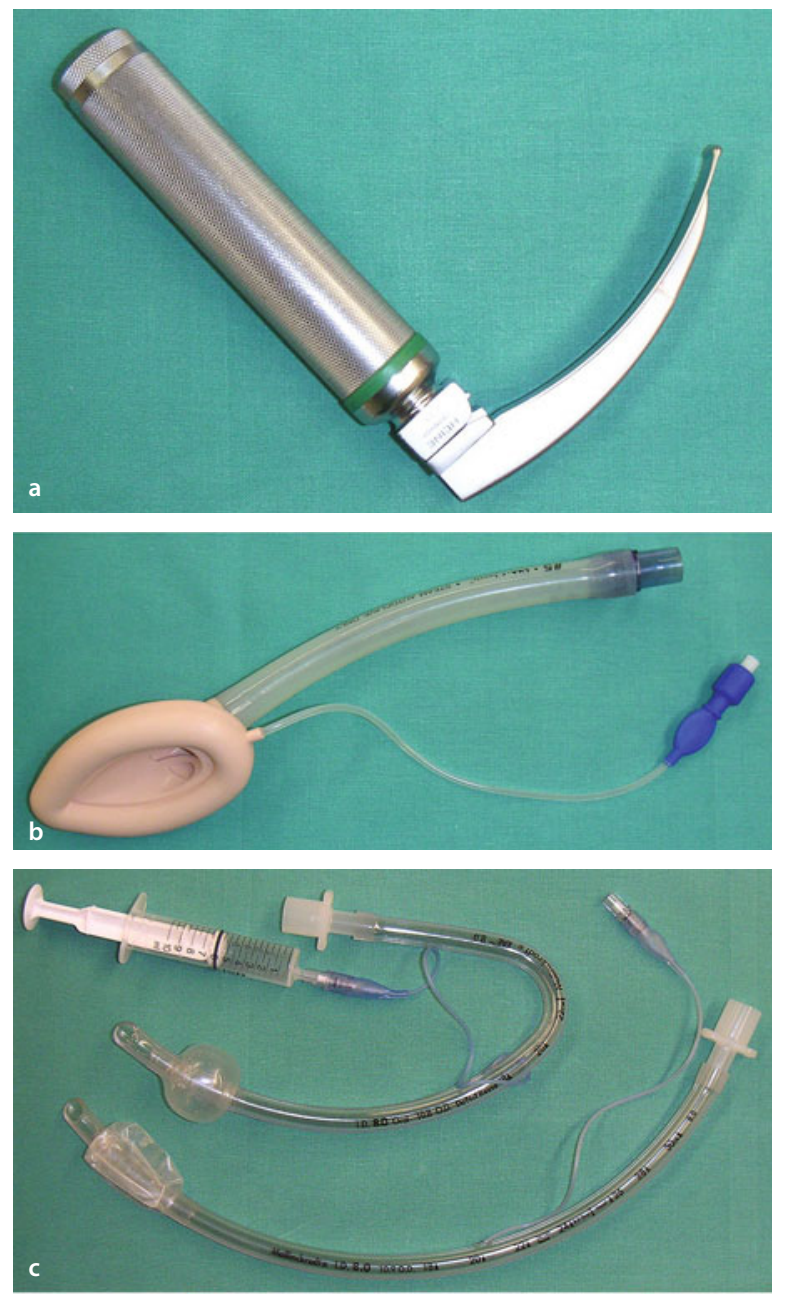

- Abb. 1.84 a Laryngoskop, b Larynxmaske, c Tubus

\section{In Kürze}

\section{Anästhesieverfahren}

Regionalanästhesie: Stand-by-Anästhesie bei Lokalanästhesie

- Lokal- oder Leitungsanästhesie (Ester- und Amidtypen, z. B. Procain und Lidocain), Nervenblockade durch Verschiebung der lonenpermeabilität der Zellmembran, selten allergische Reaktionen. Cave: toxische Reaktionen, ZNS-Reaktion als Warnzeichen (intravasale Injektion, schnelle Resorption, Überdosierung).

- Intravenöse Regionalanästhesie: Esmarch-Manschette, mindestens 10 min Nachbeobachtung, zweiter i.v.-Zugang.

- Plexusblockade: 3 Zugänge zum Plexus brachialis, langsame Verabreichung ( $\leq 10 \mathrm{ml} / \mathrm{min}$ ), venöser Zugang und Notfallbereitschaft.
- Spinalanästhesie, Periduralanästhesie: Injektion subarachnoidal (schnell und kurz, ausgeprägte Muskelrelaxation) bzw. peridural. Cave: neurologische Ausfälle.

Allgemeinanästhesie: Mono- und kombinierte Techniken, Intubation, evtl. (Larynx-)Maske

\section{Monitoring}

Alle technischen Entwicklungen und Neuerungen der letzten Jahrzehnte haben nichts daran geändert, dass unsere 5 Sinne meist die besten, immer verfügbaren Instrumente zur Beurteilung des Patientenzustandes sind. Sie erlauben jedem Arzt grundlegende Vitalfunktionen ohne Hilfsmittel zu beurteilen (- Tab. 1.40).

Im Rahmen einer Anästhesie stehen erweiterte Monitoring-Möglichkeiten zur Verfügung. Zur Optimierung der Patientensicherheit wurden in den letzten Jahren von Land zu Land leicht abweichende, minimale Monitoring-Standards definiert, die bei jeder Anästhesie eingehalten und durchgeführt werden müssen.

\section{Monitoring-Standards}

- Standard I: Qualifiziertes Anästhesiepersonal muss bei jeder Anästhesie beim Patienten anwesend sein, um eine kontinuierliche Überwachung und sofortige therapeutische Maßnahmen zu ermöglichen. Dies gilt für Allgemeinanästhesie- wie Regionalanästhesieverfahren. In speziellen Situationen (z. B. Radiotherapie) ist eine Remote-Überwachung zulässig.

- Standard II: Bei allen Anästhesieverfahren muss die Oxigenation, die Beatmung und der Kreislauf des Patienten kontinuierlich überwacht werden.

Die Überwachung der Oxigenation soll eine genügende Sauerstoffkonzentration im Inspirationsgas und damit im Blut si-

- Tab. 1.40 Beurteilung des Patientenzustandes

\begin{tabular}{|l|l|}
\hline $\begin{array}{l}\text { Atmet der Patient? } \\
\begin{array}{l}\text { Atembewegungen } \\
\text { (paradox?, obstruktiv?) }\end{array}\end{array}$ & $\begin{array}{l}\text { Patient ansprechbar } \\
\text { (Hirnperfusion?) }\end{array}$ \\
\hline $\begin{array}{l}\text { Atemfrequenz } \\
\text { (Norm }>12 / \mathrm{min})\end{array}$ & $\begin{array}{l}\text { Palpabler Puls, normale Herz- } \\
\text { frequenz }(50-100 / \mathrm{min})\end{array}$ \\
\hline $\begin{array}{l}\text { Auskultationsbefund } \\
\text { (gleichseitig?) }\end{array}$ & $\begin{array}{l}\text { Peripherie warm } \\
\text { (Vasokonstriktion?) }\end{array}$ \\
\hline $\begin{array}{l}\text { Zyanose }\left(\mathrm{p}_{\mathrm{a}} \mathrm{O}_{2} \text { wahr- }\right. \\
\text { scheinlich }<80-90 \mathrm{mmHg})\end{array}$ & Diurese (Cardiac output) \\
\hline
\end{tabular}




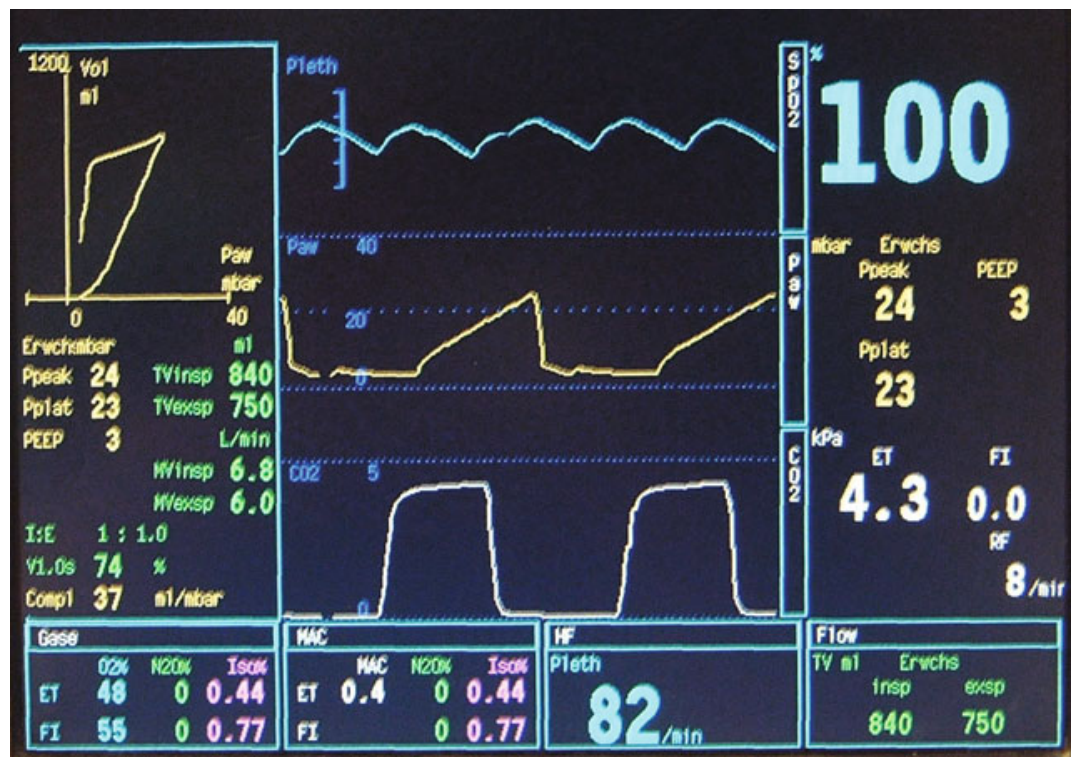

- Abb. 1.85 Monitoring

cherstellen. Dazu werden Sauerstoffmessgeräte im Inspirationsschenkel des Beatmungsgerätes eingesetzt, die Oxigenation des Blutes kontinuierlich mittels Pulsoxymeter gemessen und die Hautfarbe (Zyanose?) klinisch beurteilt.

$(7$ Zur Überwachung der Beatmung dient in jedem Fall die klinische Beurteilung (Thoraxexkursionen, Auskultation).

Bei intubierten Patienten müssen Beatmungsdruck (Diskonnektionsalarm) und das endexspiratorische $\mathrm{CO}_{2}$ (Kapnographie) gemessen werden. Die regelmäßige Palpation des Pulses und eine kontinuierliche Überwachung mittels Pulsoxymeter sind zuverlässige Methoden der Kreislaufüberwachung. Der Kreislauf wird mittels EKG monitorisiert und Herzfrequenz und Blutdruck sollen mindestens 5-minütlich gemessen werden. Die Körpertemperatur muss gemessen werden, falls Änderungen möglich oder zu erwarten sind. Die in- und exspiratorische Anästhesiegasmessung gewährleistet eine kontinuierliche Überwachung der Applikation der volatilen Anästhetika. Die Anästhesietiefe kann mittels Monitoring des BIS-Index (Bispectral Index, mittels EEG ermittelter rechnerischer Wert) überwacht werden.

Minimale Anästhesie-Sicherheitsstandards:

- Dauerpräsenz einer qualifizierten Anästhesieperson

- Klinische Überwachung und Pulsoxymetrie bei jedem Patienten

- Blutdruck-, EKG- und Temperatur-Monitoring

- Kapnographie, Oxymetrie und Beatmungsdruckmessung bei jedem intubierten Patienten

\section{Charakteristik wichtiger Anästhesie-Monitoring- Verfahren}

Neben dem EKG-Monitor (• Abb. 1.85) und der automatischen Blutdruckmessung stehen die nachfolgenden Verfahren zur Verfügung.

\section{Pulsoxymetrie}

Diese Überwachungsmethode ist eine der wesentlichsten Fortschritte in der Patientenüberwachung der letzten Jahre und hat unterdessen auch außerhalb von Anästhesie und Intensivmedizin Verbreitung gefunden. Die Geräte berechnen die arterielle $\mathrm{O}_{2}$-Sättigung, indem sie die Variationen der Absorption von rotem (misst reduziertes Hämoglobin) und infrarotem Licht (misst Oxyhämoglobin), verursacht durch die Pulsationen des arteriellen Blutes, messen. Die Sättigung wird typischerweise mit einem Clip am Finger gemessen. Eine Sättigung von 90\% entspricht dabei bei normaler Sauerstoffdissoziationskurve ungefähr einem $\mathrm{pO}_{2}$ von $60 \mathrm{mmHg}$ $(8 \mathrm{kPa})$ im arteriellen Blut.

\section{Kapnographie $\left(\mathrm{CO}_{2}\right.$-Monitoring)}

Die kontinuierliche Messung der $\mathrm{CO}_{2}$-Konzentration in der Exspirationsluft von beatmeten Patienten erlaubt 2 wichtige Aussagen:

- Der Patient wird beatmet (qualitative Aussage), da nur aus der Lunge andauernd $\mathrm{CO}_{2}$ abgeatmet werden kann. Eine relativ sichere Lagekontrolle eines Endotrachealtubus (tracheal vs. ösophageal) ist damit möglich.

- Da sich das $\mathrm{CO}_{2}$ in der Alveole äußerst schnell mit dem $\mathrm{CO}_{2}$-Spiegel im kapillären Blut äquilibriert, korreliert die $\mathrm{CO}_{2}$-Konzentration am Ende der Exspirationsphase (endtidaler, alveolärer Gasanteil) eng mit dem arteriellen $\mathrm{CO}_{2}$ und kann damit zur Steuerung der Beatmung eingesetzt werden (quantitative Aussage). 
Indirekt erlaubt die Kapnographie auch ein Kreislaufmonitoring: Veränderungen des pulmonalen Blutflusses bei Reanimationsbemühungen oder bei plötzlicher Verlegung der pulmonalen Strombahn werden beurteilbar.

Hypermetabole Zustände wie die maligne Hyperthermie (MH) können frühzeitig dank des steten Anstiegs der endexspiratorischen $\mathrm{CO}_{2}$-Konzentration erkannt werden.

Diese seltene, gefürchtete Anästhesiekomplikation nach Triggerexposition (volatile Inhalationsanästhetika, Succinylcholin) kann bei empfindlichen Patienten unbehandelt zum Tode führen. Die Behandlung besteht aus sofortigem Stopp der Triggersubstanzen, Hyperventilation mit $\mathrm{O}_{2}$ und sofortige Applikation von Dantrolen als spezifisches Antidot.

\section{Anästhesiegasmessung}

Verschiedene neuere Absorptions- oder Spektroskopieverfahren erlauben es heute, die in- und exspiratorische Gaskonzentration kontinuierlich zu messen. Da diese Medikamente eine sehr enge therapeutische Breite und ein beträchtliches Nebenwirkungspotenzial haben, kommt einer andauernden Messung der Medikamentenkonzentration eine wesentliche Bedeutung zu. Die Überdosierungsgefahr bei apparativen oder menschlichen Fehlern wird damit reduziert und die Präzision der Anästhesieführung wird verbessert. Die Gefahr einer sog. Awareness (Wachzustand während der Anästhesie) wird dadurch vermindert.

\section{EKG}

Das Elektrokardiogramm war eines der ersten technischen Hilfsmittel in der Patientenüberwachung. Es hat in den letzten Jahrzehnten nicht an Bedeutung verloren und dient intraoperativ hauptsächlich folgendem Zweck:

- Früherkennung von Rhythmusstörungen, einer relativ häufigen Komplikation bei Allgemeinanästhesien,

- Früherkennung von myokardialen Ischämien.

( Typischerweise werden intraoperativ die Ableitungen II und $V_{5}$ monitorisiert: Diese Kombination hat eine hohe Sensitivität für ischämische Ereignisse.

\section{Automatische, nichtinvasive Blutdruckmessung}

Die Einführung von Mikroprozessor-gesteuerten Oszillotonometriegeräten hat die manuelle Messung des Blutdrucks zum Anästhesiemonotoring praktisch verdrängt.

\section{Temperatur}

Der intraoperativen Temperaturmessung kommt eine große Bedeutung zu. Im Alltag viel häufiger als eine Hyperthermie ist eine Hypothermie: Klimatisierte, »tiefgekühlte« Operationssäle, Flüssigkeitsverluste und exponiert-ungeschützte Patienten führen notwendigerweise zu einem steten Abfall der Körpertemperatur. Dieser Temperaturverlust hat negative Auswirkungen auf den Patienten (häufiger postoperative Infekte, Gerinnungsstörungen) und kann häufig nur mit Mühe und technischen Hilfsmitteln in einem akzeptablen Rahmen gehalten werden.

\section{Diurese}

Die kontinuierliche Erfassung der Urinproduktion lässt Rückschlüsse nicht nur auf die Nierenfunktion, sondern, für den Anästhesisten viel wichtiger, auf die Kreislauffunktion zu. Häufig ist eine suffiziente Diurese ( $>0,5 \mathrm{ml} / \mathrm{kgKG} / \mathrm{h})$ der beste Hinweis auf ein für den individuellen Patienten genügendes Herzminutenvolumen. Dies gilt trotz der Tatsache, dass die Urinausscheidung durch viele Faktoren (renaler Blutfluss, GFR-Autoregulation, hormonelle Faktoren, positive Druckbeatmung usw.) beeinflusst wird.

\section{Neuromuskuläre Funktion}

Die potenziellen Probleme, die mit einer unkontrollierten, respektiv verlängerten Relaxation von Patienten verbunden sind, haben dazu geführt, dass neben klinischen Merkmalen auch die elektrische Stimulation der peripheren motorischen Nerven (typischerweise N. ulnaris) zur Beurteilung der neuromuskulären Funktion herangezogen werden können.

\section{Weitere Monitoring-Verfahren}

Komplexere Patienten und spezielle Anästhesie- oder Operationsverfahren bedingen im Alltag den Einsatz von weiteren, aufwändigeren Monitoring-Verfahren.

\section{Spezifisches Monitoring}

- Arterielle Blutgasanalysen

- Invasive arterielle Blutdruckmessung (meist A. radialis)

- Zentraler Venendruck (ZVD)

- Pulmonaliskatheter (pulmonalarterieller Druck, Wedge-Druck, Herzminutenvolumen)

- Transösophageale Echokardiographie (TEE) durch den Anästhesisten

- Transkranielle Dopplersonographie (zerebrale Blutflussmessung in der A. cerebri media)

- Bulbus-jugularis-Sauerstoffsättigung

- Somatosensorische, evozierte Potenziale (Eingriffe an der Wirbelsäule)

\section{Ambulante Anästhesie}

Eine große Zahl von chirurgischen Eingriffen kann heute ambulant durchgeführt werden. Typische Patienten gehören den ASA-Klassen I und II an und sind zwischen 6 Monaten und 70 Jahren alt. Ausnahmsweise können aber auch ASAIII-Patienten für kleinere Eingriffe akzeptiert werden, sofern ihre medizinischen Probleme stabil und optimal behandelt sind. Die Operation sollte nicht länger als $\mathbf{9 0}$ min dauern und nicht mit massivem Blutverlust oder großen Flüssigkeitsverschiebungen verbunden sein. Der postoperative Schmerz muss mit oralen Analgetika behandelbar sein. Entscheidend für die erfolgreiche Durchführung von ambulanten Eingriffen sind eine sorgfältige präoperative Evaluation mit guter Patienteninformation und eine enge Kommunikation zwischen dem behandelnden Chirurgen und dem zuständigen Anästhesisten. 


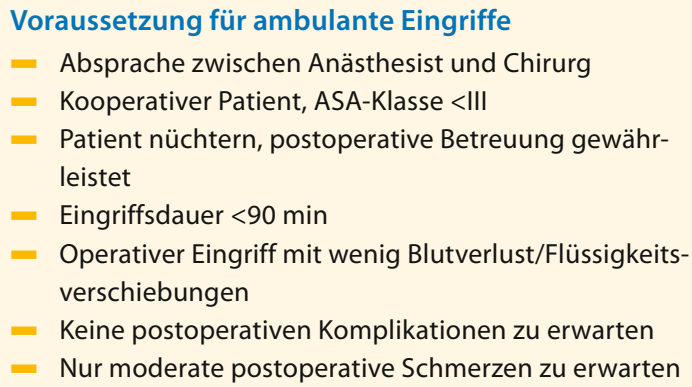

\section{Prämedikation}

Die psychische Belastung für ambulante Patienten unterscheidet sich nicht wesentlich von der stationärer Patienten. Der grundsätzliche Verzicht auf eine Prämedikation aus Gründen einer früheren Entlassbarkeit ist daher fragwürdig, zumal kurzwirksame Benzodiazepine wie Midazolam die Entlassung nicht signifikant verzögern. Eine Prämedikation z. B. mit Midazolam (Erwachsene: 7,5-15 mg oral, 1-2 $\mathrm{h}$ präoperativ) ist daher bei ängstlichen Patienten zu empfehlen.

\section{Nüchternheit präoperativ}

Wegen der Gefahr einer pulmonalen Aspiration von Mageninhalt müssen alle Patienten, ob ambulant oder stationär, eine präoperative Nüchternheit von $6 \mathrm{~h}$ Dauer aufweisen. Dies gilt für feste Speisen. Klare Flüssigkeiten wie Tee oder Wasser dürfen bis $2-3 \mathrm{~h}$ vor dem Eingriff getrunken werden. Bei zweifelhafter Anamnese oder gastroösophagealem Reflux ist die präoperative Gabe von Ranitidin (Erwachsener: $150 \mathrm{mg}$ oral, $2 \mathrm{~h}$ präoperativ) sinnvoll. Dies reduziert die Menge des Nüchternsekretes und erhöht den $\mathrm{pH}$ des Magensaftes signifikant.

\section{Anästhesiemethoden}

Die Anästhesie für ambulante Eingriffe hat denselben Standards zu genügen, wie die Anästhesie bei größeren Eingriffen für stationäre Patienten. Es gibt kein »ideales« Anästhesieverfahren für ambulante Patienten, da die Art des Eingriffes und die Merkmale des Patienten für die Wahl des geeigneten Verfahrens entscheidend sind.

Eine typische Allgemeinanästhesietechnik ist die Verwendung der Larynxmaske für kürzere Eingriffe bei geeigneten Patienten. Lokal- und Regionalanästhesieverfahren mit kurzwirkenden Lokalanästhetika sind in erfahrenen Händen eine gute Alternative für Operationen an den Extremitäten oder der unteren Körperhälfte. Dazu gehören insbesondere die intravenöse Regionalanästhesie am Arm (i.v.-Block) oder die Spinalanästhesie bei älteren Patienten.

\section{Postoperative Überwachung}

Unter idealen Umständen ist die postoperative Zeit bis zur Krankenhausentlassung in 2 Phasen aufgeteilt:

- In einer 1. Periode wird der Patient in einem regulären Aufwachraum betreut. Eine engmaschige kardiopulmonale Überwachung (mindestens Pulsoxymeter) und die sofortige Behandlung von etwaigen Komplikationen sind dort gewährleistet.

- Nach Erreichen der sog. Verlegungsfähigkeit wird der Patient in eine Betreuungszone verlegt, in der eine losere Überwachung, ein Kontakt mit Angehörigen, eine 1. Flüssigkeitsaufnahme und eine definitive Mobilisierung möglich ist. Die Entlassung des Patienten nach Hause darf nur durch eine qualifizierte Person erfolgen, die den Patienten kennt und das Einhalten von Entlassungskriterien überprüfen kann.

\section{Entlassungskriterien}

- Stabile kardiopulmonale Situation seit mehr als einer halben Stunde

- Zeitlich, örtlich und psychisch orientiert

- Keine Blutung im Operationsgebiet

- Keine neuen oder unklaren Beschwerden

- Keine oder nur minimale Übelkeit seit mehr als einer halben Stunde

- Extremitätenchirurgie: normale Durchblutung und Sensomotorik

- Spontandiurese erfolgt (nach rückenmarksnaher Regionalanästhesie)

- Mobilisiert seit mindestens 10 min

- Schmerz erträglich und mit oralen Analgetika behandelbar

- Begleitperson für Transport nach Hause vorhanden (Patient darf nicht selbst fahren!)

- Patient mündlich und schriftlich über weiteres Verhalten informiert, Notfallnummer bekannt

\section{Typische Komplikationen nach ambulanten Eingriffen}

$>$ Die häufigsten Komplikationen nach ambulanten Eingriffen sind persistierende Übelkeit und Erbrechen, starke Schmerzen, Atemwegsprobleme, Blutung im OP-Gebiet, Miktionsprobleme und verstärkte Sedation.

Eines der Hauptprobleme, die postoperative Übelkeit, ist multifaktorieller Genese:

- Patientenfaktoren (anamnestische Kinetosen, postoperatives Erbrechen etc.),

- Medikamenteneffekte (Opiate, $\mathrm{N}_{2} \mathrm{O}$ ),

- chirurgische Faktoren (Laparoskopie, Strabismus, Orchidopexie) und

- postoperative Faktoren (Hypotension, Schmerz) sind mitverantwortlich.

Dieses Problem kann in vielen Fällen gut beeinflusst werden. Gewisse Anästhesieverfahren zeichnen sich durch eine geringe postoperative Inzidenz von Nausea und Erbrechen aus, so z. B. Regionalanästhesieverfahren und Propofolanästhesien. Bei Risikopatienten kann eine intraoperative Prophylaxe mit tiefdosiertem Droperidol oder eine Prophylaxe und The- 
rapie mit 5-HT3-Antagonisten (Ondansetron, Tropisetron, Granisetron) angezeigt sein.

In Kürze
Monitoring
Minimale Sicherheitsstandards: klinische Beurteilung
durch die eigenen 5 Sinne, Puls(oxymetrie), EKG, RR, Kör-
pertemperatur, Beatmungsdruck, endexspiratorischer
$\mathrm{CO}_{2}$ (Kapnographie). Zusätzlich spezifisches Monitoring,
z. B. Blutgasanalyse, ZVD, Pulmonaliskatheter, TEE.
Ambulante Anästhesie
Verschiedene Voraussetzungen, z. B. ASA-Klasse <III,
Eingriffsdauer < 90 min, keine postoperativen Kompli-
kationen und nur moderate Schmerzen zu erwarten,
präoperativ nüchtern und geeignete Prämedikation.
Postoperative Überwachung: Aufwachraum und an-
schließende Betreuungszone, Einhalten der Entlas-
sungskriterien (in Begleitung, Patient darf nicht
selbst fahren).
Komplikationen: Übelkeit und Erbrechen, starke
Schmerzen, Luftwegsprobleme, Blutung im OP-Ge-
biet, Miktionsprobleme und verstärkte Sedation.

\subsubsection{Postoperative Schmerztherapie}

\section{Grundlagen

Definition -
Unter Schmerz versteht man »Ein unangenehmes Sinnes-
und Gefühlserlebnis, das mit aktueller oder potenzieller
Gewebeschädigung verknüpft ist oder mit Begriffen einer
solchen Schädigung beschrieben wird« (International
Association for the study of pain, IASP, pain terminology,
2011)

Fast alle Patienten leiden postoperativ unter Schmerzen, da praktisch jede Operation zu einem lokalen Gewebeschaden mit der Freisetzung von schmerzauslösenden Substanzen wie Histamin, Prostaglandinen, Serotonin, Bradykinin und Substanz P führt. Trotz der Entwicklung von neuen Analgetika, neuen pathophysiologischen Erkenntnissen und neuen Behandlungsmethoden ist die postoperative Schmerzbehandlung auch heute noch meist insuffizient. Die Hauptgründe der ungenügenden Behandlung sind eine ungenügende Kenntnis der Pharmakodynamik und eine unbegründete Angst vor der Verursachung einer Opiatabhängigkeit beim Gebrauch der stark wirksamen Analgetika.

\section{Bedeutung der postoperativen Schmerztherapie}

Da die postoperative Schmerztherapie den Outcome unter Umständen entscheidend mit beeinflussen kann, kommt ihr eine wesentliche Bedeutung zu. So führt eine ungenügende postoperative
Schmerztherapie vermehrt zu respiratorischen, kardialen und endokrinologischen Komplikationen; höhere Infektraten und häufigere thrombembolische Ereignisse sind weitere negative Folgen ungenügender Schmerztherapie. Zudem vermindert eine gute postoperative Analgesie nicht nur unnötiges Leiden, sondern trägt auch wesentlich zum positiven Gesamteindruck bei, den der Patient vom Krankenhausaufenthalt mit nach Hause nimmt. Entscheidend sind insgesamt die Wahl der für den individuellen Patienten richtigen Schmerztherapietechnik und deren optimale Durchführung. Dies kann durch den nachbehandelnden Arzt, in der Regel durch den Anästhesisten oder im Idealfall durch ein spezifisches Team, den »acute pain service«, geschehen.

\section{$>$ Schmerztherapie sollte auf einem Verständnis der zugrunde liegenden Pathophysiologie beruhen.}

Die vielfältig verknüpften neuronalen Leitungsbahnen versorgen das Zentralnervensystem mit Informationen über schädliche oder schmerzhafte Stimuli. Um eine Analgesie zu bewirken, kann dieser Informationsfluss an verschiedenen Orten unterbrochen werden. Informationen über somatische oder viszerale Schmerzstimuli werden hauptsächlich über 2 Nerventypen weitergeleitet:

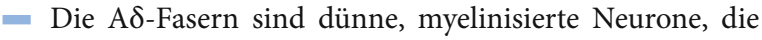
dominant mechanische Reize weiterleiten,

- C-Fasern sind unmyelinisierte Neurone, die mechanische, thermische und chemische Reize weiterleiten.

Diese beiden Fasern geben ihren Input über die Spinalwurzeln an das Rückenmarkshinterhorn weiter. Vom Hinterhorn gehen die Afferenzen weiter via Hinterstrangbahnen und Tractus spinothalamicus. Diese neuronalen Zellen sind reich an Opiatrezeptoren. In diesem komplexen Netzwerk, interagierend mit absteigenden Bahnen, werden die Afferenzen weiter verstärkt oder abgeschwächt. Diese Modulation der Afferenzen findet auf praktisch allen Stufen der Schmerzbahn, insbesondere aber auch schon im Rückenmark, statt (- Abb. 1.86).

$\mathrm{Zu}$ den Folgen des postoperativen Schmerzes gehören:

- Kardiovaskulär: Der erhöhte Sympathikotonus führt zu Tachykardie, Blutdruckerhöhung und insgesamt einer erhöhten Herzarbeit. Dies birgt das Risiko einer kardialen Ischämie bei einer vorbestehenden KHK in sich. Dazu trägt auch die veränderte Gerinnungssituation mit Gefahr von Thrombosen und erhöhter Plättchenaggregation bei.

- Pulmonal: Eingriffe im oberen Abdominalbereich oder im Thorax führen zu einer Abnahme von Vitalkapazität (VC), Zugvolumen, Residualvolumen und funktioneller Residualkapazität (FRC). Die diaphragmale Funktion ist beeinträchtigt. Es resultiert eine reduzierte pulmonale Compliance mit erschwerter Tiefatmung, der Gefahr von Atelektasen und Sekretretention bedingt durch einen schlechteren Hustenstoß. Ein postoperativer Ileus verschlechtert die respiratorische Situation weiter.

- Gastrointestinal: Ileus, Übelkeit und Erbrechen sind häufige postoperative Erscheinungen.

- Endokrin: Der postoperative Schmerz führt zu einem Anstieg des Sympathikotonus, einer hypothalamischen Stimulation, einem erhöhten Spiegel von vielen Hormonen (Ka- 


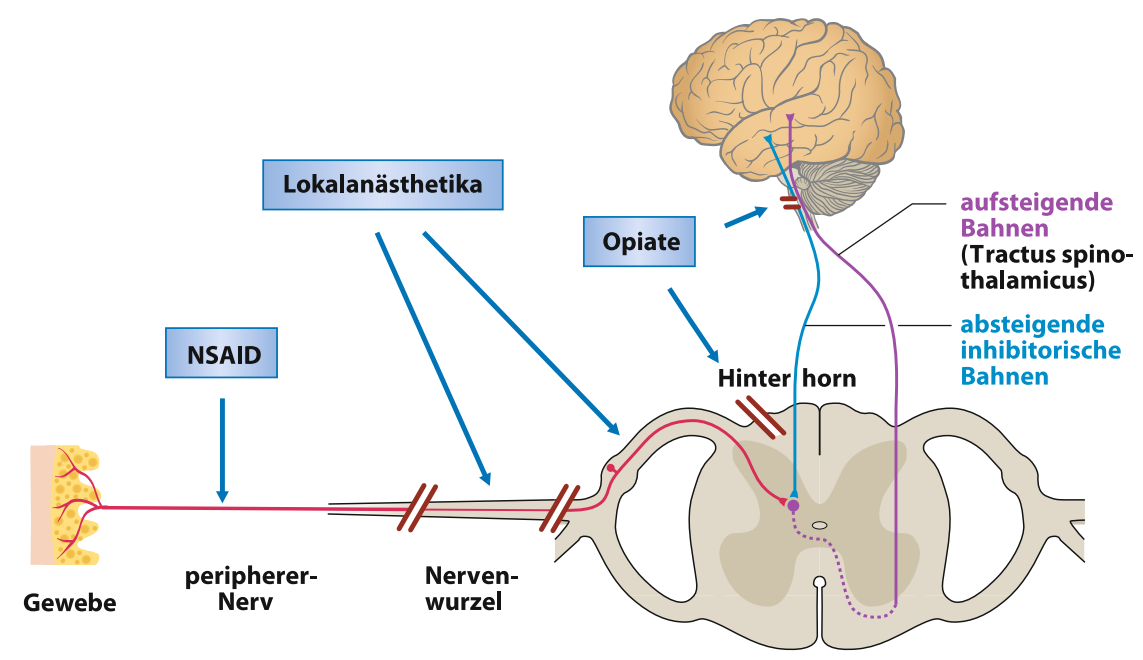

- Abb. 1.86 Angriffspunkte von Opiaten, Lokalanästhetika und nichtsteroidalen antiinflammatorischen Medikamenten (NSAID). Verschiedene Techniken und Medikamente können nach dem Be- darf des Patienten einzeln oder in Kombination zur Schmerztherapie eingesetzt werden techolaminen, Kortisol, ACTH, ADH, GH, Glukagon, Aldosteron, Renin, Angiotensin) und einem gleichzeitigen Abfall von anabolen Hormonkonzentrationen (z. B. Insulin). Dies hat u. a. eine Salz- und Wasserretention zur Folge, der Blutzucker, die Ketonkörper und der Laktatspiegel steigen und ein kataboler Zustand kann daraus resultieren.

- Psychologisch: Der postoperative Schmerz ist nicht selten ein wesentlicher Grund für die geäußerte oder versteckte Angst der Patienten in Zusammenhang mit einem operativen Eingriff. Diese Belastungssituation kann die Beziehung zwischen dem Betreuerteam und dem Patienten wesentlich beeinträchtigen.

$>$ Der postoperative Schmerz ist häufig unterbehandelt! Dies kann für den Patienten sehr gefährlich sein.

\section{Formen der postoperativen Schmerztherapie Nichtopiatanalgetika}

Nichtsteroidale antiinflammatorische Substanzen (NSAID) wirken hauptsächlich peripher durch eine Hemmung der Prostaglandinsynthese. Diese Substanzen wirken v. a. bei entzündlichen Schmerzen, können jedoch auch bei weniger starken postoperativen Schmerzen oder in Kombination mit Opiatanalgetika eingesetzt werden. Vorteilhaft verglichen mit der Opiatanalgesie ist das Fehlen von typischen Opiatnebenwirkungen wie Atemdepression, Toleranz und Sedation. Eine mögliche Komplikation ist eine vermehrte postoperative Blutungsneigung (Hemmung der Thrombozytenaggregation) oder die Beeinträchtigung einer vorbestehenden eingeschränkten Nierenfunktion (•Tab. 1.41). Eine länger dauernde Therapie mit gewissen COX-Inhibitoren kann die Inzidenz von kardiovaskulären Komplikationen bei Risikopatienten erhöhen (z. B. Rofecoxib, Diclofenac).

NSAID's haben unmittelbar postoperativ sogar eine bessere analgetische Wirkung als Opiate. Es ist daher sinnvoll, bei schweren postoperativen Schmerzen NSAID's und Opiate zusammen zu verabreichen.

\section{Systemische Opiatanalgetika}

Systemisch verabreichte Opiate produzieren Analgesie durch einen agonistischen Effekt an den Opiatrezeptoren im Zentralnervensystem (• Tab. 1.42). Opiate können $\mathrm{zu}$ diesem Zweck peroral, subkutan, intramuskulär oder intravenös verabreicht werden. Leider sind die üblichen Standardverordnungen für den individuellen Patienten oft ungenügend, da aufgrund einer hohen interindividuellen Variabilität der Opiatbedarf für eine bestimmte klinische Situation sehr unterschiedlich sein kann. Zusätzlich ist nach s.c.- oder i.m.Verabreichung der Opiatspiegel von Patient zu Patient sehr variabel und diese Applikationsform wird von Patienten nicht besonders geschätzt. Orale Opiatgaben sind eine Alternative, benötigen aber einen funktionierenden Gastrointestinaltrakt.

Intravenöse Gaben auf der anderen Seite produzieren voraussagbare Plasmakonzentrationen und erlauben eine Titration entsprechend den Bedürfnissen des Patienten. Die Gefahr von schweren Nebenwirkungen bei unsachgemäßer intravenöser Opiatverabreichung hat dazu geführt, dass in der Vergangenheit diese Form der Schmerztherapie mehrheitlich dem Anästhesiebereich und den Intensivstationen vorbehalten war. Erst die Entwicklung und erfolgreiche klinische Erprobung der Patienten-kontrollierten Analgesie (PCA) hat diese Form der Schmerztherapie auch für den Patienten außerhalb von spezialisierten Überwachungsbereichen zugänglich gemacht. Bei der PCA kann der Patient mithilfe einer speziellen, Mikroprozessor-kontrollierten Spritzenpumpe per Knopfdruck die intravenöse Verabreichung einer vorbestimmten Dosis eines Opiatanalgetikums auslösen und so die Dosierung dem subjektiv empfundenen Leidensdruck anpassen. 
Tab. 1.41 Nichtopioid-Analgetika: pharmakologische Werte bei Erwachsenen (ausgewählte Analgetika)

\begin{tabular}{|c|c|c|c|c|c|}
\hline Generic name & Acetylsalicylsäure & Paracetamol & Ibuprofen & Ketorolac & Metamizol \\
\hline Handelsname (Beispiele) & Aspirin $^{\circledR}$, Aspegic $^{\circledR}$ & $\begin{array}{l}\text { Panado }^{\circledR} \text {, Dafalgan }{ }^{\circledR}, \\
\text { Perfalgan }^{\circledR}\end{array}$ & Brufen ${ }^{\circledR}$ & Tora-Dol $^{\circledR}$ & Novalgin ${ }^{\circledR}$ \\
\hline Dosierung per os & $325-1000 \mathrm{mg}$ & $500-1000 \mathrm{mg}$ & $200-600 \mathrm{mg}$ & $10 \mathrm{mg}$ & $500-1000 \mathrm{mg}$ \\
\hline Max. Tagesdosis per os & $4 \times 1000 \mathrm{mg}$ & $4 \times 1000 \mathrm{mg}$ & $4 \times 600 \mathrm{mg}$ & $4 \times 10 \mathrm{mg}$ & $4 \times 1000 \mathrm{mg}$ \\
\hline Dosierung i.v. & $500 \mathrm{mg}$ & $1000 \mathrm{mg}$ & - & $10-30 \mathrm{mg}$ & $1000 \mathrm{mg}$ \\
\hline Max. Tagesdosis i.v. & $3 \times 1000 \mathrm{mg}$ & $4 \times 1000 \mathrm{mg}$ & - & $3 \times 30 \mathrm{mg}$ & $4 \times 1000 \mathrm{mg}$ \\
\hline Wirkeintritt nach ca. & $20 \mathrm{~min}$ & $20-45 \min$ & $15-30 \mathrm{~min}$ & Rasch & Rasch \\
\hline Max. Wirkeffekt & $2 \mathrm{~h}$ & $0.5-1 \mathrm{~h}$ & $1-2 \mathrm{~h}$ & $0,5-0,75 \mathrm{~h}$ & $1-1,5 \mathrm{~h}$ \\
\hline Wirkdauer & $4-6 h$ & $4-6 \mathrm{~h}$ & $4-6 \mathrm{~h}$ & $4-5 \mathrm{~h}$ & $4-6 h$ \\
\hline \multicolumn{6}{|l|}{ Nebenwirkungen } \\
\hline - Magen-Darm: Verdauung & +++ & - & ++ & +++ & - \\
\hline - Magen-Darm: Blutung & +++ & - & + & ++ & - \\
\hline - Blutbildung & Tc-Hemmung & - & Tc-Hemmung & Tc-Hemmung & Agranulozytosen \\
\hline - Niere & + & - & + & ++ & - \\
\hline - Leber & ++ & +++ & + & + & - \\
\hline - Allergie & +++ & & + & + & +++ \\
\hline - Bemerkungen & & $\begin{array}{l}\text { Cave: Kombination } \\
\text { mit »over the coun- } \\
\text { ter« - Paracetamol } \\
\text { (Gefahr von Intoxika- } \\
\text { tionen). Fragliche } \\
\text { Kardiotoxizität wird } \\
\text { diskutiert }\end{array}$ & & & $\begin{array}{l}\text { Lebensbedrohliche } \\
\text { Agranulozytosen bei } \\
\text { kurzfristigem Einsatz } \\
\text { sehr unwahrschein- } \\
\text { lich }\end{array}$ \\
\hline
\end{tabular}

PCA-Pumpensysteme sind, vorausgesetzt richtig programmiert, sehr sicher.

\section{$\checkmark$ Starke, andauernde postoperative Schmerzen $\rightarrow$ Patienten-kontrollierte Analgesie als mögliche Thera- pieoption.}

Verschiedene Opiate eignen sich für den Einsatz mit der PCA, so z. B. Morphin. Da der unmittelbare postoperative Schmerz stark von der Anästhesietechnik abhängig ist, kann eine initiale Aufsättigung mittels einer sog. Loading-Dose durch den behandelnden Arzt vor dem Einsatz der PCA-Pumpe sinnvoll sein. Die klinische Überwachung des Patienten muss sichergestellt sein, so dass die schwerwiegendste Komplikation, eine Atemdepression, rechtzeitig erkannt und behandelt werden kann. Neben dieser, bei korrektem Einsatz der Methode unwahrscheinlichen Komplikation, kommt es relativ häufig zu Nausea, Sedation, Urinretention und Pruritus unter der Opiattherapie. Bei gefährdeten Patienten kann die prophylaktische, simultane Verabreichung eines Antiemetikums (z. B. 5-HT-Antagonisten) sinnvoll sein. Nach 2-3 Tagen postoperativ ist in der Regel der Übergang zu einer konventionellen Form der Schmerztherapie möglich.

\section{Spezielle Analgesietechniken des Anästhesisten} Kontinuierliche Epiduralanalgesie mit Lokalanästhetika ( \pm Opiaten)

- Indikation: Schmerztherapie nach größeren Operationen unterhalb des Schultergürtels. Individuelle Optimierung durch Patienten-kontrollierte Verfahren analog der PCA möglich. Kombination von Lokalanästhetika und Opiaten ermöglicht Dosisreduktion dank synergistischer Wirkungsverstärkung.

- Kontraindikation: Lokalanästhesie- oder Opiatallergie, keine hypotensiven Episoden tolerierbar.

- Vorteil: Sehr starke bis komplette Analgesie, kaum Opiatnebenwirkungen.

- Nachteil: Hypotensionsgefahr, Urinretention, evtl. Nausea und Pruritus. Postoperative Komplikationen (z.B. Nahtinsuffizienz) können durch die Analgesie im Operationsgebiet unbemerkt bleiben. 
- Tab. 1.42 Opiate: Pharmakologische Werte bei Erwachsenen (ausgewählte Opiate)

\begin{tabular}{|c|c|c|c|c|}
\hline Opiat & Morphin & Methadon & Fentanyl & Nalbuphin \\
\hline Analgetische Potenz & 1 & $1-1,5$ & $100-125$ & 1 \\
\hline Dosierung in mg/kgKG i.v. & $0,05-0,1$ & $0,05-0,1$ & 0,001 & 0,2 \\
\hline Dosierung in mg/kgKG p.o. & 0,2 & 0,12 & - & - \\
\hline Repetitionsdosis nach & $3-5 h$ & $3-5 h$ & $30-60 \mathrm{~min}$ & $5 \mathrm{~h}$ \\
\hline Wirkungseintritt bei i.v.-Gabe & Sofort & Sofort & Sofort & Sofort \\
\hline Max. Wirkeffekt nach i.v.-Gabe & $30 \mathrm{~min}$ & $10-30 \mathrm{~min}$ & $3-5 \min$ & $3-5 \min$ \\
\hline Wirkdauer & $3-5 h$ & $3-5 h$ & $30-60 \mathrm{~min}$ & $5 \mathrm{~h}$ \\
\hline Eliminationshalbwertszeit & $3 \mathrm{~h}$ & $10-120(!) \min$ & $3,5 \mathrm{~h}$ & $3 \mathrm{~h}$ \\
\hline Metabolisierung & Leber und Niere & Leber & Leber & Leber \\
\hline Ausscheidung & Galle und Niere & Galle und Niere & Galle und Niere & Galle und Niere \\
\hline \multicolumn{5}{|l|}{ Nebenwirkungen } \\
\hline Atemzentrum & \multicolumn{4}{|c|}{ Nach 15 min max. Dämpfung } \\
\hline Sedation & \multicolumn{4}{|l|}{ Dosisabhängig } \\
\hline Nausea/Erbrechen & ++ & ++ & ++ & ++ \\
\hline Thoraxrigidität & & & ++ & \\
\hline Miosis & + & + & + & \\
\hline Bradykardie & & & ++ & \\
\hline Kardiovaskuläre Kompensation & \multicolumn{4}{|c|}{ Bei allen gedämpft } \\
\hline Darmmotilität & \multicolumn{4}{|c|}{ Bei allen gedämpft } \\
\hline Tonus der Gallenwege & ++ & ++ & ++ & ++ \\
\hline Tonus der Bronchialmuskulatur & ++ & ++ & ++ & ++ \\
\hline Histaminfreisetzung & ++ & & & \\
\hline $\begin{array}{l}\text { Interaktion mit anderen } \\
\text { Medikamenten }\end{array}$ & \multicolumn{4}{|c|}{ Mit allen sedativ wirkenden Medikamenten Verstärkung der Wirkung } \\
\hline Antagonisierung & \multicolumn{4}{|c|}{ Naloxon (Narcan ${ }^{\oplus}$ ) bei allen Präparaten außer bei Buprenorphin, Wirkungsdauer max. 60 min } \\
\hline Bemerkungen & \multicolumn{4}{|c|}{ Buprenorphin kann gemäß neuerer Studien mit reinen $\mu$-Antagonisten kombiniert werden } \\
\hline
\end{tabular}

\section{Epidurale oder subarachnoidale Opiatverabreichung}

- Indikation: Schmerztherapie nach größeren Operationen unterhalb des Schultergürtels, sofern eine Frühmobilisierbarkeit erwünscht ist.

- Kontraindikation: Opiatallergie, Risikopatienten für Atemdepression:Schlaf-Apnoe-Patienten, Adipositas permagna, schwere COLD.

- Vorteil: Gute Analgesie bei erhaltenen motorischen, sensorischen und sympathischen Funktionen.

- Nachteil: Atemdepressionsgefahr, Nausea und Pruritus, Spezialüberwachung in den ersten 12-24 h in der Regel erforderlich (speziell nach subarachnoidal applizierten, langwirksamen Opiaten wie Morphin).
(D) Cave

Die zusätzliche Gabe von parenteralen Opiaten bei rückenmarksnaher Opiatapplikation soll nur mit großer Zurückhaltung durchgeführt werden.

\section{Periphere Nervenblockaden}

- Indikation: Eingriffe an den Extremitäten, evtl. im Bereich von thorakalen Dermatomen.

- Kontraindikation: Frühe neurologische Beurteilung erforderlich, zirkuläre Gipsverbände.

- Vorteil: Sehr starke bis komplette Analgesie, Vasodilatation (evtl. verbesserter kutaner Blutfluss).

- Nachteil: Andauerndes motorisches und sensorisches Defizit, erfordert Kathetertechnik. 


\section{In Kürze}

\section{Postoperative Schmerztherapie}

- Schmerz durch lokalen Gewebeschaden (Histamin Prostaglandine, Serotonin, Bradykinin und Subs$\operatorname{tanz}$ P). Meist insuffizient behandelt. Nachteilige Effekte starker Schmerzen (erhöhter Stress, kardiale und pulmonale Belastung, katabole Effekte, negative psychologische Auswirkungen).

- Nichtopiatanalgetika wie NSAID (Blutungsneigung, Nierenfunktion), systemische Opiatanalgetika (oft zu niedrig dosiert). Patienten-kontrollierte Analgesie (PCA), z. B. mit Morphin, mit klinischer Überwachung (Nausea, Sedation, Urinretention, Pruritus, Cave: Atemdepression).

- Spezielle Analgesietechniken: kontinuierliche Epiduralanalgesie mit Lokalanästhetika, epidurale oder subarachnoidale Opiatverabreichung, periphere Nervenblockaden.

\subsubsection{Häufige postoperative Komplikationen}

Durch die Fortschritte in der Anästhesie wurde es möglich, längere und schwierigere operative Eingriffe durchzuführen. Die unmittelbar perioperative Mortalität veränderte sich kaum. Die schweren Komplikationen ereigneten sich erst nach Tagen und wurden zunächst als Ereignisse angesehen, die nichts mit der Anästhesie oder Operation zu tun hatten. Neben den Folgen der tiefen Venenthrombosen, mit möglichen Embolien, sind es v. a. pulmonale und kardiale Komplikationen, die für die immer älter werdenden chirurgischen Patienten für einen schlechten Outcome verantwortlich sind. Eine deutliche Verbesserung in der Behandlung solcher Komplikationen erfolgte erst, als in den chirurgischen Lehrbüchern die pathophysiologischen Grundlagen für solche unerwünschte Verläufe erklärt wurden und dadurch eine evidenzbasierte Behandlung zur Routine wurde.

\section{Kardiale Komplikationen}

Die Häufigkeit und die pathophysiologischen Grundlagen kardialer Komplikationen bei allgemeinchirurgischen Patienten sind heute bekannt. Ein Myokardinfarkt, die gefährlichste kardiale Komplikation, tritt bei Patienten mit hohem Risiko in 3-5\% der Fälle auf. Normalerweise sind diese Infarkte subendokardial und asymptomatisch, aber sie beeinflussen die Mortalität in der postoperativen Periode massiv. Hämodynamische, mechanische und entzündliche Veränderungen, sowie eine verstärkte Blutgerinnung in der perioperativen Phase sind in den meisten Fällen für diese Minderdurchblutung des Myokards verantwortlich.

( Kardiale Komplikationen treten meist in den ersten $48 \mathrm{~h}$ nach einer Operation auf, da es in dieser Zeit zu metabolischem Stress und einer sympathischen Hyperaktivität kommt.
Idealerweise sollten kardiale Risikopatienten postoperativ während dieser $48 \mathrm{~h}$ intensiv überwacht werden. Durch den Kostendruck und den Mangel an Intensivbetten ist dies aber heute nicht möglich. Alle kardialen Risikopatienten sollten heute perioperativ mit $\beta$-Blockern behandelt werden, sofern keine absolute Kontraindikation besteht. Groß angelegte, kontrollierte Studien konnten zeigen, dass dadurch die kardiale Komplikationsrate gesenkt werden kann.

\section{Pulmonale Komplikationen}

Nebst den glücklicherweise selteneren Lungenembolien ist die Lungenatelektase die häufigste pulmonale Komplikation (- Abb. 1.87). Sie führt zu einem Rechts-links-Shunt und dadurch zu einer Hypoxämie. Vor allem bei älteren Patienten, die längere Zeit unbeweglich in einer Position verweilen müssen, kommt es in den unten liegenden Lungenabschnitten zu Atelektasen. Diese Atelektasen führen, falls sie unbehandelt bleiben, zu einer Pneumonie.

Untersuchungen mittels Computertomographie haben gezeigt, dass sich bei einer Allgemeinanästhesie schon nach 45 min Atelektasen in den abhängigen Lungenpartien bilden. Die frühe Mobilisation frisch operierter Patienten ist eine wirksame Therapie, um solche nicht mehr belüftete Lungenanteile wieder zu eröffnen. Dort, wo dies aufgrund der Operation nicht möglich ist, werden heute einfache Atemhilfsgeräte eingesetzt, die den Patienten zu einer forcierten Inspiration zwingen und dadurch die atelektatischen Lungenanteile wieder am Gasaustausch teilnehmen lassen. Bei Thoraxund Abdominaleingriffen muss auf eine gute postoperative Schmerzbehandlung geachtet werden. Wenn die Schmerzen postoperativ ungenügend behandelt sind, kann der Patient keine forcierte Inspiration vornehmen und die verschlossenen Lungenanteile bleiben $\mathrm{zu}$ und es wird $\mathrm{zu}$ einer Pneumonie kommen.

\section{Sicherheit in der Anästhesie}

\section{$\checkmark$ Eine Anästhesie ohne Risiko gibt es nicht!}

Die Anästhesie hat in den letzten 15 Jahren enorme Fortschritte gemacht und die Gefahr, an einem Anästhesiezwischenfall zu sterben, ist gering geworden. Das Risiko entspricht etwa dem, als Passagier bei einem Flugzeugabsturz in der zivilen Luftfahrt umzukommen. Die technischen Verfeinerungen haben aber in den letzten 3-5 Jahren nicht mehr zu einer weiteren Abnahme des perioperativen Risikos geführt. Auch in der zivilen Luftfahrt wurde versucht, mit immer neueren technischen Hilfsmitteln die Sicherheit von Flugzeugen zu verbessern. Es ist aber heute bekannt, dass $70-80 \%$ aller Flugzeugabstürze in der zivilen Luftfahrt durch menschliches Versagen bedingt sind. Zurzeit gibt es nur wenige Angaben, wodurch kritische Ereignisse im Operationssaal bedingt sind. Die wenigen Arbeiten auf diesem Gebiet zeigen aber, dass in unserem Fach das menschliche Versagen in bis zu 80\% Ursache der schweren Zwischenfällen ist.

Obwohl das Risiko an einer Operation zu sterben in den letzten 20 Jahren stark abgenommen hat, haben größere Untersuchungen in Kalifornien 1974, in New York 1984 und in 

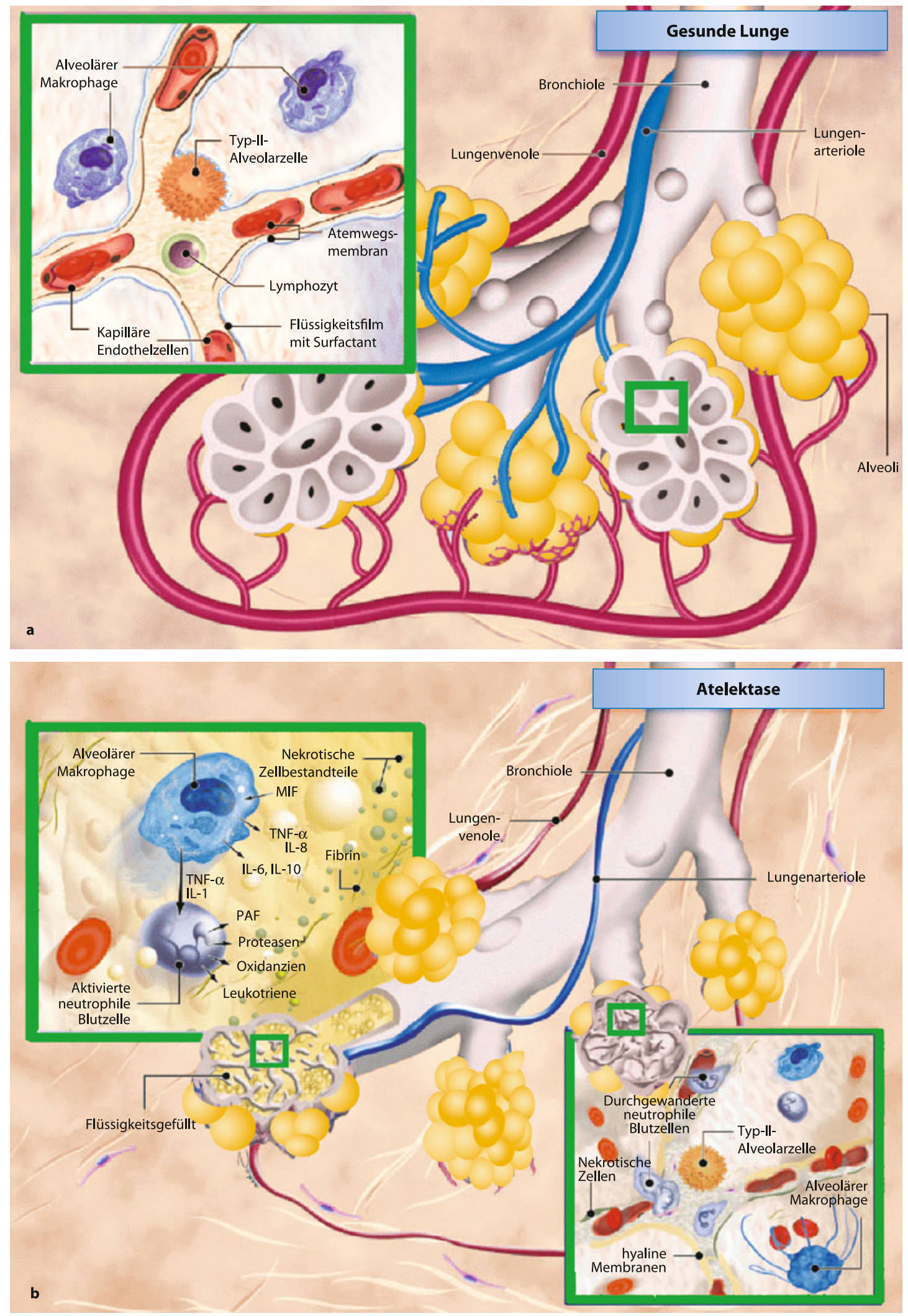

- Abb. 1.87 a Gesunde Lunge, b Atelektase 


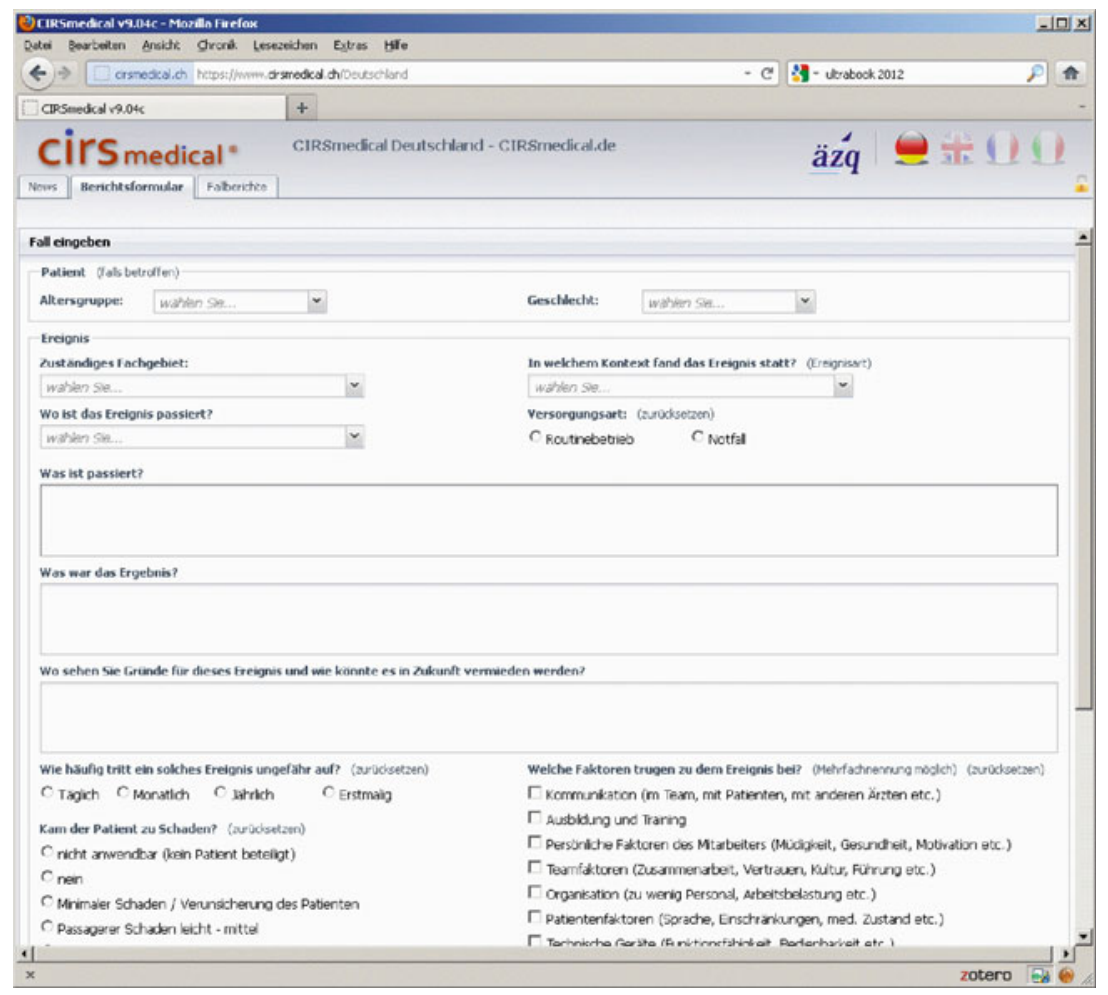

- Abb. 1.88 »CIRS« (Critical Incident Reporting System) - Lernen aus Fehlern (https://www.cirsmedical.ch/Deutschland, zugegriffen am 5.1.2012)

Colorado und Utah 1992 gezeigt, dass die Anzahl von Zwischenfällen (»adverse events«), d.h. Patienten, die unbeabsichtigt während ihrer Behandlung zu Schaden gekommen sind, über die Jahre stabil hoch geblieben ist, obwohl dieses Thema in der Öffentlichkeit und in der medizinischen Literatur einen viel höheren Stellenwert erhalten hat.

In diesen Untersuchungen kamen solche unerwünschten Zwischenfälle in beinahe $4 \%$ aller Hospitalisationen vor. Diese Zahl konnte in Untersuchungen in England und Australien bestätigt werden. 70\% dieser Zwischenfälle haben zu keinen oder nur zu kurzzeitigen Beschwerden bei den betroffenen Patienten geführt. Bei 7\% sind aber bleibende Schäden aufgetreten und 14\% sind an den Folgen gestorben.

In den zu diesem Thema verfassten Expertenberichten aus den USA, England und der Schweiz wurden zur Verminderung dieser Adverse Events anonyme Fehlermeldesysteme als erste Maßnahme vorgeschlagen. Im Bericht des Institute of Medicine »To err is human « werden solche Meldesysteme, die in der zivilen Luftfahrt schon lange verwendet werden, ultimativ gefordert, insbesondere weil gezeigt werden konnte, dass beinahe die Hälfte dieser Adverse Events meist auf der Basis von kritischen Zwischenfällen (critical incidents) grundsätzlich vermeidbar gewesen wären. Wenn man bedenkt, wie viele größere Krankenhäuser in Deutschland mehr als 100.000 Patienten pro Jahr ambulant und stationär behandeln, wird sichtbar, wie relevant dieses Problem in Wahrheit ist und welche Kostenfolgen (Verlängerung des Krankenhausaufenthalts, bleibende Morbidität, reduzierte Erwerbsfähigkeit, Haftpflicht) für das Gesundheitswesen und die Gesellschaft daraus resultieren.

Solche einzelne Adverse Events werden häufig als Fehlhandlung oder Versagen von Einzelnen dargestellt (human error). Analysen von Critical Incidents wie auch Erfahrungen aus der Fliegerei, der Nuklear- und Ölindustrie oder anderen komplexen Systemen haben aber deutlich gezeigt, dass solche Ereignisse fast immer multifaktoriell verursacht sind: Arbeitsbelastung, Kommunikations-, Ausbildungs- und Überwachungsprobleme, ungenügende Ressourcen, Teamfaktoren, inadäquate Umgebung und auch Patientenfaktoren sind meist entscheidend mitbeteiligt.

\section{Lernen aus Fehlern}

Da schwere Adverse Events relativ selten sind, macht es nur bedingt Sinn, die Systemsicherheit durch die akribische Analyse von seltenen Einzelereignissen zu verbessern, wenn tagtäglich bei der Arbeit im Gesundheitswesen häufig Vorstufen, die Critical Incidents (CI) passieren (• Abb. 1.88).

Solche CI haben das Potenzial unter bestimmten Umgebungsbedingungen ein Adverse Event zu werden. Durch die hohe Frequenz von CI im klinischen Alltag stellt deren Untersuchung eine viel größere und fundiertere Basis für Bemühungen zur Erhöhung der Systemsicherheit dar. Solche Incidents decken kleine und große Sicherheitslöcher im System auf, deren Schließung zur Erhöhung der Gesamtsicherheit 
beiträgt. Die Critical-incident-Technik zeichnet sich mit anderen Worten dadurch aus, dass durch das Sammeln von Informationen über kritische Zwischenfälle Erkenntnisse für Korrekturen gewonnen werden können und damit künftige Fehler vermieden werden. Kritische Zwischenfälle werden in der Regel kurzfristig durch die direkt Involvierten an der Front gut memoriert. Eine Sammlung von solchen Ereignissen kann strukturiert untersucht werden, Folgerungen daraus können u. a. auch verwendet werden, um die positiven Faktoren eines Systems zu verstärken. Diese Technik ist bereits mehr als 60 Jahre alt und wurde anfänglich hauptsächlich in der Fliegerei eingesetzt. Anonyme Critical-incident-Reportingsysteme wie z.B. http://www.CIRSmedical.org haben das Potenzial, Schwachstellen aufzuzeigen und die lokale Fehlerkultur zu beeinflussen.

\section{In Kürze}

\section{Häufige postoperative Komplikationen}

- Kardiale Komplikationen: in den ersten $48 \mathrm{~h}$ (metabolischer Stress, sympathische Hyperaktivität).

- Pulmonale Komplikationen: Lungenembolien, Lungenatelektase, Pneumonie. Frühe Mobilisation und Atemtherapie.

- Meist menschliches Versagen, Erhöhung der Sicherheit durch »CIRS« (Critical-incident-Reportingsysteme) Lernen aus Fehlern.

\section{Weiterführende Literatur}

Barash PG, Cullen BF, Stoelting RK, Cahalan M (2009) Clinical anesthesia. Lippincott, Philadelphia

Cousins MJ, Bridenbaugh PO (1988) Neural blockade in clinical anesthesia and management of pain. Lippincott, Philadelphia

Döberl A, Eriksson E (1980) Atlas der Lokalanästhesie. Springer, Heidelberg

Duggan M, Kavanagh BP (2005) Pulmonary atelectasis. A pathogenic perioperative entity. Anesthesiol 102:838-854

Eagle KA et al. (2002) ACC/AHA guideline update for perioperative cardiovascular evaluation for noncardiac surgery: executive summary. A report of the American College of Cardiology/American Heart Association Task Force on Practice Guidelines. J Am Coll Cardiol 39:542-553

Helmreich RL, Schaefer HG (1994) Team performance in the operating room. Lawrence Erlbaum, Hillsdale

Hines RL, Marschall K (2008) Stoelting's Anesthesia and co-existing disease. Churchill Livingstone, New York

Miller RD (2004) Anesthesia. Churchill Livingstone, New York

Stoelting RK (2005) Pharmacology and physiology in anesthetic practice. Lippincott, Philadelphia

Vanstrum GS (1989) Anesthesia in emergency medicine. Little \& Brown, Boston

West JB (2000) Respiratory physiology - The essentials, 9. Aufl. William \& Wilkins, Baltimore

Wilkins EW Jr (1989) Emergency medicine - scientific foundations and current practice. Williams \& Wilkins, Baltimore

\subsection{0 \\ Klinische Studien und Forschung in der Chirurgie}

\subsubsection{Klinische Studien}

\author{
M. K. Diener, Ph. Knebel, \\ Chr. Fink, I. Rossion, B. Maichle, \\ M.W. Büchler/B. Vollmar
}

Die klinische Forschung in der Chirurgie kann grob in 3 Bereiche gegliedert werden: grundlagen-, krankheits- und patientenorientierte Forschung. Dieses Kapitel soll vor allem den letztgenannten Bereich aus chirurgischer Sicht darstellen und zugehörige Inhalte verdeutlichen.

Neue operative Verfahren werden bis heute oft nicht über einen wissenschaftlich belegbaren Weg in die Krankenversorgung eingeführt. Um fundierte und nachprüfbare Aussagen über den Erfolg eines neuen Verfahrens machen zu können, müssen vermehrt klinische Studien entsprechend international anerkannter Standards durchgeführt werden. Hierzu sind in der Chirurgie, wie auch in anderen medizinischen Fachbereichen, spezielle methodische Kenntnisse zur Planung, Durchführung und Auswertung zwingende Voraussetzung.

Die Fragestellungen im chirurgischen Fachbereich sind äußerst vielfältig und beziehen folgende Gebiete mit ein: Ursachen von Krankheiten, Risikoabschätzung, Diagnostik einschließlich klinischer Entscheidungsfindung, Abgrenzung von Normalität, Operationsmethoden, perioperative Behandlung, Prognosen und Kosten-Management.

Die patientenorientierte Forschung in der Chirurgie stellt besondere Herausforderungen. Im Gegensatz zur pharmakologischen Forschung stehen hier der Chirurg und sein Können im Mittelpunkt. Daraus ergeben sich bei der Bewertung von chirurgischen Therapieverfahren spezielle Ansätze.

Dieses Kapitel soll in die Rationale und Methodik der patientenorientierten klinischen Forschung einführen und den aktuellen Stand der Evidenzbasierten Medizin (EBM) in der deutschen Chirurgie darstellen.

\section{Evidenzbasierte Chirurgie (EBC)}

Chirurgische Therapiekonzepte sollten auf objektiver und systematisch bewerteter wissenschaftlicher Erkenntnis (Evidenz) beruhen. Um diese grundlegende Forderung der EBM auch in der Chirurgie umzusetzen, wird Evidenz aus Studienergebnissen benötigt.

Für 5-20\% aller Therapien in der Chirurgie fehlt zurzeit jegliche gesicherte externe Evidenz. 60-70\% beruhen zwar auf überzeugender klinischer Forschung, ohne jedoch durch experimentellen Ansatz und prospektiv randomisiertes kontrolliertes Studiendesign (RCTs) gestützt zu sein. Nur 10-20\% aller Maßnahmen basieren auf Ergebnissen aus RCTs.

$>$ Evidenzbasierte Chirurgie integriert bei der Entscheidung über die Versorgung einzelner Patienten die beste verfügbare externe Evidenz mit der persönlichen Erfahrung des Chirurgen unter Berücksichtigung des Patientenwunsches. 
Die praktische Anwendung der EBC sieht 5 Teilschritte vor:

1. Formulierung einer beantwortbaren Frage: Für den Aufbau einer adäquaten Fragestellung ist die Anwendung der sog. PICOT-Regel sinnvoll, d. h. das medizinische Problem des Patienten (Population), die in Frage kommende Intervention, die zu vergleichende Kontrollgruppe (Control group), der passende Endpunkt (Outcome) und Zeitpunkt (Time) sollten in der Fragestellung definiert werden.

2. Literatursuche: Grundlage hierfür ist die Zugangsmöglichkeit zu elektronischen Suchmaschinen medizinischer Datenbanken wie Medline der National Library of Medicine (kostenlose Suchplattform auf www.pubmed.org). Eine Literatursuche, die mit dem Anspruch auf Vollständigkeit durchgeführt wird, z. B. als Grundlage für eine systematische Übersichtsarbeit, sollte zusätzlich Datenbanken wie Embase (www.embase.com) und die Cochrane Library (www.thecochranelibrary.com) berücksichtigen.

3. Kritische Beurteilung der aufgefundenen Studien (Evidenz): Nach epidemiologischen Prinzipien wird die methodologische Qualität (interne Validität) und die resultierende Aussagekraft der Ergebnisse und deren Anwendbarkeit (externe Validität) überprüft. Von entscheidender Bedeutung ist hierbei, ob eine relevante klinische Fragestellung mit dem geeigneten Studiendesign methodisch korrekt untersucht wurde. Die hierarchische Anordnung des Studiendesigns (Levels of Evidence) beruht auf dessen jeweiliger Robustheit gegenüber zufälliger und systematischer Verzerrungen und dient zur Einschätzung der potentiellen Validität (•Tab. 1.43).

4. Anwendung der Evidenz: Im 4. Schritt der EBC sollte die aufgefundene Evidenz und deren kritische Beurteilung mit der bestehenden klinischen Expertise verknüpft werden. Bei der Anwendung des Fachwissens ist auf die individuelle Patientensituation und dessen Wünsche zu achten. Die partizipative Einbindung des mündigen Patienten in den Prozess der chirurgischen Entscheidungsfindung ist an dieser Stelle sinnvoll.

5. Reflektion und Beurteilung des eigenen Handelns: Die abschließende Beurteilung der Wirksamkeit der Schritte 1-4 sollte sowohl aus Patientenperspektive als auch aus Sicht des Chirurgen erfolgen und - falls angebracht - eine weitere Prozessoptimierung anstreben.

\section{Studiendesigns}

Patientenorientierte Studien in der Medizin lassen sich nach den folgenden 4 Kategorien unterscheiden:

- Beobachtende oder experimentelle Studien

- Prospektive oder retrospektive Studien

- Längsschnitt- oder Querschnittstudien

- Kontrollierte oder unkontrollierte Studien

Bei Beobachtungsstudien werden Merkmale von Patienten erhoben, die ein bestimmtes Charakteristikum aufweisen (z. B. ob diese eine positive Anamnese für ein hereditäres, nicht polypöses Kolonkarzinom haben). Experimentelle Stu-
- Tab. 1.43 Levels of Evidence

\begin{tabular}{|c|c|}
\hline Level & Studiendesign zur Therapie \\
\hline $1 \mathrm{a}$ & $\begin{array}{l}\text { Systematische Übersichtsarbeit randomisiert } \\
\text { kontrollierter Studien }\end{array}$ \\
\hline $1 b$ & Randomisiert kontrollierte Studie \\
\hline 1c & Alles-oder-Nichts-Prinzip \\
\hline $2 a$ & $\begin{array}{l}\text { Systematische Übersichtsarbeit von Kohorten- } \\
\text { studien }\end{array}$ \\
\hline $2 b$ & $\begin{array}{l}\text { Kohortenstudie; randomisiert kontrollierte } \\
\text { Studie niederer Qualität }\end{array}$ \\
\hline 2c & Ergebnisforschung: ökologische Studien \\
\hline $3 a$ & $\begin{array}{l}\text { Systematische Übersichtsarbeit von Fall-Kontroll } \\
\text { Studien }\end{array}$ \\
\hline $3 b$ & Fall-Kontroll Studie \\
\hline 4 & Fallserie \\
\hline 5 & Expertenmeinung \\
\hline
\end{tabular}

dien hingegen weisen den Patienten einer Intervention $\mathrm{zu}$ (z. B. laparoskopische versus offene Therapie) und schreiben damit auch dem Operateur die chirurgische Technik vor. Im Gegensatz dazu werden in Beobachtungsstudien die vom Chirurgen gewählte Intervention und deren Ergebnis erfasst, ohne dass in die Interaktion zwischen Patient und Chirurg eingegriffen wird.

Bei retrospektiven Studien wird auf Daten zurückgegriffen, die bei Studienbeginn schon vorliegen, bei prospektiven Studien entstehen diese Daten erst nach Studienbeginn.

In Querschnittstudien werden die Merkmale der Patienten $\mathrm{zu}$ einem bestimmten Zeitpunkt erhoben, während in Längsschnittstudien dies mehrfach über die Zeit hinweg erfolgt. In Längsschnittstudien können somit zeitliche Veränderungen erfasst werden (z. B. die Inzidenz einer Erkrankung), wohingegen in Querschnittsstudien ein Ist-Zustand zu einem bestimmten Zeitpunkt beschrieben werden soll (z. B. die Prävalenz einer Erkrankung). Experimentelle Untersuchungen sind immer Längsschnittstudien.

Bei kontrollierten Studien werden Beobachtungen über Zustände oder Veränderungen einer Gruppe von Personen, die ein interessierendes Charakteristikum aufweist, denen einer Kontrollgruppe gegenübergestellt, die diese Eigenschaft nicht auszeichnet. In unkontrollierten Studien werden Unterschiede oder Veränderungen ohne Kontrollgruppe intraindividuell erfasst, beispielsweise vor und nach einer Intervention als »Vorher-Nachher-Vergleich $«$.

In den folgenden Abschnitten soll auf die wichtigen Designs in der patientenorientierten Forschung eingegangen werden. Diese Ausführungen dienen nur als grobe Orientierung, es können nicht die methodischen Anforderungen der jeweiligen Designs umfassend dargestellt werden. 


\section{Systematische Übersichtsarbeiten und Meta-Analysen}

Systematische Übersichtsarbeiten (SR) mit oder ohne quantitative Zusammenfassung in Form von Meta-Analysen (MA) gehören zu den jüngsten und derzeit sehr populären Studienformen in der Chirurgie, um einen umfassenden Überblick zu einem Forschungsthema zu gewinnen. Leider ist die methodische Qualität sehr unterschiedlich und die hohen Anforderungen der Cochrane Collaboration (CC) oder des PRISMA Statements werden nur von wenigen chirurgischen Arbeiten erfüllt. Die Erstellung der Übersichten folgt einer einheitlichen Struktur und muss hohen formalen Kriterien gerecht werden. Die Abfassung eines SR entspricht somit einer eigenständigen Forschungsleistung mit den Punkten: Fragestellung, Literatursuche, Studienauswahl und Qualitätsbeurteilung nach Protokoll, Ergebnisteil und praktischer Schlussfolgerung. Für die Klinik sind diese Arbeiten im Rahmen der EBM und für die Erstellung von Leitlinien von besonderer Bedeutung. Ein SR von RCTs hoher Homogenität stellt die derzeit höchste Evidenzstufe im Bereich der Therapiestudien dar.

\section{Randomisiert kontrollierte Studie}

Eine experimentelle Studie im eigentlichen Sinne ist eine Interventionsstudie mit Randomisierung; sie wird auch als randomisiert kontrollierte Studie (RCT) bezeichnet. Um zu aussagekräftigen Ergebnissen aus solchen Studien zu gelangen, muss neben der Strukturgleichheit auch die Beobachtungsgleichheit gewährleistet sein, $d$. h. auch nach der zufälligen Zuteilung der Personen zu den Behandlungsgruppen sollten die weiteren Bedingungen der Studie für alle gleich sein. Beobachtungsgleichheit kann durch Verblindung erzielt werden.

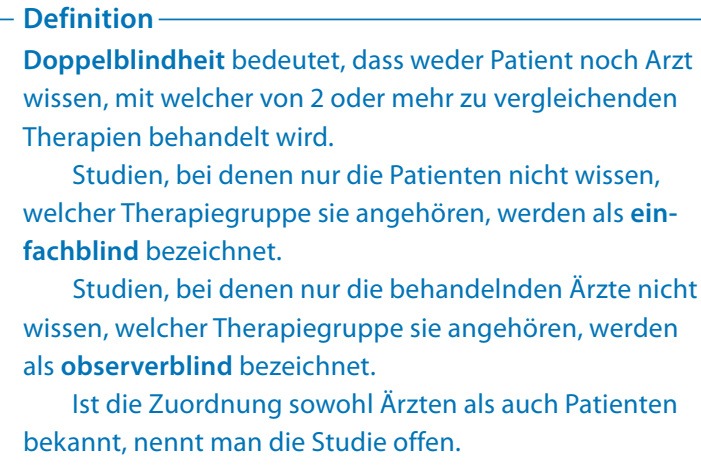

Beim Vergleich von Medikamenten mit unterschiedlichen Applikationsarten kann Doppelblindheit durch die »Double Dummy Technik« erreicht werden. Diese besteht darin, dass alle Patienten der Studie beide Applikationsarten entsprechend ihrer Gruppenzugehörigkeit erhalten, die eine als aktive Substanz (Verum), die andere als Placebo.

Um die Vergleichbarkeit der Gruppen auch bei der statistischen Auswertung aufrecht zu erhalten, ist es notwendig, alle eingeschlossenen, d. h. randomisierten Patienten entsprechend ihrer Gruppenzugehörigkeit in die statistische Analyse einzubeziehen: Das bedeutet, es müssen auch solche Patienten in die Auswertung eingehen, bei denen das Prüfprotokoll (also insbesondere Vorschriften zur Einnahme der zu prüfenden Präparate oder Einnahme von nicht erlaubten Begleittherapien) nicht eingehalten wurde, die vorzeitig aus der Studie ausgeschieden oder die nicht zu allen vorgesehenen Kontrolluntersuchungen erschienen sind. Eine solche Analyse bezeichnet man als »Intention-to-Treat-Analyse« (ITT).

Die Erstellung von RCTs erfolgt im Rahmen wissenschaftlicher Vorgaben, wie z. B. dem CONSORT-Statement. Chirurgische RCTs weisen einige Besonderheiten gegenüber den Arzneimittelstudien auf. Eine Randomisierung in der Chirurgie ist in der Regel kurz vor der eigentlichen Intervention vorzunehmen und orientiert sich an der Grundbedingung von RCTs, der »Clinical Equipose«. Nur wenn in einer spezifischen Situation beide Behandlungsverfahren nach aktueller Evidenzlage gleichwertig sind, kann ein Patient zufällig einem von beiden zugeteilt werden.

Der Behandlungsgleichheit kommt eine besondere Bedeutung, insbesondere zur Vermeidung von zufälligen und systematischen Fehlern zu, sie ist die eigentliche Hauptaufgabe für die Chirurgie. Neben der klassischen Randomisierung auf Patientenbasis können weitere Verfahren herangezogen werden, wie faktorielle (mehrfache Randomisierungen) oder "Expertise Based» Designs. Das »Expertise Based« Design, bei dem Patienten dem Chirurgen mit der höchsten Erfahrung in der jeweiligen randomisierten Operationstechnik zugeteilt werden, ist besonders für den Vergleich von chirurgischen Interventionen/Operationen geeignet. Die Umsetzung stellt aber in multizentrischen Studien oft eine große Herausforderung dar.

\section{$(8$ Bei der Einführung von neuen Verfahren oder neuen Materialien in der Chirurgie sollte in der Regel stets ein RCT zur Evaluation des tatsächlichen Nutzens er- folgen.}

Auch die Berücksichtigung der Lernerfahrung des Chirurgen ist heute, wenn auch methodisch durchaus anspruchsvoll, in RCTs quantitativ darzustellen und sollte bei der Interpretation der Ergebnisse berücksichtigt werden. Die rasante Entwicklung neuer biometrischer Methoden wird in Zukunft die Bedeutung von RCTs in der Chirurgie weiter hervorheben.

\section{Multizentrische Studien}

Einige chirurgische Erkrankungen treten relativ selten auf, so dass die Rekrutierung einer adäquaten Zahl an Studienpatienten an einem Zentrum langwierig bzw. unmöglich ist. In solchen Situation können oft nur multizentrische Studienprojekte eine ausreichende Fallzahl generieren. Jedoch ist hierbei, wie bereits angesprochen, die Gefahr einer schlechteren Standardisierung der zu vergleichenden Therapie größer als in monozentrischen Studien. Auch der Planungs-, Monitor- und Managementaufwand darf in diesem Bereich nicht unterschätzt werden. Dennoch versprechen multizentrische Ansätze bei idealer Planung und Durchführung eine höhere externe Validität und damit verbunden Generalisierbarkeit als monozentrisch geplante Studien (Zentrumseffekt). 


\section{Kohortenstudie}

In Kohortenstudien stellt das interessierende Merkmal, nach dem die zu vergleichenden Gruppen unterschieden werden, einen (vermutlich) krankheits- oder ereignisauslösenden oder -beeinflussenden Faktor (Expositionsfaktor) dar. Die Blickrichtung erfolgt von der Exposition zur Krankheit oder zum Ereignis (z. B. chirurgische Komplikation) hin, d. h. es wird beobachtet, ob diejenigen Personen, die den Expositionsfaktor aufweisen, seltener (protektiver Faktor) oder häufiger (Risikofaktor) eine bestimmte Erkrankung erleiden, bzw. kein Unterschied in der Krankheitshäufigkeit besteht. Kohortenstudien können prospektiv oder retrospektiv durchgeführt werden.

\section{Fall-Kontroll-Studie}

In Fall-Kontroll-Studien wird, umgekehrt zur Kohortenstudie, von der Erkrankung oder dem Ereignis (z. B. Spätkomplikation) auf die Exposition (z. B. Operation) geblickt, d. h. es werden Personen mit einer bestimmten Komplikation (Fälle) mit Personen ohne dieses Ereignis (Kontrollen) dahingehend verglichen, ob sie seltener oder häufiger einem Expositionsfaktor (z. B. einer bestimmten OP-Technik) ausgesetzt waren. Fall-Kontroll-Studien sind immer retrospektiv und erfordern besondere Sorgfalt bei der Auswahl der Vergleichsgruppen. Kohortenstudien sind zumeist sehr zeit- und geldaufwändig, Fall-Kontroll-Studien können demgegenüber häufig mit einem wesentlich geringeren Aufwand durchgeführt werden und sind gerade bei seltenen Erkrankungen/Ereignissen oft das einzige wissenschaftlich realisierbare Studiendesign. Sie haben allerdings den Nachteil, dass sie besonders anfällig für Verzerrungen (Bias) sind, d.h. dass die beobachtete Beziehung zwischen Expositionsfaktor und Erkrankung durch weitere Störgrößen, die »Confounder«, beeinflusst wird.

\section{Spezielle Anforderungen chirurgischer Studien}

Die Anforderungen und Schwierigkeiten bei der Durchführung chirurgischer Therapiestudien sind vielseitig. Folgende methodische und situative Anforderungen stellen dabei typische Hürden dar.

\section{Standardisierung der chirurgischen Therapie}

Ein wesentlicher und oftmals limitierender Faktor für die Durchführung von chirurgischen Studien ist die fehlende Standardisierung der Therapie. Das handwerklichen Können des einzelnen Chirurgen und seine Erfahrung beeinflussen weit mehr als die Pharmakotherapie das Behandlungsergebnis. Für die Durchführung einer chirurgischen Intervention stehen nicht selten mehrere chirurgische Verfahren zur Auswahl, die je nach Präferenz des Chirurgen oder der jeweiligen Klinik zur Anwendung kommen können. Darüber hinaus können unterschiedliche lokale Standards für die peri- und postoperative Therapie unabhängig von der direkten chirurgischen Maßnahme als wichtige Einflussfaktoren identifiziert werden.

\section{Lernkurve des Chirurgen}

Die Frage nach dem optimalen Timing einer chirurgischen Studie ist nicht leicht zu beantworten und hängt maßgeblich davon ab, wie viel wissenschaftliche Vorleistung in diesem Themenfeld bereits erbracht wurde. Idealerweise sollte die Wirksamkeit jeder neuen chirurgischen Therapie bzw. Technik durch eine (randomisiert kontrollierte) Studie beurteilt werden. Findet diese Überprüfung zeitgleich mit der Einführung einer neuen Technik statt, so ist regelmäßig eine gewisse Lernkurve der Chirurgen im Verlauf der Studie zu erwarten, die die Ergebnisse eventuell verzerrt. In Abhängigkeit vom Ausbildungsstand und der einschlägigen Operationserfahrung des einzelnen Chirurgen ist jedoch auch zu einem späteren Zeitpunkt ein Lerneffekt nicht auszuschließen.

Vier Punkte sollten in diesem Kontext bei der Studienplanung bedacht werden:

1. "Clinical Equipoise« (augenscheinliche, jedoch nicht bewiesene Gleichwertigkeit zweier Therapieverfahren) prädisponiert zur Überprüfung der Wirksamkeit in einer randomisiert kontrollierten Studie. Dies sollte aus ethischen und wissenschaftlichen Gründen eher früher als später geschehen.

2. Eine mögliche Verzerrung durch die Lernkurve der Chirurgen sollte bei Studienplanung und Präsentation der Ergebnisse diskutiert werden.

3. Stratifikation der Ergebnisse nach der chirurgischen Expertise kann die Lernkurve relativieren.

4. Da chirurgische Techniken einer ständigen Weiterentwicklung unterworfen sind, kann eine weitere Evaluation nach dem originären Wirksamkeitsnachweis durchaus gerechtfertigt sein (»evaluate early and evaluate often«).

\section{Definition des Studienendpunktes}

Für die Definition der Zielparameter sollten patientenrelevante Endpunkte ausgewählt werden sowie anerkannte und standardisierte Definitionen verwendet werden, da letztere die Vergleichbarkeit der Ergebnisse mit anderen Studien ermöglicht. Je nach Studienfragestellung kann bei der Bewertung chirurgischer Methoden jedoch häufig nicht auf bereits etablierte Zielparameter wie Gesamtüberleben oder validierte Patientenfragebögen zurückgegriffen werden. In diesen Fällen ist die Erarbeitung von Konsensusdefinitionen durch nationale oder internationale Expertengruppen hilfreich. Mindestvoraussetzung ist die exakte Definition der verwendeten objektivierbarer Zielparameter im jeweiligen Studienprotokoll.

\section{Bestandteile eines Studienprotokolls}

Das Studienprotokoll stellt den Prüfplan und somit das zentrale Dokument einer klinischen Studie dar. In diesem Protokoll werden alle wichtigen Aspekte einer klinischen Studie im Vorfeld festgelegt. Neben der Definition der Fragestellung, der Studienpopulation und des Studiendesigns müssen der statistische Analyseplan und ethische Aspekte beachtet werden. Die klassischen Inhalte eines Studienprotokolls können der Tabelle (•Tab. 1.44) entnommen werden. 
- Tab. 1.44 Inhalte eines Studienprotokolls

Studiensynopse

Hintergrund

Studiendesign

Ein-/Ausschlusskriterien

Primäre/sekundäre Endpunkte

Sicherheitsaspekte

Statistische Auswertung

Ethische Gesichtspunkte

Qualitätssicherung

Datenmanagement

Management der Studie
Zusammenfassung der wichtigsten Eckpunkte der Studie

Beschreibung der medizinischen Fragestellung, der bereits verfügbaren Evidenz, sowie der Notwendigkeit der Studie

Definition und Begründung der Auswahl des Studiendesigns, der gewählten Vergleichsgruppen, der Ein-/Ausschlusskriterien, Endpunkte und Fallzahlplanung

Definition der zu untersuchenden Studienpopulation

Definition der Zielparameter, Ablauf und Zeitpunkte der Erhebung

Darstellung möglicher unerwünschter Nebenwirkungen im Rahmen der Studie. Festlegung des Umgangs mit unerwünschten Ereignissen

Festlegung der Fallzahl und des statistischen Analyseplans, ggf. Definition von Subgruppenanalysen

Risiko-Nutzen-Analyse der Studieninterventionen, Abschätzung des Risikos für den Einzelnen und des Benefits für die Grundgesamtheit

Beschreibung der Qualitätssicherungsprinzipien und -maßnahmen zur Überprüfung der Einhaltung ethischer und methodischer Standards (Good Clinical Practice, Declaration of Helsinki)

Beschreibung des Umgangs mit den erhobenen Daten, des Datenflusses, Überprüfung von Vollständigkeit und Korrektheit

Festlegung der Verantwortlichkeiten von Studienleitung und Kooperationspartner

\section{Studienregistrierung und Protokollveröffent- lichung}

Die Publikation von Protokollen und die Registrierung der Studien sollten heute selbstverständlich sein. Zur Erhöhung der Transparenz in der klinischen Forschung, sollten Studienprotokolle noch vor Beginn national und international registriert werden (z. B. International Standard Randomised Controlled Trial Number - ISRCTN; http://www.controlled-trials. com). Es ist unethisch, die wissenschaftliche Öffentlichkeit nicht über eine gegenwärtig laufende Untersuchung zu informieren. In der Chirurgie gibt es in der Zwischenzeit eine Vielzahl derartiger Arbeiten, die bei späterer Publikation der Ergebnisse die Hypothesen und Studienplanung transparent machen.

\section{Das Studienzentrum der Deutschen Gesellschaft für Chirurgie (SDGC)}

Das Präsidium der Fachgesellschaft hat sich zur Gründung eines eigenen Zentrums für die patientenorientierte Forschung entschlossen. Aufgabe dieser Einrichtung ist die Planung, Durchführung und Auswertung von mono- und multizentrischen chirurgischen Therapiestudien in der Chirurgie unter Verantwortung der Fachgesellschaft nach den Kriterien der sog. guten klinischen Praxis (Good Clinical Practice).

Das SDGC erfüllt darüber hinaus eine wichtige Aufgabe im Bereich der Aus- und Weiterbildung. Weitere Informationen zu laufenden Studienprojekten und Fortbildungsangeboten sind auf der Homepage des SDGC abrufbar (www.sdgc.de).

\section{In Kürze}

\section{Klinische Studien}

Die Chirurgie ist auf den Einsatz von wissenschaftlich geprüften Therapieverfahren angewiesen. Sie legitimiert Ihren Anspruch in der Krankenversorgung durch Operationen, die einen nachgewiesenen Nutzen in Form von Heilung oder Linderung von Beschwerden haben. Klinische Studien in der Chirurgie haben ein erhebliches Entwicklungspotential. Die Evaluation neuer operativer Verfahren sollte im Regelfall durch randomisiert kontrollierte Studien erfolgen. Die Anwendung anderer Studiendesigns ist besonders zu begründen und sollte die Ausnahme darstellen. Durch neue Studienmethoden und Kreativität bei der Planung und Durchführung lassen sich die bisher als unlösbar oder schwierig geltenden Herausforderungen meistern. Initial helfen systematische Übersichtsarbeiten und Meta-Analysen den aktuellen Stand des Wissens zu beurteilen, die Notwendigkeit weiterer Studien zu begründen und den Transfer von Studienergebnissen in die klinische Praxis zu erleichtern und zu beschleunigen.

Leistungsfähige Strukturen für chirurgische Studien mit fachspezifischer Expertise, wie sie in Deutschland erfolgreich entwickelt werden, helfen den Chirurgen ihren wichtigen Beitrag für die Krankenversorgung auch in der Zukunft sicherzustellen. 


\section{Weiterführende Literatur}

Devereaux PJ, Bhandari M, Clarke M, Montori VM, Cook DJ, Yusuf S, Sackett DL, Cina CS, Walter SD, Haynes B, Schunemann HJ, Norman GR, Guyatt GH (2005) Need for expertise based randomised controlled trials. BMJ Jan 8;330(7482):88

Diener MK, Seiler CM, Antes G (2007) Systematische Übersichtsarbeiten und Meta-Analysen in der Chirurgie. Chirurg;78(10):938-44

Dixon E, Hameed M, Sutherland F, Cook DJ, Doig C (2005) Evaluating meta-analyses in the general surgical literature: a critical appraisal. Ann Surg. 241 (3): 450-9

Meyer K-H (1999) Klinische Forschung: Denkschrift/Deutsche Forschungsgemeinschaft. Weinheim; New York: Wiley-VCH Verlag

Moher D, Liberati A, Tetzlaff J, Altman DG (2009) PRISMA Group. Preferred reporting items for systematic reviews and meta-analyses: the PRISMA statement. BMJ;339:b2535

Moher D, Schulz KF, Altman DG (2004) Das CONSORT Statement: Überarbeitete Empfehlungen zur Qualitätsverbesserung von Reports randomisierter Studien im Parallel-Design; Dtsch Med Wochenschr 129: T16-T20

Wente MN, Seiler CM, Uhl W, BÜchler MW (2003) Perspectives of evidence-based surgery. Dig Surg 20:263-269

\subsubsection{Chirurgische Forschung}

\section{B. Vollmar}

Die chirurgische Forschung ist integraler Bestandteil der akademischen Chirurgie. Sie ist eine der spannendsten Medizinwissenschaften und analysiert die Ursachen, die Entstehung, den Verlauf und die Behandlung von chirurgischen Krankheiten. Mit dem Ziel, chirurgische Forschung zu definieren, sei eine Arbeit von Francis D. Moore aus dem Jahre 1973 zitiert: Moore stellt die Frage, ob chirurgische Forschung Forschung ist, welche (a) ein Chirurg bewerkstelligt, (b) sich mit chirurgischen Themen befasst oder (c) in chirurgischen Laboratorien durchgeführt wird. Oder definiert sich die chirurgische Forschung gar aus der Kombination aller 3 Aspekte? Wohl kaum! Moore definiert chirurgische Forschung schließlich als Forschung zum Wohle der Versorgung chirurgischer Patienten. Nicht die Forschungsmethodik ist chirurgisch, sondern die Problemstellung befasst sich mit Fragen aus der Chirurgie.

Wesentliches Ziel chirurgischer Forschung ist, die Kenntnisse der Pathomechanismen chirurgischer Krankheitsbilder als Grundlage für die Entwicklung neuer diagnostischer und therapeutischer Methoden zu vertiefen. Somit reicht das Spektrum chirurgischer Forschung von der Grundlagenforschung, der krankheitsorientierten und krankheitsevaluativen Forschung über die epidemiologische Forschung bis hin zur Versorgungsforschung. Strukturell wird eine integrative Organisation dieser verschiedenen Bereiche zur Förderung der Translation favorisiert (• Abb. 1.89). Erkenntnisse der molekularen und biomedizinischen Grundlagenforschung sollen möglichst rasch in klinische Diagnoseverfahren und Therapien umgesetzt werden. Umgekehrt sollen klinische Beobach- tungen als Anregung und Rückkopplung in die Grundlagenforschung einfließen. Grundsätzlich unterscheidet man 2 Bereiche der translationalen Forschung:

a) die Translation von der Grundlagenforschung in die angewandte und patientenorientierte Forschung und

b) die Translation von Ergebnissen aus der klinischen Forschung in die klinische Praxis.

Da die klinische Relevanz einer wissenschaftlichen Beobachtung wesentlich die Wertigkeit chirurgischer Forschung bestimmt, werden primär vertikale Forschungsansätze betrieben. Erkenntnisse, die auf subzellulärer Ebene gewonnen werden, werden zunächst im Zellverband, dann auf der Organebene und in integrativen Modellsystemen, wie transgenen Tieren oder Knock-out-Modellen, analysiert und schließlich klinisch überprüft (• Abb. 1.90).

Das Spektrum an notwendigen Disziplinen für die chirurgische Forschung reicht von der Genetik und Molekularbiologie über die sog. »omics«-Methoden, wie »genomics«, »transcriptomics«, "proteomics« und »metabolomics«, die vielfältigen Werkzeuge der Zellbiologie bis hin zu In-vitro-, Ex-vivound In-situ-Methoden. Es schließen sich komplexe integrative In-vivo-Modelle zur Untersuchung und Behandlung pathophysiologischer Prozesse am Tier an, gefolgt von der klinischen Evaluation und Überprüfung der Gültigkeit der wissenschaftlichen Erkenntnisse am Patienten (• Abb. 1.90).

Diese thematische und methodische Komplexität lässt heute bestenfalls noch die Lösung von Detailfragen durch den einzelnen Forscher und akademischen Chirurgen zu und unterstreicht eindringlich die Notwendigkeit fachübergreifender Zusammenarbeit und Forschungskooperation. Entsprechend hat sich in den letzten beiden Jahrzehnten auch die Forschung in der Chirurgie von einer fachspezifischen zu einer interdisziplinären Forschung gewandelt mit Forschungsansätzen, die sich in beträchtlichem Maße mit denen anderer Fachdisziplinen überschneiden.

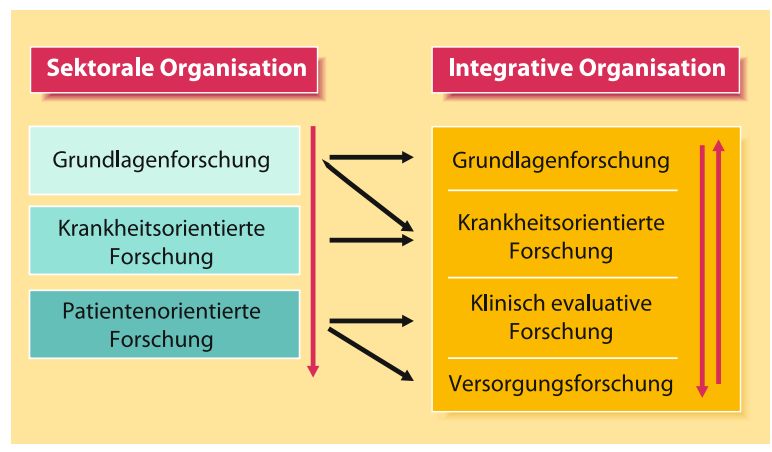

- Abb. 1.89 Forschungsstrukturmodelle. Im Gegensatz zu einer sektoralen Organisation in grundlagen-, krankheits- und patientenorientierte Forschung, von der die Denkschrift der DFG zur Klinischen Forschung aus dem Jahre 1999 noch ihren Ausgangspunkt nahm, wird heute im Sinne der translationalen Forschung eine integrative Organisation von Grundlagenforschung, krankheitsorientierter und klinisch evaluativer Forschung bis hin zur Versorgungsforschung favorisiert 


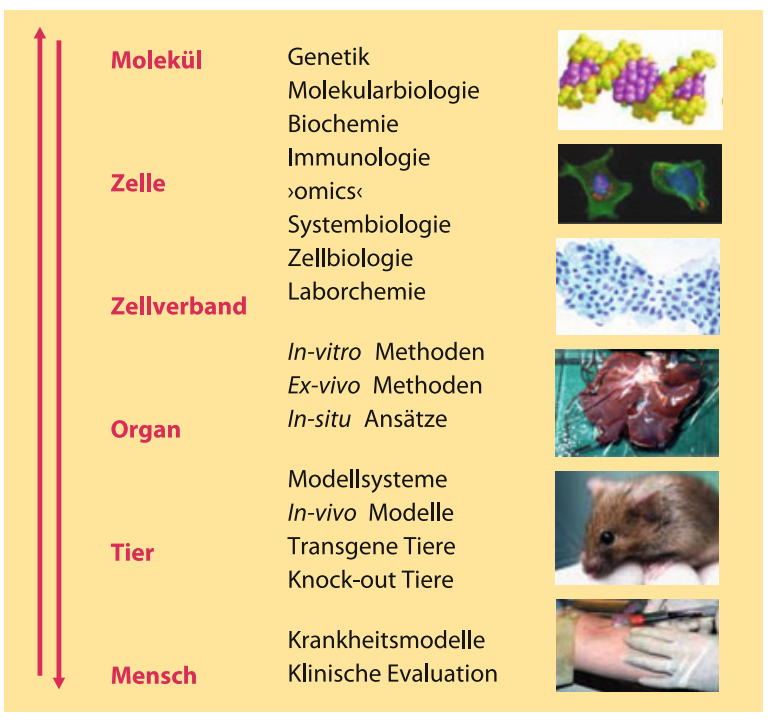

- Abb. 1.90 Darstellung der Forschungsebenen und der wissenschaftlichen Disziplinen. Da die klinische Relevanz einer wissenschaftlichen Beobachtung die Wertigkeit medizinischer Forschung bestimmt, werden primär vertikale Forschungsansätze betrieben. Der sog. »bench-to-bedside«-Prozess ist ein kontinuierlicher Prozess und wird - bei Bedarf und Notwendigkeit der Überprüfung klinischer Sachverhalte im Tier oder in der Zellkultur - auch rückwärts von »bedside-to-bench « beschritten. Das Spektrum an notwendigen Disziplinen ist äußerst vielfältig und reicht von der Genetik und Molekularbiologie über die sog. »omics«-Methoden, den Werkzeugen der Zellbiologie bis hin zu In-vitro-, Ex-vivo- und In-situ-Methoden. Es folgen komplexe integrative In-vivo-Modelle zur Untersuchung und Behandlung pathophysiologischer Prozesse am Tier, gefolgt von der klinischen Evaluation und Überprüfung der Gültigkeit der wissenschaftlichen Erkenntnisse am Patienten

\section{Schwerpunkte chirurgischer Forschung (Tabelle 1)}

\author{
"Klassische« Themenkomplexe chirurgischer \\ Forschung \\ - Molekulare Onkologie \\ - Klinische Onkologie \\ - Transplantationschirurgie \\ - Transplantationsimmunologie \\ - Sepsis \\ - Entzündung \\ - Perioperative Pathophysiologie \\ - Erkrankungen von Leber, Galle und Pankreas \\ - Endokrine Chirurgie \\ - Wundheilung \\ - Tissue Engineering \\ - Biomaterialien \\ - Regeneration \\ - Laparoskopische Chirurgie, inkl. NOTES-Chirurgie \\ (Natural Orifice Transluminal Endoscopic Surgery) \\ - Robotertechnik und Navigationssysteme
}

\section{Molekulare Tumorbiologie und klinische Onkologie}

Maligne Grunderkrankungen stellen nach den kardiovaskulären Erkrankungen die häufigste Todesursache in der westlichen Welt dar. Trotz weitreichender Erfolge in der Therapie von malignen Tumoren bedingen das aggressive Primärtumorwachstum, das frühzeitige lymphogene und hämatogene Metastasierungspotential und die oftmals späte Diagnosestellung die Notwendigkeit, neue diagnostische und therapeutische Verfahren zu identifizieren. Entsprechend stellt die onkologische Forschung ein zentrales Thema der chirurgischen Forschung dar und widmet sich mehreren Schwerpunktthemen, wie

a) Tumorgenetik,

b) Tumorbiologie mit Tumorwachstum und Metastasierung,

c) Tumorvaskularisation und Angiogenese,

d) Tumorstammzellen und

e) Tumorimmunologie.

Die Tumorgenetik beschäftigt sich mit den genetischen Grundlagen bei der Entstehung und der malignen Progression von Tumoren und dient der Identifizierung neuer tumorrelevanter chromosomaler Regionen (Translokations-Bruchpunkte) und Gene, sog. Tumorsuppressorgene und Onkogene. Es ist das Ziel, deregulierte Gene und genomische Aberrationen $\mathrm{zu}$ identifizieren, welche $\mathrm{z}$. B. progressions-assoziiert sind, eine Resistenz gegenüber Chemotherapeutika vermitteln oder als diagnostische Marker dienen. Zusätzlich werden Genveränderungen charakterisiert, welche für die Behandlung von Krebs nutzbar sind oder Voraussagen über den Krankheitsverlauf zulassen. Hier kommen Techniken der Chromosomenuntersuchung, der Bestimmung von komplexen Profilen der Genexpression sowie biochemische und molekulargenetische Verfahren zum Einsatz. Für eine effektive genomweite Untersuchung haben sich vor allem Microarray-basierte Verfahren (»Genchip«) bewährt.

Tumorbiologen beschäftigen sich hauptsächlich mit Wachstumsfaktoren, membrangebundenen Rezeptoren und intrazellulären Signalpfaden, und hier vor allem mit Proteinkinasen, GTPasen und Inositoltrisphosphat. Mit dem Ziel, Tumorwachstum und den Vorgang von Invasion und Metastasierung besser zu verstehen, fokussieren diese grundlagenorientierten Projekte auf die Regulation durch Onkogene, Signalkaskaden und Tumorsuppressorgene. Gegenstand aktueller chirurgischer Forschung ist darüber hinaus die Charakterisierung transkriptionaler Regulationsmechanismen mit der Charakterisierung von Promotoren und Transkriptionsfaktoren.

Im Bereich der Tumorvaskularisation und -angiogenese führten nachhaltige Bemühungen chirurgischer Forschung zur Identifikation neuer therapeutischer Ziele. So konnte in präklinischen Studien zur Untersuchung diverser anti-angiogener Therapieansätze beim Pankreas- und Kolonkarzinom nachgewiesen werden, dass Substanzen, welche die Proliferation von Endothelzellen inhibieren, auch das Wachstum von soliden Tumoren hemmen. Einige dieser Forschungsergebnisse haben bereits Einzug in die klinische Praxis genommen. 


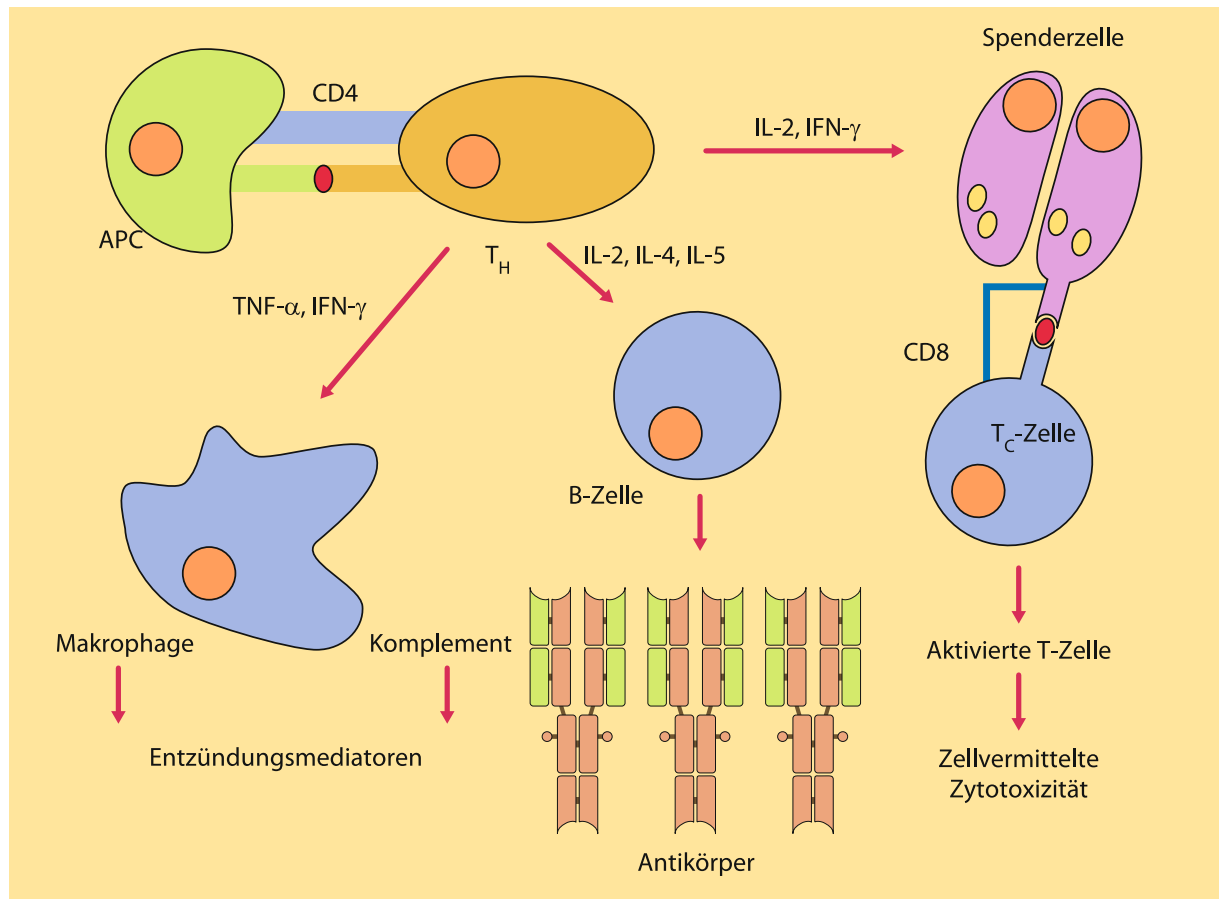

- Abb. 1.91 Aktivierung von Immunzellen nach Transplantation. Die T-Helferzellen ( $\mathrm{TH}$ ) werden durch antigen-präsentierende Zellen (APC) zur Freisetzung von Lymphokinen stimuliert. Für die Aktivierung der zytotoxischen T-Zellen (TC) werden die Lymphokine IL-2 und IFN- $\gamma$ benötigt, während an der Aktivierung von B-Zellen IL-2,

Die Translation und klinische Implementierung anti-angiogener Strategien sind ein Paradebeispiel erfolgreicher chirurgischer Forschung und mittlerweile integraler Baustein der multimodalen klinischen Tumortherapie.

Mit der Identifizierung von Tumorstammzellen wurde deren mögliche Bedeutung für die Entwicklung und Aufrechterhaltung verschiedener menschlicher Krebsarten erkannt. Der wissenschaftliche Schwerpunkt liegt dabei auf der Identifizierung von Zell-Subpopulationen, welche für das Tumorwachstum und die Tumormetastasierung verantwortlich sind. Durch die Verschiedenheit dieser Tumorstammzellen ergeben sich zukünftig völlig neue Ansätze für eine erfolgreiche Krebsbehandlung.

\section{Transplantationsimmunologie}

Eine Grundvoraussetzung der Transplantationsmedizin, die allogene Spenderorgane verwendet, stellt die Modulation des Immunsystems dar. Hier waren u. a. die experimentellen Arbeiten des Biologen Sir Peter Medawar aus den 40er-Jahren des 20. Jahrhunderts wegweisend. Diese zeigten, dass die Abwehrfunktion des Immunsystems mit Immunsuppressiva gezielt geschwächt und damit das Transplantat vor Zerstörung geschützt werden kann. Nachdem Medawar bei Hauttransplantationen an den verbrannten Bombenopfern von Coventry die grundlegenden genetisch determinierten Gesetzmäßigkeiten der Abstoßungsreaktion erkannt hatte, wurde die Organtransplantation zu einem Problem der zellulären Immunologie. Ex-
IL-4 und IL-5 beteiligt sind. Makrophagen werden durch TNF-a und IFN- $\gamma$ stimuliert. Die Gesamtheit dieser Zellen stößt das Transplantat durch spezifische zellvermittelte und antikörpervermittelte immunologische Reaktionen oder durch unspezifische entzündliche Reaktionen $\mathrm{ab}$

perimentell tätige Chirurgen trugen mit tierexperimentellen Untersuchungen zur Organtransplantation wesentlich zur Erforschung der Funktion von Lymphozyten und deren Subpopulationen bei. Durch die Entdeckung der Histokompatibilitäts-Antigene (»major histocompatibility complex«, MHC) und deren genetischer Determinierung lieferten sie entscheidende Erkenntnisse zur Erforschung der Genetik von Mensch und Tier, welche auch das tumorbiologische Verständnis und die onkologische Forschung positiv prägten.

Die chirurgische Forschung hat Pionierarbeit auf dem Gebiet der immunsuppressiven Therapie geleistet. Diese für den klinischen Erfolg der Organtransplantation wichtigen Verfahren der immunsuppressiven Therapie wurden von experimentell tätigen und akademisch aktiven Chirurgen eingeführt: Azathioprin und Cyclosporin durch den Chirurgen Calne (Cambridge) sowie das Antilymphozytenserum durch Sir Michael Woodruff (Edinburgh), Starzl (Denver), Pichlmayr (Hannover) und Brendel (München).

Die heutigen Erfolge der Transplantationsmedizin mit gutem Langzeitüberleben beruhen auf der medikamentösen Möglichkeit der iatrogenen Immunsuppression durch lebenslange Einnahme entsprechender Pharmaka. Aktuelle Aktivitäten auf dem Bereich der Immunsupression zielen auf die Entwicklung neuer, sog. "small molecules« ab, die eine Langzeitimmunsuppression bei geringer Toxizität zum Ziel haben. Fortschritte der Immunsuppression verbinden grundlagenwissenschaftliche Erkenntnisse der Alloimmunität (• Abb. 1.91) 


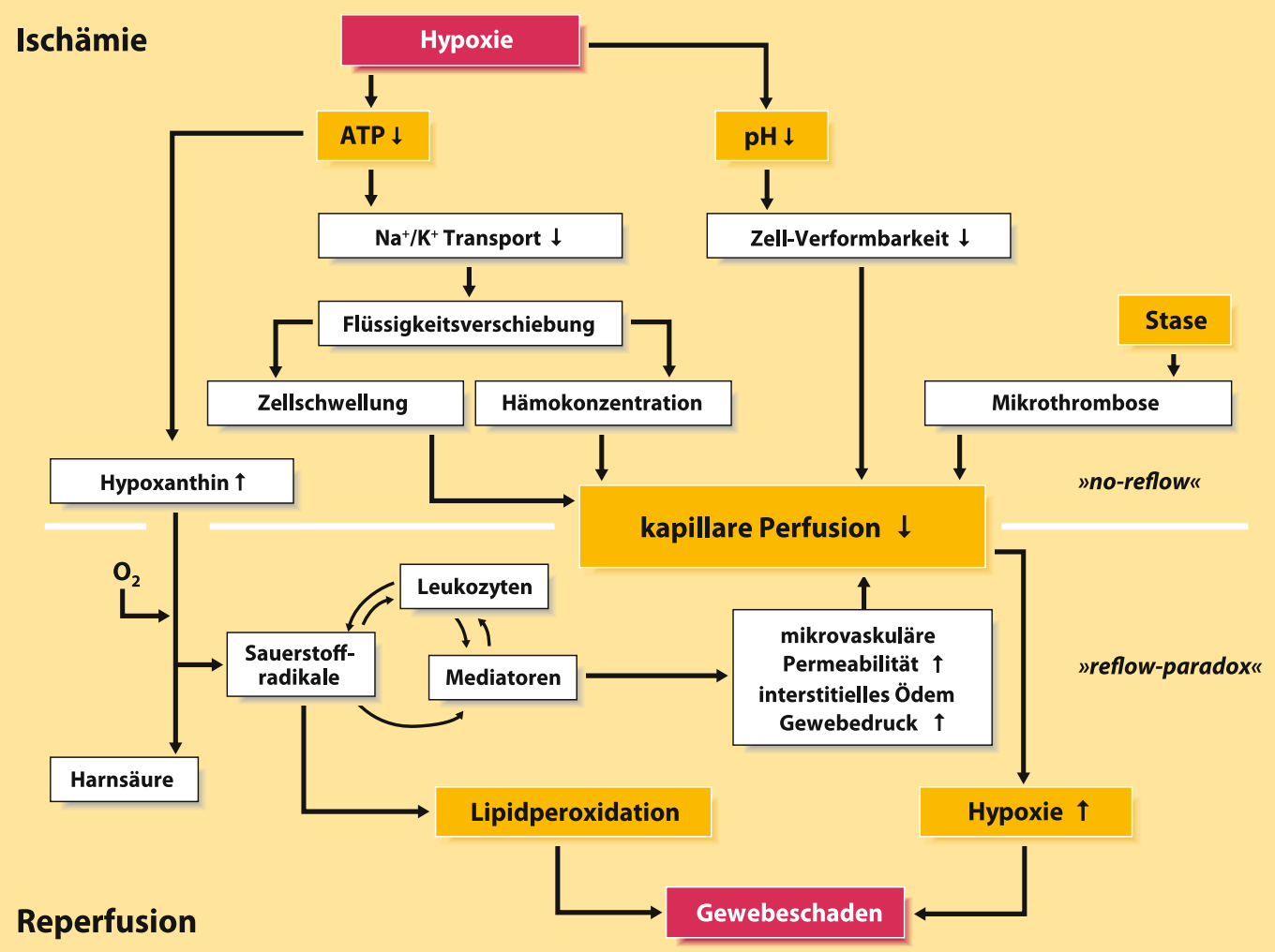

- Abb. 1.92 Pathophysiologische Mechanismen des mikrovaskulären Ischämie/Reperfusionsschadens. Der durch Ischämie bedingte Verlust energiereicher Phosphate führt zu Einschränkungen der ATPabhängigen lonenpumpen mit konsekutiver transmembranärer Verschiebung von Wasser und Elektrolyten. (Endothel)zellschwellung, reduzierte Deformabilität zellulärer Blutbestandteile und Erhöhung des Mikrohämatokrits führen zur Beeinträchtigung der mikrovaskulären Perfusion mit fehlender kapillarer Reperfusion nach Ischämie, dem sog. »no-reflow« Phänomen. Mit Wiedereinfuhr von Sauerstoff

mit dem praktischen klinischen Management transplantierter Patienten, ihren Grunderkrankungen und den Nebenwirkungen der Immunsuppressiva.

\section{Ischämie/Reperfusion, Schock und Trauma}

Der ischämische Insult mit fehlender nutritiver Versorgung des Gewebes sowie die inflammatorische Antwort auf die Wiederherstellung der Perfusion nach temporärer Ischämie prägen die Pathophysiologie einer Vielzahl chirurgischer Erkrankungen und deren Komplikationen. Die daraus resultierende Organdysfunktion bzw. das drohende Organversagen bestimmen das funktionelle postoperative Ergebnis, in Sonderheit dann, wenn zentrale Organe, wie z. B. die Leber, das Herz oder die Lunge betroffen sind. Das Ischämie/Reperfusions (I/R)-Syndrom von Organen stellt bis heute eine oftmals nur schwer zu behandelnde Komplikation in der Viszeralchirurgie, der Leber- und Pankreaschirurgie und speziell der während der Reperfusion kommt es zur Bildung von Sauerstoffradikalen, der Aktivierung von Leukozyten und der Freisetzung einer Vielzahl pro-inflammatorischer, hydrolytischer und proteolytischer Enzyme und Mediatoren. Obgleich es der Reperfusion und Reoxygenierung des Gewebes nach Ischämie zur Verhinderung der Gewebenekrose bedarf, bewirkt das als »reflow-paradox« bezeichnete Phänomen eine Aggravierung des ischämiebedingten Gewebeschadens

Transplantationschirurgie dar. Vergleichbar dem I/R-Syndrom individueller Organe entspricht der protrahierte Schock aufgrund von Sepsis, Blutverlust und Trauma mit nachfolgender Volumensubstitution einer systemischen Ischämie. Entsprechend sind postischämische Organveränderungen zu beobachten, welche im schwerwiegendsten Falle durch ein multiples Organversagen mit hoher Letalität charakterisiert sind.

Intensive chirurgische Forschungsaktivitäten der letzten Jahrzehnte haben zu einer klaren Analyse des Zusammenspiels mikrohämodynamischer, zellulärer und molekularer Mechanismen geführt (• Abb. 1.92), die aktuell die Etablierung gezielter therapeutischer Interventionen erlaubt. In diesem Zusammenhang kommt der Idee konditionierender Verfahren zur Erhöhung der Ischämietoleranz des Gewebes besondere Bedeutung zu. 


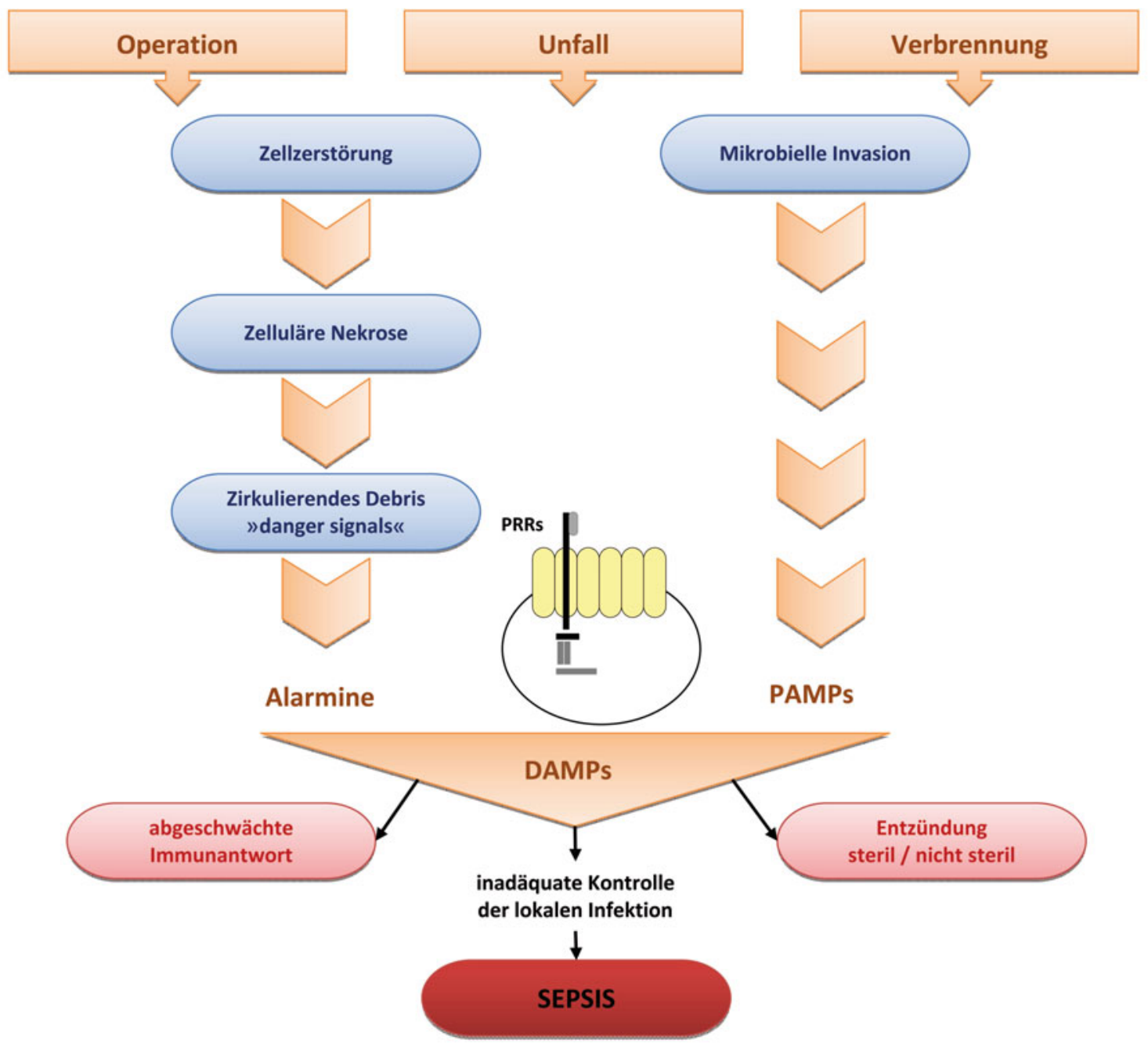

- Abb. 1.93 Auslösung der inflammatorischen Antwort bei Sepsis. Endogene Alarmine und exogene PAMPs, welche als sog. DAMPs von Mustererkennungsrezeptoren auf Immunzellen den sog. PRRs erkannt werden, interagieren und lösen eine Inflammation aus (DAMPs $=$ damage-associated molecular patterns; PAMPs $=$ patho-

\section{SIRS, Sepsis und septischer Schock}

Infektionen und Traumata, einschließlich operativer Eingriffe, führen über eine ungehemmte Freisetzung von Mediatoren des Entzündungs-, Gerinnungs-, und Komplementsystems zu einer systemischen inflammatorischen Antwort des Organismus, welche sich in Abhängigkeit von der Zahl, Pathogenität und Virulenz der Erreger, dem Zustand der körpereigenen Abwehrmechanismen und der Reaktion des Wirtsorganismus rasch zu einer Sepsis entwickeln kann. Die Pathophysiologie der chirurgisch bedingten postoperativen Sepsis zeichnet sich durch eine außerordentlich hohe Komplexität mit vielfältig interagierenden Komponenten aus. Jedes operative Trauma geht in Abhängigkeit vom Ausmaß mit einer postoperativen Immundysfunktion einher und stellt daher einen wesentlichen Trigger für die Initiation und gen-associated molecular patterns; PRRs = pattern-recognition receptors). Die extrem hohen Konzentrationen der DAMPs bei Sepsis führen zur Überstimulation des Immunsystems mit einer unbalancierten Zytokinantwort

Propagation der Sepsis dar. Chirurgische Forschung befasst sich mit zugrunde liegenden Pathomechanismen der Sepsis. Heute weiß man, dass es sich bei der Sepsis um eine sehr komplexe, in verschiedenen Phasen ablaufende, immunologische Reaktion des Körpers auf eine lokale oder generalisierte Infektion handelt (• Abb. 1.93, - Abb. 1.94). Trotz enormer Detailkenntnisse über diese Mechanismen gehen die Sepsis und der septische Schock unverändert mit einer inakzeptabel hohen Mortalität einher. Aktuelle Strategien chirurgischer Forschung fokussieren daher auf die Entwicklung neuartiger Therapeutika, welche die Modulation und weniger die Inhibition der Wirtsreaktion zum Ziel haben. Weitere Anstrengungen dienen der Etablierung eines Monitorings der postoperativen Immundysfunktion für die Prävention der chirurgisch bedingten Sepsis. 


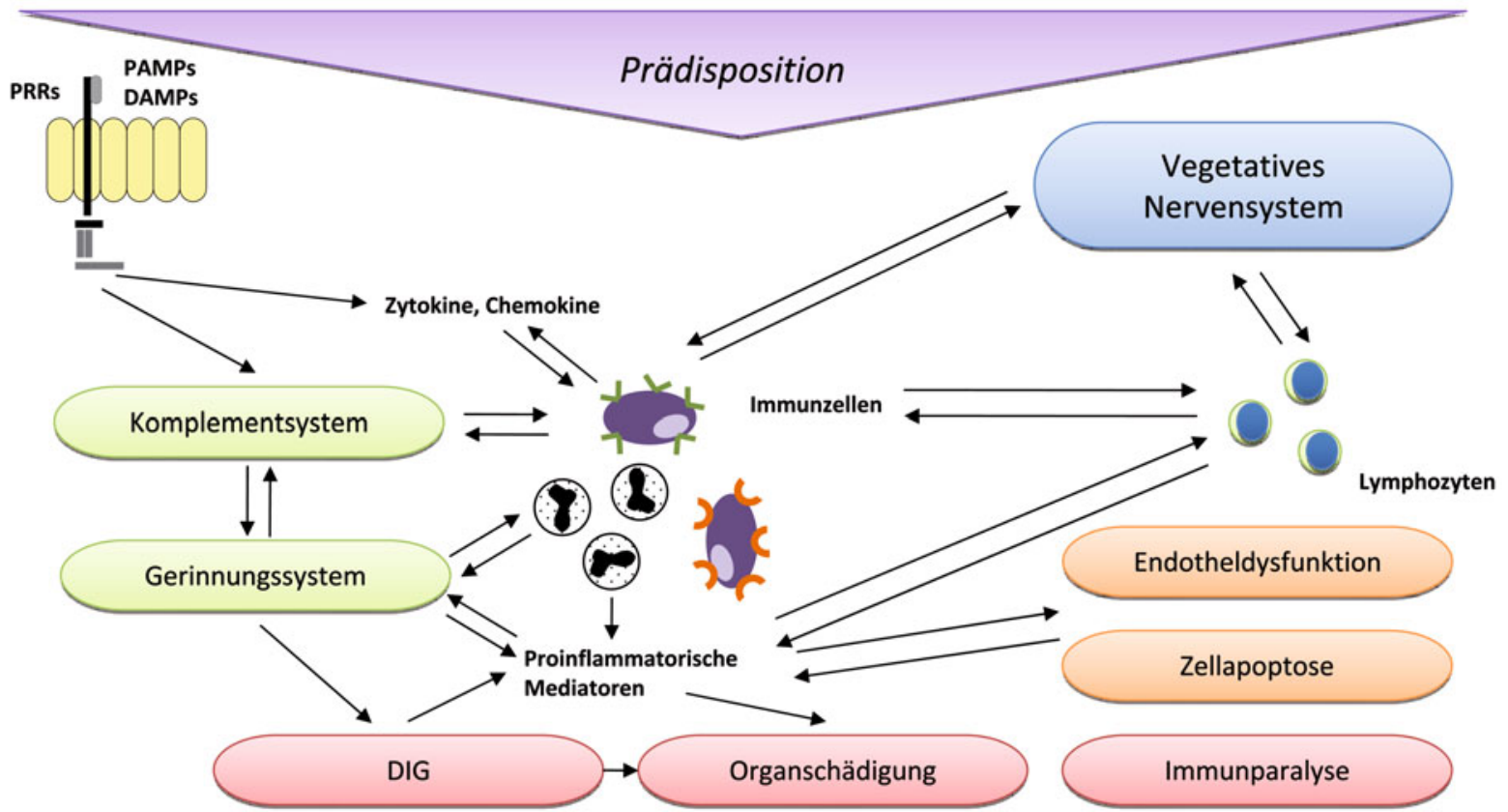

- Abb. 1.94 Pathophysiologisches Netzwerk der Sepsis. Dargestellt sind die wesentlichen molekularen, humoralen, zellulären und mikrovaskulären Komponenten, welche multiple Interaktionen ausüben und ganz wesentlich die Komplexität des Krankheitsbildes der Sepsis prägen. Die Identifikation der hier gezeigten zentralen Mechanismen erlaubt, zukünftig gezielt Werkzeuge zu entwickeln, welche weniger auf die Inhibition, sondern eher auf die Modulation der pathophysiologischen Abläufe mit Erreichen einer balancierten Wirts- reaktion abzielen. Besondere Bedeutung wird der Erfassung der individuellen Prädisposition zur Entwicklung einer Sepsis zukommen, welche durch das operative Trauma und Komorbiditäten sowie genetische Faktoren bestimmt ist (DAMPs = damage-associated molecular patterns; PAMPs = pathogen-associated molecular patterns; PRRs = pattern-recognition receptors; DIG = disseminierte intravasale Gerinnung)

schritte auf dem Gebiet der Kardiogenese über induzierbare pluripotente Stammzellen.

Auch in der Viszeralchirurgie hat - neben der soliden Organtransplantation - die zellbasierte regenerative Therapie in den letzten Jahren an Bedeutung gewonnen. Von vorrangigem Forschungsinteresse ist die Regeneration von Leber und endokrinem Pankreas. Großes Potential wird hierbei u. a. der Transplantation von aus mononukleären Zellen des peripheren Bluts gewonnenen Hepatozyten- bzw. Betazell-ähnlichen Zellen beigemessen.

Ein weiterer Ansatz des Tissue Engineering von Organen beinhaltet die komplette Dezellularisierung eines Organs und die Re-Besiedelung des biologischen Scaffolds (»Baugerüst «). Der Versuch, eine natürliche Matrix als zukünftiges Organgerüst zu schaffen, nahm seinen erfolgreichen Ausgang bei Herzklappen, Gefäßsegmenten und Harnblasengewebe des Schweins. Aktuelle bahnbrechende Ergebnisse zeigen, dass die Besiedelung dezellularisierter Lungen mit Endothelund Epithelzellen zur Wiederaufnahme des physiologischen Gasaustausches vergleichbar nativer Lungen führt. Ähnliche Ansätze existieren für die Leber und die Niere. Da diese Organgerüste weniger immunogen sind, kann zukünftig an die Nutzung von Xenotransplantaten zur langfristigen und effizienten Begegnung der Organknappheit gedacht werden. 
Ein weiterer zentraler Fokus chirurgischer Forschung ist die Regeneration des muskuloskeletalen Systems. Ziel dieser sich oftmals interdisziplinär mit (Unfall)-Chirurgen und Orthopäden, Zellbiologen und Biomechanikern zusammensetzenden Arbeitsgruppen ist es, das Skelettsystem, d. h. Knochen und Knorpel, sowie Muskel- und Weichteilgewebe auf Zell-, Organ- und Körperebene zu verstehen. Um Heilung positiv beeinflussen und sogar vollständig kontrollieren zu können, müssen die biologischen und mechanischen Wechselwirkungen während der Regeneration im Sinne der zugrundeliegenden Mechanismen verstanden werden. Diesen Aufgaben widmen sich wesentliche Teilbereiche der chirurgischen Forschung. Mögliche Therapieansätze werden in Frakturheilungsmodellen und Modellen zum Weichteiltrauma analysiert.

\section{Biobanking}

Das Biobanking sieht die systematische Sammlung von menschlichem Gewebe zum Zwecke der nachfolgenden Forschung vor. Im Gegensatz zu populationsbasierten Biobanken, die für meist großangelegte Populationsstudien angelegt sind und in der Regel Proben von gesunden Probanden sammeln, handelt es sich hier meist um krankheitsspezifische Biobanken, die Proben von Erkrankten zur Diagnose, Therapie und Forschung umfassen und einen aussagekräftigen Vergleich verschiedener Individuen hinsichtlich ihres genetischen Materials, ihrer unterschiedlichen Krankheiten und ihrer Krankheitsverläufe unter dem Einfluss von Umweltfaktoren erlauben. Auf dieser Basis ermöglichen sie eine krankheitsbezogene Genomforschung, die neue Kenntnisse über die Entstehung und den Verlauf von Krankheiten liefert und zur Entwicklung neuer therapeutischer Ansätze oder wirkungsvollerer Methoden der Prävention führen kann. Das klassische Beispiel für Biobanking ist das im Rahmen von Krebsoperationen gewonnene Tumorgewebe mit Aufbau einer sog. Tumorbank (• Abb. 1.95).

Die Forschung an humanem Gewebe sieht sich im Spannungsfeld zwischen medizinischem Fortschritt und ethischer Verantwortung und wirft zahlreiche juristische und ethische Fragen auf. Aufgrund dieser hohen ethischen Verpflichtung bedarf es eines spezifischen Regelwerks, eines sog. "code of conduct«, das klare und strikte Regeln definiert, nach denen die Analyse und der Gebrauch von humanem Spendergewebe mit Einbezug der damit verbundenen Patientendaten zu gestalten ist. Die Diskussion um die Nutzung von embryonalen Stammzellen hat das Biobanking wesentlich in den Fokus der Aufmerksamkeit gelenkt. Weniger im Fokus, ethisch wie rechtlich jedoch nicht minder problematisch, ist die Verwendung von adultem Gewebe, wie es bei Operationen anfällt. In der Vergangenheit klaffte hier eine große Lücke, welche aber mit dem Verständnis für die Anforderungen von Ethik, Wissenschaft und Recht geschlossen wurde. Die systematische Entgegennahme von verworfenem Gewebe, wie z. B. Lebertumorgewebe, dessen Konservierung und Bereitstellung in einer Gewebebank und die verblindete Dokumentation der klinischen Patientendaten erlaubt in der Folge Forschung an diesem menschlichen Gewebe, um das komplexe Wechsel-
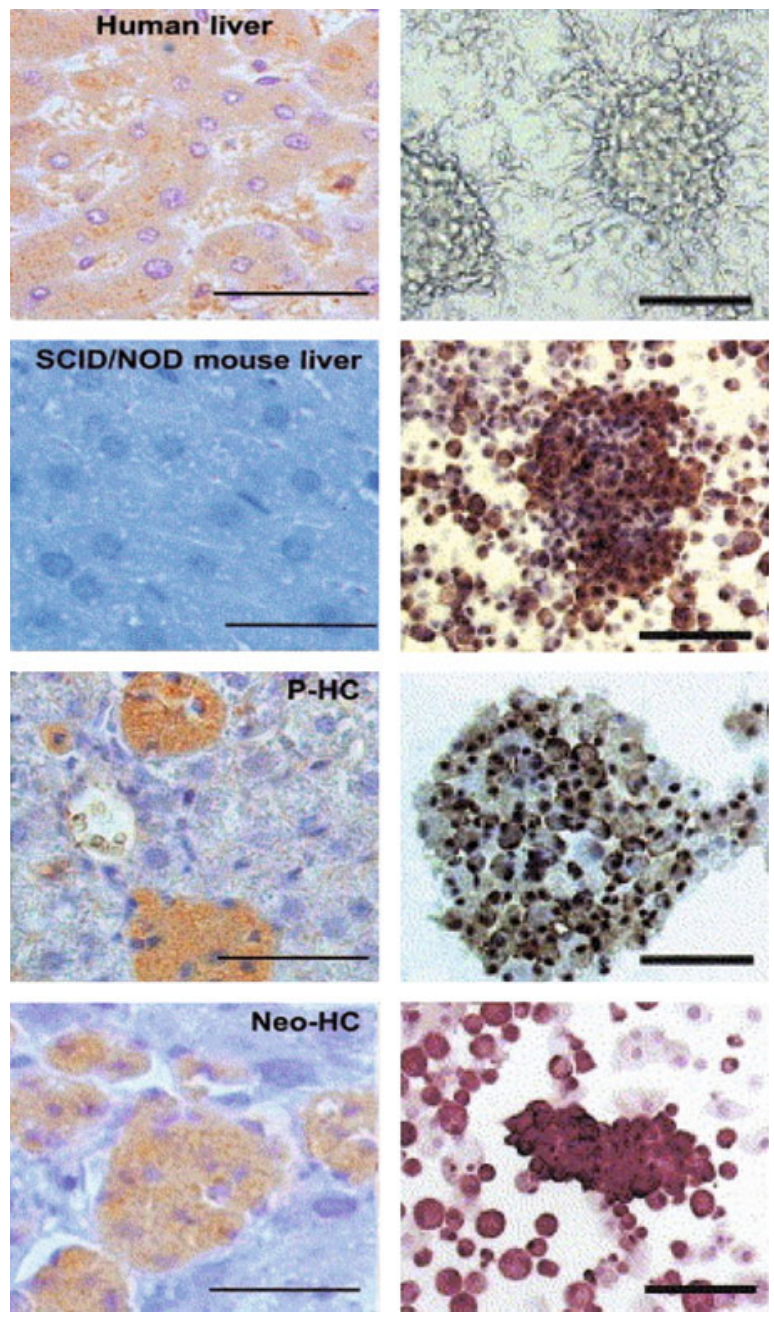

- Abb. 1.95 Struktur und Handlungsabläufe einer Tumorbiobank. Die hinter einer Tumorbank bestehende Logistik mit systematischer Entgegennahme von Gewebe, dessen fachgerechten Konservierung und Bereitstellung in einer Gewebebank sowie die verblindete Dokumentation der klinischen Patientendaten ist äußerst komplex und erfordert aufwändige personelle und infrastrukturelle Maßnahmen mit der Installation entsprechender Hard- und Software

spiel zwischen Erbgut und Umwelt sowie den vielfältigen genetischen und exogenen Faktoren zu klären.

\section{Weitere Themen chirurgischer Forschung}

Zahlreiche chirurgische Arbeitsgruppen beschäftigen sich mit dem Thema der Entzündung, insbesondere des Pankreas, der Leber sowie des Magens und des Darms. Es existieren entsprechend zahlreiche Modelle zur Simulation der akuten und chronischen Pankreatitis, der Hepatitis, des entzündungsbedingten Leberversagens sowie der Gastritis und Colitis. Das übergeordnete Ziel dieser Untersuchungen ist, die zugrunde liegenden Mechanismen der entzündlichen Erkrankungen zu erkennen, diese auf Gültigkeit zu überprüfen sowie therapeutische Ansätze zu erarbeiten. So wurden molekulare, zelluläre 
und humorale Kandidaten als mögliche kausale Faktoren identifiziert und auf deren Basis pharmakologische Strategien erarbeitet.

\section{Klinische Studien}

Der Fortschritt in der klinischen Chirurgie ist unabdingbar mit einem Verständnis der den chirurgischen Krankheitsbildern zugrunde liegenden Pathophysiologie und der Erarbeitung von basiswissenschaftlichen Erkenntnissen sowie deren Transfer in die klinische Überprüfung verbunden.

Klinische Studien in der Chirurgie beschäftigen sich in aller Regel mit der Evaluation operativer Verfahren und neuer, oft adjunktiver Therapieansätze. Erhebliche methodische Herausforderungen, die zur Durchführung notwendige Zeitdauer für Studienplanung, Patientenakquisition, Datenauswertung und Ergebnisanalyse und die z. T. mit aufwändigen Verfahren einhergehende Nachuntersuchung der Patienten und der sich daraus ergebende hohe organisatorische, finanzielle und regulatorische Aufwand erschweren die Durchführung randomisierter kontrollierter Studien (randomized controlled trials, RCTs). Da RCTs als Referenzverfahren mit Evidenziveau 1 für ein klinisches Studiendesign gelten, wurden in Deutschland Netzwerke und Studienzentren geschaffen, die eine koordinierte und qualitative hochwertige Durchführung von RCTs erleichtern sollen. Zu detaillierten Ausführungen zu den Prinzipien, der Klassifikation und der Durchführung klinischer Studien, welche neben RCTs auch vergleichende Kohortenstudien, Fallkontrollstudien und Fallserien beinhalten können, \ Abschn. 1.10.1.

\section{In Kürze}

\section{Chirurgische Forschung}

Die chirurgische Forschung trägt entscheidend zum medizinischen Fortschritt in der Chirurgie bei. Vorrangigstes Ziel der chirurgischen Forschung ist und bleibt die Entwicklung neuer Strategien und Konzepte zur verbesserten Behandlung chirurgischer Patienten. Dies erfordert die Pathogenese und die Pathophysiologie chirurgischer Erkrankungen zu verstehen und lernen zu modulieren. Dazu bedient sich die chirurgische Forschung aller notwendigen technischen und methodologischen Werkzeuge, die aus nahezu allen Bereichen der Lebenswissenschaften stammen und begrüßenswerter Weise oftmals auch in enger Kooperation mit den entsprechenden Partnern durchgeführt werden. Die hohe Begeisterung und Motivation chirurgischer Forscher, Ungeklärtes zu erkennen und zu lösen sowie Neues zu suchen und zu finden, hält die Entität der akademischen Chirurgie aufrecht und bestimmt die wissenschaftliche Leistungsfähigkeit der Chirurgie im Wettbewerb mit anderen Fachdisziplinen.

\section{Danksagung}

Die Autorin dankt Frau Anja Gellert für die hervorragende Unterstützung bei der Erstellung der Abbildungen und den wissenschaftlichen Mitarbeitern des Instituts für Experimen- telle Chirurgie der Universität Rostock für hilfreiche Anmerkungen und Kommentare sowie die Durchsicht des Manuskriptes.

\section{Weiterführende Literatur}

Brendel W (1984) Experimental surgery. MMW126:819-20

Deutsche Forschungsgemeinschaft (1999) Klinische Forschung. Denkschrift. Wiley-VCH Verlag

Messmer K (1998) Basic surgical research. Langenbecks Arch Surg; 383:297-9

Moore FD (1973) What is surgical research? Eur Surg Res; 5:245-58

Vollmar B, Menger MD (2010) Does experimental surgery still exist? Chirurg 2010; 81:323-7

Vollmar B (2011) Pathophysiological basis of surgery-linked sepsis. Chirurg 2011; 82:199-207

\subsection{Klassifikationen von Tumoren}

\section{Wittekind}

Tumoren zeigen eine ungeheure Vielfalt in ihrem biologischen Verhalten. Diese Vielfalt zeigt sich im klinischen Erscheinungsbild (z. B. Symptomatologie, Therapierbarkeit und klinischer Verlauf) und in ihren pathologischen Eigenschaften (z. B. makroskopischer und mikroskopischer Aspekt, molekularpathologische Eigenheiten). Angesichts dieser biologischen Vielfalt von Tumoren sind Verfahren wichtig, um bestimmte Tumortypen so zu beschreiben, dass eine Vergleichbarkeit wenigstens in einigermaßen klar definierten Eigenschaften gegeben ist. Diese Verfahren zur Charakterisierung von Tumoren werden Tumorklassifikationen genannt. Grob unterscheidet man zunächst gutartige (benigne) und bösartige (maligne) Tumoren. In diesem Beitrag soll aus Platzgründen überwiegend von bösartigen Tumoren die Rede sein.

Innerhalb der Tumoren der einzelnen Organe (Organsysteme) gibt es eine große Zahl unterschiedlicher Tumortypen. Ziel der Tumorklassifikationen muss es sein, die unterschiedlichen Tumortypen sinnvoll in Gruppen einzuordnen, die eine möglichst individualisierte Therapie vorgeben. Der Prozess der Erstellung von Klassifikationen ist ein fließender und andauernden Änderungen durch neue Erkenntnisse unterworfen.

Eine moderne Krebstherapie muss die individuelle Situation eines Patienten berücksichtigen. Voraussetzung hierfür ist eine sorgfältige Klassifikation der Tumoren. Als wesentliche Säulen der Tumorklassifikationen dienen die Lokalisation, Histomorphologie (Typing und Grading) und anatomischer Ausbreitung (Staging). Der größere Teil aller Patienten mit malignen Tumoren wird chirurgisch behandelt. Viele Patienten werden zusätzlich mit einer Chemo-, Radio-, Hormon- oder Immunotherapie behandelt oder erfahren eine Kombination von Radio- und Chemotherapie. Die Wahl der verschiedenen Therapieverfahren muss in erster Linie histologie- und stadiengerecht erfolgen. $\nabla$ 
Eine vollständige Krebstherapie umfasst nicht nur die Erstbehandlung, sondern auch die anschließende Nachsorge und die Behandlung etwaiger Tumorrückfälle.

Abgesehen von extremen Ausnahmefällen (außer den malignen Tumoren der Haut) führen maligne Tumoren ohne entsprechende Behandlung immer zum Tode. Ihre individuell angepasste Therapie erfordert vom Chirurgen eine sorgfältige Planung des Therapiekonzeptes und eine strikte Einhaltung der Regeln der chirurgischen Onkologie.

\subsubsection{Klinisches und biologisches Verhalten von Tumoren}

\footnotetext{
Definition

Tumor bedeutet wörtlich eine abnorme Gewebezunahme. In der Sprache der modernen Medizin versteht man unter einem Tumor eine Neubildung, die durch ein autonomes oder relativ autonomes Wachstum entsteht, das persistiert, wenn der initiierende Stimulus wegfällt.
}

Tumoren entstehen durch neoplastische Transformation, zu der praktisch Zellen jeglichen Gewebes des Körpers in der Lage sind. Inwieweit es sich bei diesen neoplastisch transformierten Zellen immer um Stammzellen handeln muss oder ob auch andere Zellen, aus denen die Regeneration von Zellen bewirkt wird, dafür in Frage kommen, ist noch nicht endgültig geklärt. Einige Zellen sind für solche neoplastische Transformationen anfälliger als andere. Bei der Transformation sind eine Reihe von genetischen Ereignissen (Mutationen) beteiligt. Durch die Anhäufung von genetischen Veränderungen gelingt es den Zellen, der normalen Wachstumsregulation zu entkommen. Die neoplastischen Zellen maligner Tumoren besitzen zusätzliche für den Organismus letztlich tödliche Eigenschaften, die sie befähigen, invasiv zu wachsen und zu metastasieren.

\section{Gut- und bösartige Tumoren}

Nach ihrem biologischen Verhalten kann zwischen gutartigen (benignen) und bösartigen (malignen) Tumoren unterschieden werden.

\section{Das entscheidende Kriterium der Malignität ist die Fähigkeit zur Metastasierung!}

Für die Unterscheidung zwischen benigne und maligne gibt es klinische Hinweise (•Tab. 1.45). In der großen Mehrzahl der Fälle ist Malignität - abgesehen vom Nachweis von Metastasen - nur durch die mikroskopische Untersuchung des Tumorgewebes (Histopathologie) zu diagnostizieren. Neben den Methoden der konventionellen Histologie und Zytologie müssen bei einem kleinen Teil der Fälle auch immunhistologische, zellbiologische und molekularbiologische Untersuchungsverfahren herangezogen werden.
- Tab. 1.45 Klinische Charakteristika benigner und maligner Tumoren

\begin{tabular}{|l|l|l|}
\hline & Benigne Tumoren & Maligne Tumoren \\
\hline $\begin{array}{l}\text { Makroskopische } \\
\text { Begrenzung }\end{array}$ & Scharf & Unscharf \\
\hline Kapsel & Meist vorhanden & Fehlend \\
\hline Wachstum & Expansiv & $\begin{array}{l}\text { Infiltrativ- } \\
\text { destruierend }\end{array}$ \\
\hline $\begin{array}{l}\text { Verschieblichkeit } \\
\text { Wachstums- } \\
\text { geschwindigkeit }\end{array}$ & Vorhanden & Fehlend \\
\hline Metastasierung & Nein & Oft rasch \\
\hline
\end{tabular}

Histomorphologische, zellbiologische und molekularpathologische Charakteristika maligner Tumoren

\section{- Konventionelle Histologie}

- Strukturelle Veränderungen

- Verringerte bis fehlende Differenzierung

- Zeichen der gesteigerten und abnormen Proliferation

- Infiltration des und destruierendes Wachstum im umgebenden Gewebe

- Lymphgefäß-, Venen- und Perineuralscheideninvasion

- Zelluläre Veränderungen

- Unterschiede in Größe und Form der Zellen (Zellpolymorphie)

- Verschiebung der Kern-Plasma-Relation zugunsten der Kerne

- Unterschiede in Größe und Form der Kerne (Kernpolymorphie)

- Unterschiede im Chromatingehalt (Färbbarkeit) der Kerne (Polychromasie)

- Vermehrte, auch pathologisch ablaufende Kernteilungsfiguren

- Immunhistologie

- Häufigere Expression onkofetaler Antigene (z. B. AFP, a-Fetoprotein; CEA, karzinoembryonales Antigen; $\beta$-HCG, humanes Choriogonadotropin)

- Proliferationsmarker (z. B. Ki 67; AgNOR; PCNA, proliferating cell nuclear antigen).

- DNS-Analyse

- Erhöhung der S-Phase-Fraktion, Aneuploidie

- Molekularpathologie

- Onkogenaktivierungen, z. B. Punktmutationen, Translokationen, Genamplifikation

- Suppressorgen-Deletionen z. B. p53 


\section{Semimaligne Tumoren}

Eine seltene Gruppe von Tumoren verhält sich am Ort ihrer Entstehung wie bösartige Tumoren mit invasivem und lokal destruierendem Wachstum. Sie metastasieren jedoch nicht oder extrem selten. Hierzu gehören z. B. das Dermatofibrosarcoma protuberans (ein Weichteiltumor) oder Basalzellkarzinome der Haut (früher auch Basaliome genannt).

\section{Tumoren fraglicher Dignität}

In sehr seltenen Fällen gelingt es mit der histologischen Untersuchung nicht, einen Tumor als benigne oder maligne zu klassifizieren. Man spricht dann von einem Tumor mit fraglicher Dignität. Beispiele sind der Riesenzelltumor des Knochens und das Hämangioperizytom der Weichteile.

\section{In Kürze}

Klinisches und biologisches Verhalten von Tumoren Benigne und maligne Tumoren (Fähigkeit zur Metastasierung ist entscheidendes Kriterium der Malignität), semimaligne Tumoren, fragliche Dignität.

Meist Unterscheidung nur mikroskopisch (histopathologisch): strukturelle Veränderungen, Zellpolymorphie, onkofetale Antigene, Proliferationsmarker, DNSAnalyse, Molekularpathologie.

\subsubsection{Ausbreitung maligner Tumoren}

$>$ Die Kenntnis der möglichen Ausbreitungswege maligner Tumoren ist Voraussetzung für die Planung der Therapie, insbesondere chirurgischer Eingriffe.

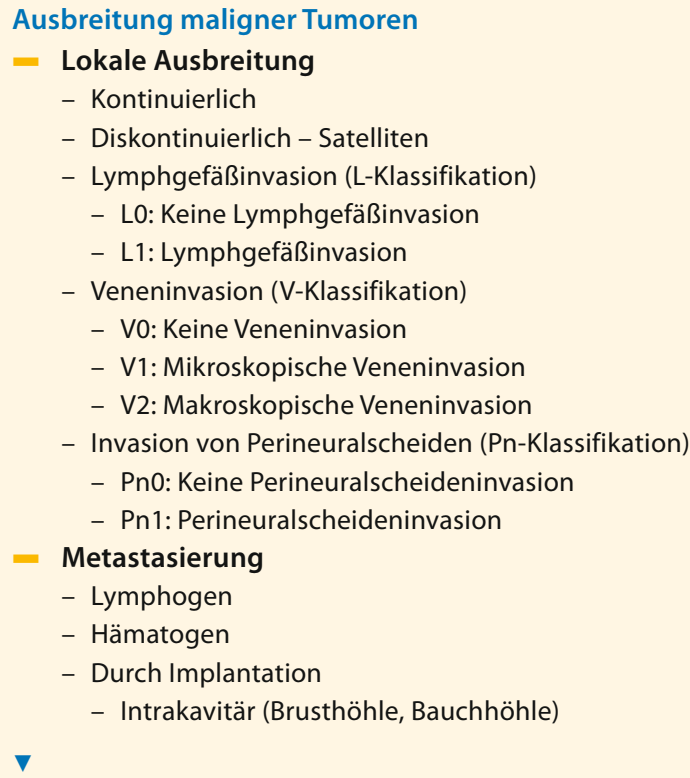


gezeigt, dass sich Tumorzellen im Blutkreislauf vom Primärtumor in andere Organsysteme ausgebreitet haben.

$\checkmark$ Von Metastasierung wird erst gesprochen, wenn ein Arrest der Tumorzellen im Kapillarbett, Adhärenz, Extravasation und Tumorzellproliferation mit Neovaskularisierung nachweisbar sind.

Der histologische Nachweis von Lymphgefäß-, Venen- oder Perineuralrauminvasion in der Umgebung des Primärtumors weist auf ein aggressives Verhalten des Tumors hin und gibt gewisse prognostische Hinweise, ist aber nicht mit tatsächlicher Metastasierung gleichzusetzen. Gleiches gilt für den Nachweis isolierter Tumorzellen in afferenten Lymphbahnen oder Lymphsinus eines Lymphknotens oder in Knochenmarksbiopsien.

\section{Lymphogene Metastasierung}

Die lymphogene Metastasierung erfolgt regelhaft entsprechend den anatomischen Gegebenheiten des Lymphabflusses: Zuerst werden die dem Primärtumor nächstgelegen Lymphknoten befallen und erst danach die folgenden, weiter entfernten Lymphknoten.

( Lymphknotensprünge (»skipping of nodes«), d. h. Metastasen in weiter entfernt liegenden Lymphknoten bei freien tumornahen Lymphknoten treten nur in etwa 1-3\% der Fälle mit Lymphknotenmetastasen auf.

Für die Planung des Ausmaßes des chirurgischen Eingriffs ist die Wahrscheinlichkeit bereits aufgetretener Lymphknotenmetastasen von Bedeutung. Es muss damit gerechnet werden, dass bei etwa 20-30\% aller Patienten die regionären Lymphknotenmetastasen kleiner als 3-5 mm sind. Die Diagnose solch kleiner Metastasen ist mit bildgebenden Verfahren nur mit einer beschränkten Trefferquote möglich. Wichtige Hinweise auf die Wahrscheinlichkeit bereits vorhandener Lymphknotenmetastasen ergeben sich aus den Befunden am Primärtumor.

Die Häufigkeit regionärer Lymphknotenmetastasen ist abhängig von:

- Histomorphologie:

- häufig bei Lymphgefäßinvasion,

- häufig bei Karzinomen hohen Malignitätsgrades,

- selten bei Sarkomen;

- Lokaler Ausbreitung des Primärtumors: Mit zunehmender Infiltrationstiefe, Tumorgröße bzw. Tumormasse steigt die Wahrscheinlichkeit einer lymphogenen Metastasierung.

Von Lymphknotenmetastasen können Tumorzellen über lymphovenöse Verbindungen oder über den Ductus thoracicus in die Blutbahn gelangen und Ausgangspunkt für eine hämatogene Metastasierung werden.

\section{Hämatogene Metastasierung}

Zeitpunkt und Häufigkeit hämatogener Metastasierung hängen in erster Linie vom Tumortyp ab.
Tumoren mit früher hämatogener Metastasierung

- Kleinzellige Lungenkarzinome

- Mammakarzinome

- Nierenkarzinome

- Prostatakarzinome

- Osteosarkome

- Andere Sarkome hohen Malignitätsgrades

Demgegenüber treten bei anderen Tumoren, z. B. gastrointestinalen Karzinomen oder solchen des Kopf- und Halsbereiches, hämatogene Metastasen in der Regel erst auf, wenn der Primärtumor lokal relativ weit fortgeschritten ist und regionäre Lymphknotenmetastasen gesetzt hat. Bei diesen Tumoren erfolgt die hämatogene Ausbreitung in der Regel kaskadenartig: Zunächst finden sich solitäre oder einige wenige Metastasen in einem Organ.

$\checkmark$ Die kaskadenartige hämatogene Metastasierung mit zunächst mono- oder oligotoper Metastasierung in Leber und Lunge ermöglicht bei rechtzeitiger Diagnose die komplette chirurgische Beseitigung von hämatogenen Metastasen und damit noch für etwa $30 \%$ der betroffenen Patienten eine definitive Heilung.

Die Lokalisation hämatogener Metastasen wird in erster Linie von anatomischen Gegebenheiten bestimmt, d. h. von der Lokalisation des Primärtumors und seinem venösen Abfluss. Man unterscheidet 4 Haupttypen der hämatogenen Metastasierung (• Abb. 1.96), wobei die 1. Metastasenmanifestation in unterschiedlichen Organen erfolgt.

$>$ Die klinische Diagnostik von Fernmetastasen muss sich nach den Typen der hämatogenen Metastasierung richten, $d$. h. es muss berücksichtigt werden, wo in erster Linie mit Fernmetastasen zu rechnen ist.

Neben den anatomischen Gegebenheiten wird die Lokalisation von Fernmetastasen auch durch andere Faktoren mit beeinflusst, etwa die durch molekulare Strukturen an der Tumorzelloberfläche festgelegte Affinität einzelner Tumorzellklone zu bestimmten Organen oder das sog. Mikroenvironment in bestimmten Organen, welches das Anwachsen bestimmter Tumorzellarten begünstigen kann.

Von Fernmetastasen kann nicht nur eine weitere hämatogene, sondern auch eine lymphogene Ausbreitung erfolgen. So können z. B. große Lungenmetastasen eines Rektumkarzinoms auch intrapulmonale und hiläre Lymphknotenmetastasen zeigen, ohne dass sonstige Lymphknoten tumorbefallen wären.

\section{Metastasen durch Implantation}

Metastasen können durch Implantation auf 3 Wegen entstehen:

- Intrakavitäre Metastasierung: Nach Durchbruch des Primärtumors durch die Serosa können sich Tumorzellen in der Pleura- oder Peritonealhöhle ausbreiten und zu 


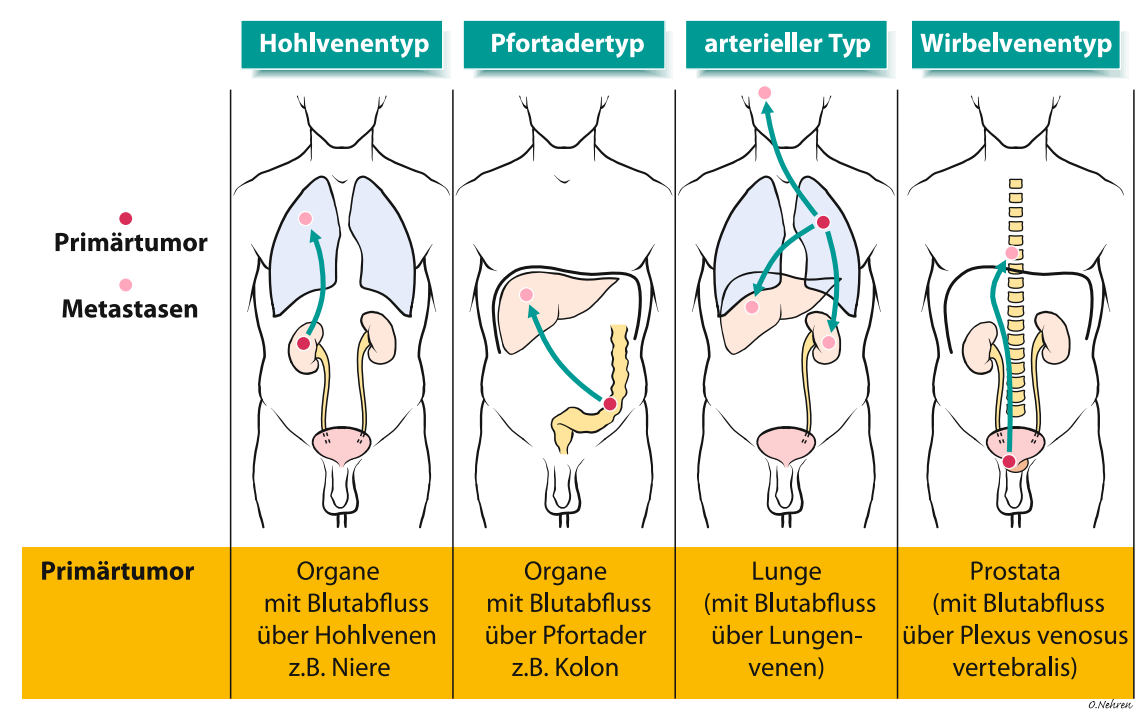

- Abb. 1.96 Typen der hämatogenen Metastasierung

Metastasen an der Pleura, am Peritoneum oder z. B. am Ovar führen.

- Intraluminale Metastasierung: In der Lichtung von Hohlorganen können sich abgestoßene Tumorzellen an anderen Stellen des Organs einnisten und Metastasen bilden. Wahrscheinlich ist dies in erster Linie dann möglich, wenn Epitheldefekte vorliegen, z. B. operative Wunden wie etwa Anastomosen nach Darmresektion. Die Metastasenbildung an einer unversehrten Schleimhaut wird heute im Allgemeinen als große Seltenheit angesehen, wahrscheinlich handelt es sich bei den meisten berichteten Fällen um eine multizentrische Entstehung neuer Tumoren. Nur bei den Karzinomen des Übergangsepithels von Nierenbecken und Harnleiter scheint die intraluminale Metastasierung (z. B. in die Harnblase) häufiger zu sein.

- latrogene Implantation: Bei Operationen, bei denen durch Tumorgewebe geschnitten wird (z. B. Entfernung des Primärtumors und eines mitbefallenen Nachbarorgans nicht en bloc, sondern in 2 Teilen) oder bei denen ein Einriss im Tumorbereich erfolgt (z. B. bei Mobilisation eines Rektumkarzinoms), werden im Operationsgebiet örtlich Tumorzellen verstreut. Sie können zum Ausgangspunkt von Implantationsmetastasen werden. Klinisch imponiert ein Teil dieser als lokoregionäres Rezidiv. In gleicher Weise erklären sich Implantationsmetastasen in Operationswunden, die besonders nach laparoskopischer Chirurgie beschrieben worden sind. Auch nach Entnahme von Biopsien können sich im Biopsiekanal in der Subkutis Implantationsmetastasen bilden, allerdings gehört dies zu den extremen Seltenheiten.

\section{In Kürze}

\section{Ausbreitung maligner Tumoren}

Lokal, Satelliten, Invasion von Lymphgefäßen, Venen, Perineuralscheiden (Hinweis auf aggressives Verhalten).

\section{Metastasierung:}

- Lymphogen (nach anatomischen Gegebenheiten)

- Hämatogen (venöser Abfluss, Fernmetastasen): kaskadenartig, oft mono- oder oligotop in Leber und Lunge, chirurgische Heilung in 30\% möglich

- Durch Implantation (intrakavitär, intraluminal, iatrogen)

\subsubsection{Präkanzerosen und Krebsfrüherkennung}

Bei bestimmten Personengruppen und bei Trägern bestimmter histologischer Veränderungen treten maligne Tumoren häufiger auf als bei Personen, die derartige Kriterien nicht erfüllen. Man sprach früher ohne Verwendung einer einheitlichen Nomenklatur von Krebsrisikogruppen oder -patienten, von Risikosituationen oder Präkanzerosen bzw. Präneoplasien. Heute unterscheidet man nach den Vorschlägen der WHO zwischen präkanzerösen Bedingungen und präkanzerösen Läsionen.

Definition

Eine präkanzeröse Bedingung ist ein klinisch oder anamnestisch definierter Zustand, bei dem mit erhöhter Häufigkeit mit dem Auftreten von präkanzerösen Läsionen und malignen Tumoren zu rechnen ist. 
Beispiele für präkanzeröse Bedingungen sind familiäres Auftreten von Krebsen (von Bedeutung z. B. für kolorektales Karzinom, Mamma-, Ovar- oder Magenkarzinom), angeborene oder erworbene Immunmangelsyndrome, länger bestehende chronische Entzündungen (z. B. Colitis ulcerosa für kolorektale Karzinome) oder berufliche Exposition mit chemischen Karzinogenen (z. B. bei Lungenkarzinomen, Mesotheliom der Pleura, Karzinomen der ableitenden Harnwege).

\section{Definition \\ Unter einer präkanzerösen Läsion wird eine histopatho- logisch definierte Gewebeveränderung verstanden, in der maligne Tumoren sich häufiger entwickeln als in dem entsprechenden Normalgewebe.}

Die typische präkanzeröse Läsion ist die intraepitheliale Neoplasie (früher: Dysplasie).

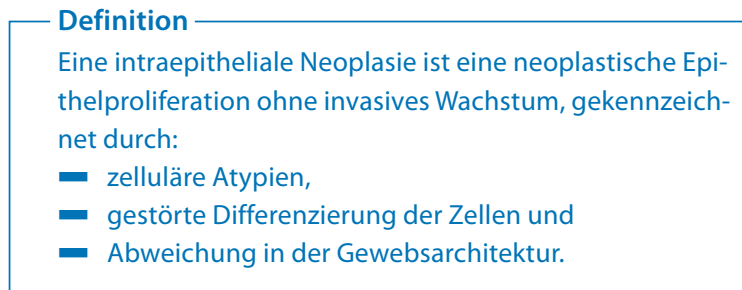

Intraepitheliale Neoplasien werden in niedriggradige und hochgradige unterteilt, letztere schließen auch das sog. Carcinoma in situ ein. Hierbei finden sich zytologisch alle Kriterien der Malignität, aber die atypischen Zellen sind auf das Epithel beschränkt und haben die Basalmembran nicht durchbrochen. Infiltrieren atypische Tumorzellen durch die Basalmembran in das angrenzende Stroma (z. B. kutanes Bindegewebe oder Schleimhautstroma des Gastrointestinaltraktes), liegt im Allgemeinen ein bereits metastasierungsfähiger Tumor vor. Einzige Ausnahme ist das Kolorektum, bei dem mit einer Metastasierung erst nach Infiltration in die Submukosa zu rechnen ist. Von einem »invasiven kolorektalen Karzinom « wird daher erst bei Invasion der Submukosa gesprochen. Invasion des Schleimhautstromas wird in dieser
Lokalisation in Europa der intraepithelialen Neoplasie (Dysplasie) zugeordnet, kann aber auch als Carcinoma in situ bezeichnet werden.

\section{4-Phasen-Konzept der malignen Tumor- erkrankung}

Wenn man die Entwicklung eines malignen Tumors vom ersten Anbeginn bis zur voll ausgebildeten Erkrankung mit generalisierten Metastasen betrachtet, handelt es sich um einen länger dauernden Prozess, der wahrscheinlich in der Regel Jahrzehnte dauert. Man kann hierbei 4 Phasen unterscheiden (- Abb. 1.97). Dieses phasenhafte Geschehen wird auch im molekularen Bereich beobachtet: Im Laufe der Progression treten zunehmend verschiedene genetische Veränderungen auf, wobei deren Akkumulation zum klinisch malignen Verhalten führt.

\section{Krebsfrüherkennung (Krebsvorsorge)}

Die Kenntnis präkanzeröser Bedingungen und Läsionen sowie die Entwicklung eines malignen Tumors über eine In-situPhase, geben die Möglichkeit, Untersuchungen zur Vorsorge oder Krebsfrüherkennung durchzuführen. Ihre Ziele sind:

- Präkanzeröse Läsionen zu erkennen und zu entfernen und damit die Entstehung von invasiv wachsenden Tumoren zu verhindern

- Krebserkrankungen in einem möglichst frühen Stadium (als sog. Frühkrebse) zu diagnostizieren, da für die betroffenen Patienten in diesen Fällen die besten Ergebnisse zu erwarten sind und Heilungen vielfach auch durch weniger ausgedehnte operative Eingriffe erreicht werden können

Krebsfrüherkennungsuntersuchungen sind in erster Linie bei Personen mit präkanzerösen Bedingungen angezeigt. Sie sind auch bei Personen sinnvoll, bei denen maligne Tumoren in früherem Lebensalter auftreten und bei denen entsprechende Screening-Untersuchungen früher einsetzen müssen. Beispiele für die hierbei angewandten primären diagnostischen Methoden (Screening) sind in der folgenden Übersicht aufgelistet. Bei positiven oder verdächtigen Befunden ist eine entsprechende bestätigende und weiterführende Diagnostik anzuschließen.
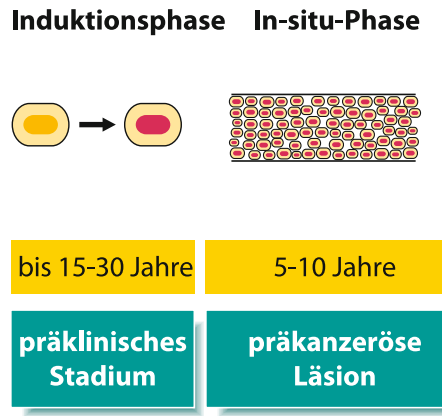

Infiltrationsphase

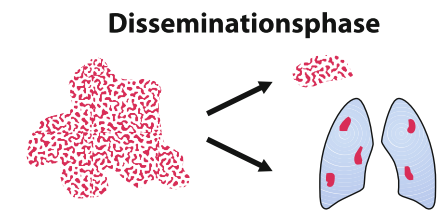

1-5 Jahre

klinisch etabliertes Malignom

- Abb. 1.97 4-Phasen-Konzept der malignen Tumorerkrankung 


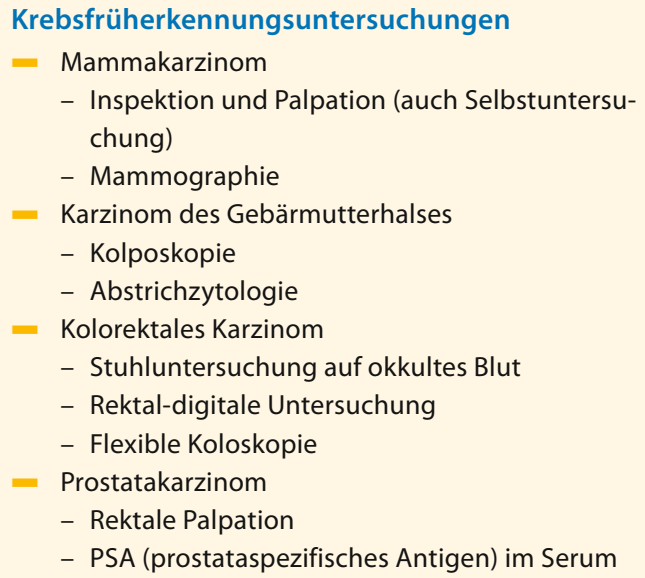

\section{In Kürze}

\section{Präkanzerosen und Krebsfrüherkennung}

1. Präkanzerosen

- Präkanzeröse Bedingungen: familiäre Häufung, Immunmangelsyndrome, chron. Entzündungen, chemische Kanzerogene.

- Präkanzeröse Läsionen: Gewebeveränderung (intraepitheliale Neoplasie bzw. Dysplasie, Epithelproliferation ohne invasives Wachstum), niedriggradige und hochgradige (Carcinoma in situ) ohne Durchbrechen der Basalmembran.

- 4-Phasen-Konzept der Tumorentwicklung.

\section{Krebsfrüherkennung}

Möglichst als Präkanzerose bzw. Frühkrebs (Screening:

Mamma, Cervix, Kolon, Prostata), Kenntnis präkanzeröser

Bedingungen und Läsionen.
- Exulzeration und Infektion

- Blutung, z. B. Lunge, Harnwege, Gastrointestinaltrakt

- Perforation in seröse Höhlen, z. B. Magen, Kolon

- Fistelbildung, z. B. ösophagotracheal, gastrokolisch, rektovesikal, rektovaginal

- Infiltration von Nerven (Schmerz), z. B. Armplexus, präsakraler Plexus

- Einflussstauung (bei Tumoren im oberen Mediastinum)

- Hirndruck (bei primären Tumoren der Schädelhöhle oder bei Hirnmetastasen)

- Parenchymausfall durch Metastasen, z. B. Leber, Gehirn

- Spontanfraktur (bei primären Knochentumoren oder Metastasen)

\section{Systemische Tumorkomplikationen}

- Hämatologische Symptome: Anämien verschiedener Genese, hämorrhagische Diathesen verschiedener Genese

- Hormonproduktion bei hormonaktiven Tumoren endokriner Organe

- Paraneoplastische Syndrome (Auswirkungen, die nicht lokal durch den Tumor oder dessen Metastasen bedingt sind)

- Endokrinopathien z. B. bei kleinzelligem Lungenkarzinom, Pankreas- und Nierenkarzinom

- Neuro-, Myo- und Dermatopathien (z. T. kombiniert wie Dermatomyositis)

- Pulmonale Osteoarthropathie, z. B. Trommelschlegelfinger bei Lungenkarzinom

- Vaskulopathien, z. B. Thrombophlebitis migrans bei Pankreaskarzinom

- Kardiopathien, z. B. marantische abakterielle Endokarditis

\section{Mikroskopische Tumordiagnostik}

Im Rahmen dieses Kapitels soll nur kurz auf diagnostische Verfahren eingegangen und überwiegend die Prinzipien der mikroskopischen Diagnostik dargestellt werden.

\section{Symptomatik}

Nur selten weisen Beschwerden eines Patienten eindeutig auf einen Tumor oder gar dessen Sitz hin. Vielfach verursachen lokale oder systemische Tumorkomplikationen die ersten Symptome.

Lokale und systemische Tumorkomplikationen

1. Lokale Tumorkomplikationen

- Obstruktion von Hohlorganen, z. B. Luftwege, Gastrointestinaltrakt, Gallengänge, Harnwege

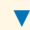

Jeder maligne Tumor sollte prätherapeutisch mikroskopisch gesichert werden. Für die erforderliche detaillierte Klassifikation des Tumors nach histologischem Typ und Differenzierungsgrad ist die histologische Untersuchung erforderlich, für die Verifikation von Metastasen kann die zytologische Untersuchung ausreichend sein.

Für die Ergebnisse der prätherapeutischen morphologischen Diagnostik sind entscheidend:

- der Situation angepasste Materialentnahme,

- korrekte Behandlung des entnommenen Materials bis zur Übergabe an den Pathologen (Fixation),

- ausreichende klinische Informationen für den Pathologen,

- adäquate Methodik und persönliche Qualifikation des Pathologen. 
Verfahren zur präoperativen mikroskopischen Tumordiagnostik

\section{- Biopsiemethode}

- Feinnadelbiopsie

- Zur zytologischen Untersuchung (Aspirationszytologie)

- Zur histologischen Untersuchung

- Stanz-(Grobnadel-)biopsie

- Inzisionsbiopsie (Zangenbiopsie, chirurgische Inzisionsbiopsie)

- Exzisionsbiopsie (Probeexstirpation, totale Biopsie, Lymphknotenexzision)

- Zugangswege

- Perkutan

- Blind

- Unter Einsatz bildgebender Verfahren (CT, Sonographie, Angiographie)

- Endoluminal-endoskopisch (z. B. Broncho-, GastroKolo-, Rekto-, Zystoskopie)

- Thorakoskopie

- Laparoskopie

Die Aussagekraft von Biopsien ist vom Umfang der Biopsie abhängig. Sie ist am größten bei der Exzisionsbiopsie, geringer bei der Inzisionsbiopsie, am geringsten bei der Feinnadelbiopsie.

( Wenn möglich, ist primär eine Exzisionsbiopsie anzustreben.

Bei Inzisionsbiopsien sollte nicht nur krankhaftes Gewebe, sondern immer auch angrenzendes Gewebe miterfasst werden, multiple Biopsien sind anzustreben. Feinnadelbiopsien (Aspirationszytologie) sind nahezu komplikationslos und können bei entsprechender Zugänglichkeit als primäres Verfahren angewandt werden, bei negativem oder fraglichem Befund sind eingreifendere Biopsieverfahren anzuschließen.

( Tumorverdächtige Lymphknoten sollen, wenn immer möglich, vollständig entfernt werden.

\section{Prätherapeutisches Staging}

Moderne bildgebende Verfahren (insbesondere die endoluminale Sonographie) ermöglichen heute eine relativ verlässliche Bestimmung der lokalen Ausbreitung des Primärtumors. Für die Diagnose von Fernmetastasen werden neben bildgebenden Verfahren wie Sonographie, CT, MRT und PET auch die Thorako- und Laparoskopie mit zunehmendem Erfolg eingesetzt. Hingegen ist die Beurteilung, ob in regionären Lymphknoten Metastasen vorhanden sind, noch unbefriedigend. Das prätherapeutische Staging schließt auch die Beurteilung der Möglichkeit einer kompletten Tumorentfernung (R0-Resektion) mit ein.

Zur Planung des therapeutischen Vorgehens bei malignen Tumoren ist eine prätherapeutische Abschätzung der anatomischen Tumorausbreitung (Staging) erforderlich.

\section{In Kürze}

\section{Diagnostik}

- Tumorkomplikationen: lokal (z. B. Obstruktion, Blutung, Perforation) oder systemisch (z. B. Anämie, paraneoplastische Syndrome).

- Immer prätherapeutische mikroskopische Sicherung: Biopsie (Feinnadel-, Stanz-, Inzisions- und v. a. Exzisionsbiopsie mit Entfernung tumorverdächtiger Lymphknoten).

- Prätherapeutisches Staging.

\subsubsection{Klassifikationen von Tumoren}

Die Klassifikationen eines Tumors sollen seine Individualität erfassen und beschreiben. $\mathrm{Zu}$ den heutigen Grundelementen der Tumorklassifikationen, wie sie international durch WHO (World Health Organisation) und UICC (Union for International Cancer Council Contre Cancer) festgelegt sind, - Abb. 1.98. Diese Klassifikationen haben mehrere Aufgaben:

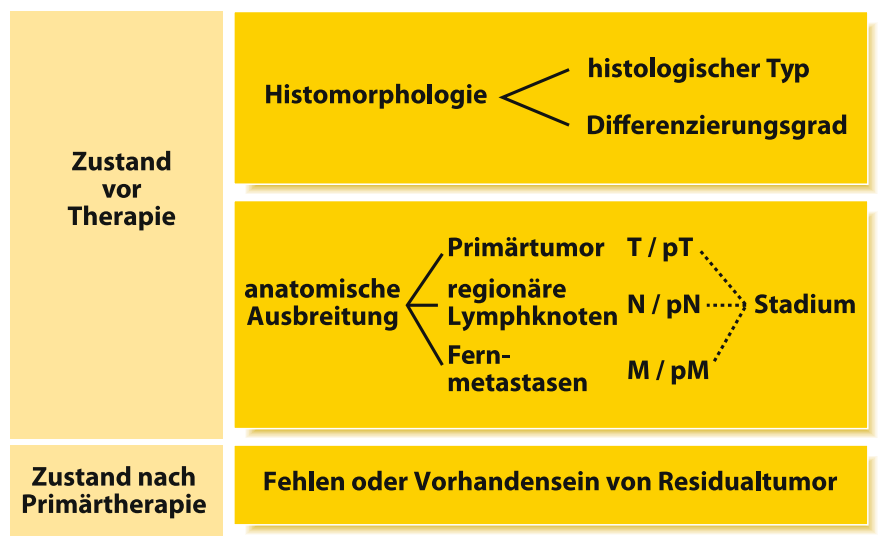

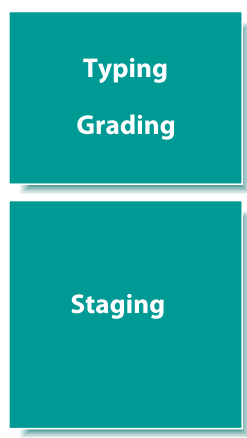

R-Klassifikation

- Abb. 1.98 Grundelemente der heutigen Tumorklassifikation 
- Grundlagen für die Planung und Durchführung der Therapie zu schaffen, v. a. in Hinblick auf eine differenzierende histologie- und stadiengerechte Therapie

- Wichtige Daten für die Schätzung der individuellen Prognose zu liefern

- Voraussetzungen für eine aussagekräftige Beurteilung von Behandlungsergebnissen zu schaffen

- Den Vergleich diagnostischer und therapeutischer Leistungen unterschiedlicher Behandlungszentren zu ermöglichen

\section{Tumorlokalisation}

Für die Einordnung der Tumorlokalisation ist der Topographieteil der ICD-O-3 (International Classification of Diseases for Oncology, 3. Auflage, 2000) maßgebend, der seit 2003 in deutscher Übersetzung (DIMDI) vorliegt. Er beschreibt die anatomischen Bezirke und Unterbezirke mit einem 3-, z. T. auch 4-stelligen Schlüssel.

\section{Fallbeispiel}

Verschlüsselung der Lokalisation: Als Beispiel sei die Drittel-Unterteilung des Rektum angegeben. Bei diesem Organ sind einige Messregularien zu beachten. Die Abgrenzung erfolgt nach der mit dem starren Rektosigmoidoskop gemessenen Entfernung des unteren Tumorrandes von der Anokutanlinie:

- C 20.93: oberes Rektumdrittel $(12-16 \mathrm{~cm})$

- C 20.92: mittleres Rektumdrittel $(6,0-<12 \mathrm{~cm})$

- C 20.91: unteres Rektumdrittel $(<6,0 \mathrm{~cm})$

Für gewisse Tumoren, die mehr als einen anatomischen Unterbezirk befallen haben, sind umfassende Schlüssel vorgesehen, z. B.:

- C 21.8: überlappender Tumor von Rektum, Anus und Analkanal

- C 24.8: überlappender Tumor der Gallengänge

- C 41.8: überlappender Tumor der Knochen und Gelenke

Exakte Angaben zur Tumorlokalisation sind wichtig, um einen Tumor hinsichtlich seines Entstehungsortes und seiner Ausdehnung richtig zuordnen zu können, insbesondere was die Einteilung nach der anatomischen Ausdehnung betrifft. Zudem lassen sich aus den exakten Zuordnungen der Lokalisation auch Empfehlungen für die Art der Therapie ableiten.

\section{Histologische Klassifikation (Typing)}

Eine erste Großunterteilung der Tumoren erfolgt nach dem Ausgangsgewebe (• Tab. 1.46). Die weitere Typisierung der Karzinome und Sarkome berücksichtigt die Ähnlichkeit mit dem Normalgewebe. Karzinome und Sarkome, die keinerlei Ähnlichkeit mit dem entsprechenden Normalgewebe erkennen lassen, werden als undifferenziert klassifiziert. Für die histologische Typenbestimmung sind die Empfehlungen der WHO (International Histological Classification of Tumours)
- Tab. 1.46 Histologische Tumortypen/Typing maliger Tumoren

\begin{tabular}{|c|c|c|}
\hline $\begin{array}{l}\text { Ausgangs- } \\
\text { gewebe }\end{array}$ & $\begin{array}{l}\text { Tumor- } \\
\text { gruppen }\end{array}$ & $\begin{array}{l}\text { Tumortypen } \\
\text { (Beispiele) }\end{array}$ \\
\hline Epithel & Karzinom & $\begin{array}{l}\text { Adenokarzinom } \\
\text { Plattenepithelkarzinom } \\
\text { Übergangszellkarzinom } \\
\text { Duktales Karzinom } \\
\text { Lobuläres Karzinom }\end{array}$ \\
\hline $\begin{array}{l}\text { Mesenchymales } \\
\text { Gewebe }\end{array}$ & Sarkom & $\begin{array}{l}\text { Osteosarkom } \\
\text { Chondrosarkom } \\
\text { Leiomyosarkom } \\
\text { Rhabdomyosarkom } \\
\text { Fibrosarkom }\end{array}$ \\
\hline $\begin{array}{l}\text { Lymphatisches } \\
\text { Gewebe }\end{array}$ & $\begin{array}{l}\text { Malignes } \\
\text { Lymphom }\end{array}$ & $\begin{array}{l}\text { Hodgkin-Lymphom } \\
\text { Non-Hodgkin-Lymphom }\end{array}$ \\
\hline $\begin{array}{l}\text { Blutbildendes } \\
\text { Gewebe }\end{array}$ & Leukämien & $\begin{array}{l}\text { Akute lymphatische } \\
\text { Leukämie } \\
\text { Chronische myeloische } \\
\text { Leukämie }\end{array}$ \\
\hline Keimdrüsen & $\begin{array}{l}\text { Germinale } \\
\text { Tumoren }\end{array}$ & $\begin{array}{l}\text { Seminom/Dysgerminom } \\
\text { Embryonales Karzinom } \\
\text { Chorionkarzinom } \\
\text { Teratom }\end{array}$ \\
\hline $\begin{array}{l}\text { Embryonales } \\
\text { Gewebe }\end{array}$ & $\begin{array}{l}\text { Embryonale } \\
\text { Tumoren }\end{array}$ & $\begin{array}{l}\text { Nephroblastom } \\
\text { Neuroblastom }\end{array}$ \\
\hline
\end{tabular}

maßgebend, deren Beachtung ein international einheitliches Typing mit dem ICD-O M-Code ermöglicht.

\section{Grading}

Innerhalb eines histologischen Tumortyps kann die Ähnlichkeit mit dem Normalgewebe unterschiedlich stark ausgeprägt sein. Dies sind oft auch zytologische Kriterien, wie z. B. Ausmaß der Kernatypien, Zellpolymorphie, Mitosezahl oder bei Sarkomen die Ausbildung von Zwischensubstanzen. Sie bestimmen die Einordnung in Differenzierungsgrade. Traditionell werden 4 Grade unterschieden. Zunehmend wird heute eine Unterteilung in nur 2 Grade bevorzugt, da diese besser reproduzierbar ist und für klinische Zwecke ausreicht.

\section{Histologische Differenzierungsgrade \\ - G1: gut differenziert, Low Grade \\ - G2: mäßig differenziert, Low Grade \\ - G3: schlecht differenziert, High Grade \\ - G4: undifferenziert, High Grade}

Auch das Grading ist in der von der WHO herausgegebenen internationalen histologischen Klassifikation der Tumoren heute international vereinheitlicht. 


\section{Staging/TNM-System}

Nach internationalen Vereinbarungen erfolgt die Beschreibung der anatomischen Tumorausbreitung heute allgemein nach dem TNM-System. Für maligne Lymphome und Leukämien sind dabei spezielle Regeln vorgesehen. Das TNM-System, von Denoix zwischen 1942 und 1952 entwickelt, wurde von der UICC allmählich ausgebaut und ist seit der 4. Auflage (1987) von allen nationalen TNM-Komitees akzeptiert und weltweit gültig. $\mathrm{Zu}$ den einheitlichen Prinzipien des TNMSystems, • Tab. 1.47.

Von besonderer Bedeutung ist die Unterscheidung zwischen klinischer und pathologischer Klassifikation (TNM vs. pTNM).

\section{- Definition \\ TNM - Klinische Klassifikation beruht auf prätherapeu- tisch erhobenen klinischen Befunden wie allgemeiner kli- nischer Untersuchung, bildgebenden Verfahren, Endos- kopie, Biopsie und chirurgischer Exploration. pTNM - Pathologische Klassifikation berücksichtigt zu- sätzlich Befunde, die beim chirurgischen Eingriff und durch die pathologische Untersuchung gewonnen wurden.}

Die Voraussetzungen für eine pTNM-Klassifikation sind für jedes Organ im TNM-Supplement 2003 und bezüglich der

- Tab. 1.47 Einheitliche Prinzipien des TNM-Systems, UICC 2010

Beschreibung der Tumorausbreitung durch das TNM-System Präfix vor das TNM-System (auch in Kombination)

\begin{tabular}{|l|l|}
\hline $\mathrm{p}$ & Pathologisch gesichert \\
\hline $\mathrm{u}$ & $\begin{array}{l}\text { Untersuchung klinisch, z. B. Endosonographie, } \\
\text { CT, MRT, etc. }\end{array}$ \\
\hline $\mathrm{c}$ & Clinical = klinisch \\
\hline $\mathrm{y}$ & Vorbehandlung, z. B. nach RTx, CTx \\
\hline $\mathrm{r}$ & Rezidivtumor \\
\hline $\mathrm{m}$ & Multiple Primärtumoren \\
\hline $\mathrm{a}$ & $\begin{array}{l}\text { Tumorklassifikation wurde erstmalig bei der } \\
\text { Sektion bestimmt }\end{array}$ \\
\hline
\end{tabular}

\section{T - Primärtumorgröße}

\begin{tabular}{|l|l|}
\hline TX & Primärtumor kann nicht bestimmt werden \\
\hline Tis & Carcinoma in situ \\
\hline T0 & Kein Nachweis eines Tumors \\
\hline T1, T2, T3, T4 & $\begin{array}{l}\text { Abhängig von der Größe, Ausdehnung bzW. } \\
\text { Infiltration der entsprechenden Tumorentität }\end{array}$ \\
\hline
\end{tabular}

Tab. 1.47 (Fortsetzung)

Beschreibung der Tumorausbreitung durch das TNM-System $\mathrm{N}$ - Lymphknotenbefall

NO

Lymphknoteninfiltration nicht vorhanden bei ausreichender Anzahl von resezierten Lymphknoten

N1-N3 Zunehmender Anteil von tumorbefallenen Lymphknoten

\begin{tabular}{l|l} 
NX & Lymphknotenbefall nicht bestimmbar
\end{tabular} oder nicht ausreichend viele Lymphknoten reseziert

M - Metastasen

\begin{tabular}{l|l|l}
\hline M (HEP) & Lebermetastase \\
\hline M (OSS) & Knochenmetastase \\
\hline M (PUL) & Lungenmetastase \\
\hline M (PER) & Peritonealmetastase \\
\hline M (LYM) & $\begin{array}{l}\text { Lymphknotenmetastase außerhalb des } \\
\text { regionären Lymphabflusses }\end{array}$ \\
\hline M (BRA) & Hirnmetastase \\
\hline M (SKI) & Hautmetastase \\
\hline G - Grading & & \\
\hline G1 & Gut differenziert & Low Grade \\
\hline G2 & Mäßig differenziert & Low Grade \\
\hline G3 & Schlecht differenziert & High Grade \\
\hline G4 & Undifferenziert & High Grade \\
\hline
\end{tabular}

L - Lymphgefäßinvasion

\begin{tabular}{l|l} 
LX Lymphgefäßinvasion kann nicht bestimmt \\
\hline
\end{tabular} werden

Lo Keine Lymphgefäßinvasion

L1 Lymphgefäßinvasion

V-Veneninvasion

\begin{tabular}{l|l} 
VX & Veneninvasion kann nicht bestimmt werden
\end{tabular}

Vo Keine Veneninvasion

V1 Mikroskopische Veneninvasion

V2 Makroskopische Veneninvasion

$\mathrm{Pn}$ - Perineuralscheideninvasion

\begin{tabular}{l|l}
$\mathrm{Pn}$ & Perineuralscheideninvasion kann nicht
\end{tabular} bestimmt werden

\begin{tabular}{l|l} 
Pno & Keine Perineuralscheideninvasion
\end{tabular}

\begin{tabular}{l|l} 
Pn1 Perineuralscheideninvasion &
\end{tabular} 
- Tab. 1.48 Beispiel für die Erfordernisse der pTNM-Klassifikation anhand des kolorektalen Karzinoms

pT Histologische Untersuchung des durch limitierte oder radikale Resektion entfernten Primärtumors ohne makroskopisch erkennbaren Tumor an den zirkumferenziellen (lateralen), oralen und aboralen Resektionsrändern

oder

histologische Untersuchung des durch endoskopische Polypektomie oder lokale Exzision entfernten Primärtumors mit histologisch tumorfreien Resektionsrändern

oder

mikroskopische Bestätigung einer Perforation der viszeralen Serosa ${ }^{a}$

oder

mikroskopische Bestätigung der Infiltration benachbarter Organe oder Strukturen

pNO Regionäre Lymphadenektomie und histologische Untersuchung üblicherweise von 12 oder mehr Lymphknoten

pN1 Histologische Bestätigung von Metastasen in nicht mehr als 3 regionären Lymphknoten

pN2 Histologische Bestätigung von Metastasen in mehr als 3 regionären Lymphknoten

pM1 Mikroskopischer (histologischer oder zytologischer) Nachweis von Fernmetastasen

a Die mikroskopische Bestätigung einer Perforation des viszeralen Peritoneums durch Tumorgewebe kann durch Untersuchung von Biopsien oder durch Abstrichzytologie von der Serosa über dem Tumor erfolgen.

pN-Klassifikation auch in der TNM-Klassifikation 2010 definiert (•Tab. 1.48).

Die pathologische Klassifikation ist verlässlicher als die klinische. Sie liefert die zuverlässigen Daten für die Beurteilung der Prognose und für die Analyse chirurgischer Therapieresultate. Die pTNM-Klassifikation ist auch für die Indikation zur postoperativen Radio- und/oder Chemotherapie maßgebend.

Die klinische Klassifikation ist wesentlich für die primäre Therapieauswahl und für Vergleiche mit bzw. von nichtchirurgisch behandelten Patienten.

Bei jedem Patienten mit einem malignem Tumor ist grundsätzlich zunächst die klinische Klassifikation vorzunehmen und zwar auch dann, wenn später eine pathologische Klassifikation möglich ist.

\section{TNM zur Beschreibung des Krankheits- verlaufes}

Im weiteren Krankheitsverlauf können im Rahmen der Nachsorge die zu erhebenden Befunde immer wieder durch eine TNM-Formel charakterisiert werden. Ein Rezidivtumor wird dabei durch das Präfix »r« gekennzeichnet.

\section{Fallbeispiel}

»Pathogramm« eines Patienten mit Rektumkarzinom

April 2006: T1NOM0, chirurgische lokale Exzision (transanale »disc excision«), pT1NOMO/RO

Juli 2006: TONOMO

Oktober 2007: T1NOMO $\rightarrow$
November 2007: rT1N0M0, tiefe anteriore Resektion, rpT1pN1M0/R0

Januar 2008: TONOMO

April 2008: $\downarrow$

Juli 2008: $\downarrow$

Oktober 2009: TONOM1 (Leber), Segmentresektion Leber, TONOpM1/R0

Januar 2010: T0N0M0

und fortlaufend, letzter Kontakt Januar 2011

Die Klassifikation durch das TNM/pTNM-System erlaubt eine präzise Beschreibung und Dokumentation der anatomischen Tumorausbreitung. Für die einzelnen Organe ergibt sich dabei allerdings eine relativ große Zahl von TNM-Kategorien, beim Magen z. B. 32 (4 T-Kategorien, $4 \mathrm{~N}$-Kategorien und $2 \mathrm{M}$-Kategorien). Wenn keine großen Patientenzahlen vorliegen, ist es für die Analyse des Krankengutes notwendig, diese umfangreiche Zahl von Kategorien in eine kleinere Zahl von »Stadien « zusammenzufassen. Dabei soll gewährleistet sein, dass jedes Stadium in Bezug auf die Prognose mehr oder weniger homogen ist und dass sich die verschiedenen Stadien entsprechend unterscheiden (• Abb. 1.99).

Im Allgemeinen wird zwischen den Stadien I-IV unterschieden, fallweise kommen noch Substadien, bezeichnet mit großen Buchstaben (z. B. IIIA oder IIIB), hinzu. Für In-situKarzinome wird die Bezeichnung Stadium 0 angewandt.

Nur bei einigen wenigen Organtumoren werden zur Definition der Stadien zusätzliche Parameter berücksichtigt, z. B. bei Tumoren von Knochen, Weichteilen und Prostata der Differenzierungsgrad, bei Tumoren der Schilddrüse der histologische Typ und das Alter, bei trophoblastären Schwanger- 


\begin{tabular}{|c|c|c|c|c|c|c|}
\hline \multirow[t]{7}{*}{ Magenkarzinom } & & \multicolumn{4}{|c|}{ MO } & \multirow[t]{2}{*}{ M1 } \\
\hline & & (p)NO & (p)N1 & (p)N2 & (p)N3 & \\
\hline & (p) $\mathrm{T1}$ & IA & IB & IIA & IIB & IV \\
\hline & (p) $\mathrm{T} 2$ & IB & IIA & IIB & IIIA & IV \\
\hline & (p) T3 & IIA & IIB & IIIA & IIIB & IV \\
\hline & (p) $\mathrm{T} 4 \mathrm{a}$ & IIB & IIIA & IIIB & IIIC & IV \\
\hline & (p) $T 4 b$ & IIIB & IIIB & IIIC & IIIC & IV \\
\hline
\end{tabular}

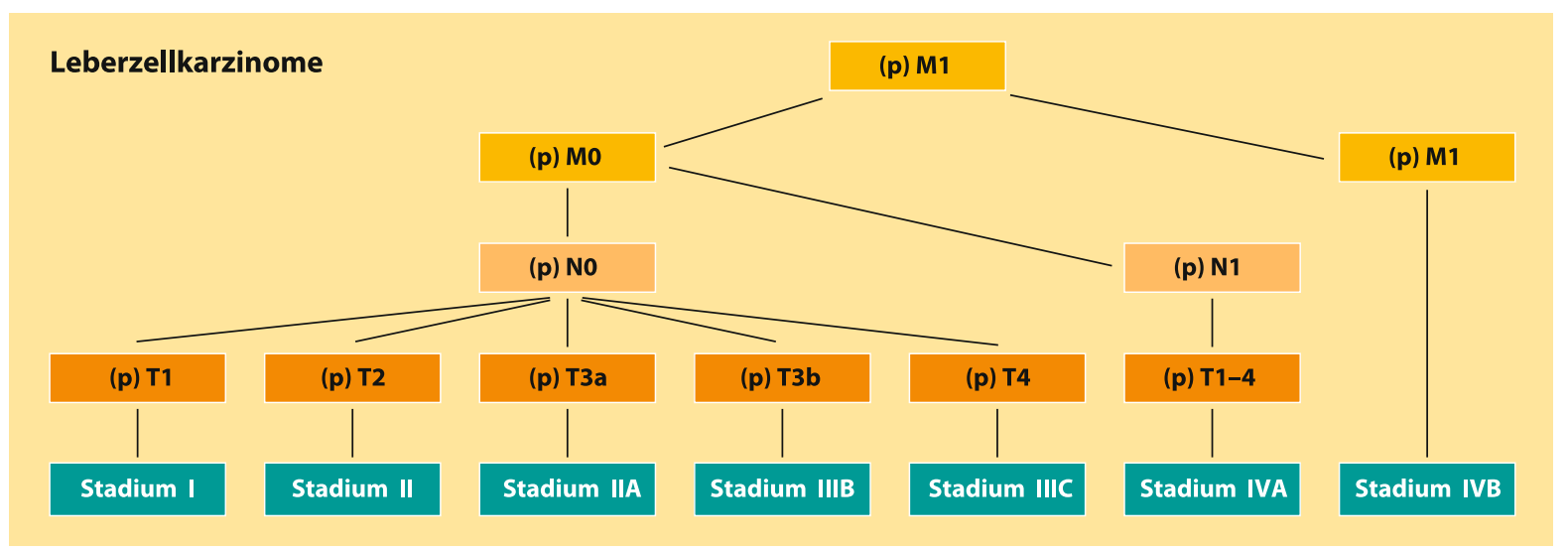

- Abb. 1.99 Beispiele für Stadiengruppierungen

schaftstumoren sog. Risikofaktoren und bei germinalen Hodentumoren der Serumspiegel der Tumormarker.

\section{Residualtumor(R)-Klassifikation}

Bei der großen Mehrzahl der Tumoren ist eine nennenswerte Chance auf Heilung oder längeres Überleben nur gegeben, wenn nach Abschluss der Erstbehandlung kein Hinweis auf zurückbleibenden Residualtumor besteht (Erreichung einer R0-Situation).

Die R-Klassifikation ist aus historischen Gründen nicht obligater Bestandteil der TNM-Klassifikation. Aufgrund ihrer prognostischen Bedeutung ist sie aber, insbesondere nach chirurgischer Therapie, unerlässlich und daher auch im Dokumentarsystem der Arbeitsgemeinschaft Deutscher Tumorzentren (ADT) als essenzieller Bestandteil der Tumorklassifikation neben der Erfassung der TNM-Kategorien zur Beschreibung des Tumorstatus nach Therapie zwingend vorgesehen.

R-Klassifikation (Residualtumorklassifikation) UICC

- RX: Vorhandensein von Residualtumor kann nicht beurteilt werden

- R0: Kein Residualtumor (exakter: Residualtumor nicht feststellbar)

- R1: Mikroskopisch Residualtumor

- R2: Makroskopisch Residualtumor

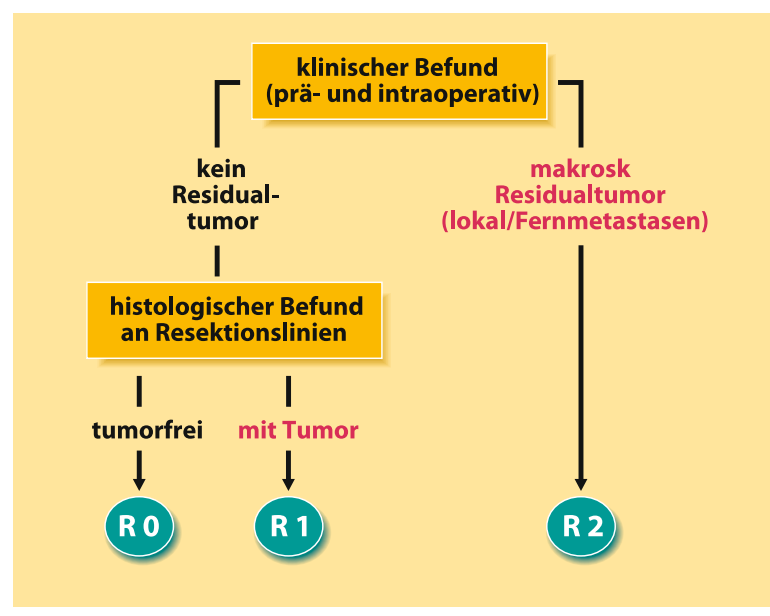

- Abb. 1.100 Bestimmung der R-Klassifikation nach chirurgischer Behandlung

Die Designation R0 entspricht einer kurativen Tumorentfernung oder in Fällen, bei denen nur eine Chemotherapie angewendet wurde, einer kompletten Remission.

Nach internistischer oder Strahlentherapie erfolgt die RKlassifikation in der Regel durch klinische Untersuchungsmethoden einschließlich Biopsie. Nach chirurgischer Therapie ist die R-Klassifikation das Ergebnis einer Zusammenschau von klinischen Befunden und des Befundes der pathohistologischen Untersuchung des Tumorresektates (• Abb. 1.100). 
( Ein makroskopischer Residualtumor jeglicher Lokalisation sollte stets mikroskopisch (zytologisch oder histologisch) gesichert werden!

Bei Tumoren des Gastrointestinaltraktes muss die histologische Untersuchung im Rahmen der R-Klassifikation in erster Linie die zirkumferentiellen Resektionsränder (Synonyme: laterale, radiäre, tiefe Resektionsränder) im Bereich des Halteapparates (Mediastinum, Retroperitoneum, kleines Netz, Lig. hepatoduodenale, Lig. gastrocolicum, Mesokolon, Mesorektum) berücksichtigen, da in erster Linie an diesen Resektionsrändern, viel seltener an den oralen oder aboralen Rändern, histologisch Tumorausläufer oder Satelliten nachgewiesen werden können.

\section{In Kürze}

\section{Klassifikation von Tumoren}

- TNM-(klinische) und pTNM-(pathologische) Klassifikation nach UICC: grundsätzlich zuerst eine klinische Klassifikation (wesentlich für primäre Therapieauswahl und Vergleiche)

- Stadiengruppierung (I-V, 0 = Carcinoma in situ).

- R-Klassifikation (Residualtumorklassifikation): stets mikroskopische Sicherung, bei gastrointestinalen Tumoren histologische Untersuchung besonders der lateralen Resektionsränder

\subsubsection{Ziele der operativen Tumorbehandlung}

Bei etwa $80 \%$ aller Patienten mit malignem Tumor werden chirurgische Eingriffe vorgenommen. Diese können nach der Zielsetzung unterteilt werden in:

- Entfernung eines Tumors in kurativer Intention (Erzielung einer R0-Resektion)

- Entfernung eines Tumors im Rahmen der Palliation (nichtkurative Therapiemaßnahme)

- Eingriffe zur Diagnostik, eingeschlossen die Bestimmung der anatomischen Ausbreitung

\section{Chirurgie in kurativer Intention}

Die Voraussetzung jedweder chirurgischen Behandlung in kurativer Absicht ist die primäre lokale und lokoregionäre Begrenzung, d. h. Entfernung der malignen Tumoren.

( Maligne Tumoren sind nicht von vornherein "Allgemeinerkrankungen«, sondern zunächst mehr oder minder lange Zeit auf das Ursprungsorgan (lokal) und die regionären Lymphknoten (lokoregionär) beschränkt!

Lokalisierte und lokoregionär beschränkte maligne Tumoren, wie auch jene mit mono- oder oligotoper Fernmetastasierung, sind Domäne der Chirurgie mit dem Ziel, die nachgewiesenen Tumoren vollständig (kurative Intention) zu entfernen. Weder mit einer Strahlentherapie noch durch eine Chemotherapie können örtliche Tumormanifestationen mit der gleichen Sicherheit definitiv beseitigt werden wie durch eine der jeweiligen Tumorausbreitung angepasste Chirurgie.

D Cave

Bei Strahlen- und Chemotherapie besteht immer die Gefahr, dass trotz klinisch kompletter Remission mehr oder weniger umfängliche - nur histologisch nachweisbare - vitale Tumorformationen zurückbleiben und Ausgangspunkt klinischer Rückfälle werden.

Es gibt bis heute keine sicheren Kriterien, mit der jene Fälle bestimmt werden könnten, bei denen die Möglichkeit einer kompletten Tumordestruktion durch Radio- oder Chemotherapie mit Sicherheit vorauszusagen wäre.

$>$ Daher ist für den lokal begrenzten Tumor die operative Entfernung nach wie vor die onkologisch sicherste Methode.

\section{Chirurgische Methoden}

$\mathrm{Zu}$ den wichtigsten Fortschritten der chirurgischen Tumortherapie in den letzten 20 Jahren gehört die zunehmende Realisation einer differenzierten Behandlung in Abhängigkeit von der individuellen onkologischen Situation des Patienten. Tumoren eines bestimmten Organs werden nicht stets in gleicher Weise durch einen sog. Standardeingriff behandelt. Man ist vielmehr bemüht, je nach individueller Situation eine »Chirurgie nach Maß « durchzuführen. Typisches Beispiel dafür ist das Rektumkarzinom, das früher in kurativer Absicht grundsätzlich durch Rektumexstirpation behandelt wurde. Heute steht ein großes Spektrum chirurgischer Eingriffe zur Verfügung, das von der endoskopischen Polypektomie bis zur erweiterten multiviszeralen radikalen Resektion reicht.

Voraussetzung für eine differenzierende histologieund stadiengerechte Chirurgie ist eine Klassifikation der Histomorphologie und der anatomischen Ausbreitung des Tumors ( $\triangleright$ Abschn. 1.11.2) und damit die Integration des Pathologen in das Team der behandelnden Ärzte.

$\mathrm{Zu}$ den verschiedenen Möglichkeiten kurativer chirurgischer Eingriffe, - Tab. 1.49.

\section{Verzicht auf systematische regionäre Lymphadenektomie}

Auf die Mitentfernung des regionären Lymphabflussgebietes könnte immer dann verzichtet werden, wenn präoperativ Tumorfreiheit der regionären Lymphknoten mit Sicherheit festzustellen wäre. Dies trifft heute bei weitem nicht zu, insbesondere weil auch die modernen bildgebenden Verfahren Metastasen bis zu 3-5 mm Größe (die durchaus nicht selten vorkommen) nicht sicher identifizieren. Die sichersten Hinweise auf die Wahrscheinlichkeit bereits bestehender regionärer Lymphknoten ergeben sich aus der sorgfältigen histologischen Untersuchung des Primärtumors. Zum Beispiel liegt bei kolorektalen Adenokarzinomen und muzinösen Adeno- 
- Tab. 1.49 Möglichkeiten chirurgischer Eingriffe in kurativer Intention

Klassische Chirurgie

Radikale Resektion = Entfernung des Tumors weit im Gesunden und en bloc mit dem regionären Lymphabflussgebiet (Lymphbahnen und alle regionären Lymphknoten), z. B. Gastrektomie mit systematischer Lymphadenektomie oder Mastektomie mit Axilladissektion (Level I-III)

Eingeschränkte Eingriffe

Limitierte (nicht komplette) Lymphadenektomie, z. B. Kolonsegmentresektion

Keine Lymphadenektomie, z. B. Exzision eines malignen Melanoms der Haut ohne Lymphadenektomie oder tubuläre Resektion des Kolons

Eingeschränkte Sicherheitsabstände am Primärtumor, z. B. Tumorexzision eines Mammakarzinoms (brusterhaltende Therapie) oder lokale Exzision oder endoskopische Polypektomie im Rektum
Erweiterte radikale Resektion

Erweiterung der Lymphadenektomie: Mitentfernung nicht regionärer Lymphknoten, z. B. paraaortale Lymphknoten bei Magenoder Kolonkarzinom

Mitentfernung von Nachbarorganen als sog. multiviszerale radikale Resektion

Resektion von Fernmetastasen, sofern mono- oder oligotop, z. B. Leberresektion bei kolorektalem Karzinom karzinomen der Malignitätsgrade 1 und 2 mit Infiltration nur der Submukosa und bei fehlendem histologischen Nachweis von Lymphgefäßinvasion die Wahrscheinlichkeit bereits vorhandener regionärer Lymphknotenmetastasen bei nur 3\%. Immer dann, wenn in solchen Fällen das Operationsrisiko einer radikalen Resektion für den Patienten höher erscheint, sollte man daher das eingeschränkte Verfahren mit sehr geringem Operationsrisiko bevorzugen.

\section{Eingeschränkte Operationen mit knappen Sicherheits- abständen}

Solche Operationen in kurativer Absicht sind dann berechtigt, wenn:

- der Tumor auch histologisch relativ scharf gegen die Umgebung begrenzt ist,

- in seinem Umfeld mit nur histologisch erkennbaren Ausläufern oder Satelliten nicht zu rechnen ist,

- in der Umgebung präkanzeröse Läsionen und zusätzliche multifokale Herde fehlen.

\section{Erweiterte Operationen}

Wird eine erweiterte Operation wegen des Verdachts auf Infiltration eines Nachbarorganes erwogen, so ist eine En-blocMitentfernung des Nachbarorgans (sog. multiviszerale Resektion) erforderlich.

\section{Cave}

Auf Biopsien (intraoperativ) aus dem Gebiet der Adhärenz mit dem Nachbarorgan soll grundsätzlich verzichtet werden, da beim Einschnitt in den Tumor mit einer örtlichen Tumorzelldissemination und lokoregionären Rezidiven zu rechnen ist.

\section{Verfahrensregeln der kurativen Tumorchirurgie}

Bei chirurgischen Eingriffen in kurativer Intention sind allgemeine Grundsätze und Verfahrensregeln einzuhalten. Bei strikter Beachtung dieser Grundsätze der onkologischen Chi- rurgie kann das Risiko lokoregionärer Rezidive erheblich verringert werden.

\section{Verfahrensregeln für Tumorchirurgie}

1. Operationsplanung

- Histologisches Typing und Grading an Biopsien

- Präoperatives klinisches Staging

2. Intraoperatives Staging

- Fernmetastasen?

- Adhärenz zu Nachbarorganen?

- Ausdehnung im Ursprungsorgan?

3. Tumorresektion

- Adäquate Sicherheitsabstände:

- Primärtumor: Beseitigung nur histologisch erkennbarer Tumorausläufer und Satelliten, Beachtung der Grenzen in allen 3 Dimensionen, bei Weichteil- und Knochensarkomen Muskelgruppen- bzw. Kompartmentresektionen

- Lymphabflussgebiet: Ausdehnung entsprechend vermutlichem Lymphknotenbefall, nahe Resektionslinien tumorfreie Lymphknoten!

- Verhinderung einer örtlichen Tumorzelldissemination:

- En-bloc-Entfernung von Primärtumor und Lymphabflussgebiet, ggf. auch von Nachbarorganen (keine Eröffnung von Lymphspalten)

- »No-touch-Technik«: Ligatur von Venen und Arterien und Abbinden von Hohlorganen vor Tumormobilisation

- Mitentfernung des Biopsieareals (wo möglich)

- Cave: Einschnitt oder Einriss im Tumor unbedingt vermeiden!

- Spülung des Operationsgebietes (physiologische $\mathrm{NaCl}$-Lösung, tumorizide Flüssigkeiten)

- Instrumenten- und Handschuhwechsel nach Kontakt mit Tumor 


\section{Lokoregionäre Rezidive/Qualität der Chirurgie}

Das lokoregionäre Rezidiv nach R0-Resektion ist nicht - wie immer noch manchmal behauptet - ein schicksalsbedingtes Ereignis. Lokoregionäre Rezidive sind Folge eines Zurückbleibens von Tumorzellen im Operationsgebiet und damit Indikator der Qualität des chirurgischen Ersteingriffs.

\section{Lokoregionäre Rezidive beim Rektumkarzinom}

Dass durch striktes Einhalten der Regeln der chirurgischen Onkologie lokoregionäre Rezidive tatsächlich weitgehend verhindert werden können, ist am Beispiel des Rektumkarzinoms in den letzten 10 Jahren bewiesen worden. Die deutsche Multizenterstudie (Studiengruppe kolorektales Karzinom) bestätigte, dass in Abhängigkeit des Chirurgen die Rate lokoregionärer Rezidive nach allein chirurgischer Behandlung tatsächlich $<5 \%$ liegt, und dass dies nicht durch Auswahl besonders günstiger Fälle und Ausschluss weniger günstiger Fälle zu erklären ist. Es zeigte sich aber auch, dass die Häufigkeit lokoregionärer Rezidive je nach Klinik und je nach Operateur und unabhängig von anderen Einflussfaktoren zwischen $<5 \%$ und $>50 \%$ schwankt.

$>$ Oberstes Ziel chirurgischer Tumoroperationen in kurativer Intention ist die Vermeidung späterer lokoregionärer Rezidive. Damit wird zugleich auch das Überleben entscheidend verbessert.

\section{Nichtkurative Chirurgie}

Indikationen zur nichtkurativen Chirurgie ergeben sich in erster Linie bei Tumorkomplikationen wie Stenosen, massiven Blutungen, Verjauchungen, pathologischen Frakturen (bei Knochenmetastasen), in Einzelfällen auch zur Schmerzbehandlung.

Verfahren nichtkurativer chirurgischer Therapie

\section{Nichtkurative Tumorresektion}

- In erster Linie bei Stenosen im Kolon, selten bei verjauchenden Nekrosen von Lungen- oder Rektumkarzinom

2. Nichtresezierende Verfahren

- Tumordestruktion durch Laser, Kryotherapie, Elektrokoagulation, z. B. Stenosen im Rektum oder Ösophagus

- Prothesen/Tuben (meist endoskopisch eingelegt), z. B. Ösophagus, Gallengänge

- Tracheostomie, z. B. bei Trachealstenose durch Schilddrüsenkarzinom

- Umgehungsanastomosen, z. B. biliodigestive Anastomosen bei Pankreas- oder Gallengangskarzinomen, gastrojejunale Anastomose bei Zökumkarzinom

- Stabilisierende Operation (Verbundosteosynthesen, Markraumnagelung, Wirbelsäulenfusion) oder Alloarthroplastiken bei Knochenmetastasen (pathologische Fraktur!)

- Schmerztherapie: Nervenblockaden des zervikalen Grenzstranges oder des Ganglion coeliacum, Chordotomie, stereotaktische Hirnoperation

- Chirurgische hormonale Beeinflussung, z. B. Orchiektomie bei Prostatakarzinom
Dabei sind auch die zumindest bei manchen Tumorentitäten durch palliative Chemotherapie erreichbaren relativ langen Überlebenszeiten vergleichend zu berücksichtigen.

$\checkmark$ Für nichtkurativ behandelbare Patienten kommen chirurgische Maßnahmen nur dann in Frage,

- wenn die Risiken postoperativer Letalität und Morbidität in einem angemessenen Verhältnis zu einer zu erwartenden Verbesserung der Lebensqualität und/oder Verlängerung der Überlebenszeit stehen und

- wenn interventionelle Methoden unter Berücksichtigung funktioneller Aspekte und der Lebensqualität keine Alternative bieten.

Ob nichtkurative Tumorresektionen die Überlebenszeit verlängern können, ist umstritten. Während früher vielfach der Nutzen einer »chirurgischen Tumorreduktion « « angenommen wurde, ist man heute diesbezüglich sehr skeptisch und bevorzugt multimodale Konzepte mit primärer Chemo- bzw. Radiochemotherapie und dem sekundären Versuch einer R0-Resektion.

\section{Chirurgische Eingriffe zur Diagnostik und zum Staging}

Trotz großer Fortschritte bei den bildgebenden Verfahren, in der Endoskopie und bei perkutanen Nadelbiopsien, sind fallweise diagnostische chirurgische Eingriffe immer noch notwendig. Bei chirurgischen Probeexzisionen ist stets darauf $\mathrm{zu}$ achten, dass der Zugang so gewählt wird, dass er ein evtl. anschließendes operatives Vorgehen nicht stört bzw. die Entfernung des Biopsieareals ermöglicht und somit die Gefahr von Implantationsmetastasen wesentlich verringert.

Bei malignen Lymphomen oder bei Prostatakarzinomen werden fallweise sog. Staging-Laparotomien zur Therapieplanung vorgenommen, um die Ausdehnung der Erkrankung exakt bestimmen zu können. Zunehmend wird dies durch ein laparoskopisches Staging ersetzt.

\section{In Kürze}

Ziele der operativen Tumorbehandlung

- Bei lokaler bzw. lokoregionärer Beschränkung: Entfernung des Tumors in kurativer Intention (Erzielung eine R0-Resektion): »Chirurgie nach Maß«.

- Nichtkurative (= palliative) Therapiemaßnahme, z. B. bei Tumorkomplikationen.

- Eingriffe zur Diagnostik und zum Staging (anatomische Ausbreitung): Laparotomie, Laparoskopie.

\subsubsection{Multimodale Primärtherapie maligner Tumoren}

Das Konzept, die chirurgische Therapie mit anderen Therapiemodalitäten im Sinne einer kombinierten Therapie (mul- 
- Tab. 1.50 Gründe für eine multimodale Primärtherapie

Lokoregionäre postoperative Strahlentherapie

Peri-/postoperative Chemotherapie und/oder Immuntherapie

- Systemisch

- Lokal über V. portae, intrakavitär (Peritoneum), intraluminal (Harnblase

Initiale (präoperative oder neoadjuvante) Radio- und/oder Chemotherapie, gefolgt von chirurgischer Tumorentfernung
Im Operationsgebiet zurückgelassene Tumorreste/bei der Operation örtlich disseminierte Tumorzellen

Klinisch nicht manifeste disseminierte Tumorzellen und Tumorzellverbände (isolierte Tumorzellen) oder Mikrofernmetastasen

Partielle (komplette?) Regression des Primärtumors (und der regionären Lymphknoten)

- Bessere Operabilität, erhöhte Chancen einer R0-Resektion

- Biologischer Test auf Ansprechen gegenüber der angewandten Chemotherapie (bei Nichtansprechen anderes Schema für postoperative Chemotherapie)

- Tab. 1.51 Kurative multimodale Primärtherapie

A. Kurative chirurgische Tumorentfernung/nachfolgende adjuvante Therapie
Durch Strahlentherapie

Durch systemische Chemotherapie

Durch lokale Chemotherapie

Durch Radiochemotherapie

Durch Hormontherapie

Durch Chemotherapie

B. Initiale (neoadjuvante) Therapie mit nachfolgender kurativer chirurgischer Tumorentfernung

C. Initiale (neoadjuvante) Therapie/ kurative chirurgische Tumorentfernung/ postoperative Therapie

Durch Radiochemotherapie

Systemische Chemotherapie/ therapie z. B. lokal fortgeschrittene Plattenepithelkarzinome von Mundhöhle, Oro- und Hypopharynx

z. B. prämenopausales Mammakarzinom mit regionären Lymphknotenmetastasen; fortgeschrittenes Kolonkarzinom mit hohem Lebermetastasenrisiko

z. B. hypertherme Extremitätenperfusion bei malignem Melanom pT3-4

z. B. Nephroblastom (ausgenommen Kinder unter 2 Jahre); fortgeschrittenes Rektumkarzinom mit hohem Risiko für ein lokoregionäres Rezidiv

z. B. Tamoxifen bei postmenopausalem Mammakarzinom mit regionären Lymphknotenmetastasen und positivem Steroidrezeptorstatus

z. B. weit fortgeschrittenes Plattenepithelkarzinom des Kopf-Hals-Bereiches

z. B. weit fortgeschrittenes Rektumkarzinom

z. B. Osteosarkom Chirurgie/systemische Chemo-

Radiotherapie/Chirurgie/ Radiotherapie z. B. peripheres Plattenepithelkarzinom der Lunge mit Pancoast-Syndrom (Sulcus superior-Tumor) timodale Therapie) zu ergänzen, beruht im Wesentlichen auf 3 Überlegungen (- Tab. 1.50).

$\mathrm{Zu}$ Beispielen für heute übliche multimodale Verfahren in der Primärtherapie maligner Tumoren, - Tab. 1.51.

( Für den Chirurgen ist ein Grundsatz wichtig: Multimodale Behandlungskonzepte entbinden nicht von der Notwendigkeit, die Prinzipien der chirurgischen Onkologie strikt einzuhalten ( $\triangleright$ Abschn. 1.11.6).

Bei vielen Tumorentitäten sind wichtige Fragen der multimodalen Therapie bisher nicht definitiv geklärt. Dies gilt v. a. für die Identifikation jener Untergruppen von Patienten, die tatsächlich von multimodalen Verfahren profitieren, für die Wahl der Medikamente und ihre Dosierung und für die Dauer der Durchführung der adjuvanten Therapie. Daher ist für viele Tumoren heute eine multimodale Behandlung nicht als Standardverfahren anzusehen. Stets sind auch die hiermit verbundenen Nebenwirkungen zu berücksichtigen. Zur Klärung all dieser Fragen laufen vielfach multizentrische klinische Studien. In Frage kommende Patienten sollten möglichst in großer Zahl solchen Studien zugeführt werden. 
In vielen bisherigen Studien über multimodale Behandlungsverfahren wurde die chirurgische Therapie nicht hinreichend definiert und es fällt auf, dass die Ergebnisse der allein chirurgisch behandelten Patienten in solchen Studien ganz auffallend ungünstig sind und nicht dem modernen Standard entsprechen. Daher sollte heute bei Studien über multimodale Therapieverfahren stets besondere Sorgfalt auf die Dokumentation des chirurgischen Vorgehens gerichtet werden, um den »Prognosefaktor Chirurg« zu erfassen.

\section{In Kürze}

\section{Multimodale Primärtherapie maligner Tumoren}

- Kombinierte bzw. (neo)adjuvante Therapie mit Strahlen-, Chemo-, Radiochemo-, Hormontherapie.

- Trotzdem striktes Einhalten der Prinzipien der chirurgischen Onkologie: Operationsplanung (Typing, Staging, Grading), intraoperatives Staging, Tumorresektion: adäquate Sicherheitsabstände, keine Tumorzelldissemination (Cave: Einschnitt oder Einriss im Tumor).

\subsubsection{Prognose}

Für die Bewertung der Prognose nach Therapie eines malignen Tumors stehen verschiedene Parameter zur Verfügung (• Tab. 1.52).

Die Langzeitprognose ist je nach Tumorlokalisation unterschiedlich. Zum Beispiel liegen die Heilungschancen bei malignen Tumoren der Haut (Basalzellkarzinome, Plattenepithelkarzinome), der differenzierten Schilddrüsenkarzinome und des Hodens zwischen 80 und 90\%, jene für Karzinome von Magen, Ösophagus, Pankreas und Lunge $<20 \%$.

Innerhalb der einzelnen Organtumoren wird die Prognose in erster Linie durch die anatomische Ausbreitung des Tumors vor und nach Primärtherapie, also durch pTNM (Stadium) und R (Residualtumor) bestimmt.

Zu weiteren Prognosefaktoren, • Tab. 1.53. Für die einzelnen Organtumoren ist ihre jeweilige Bedeutung unterschiedlich.

Zwischen den einzelnen möglichen Prognosefaktoren bestehen vielfach Wechselwirkungen; z. B. stehen anatomische Ausbreitung und Differenzierungsgrad bei manchen Tumo-

- Tab. 1.52 Parameter für die Beurteilung der Prognose nach chirurgischer Therapie von Tumoren
Frühergebnisse
Letalität (Mortalität) durch Therapie
- Postoperative Letalität
- Letalität durch frühe Komplikationen nichtchirurgischer Therapie
Nichtletale Tumorkomplikation
Langzeitprognose
Überleben
- Gesamt (overall)
- Tumorfrei (disease free)
Rückfallquote
- Lokoregionäre Rezidive
- Fernmetastasen

Beurteilung des Überlebens ${ }^{a}$

Lebensqualität ${ }^{b}$

Zielkriterien

\begin{tabular}{|l}
\hline Berechnung \\
\hline Alterskorrektur \\
(relatives Überleben)
\end{tabular}

Darstellung

$$
\begin{aligned}
& \text { Tod jeder Art } \\
& \text { Tod mit Tumor }
\end{aligned}
$$

Direkte Methode

Aktuarsmethode (Sterbetafel)

Nach Kaplan-Meier

- Mit oder ohne Berücksichtigung der Operationsletalität

abzüglich »normaler Sterbewahrscheinlichkeit«, d. h. aus der Bevölkerungsstatistik bekannte Rate an Todesfällen bei einer alters- und geschlechtsgleichen Bevölkerung

5-Jahres-Überlebensraten mit 95\%-Vertrauensbereich (bei manchen Tumoren, z. B. Mamma- oder Prostatakarzinom 10- und 15-JahreÜberlebensraten erforderlich!)

\footnotetext{
a Bei allen Angaben über Überleben müssen vollständige Daten über die Berechnungsmethoden vorliegen!
}

b Erfasst durch spezielle Fragebogen über die Befindlichkeit des Patienten 
- Tab. 1.53 Prognosefaktoren bei malignen Tumoren

\begin{tabular}{|c|c|}
\hline $\begin{array}{l}\text { R-Klassifikation/ } \\
\text { pTNM-Klassifikation }\end{array}$ & Stadium \\
\hline \multicolumn{2}{|c|}{ Weitere mögliche Prognosefaktoren } \\
\hline Tumorabhängig & $\begin{array}{l}\text { Histologischer Typ } \\
\text { Differenzierungsgrad } \\
\text { Lymphgefäß-, Venen-, } \\
\text { Perineuralrauminvasion } \\
\text { Peritumoröse Entzündung } \\
\text { Proliferationsverhalten } \\
\text { Ploidie } \\
\text { Hormonrezeptoren } \\
\text { Tumorassoziierte Antigene } \\
\text { Differenzierungsantigene } \\
\text { Molekularpathologische Befunde }\end{array}$ \\
\hline Patientenabhängig & $\begin{array}{l}\text { Alter } \\
\text { Geschlecht } \\
\text { Dauer der Symptome } \\
\text { Leistungszustand (ECOG-Skala, } \\
\text { Karnofsky-Index) } \\
\text { Komorbidität } \\
\text { Immunstatus }\end{array}$ \\
\hline $\begin{array}{l}\text { Environment-abhängig } \\
\text { (therapieabhängig) }\end{array}$ & $\begin{array}{l}\text { Qualität der Therapie einschl. } \\
\text { »Prognosefaktor Chirurg« }\end{array}$ \\
\hline
\end{tabular}

ren in enger Beziehung, so dass bei gleichem Ausbreitungsstadium des Tumors der Differenzierungsgrad keine prognostischen Unterschiede anzeigt. Die isolierte Betrachtung eines möglichen Prognosefaktors gibt daher keine Information darüber, ob der betreffende Faktor tatsächlich einen unabhängigen Einfluss auf die Prognose ausübt. Nur durch spezielle biometrische Methoden, sog. multivariate Analyseverfahren, ist es möglich, unabhängig wirksame Prognosefaktoren zu identifizieren. Prognosefaktoren für kurativ behandelte Patienten sind vielfach unterschiedlich von jenen für nichtkurativ behandelte Patienten, oft sind bestimmte Prognosefaktoren nur bei manchen Patientenuntergruppen wirksam - z. B. bestimmten Stadien oder pTNM-Kategorien - oder nur bei Patienten mit einer bestimmten Behandlungsart.

Die Aufklärung der neben R und pTNM wirksamen Prognosefaktoren ist noch keineswegs abgeschlossen, insbesondere ist die Bedeutung der erst in den letzten Jahren bestimmbaren modernen tumorbiologischen und molekularpathologischen Faktoren noch weitgehend unklar.

Die Identifikation unabhängiger Prognosefaktoren ist nicht nur für die Therapiewahl individuell (differenzierende Therapie je nach Tumoraggressivität) und die Schätzung der Prognose für den einzelnen Patienten von Bedeutung, sondern auch wichtige Vorbedingung einer verlässlichen Analyse von Therapieergebnissen.

\section{In Kürze}

\section{Prognose}

Insbesondere von der Residualtumorklassifikation (R) und der pTNM-Klassifikation bestimmt. Zusätzliche Prognosefaktoren sind fallweise von Bedeutung, bedürfen aber noch weiterer Klärung.

\subsubsection{Tumornachsorge}

Moderne Tumortherapie schließt nach der Primärtherapie eine umfassende Patientenbetreuung ein. Diese Tumornachsorge hat zunächst Aufgaben für den betreffenden Patienten zu erfüllen, aber auch solche der allgemeinen Gesundheitspolitik (Krebsprävention im Umfeld) wie auch der Qualitätssicherung der Krebstherapie.

Aufgaben der Nachbetreuung nach chirurgischer Krebsbehandlung

- Allgemeine Patientenbetreuung im weiteren Verlauf

- Medizinische Rehabilitation: Behandlung therapiebedürftiger Nebenwirkungen und Folgeerkrankungen (z. B. Stomapflege, Prothesenbetreuung, Therapie von Verdauungs- und Stoffwechselstörungen, z. B. nach Gastrektomie oder Pankreasresektion, Hautpflege nach Strahlentherapie, Bekämpfung der Inappetenz, Schmerzbekämpfung)

- Psychosoziale Nachsorge: psychische Betreuung, soziale Rehabilitation (beruflich, wirtschaftlich)

- Spezielle Nachsorge nach kurativer Operation

- Frühdiagnose von lokoregionären Rezidiven und Fernmetastasen

- Früherkennung von metachronen Karzinomen im erkrankten Organ

\section{- Krebsprävention im Umfeld}

- Beratung und Untersuchung von Angehörigen, sofern bei diesen erhöhtes Krebsrisiko zu erwarten ist, z. B. bei Angehörigen von Personen mit kolorektalem Karzinom auf dem Boden einer familiären adenomatösen Polypose oder bei hereditärem Nicht-Polypose-Kolonkarzinom (HNPCC, LynchSyndrom)

- Einleitung arbeitsmedizinischer Untersuchungen bei Diagnose einer möglicherweise beruflich bedingten Krebserkrankung

\section{- Qualitätssicherung der Krebstherapie}

- Regelmäßige Verlaufskontrollen (Erfassung von Tumorrückfällen) sind Voraussetzung für die Beurteilung des langfristigen Therapieergebnisses und geben entscheidende Auskunft über die Qualität der Therapie 
Für die einzelnen Tumorlokalisationen wurden umfangreiche Nachsorgepläne erstellt, die ein meist viel zu großes Programm an technischen und Laboruntersuchungen empfehlen.

( Im Vordergrund der Nachsorge muss immer die klinische Untersuchung stehen.

Derzeit bemüht man sich vielfach, die Nachuntersuchungen für jede Tumorerkrankung auf eine vernünftige und ökonomisch vertretbare Basis zu stellen.

Bei Nachuntersuchungen nach kurativer Behandlung muss die Früherkennung von lokoregionären Rezidiven und Fernmetastasen, die noch erfolgreich behandelbar sind, im Vordergrund stehen. Dies ist z. B. bei lokoregionären Rezidiven oder Lebermetastasen nach kolorektalem Karzinom oder bei Fernmetastasen von Hodentumoren oder Osteosarkomen der Fall.

Nichtkurativ behandelte Patienten können durch ein standardisiertes Nachsorgeprogramm nicht sinnvoll betreut werden. Hier ist ein individuelles Vorgehen angezeigt, wobei insbesondere auch die psychosoziale Betreuung sowie supportive Therapie und Schmerzbekämpfung von Bedeutung sind.

\section{In Kürze}

\section{Tumornachsorge}

Nachbetreuung nach der Primärtherapie ist integrierender Teil der Krebsbehandlung: klinische Untersuchung im Vordergrund.

\section{Weiterführende Literatur}

Deutsche Krebsgesellschaft (2002) Klassifikation maligner Tumoren des Gastrointestinaltraktes I. Junginger T, Hermanek P, Klimpfinger $M$ (Hrsg.) In: Klassifikation maligner Tumoren. Hermanek $P$, Junginger T, Klimpfinger M. Wagner G, Wittekind Ch (Hrsg.) Springer, Heidelberg

Deutsche Krebsgesellschaft (2003) Klassifikation maligner Thoraxtumoren. Drings P, Hasse J, Hermanek P, Wagner G (Hrsg.) In: Klassifikation maligner Tumoren. Hermanek $P$, Junginger $T$, Klimpfinger M. Wagner G, Wittekind Ch (Hrsg.) Springer, Heidelberg

Deutsche Krebsgesellschaft (2006). Empfehlungen zur Diagnostik und Therapie maligner Erkrankungen. Kurzgefasste interdisziplinäre Leitlinien 2006. Grabe C, Albers P, Beckmann M, et al. (Hrsg.) W. Zuckerschwerdt, München Wien New York

Deutsche Krebsgesellschaft (2007) Klassifikation maligner Tumoren des Gastrointestinaltrakts II. Neuhaus P, Wittekind C (Hrsg.) In: Klassifikation maligner Tumoren. Hermanek $P$, Junginger T, Klimpfinger M. Wagner G, Wittekind Ch (Hrsg.) Springer, Heidelberg

Grundmann E, Hermanek P, Wagner G (1997) Tumorhistologieschlüssel, 2. Aufl. Arbeitsgemeinschaft Deutscher Tumorzentren (ADT). Springer, Heidelberg

Hermanek P (1995) Prognostic factors of rectum carcinoma. Experience of the German multicentric study (SGCRC). Tumori 81(Suppl): 60-64

ICD-O (2000) International Classification of Diseases for Oncology, 3rd edn. Fritz A, Percy C, Jack A et al. (eds) WHO, Geneva. Deutsche Übersetzung: Internationale Klassifikation der Krankheiten für die Onkologie, Dritte Revision (ICD.O-3), Deutsches Institut für Medizinische Dokumentation und Information, DIMDI
Seeber S, Schütte J (1995) Therapiekonzepte Onkologie, 2. Aufl. Springer, Heidelberg

Siewert JR, Schumpelick V, Rothmund M (2004) Praxis der Viszeralchirurgie. Onkologische Chirurgie. Springer, Heidelberg

UICC (2005) Prognostic factors in cancer, 3. Aufl. Gospodarowicz MK, Henson DE, Hutter RVP et al. (Hrsg) Wiley \& Sons, New York

UICC (2010) TNM Classification of Malignant Tumours, 7th ed. Sobin LH, Wittekind Ch (eds.) Wiley \& Sons, New York [Deutsche Übersetzung: TNM-Klassifikation maligner Tumoren, 7. Aufl. (2010) Wittekind Ch, Meyer HJ (Hrsg.) Wiley-VCH, Weinheim]

UICC (2012) TNM Supplement. A commentary on uniform use, 4th ed. Wittekind Ch, Compton CC, Brierley J et al. (eds). BlackwellPublisihing Ltd., Oxford

Wagner G, Hermanek P (1995) Organspezifische Tumordokumentation Arbeitsgemeinschaft Deutscher Tumorzentren (ADT) - Tumordokumentation in Klinik und Praxis, Bd 2. Springer, Heidelberg

\subsection{Molekulare Biologie und Genetik in der Chirurgie}

\author{
H. K. Schackert
}

Revolutionäre neue Techniken erschlossen in den letzten Jahrzehnten des 20. Jahrhunderts erstmals den Zugang zu den molekularen Grundlagen der belebten Natur. Die molekulare Biologie und Genetik ist seitdem der Motor des Fortschritts in Biologie und Medizin. Das rasch zunehmende Wissen in der molekularen Grundlagenforschung und die Daten aus dem menschlichen Genomprojekt (http://www.ncbi.nlm.nih.gov/ genbank/), das zum Ziel hatte, die Basensequenz aller menschlichen Gene zu identifizieren, werden zunehmend in die klinische Praxis übertragen. Fortschritte in Diagnostik und Therapie benigner und maligner Erkrankungen sind die Folge. Dies gilt insbesondere für die molekularen Grundlagen der Tumorentstehung, deren Kenntnis die Voraussetzung für Maßnahmen zur Prädiktion und Prävention hereditärer Tumorerkrankungen sind. Darüber hinaus werden gentherapeutische Ansätze zur Behandlung solider Tumoren entwickelt.

\subsubsection{Techniken der molekularen Biologie und Genetik}

Drei Techniken revolutionierten die molekularbiologische und molekulargenetische Forschung und sind der Motor des Fortschritts. Es handelt sich um die Polymerasekettenreaktion (PCR), die die spezifische Amplifikation von DNA ermöglicht. Die DNA-Sequenzierung nach Sanger erlaubt die Analyse der Basenfolge in der DNA. DNA-Fragmente werden mit Hilfe der rekombinanten DNA-Technologie neu zusammengestellt und können gezielt in Zellen eingeschleust und exprimiert werden.

1. Polymerasekettenreaktion (PCR): Anfang der 1980erJahre entwickelte Kary Mullis die Polymerasekettenreaktion (• Abb. 1.101) und wurde dafür 1993 mit dem Nobel- 


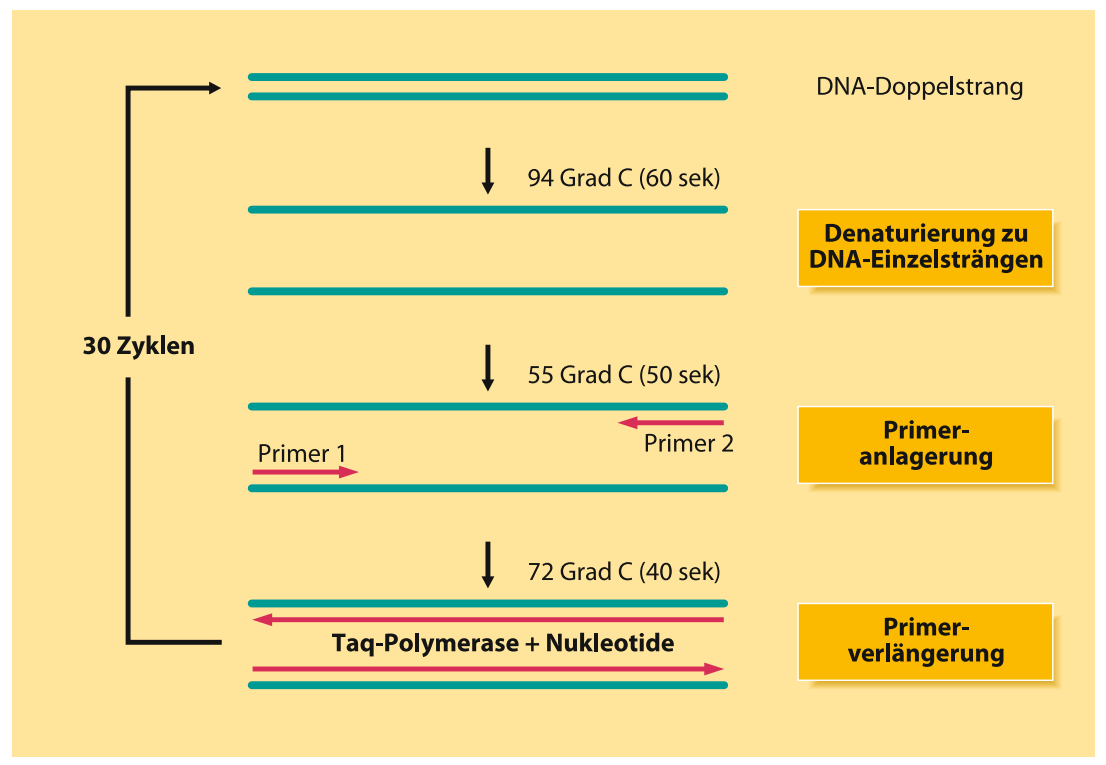

- Abb. 1.101 Polymerasekettenreaktion (PCR)

preis für Chemie ausgezeichnet. Die Technik erlaubt die spezifische exponentielle Amplifikation eines bis zu mehrere tausend Basen langen DNA-Abschnittes (Template), der durch 2 Primer markiert wird. Die PCR-Primer sind künstlich synthetisierte DNA-Fragmente, meist zwischen 15 und 25 Basen lang, und weisen die komplementäre Basensequenz der beiden Enden der Zielsequenz auf.

\section{Praxisbox \\ Technik der PCR}

Nach Trennung des DNA-Doppelstranges - z. B. menschlicher genomischer DNA - bei $94^{\circ} \mathrm{C}$ lagern sich bei $55^{\circ} \mathrm{C}$ die spezifischen Primer an die komplementären Enden der Zielsequenz an (Annealing). Bei $72^{\circ} \mathrm{C}$ (Extension) baut die Polymerase Nukleotide ein und verlängert die beiden Primer, so dass jeweils der komplementäre Strang zum vorliegenden Einzelstrang entsteht. Die Verwendung der hitzestabilen Taq-Polymerase des thermophilen Bakteriums Thermus aquaticus erlaubt die Automatisierung des Reaktionsablaufes auf einem Thermocycler. Nach 30 PCRZyklen exponenzieller Vervielfältigung steht innerhalb weniger Stunden ein milliardenfach amplifizierter spezifischer DNA-Abschnitt zur Verfügung (• Abb. 1.101).

( PCR-Produkte sind Ausgangsprodukte für die DNASequenzierung nach Sanger und die rekombinante DNA-Technologie.

2. DNA-Sequenzierung nach Sanger: Frederick Sanger entwickelte in den 1970er-Jahren die nach ihm benannte enzymatische Methode zur Analyse der Basenfolge in DNASträngen und erhielt dafür im Jahre 1980 den Nobelpreis für Chemie (• Abb. 1.102). Das Grundprinzip der Technik ist dem der PCR ähnlich. Im Gegensatz zur PCR wird jedoch nach Trennung des DNA-Doppelstranges nur ein Primer angelagert und verlängert (Extension).

Praxisbox
Technik der DNA-Sequenzierung
Die Strangverlängerung findet parallel in den 4 Reaktions-
gefäßen A, C, G und T milliardenfach statt und enthält ne-
ben der DNA-Vorlage (Template) die Polymerase, Puffer-
lösung und die Desoxynukleotide dATP, dCTP, dGTP und
dTTP. Die Zugabe des Didesoxynukleotides ddATP (A*) im
Verhältnis 1:200 zum Desoxynukleotid dATP (A) im Reak-
tionsgefäß A ( $\left.A^{*}: A=1: 200\right)$ führt zum seltenen, randomi-
sierten Einbau von ddATP (Terminator) anstelle von dATP
in die Strangverlängerung der Reaktion A. Ist dies der
Fall, kann der DNA-Strang nicht weiter verlängert wer-
den, was zum irreversiblen Abbruch der DNA-Strangver-
längerung führt (Strangabbruch). Es entstehen unter-
schiedlich lange DNA-Stränge, die alle mit Adenin ( $A^{*}$ )
enden. In Reaktion C, die ddCTP enthält, brechen alle
Stränge nach einem Cytosin ab (C*) und in Reaktion G
(ddGTP) und T (ddTTP) brechen die DNA-Stränge jeweils
nach einem Guanin (G*) bzW. einem Thymin ( $T^{*}$ ) ab.
Trennt man nach Abschluss der Sequenzierreakti-
onen die unterschiedlich langen DNA-Stränge auf einem
hochauflösenden Polyacrylamidgel in einem elektrischen
Feld auf, wandern kürzere DNA-Stränge schneller als län-
gere. In dem entstehenden Bandenmuster entspricht die
Reihenfolge von kürzerer zu jeweils nächstlängerer Ban-
de - den entsprechenden Basen A, C, G oder T zugeord-
net - der komplementären DNA-Sequenz des Templates.
v


a

Strangverlängerung
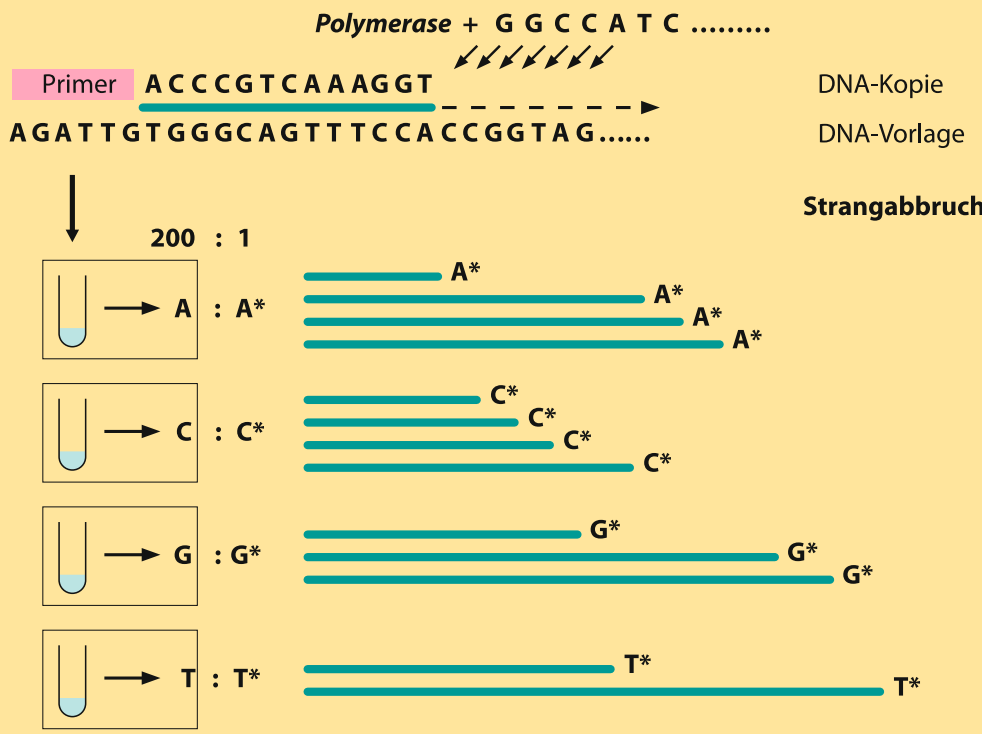

$\mathbf{T}^{*}$

Strangabbruch

b

Reaktionsgemisch aus A, C, G und T auf Polyacrylamidgel aufgetragen
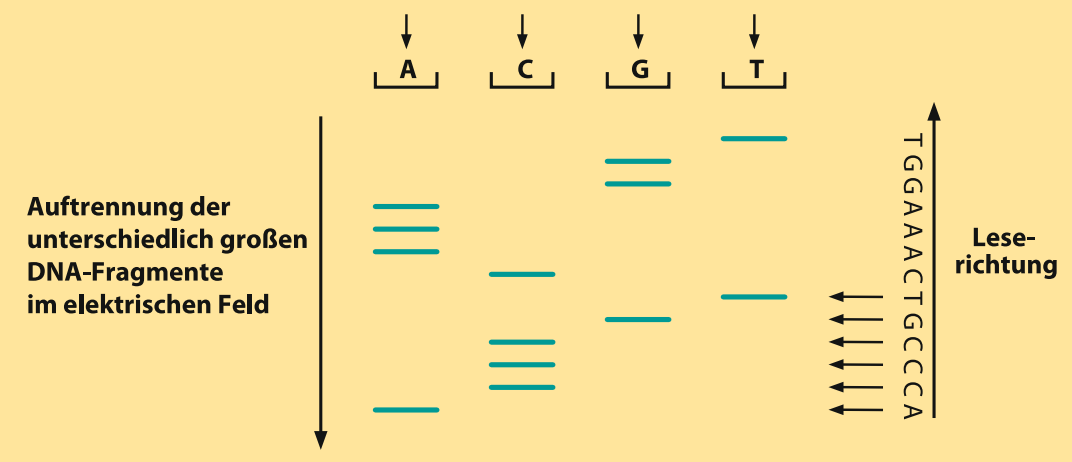

- Abb. 1.102 DNA-Sequenzierung nach Sanger

Markiert man die 4 Terminatoren ddATP, ddCTP, ddGTP, ddTTP mit 4 unterschiedlichen Fluoreszenzmolekülen, kann die Sequenzierreaktion in einem Reaktionsgefäß durchgeführt werden. Die Analyse der Strangabbrüche mittels Laserfluoreszenz auf Kapillar-Sequenzierern ermöglicht Leseweiten von über 1.000 Basen.

3. Rekombinante DNA-Technologie: Herstellung und $\mathrm{Zu}$ sammenfügen beliebiger DNA-Fragmente setzt verschiedene Techniken voraus. Gentechnische Arbeiten wurden deshalb erst durch einige bahnbrechende Entdeckungen des 20. Jahrhunderts möglich. Dazu zählen die Aufklä- rung der DNA-Struktur durch Watson und Crick im Jahre 1953, die Entschlüsselung des genetischen Codes und die Entdeckung von Enzymen, die DNA schneiden und zusammenfügen können. Paul Berg erhielt für die Entwicklung der rekombinanten DNA-Technologie 1980 den Nobelpreis für Chemie. Versehen mit den Anweisungen für Transkription und Translation gelingt es heute, verschiedenste Gensequenzen zu rekombinieren, in Zielzellen einzuschleusen und zu exprimieren. Die rekombinante DNA-Technologie ist z. B. die Basis für die Produktion menschlichen Insulins oder Erythropoietins. Aber auch für die Gentherapie benigner und maligner Erkrankungen ist sie unverzichtbar (Watson et al. 2007). 


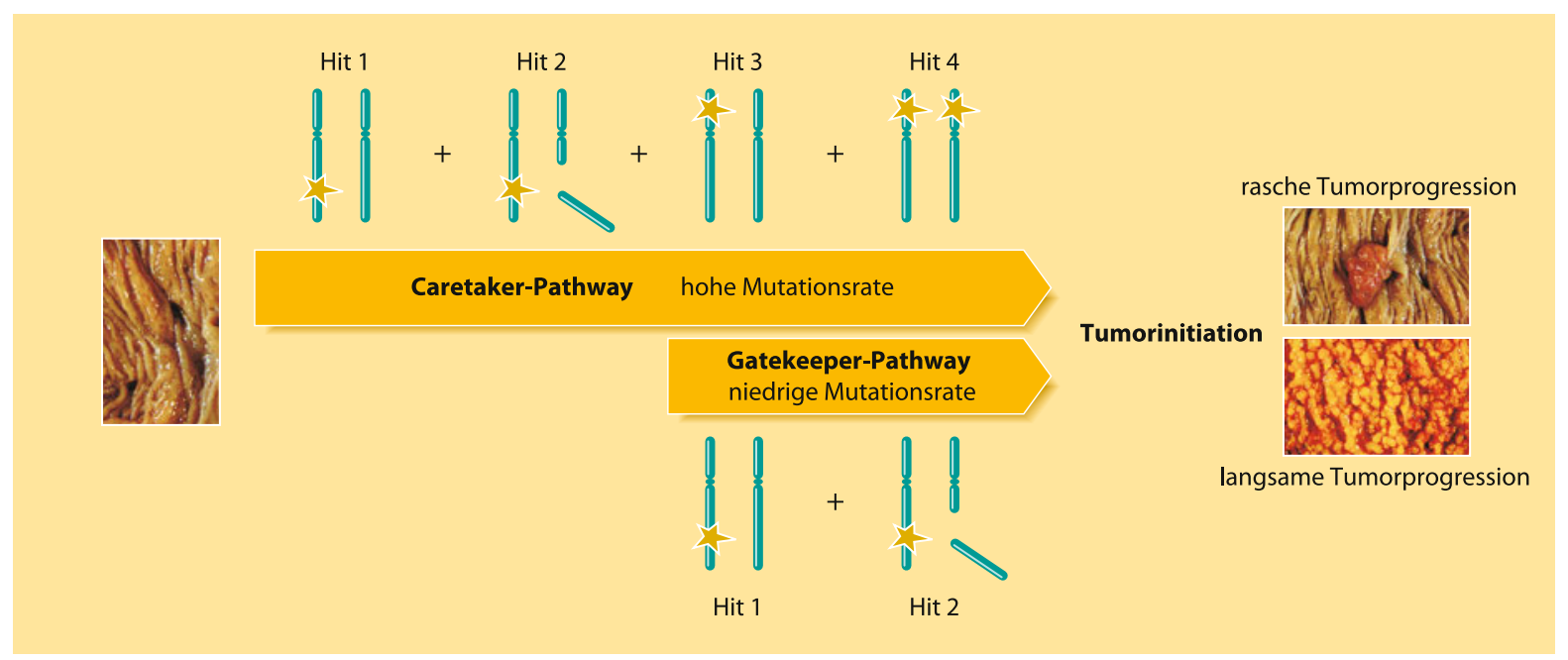

- Abb. 1.103 Zwei Wege zur Tumorentstehung am Beispiel hereditärer kolorektaler Karzinome (mod. nach Kinzler u. Vogelstein 1997)

\subsubsection{Molekulare Grundlagen der Entstehung maligner Tumoren}

Bereits Anfang des 20. Jahrhunderts wurde vermutet, dass Genänderungen in Zellen die Ursache für die Geschwulstentstehung sein könnten. Karl Heinrich Bauer, später Ordinarius für Chirurgie in Breslau und Heidelberg, publizierte im Jahre 1928 die »Mutationstheorie der Geschwulstentstehung Übergang von Körperzellen in Geschwulstzellen durch Genänderung «, eine aus heutiger Sicht visionäre Idee. Endogene und exogene Faktoren spielen bei der Entstehung jedes Tumors eine unterschiedlich starke Rolle. Molekulargenetische Bestätigungen der Mutationstheorie fanden sich erst Ende des 20. Jahrhunderts.

Alfred. G. Knudson studierte in den 1970er-Jahren die Häufigkeit familiärer und nichtfamiliärer Retinoblastome und schlug als Ergebnis seiner Untersuchungen ein »Zwei-TrefferModell« der Tumorentstehung vor. Beide Kopien eines Tumorsuppressorgens, das in seiner normalen Funktion die Tumorentstehung unterdrückt, müssen ausgeschaltet werden. Dieses Modell ist heute beim Studium der molekularen Karzinogenese unverzichtbar und lässt sich gleichermaßen auf die Entwicklung hereditärer als auch sporadischer Tumoren anwenden (Knudson 1996). Aufbauend auf dem »two-hitmodel « publizierten Fearon und Vogelstein 1990 ein genetisches Model für die Entstehung des kolorektalen Karzinoms. Das kolorektale Karzinom kann auf unterschiedlichen Wegen entstehen, nämlich dem Gatekeeper-Pathway und dem Caretaker-Pathway.

1. Gatekeeper-Pathway: Die molekularen Ereignisse bei der Entstehung eines Tumors sind beim kolorektalen Karzinom detailliert untersucht worden. Das APC-Tumorsuppressorgen scheint bei vielen kolorektalen Adenomen das Gatekeeper-Gen zu sein, dessen Ausschaltung mit der Adenomentstehung assoziiert ist. Gatekeeper-Gene sind wichtige Regulatoren des Zellzyklus. Mutationen im APC-
Gen werden daher nicht selten bereits in kleinen kolorektalen Adenomen beobachtet. Der Verlust beider WildtypAllele ist ein ursächliches molekulares Ereignis bei der Polypentwicklung. Vererbte Mutationen des APC-Gens sind die Ursache für die familiäre adenomatöse Polyposis (FAP), die mit sehr hoher Wahrscheinlichkeit in einem Karzinom resultiert. Auf die APC-Geninaktivierung folgt sowohl bei sporadischen als auch hereditären Adenomen eine Kaskade von somatischen Mutationsereignissen in Genen, die für die Tumorprogression relevant sind. Die jeweilige Inaktivierung eines Tumorsuppressorgens scheint der betroffenen Zelle einen Wachstumsvorteil gegenüber anderen Zellen zu vermitteln mit der Konsequenz, dass sie klonal expandiert. Mutationen betreffen Protoonkogene und Tumorsuppressorgene, die aktiviert bzw. inaktiviert werden. Offensichtlich ist jedoch nicht nur die Akkumulation der Genmutationen von Bedeutung, sondern auch eine gewisse Reihenfolge der Mutationsereignisse (Kinzler u. Vogelstein 1996). Da die Mutationsrate in diesen Tumoren vergleichsweise gering ist, erstreckt sich die Tumorprogression über viele Jahre (• Abb. 1.103).

2. Caretaker-Pathway: Im Gegensatz zu Gatekeeper-Genen, die wichtige Regulatoren des Zellzyklus sind, können Caretaker-Gene zur Tumorentstehung nur indirekt beitragen. $\mathrm{Zu}$ den Caretaker-Genen zählen die Mismatch-Repair-Gene MSH2, MLH1, MSH6 und PMS2, die in ihrer mutierten Form zum hereditären nicht-Polyposis-assoziierten kolorektalen Karzinom-Syndrom (HNPCC) oder Lynch-Syndrom prädisponieren. Mismatch-Repair-Proteine korrigieren Fehler, die bei der Verdopplung der DNA entstehen. Der mutationsbedingte Funktionsverlust eines Caretaker-Genallels, vererbt oder spontan, gefolgt vom Funktionsverlust des Wildtyp-Allels, führt zur Mismatch-Repair-Defizienz. Daraus resultiert eine hohe $\mathrm{Mu}-$ tationsrate in betroffenen Zellen. Zufällige Mutationen in Gatekeeper-Genen oder anderen tumorrelevanten Zielge- 
nen führen zur Tumorinitiation und zur nachfolgenden schnellen Tumorprogression (Kinzler u. Vogelstein 1997, Lynch u. de la Chapelle 2003, • Abb. 1.103).

\subsubsection{Gezielte Vorsorge und präventive chirurgische Therapie}

Bei den klinischen Konsequenzen der prädiktiven molekularen Diagnostik ist v. a. die gezielte Vorsorge zu nennen. Ist die ursächliche Genmutation bei einem erkrankten Familienangehörigen (Indexperson) identifiziert worden, eröffnet sich die Möglichkeit einer prädiktiven molekularen Diagnostik bei gesunden Verwandten (Risikopersonen).

$(8$ Mutationsträger werden in ein Vorsorge- und Krebsfrüherkennungsprogramm aufgenommen.

Verwandte, bei denen die familienspezifische ursächliche Genmutation nicht nachweisbar ist, können aus dem speziellen Vorsorgeprogramm entlassen werden. Sie tragen jedoch unverändert das Risiko für eine sporadische Tumorentstehung, das annähernd dem der Allgemeinbevölkerung entspricht.

Die prädiktive molekulare Diagnostik muss von einer humangenetischen Beratung begleitet werden.

\section{Präventive Therapie}

$(7$ Präventive Therapie ausschließlich aufgrund einer molekularen Diagnose wird derzeit nur in Form der präventiven Thyreoidektomie bei der multiplen endokrinen Neoplasie Typ 2 durchgeführt.

Entsprechende präventiv-chirurgische Maßnahmen werden beim HNPCC-Syndrom in Einzelfällen durchgeführt, ohne dass Evidenz aus klinischen Studien vorliegt.

Die restaurative Proktokolektomie bei der familiären adenomatösen Polyposis ist ein Standardverfahren zur Prävention des kolorektalen Karzinoms. Die Indikation wird jedoch ausschließlich aufgrund des eindeutigen Phänotyps gestellt.

\subsubsection{Molekulargenetische Diagnostik und Prävention maligner Tumoren am Beispiel des vererbbaren kolorektalen Karzinoms}

Jährlich werden in Deutschland ungefähr 70.000 kolorektale Karzinome neu diagnostiziert.

$(7$ Lediglich bei 3-5\% dieser Tumorerkrankungen sind vererbbare genetische Faktoren bekannt.

Der Erbgang ist meist autosomal-dominant. Das CowdenSyndrom (Gen: PTEN), das Peutz-Jeghers-Syndrom (Gen: STK11) und das familiäre juvenile Polyposis-Syndrom (Gene: SMAD4, BMPR1A) sind selten und sind durch hamartomatöse Polypen gekennzeichnet. Die familiäre adenomatöse
Polyposis coli (FAP) ist mit einem eindeutigen Phänotyp assoziiert, nämlich weit mehr als 100 Polypen und kann als attenuierte Form mit weniger als 100 Polypen imponieren. Die familiäre adenomatöse Polyposis wird meist autosomaldominant vererbt (Gen: $A P C$ ). Die MUTYH-assoziierte Polyposis (MAP) folgt einem autosomal-rezessiven Erbgang (Gen: MUTYH).

Das HNPCC-Syndrom (hereditäres nicht-Polyposis-assoziiertes kolorektales Karzinom-Syndrom, Lynch-Syndrom) ist die häufigste Form des familiären Darmkrebses. Es wird autosomal-dominant mit inkompletter Penetranz vererbt und umfasst ein großes Tumorspektrum. Das kolorektale Karzinom ist der mit Abstand häufigste Tumor. Bei weiblichen HNPCCPatienten ist das Endometriumkarzinom jedoch ähnlich häufig wie das kolorektale Karzinom. HNPCC kann durch die Mutation eines der Mismatch-Repair-Gene (MMR-Gene) MSH2, MLH1, MSH6 oder PMS2 ausgelöst werden. Die Proteine, die von diesen Genen kodiert werden, wirken wesentlich bei der Erkennung und Korrektur von Mutationen mit (Mismatch Repair), die bei der Verdopplung der Erbsubstanz vor der Zellteilung auftreten. Die Inaktivierung eines MMRGens durch pathogene (meist proteinverkürzende) Mutationen resultiert in einem Zusammenbruch des MMR-Systems (MMR-Defekt) und ist mit Tausenden Mutationen pro Zellteilung assoziiert. Aufgrund der hohen Mutationsrate können HNPCC-assoziierte Tumoren in sehr kurzer Zeit entstehen. Koloskopische Früherkennungsmaßnahmen sollten deshalb jährlich durchgeführt werden.

Das Deutsche HNPCC-Konsortium hat Standards bei der Beratung, Gendiagnostik, Prävention und Behandlung des familiären Darmkrebses entwickelt und etabliert. Es wird seit 1999 von der Deutschen Krebshilfe gefördert und setzt sich aus Zentren an den Universitäten Bochum, Bonn, Dresden, Düsseldorf, Heidelberg und München zusammen (http:// www.hnpcc.de und http://cf.uniklinikum-dresden.de/zfd. htm). Auf der Basis der weltweit größten Population von HNPCC-Patienten sind umfangreiche Forschungsprojekte möglich mit dem Ziel, die Standards der Patientenversorgung zu evaluieren und stetig zu verbessern.

\section{Diagnostisches Vorgehen bei HNPCC}

Phänotypisch können Patienten mit HNPCC nicht von Patienten mit sporadischem Karzinom unterschieden werden, da keine Polyposis vorliegt und meist nur ein einziger Tumor (Polyp oder Karzinom) diagnostiziert wird. Verschiedene diagnostische Schritte sind nötig, um HNPCC-Patienten zu identifizieren.

Bei Verdacht auf HNPCC: Bethesda-Richtlinien Der Verdacht auf ein HNPCC-Syndrom besteht dann, wenn mindestens ein Kriterium der Bethesda-Richtlinien erfüllt ist (Umar 2004). 
Bethesda-Richtlinien bei Verdacht auf HNPPC (Umar 2004).

1. Patient mit kolorektalem Karzinom (CRC), welches vor dem 50. Lebensjahr diagnostiziert worden ist.

2. Patient mit synchronen oder metachronen kolorektalen Karzinomen oder anderen HNPCC-assoziierten Tumoren ${ }^{1}$ ohne Altersbeschränkung.

3. Patient mit CRC mit MSI-H typischer Histologie2, welches vor dem 60. Lebensjahr diagnostiziert worden ist.

4. Patient mit CRC (unabhängig vom Alter), der mindestens einen Verwandten 1. Grades mit einem CRC oder einem HNPCC-assoziierten Tumor ${ }^{1}$ hat, der vor dem 50. Lebensjahr diagnostiziert worden ist.

5. 5. Patient mit $\mathrm{CRC}$, der mindestens zwei Verwandte 1. oder 2. Grades mit einem CRC oder einem HNPCCassoziierten Tumor ${ }^{1}$ hat, unabhängig vom Erkrankungsalter.

1 HNPCC-assoziierte Tumoren schließen Tumoren folgender Organe bzw. Gewebe ein: Kolon und Rektum, Endometrium, Magen, Ovar, Pankreas, Ureter und Nierenbecken, biliäres System, Dünndarm, Gehirn (meist Glioblastome wie bei Turcot-Syndrom) und Talgdrüsenadenome und Keratoakanthome (bei Muir-Torre-Syndrom).

2 Tumorinfiltrierende Lymphozyten, "Crohn's-like lesions", muzinöse/siegelringzellige Differenzierung oder medulläres Wachstumsmuster

Erfüllt der Indexpatient (Familienangehöriger mit Tumor) eines der Einschlusskriterien, dann kann er nach ärztlicher Aufklärung sein Einverständnis zur genetischen Diagnostik geben (Checkliste: http://cf.uniklinikum-dresden.de/zfd.htm). Den Ablauf der Gendiagnostik regelt das Gendiagnostikgesetz (GenDG), das am 01.02.2010 in Kraft getreten ist (GenDG http://www.gesetze-im-internet.de/gendg/index.html).
Der Verlust der Proteinexpression im Tumor identifiziert das betroffene Gen Der Expressionsverlust eines MismatchRepair-Proteins (MSH6) im Tumor weist auf einen MismatchRepair-Defekt (• Abb. 1.104) hin.

D Cave

Bei mehr als 50\% aller Patienten, die mindestens ein Bethesda-Kriterium erfüllen, weist der Tumor keinen MMR-Defekt auf. Die Gene, die diese Tumoren auslösen, sind weitgehend unbekannt.

Die Analyse des betroffenen Gens (hier MSH6) in peripheren Blutleukozyten identifiziert die vererbbare pathogene Mutation (• Abb. 1.105) Die spezifische Amplifikation der Exons von MSH6 und die anschließende Analyse der Basensequenz mittels Sanger Sequenzierung lässt eine Deletion von 2 Basen auf einem Allel des MSH6-Gens erkennen. Die Mutation erzeugt einen Frameshift, der zu einer Proteinverkürzung führt.

Wird beim Indexpatienten eine pathogene (meist proteinverkürzende) Mutation identifiziert, kann bei blutsverwandten Angehörigen nach humangenetischer Beratung die prädiktive Gendiagnostik durchgeführt werden Den Angehörigen, die Träger der pathogenen Mutation sind, wird das HNPCC-spezifische Vorsorgeprogramm empfohlen. Angehörige, die die Mutation nicht tragen, sollen das Vorsorgeprogramm für die Allgemeinbevölkerung wahrnehmen (Schmiegel 2008).

Patienten und ihren Angehörigen wird ein spezifisches Vorsorgeprogramm empfohlen $\mathrm{Ab}$ dem 25. Lebensjahr (bzw. 5 Jahre vor dem Erstmanifestationsalter eines Tumors in der Familie) werden folgende Vorsorgeuntersuchungen lebenslang empfohlen (•Tab. 1.54).

Das HNPCC-Vorsorgeprogramm gilt für folgende Personen:

- Mutationsträger und deren leibliche Verwandte, bei denen die Mutation noch nicht durch eine prädiktive Diagnostik ausgeschlossen worden ist.

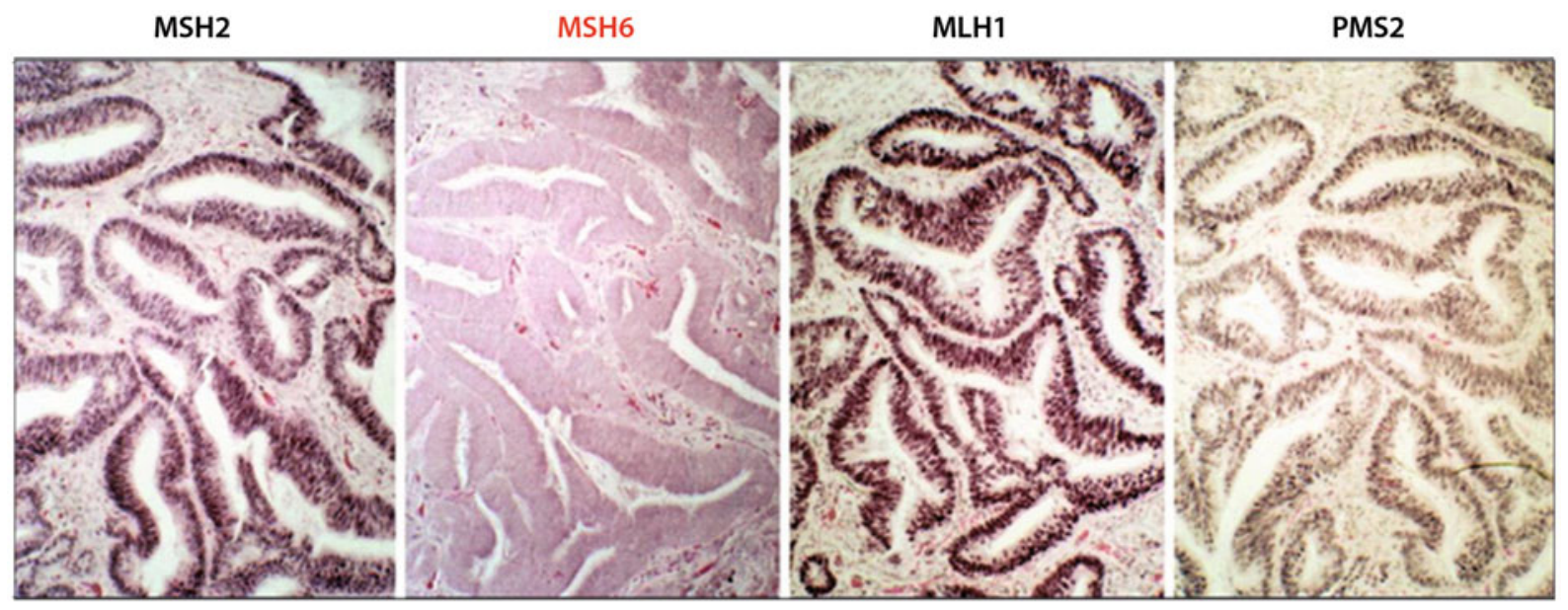

- Abb. 1.104 Verlust der Expression von MSH6 im Tumor 


\section{Proteinverkürzende MSH6-Keimbahnmutation}

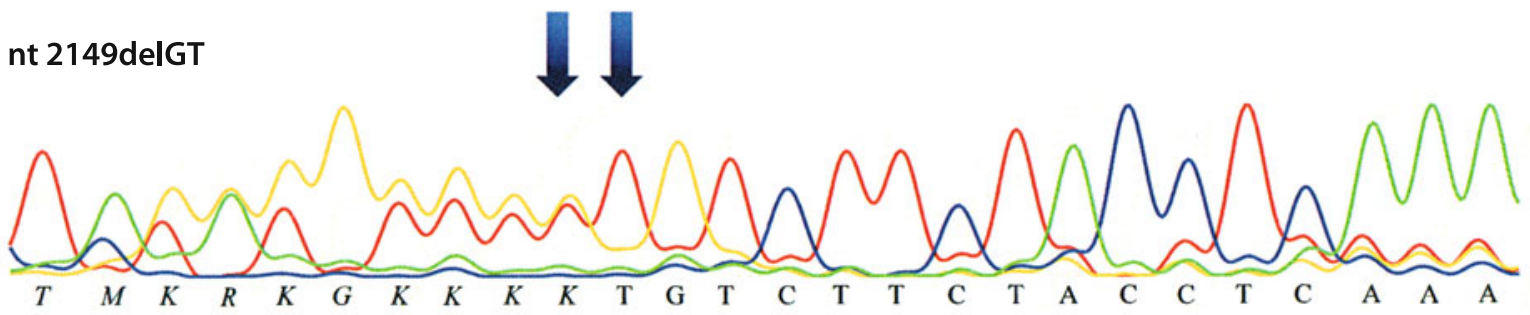

KB2449

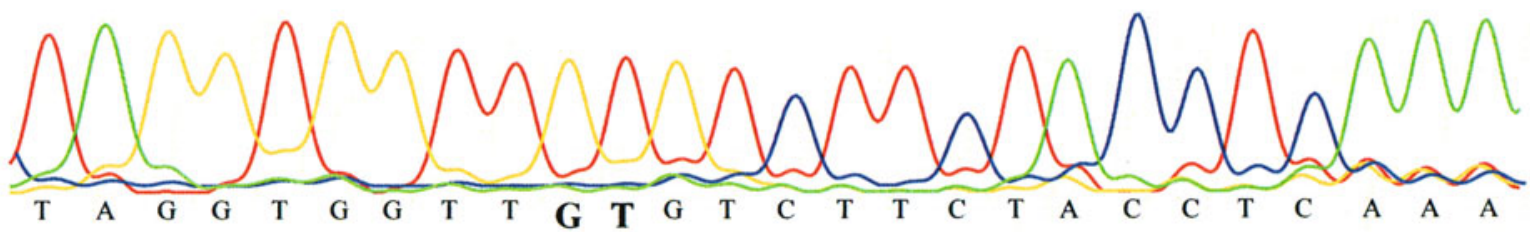

Wildtypsequenz

- Abb. 1.105 Proteinverkürzende MSH6-Keimbahnmutation (Pfeile)

- Patienten ohne nachweisbare Mutation, die die BethesdaRichtlinien erfüllen und deren Tumor einen MMR-Defekt aufweist und deren leiblichen Verwandten.

Die strukturierte Diagnostik identifiziert Patienten, die ein hohes Risiko für kolorektale Karzinome und andere HNPCCassoziierte Tumoren haben. Wir finden bei ungefähr 50\% aller Bethesda-positiven Patienten mit einem MMR-defizienten Tumor eine pathogene vererbbare MMR-Genmutation. Die Zahl der prädiktiv getesteten Verwandten ist mit 1,5 Fällen pro HNPCC-Familie jedoch zu gering (persönliche Mitteilung: Deutsches HNPCC Konsortium). Fehlender Informationsfluss in den Familien könnte ein Grund sein. Indexpatienten mit HNPCC muss deshalb empfohlen werden, ihre Verwandten auf das HNPCC-spezifische Vorsorgeprogramm

- Tab. 1.54 HNPCC-Vorsorgeprogramm

Untersuchung

Körperliche Untersuchung

Abdomensonographie

Komplette Koloskopie

Frauen: Gynäkologische Untersuchung zum Ausschluss eines Endometrium- oder Ovarialkarzinoms, einschließlich transvaginaler Sonographie

Frauen: Endometriumbiopsie, ab dem 35. Lebensjahr

Ösophago-Gastro-Duodenoskopie, ab dem 35. Lebensjahr und die Möglichkeit der prädiktiven Diagnostik aufmerksam zu machen.

Das Deutsche HNPCC-Konsortium hat in einer Studie bestätigt, dass die jährliche koloskopische Vorsorgeuntersuchung bei HNPCC effizient ist und deshalb unverändert weiter empfohlen wird. (Engel 2010). Weitere Untersuchungen zur Effizienz der Vorsorgeempfehlungen sind im Gange.

\subsubsection{Gentherapie maligner Tumoren}

Wenn Genmutationen ursächlich für die Entstehung maligner Tumoren verantwortlich sind, sollte die Korrektur der Mutationen den malignen Phänotyp rückgängig machen können.

Das $p 53$-Tumorsuppressorgen wird während der Progression zahlreicher Tumoren ausgeschaltet und ist deshalb ein therapeutisches Gen der kausalen Gentherapie. Der Transfer des p53-Wildtyp-Gens in Tumorzellen kann die Zellzyklusregulation wiederherstellen oder Apoptose auslösen. Überexpression von immunstimulierenden Molekülen wie z. B. IL-2, IL-4 oder GM-CSF nach Transfer des kodierenden Gens in Tumorzellen wird im Rahmen der Immuntherapie erprobt.

Die Suizidgentherapie verwendet bakterielle und virale Gene, die meist mit Hilfe von Viren in die Tumorzellen eingeschleust werden. Die Gene kodieren für Proteine, die ein intravenös verabreichtes wenig toxisches Substrat im Tumor in ein hochtoxisches Chemotherapeutikum überführen. Die bakterielle Cytosindeaminase wandelt das Antimykotikum 5Fluorcytosin in 5-Fluoruracil um. Die Thymidinkinase des Herpes-simplex-Virus ist an der Umsetzung des Virostatikums Ganciclovir in das toxische Ganciclovirtriphosphat beteiligt. Sämtliche Gentherapieansätze sind im Stadium der klinischen Erprobung (http://www.abedia.com/wiley/index. html). Während das Funktionsprinzip vieler verwendeter 
Gene weitgehend aufgeklärt ist, stellt der effiziente Gentransfer in den Tumor ein ungelöstes Problem dar. Weniger als 4\% aller Gentherapiestudien sind Phase III-Studien.

$\checkmark$ Die Gentherapie ist auch nach über 20 Jahren Forschung und Entwicklung noch kein klinisch anerkanntes Behandlungskonzept maligner Tumoren.

In der Deutschen Gesellschaft für Chirurgie beschäftigt sich die Sektion Chirurgische Forschung (SCF) mit der Thematik Molekulare Biologie und Genetik in der Chirurgie.

\section{In Kürze}

Molekulare Biologie und Genetik in der Chirurgie

- Wichtigste neue Techniken: Polymerasekettenreaktion (PCR), DNA-Sequenzierung nach Sanger, rekombinante DNA-Technik.

- Übertragen der Kenntnisse der molekularen Grundlagen in die klinische Praxis.

- Prädiktive Diagnostik und präventive Therapie hereditärer maligner Tumoren als erste Konsequenzen für die Chirurgie.

- Gentherapeutische Studien durch zunehmendes Verständnis der molekularen Pathogenese benigner und maligner Erkrankungen.

\section{Weiterführende Literatur}

Bauer KH (1928) Mutationstheorie der Geschwulst-Entstehung. Übergang von Körperzellen in Geschwulstzellen durch Gen-Änderung. Springer, Berlin

Engel, C, et al. (2010) Efficacy of annual colonoscopic surveillance in individuals with hereditary nonpolyposis colorectal cancer. Clin Gastroenterol Hepatol: 8: 174-182

Fearon ER, Vogelstein B (1990) A genetic model for colorectal tumorigenesis. Cell 61:759-767

Kinzler KW, Vogelstein B (1996) Lessons from hereditary colorectal cancer. Cell 87:159-170

Kinzler KW, Vogelstein B (1997) Gatekeepers and caretakers. Nature 386:761-763

Knudson AG (1996) Hereditary cancer: two hits revisited. J Cancer Res Clin Oncol 122:135-140

Lynch HT, de la Chapelle A (2003) Hereditary colorectal cancer. N Engl J Med 348: 919-932

Schmiegel W (2008) S3-Leitlinie Kolorektales Karzinom. Z Gastroenterol 46: 1-73

Umar A (2004) Revised Bethesda Guidelines for hereditary nonpolyposis colorectal cancer (Lynch syndrome) and microsatellite instability. J Natl Cancer Inst 96:261-268

Watson JD, Gilman M, Witkowski J, Zoller M (2007) Recombinant DNA. W.H. Freeman, New York 